\title{
A systematic and ecomorphological investigation of the early amniotes from Mazon Creek, Francis Creek Shale, Illinois, USA.
}

by

Arjan Mann

A thesis submitted to the Faculty of Graduate and Postdoctoral Affairs in partial fulfillment of the requirements for the degree of

Doctor of Philosophy

in

Earth Sciences

Carleton University

Ottawa, Ontario

(C)2020, Arjan Mann 


\section{Abstract}

The late Carboniferous-aged (309-307 Ma) Mazon Creek lagerstätte produces some of the earliest tetrapod fossils, including those of major Paleozoic lineages such as the second oldest reptile. Despite this, the Mazon Creek lagerstätte has remained a difficult and unproductive vertebrate locality for researchers to utilize in tetrapod diversity studies due to the scarcity of fossils of this kind. Over the past decades, several new terrestrial tetrapod fossils collected from Mazon Creek have come to light. These include several new virtually-complete fossils of the earliest fossorially adapted recumbirostrans. Here I provide a revised systematic study of the Mazon Creek panamniote fauna, in an attempt to reassess the terrestrial ecosystem diversity present at the late Carboniferous lagerstätte. The results accumulate to systematic descriptions of four new and unique recumbirostran taxa (Diabloroter bolti, Infernovenator steenae, FMNH 1309, and MPM VP359229.2) and a re-description of the basal eureptile Cephalerpeton ventriarmatum leading to the anointment of the oldest parareptile Carbonodraco lundi (formerly Cephalerpeton aff. C. ventriarmatum from Linton, Ohio). Descriptions are aided by modern imaging techniques and updated phylogenetic analyses using Maximum parsimony and Bayesian methods where applicable.

Across the newly described terrestrial fauna there is an unexpected ecomorphological diversity of bauplans present. These range from the short-bodied Diabloroter to the serpentine, long-bodied, and limb-reduced MPM VP359229.2. This diversity in combination with an array of unique cranial specializations present in the new taxa highlight the early experimentation with fossoriality in terrestrial vertebrate ecosystems. Exceptional preservation of soft tissues in FMNH 1309 even reveal integumentary adaptations to a fossorial lifestyle. Collectively, I am able to provide a revised taxonomic list for the Mazon Creek Tetrapoda that reveals the fauna is compositionally similar to that of most Permo-Carboniferous tetrapod localities. Given recent studies that suggest that recumbirostrans are crown-group reptiles, the results of this thesis imply a more rapid mid-Carboniferous diversification of amniotes into a variety of terrestrial niches and consequently an earlier establishment of terrestrial vertebrate ecosystems. 


\section{Acknowledgements}

First and foremost, I thank my mother, Pam, who first introduced me to paleontology, science, and a love of the natural world. Her kindness and love are immeasurable to me. I also thank my father, Jas, and my sister, Selena, for their continued love and support throughout my journey. I also extend thanks to all of my family and friends who provided me with kindness and support, especially my grandmother, who recently passed away. Little did she know, the stuffed Triceratops toy she bought me as a baby would spark a life-long pursuit.

To my best friend, Iain Ching, knowing you'll always have my back has been a comfort that words cannot express. To my dear friend, Alissa Fraser, thank you for your kindness, and support, seeing your life unfold has been an honour. I also extend a warm thanks to all of my friends for making my life so loving and complete.

Thank you to Jesse Lewis, Kayley Lenders, Michael MacKinnon, Carolyn Chen, Michael Thompson, and Ryan Paterson, you were the best roommates in the world, whose company without, my time in Ottawa would not have been bearable. I am deeply grateful to Braden Gregory, for joining me on my quest to become a master swordsman.

To my fellow Avengers, Jason Pardo, and Bryan Gee, I am grateful for our found comradery and friendship. I feel I have found life-long collaborators in the two of you, and I look forward to our next meeting, as Doctors in Philosophy.

I sincerely thank Ami Calthorpe, Emily McColville, Emily McDaniel, and Gabrielle Adams for giving me the chance to be a mentor and friend. I give a special thanks to Ami Calthorpe who provided me with support, motivation, and discussion in the final days of my thesis research.

In the field of Vertebrate Paleontology there are far too many people to thank, and they are acknowledged at the end of each chapter. However, two names stand out, the first of whom is the Late Dr. John R. Bolt, which I had the fortune of meeting before he passed. Without Johns willingness to share his knowledge and resources nothing in the following thesis would have been possible. I recall a conversation between John and I, where he mentioned he had received an NSF grant to essentially do the same Mazon 
Creek project in the 80 's, however, it never took off. John concluded our conversation by telling me, that he thought I was going to do good job. I think about that reassurance often.

The second individual to whom I am equally indebted, is Dr. Robert W. Hook. Bob graciously offered notes, and comparative material from the cannel coal localities of Linton and the Five Points, Ohio, that were originally discovered by himself and Dr. Donald Baird. Without Bobs willingness to share resources, and offer insightful discussion on the tetrapod material of the Carboniferous my thesis would not be where it is today. Bob also played host to me several times in Austin, Texas where he was a most gracious host. Our meetings are always a rush of research filled adrenaline, and I look forward to continuing working with him in the future

Finally, I would like to thank my former Masters supervisors Marc Laflamme, David Evans, and David Rudkin for their continued support in my research endeavors, including allowing me to work at the Royal Ontario Museum and University of Toronto in the summers. Last but certainly not least, I would like to thank my doctoral supervisor Dr. Hillary C. Maddin for giving me this opportunity, having patience with me, and joining me on this learning experience.

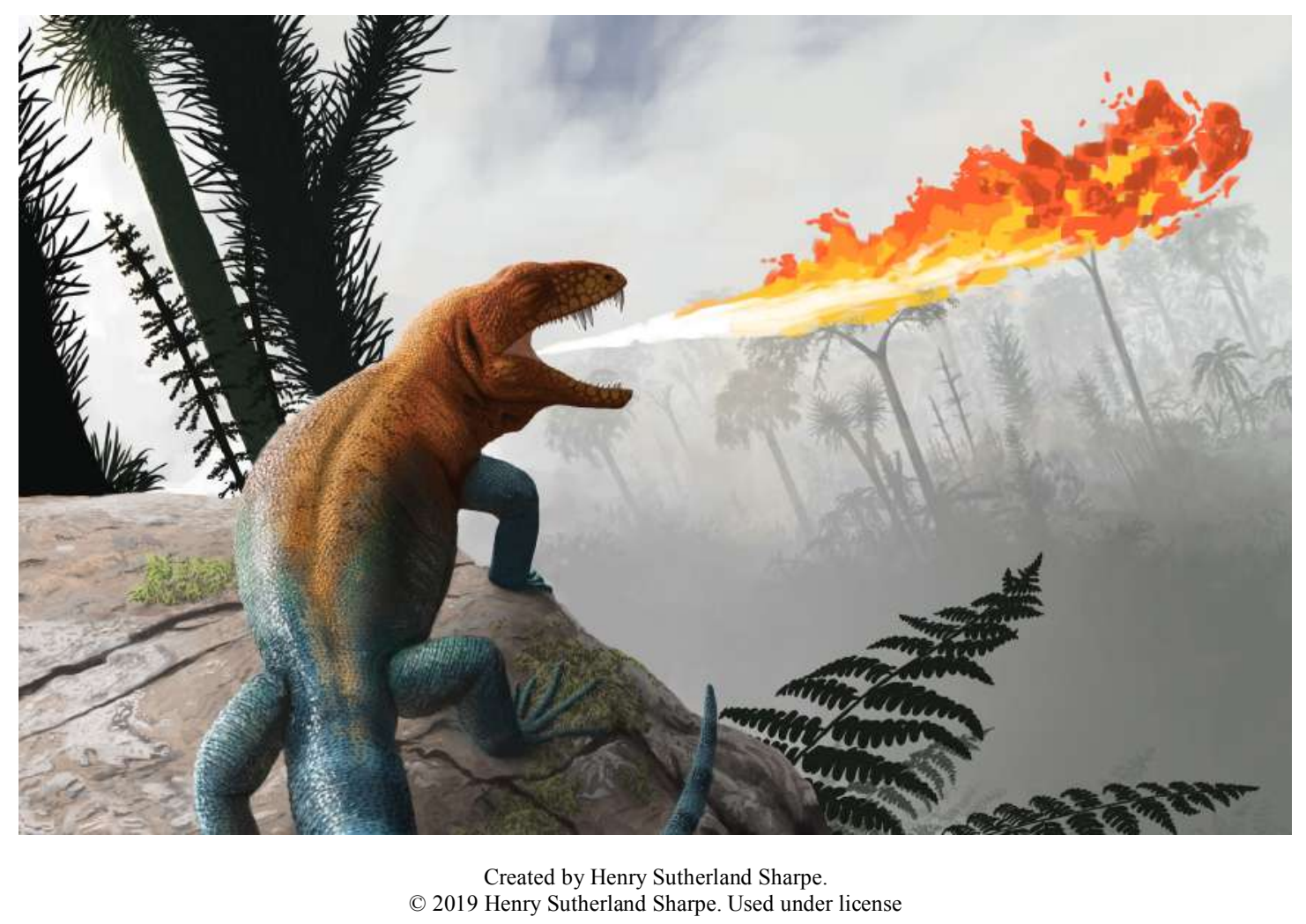




\section{Dedication}

For my Grandmother, Persin Kaur Buadhwal (1925-2020).

And for my rabbit, Maddy (2007-2020). 


\section{Table of Contents}

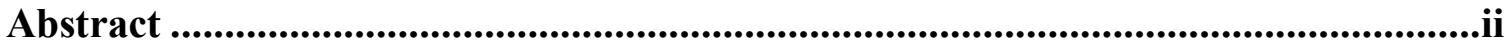

Acknowledgements................................................................................................................ iii

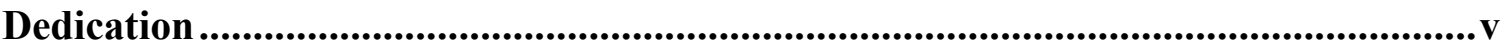

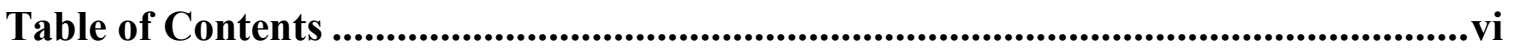

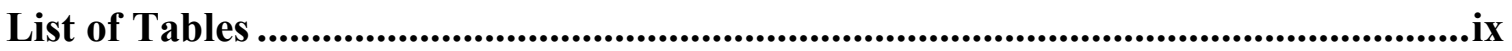

List of Figures....................................................................................................................

List of Appendices ............................................................................................................... xiv

Chapter 1: Introduction .....................................................................................................1

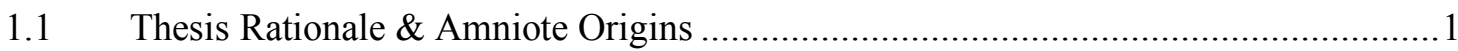

1.2 The Mazon Creek Lagerstätte \& Thesis Structure …………………………………....

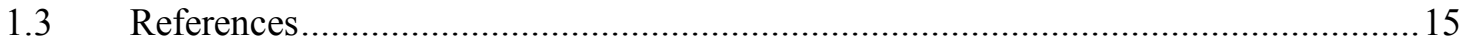

Chapter 2: Diabloroter bolti gen. et sp. nov. a short-bodied recumbirostran

'microsaur' from the Francis Creek Shale, Mazon Creek, Illinois ..............................25

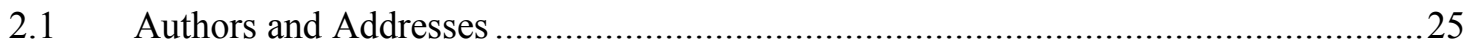

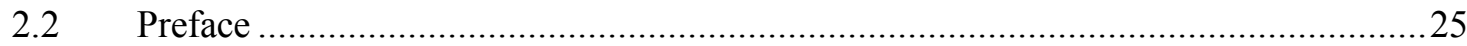

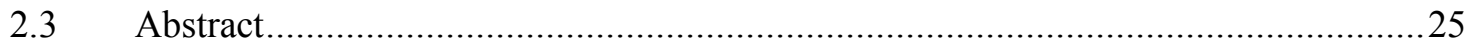

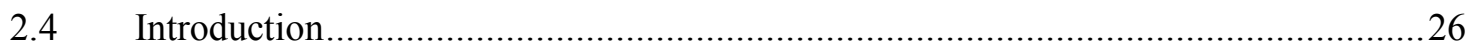

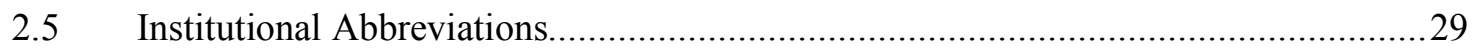

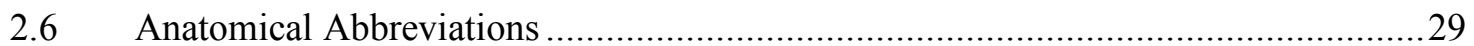

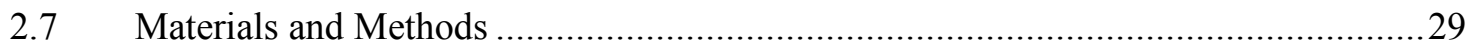

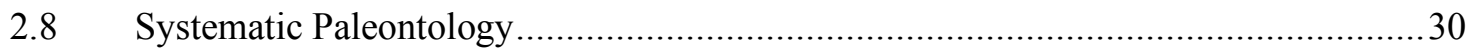

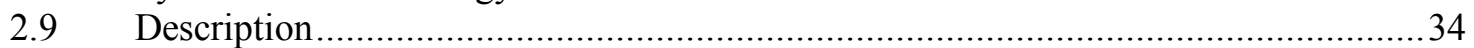

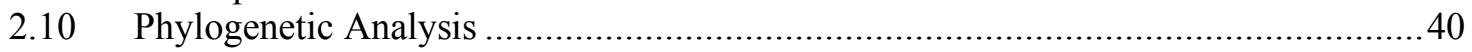

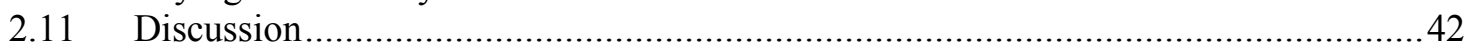

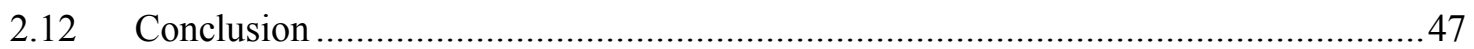

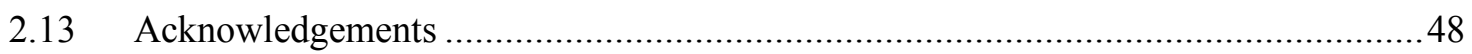

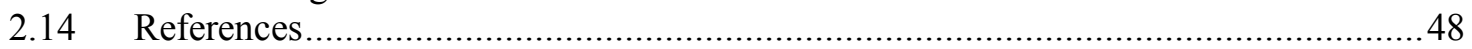

Chapter 3: Infernovenator steenae gen. et sp. nov. a new serpentine recumbirostran

from the 'Mazon Creek' Lagerstätte further clarifies lysorophian origins. ..............53

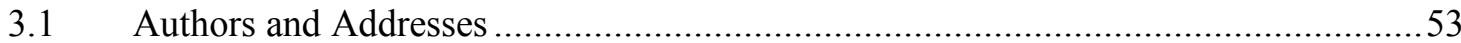

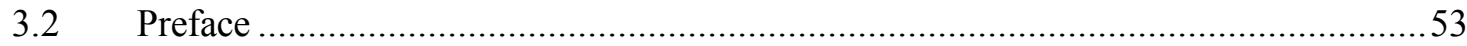

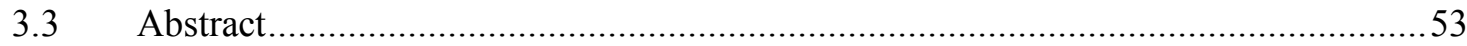

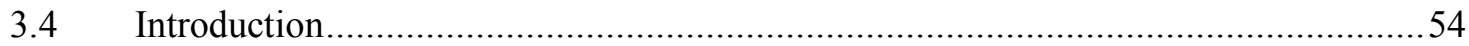

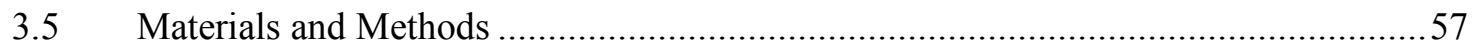

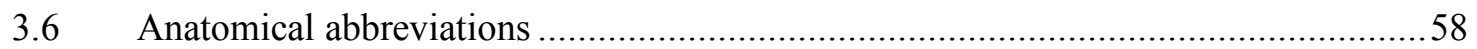

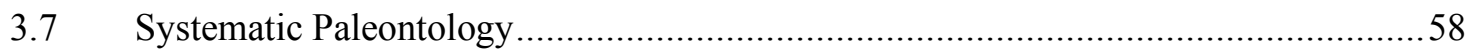




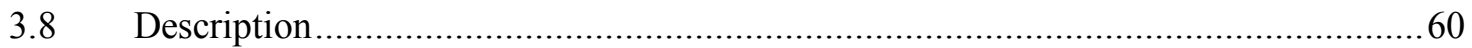

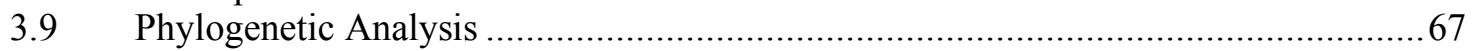

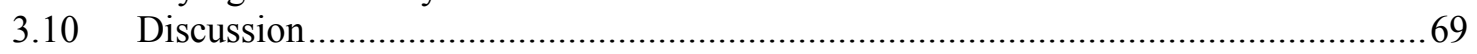

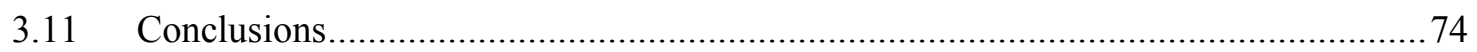

3.12 Acknowledgements ................................................ Error! Bookmark not defined.

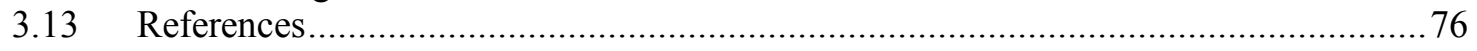

Chapter 4: Carbonodraco lundi gen et sp. nov., the oldest parareptile, from Linton,

Ohio, and new insights into the early radiation of reptiles. ...................................81

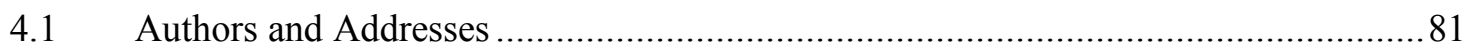

4.2 Preface

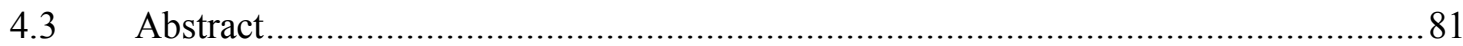

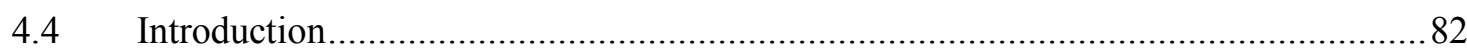

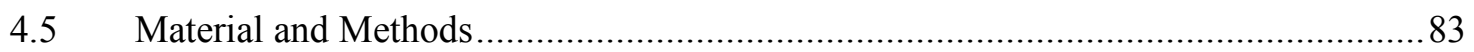

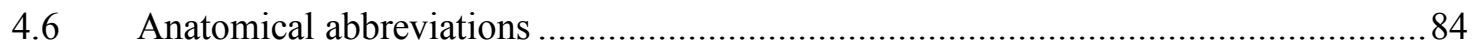

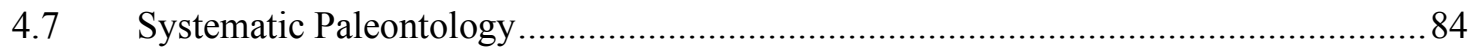

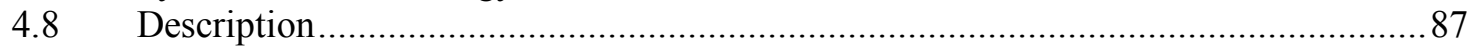

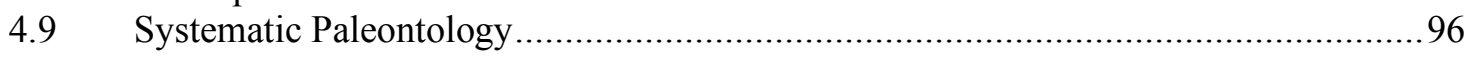

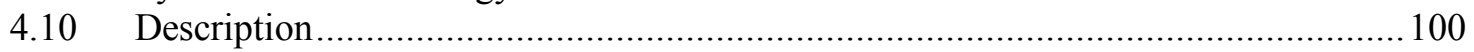

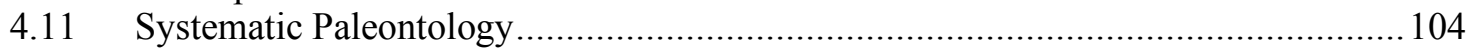

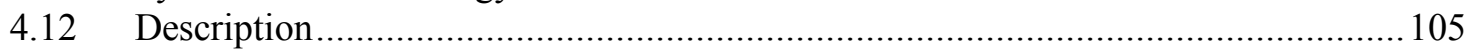

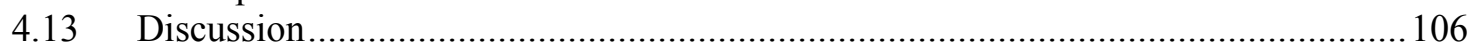

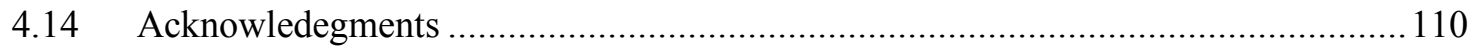

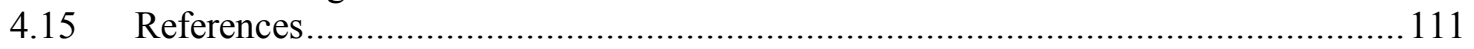

Chapter 5: A new, exceptionally preserved, recumbirostran from the Mazon Creek

Lagerstätte reveals patterns of integumentary evolution in Recumbirostra........... 116

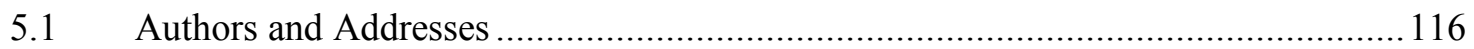

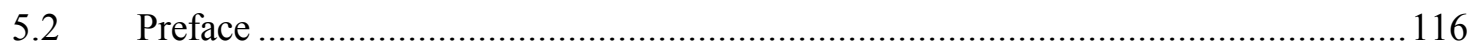

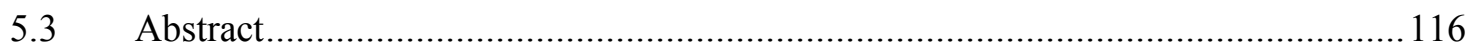

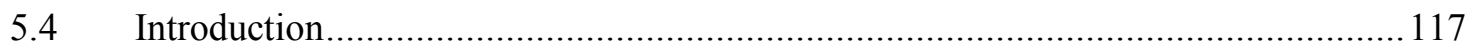

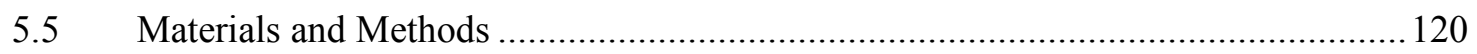

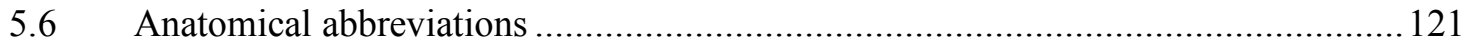

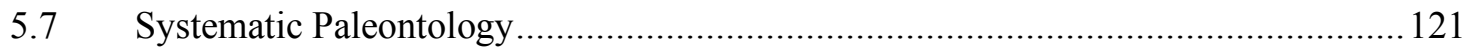

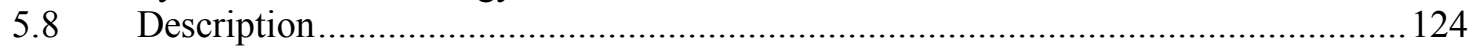

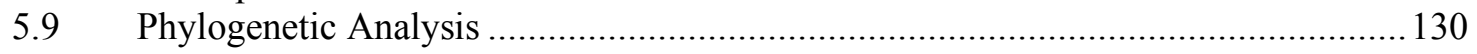

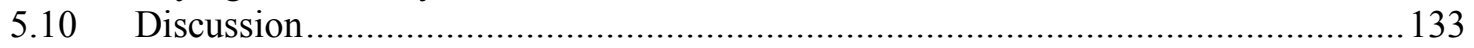

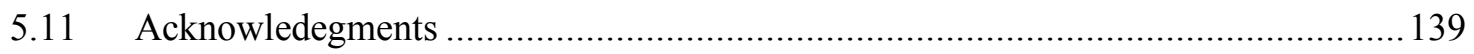

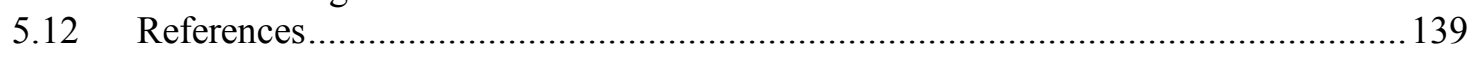

Chapter 6: A farewell to arms: a new molgophid reveals amniote-like limb loss in

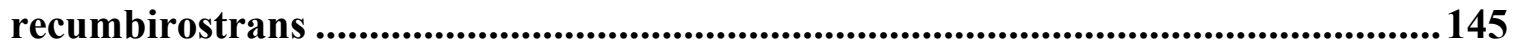

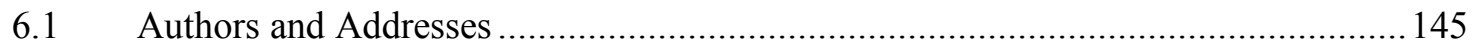

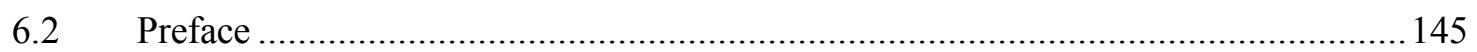

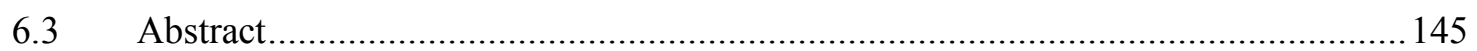

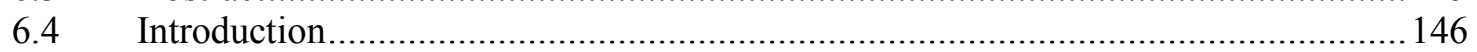

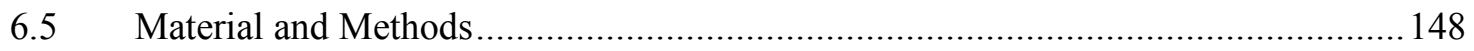

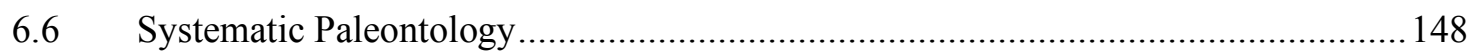




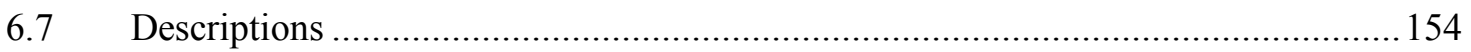

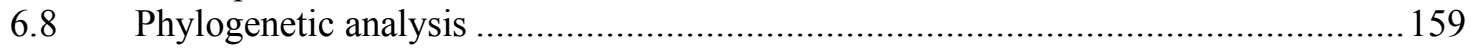

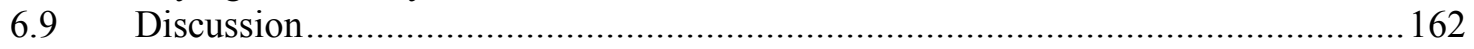

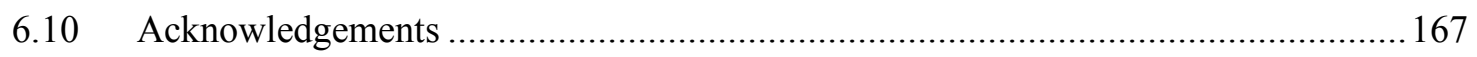

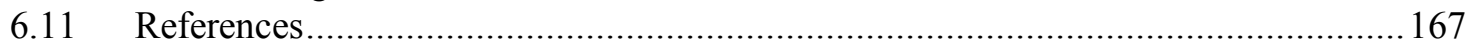

Chapter 7: Conclusions .................................................................................................172

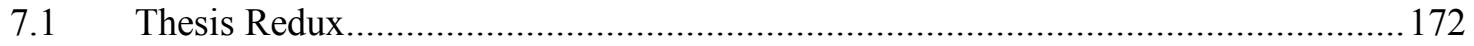

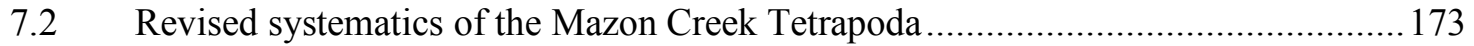

7.3 Future systematic research on the Mazon Creek Tetrapoda .................................... 175

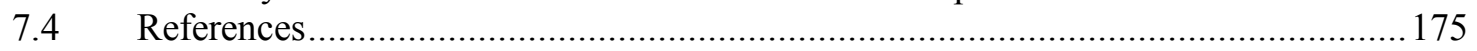

Appendices......................................................................................................................... 177

Appendix A - Chapter 2 Supplementary Information......................................................... 177

A.1 Parsimony strict consensus tree recovered using the heuristic search option of Pardo et al. (2017), including the new taxon, Diabloroter bolti gen et sp. nov. .......................... 177

A.2 Resulting Bayesian tree using the matrix of Pardo et al. (2017), including the new taxon, Diabloroter bolti gen. et sp. nov. Posterior probability values are present above nodes. 178

A.3 Nexus File used for phylogenetic analyses of Diabloroter bolti gen et sp. nov. ... 178

A.4 List of 370 cranial, dental, and postcranial characters used in the analysis of Pardo et al. (2017). The original source of character is noted by the following acronyms: HPSA: Huttenlocker, Pardo, Small, and Anderson (2013), MA: Maddin \& Anderson (2012), CABF: Clack, Ahlberg, Blom, and Finney (2012), N: Neurocranial character novel to Pardo et al. (2017), C: Composite character. Finally, this is the phylogenetic character list used

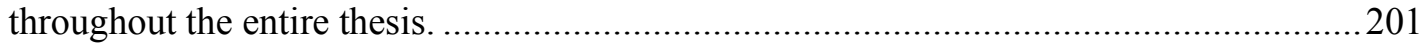

Appendix B - Chapter 3 Supplemental Information .................................................... 220

B.1 Nexus File used for phylogenetic analyses of Infernovenator steenae gen et sp. nov. 220

Appendix C - Chapter 5 Supplemental Information .....................................................242

C.1 Modified Nexus File of phylogeny from Gee et al. (2020) used in Chapter 5.....242

C.2 The only existing latex peel of FMNH 1309, representing a peel of the dorsal

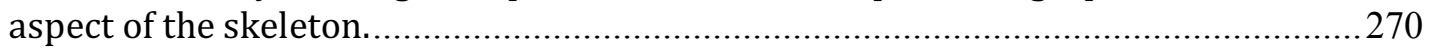

C.3 Scanning Electron Micrograph of cranial scales on FMNH 1309. ...................2271

C.4 Preserved reptile specimens at the Canadian Musseum of Nature used for

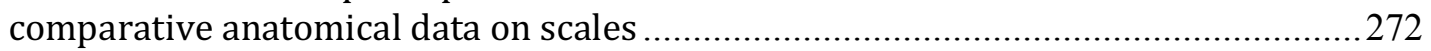

Appendix D - Chapter 6 Supplementary Information......................................................2 275

D.1 Codings for the matrix of Gee et al., 2020, including the new taxon from

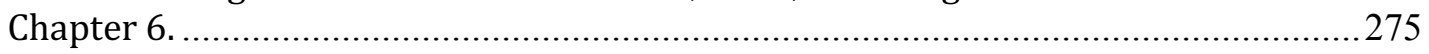

D.2 Digitally stitched (using photoshop CS6), high resolution image of FMNH PR 1301. 304

D.3 Scanning Electron Micrographs (SEMs) of FMNH PR 1301 A-D, showing incomplete

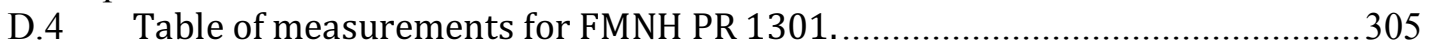




\section{List of Tables}

Table 1 The fauna of the Mazon Creek lagerstätte. (Reproduced from Clements et al. (2019), 1/3 items freely reproduced under the Geological Society of London copyright

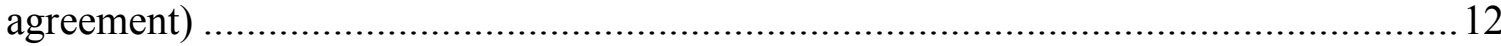




\section{List of Figures}

Figure 1.1 Carboniferous correlative stratigraphic relationships of the Illinois Basin. The Carbondale Formation is highlighted in a red box. (Reproduced with permission from Dr.

Chistopher S. Swezey).

\section{6}

Figure 1.2 Mazon Creek locality information. A, The Mazon Creek fossil assemblage (beige rectangle) in relation to Illinois. B, Illinois during the Pennsylvanian showing the epeiric sea in relation to landmasses $\mathrm{C}$, Illinois (Beige highlight) during the Late Carboniferous. D, Map of the Mazon Creek localities; strip mines/pits are marked with their designate numbers. E, A photograph of the type locality along the banks of the Mazon River. (Reproduced from Clements et al. (2019), 1/3 items freely reproduced under the Geological Society of London copyright agreement)

Figure 1.3 A diagrammatic representation of the Mazon Creek Lagerstätte. A, Showing terrestrial to marine distribution of fossils. B, stratigraphic sequence of the lower metres of the Francis Creek Shale Member and members of the Carbondale Formation. C, Sequence of events required for fossilization in siderite concretions. (Reproduced from Clements et al. (2019), 1/3 items freely reproduced under the Geological Society of London copyright agreement)

Figure 1.4 Historic images of the famous 'Pitt 11' strip min locality A,B. (Images gifted

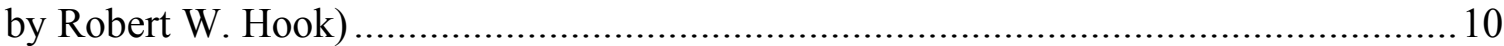

Figure 1.5 Historic images of various Mazon Creek fossils. A-E, some invertebrates and $\mathrm{F}$, a vertebrate. Shows the range of soft tissue preservation found in the lagerstätte. (Images gifted by Robert W. Hook)

Figure 2.1 A, photograph of Diabloroter bolti gen. et sp. nov. in concretion (ACFGM V1634). B, close up of the thoracic region of ACFGM V-1634 with arrow pointing to a cluster of preserved gastralia. C, comparative figure of the thoracic region of Batropetes

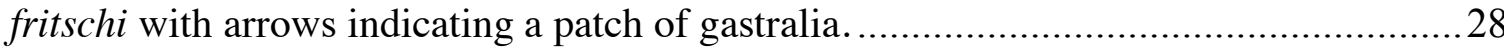

Figure 2.2 A-B, photograph and line drawing of the cranial anatomy of Diabloroter bolti gen. et sp. nov. (ACFGM V-1634) as revealed by a latex peel. C-D, photograph and line drawing of a close-up view of the right dental anatomy of Diabloroter bolti. 32

Figure 2.3 A, photograph and B, line drawing of skeletal anatomy of Diabloroter bolti gen. et sp. nov. (ACFGM V-1634) as revealed by a latex peel (FMNH PR 847). Numbers represent vertebral count position. 33

Figure 2.4 Strict consensus tree of the phylogenetic analysis using parsimony. Major clades indicated at nodes. Diabloroter bolti gen. et sp. nov. (ACFGM V-1634) is indicated in bold. Bootstrap values indicated above nodes; only values above 50 reported. 
Figure 2.5 Life reconstruction of Diabloroter bolti gen et sp. nov. This sculpture was created by D. Duck

Figure 3.1 Photograph A, and illustration B, of the skeletal anatomy of the holotype specimen of Infernovenator steenae gen. et sp. nov. (FMNH MCP 367)

Figure 3.2 Cranial anatomy of the holotype specimen of Infernovenator steenae gen. et sp. nov. (FMNH MCP 367).

Figure 3.3 A-B, Wellstead's (1991) Brachydectes (USNM 4313). C-D, a new immature specimen of Brachydectes newberryi (FMNH PR 1031). E-F, close up views of the dorsal vertebrae and pelvic regions of FMNH PR 1031, respectively. .66

Figure 3.4 Strict consensus tree of the parsimony analysis. Infernovenator steenae gen. et sp. nov. is indicated in bold. Numbers above branches represent bootstrap values. 68

Figure 3.5 A pruned phylogenetic tree depicting relationships of recumbirostrans highlighting fossorial morphology of the cranium. Ancestral character states for cheek condition represent hypothetical optimizations given their distributions among terminal taxa. Different snout shapes are indicated by coloured boxes adjancent to the taxa, representing the conditions explained in the figure legend.

Figure 3.6 Flesh reconstruction of Infernovenator steenae gen et sp. nov. (sculpted by David Duck).....

Figure 4.1 Cephalerpeton ventriarmatum (YPM 796), A) original nodule (cranium in ventral aspect: postcranium in dorsal lateral aspect), and B) resin cast of the original nodule.

Figure 4.2 Illustration of the cranial and postcranial anatomy of Cephalerpeton ventriarmatum (YPM 796), modified from Carroll and Baird (1972), and a cranial reconstruction

Figure 4.3 Carbonodraco lundi gen. et sp. nov., A) the holotype specimen (CM 23055) (Amy C. Henrici photo) and B) latex peel of the holotype specimen.

Figure 4.4 Illustration of the cranial anatomy of the holotype of Carbonodraco lundi gen. et sp nov. (CM 23055), and a reconstruction.

Figure 4.5 Referred specimens of Carbonodraco lundi gen. et sp. nov. A) Latex peel of NHMUK R. 2667 showing a right jaw in lingual perspective (Kathy Bossy peel). B-D) CM 81536. B) Original cannel coal specimen, C) latex peel, and D) drawing, showing a pair of dentaries preserved in lingual perspective. 100

Figure 4.6 Indeterminate reptilian amniote from Linton, Ohio (CM 41714). A) Latex peel, B) drawing, and C) actual specimen. 
Figure 5.1 Photographs of the holotype (FMNH 1309). A, the part specimen showing the dorsal view; $\mathrm{B}$, the counterpart specimen showing the ventral view.

Figure 5.2 Illustrations of the holotype (FMNH 1309). A, dorsal and B, ventral aspects of FMNH 1309

Figure 5.3 Illustrations of the dorsal (A and B) and ventral (C and D) aspects of the skull of FMNH 1309. Illustrations have been digitally reversed in photoshop to show true anatomical orientations

Figure 5.4 A-C, Scanning Electron Micrographs (SEMs) of FMNH 1309, showing progressively closer structures of the dermal scales. D, an idealised illustration of a single dermal scale (not to scale). 130

Figure 5.5 Results of the parsimony phylogenetic analysis showing the position of FMNH 1309 as sister taxon to all brachystelechids. Bootstrap values are located on top of nodes (only those over 50 reported). Total-group Recumbirostra indicated in orange and total-group Amniota is indicated in red.

Figure 5.6 Simplified phylogeny of recumbirostrans showing integumentary structures and body elongation, (?) indicates uncertain states. Body elongation is indicated in silhouettes with grey=no body elongation; black=body elongation present..

Figure 5.7 Flesh reconstruction of FMNH 1309. (sculpted by David Duck)

Figure 6.1 Photographs of the new molgophid (MPM VP359229.2). A and B, the entire holotype, MPM VP359229.2, part and counterpart, respectively. C and D, close up photographs of the skull in part and counterpart, respectively.

Figure 6.2 Illustrations of the part A, and counterpart B, of the holotype of the new molgophid taxon (MPM VP359229.2).....

Figure 6.3 Photographs of the specimen FMNH PR 1301, that is referred to the new molgophid genus and species, revealing both part A, and counterpart B.....

Figure 6.4 Illustrations of the part A, and counterpart B, of the referred specimen (FMNH PR 1301) of the new molgophid.

Figure 6.5 Results of the phylogenetic parsimony analysis showing the position of the new molgophid as sister taxon to Infernovenator. Bootstrap values are located on top of nodes (only those over 50 reported). Total-group Recumbirostra indicated in orange and total-group Amniota is indicated in red.....

Figure 6.6 Simplified time-calibrated phylogeny of recumbirostrans showing limb reduction and body elongation. Limb reduction is indicated by coloured dots on terminal 
branches, pale orange $=$ indicates no reduction; pink $=$ slightly reduced limbs (including digital reduction); light blue $=$ fore or hindlimb absence or extreme limb reduction. Body elongation is indicated in silhouettes with light grey=no body elongation; dark grey=slight elongation; black=extreme body elongation.

Figure 6.7 Comparative pectoral and forelimb morphology of Mazon Creek amniotes and amniote-like taxa. Note the diverse ecomorphology of the Mazon Creek pan-amniote fauna revealing a range of well-developed (Cephalerpeton) to completely absent forelimb

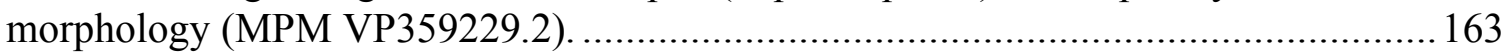




\section{List of Appendices}

Appendix A - Chapter 2 Supplementary Information...................................................... 177

A.1 Parsimony strict consensus tree recovered using the heuristic search option of Pardo et al. (2017), including the new taxon, Diabloroter bolti gen et sp. nov. .......................... 177

A.2 Resulting Bayesian tree using the matrix of Pardo et al. (2017), including the new taxon, Diabloroter bolti gen. et sp. nov. Posterior probability values are present above nodes. 178

A.3 Nexus File used for phylogenetic analyses of Diabloroter bolti gen et sp. nov. ... 178

A.4 List of 370 cranial, dental, and postcranial characters used in the analysis of Pardo et al. (2017). The original source of character is noted by the following acronyms: HPSA: Huttenlocker, Pardo, Small, and Anderson (2013), MA: Maddin \& Anderson (2012), CABF: Clack, Ahlberg, Blom, and Finney (2012), N: Neurocranial character novel to Pardo et al. (2017), C: Composite character. Finally, this is the phylogenetic character list used throughout the entire thesis.

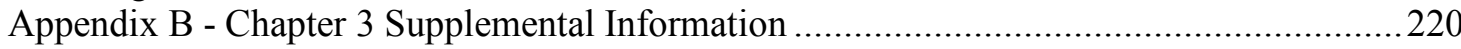

B.1 Nexus File used for phylogenetic analyses of Infernovenator steenaegen et sp. nov. 220

Appendix C - Chapter 5 Supplemental Information .242

C.1 Modified Nexus File of phylogeny from Gee et al. (2020) used in Chapter 5.....242

C.2 The only existing latex peel of FMNH 1309, representing a peel of the dorsal

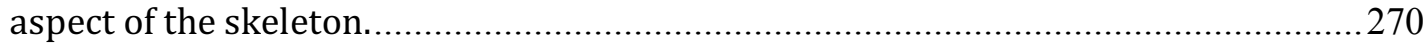

C.3 Scanning Electron Micrograph of cranial scales on FMNH 1309...................227

C.4 Preserved reptile specimens at the Canadian Musseum of Nature used for

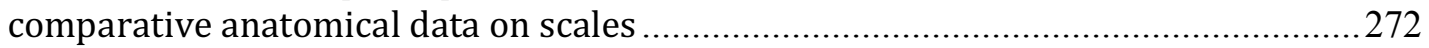

Appendix D - Chapter 6 Supplementary Information....................................................2 275

D.1 Codings for the matrix of Gee et al., 2020, including the new taxon from

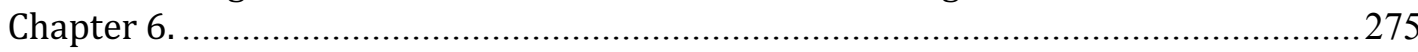

D.2 Digitally stitched (using photoshop CS6), high resolution image of FMNH PR 1301. 304

D.3 Scanning Electron Micrographs (SEMs) of FMNH PR 1301 A-D, showing incomplete

D.4 Table of measurements for FMNH PR 1301 


\section{|Chapter 1: Introduction}

\subsection{Thesis Rationale \& Amniote Origins}

The fossil record documents major transitions in the evolution of vertebrates and contributes to understanding the earth system as a whole. It is by studying the fossil record that we can understand the origins and maintenance of biodiversity on earth through time. Tetrapoda, the clade that includes all land-dwelling vertebrates such as lissamphibians, reptiles, and mammals (including Homo sapiens) (Jaekel 1909), evolved from sarcopterygian 'lobe-finned' fishes sometime during the mid-late Devonian Period (Ahlberg et al., 1996; Shubin et al., 2006). The acquisition of living tetrapod-like anatomies, such as the acquisition of a limb from a fin, are captured in the ever-growing fossil record of stem-tetrapods otherwise known as tetrapodomorph fishes (Ahlberg et al., 1996; Shubin et al., 2006; Downs et al., 2008; Boisvert et al., 2008; Shubin et al., 2014; Clack et al., 2016; Cloutier et al., 2020). Recent studies (e.g. Clack et al., 2016, Pardo et al., 2017, Pardo and Mann, 2018) have revealed that the tetrapod stem-group were more ecologically diverse than previously recognized, with some members possessing unique body forms and craniodental specializations. Some of these stem-tetrapod lineages, such as the serpentine, long-bodied, limbless group known as Aïstopoda, continued to play a major role in terrestrial ecosystems throughout the Permo-Carboniferous (Pardo et al., 2017).

Shortly after the Devonian origins of limbed tetrapodomorph fishes, a second event critical to the terrestrialization of vertebrates occurred during the midCarboniferous that saw the rise of crown-group tetrapods including ancestors of modern amphibians and amniotes (i.e., those with a cleidoic/amniotic egg including mammals and reptiles). The permanent colonization of the land by amniotes began the emancipation from the aquatic realm, which in turn allowed for the exploitation of new terrestrial niches and in turn the establishment of modern terrestrial ecosystems (Sues and

Reisz, 1998). The current understanding of amniote phylogeny (Laurin and Reisz, 1995; Ford and Benson, 2020) posits that there is a basal dichotomy leading to two distinct lineages of amniotes: the Synapsida (Osborn, 1903; Gauthier et al., 1988) that includes 
mammals and their kin, and Reptilia that includes all crocodiles, birds, lepidosaurs and their extinct relatives (Laurenti, 1768; Modesto and Anderson, 2004).

The early fossil record of crown-group tetrapods, including amniotes, is captured by a series of Pennsylvanian-aged fossil localities. The earliest unequivocal fossil evidence of amniotes comes from the Bashkirian-aged deposits ( 318-315 mya) of Joggins, Nova Scotia, where both the oldest reptile, Hylonomus lyelli (Dawson, 1860), and more recently the likely oldest synapsid, Asaphestera platyris (Mann et al., 2020), have been found. In addition to Joggins, there are also a number of other principal 'Westphalian' tetrapod localities such as Florence, Nova Scotia; Jarrow, Ireland; Mazon Creek, Illinois; Linton and Five points, Ohio; Nýřany, Czech Republic; and Newsham, United Kingdom. Many of the Moscovian-aged Pennsylvanian localities including Mazon Creek, and Linton, Ohio, qualify as lagerstätten or sites of exceptional preservation in both number and quality of fossils. These sites offer unique windows into Carboniferous ecosystems, often preserving representatives of every trophic level (e.g. plants, insects, fish, and tetrapods).

Even within these Carboniferous lagerstätten, fossil amniotes are exceedingly rare, represented only by a handful of taxa. This has led to the notion that amniotes only began to diversify around the Permo-Carboniferous boundary, followed shortly by the establishment of synapsid-dominated terrestrial communities in the Permian. The latest Pennsylvanian localities (Kasimovian-Gzhelian), such as Garnett, Kansas (305 Ma), show a spike in amniote diversity ( 8 amniotes: 6 synapsids) providing support for this terminal Carboniferous radiation (Reisz, 1977; Reisz and Berman, 1986; Kissel and Reisz, 2004). Thus, there is an approximate 13-million-year lag between the Bashkirian origin of amniotes, and when an amniote-dominated fauna appears at the terminal Carboniferous. One prevalent theory explaining the 'long-fuse' diversification of amniotes is that Carboniferous climate change causing global rainforest collapse drove the diversification of amniotes along with other tetrapods (Sahney et al., 2010; Dunne et al., 2018; Pardo et al., 2019). Prior to the Quaternary, the Carboniferous-Permian transition was Earth's last icehouse-greenhouse transition, where major climatic and environmental shifts led to the fragmentation of dense Carboniferous coal swamps opening a variety of new dryland environmental systems. During the Moscovian Stage, 
amniotes are already thought to have inhabited dryer upland environments (Riesz, 1972; Olson, 1975); by the end of the Moscovian, the fragmentation of vast wetland rainforests and resulting emergence of more arid landscapes is thought to have further facilitated the diversification and dispersal of amniotes and in turn the emergence of dry-land terrestrial communities (Dunne et al., 2018). Although recent metadata studies (e.g. Sahney et al., 2010; Dunne et al., 2018; Pardo et al., 2019) have linked Carboniferous climate change to a reorganization of vertebrate diversity (including several extinctions), most of these analyses have relied on an outdated and aging systematic framework for early tetrapods, and in particular amniote tetrapods (Laurin and Reisz, 1995).

In contrast to the 'long-fuse' hypothesis, a second 'short-fuse' hypothesis may be postulated that predicts the initial adaptive radiation of amniotes to have occurred much earlier around the Mississippian-Pennsylvanian boundary (Pardo et al., 2017). This would posit that the establishment of major Permo-Carboniferous clades of amniotes was rapid after the initial origin of amniotes. This hypothesis also aligns better with the predicted divergence dates for the oldest fossil amniotes (Reisz and Müller, 2004). Theoretically, the reproductive and physiological adaptations of early amniotes should have allowed for the immediate exploitation of unnumbered new terrestrial niches - such ecological opportunity is ideal for adaptive radiations (Schluter, 2000; Stroud and Losos, 2016). Identifying adaptive radiations in the fossil record, however, is notoriously difficult as the coarseness of the fossil record, often with gaps of millions of years between evolutionary forms, does not lend itself to the rapid timeframe of adaptive radiations. Despite this, adaptive radiations can be inferred from the fossil record on the basis of a combination of high rates of taxonomic and ecomorphological diversity appearing in a relatively short geological time. At present, an abundance of fossil species supporting an early adaptive radiation of amniotes is lacking, but may be an artifact of poor sampling and/or misidentification of amniote fossils at Carboniferous localities. Unlike later Permian-aged fossil deposits (e.g. Richard Spur), Carboniferous paleontology has not benefited from the same sampling or research efforts. It is one of the objectives of this thesis to begin the process of rectifying this deficiency.

In order to adequately predict the timing of the adaptive radiation of amniotes a renewed systematic treatment of the group is required. A recent set of phylogenetic 
hypotheses for early amniote relationshipshave proposed new configurations to the amniote tree (Pardo et al., 2017; Klembara et al., 2020; Ford and Benson, 2020). Ford and Benson (2020) have proposed that both the synapsid clade Varanopidae and reptilian clade Parareptilia are both groups of diapsid reptiles, suggesting diapsid-like temporal fenestration evolved fewer times than previously recognised. Klembara et al. (2020) recovered the traditionally stem-amniote group, Diadectomorpha, as amniotes more closely related to synapsids than reptiles. Finally, Pardo et al. (2017) recovered a diverse group of fossorially adapted 'microsaurs' known as recumbirostrans as bona-fide reptiles rather than as stem-amniotes. 'Microsaurs' have had a long history of flipping in-and-out of the amniote crown-group (Romer, 1950; Vaughn, 1962; Gregory, 1965; Carroll and Baird, 1968). In recent years, the order Microsauria, as described by Carroll and Gaskill (1978), has been found to be a paraphyletic assemblage, despite a core-group of 'microsaurs' known as recumbirostrans forming a natural, monophyletic group (Anderson, 2007; Huttenlocker et al., 2013). The newest phylogenetic hypothesis for recumbirostrans, put forward by Pardo et al. (2017), takes a novel approach by intensely sampling neurocranial morphology. The tetrapod braincase has been shown to be a conservative evolutionary module, that is constrained by its development from a cartilaginous precursor and by the influence of the central nervous system, and thus is a more reliable indicator of phylogeny than other aspects of the skeleton (Cardini and Elton, 2008; Goswami and Polly, 2010; Maddin, 2011; Maddin et al., 2012). Because the skulls of recumbirostrans are hyperossified and highly modified for burrowing, this approach is particularly useful. Hyperossification of the recumbirostran braincase has resulted in regions that normally remain cartilaginous in the tetrapod endocranium to become full ossified (e.g. pleurosphenoid, presphenoid etc.). While this anatomy in recumbirostrans is not directly comparable to the ossified endocranial structures in early tetrapods, it can be directly compared to distinct regions of the cartilaginous neurocranial template-particularly of the amniote skull (Pardo et al., 2015). This unconventional method of deriving homologous structures is used by Pardo et al. (2017) to reinterpret recumbirostran neurocranial elements (previously noted as neomorphs), as homologous with observed anatomical structures in basal eureptiles. This new data, alongside recognition of more 'classic' amniote characters in recumbirostrans (e.g. astragalas and 
calcaneum) makes for a robust hypothesis that is favoured in this thesis. In addition to its novel approach, this phylogenetic hypothesis for recumbirostran relationships is presently favoured for its up-to-date systematic treatment of tetrapod interrelationships, in particular the recognition of a polyphyletic 'Lepospondyli'.

The inclusion of Recumbirostra into Amniota is potentially the most important of these new findings, and would increase the taxonomic diversity of reptiles at their onset from one to several genera, as predicted by the 'short-fuse' hypothesis (Mann et al., 2020). This inclusion would also indicate there is an unprecedented amount of ecomorphological diversity within early reptiles, as recumbirostrans show a variety of fossorial adaptations many of which are comparable to those of extant fossorial squamates (Maddin et al., 2011; Huttenlocker et al., 2013; Pardo et al., 2015; Szostakiwskyj et al., 2015; Pardo and Anderson, 2016; Gee et al., 2019; Gee et al., 2020). Coinciding with these new phylogenetic investigations, a plethora of new recumbirostran fossils have come to light, hailing from the Mazon Creek fossil localities (307-309 Ma) (Figs. 1.1 and 1.2). These new fossils, which have formed the basis for this doctoral dissertation, are represented by extremely small, but virtually complete tetrapod fossils, that are preserved in siderite concretions. The exceptional quality of preservation at Mazon Creek allows for the study of delicate anatomy, including soft tissues and other labile structures, that can further aid in deciphering ecomorphology. Collectively, given the age and quality of fossils from Mazon Creek, this new dataset provides the perfect starting point for reappraising systematics of Carboniferous fossil amniotes. The following dissertation aims to address three primary questions: first, what is the alphataxonomic diversity of the amniote fauna of Mazon Creek? Second, what is the ecomorphological diversity of the amniote fauna of Mazon Creek? Third, and finally, what can the Mazon Creek amniote fauna tell us about adaptive radiation of amniotes? The next section provides historical and geological background on the Mazon Creek fossil assemblage to place these questions in context. 


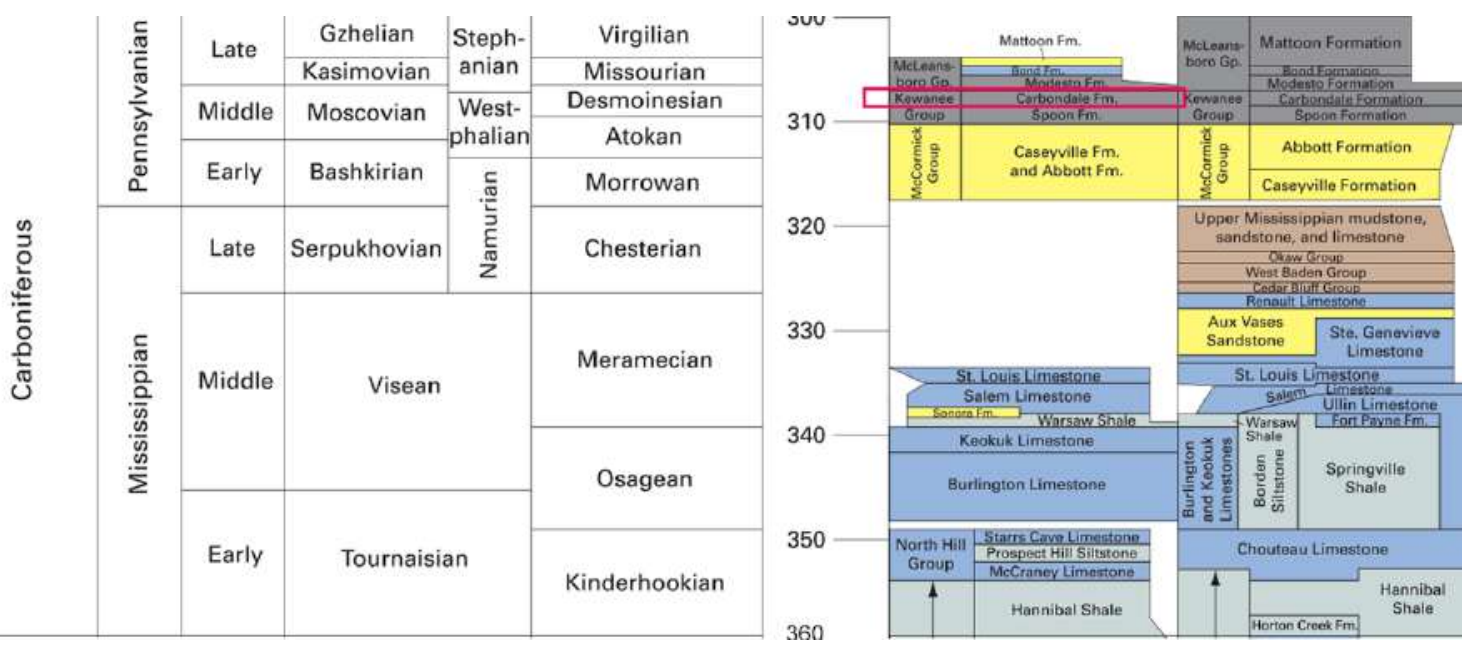

Figure 1.1 Carboniferous correlative stratigraphic relationships of the Illinois Basin. The Carbondale Formation is highlighted in a red box. (Reproduced with permission from Dr. Chistopher S. Swezey)
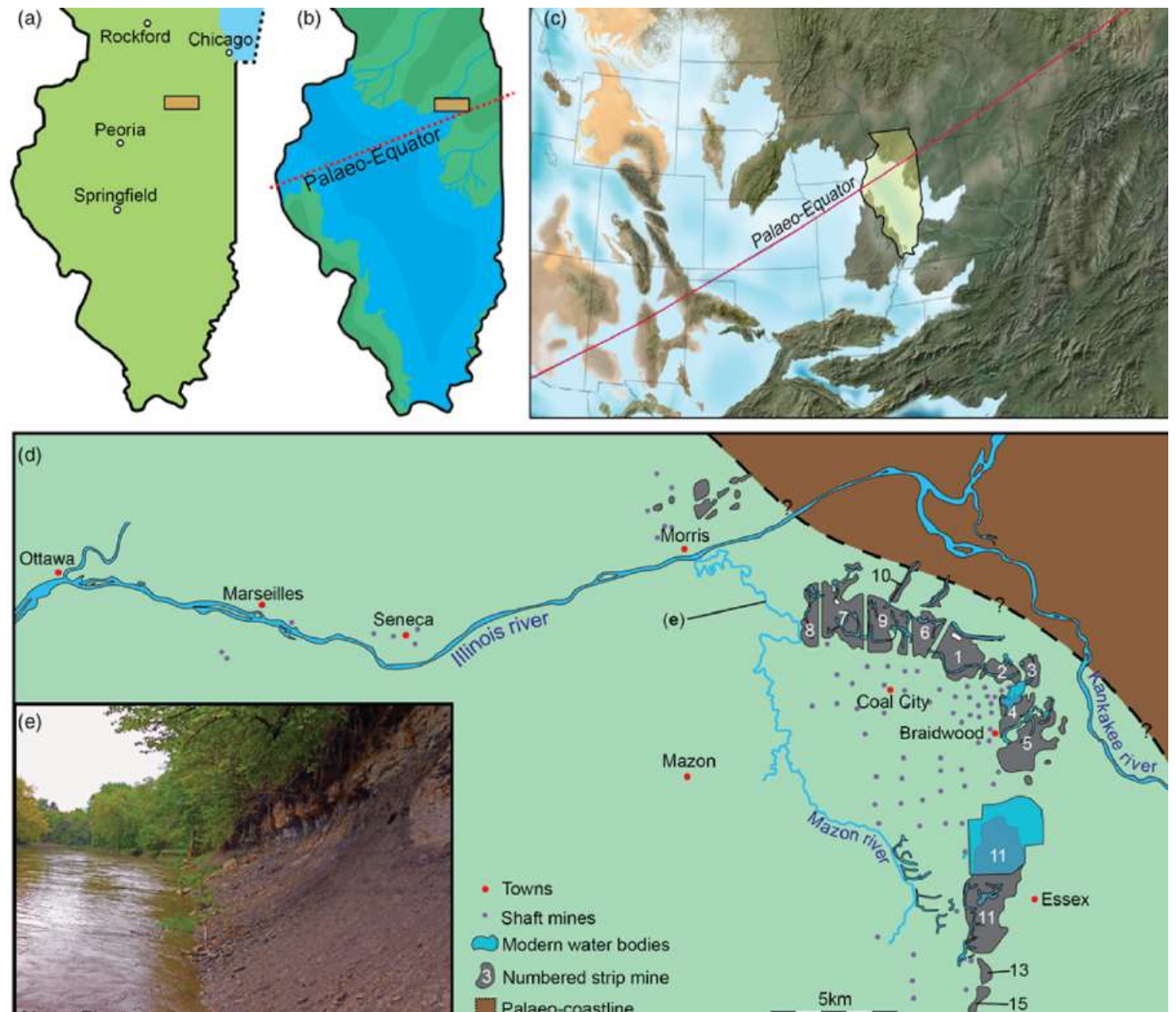

Figure 1.2 Mazon Creek locality information. A, The Mazon Creek fossil assemblage (beige rectangle) in relation to Illinois. $\mathrm{B}$, Illinois during the Pennsylvanian showing the epeiric sea in relation to landmasses $\mathrm{C}$, Illinois (Beige highlight) during the Late Carboniferous. D, Map of the 
Mazon Creek localities; strip mines/pits are marked with their designate numbers. E, A photograph of the type locality along the banks of the Mazon River. (Reproduced from Clements et al. (2019), 1/3 items freely reproduced under the Geological Society of London copyright agreement)

\subsection{The Mazon Creek Lagerstätte \& Thesis Structure}

One of the most enigmatic Carboniferous tetrapod bearing deposits is the Pennsylvanian-aged (Westphalian C; 309-307 Ma) Mazon Creek lagerstätte, Illinois (Moodie, 1912; Shabica and Hay, 1997) (Fig. 1.1). The Mazon Creek lagerstätte, unlike other early tetrapod sites, is comprised of multiple localities distributed throughout the Francis Creek Shale Member, of the Carbondale Formation, Illinois Basin, that spans six counties including Will, Grundy, Kankakee, Livingston, LaSalle, and Fulton (Shabica and Hay, 1997) (Fig. 1.2). The geographically wide separation of these localities make it difficult to associate fossils to one fauna, and it is rather best viewed as an assemblage or a collection of faunas sharing similar depositional and taphonomic modes of preservation (Fig. 1.3). The Francis Creek Shale Member of the Carbondale Formation was originally identified and described by Savage (1927) but the present definition comes from Wanless (1929) who restricted the Francis Creek to the 30-39 ft soft gray shale facies. The shale's name derives from the Francis Creek in Fulton County, Illinois, where the type section is located (Savage, 1927; Wanless, 1929). The Francis Creek Shale directly overlies the Colchester No. 2 coal seam and underlies the Mecca Quarry Shale (Wanless, 1929) (Figs. 1,3). The lithology of the shale is best described as a mudstone or weakly layered shale that is light to medium gray in colour and clay to finely silty in texture (Wanless, 1929; Baird, 1997). The shale exhibits rhythmic, pin-stripe lamination with clearly defined tidal neap and spring cycles (Kuecher et al., 1990; Archer et al., 1995). 

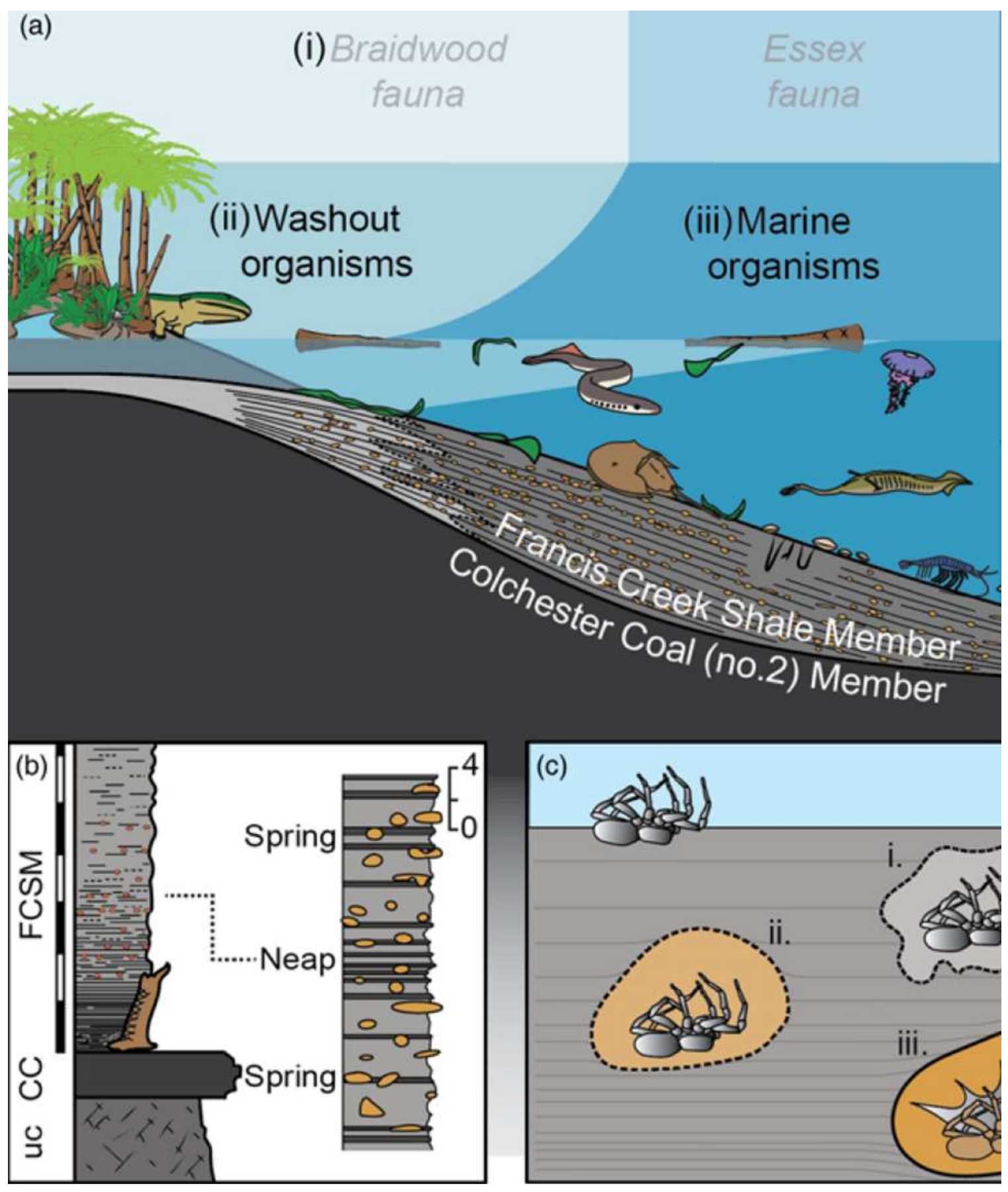

Figure 1.3 A diagrammatic representation of the Mazon Creek Lagerstätte. A, Showing terrestrial to marine distribution of fossils. B, stratigraphic sequence of the lower metres of the Francis Creek Shale Member and members of the Carbondale Formation. $C$, Sequence of events required for fossilization in siderite concretions. (Reproduced from Clements et al. (2019), 1/3 items freely reproduced under the Geological Society of London copyright agreement) 
The paleoenvironment represented in the Francis Creek Shale facies has been interpreted by Baird (in Shabica and Hay 1997) as deltas that rapidly prograded into an embayment or estuary that opened outward toward the west (Fig. 1.2). Kuecher et al. (1990) and Archer et al. (1995) identified rhythmic lamination patterns indicating semidiurnal mesotidal to macrotidal ranges, or simply put, twice-daily tides with moderate to high tidal range. The preservation of upright tree trunks, sideways leaves, escape burrows, and soft-bodied animals demands near torrential sediment aggradation (Baird et al., 1985ab; 1986). Kuecher et al. (1990) was able to determine the average sedimentation rate by counting neap-spring tidal cycles in the Braidwood area; they determined an average sedimentation rate of $1.0 \mathrm{~m}$ (3.3 feet) per year. This great burial rate may partially explain preservation of soft-bodied organisms.

Mazon Creek fossils are preserved in siderite nodules that can be found within the exposed beds at surrounding creeks or in the many spoil heaps of coal mines in the area (Shabica and Hay, 1997) (Figs. 1.2-1.5). In situ, siderite nodules are typically found in the 3-5 m overlying the Colchester No. 2 coal seam (Baird, 1997) (Figs. 1.2, 1.3). Nodules may split naturally to reveal part and counterpart preserving differing aspects of fossil organisms (Fig. 1.5), or can be artificially split using a variety of methods including the 'freeze-thaw' method - leaving concretions in water-filled buckets outside over seasonal freeze-thaw cycles (see Shabica and Hay, 1997). Tetrapods from the site are preserved as natural molds, usually infilled with kaolinite, pyrite, among other less common minerals. These natural molds can be cleaned out in order to make latex peels to study the anatomy in positive relief. Like other lagerstätten, Mazon Creek is notable for its exceptional preservation of fossil soft tissues on tetrapods. These include integumentary impressions of the body cavity, scales, and organ systems (Moodie, 1912; Milner, 1982). 


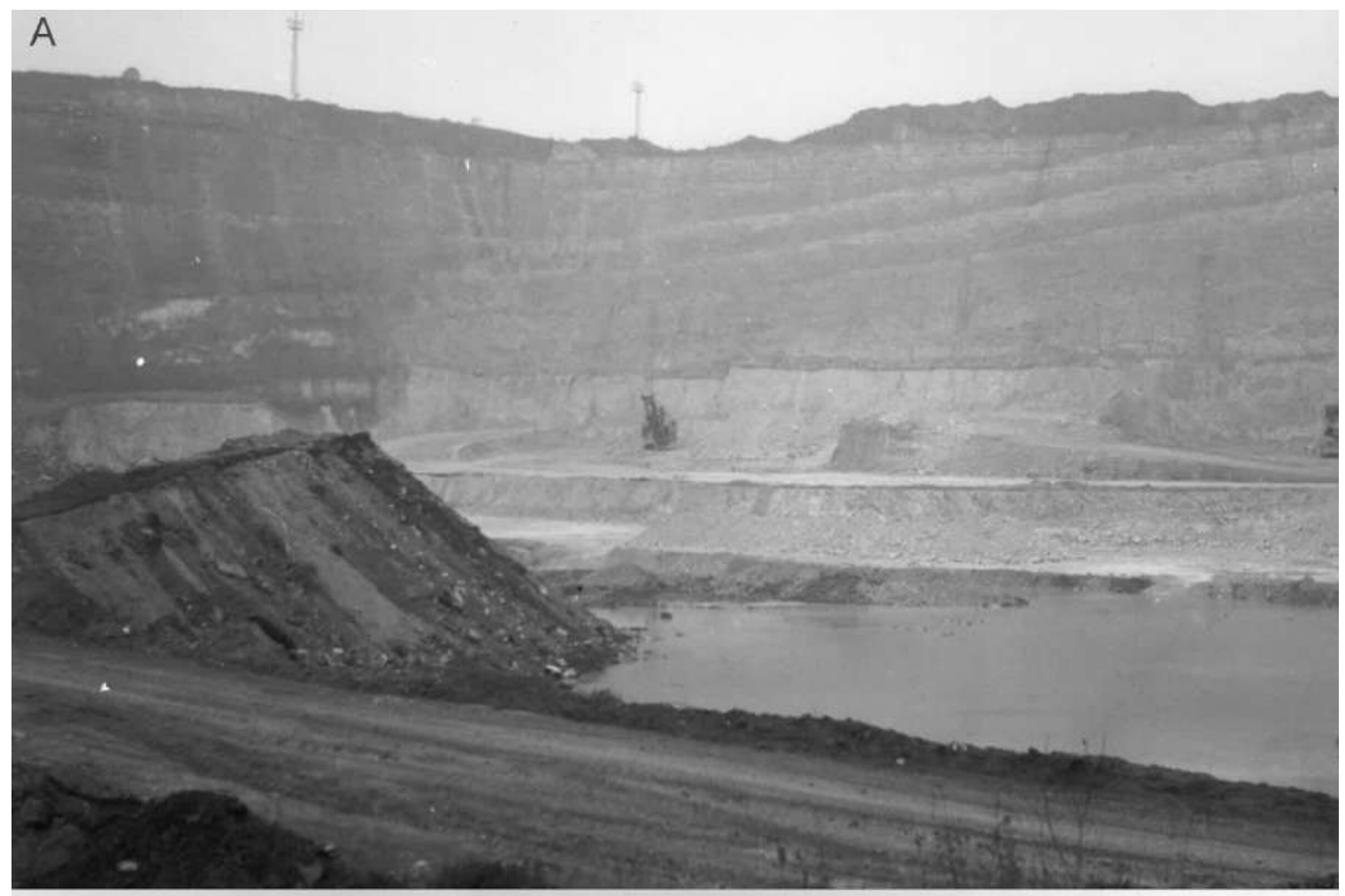

B

c

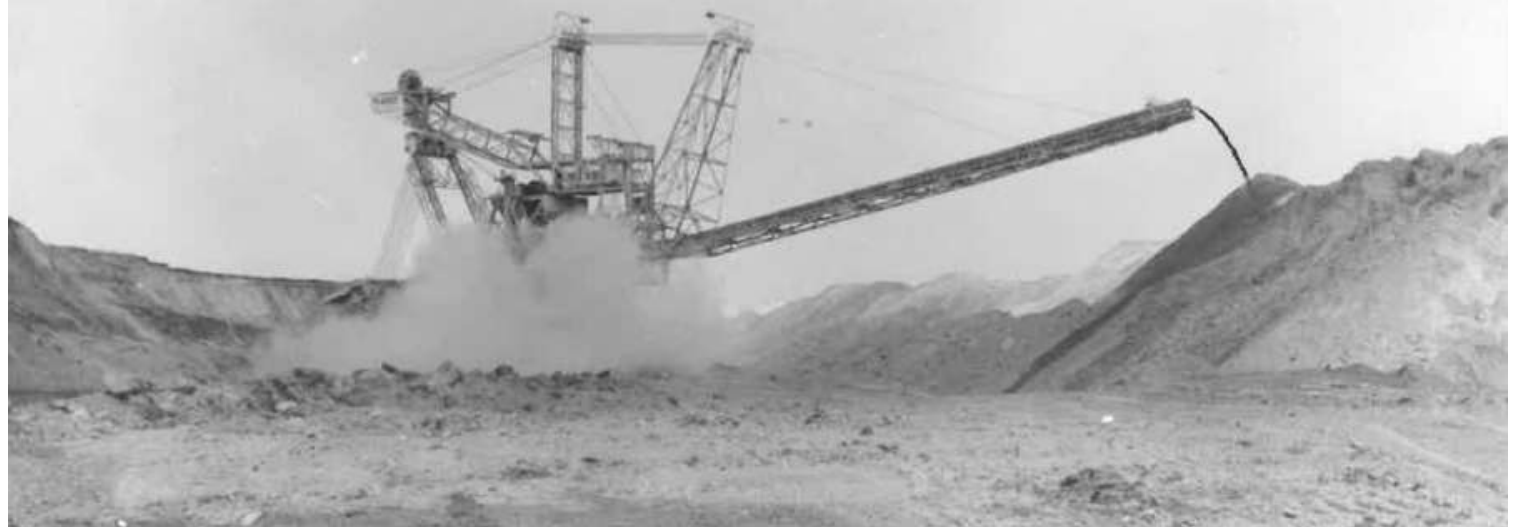

Figure 1.4 Historic images of the famous 'Pitt 11' strip mine locality A,B. (Images gifted by Robert W. Hook) 


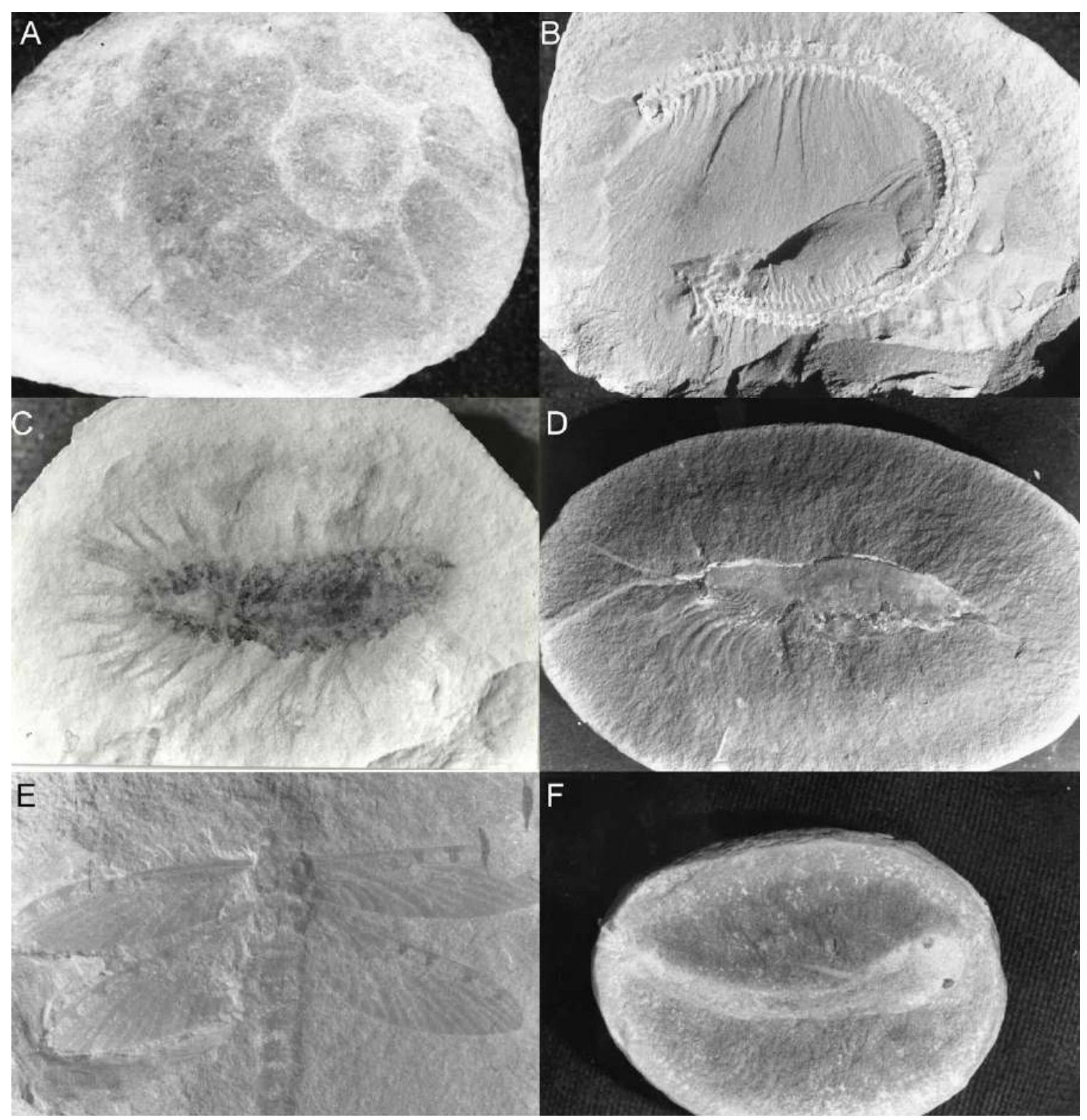

Figure 1.5 Historic images of various Mazon Creek fossils. A-E, some invertebrates and F, a vertebrate. Shows the range of soft tissue preservation found in the lagerstätte. (Images gifted by Robert W. Hook)

Historically, the Mazon Creek assemblage has been split into two distinct faunaethe nearshore Braidwood and the deeper marine Essex (Richardson and Johnson, 1971; Baird et al., 1985b, 1986; Baird, 1997) (Figs. 1.2, 1.3). However, a recent study by Clements et al. (2019) demonstrated these fossil assemblages to be indistinct and not supported by geological data, thus are artificial (Fig. 1.3). The authors instead advocate the terms 'washout organisms' and 'marine organisms' to more accurately describe the 
fossil fauna and flora (Fig. 1.3). Most localities in Mazon Creek preserve rich fossil assemblages of freshwater and marine invertebrates, fish, the famous 'tully-monster' of debated affinity and terrestrial erratics (washouts) such as spiders, insects, and very rarely tetrapods (Baird et al., 1986; Shabica and Hay, 1997; Clements et al., 2019) (Figs. 1.3, 1.5; Table 1).

\begin{tabular}{|c|c|c|c|c|}
\hline Phylum & Class & Orders represented & Number of sp. & Common name \\
\hline \multirow[t]{5}{*}{ Cnidaria } & Cuboza & 1 & 1 & Sea wasps and box jellyfish \\
\hline & Scyphozoa & 1 & 4 & 'True' jellyfish \\
\hline & Hydrozoa & 1 & 2 & Hydras and siphophores \\
\hline & Anthozoa & 1 & 1 & Sea anemones and corals \\
\hline & Unknown & $?$ & $11 ?$ & \\
\hline Nemertea & & 1 & 1 & Ribbon worms \\
\hline Nemotoda & & 1 & 1 & Nematodes \\
\hline Priapulida & & 1 & 1 & Penis worms \\
\hline Chaetognatha & & 1 & 1 & Arrow worms \\
\hline Annelida & Polychaeta & 7 & $16 ?$ & Segmented worms \\
\hline Onychophora & & 1 & 1 & Velvet worms \\
\hline \multirow[t]{11}{*}{ Arthropoda } & Chelicerata & 12 & 43 & Horseshoe crabs, arachnids and sea spiders \\
\hline & Euthycarcinoidea & 1 & 3 & Extinct arthropod group \\
\hline & Diplopoda & 2 & $17 ?$ & Millipedes \\
\hline & Chilopoda & 2 & 3 & Centipedes \\
\hline & Arthropleurideat & 1 & 2 & Extinct giant millipedes \\
\hline & Insecta & 11 & $210+$ & Insects \\
\hline & Remipedia & 1 & 1 & 'Oar-footed' marine crustaceans \\
\hline & Malacostraca & 8 & 14 & Crabs, lobsters, shrimps, etc. \\
\hline & Phyllopoda & 3 & 4 & Fairy and clam shrimp \\
\hline & Maxillopoda & 3 & 7 & Copepods, barnacles and tongue worms \\
\hline & Thylacocephalat & 2 & 3 & Extinct 'head pouch' arthropods \\
\hline \multirow[t]{4}{*}{ Mollusca } & Polyplacophora & 1 & 1 & Chitons \\
\hline & Gastropoda & 1 & 5 & Slugs and snails \\
\hline & Bivalvia & 8 & 24 & Bivalves \\
\hline & Cephalopoda & $4 ?$ & $11 ?$ & Cephalopods \\
\hline \multirow[t]{2}{*}{ Brachiopoda } & Inarticulata & 2 & 2 & Non-hinged brachiopods \\
\hline & Articulata & 1 & 1 & Hinged brachiopods \\
\hline \multirow[t]{2}{*}{ Echinodermata } & Holothuroidea & 1 & 1 & Sea cucumbers \\
\hline & Crinoidea & 1 & 1 & Crinoids \\
\hline Hemichordata & Enteropneusta & 1 & 1 & Acorn worms \\
\hline \multirow[t]{6}{*}{ Chordata } & Cyclostomata & 3 & 4 ? & Jawless fish \\
\hline & Chondrichthyes & 6 & $15 ?$ & Cartilaginous fish \\
\hline & Osteichthyes & 3 & 14 & Ray finned fish \\
\hline & Sarcopterygii & 2 & 11 & Lobe finned fish \\
\hline & Amphibia & 4 & 7 & Amphibians \\
\hline & Amniota & 1 & 6 & Reptiles \\
\hline Incertae sedis & & & $9+$ & \\
\hline Trace fossils & & & $7+$ & \\
\hline & Total: & 103 & $465+$ & \\
\hline
\end{tabular}

Table 1 The fauna of the Mazon Creek lagerstätte. (Reproduced from Clements et al. (2019), 1/3 items freely reproduced under the Geological Society of London copyright agreement)

The Mazon Creek Tetrapoda includes the earliest fossil records of highly important lineages, such as the dissorophoid Amphibamus grandiceps (Cope, 1865; Bolt, 1979). Dissorophoid temnospondyls such as the aforementioned taxa are the likely progenitors of some, if not all, modern lissamphibians (Bolt, 1977; Anderson, 2007; Ruta 
and Coates, 2007; Anderson et al., 2008; Maddin et al., 2012). At least three genera of aïstopods are known from Mazon Creek including Phlegethontia (Anderson, 2002), Oestocephalus (Anderson, 2003), and Pseudophlegethontia (Anderson, 2003). Until recently, the serpentine aïstopods were considered crown-tetrapods; however, they are now regarded as members of Tetrapodomorpha (Pardo et al., 2017). The most abundant tetrapodomorph taxon is Phlegethontia mazonensis, which is known from a few dozen specimens (Anderson, 2002; Pers. obs. A. Mann). Of greater interest to this thesis, Mazon Creek is home to one of the earliest known reptiles, the basal eureptile Cephalerpeton ventriarmatum (Godfrey, 1948), which is currently only second to the slightly older basal eureptile Hylonomus lyelli from Joggins, Nova Scotia.

Despite the importance of the Mazon Creek Tetrapoda in the greater scheme of tetrapod evolution, most systematic work on tetrapod material from Mazon Creek has steadily decreased since the 80's and in reality, has not been comprehensively addressed since R.L. Moodie's dissertation from 1909. Since Moodie (1909, 1912), few summaries of known tetrapod material have been conducted, including work by Gregory (1950) and Godfrey (1997); however, no major systematic revision of the tetrapod fauna exists in these works. The lack of tetrapod research on the locality has been attributed to a few reasons. The first is the low abundance of tetrapod material (less than $1 \%$ of examined concretions; Godfrey [1997] reports 24 concretions) present at the site (Shabica and Hay, 1997). The second is due to the collection policy of the majority of Mazon Creek sites. The sites have always been made available to the public and to private collectors. The rarity of tetrapods has made them highly desirable to private collectors, and keeping records of discovered tetrapods has been very difficult (Carman, 1990).

Fortunately, however, several recently donated private collections have produced many new and undescribed tetrapod specimens. Some of these donations have accumulated in no small effort from the museum curatorial staff, including the late Dr. John R. Bolt who oversaw efforts at the Field Museum of Natural History in Chicago up until the end of his career. These new collections of Mazon Creek tetrapods mainly housed at the Field Museum of Natural History, Chicago, the Milwaukee Public Museum, Wisconsin, and the Fryxell Geology Museum, Augustana College, Illinois, comprise a novel dataset for the study of diversity and ecology of early terrestrial 
tetrapod communities. Although these collections do provide significant new data on 'amphibians' from Mazon Creek, the most striking components are the many new terrestrial microsaurian specimens, which previously were represented only by single fragmentary fossil (i.e. FMNH PR 981). These new virtually-complete recumbirostran 'microsaurs' show a variety of bauplans and unique craniodental specialisations. This subset of fossils provides the backbone for a new systematic and ecomorphological study of the Mazon Creek amniote fauna, focusing on several new endemic species of recumbirostrans, with the ultimate goal of understanding the terrestrial ecosystem diversity present at the late Carboniferous lagerstätte.

To address the three questions presented at the end of the previous section, the new fossils will be analysed using comparative anatomical techniques including new imaging and visualization techniques (e.g. SEM), alongside modern Bayesian and parsimony phylogenetic methods (detailed methodology is provided within each chapter). The dissertation is structured into five data chapters, including systematic studies of four new species of recumbirostrans (Diabloroter bolti, Chapter 2; Infernovenator steenae, Chapter 3; FMNH 1309, Chapter 5; MPM VP359229.2, Chapter 6), and a restudy of the 'protorothyridid' Cephalerpeton ventriarmatum (see Chapter 4). In chapter 2, I describe a new species of short-bodied recumbirostran, Diabloroter bolti, making anatomical comparisons with other short-bodied recumbirostrans known as brachystelechids, that possess unique craniodental specializations including tricuspate dentition. In Chapter 3, I describe a new species of long-bodied, limb-reduced recumbirostran, Infernovenator steenae. The cranial anatomy, including cheek emargination, is compared to the serpentine recumbirostran clade Molgophidae. In this chapter I also investigate the relationship between cheek emargination and snout ecomorphology. In Chapter 4, I revise the osteology of the historic, Mazon Creek eureptile, Cephalerpeton ventriarmatum, using updated systematic and anatomical comparisons with other eureptiles, diapsids, and parareptiles. In Chapter 5, I provide a description of a new species exceptionally preserved recumbirostran, FMNH 1309, and use the detailed body impressions and scales (including scale ultrastucture) to explore integumentary adaptations to a fossorial lifestyle for the first time in recumbirostrans. In Chapter 6, I describe another new species of long-bodied recumbirostran, uniquely possessing 
complete forelimb-loss. This new taxon, MPM VP359229.2, is anatomically compared to molgophids and other long-bodied and limb-reduced recumbirostrans. Collectively, chapters touch on the high ecomorphological diversity of bauplans present, ranging from the short-bodied Diabloroter (Chapter 2) to the serpentine, long-bodied, limb-reduced MPM VP359229.2 (Chapter 6). Additionally, cranial specializations are investigated throughout, highlighting the early experimentation with fossoriality in terrestrial vertebrate ecosystems. Finally, I provide a revised taxonomic list for the Mazon Creek Tetrapoda that can be used for comparative studies to other Permo-Carboniferous tetrapod bearing strata (see Conclusions).

\subsection{References}

Ahlberg, P. E., Clack, J. A., \& Lukševičs, E. (1996). Rapid braincase evolution between Panderichthys and the earliest tetrapods. Nature, 381(6577), 61-64.

Anderson, J. S. (2003). A new aïstopod (Tetrapoda: Lepospondyli) from Mazon Creek, Illinois. Journal of Vertebrate Paleontology, 23(1), 79-88.

Anderson, J. S. (2003). Cranial anatomy of Coloraderpeton brilli, postcranial anatomy of Oestocephalus amphiuminus, and reconsideration of Ophiderpetontidae (Tetrapoda: Lepospondyli: Aistopoda). Journal of Vertebrate Paleontology, 23(3), $532-543$.

Anderson, J. S., Reisz, R. R., Scott, D., Fröbisch, N. B., \& Sumida, S. S. (2008). A stem batrachian from the Early Permian of Texas and the origin of frogs and salamanders. Nature, 453(7194), 515-518.

Anderson, J. S. (2007). Incorporating ontogeny into the matrix: a phylogenetic evaluation of developmental evidence for the origin of modern amphibians. Major transitions in vertebrate evolution, 182-227. 
Anderson, J. S. (2002). Revision of the aïstopod genus Phlegethontia (Tetrapoda: Lepospondyli). Journal of Paleontology, 76(6), 1029-1046.

Archer, A. W., Kuecher, G. J., \& Kvale, E. P. (1995). The role of tidal-velocity asymmetries in the deposition of silty tidal rhythmites (Carboniferous, Eastern Interior Coal Basin, USA). Journal of Sedimentary Research, 65(2a), 408-416.

Baird, G. C., Shabica, C. W., \& Hay, A. A. (1997). Paleoenvironmental setting of the Mazon Creek biota. Richardson's Guide to The Fossil Fauna of Mazon Creek. Chicago: Northeastern Illinois University, 35-51.

Baird, G. C., Sroka, S. D., Shabica, C. W., \& Beard, T. L. (1985a). Mazon Creek-type fossil assemblages in the US midcontinent Pennsylvanian: their recurrent character and palaeoenvironmental significance. Philosophical Transactions of the Royal Society of London. B, Biological Sciences, 311(1148), 87-99.

Baird, G. C., Shabica, C. W., Anderson, J. L., \& Richardson Jr, E. S. (1985b). Biota of a Pennsylvanian muddy coast: habitats within the Mazonian delta complex, northeast Illinois. Journal of Paleontology, 253-281.

Baird, G. C., Sroka, S. D., Shabica, C. W., \& Kuecher, G. J. (1986). Taphonomy of Middle Pennsylvanian Mazon Creek area fossil localities, Northeast Illinois; significance of exceptional fossil preservation in syngenetic concretions. Palaios, $1(3), 271-285$.

Boisvert, C. A., Mark-Kurik, E., \& Ahlberg, P. E. (2008). The pectoral fin of Panderichthys and the origin of digits. Nature, 456(7222), 636-638.

Bolt, J. R. (1977). Dissorophoid relationships and ontogeny, and the origin of the Lissamphibia. Journal of Paleontology, 235-249. 
Bolt, J. R. (1979). Amphibamus grandiceps as a juvenile dissorophid: evidence and implications. In Mazon creek fossils (pp. 529-563). Academic Press.

Cardini A., Elton S. (2008). Does the skull carry a phylogenetic signal? Evolution and modularity in the guenons. Biological Journal of the Linnean Society 93: 813834.

Carman, M. R. (1990). Catalog of type, figured, and referred Mazon Creek fossils in private collections (No. 19). Field Museum of Natural History.

Carroll, R. L., \& Baird, D. (1968). The Carboniferous amphibian Tuditanus (Eosauravus) and the distinction between microsaurs and reptiles. American Museum novitates; no. 2337 .

Carroll, R. L., \& Gaskill, P. (1978). The order microsauria (Vol. 126). American Philosophical Society.

Clements, T., Purnell, M., \& Gabbott, S. (2019). The Mazon Creek Lagerstätte: a diverse late Paleozoic ecosystem entombed within siderite concretions. Journal of the Geological Society, 176(1), 1-11.

Cope E. D. (1865). On Amphibamus grandiceps, a new batrachian from the Coal Measures. Proceedings of the Academy of Natural Sciences of Philadelphia, 134137.

Clack, J. A., Ruta, M., Milner, A. R., Marshall, J. E., Smithson, T. R., \& Smithson, K. Z. (2019). Acherontiscus caledoniae: the earliest heterodont and durophagous tetrapod. Royal Society open science. 
Cloutier, R., Clement, A. M., Lee, M. S., Noël, R., Béchard, I., Roy, V., \& Long, J. A. (2020). Elpistostege and the origin of the vertebrate hand. Nature, 579(7800), $549-554$.

Dawson, J. W. (1860). On a terrestrial mollusk, a chilognathous myriapod, and some new species of reptiles, from the coal-formation of Nova Scotia. Quarterly Journal of the Geological Society, 16(1-2), 268-277.

Downs, J. P., Daeschler, E. B., Jenkins, F. A., \& Shubin, N. H. (2008). The cranial endoskeleton of Tiktaalik roseae. Nature, 455(7215), 925-929.

Dunne, E. M., Close, R. A., Button, D. J., Brocklehurst, N., Cashmore, D. D., Lloyd, G. T., \& Butler, R. J. (2018). Diversity change during the rise of tetrapods and the impact of the 'Carboniferous rainforest collapse'. Proceedings of the Royal Society B: Biological Sciences, 285(1872), 20172730.

Ford, D. P., \& Benson, R. B. (2020). The phylogeny of early amniotes and the affinities of Parareptilia and Varanopidae. Nature Ecology \& Evolution, 4(1), 57-65.

Gauthier, J., Kluge, A. G., \& Rowe, T. (1988). Amniote phylogeny and the importance of fossils. Cladistics, 4(2), 105-209.

Gregory, J. T. (1948). The structure of Cephalerpeton and affinities of the Microsauria. American Journal of Science, 246(9), 550-568.

Gee, B. M., Bevitt, J. J., \& Reisz, R. R. Computed tomographic analysis of the cranium of the early Permian recumbirostran 'microsaur' Euryodus dalyae reveals new details of the braincase and mandible. Papers in Palaeontology. 
Gee, B. M., Bevitt, J. J., Garbe, U., \& Reisz, R. R. (2019). New material of the 'microsaur' Llistrofus from the cave deposits of Richards Spur, Oklahoma and the paleoecology of the Hapsidopareiidae. PeerJ, 7, e6327.

Godfrey, S. J., Shabica, C. W., \& Hay, A. A. (1997). Tetrapods. Richardson's guide to the fossil fauna of Mazon Creek, 256-269.

Goswami A., Polly P.D. (2010). The influence of character correlations on phylogenetic analysis: a case study of the carnivoran skull. In: Goswami A, Friscia A, editors. Carnivoran evolution: new views on phylogeny, form and function. Cambridge: Cambridge University Press. 141-164.

Gregory, J. T. (1965). Microsaurs and the origin of captorhinomorph reptiles. American Zoologist, 5(2), 277-286

Huttenlocker, A. K., Pardo, J. D., Small, B. J., \& Anderson, J. S. (2013). Cranial morphology of recumbirostrans (Lepospondyli) from the Permian of Kansas and Nebraska, and early morphological evolution inferred by micro-computed tomography. Journal of Vertebrate Paleontology, 33(3), 540-552.

Jaekel, O. (1909). Über die Klassen der Tetrapoden [About the classes of the tetrapods]. Zoologischer Anzeiger 34:193-212.

Kissel, R. A., \& Reisz, R. R. (2004). Synapsid fauna of the Upper Pennsylvanian Rock Lake Shale near Garnett, Kansas and the diversity pattern of early amniotes. Recent advances in the origin and early radiation of vertebrates, 409-428.

Klembara, J., Hain, M., Ruta, M., Berman, D. S., Pierce, S. E., \& Henrici, A. C. (2020). Inner ear morphology of diadectomorphs and seymouriamorphs (Tetrapoda) uncovered by high-resolution x-ray microcomputed tomography, and the origin of the amniote crown group. Palaeontology, 63(1), 131-154. 
Kuecher, G. J., Woodland, B. G., \& Broadhurst, F. M. (1990). Evidence of deposition from individual tides and of tidal cycles from the Francis Creek Shale (host rock to the Mazon Creek Biota), Westphalian D (Pennsylvanian), northeastern Illinois. Sedimentary Geology, 68(3), 211-221.

Laurenti, J. N. (1768). Classis Reptilium. Specimen medicum, exhibens synopsis Reptilium emendatum, cum experimentis circa venena et antidote Reptilium Austriacorum. J. Thom., Nob, et Trattnern, Vienna.

Laurin, M., \& Reisz, R. R. (1995). A reevaluation of early amniote phylogeny. Zoological Journal of the Linnean Society, 113(2), 165-223.

Maddin H.C. (2011). Deciphering morphological variation in the braincase of caecilian amphibians (Gymnophiona). Journal of Morphology 272: 850-871.

Maddin, H. C., Olori, J. C., \& Anderson, J. S. (2011). A redescription of Carrolla craddocki (Lepospondyli: Brachystelechidae) based on high-resolution CT, and the impacts of miniaturization and fossoriality on morphology. Journal of Morphology, 272(6), 722-743.

Maddin, H. C., Jenkins Jr, F. A., \& Anderson, J. S. (2012). The braincase of Eocaecilia micropodia (Lissamphibia, Gymnophiona) and the origin of caecilians. PLoS One, $7(12)$.

Mann, A., Gee, B. M., Pardo, J. D., Marjanović, D., Adams, G. R., Calthorpe, A. S., \& Anderson, J. S. (2020). Reassessment of historic 'microsaurs' from Joggins, Nova Scotia, reveals hidden diversity in the earliest amniote ecosystem. Papers in Palaeontology. 
Milner, A. R. (1982). Small temnospondyl amphibians from the Middle Pennsylvanian of Illinois. Palaeontology, 25(3), 635-664.

Modesto, S. P., \& Anderson, J. S. (2004). The phylogenetic definition of Reptilia. Systematic biology, 53(5), 815-821.

Moodie, R. L. (1912). The Mazon Creek, Illinois, shales and their amphibian fauna. American Journal of Science, (201), 277-285.

Moodie, R. L. (1909). A contribution to a monograph of the extinct Amphibia of North America. New forms from the Carboniferous. The Journal of Geology, 17(1), 3882.

Olson, E. C. (1975). Permo-Carboniferous Paleoecology and Morphotypic Series. American Zoologist, 15(2), 371-389.

Osborn, H. F. (1903). The reptilian subclasses Diapsida and Synapsida and the early history of the Diaptosauria (Vol. 1). Knickerbocker Press.

Pardo, J. D., Szostakiwskyj, M., \& Anderson, J. S. (2015). Cranial morphology of the brachystelechid 'microsaur' Quasicaecilia texana Carroll provides new insights into the diversity and evolution of braincase morphology in recumbirostran 'microsaurs'. PloS one, 10(6).

Pardo, J. D., \& Anderson, J. S. (2016). Cranial morphology of the Carboniferous-Permian tetrapod Brachydectes newberryi (Lepospondyli, Lysorophia): new data from $\mu \mathrm{CT}$. PloS one, 11(8).

Pardo, J. D., Szostakiwskyj, M., Ahlberg, P. E., \& Anderson, J. S. (2017). Hidden morphological diversity among early tetrapods. Nature, 546(7660), 642-645. 
Pardo, J. D., \& Mann, A. (2018). A basal aïstopod from the earliest Pennsylvanian of Canada, and the antiquity of the first limbless tetrapod lineage. Royal Society open science, 5(12), 181056.

Pardo, J. D., Small, B. J., Milner, A. R., \& Huttenlocker, A. K. (2019). CarboniferousPermian climate change constrained early land vertebrate radiations. Nature ecology \& evolution, 3(2), 200-206.

Richardson, E. S., \& Johnson, R. G. (1971). The Mazon Creek faunas. In Proceedings of the North American Paleontological Convention (Vol. 1, pp. 1222-1235).

Reisz, R. (1972). Pelycosaurian reptiles from the middle Pennsylvanian of North America. Harvard University, 144(2), 1-61.

Reisz, R. R. (1977). Petrolacosaurus, the oldest known diapsid reptile. Science, 196(4294), 1091-1093.

Reisz, R. R., \& Berman, D. S. (1986). Ianthasaurus hardestii n. sp., a primitive edaphosaur (Reptilia, Pelycosauria) from the Upper Pennsylvanian Rock Lake Shale near Garnett, Kansas. Canadian Journal of Earth Sciences, 23(1), 77-91.

Reisz, R. R., \& Müller, J. (2004). Molecular timescales and the fossil record: a paleontological perspective. TRENDS in Genetics, 20(5), 237-241.

Romer, A. S. (1950). The nature and relationships of the Paleozoic microsaurs. American Journal of Science, 248(9), 628-654.

Ruta, M. and M. I. Coates. (2007). Dates, nodes, and character conflict: Addressing the lissamphibians origin problem. Journal of Systematic Palaeontology, 5(1): 69122. 
Sahney, S., Benton, M. J., \& Falcon-Lang, H. J. (2010). Rainforest collapse triggered Carboniferous tetrapod diversification in Euramerica. Geology, 38(12), 10791082.

Savage, T. E. (1927). Significant breaks and overlaps in the Pennsylvanian rocks of Illinois. American Journal of Science, (82), 307-316.

Shabica, C. W., \& Hay, A. (Eds.). (1997). Richardson's guide to the fossil fauna of Mazon Creek. Northeastern Illinois University.

Shubin, N. H., Daeschler, E. B., \& Jenkins, F. A. (2006). The pectoral fin of Tiktaalik roseae and the origin of the tetrapod limb. Nature, 440(7085), 764-771.

Shubin, N. H., Daeschler, E. B., \& Jenkins, F. A. (2014). Pelvic girdle and fin of Tiktaalik roseae. Proceedings of the National Academy of Sciences, 111(3), 893-899.

Sues, H. D., \& Reisz, R. R. (1998). Origins and early evolution of herbivory in tetrapods. Trends in Ecology \& Evolution, 13(4), 141-145.

Schluter, D. (2000). The ecology of adaptive radiation. Oxford University Press, 296 pp.

Stroud, J. T., \& Losos, J. B. (2016). Ecological opportunity and adaptive radiation. Annual Review of Ecology, Evolution, and Systematics, 47(1), 507-532.

Szostakiwskyj, M., Pardo, J. D., \& Anderson, J. S. (2015). Micro-CT study of Rhynchonkos stovalli (Lepospondyli, Recumbirostra), with description of two new genera. PLoS One, 10(6).

Vaughn, P. P. (1962). The Paleozoic microsaurs as close relatives of reptiles, again. American Midland Naturalist, 79-84. 
Wanless, H. R. (1929). Geology and mineral resources of the Alexis Quadrangle. Bulletin no. 057. 


\section{| Chapter 2: Diabloroter bolti gen. et sp. nov. a short-bodied recumbirostran 'microsaur' from the Francis Creek Shale, Mazon Creek, Illinois}

\subsection{Authors and Addresses}

Arjan Mann and Hillary C. Maddin

Department of Earth Sciences, Carleton University, 1125 Colonel By Drive, Ottawa, Ontario K1S 5B6, Canada

\subsection{Preface}

The following manuscript has been published in the Zoological Journal of the Linnean Society. Arjan Mann was fully involved in setting up and conducting the research, preparing samples, running all analyses, developing methodology, writing the manuscript and drafting final figures in this co-authored article. Hillary Maddin, provided discussion and editing of content. The manuscript has been modified slightly to accommodate the formatting requirements for Carleton University dissertations. Supplemental data can be accessed through the online version of the manuscript at the publishers website. The article should be cited as such:

Mann, A., \& Maddin, H. C. (2019). Diabloroter bolti, a short-bodied recumbirostran 'microsaur' from the Francis Creek Shale, Mazon Creek, Illinois. Zoological Journal of the Linnean Society, 187(2), 494-505.

\subsection{Abstract}

The Carboniferous Pennsylvanian-aged (309-307 Ma) Mazon Creek Lagerstätte produces some of the earliest tetrapod fossils of major Paleozoic lineages. Previously, the Mazon Creek record of 'microsaurs' was known from a single specimen (FMNH PR 
981). However, the lack of key anatomy, such as the skull, precluded a confident taxonomic assignment, thus only a suggested affinity to the microbrachomorph 'microsaur' Hyloplesion was determined. Recently several new tetrapod specimens collected from Mazon Creek have come to light, of which some have recumbirostran 'microsaur' affinity. Here we describe a new short-bodied recumbirostran, Diabloroter bolti gen. et sp. nov. on the basis of a unique combination of autapomorphies. Both parsimony and Bayesian phylogenetic methods recover the new taxon within the clade Brachystelechidae, as sister taxon to the clade including Carrolla and Batropetes. We determine Diabloroter to be the earliest known member of the clade Brachystelechidae and thus establishing a Carboniferous origin of the group. We also provide an updated diagnosis for the Brachystelechidae. Finally, we comment on the evolutionary trends within the clade, including dental adaptations for a proposed algivorous diet in derived clade members.

\subsection{Introduction}

'Microsaurs' are a paraphyletic assemblage of diverse small, holospondylous tetrapods that have had importance in the debate over lissamphibians (particularly caecilians), as well as amniote origins (Anderson, 2007; Huttenlocker et al., 2013). Current hypotheses have moved towards their importance in amniote origins, including the resurrection of historic hypotheses that at least some 'microsaurs' are reptiles and thus crown-group amniotes (Vaughn, 1962; Pardo et al., 2017). The group of 'reptilian' microsaurs recovered as amniotes by Pardo et al. (2017) are the fossorially-adapted clade Recumbirostra (Anderson, 2007; Maddin et al. 2011; Pardo et al, 2015). Recumbirostra form the current core-grouping of microsaurs that draw members from the previously recognised microsaurian suborders Tuditanomorpha and Microbrachomorpha erected by Carroll \& Gaskill (1978) in their monograph The Order Microsauria.

Despite recent work on recumbirostran 'microsaurs' (Anderson, 2007, 2009; Maddin et al., 2011; Huttenlocker et al., 2013; Szostakiwskyj et al., 2015; Pardo et al., 2015; Pardo \& Anderson, 2016), details about the timing of their origin are unclear. Though largely regarded as Early Permian radiation, the possibility of an earlier origin 
has remained plausible. However, difficulty in resolving these details remains in part due to the fact that Carboniferous 'microsaur' fossils are, in general, rare and not found in the same abundance as in the Early Permian localities, such as the Dolese Brothers Quarry, Oklahoma, for example (Carroll \& Gaskill, 1978). Furthermore, the Carboniferous-aged forms remain largely unrevised, and this leaves uncertainty in their affinity to Recumbirostra. Interestingly, the recent stratocladistic framework presented in Huttenlocker et al. (2013) suggested Recumbirostra probably originated in the Pennsylvanian and diversified in the Early Permian. However, this framework notably excludes the diverse Carboniferous assemblages of microsaurian tetrapods at Joggins, Nova Scotia (Westphalian A), and those of the cannel coal localities such as Linton, Ohio, and Nýřany, Czech Republic (both Westphalian D). In order to better understand the origin and diversification of Recumbirostra, Carboniferous taxa must be revised and integrated into updated phylogenetic frameworks.

As a first step towards this larger goal, we describe a new Upper Pennsylvanianaged recumbirostran from the Mazon Creek Francis Creek Shale, Fulton County, Illinois, locality. The Mazon Creek Lagerstätte (approximately 309-307 Ma; Westphalian C-D) has produced many exceptionally preserved, important tetrapod fossils (Gregory, 1948, 1950; Carroll \& Gaskill, 1978). Diabloroter bolti gen. et sp. nov. described here is represented by a single partial concretion, ACFGM V-1634, containing a relatively complete skeleton preserved in dorsal aspect (Fig. 2.1). Of note, our new specimen represents one the shortest known recumbirostrans with only 17 presacral vertebrae. Diabloroter bolti gen. et sp. nov. bears strong resemblance to the clade of miniaturized, short-bodied recumbirostrans known as the Brachystelechidae (Carroll \& Gaskill, 1978). We provide an updated phylogenetic analysis using the matrix of Pardo et al., (2017), including all known brachystelechids, to assess the phylogenetic relationships of Diabloroter. With the addition of Diabloroter we are able to provide an updated diagnosis of the Brachystelechidae and establish a confident origin of the clade within the Upper Carboniferous. 


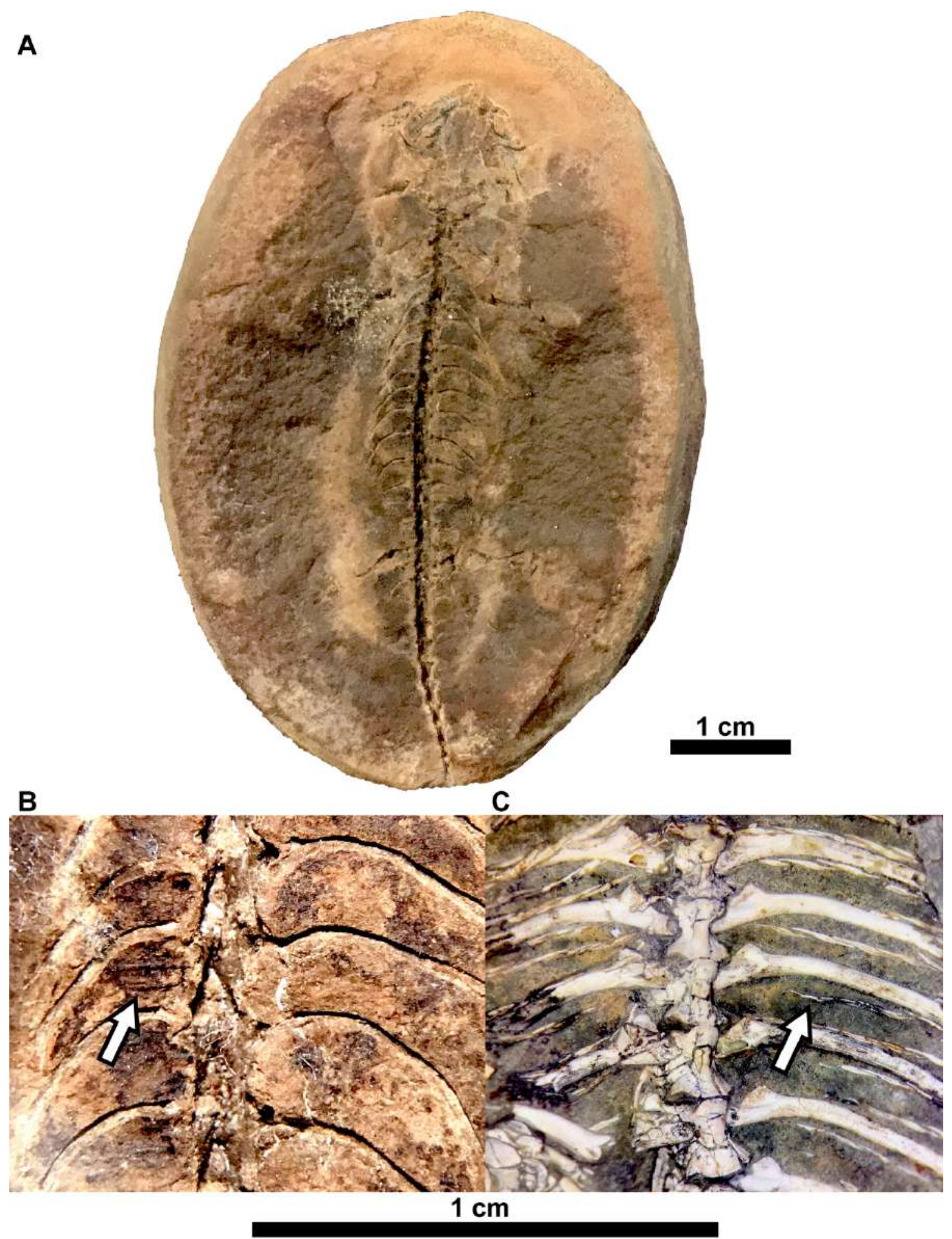

Figure 2.1 A, photograph of Diabloroter bolti gen. et sp. nov. in concretion (ACFGM V-1634). B, close up of the thoracic region of ACFGM V-1634 with arrow pointing to a cluster of preserved gastralia. $\mathrm{C}$, comparative figure of the thoracic region of Batropetes fritschi with arrows indicating a patch of gastralia. 


\subsection{Institutional Abbreviations}

ACFGM, Augustana College's Fryxell Geology Museum, Rock Island, Illinois; AMNH FARB, the American Museum of Natural History, Fossil Amphibian, Reptile, and Bird Collection; CMN, Canadian Museum of Nature, Gatineau, Canada; FMNH, Field Museum of Natural History, Chicago, USA; RM, Redpath Museum, Montreal, Canada; ROM, Royal Ontario Museum, Toronto, Canada; USNM, United States National Museum, Washington, D.C., USA; YPM, Yale Peabody Museum, New Haven, USA.

\subsection{Anatomical Abbreviations}

$\mathbf{c l}=$ clavicle; $\mathbf{d}=$ dentary; fem=femur; fi=fibula; hum=humerus; isch=ischium; $\mathbf{j}=$ jugal; $\mathbf{l}=$ lacrimal; $\mathbf{m}=$ maxilla; $\mathbf{n}=$ nasal; $\mathbf{o b}=$ os basale; $\mathbf{p}=$ parietal; $\mathbf{p c}=$ palpebral cup; po=postorbital; pf=postfrontal; prf=prefrontral; pu=pubis; $\mathbf{r}=$ radius; $\mathbf{s c}=$ scapulocoracoid; $\mathbf{s q}=$ squamosal; $\mathbf{s t}=$ stapes; ti-tibula; $\mathbf{u}=$ ulna.

\subsection{Materials and Methods}

The specimen, ACFGM V-1634, was compared to previously identified 'microsaur' specimens at the FMNH, AMNH FARB, YPM, USNM, ROM and CMN. Of note, ACFGM V-1634, was also compared directly to FMNH PR 981, currently the only other reported microsaurian tetrapod from Mazon Creek. The specimen was also compared in person to the brachystelechids Quasicaecilia texana, Carrolla craddocki as well as Batropetes and its species. Osteology of ACFGM V-1634 was studied primarily using latex peels curated at the FMNH.

All specimens were photographed with a Nikon D700 Camera using an AF-S NIKKOR 24-85mm lens. Microscope images were photographed using a Nikon DS-Fi1 camera mounted to a Nikon AZ-100 microscope. Images were processed using Nikon NIS-Elements (Basic Research) imaging software registered to D. C. Evans of the Royal Ontario Museum. Measurements of all specimen included in this study were taken with 
calibrated Mitutoyo digital calipers (model number 500-754-10, CD-12” PSX). Digital photographs were processed using Adobe Photoshop CS6. Figures were assembled using Adobe Illustrator CS6. For the phylogenetic analysis methodology see the phylogenetic analysis section below.

\title{
2.8 Systematic Paleontology
}

\author{
Tetrapoda Jaekel, 1909 \\ Recumbirostra Anderson, 2007 \\ Brachystelechidae Carroll and Gaskill, 1978
}

Revised Diagnosis - Small, short-bodied recumbirostrans with the following synapomorphies: parietals wider than frontals with anterior waisting; frontals participate in orbital margin; parietal-squamosal contact (tabulars absent); postparietals absent; interpterygoid vacuities broad; falciform prefrontals; one piece palpebral-cups; large orbits; otoccipital region massively co-ossified into a single 'os basale'; no more than 21 presacral vertebrae; up to 33 caudals; no trunk intercentra; endochondral shoulder girdle co-ossified; limbs robust; ilium with narrow dorsally directed blade.

Phylogenetic Definition (stem-based)—Recumbirostrans more closely related to Batropetes fritschi than to Brachydectes newberryi.

Diabloroter gen. nov.

Diagnosis-Monotypic, same as for species.

Diabloroter bolti gen. et sp. nov.

Holotype-ACFGM V-1634 (Fig. 2.1A, B), a near complete cranial and postcranial skeleton, preserved only in dorsal aspect, most of the autopodial elements are covered by matrix and are not visible. Additionally, two latex peels and a plaster cast of the specimen 
in dorsal aspect exist at the FMNH, under the single number of FMNH PR 847 (Figs. $2.2-2.3)$.

Etymology - The generic name is a combination of 'Diablo', derived from the spanish word for devil, referring to the hellishly-red latex peels from which the taxon was initially identified, and the latinized 'roter' meaning digger referring to the fossorial habits of recumbirostrans. The specific epithet is in honour of Dr. John Bolt, who has contributed much knowledge to the study of early microsaurs, as well as the Mazon Creek locality. In particular, Dr. John Bolt's curation of Mazon Creek tetrapod fossils has prompted this and several future studies on the fauna.

Horizon and Locality - Sunspot Mine of Ayrshire Collieries Corp. (later Amax Coal Co.), 2 miles north of Astoria, Fulton County, Illinois, Francis Creek shale, Carbondale Formation, Mazon Creek, Middle Pennsylvanian-aged (309-307 Mya), Carboniferous (Chenoweth, 2015). Collected by Mr. L. A. Lasco.

Differential Diagnosis - A brachystelechid recumbirostran diagnosed by the following combination of autapomorphies: long maxilla; cranial vault that is ornamented with radiating grooves; circular pits on the prefrontal; snout narrow and blunt. Diabloroter also differs from Batropetes in a lesser length expansion of the mid dorsal ribs and a less robust pectoral girdle. Differs from Quasicaecilia in that the skull is not as round and the nasals do not contribute significantly to the recumbent snout. Also differs from Quasicaecilia in that the lateral cheek is more extensive similar to the condition found in Batropetes and Carrolla.

Comments - Two characters not included in the above diagnosis deserve mention. First, the presence of 17 presacral vertebrae is also present in one species of Batropetes palatinus (Gleinke, 2015), to which is likely an independent acquisition of this trait in the species Batropetes palatinus and is not present in other members of the genus. Thus, this feature may be independently derived in Diabloroter. Second, re-analysis of the holotype specimen of Carrolla craddocki (Mann et al. 2018) confirms the presence of triscuspate 
teeth, revealing less dental diversity than previously recognised among brachystelechids, the presence of simple non-cuspate dentition in Diabloroter is therefore, currently, a unique feature among brachystelechids
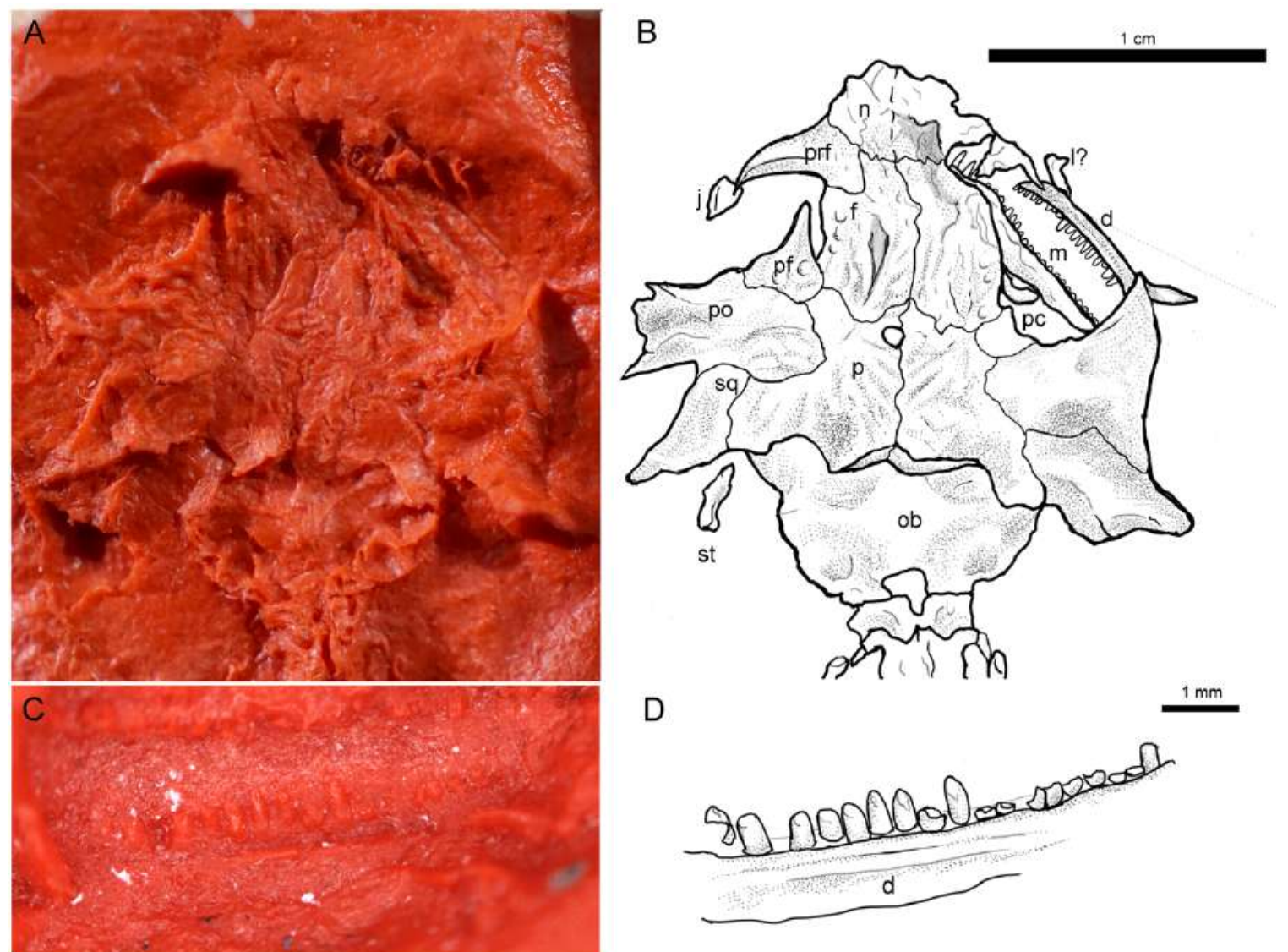

Figure 2.2 A-B, photograph and line drawing of the cranial anatomy of Diabloroter bolti gen. et sp. nov. (ACFGM V-1634) as revealed by a latex peel. C-D, photograph and line drawing of a close-up view of the right dental anatomy of Diabloroter bolti. 


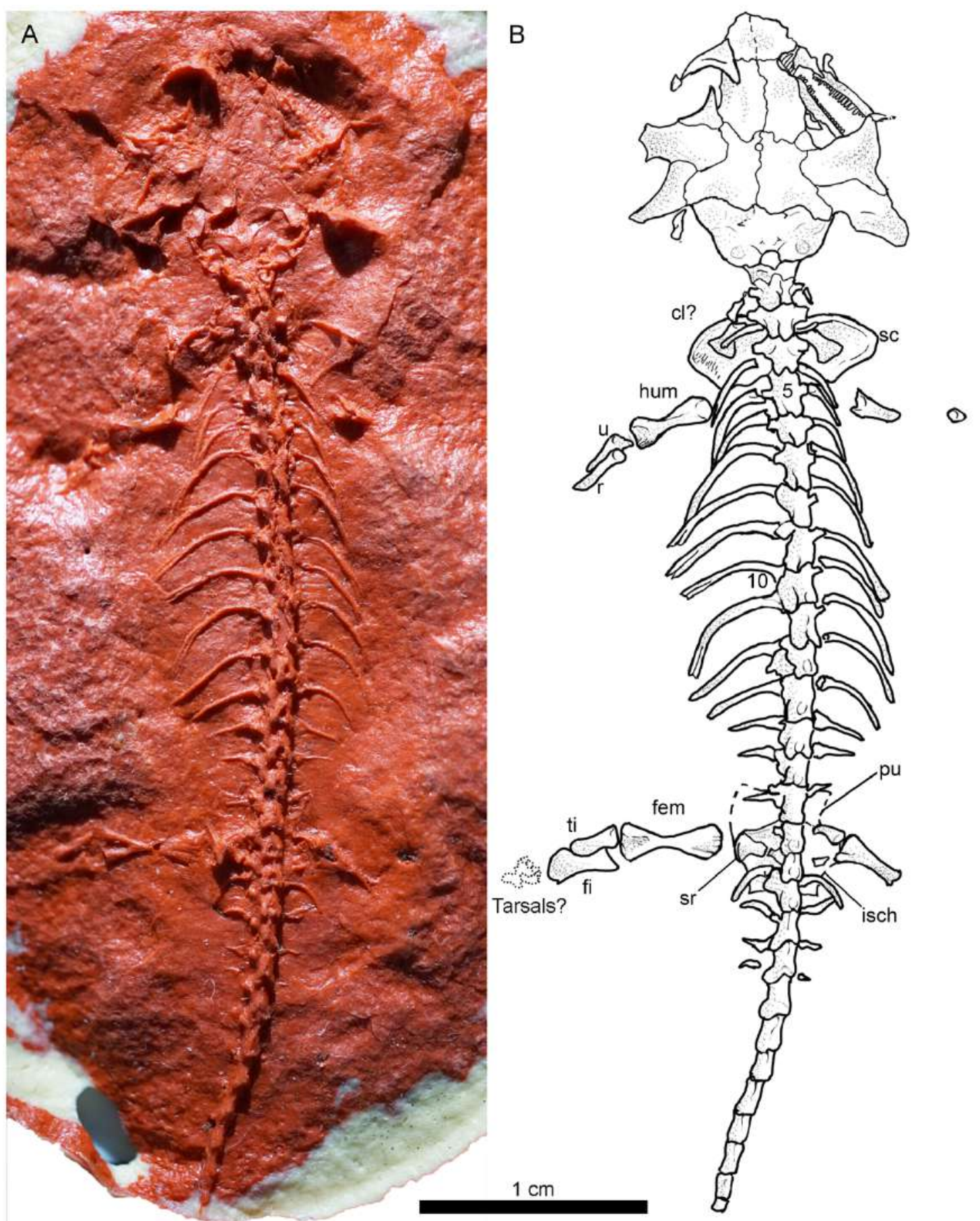

Figure 2.3 A, photograph and B, line drawing of skeletal anatomy of Diabloroter bolti gen. et sp. nov. (ACFGM V-1634) as revealed by a latex peel (FMNH PR 847). Numbers represent vertebral count position. 


\subsection{Description}

\section{General}

The cranial shape of Diabloroter is similar to that of other known brachystelechids in being very small (approx. $9.2 \mathrm{~mm}$ skull length), as well as in being short and wide (Fig. 2.2). Roughly, the cranium is triangular shaped with a snout that is a rounded point. The skull is widest between both cheek regions. The orbits are very large with wide, relatively expansive and large circumorbital bones compared to other recumbirostrans, however, typical of brachystelechids. Similar to many other recumbirostrans, the cranium possesses slight ornamentation on all cranial vault bones in the form of shallow radiating grooves. This ornamentation may indicate maturity (Mann, ecimen is approximately $53 \mathrm{~mm}$. 2018). The ornamentation on the cranium is most pronounced on the frontal and parietal bones, and dissipates towards the cheek elements. The postcranial anatomy is relatively complete despite missing the anatomy of the manus and pes which are likely concealed by matrix. In addition, the tail, although apparently approaching its terminus, is missing the posteriormost portion. The total length of the preserved portion of the fossil is approximately $53 \mathrm{~mm}$.

\section{Dental Arcade}

The right maxilla is visible in lateral aspect, having fallen flat during preservation, and thus exposes the dentition in lateral view also (Fig. 2.2). The anatomy of the maxilla is partially obstructed by the postorbital posteriorly and by the frontal dorsoanteriorly. Despite this, the element can be seen to be relatively conservative in its morphology as a simple narrow triangular shaped bone with a slight dorsoventral expansion anteriorly. Whereas the maxilla of Diabloroter is a similar shape to those of Batropetes and Carolla, it differs most noticeably in its length where it appears relatively long, with an elongate posterior process similar to Rhynchonkos. Approximately 27 tooth positions can be discerned on the maxilla; however, it is possible that there are even more under the hidden regions that are obscured by other cranial elements.

Many of the maxillary teeth are broken and are only represented by their bases aside from the anteriormost teeth that are relatively complete. The dentition also bears 
resemblance to Rhynchonkos in its apically pointed, peg-like morphology. This sharply contrasts with the durophagous dentition found in pantylids and gymnarthrids, or the cuspate morphology of other brachystelechids. No direct observation of the premaxillary anatomy is possible; implications of this are discussed in further detail in the next section.

\section{Skull Roof}

Although the premaxilla is not present, the absence of any exposure on the dorsal surface is in line with other brachystelechids such as Quasicaecilia (Pardo et al., 2015) and the limited dorsal exposure of recumbirostrans in general. It is very likely that the snout of ACFGM V-1634 (Fig. 2.2) was recumbent to some degree like other members of Recumbirostra, and that the premaxilla was excluded from the skull roof. The nasals are present at the anteriormost end of the skull roof (Fig. 2.2). They are not well preserved, being flattened and crushed inward. In general, the nasals appear to be wide. At their posterior end they are approximately the same width as the frontals. At the anteriormost end they come to a rounded point created by an anteromedial extension of each nasal. The nasals flare outward laterally at the posterior end towards the suture with the prefrontal. Very little more can be discerned about their morphology.

The prefrontal is large compared to most recumbirostrans and only present on the left side of the skull in dorsal aspect (Fig. 2.2). It is an irregularly shaped bone roughly reminiscent of a cone. The prefrontal makes up most of the anterior and dorsal orbital rim. The interior portion of the orbital rim is also slightly exposed, revealing that the element is transversely thick.

The frontals are also slightly crushed, and comprise the majority of the interorbital space (Fig. 2.2). In general, these bones are relatively wide similar to those of other brachystelechids, and contribute a portion to the dorsal margin of the orbit. Ornamentation on the frontals is limited to a few posterolaterally located pits which seem to continue onto the postfrontal. The structure of these pits resembles that of Batropetes. There is no evidence of an interfrontal such as that noted in some specimens of Batropetes (Glienke, 2013; 2015); however, we note the homology of the interfrontal in recumbirostrans, and that of tetrapods in general, is not well understood, and it is probable that this element is a dorsal appearance of the sphenethmoid as in some 
caecilians (A. Mann pers. obs.). The postfrontal of FMNH PR 847 is crescent shaped but forms part of the posterior-dorsal margin of the orbit. At least one of the aforementioned pits is present on each postfrontal. With the exception of the pits, the shape and sutural contacts of the postfrontal are similar to those of other brachystelechids.

Both parietals are present and well preserved. The inter-parietal suture is not straight and undulates. A moderately sized pineal foramen similar to most brachystelechids is located near the anterior end of the inter-parietal suture. The parietals are flat and dorsally exposed. The lateral margins of the parietals are slightly incised on each side creating the appearance of a mid-waist on the parietals. This feature is exaggerated by the overlap of the postorbital that is likely due to dorsal-ventral crushing that occurred to the skull (Fig. 2.2).

The postorbital is a large element similar to those of other brachystelechids, most closely resembling those of Carrolla and Batropetes (Fig. 2.2). In general, the shape is irregular, expanded dorsally, and subtriangular towards the ventrolateral end. Posterior to the postorbital is the squamosal which is also a rather large element in this taxon, similar to that of Carrolla (Maddin et al., 2011). The squamosals are roughly sub-rectangular shaped in dorsal aspect and posteriorly would have articulated with the occiput, but have become disarticulated due to taphonomic forces.

Some of the more poorly represented elements of the skull include a possible fragment of the lacrimal located anterior to the dentary on the right side of the skull. Other elements include a partial jugal on the left side of the skull being slightly overlapped by the prefrontal. Finally, flanking the occiput on the left side there is a partial stapes that is roughly cylindrical in shape. However, overall it is poorly represented either due to the resolution of the latex or the poor preservation of this element on the original specimen.

\section{Occiput}

Like all brachystelechids the occiput of ACFGM V-1634 protrudes significantly beyond the posterior skull margin and is well exposed in dorsal aspect. The occipital region is largely co-ossified into an 'os basale' like that found in other brachystelechids, such as Carrolla and Quasicaecilia, as well as Batropetes to some extent. This co- 
ossification of the braincase is often cited as an adaption of fossoriality in recumbirostrans (Maddin et al., 2011; Pardo et al., 2015; Pardo \& Anderson 2015; Pardo et al., 2017). The term 'os basale' is also widely used in caecilian literature to refer to an analogous co-ossification of the braincase also involved with cranial architectural support for head-first burrowing. The term has also been applied to recumbirostran 'microsaurs' (see Carroll \& Gaskill, 1978); however, we note that this structure is not homologous and instead represents an early convergence on a similar structural morphology.

The co-ossification of the braincase makes discernment of individual anatomical units difficult if not entirely impossible. Despite this a few features can be discerned including a large, raised, centrally-located, irregular-shaped polygon, that may represent a supraoccipital element based on its central position on the occiput. In addition, two semicircular depressions can be observed at the posterolateral edges of the occiput and these may be the otic capsules likely formed by the opisthotic ossifications. Finally, at the posteroventral area of the exposed occipital surface there is the dorsal margin of the foramen magnum. Apparently paired occipital condyles make articular contact with the first cervical vertebra. These are most likely formed by the exoccipital ossifications.

\section{Postcranial Skeleton}

On ACFGM V-1634 a thin soft tissue impression is present (Fig. 2.1A). This impression appears like a film around the skeleton that hugs the cranium anteriorly, expanding into a larger thick neck region, before expanding around the gut region. The anterior tail region shows a relatively wide impression at the base. Swelling at the base of the tail in extant reptiles signals the presence of hemipenes, thus it is possible that this specimen represents a male. This impression diminishes caudally towards the end of the tail. Small portions of skin impression are present around the limbs, most conspicuously around the left tibia and fibula, showing that this region was likely expansive with soft tissues.

In totality the postcranial skeleton is well-ossified, and similar in many regards to the postcranial skeletons of Batropetes and its known species (Fig. 2.3). Overall, ACFGM V-1634 is a small, short-bodied recumbirostran measuring only $53 \mathrm{~mm}$ total length. The postcranial skeleton includes: a nearly complete vertebral column missing 
only the posteriormost caudal vertebrae, pelvic and pectoral girdle elements, as well as portions of all four limbs. Due to uneven breakage of the concretion some details are missing and are likely preserved on the other half of the concretion, which could not be located.

Ventral gastralia are preserved between the ribs on ACFGM V-1634. These are best observed on ACFGM V-1634 (Fig. 2.1B and C) and are not well relieved on any latex peel that we observed. The gastralia would likely be better represented on the concretion containing the ventral component of the skeleton. Most specimens of Batropetes show well developed gastral scales that are similar in their thin, tubular chevron morphology to those of many early eureptiles including Hylonomus.

There are 17 presacral, 1 sacral, and 11 caudal vertebrae preserved on ACFGM V-1634 (Fig. 2.3). The vertebrae are holospondylous and consistent with those seen in other recumbirostrans. As in Batropetes, the vertebrae are relatively short, cubical in shape, and have relatively low, often fused neural arches to the centra. An atlas and axis are present on ACFGM V-1634; however, due to poor preservation and lack of ventral data, very little can be discerned about their anatomy. In general, the atlas vertebra is shorter and wider than the axis and the more posterior vertebrae.

The ribs are delicate, thin, and elongate (Fig. 2.3). The longest ribs are the middle region of the body, and shorten both anteriorly and posteriorly. The ribs are also strongly curved ventrally except in the posteriormost region. Together these features provide the appearance of a rotund animal with a broad trunk region, similar to the shape of Batropetes. Batropetes, however, has an even more exaggerated expansion of the ribs in the mid-trunk region. A single pair of horn-shaped sacral ribs are present on ACFGM V1634, just medial to the femora. The tail region is well preserved and appears to gradually taper until the edge of the latex peel, where it is then suddenly truncated. Despite the tail not being completely preserved on the specimen, it is highly likely the tail was markedly shortened due to the level of posterior taper already evident in the caudal vertebrae. In this aspect the tail and caudal region differs from that of the long-tailed Batropetes.

Because only the dorsal surface is known, data on the girdle elements is limited. Both scapulocoracoids are present as robust ossifications and are roughly plate-like with a convex anterior margin. Dorsally the margins are lightly ornamented with striae and 
slight rugosities along their posterior lateral margin. There is a slight raised lip on the dorsoanterior edge of the scapulocoracoids. In comparison to Batropetes, the scapulocoracoids of ACFGM V-1634 appear to represent only the anterior portion of the element. Aside from the former, the only other pectoral element that is preserved is a pair of possible clavicles. On the specimen, these are located on the dorsal surface of the scapulocoracoids as two subrectangular-shaped elements.

The pelvic girdle is even less well preserved. It consists only of the outline of the paired pubes and ischia. The pubes form the anterior portion of the pelvis represented by only a faint outline, where they appear similar in shape to those of Batropetes. The left ischium is more completely preserved in its dorsal aspect and can be seen tapering posteriorly with a concave lateral margin like in Batropetes. There are no remains of the ilia preserved.

All four limbs are represented in ACFGM V-1634; however, the autopodial elements are not visible and appear to be buried under matrix in the missing counterpart. The left hindlimb appears to have remnants of a tarsus preserved but these elements are not well preserved and at best represent a few tarsal elements and possibly a phalanx. The left humerus is better exposed than the right, and reveals a mostly complete morphology, with the exception of the distal end, which is partially buried inside the concretion. The small portion of the distal end that is exposed indicates that the morphology was considerably wide and robust in this area (Fig. 2.3). The proximal humeral head is moderately expanded; however, it appears somewhat concave at the articular surface. This may be a product of imperfections in the latex that may have collapsed from bubbles during the casting process. Conversely, it is possibly that the humeral head is incompletely ossified in this region, implying the individual is immature. The proximal and distal ends of the humerus are offset from one another by a high torsional angle, similar to those of most other recumbirostrans including Batropetes. Also, on the left side a well-preserved ulna and radius are present. Overall the morphology of both elements are quite slender, and incomplete distally. The proximal end of the ulna bears a moderately developed olecranon process.

The femoral morphology is also best represented on the left side, where a short robust femur is present with well ossified proximal and distal ends (Fig. 2.3). The shaft is 
proportionally short in comparison to the robust distal and proximal ends. Also, on the left side a well-preserved tibia and fibula occur just distal to the femur. These show a squat morphology and are strongly bowed, creating a large interosseous space between them.

\subsection{Phylogenetic Analysis}

Phylogenetic analysis of ACFGM V-1634 was performed using a modified version of the recent matrix of Pardo et al. (2017). This matrix was primarily aimed at assessing large-scale, early tetrapod relationships, but it also provides the most up-to-date matrix for assessing recumbirostran interrelationships. In addition to ACFGM V-1634 we also included the brachystelechid Batropetes to fully assess the interrelationships of known brachystelechid genera. Codings for Batropetes were derived based largely on descriptions from the literature including the work of Glienke (2015) and Carroll (1991), as well as personal observations. We conducted phylogenetic analyses using both parsimony and Bayesian approaches in order explore the data using different methodologies. Eusthenopteron was specified as the outgroup in all analyses. The parsimony analysis was performed with PAUP software v4.0b10 (Swofford, 2002). A heuristic search was performed, with 100 random sequence additions and the TBR algorithm requested. Maxtrees was set at 10,000, and automatically increased by 100 . To assess support of internal nodes, bootstrap values were calculated using the fast-stepwise addition option. Bayesian analysis was run in MrBayes v3.2.6 (Huelsenbeck, 2001) for 10,000,000 generations ( samplefreq=1000) and employed the MKv model. For each analysis, two runs were performed, and the initial $25 \%$ of the resulting trees were discarded (burn-in). Tracer v1.6 (Rambaut, 2007) for OSX was used to ensure stationarity and convergence of posterior probabilities.

The parsimony analysis recovered two most parsimonious trees (MPT), each with 1788 steps (Consistency Index $[\mathrm{CI}]=0.3160$; Homoplasy Index $[\mathrm{HI}]=0.7383$; Retention Index $[\mathrm{RI}]=0.6377$; Rescaled Consistency Index $[\mathrm{RC}]=0.2015)$. The parsimony strict consensus tree (Fig. A.1) and Bayesian majority rule consensus tree (Fig. A.2) recover ACFGM V-1634 as a brachystelechid occurring at one node more crownward than 
Quasicaecilia, as the sister taxon to a clade including Batropetes + Carrolla (see combined results on Fig. 2.4). The position of ACFGM V-1634 in the parsimony result is supported by Character 40 state $=1$ and Character 68 state $=1$ (character numbers refer to those used in the analysis of Pardo et al., 2017 and are included in Appendix A4). Bootstrap values supporting the relationships are relatively high with a percent retrieval of $72 \%$ (see Fig. 2.4). The Bayesian results were similarly strongly supported with a posterior probability of 0.94 for the position of ACFGM V-1634. Quasicaecilia is recovered as the earliest diverging brachystelechid, this position is also strongly supported with a posterior probability of 1 . The sister taxon relationship of Batropetes and Carrolla is well supported by a posterior probability of 0.99. A full report of posterior probability values can be found in the Appendix (Fig. A2). 


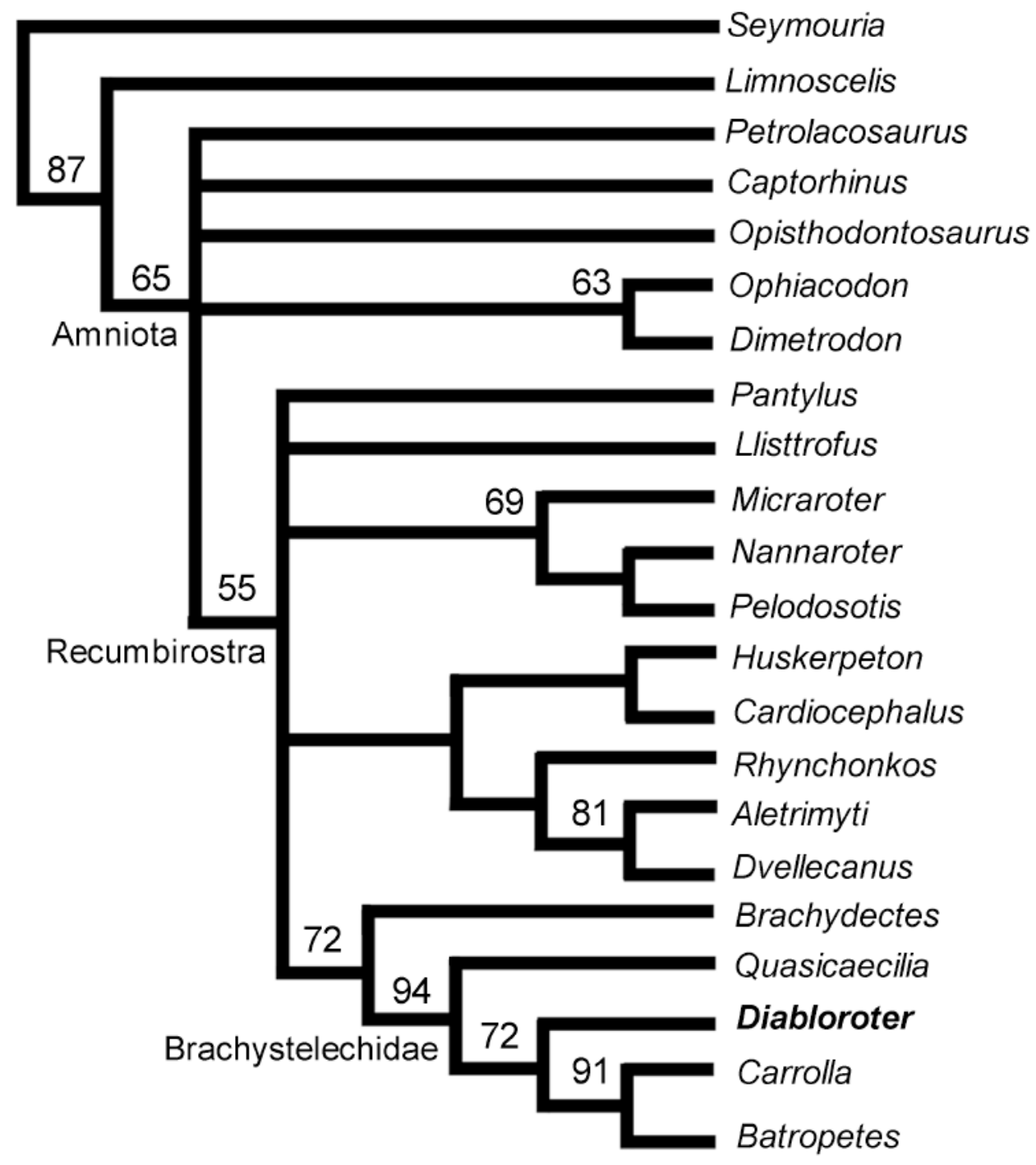

Figure 2.4 Strict consensus tree of the phylogenetic analysis using parsimony. Major clades indicated at nodes. Diabloroter bolti gen. et sp. nov. (ACFGM V-1634) is indicated in bold. Bootstrap values indicated above nodes; only values above 50 reported.

\subsection{Discussion}

The Fulton County, Sunspot Mine locality and 'microsaurs' from Mazon Creek

The Mazon Creek Lagerstätte is composed of various localities distributed throughout the Francis Creek Shale, which spans six counties including Will, Grundy, Kankakee, Livingston, LaSalle, and Fulton. The widely separated localities in this 
geographic area are difficult to associate as one fauna, as it has colloquially come to be known as, and it is rather best viewed as, an assemblage that has produced a collection of faunas sharing similar depositional and taphonomic modes of preservation. Some localities within the Mazon Creek assemblage, such as Pitt 11, have been heavily sampled and can stand alone for study as distinct ecological units. The Fulton County, Sunspot Mine locality (closest geographically to the type section of the Francis Creek Shale) has produced fossil plants and lungfish (A. Mann pers. obs.), as well as the iconic Tullymonstrum gregarium. Diabloroter bolti gen. et sp. nov. is the first tetrapod recovered from this locality, and is also the first confident record of a recumbirostran taxon from the Mazon Creek assemblage.

Previously the only record of a microsaur from Mazon Creek is a single specimen, FMNH PR 981 also from the Pit 11 locality. FMNH PR 981 is a small microsaurian tetrapod approximately $55 \mathrm{~mm}$ in length, which preserves most of the body. However, the lack of key anatomy, including most of the skull, precluded a confident taxonomic assignment, thus only a suggested affinity to the microbrachomorph Hyloplesion was made (Carroll \& Gaskill, 1978). Our observations of FMNH PR 981 did not provide any new data on the specimen, which appears to be further damaged from additional latex peeling. As such, the suggestion by Carroll \& Gaskill (1978) that FMNH PR 981 belongs to a microbrachomorph 'microsaur' is retained at present until more specimens are found. Enough features, however, were able to distinguish FMNH PR 981 from Diabloroter. Most notably, FMNH PR 981 possesses 24 presacrals, is much more gracile in every aspect of its skeletal morphology despite being longer than Diabloroter in total length. Thus, currently the Mazon Creek 'microsaur' diversity includes three taxa, a likely aquatic microbrachomorph (FMNH PR 981) and two terrestrial recumbirostrans-a partial lysorophian recumbirostran (Wellstead, 1991) and Diabloroter presented here. However, ongoing analyses by the current authors suggest an even greater recumbirostran diversity is present within the Mazon Creek assemblage.

The presence of a diverse recumbirostran fauna among the Mazon Creek localities suggests diversification of the group took place earlier than previously thought (see Huttenlocker et al., 2013). However, in some respects, an early Westphalian diversification of recumbirostrans has already been anticipated in the literature by the 
presence of gymnarthrid and pantylid microsaurs in the Westphalian A strata of Joggins, Nova Scotia (Carroll \& Gaskill, 1978). Furthermore, our new taxon, Diabloroter, also firmly pulls the diversification of brachystelechid recumbirostrans, previously known only from Permian-aged members, into the Upper Carboniferous Westphalian.

\section{Dental evolution in Brachystelechidae}

Among recumbirostrans, brachystelechids are so far the only clade known to have evolved multi-cuspid dentition. This is best observed in Batropetes and its multiple species (Gleinke, 2015), wherein strongly tricuspid dentition that are angled slightly anteriorly is observed (Anderson \& Reisz, 2003). Currently, it is thought that Carrolla craddocki also possesses only bicuspid dentition; however, Gleinke (2015) noted that at least the lower dentition possesses three cusps. Our personal observations of Carrolla also confirm that the dentary teeth are in fact tricuspid, albeit not as strongly as in Batropetes (Mann et al., 2018). The presence of tricuspid dentition in these two taxa points to a closer relationship between Batropetes and Carrolla than previously recognised (Anderson \& Reisz, 2003), and is also supported in the phylogenetic results reported in this paper (Fig. 2.4). In our phylogenetic analysis the earliest diverging member of Brachystelechidae, Quasicaecilia, is relatively incomplete lacking all data on its dentition. Thus, little can be said about the feeding habits of this taxon (Pardo et al., 2015). Conversely, Diabloroter possesses well-preserved homodont, peg-like dentition. This morphology in early amniotes and non-amniotes alike is thought to correlate with insectivory or feeding on small animal remains (Modesto et al., 2009). The relatively common, unspecialized, simple dentition present in Diabloroter likely represents the basal condition for the Brachystelechidae. This notion is supported by the relatively early occurrence of this Carboniferous taxon (309-307 Ma) and earlier diverging phylogenetic position compared most Permian-aged members of this clade that express the more specialized dental morphologies.

Aside from brachystelechids, dental diversity in recumbirostrans consists primarily of simple, sharply pointed often recurved dentition or robust, conical dentition. Both of these morphotypes can be expressed with degrees of heterodonty. Hypotheses of feeding strategies in extinct amniote and non-amniote clades are usually based on 
observations of extant herpetological taxa (Carroll \& Gaskill, 1978). This being said, studies of feeding strategy using modern methodology have yet to be widely applied to extinct taxa (see Melstrom, 2017). Whereas simple peg-like or conical, sharpely-recurved teeth are classically associated with micropredation on small insects and other animal remains, robust conical dentition is thought to have been associated with carnivorous durophagy (Reisz et al., 2015). A few recumbirostrans, including Pantlyus, bear palatal dentition that form functional tooth batteries and that may perform analogous functions to the multiple tooth rows in moradosaurine captorhinids. These may be used to process high fibre plant material (Romer, 1952); however, the possibility of herbivorous feeding strategies in recumbirostrans have yet to be thoroughly assessed.

Rarely discussed, is the function of the tricuspid tooth morphology in brachystelechids and why proposed fossorial forms (Maddin et al., 2011; Pardo et al., 2015 ) would require such a radically divergent morphology than other members of Recumbirostra (Anderson, 2007). Whereas the tricuspid teeth of Batropetes and Carrolla are unique among recumbirostrans and among 'microsaurs' in general, this morphology is not alien to the Permo-Triassic fossil record. The temnospondyl, Tungussogyrinus bergi (Wernberg, 2009), originally reported as a branchiosaurid, bears a very similar tricuspid tooth morphology. Additionally, the putative lissamphibian Albanerpeton has also been noted to possess similar tooth morphology (Fox \& Naylor, 1982). In Tungussogyrinus this tooth morphology is believed to be correlated with algivory, and related aquatic herbivorous feeding habits (Wernberg, 2009) based on observations of extant taxa including the algal specialist the marine iguana Amblyrhynchus cristatus and similar tooth morphology observed in algivorous fish (Melstrom, 2017; Streelman et al., 2003). Specifically, algivorous animals possess tricuspid tooth morphology that are spatulate, relatively elongate and work like a rasping rake, scraping algae off of surfaces. Conversely, many modern terrestrially herbivorous squamates bear a different kind of multicuspid tooth morphology that is broader at their base with shorter crowns (Melstrom, 2017).

Gleinke (2015) commented on the feeding habits of Batropetes and its species, hypothesizing that the triscuspid teeth were used for spearing and processing arthropod material. While we note, currently, there is no direct evidence of dietary preferences in 
Batropetes and Carrolla, we present an alternative hypothesis of aquatic herbivory in these brachystelechids based on the above-mentioned examples. Aquatic herbivory, including algivory, can be supported by several anatomical correlates. This includes, most importantly, the similarity in the aforementioned tricuspid tooth morphology of Amblyrhynchus cristatus and algivorous fish. Additionally, the anterior location of the tricuspid teeth in the tooth row and anteroposterior orientation of the cusps in modern algivores and Batropetes (Anderson \& Reisz, 2003) is also consistent with the function of contacting and raking algae covered surfaces. The otherwise terrestrially adapted postcranial skeleton also does not preclude our hypothesis, as the postcranial skeleton of Amblyrhynchus does not betray its aquatic feeding habits.

\section{Postcranial evolution of Brachystelechidae}

When considering this novel feeding hypothesis, postcranial morphology must also be considered. Postcranial morphology in recumbirostrans is heavily influenced by their fossorial ecology. This includes evolutionary trends towards body elongation and limb reduction analogously seen in extant fossorial reptiles and amphibians (Gans 1975; Gans \& Gasc, 1990). Brachystelechid postcrania are known from numerous specimens of Batropetes, fragmentary remains of Carrolla (a small string of vertebrae and robust rib fragments; Mann et al. 2019), and now the single specimen of Diabloroter described in this paper. The brachystelechid bauplan is unique among recumbirostrans being characterized by short-bodies with robust and well-ossified limb and girdle elements. Notably, the pectoral girdle elements of Batropetes are massive and well-ossified compared to most recumbirostrans with the exception of pantylids. Diabloroter also shows a considerable ossification in this area. Trunk morphology of most brachystelechids is extremely short, with Diabloroter and Batropetes palatinus having as few as 17 presacral vertebrae. The rib morphology among all brachystelechids is that of a relatively robust, long and curved element, creating the appearance of rotund gut region. In Batropetes this barrel-shape is particularly evident.

Gleinke (2015) noted that the robust limb morphology in conjunction with aforementioned features supports a terrestrial mode of life in brachystelechids. Here we further recognise that postcranial features present in brachystelechids are also largely 
present in Permo-Carboniferous herbivorous groups (Sues \& Reisz, 1998). An expansion of the gut region to house endosymbionts, and robust limbs and girdle elements to support this enlargement, are characteristic postcranial features associated with herbivory in diadectids, and various amniote clades (Reisz \& Sues, 1998). A gut and skeleton adapted to terrestrial herbivory may have been an important stepping stone in the evolution of specialized herbivores, such as algivores.

\subsection{Conclusion}

Diabloroter (Figs. 2.1A, 2.5) provides knowledge of a new tetrapod-bearing locality in the Francis Creek shale, geographically removed from the classic study areas of Braidwood and Essex. Diabloroter provides the earliest record of a brachystelechid recumbirostran, confirming the divergence of the clade took place in the Late Carboniferous, rather than Early Permian. Based on the cranial and postcranial anatomy of Diabloroter we are able to revise the diagnosis for the Brachystelechidae. Diabloroter allows confidence in the characterization of this clade as a group of short bodied recumbirostrans, and reveal a trend towards herbivory, possibly algivory, took place within brachystelechid lineage. Further systematic work on Mazon Creek recumbirostrans will aid in understanding this important interval in the evolution of this group of tetrapods. 


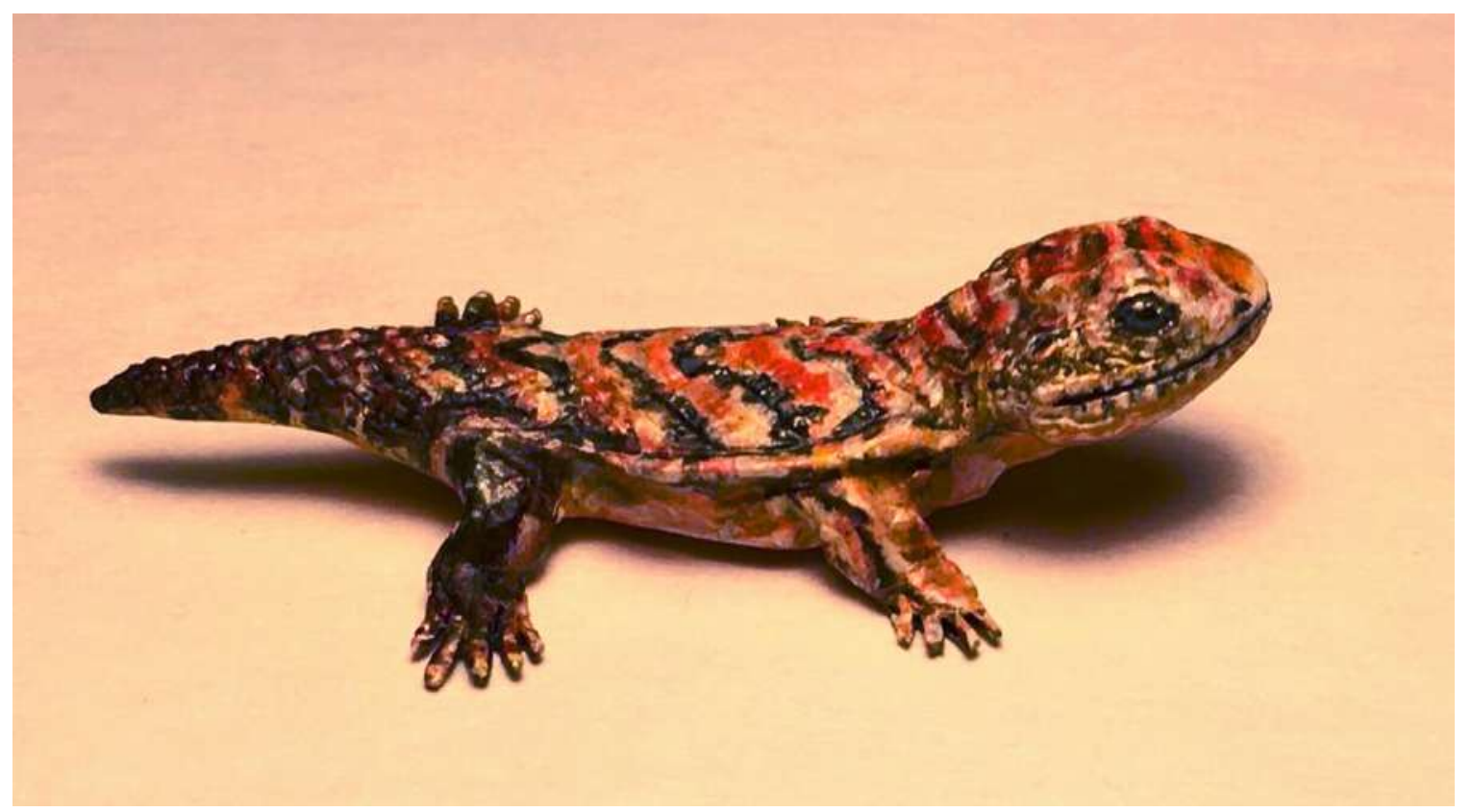

Figure 2.5 Life reconstruction of Diabloroter bolti gen et sp. nov. This sculpture was created by D. Duck.

\subsection{Acknowledgements}

We thank D. Dufault for useful discussions on figures and we thank D.Evans and K.Seymour for access to the collections at the ROM. We thank J. Bolt, W. Simpson and A. Stroup for access to collections at the FMNH, C. Mehling and M. Norell for access to collections at the AMNH, A. Howell for access to collections at the Redpath Museum and Susan Kornreich-Wolf for access to ACFGM collections. We thank J. Nelson and R. Hook for discussion on the geology of the Francis Creek Shale. In addition, we thank S. Roussel, R. Paterson, M. Thompson and the family of A. Mann for their support. Finally, we are grateful to D. Duck for his artist reconstruction (sculpture) of Diabloroter bolti.

\subsection{References}

Anderson JS. (2007). Incorporating ontogeny into the matrix: a phylogenetic evaluation of developmental evidence for the origin of modern amphibians. In: Anderson JS, Sues H-D, editors. Major Transitions in Vertebrate Evolution. Indiana: Indiana University Press. pp. 182-227. 
Bolt JR, Wassersug RJ. (1975). Functional morphology of the skull in Lysorophus: a snake-like Paleozoic amphibian (Lepospondyli). Paleobiology 1:320-332.

Chenoweth C. (2015). Directory of Coal Mines in Illinois, 7.5 minute quadrangles series ipava quadrangle Fulton County. Illinois State Geological Survey.

Carroll RL. (1968). The postcranial skeleton of the Permian microsaur Pantylus. Canadian Journal of Zoology 46:1175-1192.

Carroll RL. (1991). Batropetes from the Lower Permian of Europe - a microsaur, not a reptile. Journal of Vertebrate Paleontology 11:229-242.

Carroll RL, Gaskill P. (1978). The order Microsauria. Memoirs of the American Philosophical Society 126:1-211.

Carroll RL. (1998). Order Microsauria. In: Encyclopedia of paleoherpetology, Part 1: Lepospondyli (P. Wellnhofer, ed.). Verlag Dr. Friedrich Pfeil, Munchen 133-148.

Fox RC, Naylor BG. (1982). A reconsideration of the relationships of the fossil amphibian Albanerpeton. Canadian Journal of Earth Sciences 19(1): 118-128.

Gans C. (1975). Tetrapod limblessness: evolution and functional corollaries. American Zoologist 15:455-467.

Gans C, JP Gasc. (1990). Tests on the locomotion of the elongate and limbless reptile Ophisaurus apodus (Sauna: Anguidae). Journal of Zoology 220(4): 517-536.

Glienke S. (2013). A taxonomic revision of Batropetes (Amphibia, Microsauria) from the Rotliegend (basal Permian) of Germany. Neues Jahrbuch für Geologie und Paläontologie-Abhandlungen 269: 73-96. 
Glienke S. (2015). Two new species of the genus Batropetes (Tetrapoda, Lepospondyli) from the Central European Rotliegend (basal Permian) in Germany. Journal of Vertebrate Paleontology 35, e918041.

Gregory JT. (1948). The structure of Cephalerpeton and affinities of the Microsauria. American Journal of Science 246(9): 550-568

Gregory JT. (1950). Tetrapods of the Pennsylvanian nodules from Mazon Creek, Illinois. American Journal of Science 248(12): 833-873.

Huttenlocker AK, Pardo JD, Small BJ. (2005). An earliest Permian nonmarine vertebrate assemblage from the Eskridge Formation, Nebraska. New Mexico Museum of Natural History and Science Bulletin 30: 133-143.

Jaekel, O. (1909). Über die Klassen der Tetrapoden [About the classes of the tetrapods]. Zoologischer Anzeiger 34:193-212.

Maddin HC. (2011). Deciphering morphological variation in the braincase of caecilian amphibians (Gymnophiona). Journal of Morphology, 272(7): 850-871.

Maddin HC, Olori JC, Anderson JS. (2011). A redescription of Carrolla craddocki (Lepospondyli: Brachystelechidae) based on high-resolution CT, and the impacts of miniaturization and fossoriality on morphology. Journal of Morphology 272:722-743.

Mann A. (2018). Cranial ornamentation of a large Brachydectes newberryi (Recumbirostra: Lysorophia) from Linton, Ohio, and effects of ontogeny on skull ornamentation in recumbirostrans. Vertebrate Anatomy Morphology Paleontology 6, 91-96. 
Mann A, Olori JC, Maddin HC. (2018). Postcranial anatomy of the 'microsaur'Carrolla craddocki from the Lower Permian of Texas. Journal of Vertebrate Paleontology, 38(6), e1532436.

Melstrom KM. (2017). The relationship between diet and tooth complexity in living dentigerous saurians. Journal of morphology 278(4): 500-522.

Modesto SP, Scott DM, Reisz RR. (2009). Arthropod remains in the oral cavities of fossil reptiles support inference of early insectivory. Biology letters 5(6): 838-840.

Pardo JD, Szostakiwskyj M, Anderson JS. (2015). Cranial morphology of the brachystelechid 'microsaur' Quasicaecilia texana Carroll provides new insights into the diversity and evolution of braincase morphology in recumbirostran ‘microsaurs'. PLoS ONE 10:e0130359.

Pardo JD, Anderson JS. (2016). Cranial Morphology of the Carboniferous-Permian Tetrapod Brachydectes newberryi (Lepospondyli, Lysorophia): New Data from $\mu$ CT. PLoS ONE 11:e0161823.

Pardo JD, Szostakiwskyj M, Ahlberg PE, Anderson JS. (2017). Hidden morphological diversity among early tetrapods. Nature 546:642-645.

Streelman JT, Webb JF, Albertson RC, Kocher TD. (2003). The cusp of evolution and development: a model of cichlid tooth shape diversity. Evolution and development 5(6): 600-608.

Sues H-D, Reisz RR. (1998). Origins and early evolution of herbivory in tetrapods. Trends Ecology and Evolution 13: 141-145. 
Szostakiwskyj M, Pardo JD, Anderson JS. (2015). Micro-CT study of Rhynchonkos stovalli (Lepospondyli, Recumbirostra), with description of two new genera. PLoS One 10, e0127307.

Vallin G, Laurin M. (2004). Cranial morphology and affinities of Microbrachis, and a reappraisal of the phylogeny and lifestyle of the first amphibians. Journal of Vertebrate Paleontology 24: 56-72.

Wellstead CF. (1991). Taxonomic revision of the Lysorophia, Permo-Carboniferous lepospondyl amphibians. Bulletin American Museum of Natural History 209:190.

Werneburg R. (2009). The Permotriassic branchiosaurid Tungussogyrinus Efremov, 1939 (Temnospondyli, Dissorophoidea) from Siberia restudied. Fossil Record 12(2): $105-120$. 


\section{| Chapter 3: Infernovenator steenae gen. et sp. nov. a new serpentine recumbirostran from the 'Mazon Creek' Lagerstätte further clarifies lysorophian origins.}

\subsection{Authors and Addresses}

Arjan Mann ${ }^{1}$, Jason D. Pardo 2,3 , and Hillary C. Maddin ${ }^{1}$

Department of Earth Sciences, Carleton University, 1125 Colonel By Drive, Ottawa, Ontario K1S 5B6, Canada ${ }^{1}$

Department of Comparative Biology \& Experimental Medicine, University of Calgary, Calgary, Canada. ${ }^{2}$

McCaig Institute of Bone and Joint Health, University of Calgary, Calgary, Canada ${ }^{3}$

\subsection{Preface}

The following manuscript has been published in the Zoological Journal of the Linnean Society. Arjan Mann was fully involved in setting up and conducting the research, preparing samples, running all analyses, developing methodology, writing the manuscript and drafting final figures in this co-authored article. Hillary C. Maddin, provided discussion and editing of content. Jason D. Pardo provided discussion and editing of content, comparative data, and aid in figure construction. The manuscript has been modified slightly to accommodate the formatting requirements for Carleton University dissertations. Supplemental data can be accessed through the online version of the manuscript at the publisher's website. The article should be cited as such:

Mann, A., Pardo, J. D., \& Maddin, H. C. (2019). Infernovenator steenae, a new serpentine recumbirostran from the 'Mazon Creek' Lagerstätte further clarifies lysorophian origins. Zoological Journal of the Linnean Society, 187(2), 506-517.

\subsection{Abstract}

The Carboniferous Pennsylvanian-aged (309-307 Ma) ‘Mazon Creek' Lagerstätte produces some of the earliest tetrapod fossils of major Paleozoic lineages. Previously, the 
Mazon Creek record of lysorophians was known from a single, poorly preserved specimen consisting only of a partial vertebral column (USNM 4313). Here we describe a new, virtually complete lysorophian, Infernovenator steenae gen. et sp. nov., on the basis of a unique combination of characters, including a near complete circumorbital series and the retention of a postfrontal bone. Parsimony-based phylogenetic analysis recovers the new taxon within the family Molgophidae, as the sister taxon to Brachydectes newberryi. Those results as well as the more generalised cranial morphology present in Infernovenator further supports a recumbirostran origin of Molgophidae. Co-occurrence of two morphologically and functionally distinct molgophids in the early Moscovian suggests a rapid and underappreciated diversification of this family in the early Pennsylvanian.

\subsection{Introduction}

Molgophidae, commonly referred to as lysorophians, are a family of highly elongated, Permo-Carboniferous 'lepospondyl' tetrapods (Wellstead, 1991, 1998; Pardo \& Anderson, 2016; Pardo et al., 2017). Although initially established as a distinct lepospondyl order, Lysorophia (Cope, 1968; Wellstead, 1991, 1998), it has long been suspected that Molgophidae (the current name for the clade that includes members of the former Lysorophia; Pardo \& Anderson, 2016) are deeply-nested within the 'microsaurs', a diverse assemblage of 'lepospondyls' (Vallin \& Laurin, 2004; Marjanović \& Laurin, 2013). There is strong evidence that suggests molgophids belong to a subset of 'microsaurs' known as Recumbirostra. This has been borne out in recent anatomical (Pardo \& Anderson, 2016) and phylogenetic (Pardo et al., 2017) treatments of 'lepospondyl' morphology. Within this revised phylogenetic framework (Pardo et al., 2017), Molgophidae has been found to be a highly derived group of recumbirostrans that constitutes the sister clade to a short-bodied Brachystelechidae (Maddin et al., 2011; Glienke, 2013; Pardo et al., 2015) and, furthermore, suggests lysorophians may represent the first episode of fossorial experimentation in reptiles (Pardo et al., 2017).

These recent revelations have largely come about through re-study of cranial anatomy of the lysorophian Brachydectes newberryi Cope, 1968, employing micro- 
computed x-ray tomography $(\mu \mathrm{CT})$ (Pardo \& Anderson, 2016). These data revealed the presence of derived amniote characters of the braincase and suspensorium, including an amniote-like supraoccipital, prominent basioccipital, and pillar-like epipterygoid. Pardo \& Anderson (2016) interpreted the highly reduced cranial condition of lysorophians as analogous to the condition seen in extant fossorial reptiles, including microteiids, some lacertoids, and some skinks. In this respect, lysorophian morphology occurs within the range of functional adaptations to a fossorial lifestyle (Bolt \& Wassersug, 1975; Maddin et al., 2011; Huttenlocker et al., 2013; Szostakiwskyj et al., 2015) that is more consistent with reptiles than with the classically interpreted, stem-amniote-like ecomorphology that is comparable to lissamphibians (Sollas, 1930; Wellstead, 1991).

Because molgophids represent one of the few Paleozoic lineages that exhibit extreme trunk elongation (the other being the Aïstopoda), taxonomic and functional diversity of this clade has the potential to inform our understanding of how and when axial elongation opened new nichespace to tetrapods. Although a large number of molgophid taxa have traditionally been recognized, a revision of the order Lysorophia by Wellstead (1991) recognized that some genera (e.g. Cocytinus) were likely junior synonyms of others whereas other taxa (e.g. Lysorophus tricarinatus) were named on the basis of undiagnosable type material likely representative of multiple distinct species. Based on these observations, Wellstead (1991) reduced lysorophians to three valid taxa: Brachydectes newberryi, B. elongatus, and Pleuroptyx clavatus. As a result, molgophids show little to no variation in cranial morphology between these three taxa, with only subtle morphometric variation distinguishing Carboniferous and Permian lineages. Substantial differences in presacral vertebral count are present among molgophids (Wellstead, 1991), suggesting the presence of multiple molgophid taxa, but these cannot be distinguished according to the diagnostic criteria of Wellstead (1991). Additionally, ontogenetic sequences derived from specimens of the earliest Permian Council Grove Group of the Forest City Basin, USA, show that many of the characteristics Wellstead (1991) relied on to distinguish these three taxa are consistent with variation in postnatal maturity of the specimens (Pardo \& Anderson 2016). And finally, as most molgophid fossils are primarily represented by postcrania, craniofacial diversity among molgophids, 
particularly mosaic anatomy transitional between molgophids and other recumbirostrans, remains poorly understood.

Despite these anatomical developments, a renewed systematic study clarifying the diversity of the group remains a task yet to be accomplished. Study of new fossil material from a variety of Permo-Carboniferous communities has the potential to yield new data that would contribute to fully understanding the relationships and origin of Molgophidae. Here we report on one such exceptionally-preserved fossil from the Upper Carboniferous, Pennsylvanian-aged 'Mazon Creek' Lagerstätte (309-307 mya). Previously, a partial postcranial skeleton from Mazon Creek (USNM 4313) was attributed to Brachydectes by Wellstead (1991), but the specimen itself is fragmentary consisting only of a vertebral column, and is difficult to distinguish from other recumbirostrans. Comparisons for its assignment were drawn from Brachydectes newberryi, a well-known lysorophian from the slightly younger (Westphalian D) deposits at Linton, Ohio (Wellstead, 1991; Pardo \& Anderson, 2016). Previously, fossils from Linton, Ohio, have provided the oldest definitive record of lysorophians in the fossil record. Our new material presented here, FMNH MCP 367 (Fig. 3.1), a single part concretion containing a nearly complete cranial and postcranial skeleton, preserved as a natural mold of the dorsal aspect, is recognised as the oldest confirmed lysorophian in the fossil record. Below we describe FMNH MCP 367 and apply parsimony-based phylogenetic methods in order to ascertain its relationship. We assign the material to Infernovenator steenae gen. et sp. nov. and recognize the presence of more generalised recumbirostran characters than Brachydectes newberryi, further supporting a recumbirostran origin of Molgophidae. 
A

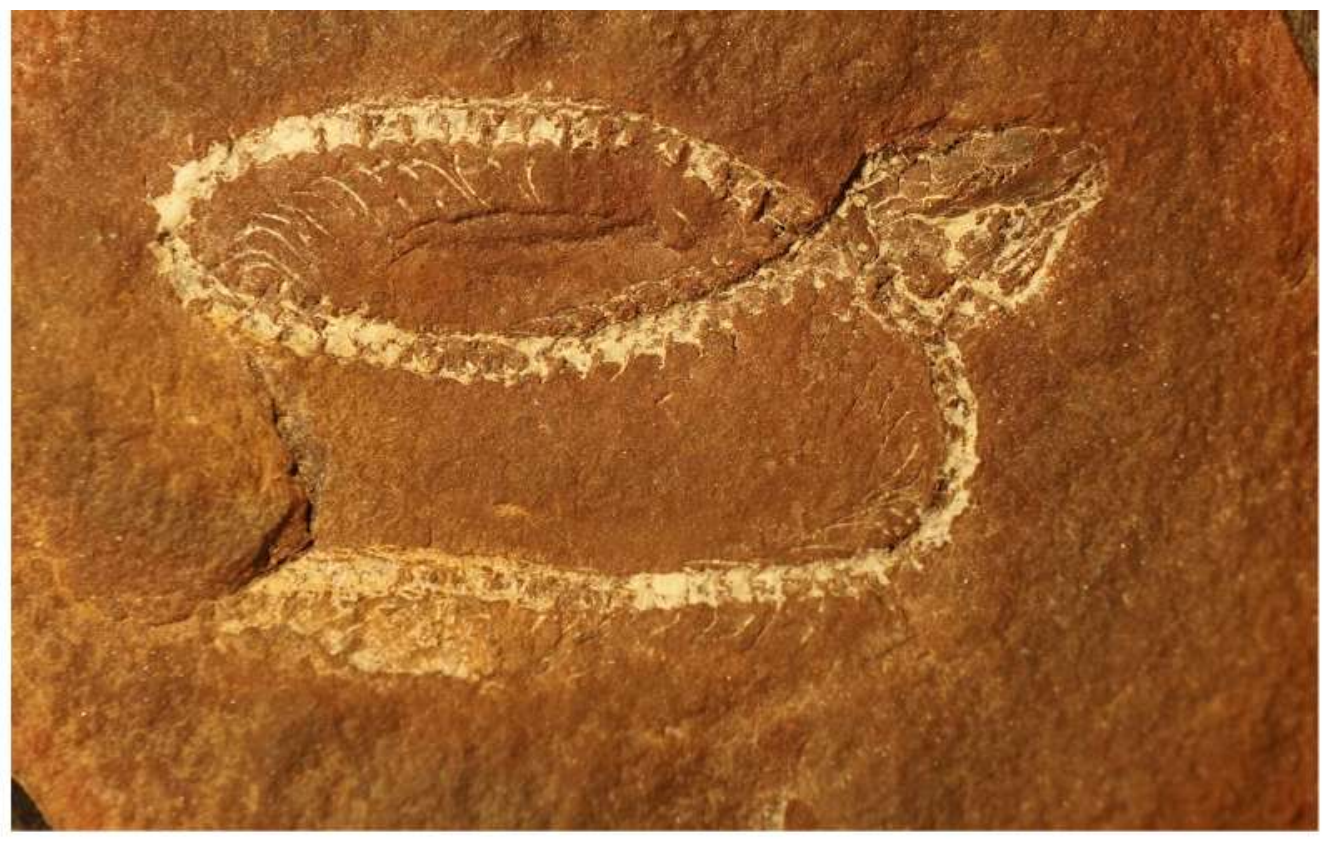

B

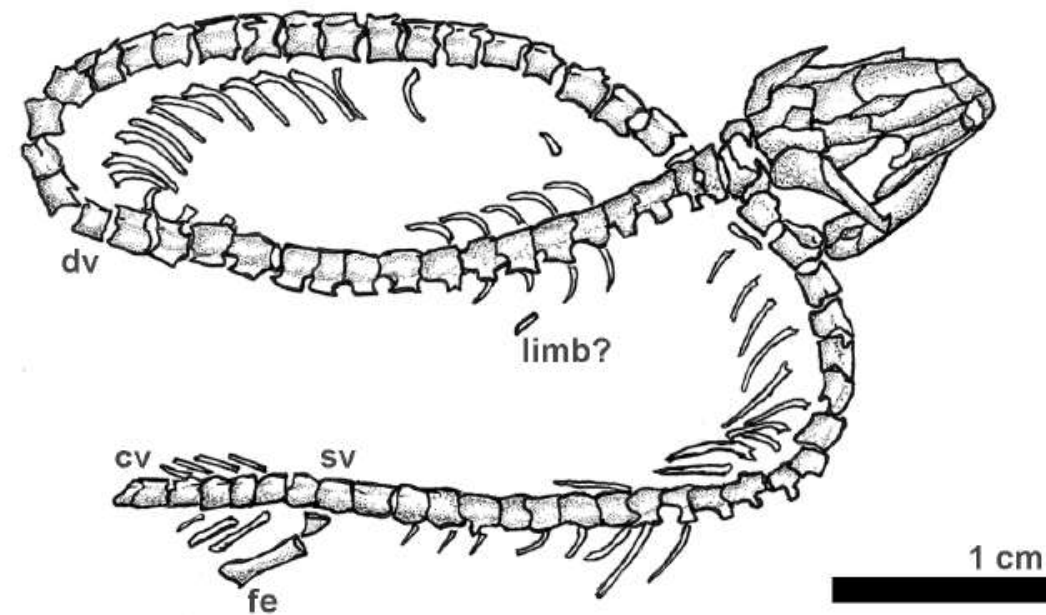

Figure 3.1 Photograph A, and illustration B, of the skeletal anatomy of the holotype specimen of Infernovenator steenae gen. et sp. nov. (FMNH MCP 367).

\subsection{Materials and Methods}

Specimens were studied at: Augustana College's Fryxell Geology Museum (ACFGM), Rock Island, USA; American Museum of Natural History (AMNH), New York, USA; Carnegie Museum of Natural History (CM), Pittsburgh, USA; Denver Museum of Nature and Science (DMNH), Denver, USA; Field Museum of Natural History (FMNH), Chicago, USA; University of Kansas Natural History Museum (KUVP), Lawrence, USA; University of Nebraska State Museum (UNSM), Lincoln, 
USA; Smithsonian Institution (USNM), Washington DC, USA; and Yale Peabody Museum (YPM), New Haven, USA. Additional comparative specimens from the British Museum of Natural History (BMNH), London, UK, the Harvard Museum of Comparative Zoology (MCZ), Cambridge, USA, Museum für Naturkunde (MB), Berlin, Germany, were compared based on casts, latex peels, and existing literature. As a result, the comparative dataset constituted nearly all reported lysorophian material from the Francis Creek Shale of Mazon Creek, Illinois and Linton, Ohio as well as material from the cannel coal below the Lower Kittanning coal of Five Points, Ohio, the Speiser Shale, Kansas, the Eskridge Shale, Nebraska, and a variety of material from Texas redbed localities. Photography was conducted using a Sony Alpha ILCE 5000 camera, F3.5 lens. All figures were drawn and formatted in Photoshop CS6 (Adobe, San Jose, CA). For phylogenetic methodology see the phylogenetic analysis section below.

\subsection{Anatomical abbreviations}

$\mathbf{a n}=$ angular; $\mathbf{b o}=$ basioccipital; $\mathbf{c v}=$ caudal vertebrae; $\mathbf{d v}=$ dorsal vertebrae;

$\mathbf{d}=$ dentary; $\mathbf{e x}=$ exoccipital; $\mathbf{f e}=$ femur; $\mathbf{f}=$ frontal; $\mathbf{h y}=$ hyobranchial element; la=lacrimal; $\mathbf{M f}=$ =Meckelian foramen; $\mathbf{m a x}=$ maxilla; $\mathbf{n}=$ nasal; $\mathbf{p}=$ parietal; $\mathbf{p f}=$ postfrontal;

$\mathbf{p m x}=$ premaxilla; $\mathbf{p p}=$ postparietal; $\mathbf{p r f}=$ prefrontral; $\mathbf{s m}=$ septomaxilla; $\mathbf{s o}=$ =supraoccipital; $\mathbf{s q}=$ squamosal; $\mathbf{s r}=$ surangular; $\mathbf{s t}=$ stapes; $\mathbf{s v}=$ sacral vertebra; $\mathbf{t}=$ tabular.

\subsection{Systematic Paleontology}

Recumbirostra, Anderson 2007

Molgophidae, Cope 1875

Infernovenator gen. nov.

Diagnosis-Monotypic, same as for species.

Infernovenator steenae gen. et sp. nov.

(Figs. $3.1 \& 3.2$ ) 
Holotype-FMNH MCP 367, a single part concretion containing a nearly complete cranial and postcranial skeleton, preserved as a mold of the dorsal aspect, anterior limbs poorly developed, posterior limbs only represented by single left femur, tail incompletely preserved posteriorly.

Etymology - The generic name is a combination of 'Infernum' latin for hell or underworld, referring to the proposed fossorial habitus, and 'venator' latin for hunter. The specific epithet 'steenae' is in honour of the Paleozoic tetrapod worker, Margaret Clair Steen Brough.

Horizon and Locality_-Pit 11, Will or Kankankee County, Francis Creek shale, Carbondale Formation, 'Mazon Creek', middle Pennsylvanian-aged (309-307 Mya), Carboniferous (Chenoweth, 2015).

Differential Diagnosis - A molgophid diagnosed by the following unique combination of features: 61 presacral vertebrae; triangular shaped postfrontal that contacts the tabular; a near-complete circumorbital series formed by postfrontal and prefrontal dorsoanteriorly and lacrimal and posterior process of maxilla anteroventrally; ossified septomaxilla. Shares with Brachydectes, and differs from other recumbirostrans, in the absence of a postorbital; presence of a cheek emargination; a bar-like tabular-squamosal complex; and a robust short dentary.

Comments - FMNH MCP 367 was originally collected by Helen and Ted Piecko (collection number: HTP 6904) and consolidated by Charles Shabica for the Mazon Creek Project. FMNH MCP 367 was previously featured in the Richardson's Guide to the Mazon Creek fossil Fauna tetrapod chapter (pg. 262) by Stephen Godfrey where it is identified as the aïstopod Phlegethontia (=Aornerpeton) mazonensis. In order to preserve the unique 'kaolinite infilling' and prevent further damage to the only known specimen, latex peels were not prepared from this fossil (preserved as a mold). As such the anatomy on the right side of the preserved skeleton actually represents anatomical left, and vice versa, and the descriptions will follow this convention. 


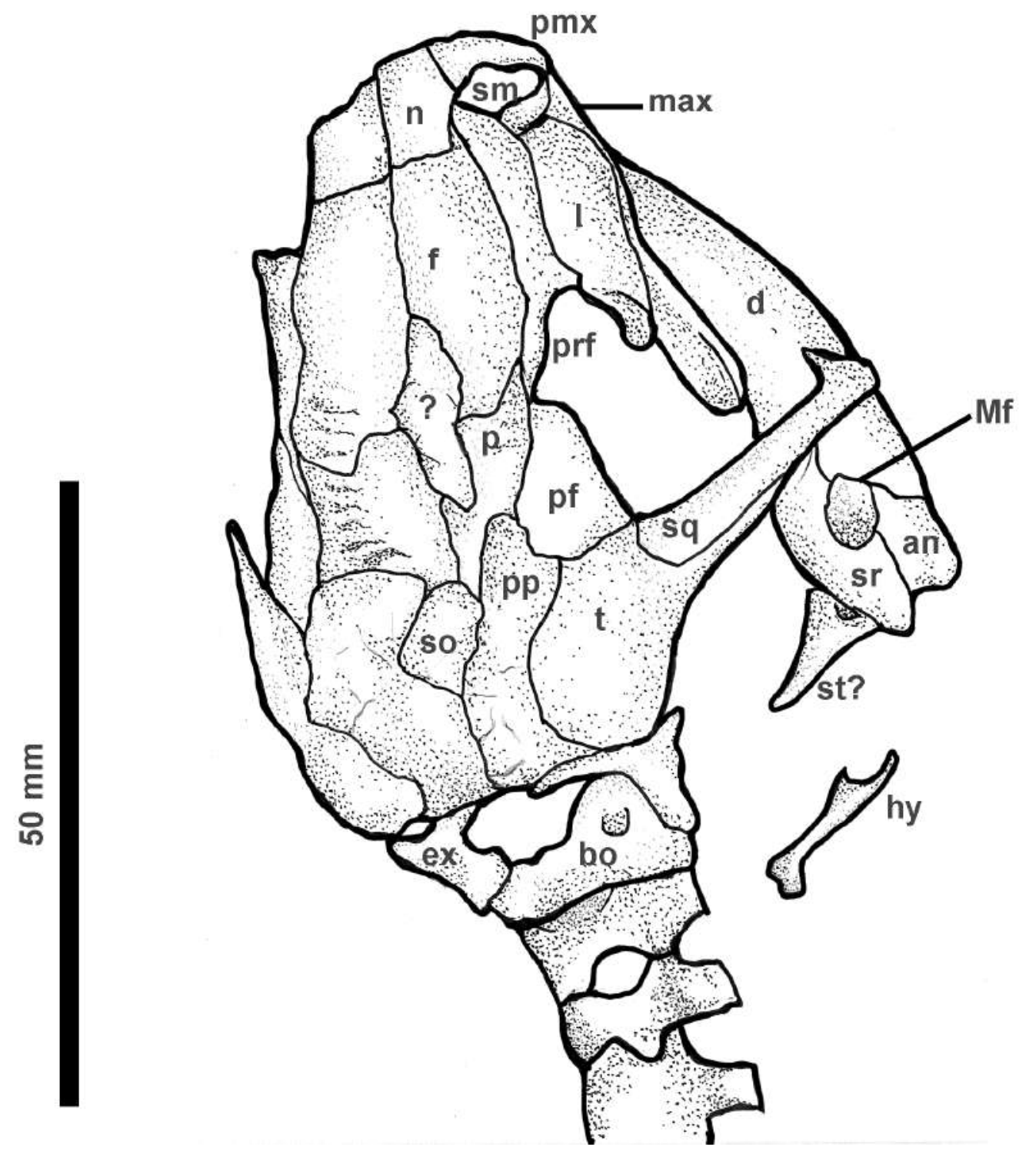

Figure 3.2 Cranial anatomy of the holotype specimen of Infernovenator steenae gen. et sp. nov. (FMNH MCP 367).

\subsection{Description}

\section{Cranial anatomy}

The holotype and only specimen of Infernovenator steenae, FMNH MCP 367, preserves a nearly complete dorsal skull roof with most of the occiput exposed posteriorly as well (approx. $55 \mathrm{~mm}$ ) (Fig. 3.2). The skull is crushed and skewed somewhat dorsolaterally, exposing the left 'cheek' region including a nearly complete 
tabular-squamosal complex. Additionally, most of the left mandible is also preserved. No dentition is preserved on any of the tooth bearing elements.

The left premaxilla is visible only in dorsal view, exposing a small medial contact with the lateral surface of the nasal (Fig. 3.2). In dorsal view the premaxilla curves slightly laterally to meet the maxilla. The premaxilla is the primary contributor to the anterior wall of the external naris. Additionally, a shallow surface curvature is indicated by an impression, indicating the snout may have been slightly recumbent. It is possible that the snout was more recumbent than the condition seen in Brachydectes, where the snout is relatively straight.

Both nasals are preserved, the left is either slightly obscured by sediment or incompletely preserved (Fig. 3.2). They are roughly short rectangles in shape and proportionally shorter compared to the frontals. The width of both nasals is also shorter than the width of the frontals, creating a noticeable taper of the snout. There is a small contribution of the nasal to the dorsal margin of the external naris that wedges between the premaxilla and the prefrontal. The prefrontal invades the posterior portion of the dorsal margin of the external naris and narrowly contacts the nasal.

Both frontals are preserved and are exceptionally large elements as they are in general in lysorophians (Fig. 3.2). They are long rectangular, plate-like ossifications that widen slightly posteriorly. The posterolateral margins of the frontals are ornamented with lateromedially oriented crenulations, similar to those found on young lysorophians including 'L. minutus'. Anteriorly, the frontal-nasal suture is not interdigitated and is a simple straight contact. The frontals are bordered by the prefrontals laterally along their entire length forming a straight suture. Posteriorly they are bordered by the parietals at an S-shaped suture. The straight frontal-frontal suture is interrupted posteriorly by a large rhomboid ossification that continues between the parietals. Because the skull roof bones in this area appear unnaturally split apart, this may be part of an anterior ossification of the braincase that has been wedged through during compaction. It is possible that this ossification is the orbitosphenoid or part of the dorsal projection of the parabasisphenoid complex (Pardo et al., 2015).

The parietals are both preserved (Fig. 3.2). The right parietal is better preserved because the left is slightly folded over obscuring its anatomy. The parietals are roughly 
square-shaped although no sutural contact is parallel. It is possible that posteriorly the parietals are strongly overlapped by the postparietals and supraoccipital, but this cannot be confirmed given the preservation. The entire lateral margins of the parietals bear the same ornamentation as the frontals. The parietal-parietal suture is relatively straight again only interrupted, by the exposure of a possible braincase ossification anteriorly. Laterally the parietals are bordered by the postfrontals, their entire length.

Posterior to the parietals both postparietals are preserved and have a strong dorsal exposure (Fig. 3.2). This may be part of a similar condition observed in Brachydectes in which the occiput is anteriorly sloping. However, these elements and the occiput in general are more severely crushed by flattening than other areas of the cranium. The postparietals are irregularly shaped elements that appear to meet each other posteriorly; however, this may be a result of the cranium being compacted inward in this area. This posterior contact may be covering a posterior dorsal exposure of the supraoccipital. The exposure of the supraoccipital that is visible is limited to a small wide-diamond shaped element anterior to where the postparietals meet, thus the supraoccipital may appear artificially restricted from the occiput.

Posterior to the postparietals, exoccipitals are present on either side of the foramen magnum (Fig. 3.2). They are roughly semi-lunate in shape forming the lateral walls of the foramen magnum. Although the exoccipitals are slightly displaced from crushing, they appear to meet the postparietals and likely the supraoccipital dorsally, the latter of which likely formed the majority of the internal dorsal wall of the foramen magnum. Preserved ventral to the exoccipitals is part of the basioccipital; however, this is incompletely preserved and obscured by other skull roof elements.

A characteristic lysorophian tabular-squamosal complex is more completely preserved on the left side (Fig. 3.2). The tabular invades the posterior lateral margins of the skull roof as a large irregularly-shaped element with a ventrolateral projection that tightly abuts the squamosal. The squamosal forms the majority of the ventrally descending bar. No identifiable remains of the quadrate can be found.

The prefrontals are exposed on both the dorsal and lateral surfaces of the snout on FMNH MCP 367 as in Brachydectes (Fig. 3.2). The left is again better preserved and likely only incomplete at its posterior end. These prefrontals are long, subrectangular 
elements that brace the nasals and frontals medially and the lacrimal ventrolaterally. Contact with the lacrimal is achieved through a ventrolateral curvature of the prefrontal, making an appearance on the lateral surface of the snout. The prefrontals also form a weak dorsoanterior orbital margin. In particular, there is a small ventral process that forms part of the dorsoanterior wall of the orbit. Recruitment of this element into an orbital rim is a unique feature of FMNH MCP 367 among lysorophians. However, it is common in most other groups of recumbirostrans.

The lacrimal is preserved on the left side, whereas the right is completely obscured by the other skull elements (Fig. 3.2). The lacrimal is also a large subrectangular skull element that is restricted to the lateral snout. Compared to other lysorophians this element is uniquely well developed contributing strongly to the anterior and dorsal orbital margin. A posteriorly projecting process of the lacrimal contributes to the anterolateral margin of the orbit. This process adjoins the posterior process of the maxilla.

Only the left maxilla is visible and preserved as a thin strip of bone ventral to the lacrimal (Fig. 3.2). The shape in lateral view cannot be fully discerned due to the element being obscured by the lacrimal; however, it appears generally similar in shape to that of Brachydectes in that it is a short element with relatively uniform lateral height (Wellstead, 1991; Pardo \& Anderson, 2016). The well-preserved posterior process of the maxilla is slightly longer than that in Brachydectes and appears to simply be hanging and does not suture to any particular element. This process likely formed the ventral extent of the orbit. Anterior to the left maxilla and lacrimal, along the posterior margin of the naris, a small septomaxilla is present as a semi-lunate shaped ossification.

Unique within lysorophians and most unusual in this fossil is this presence of a postfrontal (Fig. 3.2). The postfrontals are preserved on both sides of the skull but are much better represented on the left side. The postfrontals are roughly triangular in shape and meet the prefrontal anteriorly excluding the frontals from the orbital margin. Posteriorly the postfrontal expands to meet the tabular around the level of the squamosaltabular suture. This is seen clearly on the left side of the cranium. The medial postfrontal contact with the frontal and parietal is a simple, straight suture. Slight curvature on the anteriorolateral margin of the bone indicates that the postfrontal was part of the dorsal 
orbital margin. However, there is no descending ventral process that would indicate a suture with a postorbital or contribution to a posterior orbital margin of any kind.

Adjacent to the cranium on the left side is preserved the left mandible (Fig. 3.2). Preserved in the lateral aspect is a very robust dentary, surangular, and angular. The morphology of these elements is nearly identical to those of Brachydectes. The dentary is a short robust element similar in shape to those of other lysorophians. The dentary curves dorsally towards the symphysis. The coronoid process although slightly obscured by squamosal appears relatively low. A Meckelian foramen is present just posterior to the dentary and formed by contributions from all three preserved mandibular elements. The angular is an irregularly shaped element that is preserved ventrally to the surangular and appears relatively short showing no reflected lamina. It is likely that the element is incomplete posteriorly. The surangular, like the angular, is also irregularly shaped and is roughly ovoid in lateral profile. The surangular contracts the coronoid process of the dentary anteriorly and together with the angular form the posteriormost elements of the mandible. Preserved medial to the surangular is a funnel-shaped element that may represent the stapes. The element is not well preserved enough to rule out that it is not a part of the suspensorium. At least one rod-like hyobranchial element is preserved posterior to this element adjacent to the occiput.

\section{Postcranial anatomy}

Aside from the well-preserved cranium a near complete postcranial skeleton is present in FMNH MCP 367 (Figs. 3.1 \& 3.2). The skeleton is coiled in fashion similar to many lysorophians found in the Permian-aged red-bed deposits of Texas and Oklahoma as well as specimens of Brachydectes found in the Permian Eskridge Shale of Nebraska and Speiser Shale of Kansas within the Council Grove Group (Huttenlocker et al. 2005; Hembree et al., 2004; 2005). The estimated total length of the specimen is $8.5 \mathrm{~cm}$.

Forelimb elements here are tenuously identified as two small bar-like structures, one present on either side of the $6-7^{\text {th }}$ presacral vertebrae (Fig. 3.1). Exactly which elements these may be is uncertain, the simple bar-like structure may suggest they are radii. Conversely, it is also possible these are either elements of the pharyngeal arches or are disarticulated rib elements. Comparatively, they appear very similar to the 'limb' 
elements identified in the recumbirostran Altenglenerpeton (Glienke, 2012); however, these non-distinct elements may in fact be hyobranchials, an identification supported by their high anterior position on the axial column just posterior to the preserved cranium of Altenglanerpeton (see Figure 1 in Glienke, 2012).

A single robust and short left femur is present adjacent to a well-preserved sacral rib (Fig. 3.1). The element is well-developed and relatively long in comparison to the proposed anterior limb elements. In general, the femur is of comparable size and morphology to most known specimens of the lysorophian Brachydectes (Wellstead, 1991).

Approximately 68 holospondylous vertebrae are preserved on FMNH MCP 367, 61 of which are presacral vertebrae (Fig. 3.1). The tail is incomplete posteriorly and may dive into the matrix, thus nothing can be said about the posteriormost caudal vertebrae. The presacral vertebrae appear to be poorly ossified in some areas, particularly the lateral margins of the neural arches, which generally consist of low hat-shaped dorsal extensions completely fused to each centrum. The neural arches appear to be paired with their antimere, a feature visible in dorsolateral perspective on some presacral vertebrae. The centra are of typical recumbirostran construction being relatively cuboid in shape with cotyles on each end. Some centra including those of the cervical region appear relatively thin and poorly formed, likely indicating immaturity in the specimen. Aside from that, not much else can be discerned about their anatomy.

Among the unique traits of FMNH MCP 367 is the relatively thin rib morphology (Fig. 3.1) compared to other lysorophians from Linton as well as those from later deposits of the Early Permian. Dorsal ribs are preserved on the specimen in articulation anteriorly in the cervical region as well as slightly detached from the vertebrae more caudad on the vertebral column. The dorsal rib heads are well ossified consisting of $Y$-shaped processes (Fig. 3.1). Laterally the dorsal ribs curve ventrodistally while maintaining their thin morphology. This morphology is divergent from most specimens of Brachydectes including of the same size class or even smaller (Fig. 3.3E) where the ribs are strongly expanded distally often accentuated into a fan shaped in adult specimens. The thin dorsal rib morphology present in FMNH MCP 367 bears resemblance to many other longbodied recumbirostran taxa including Aletrimyti and Rhynchonkos (Carroll and Gaskill, 
1978; Szostakiwskyj et al., 2015). At least one funnel-shaped sacral rib is preserved medial to the femur and, posterior to that, a few relatively long caudal ribs can be observed which consecutively taper in length to presumably would be terminal caudal vertebra. The caudal ribs appear to be slightly elongated posterior to the pelvic region (Fig. 3.1).
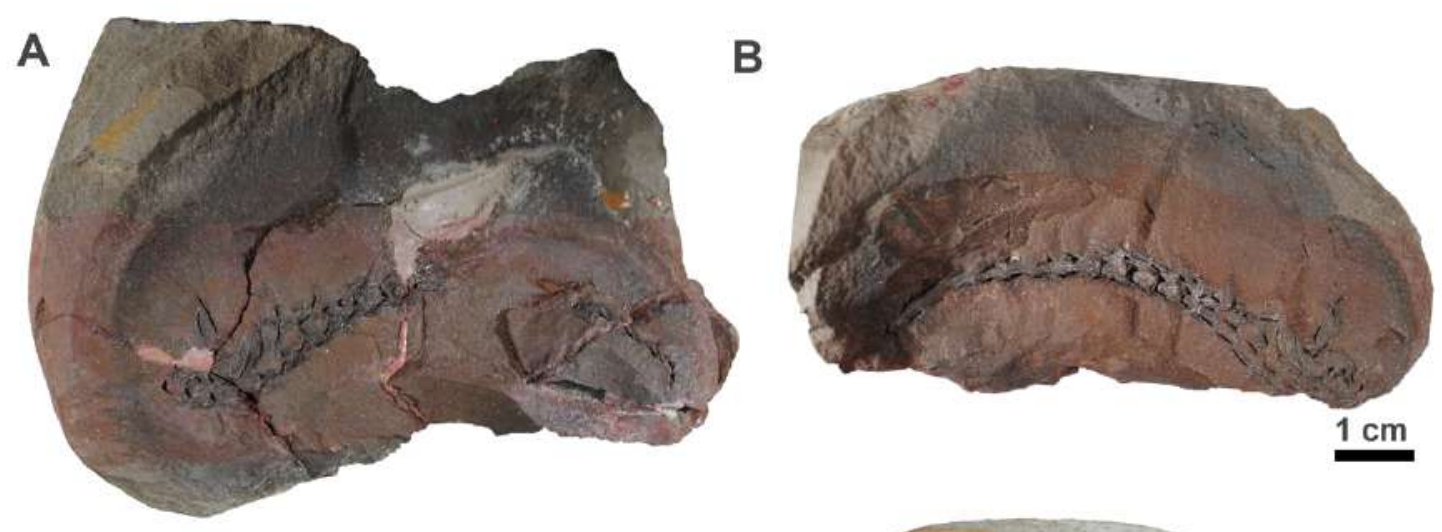

C

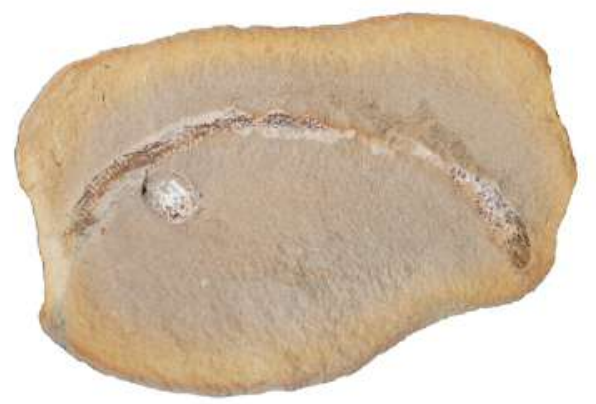

E

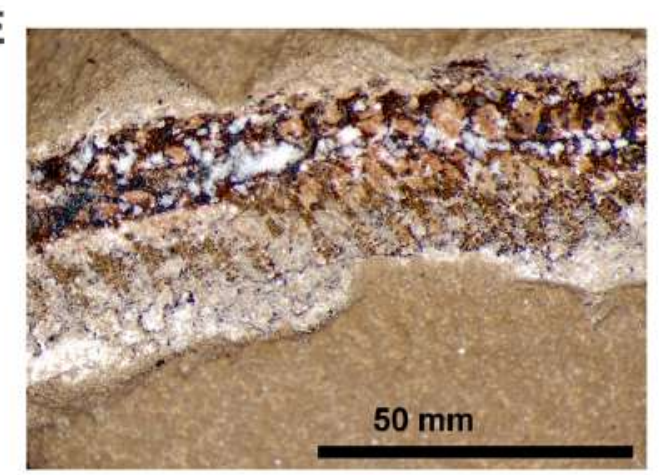

D
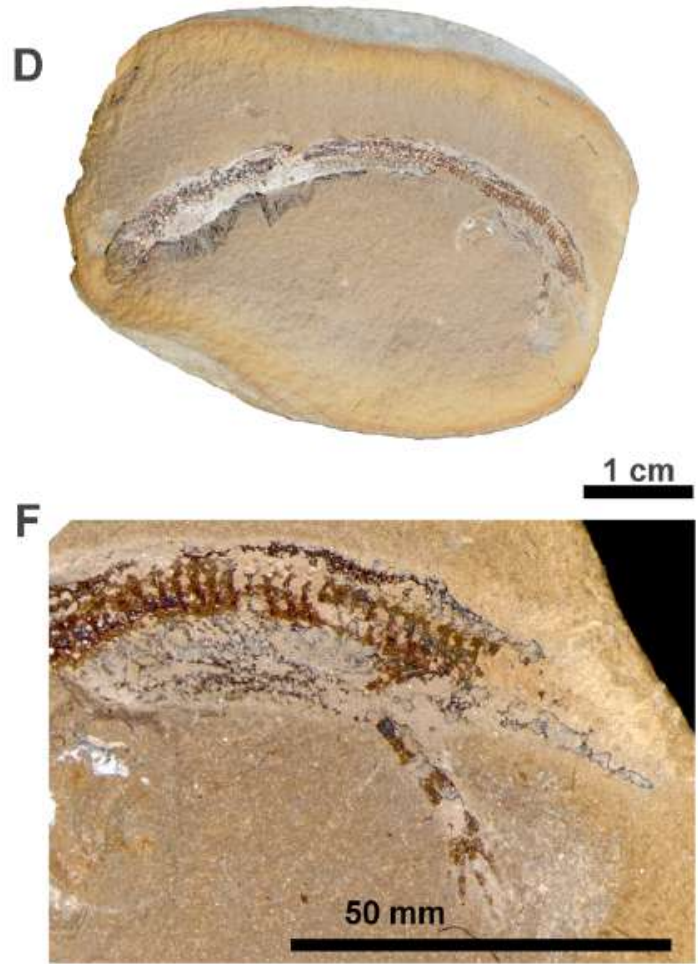

Figure 3.3 A-B, Wellstead's (1991) Brachydectes (USNM 4313). C-D, a new immature specimen of Brachydectes newberryi (FMNH PR 1031). E-F, close up views of the dorsal vertebrae and pelvic regions of FMNH PR 1031, respectively. 


\subsection{Phylogenetic Analysis}

We explored the phylogenetic relationships of FMNH MCP 367 using a modified version of the recent matrix of Pardo et al. (2017; see Appendix B.1 for matrix). Although this matrix was primarily designed to assess large-scale, early tetrapod relationships, it also heavily samples recently-described anatomy of the recumbirostran braincase and therefore provides the most up to date matrix for assessing recumbirostran interrelationships. Given the hypothesized close relationship between molgophids and brachystelechids, we also added another undescribed brachystelechid recumbirostran from Mazon Creek (ACFGM V-1634) and the brachystelechid Batropetes. We performed parsimony analysis using PAUP software v4.0b10 (Swofford, 2002) and Eusthenopteron was specified as the outgroup. We used a heuristic search option with 100 random sequence additions with a TBR search algorithm. Maxtrees was set at 10,000, and automatically increased by 100 . All characters were equally weighted. All multistate taxa were treated as polymorphic. All ambiguous character states were resolved using the ACCTRAN setting. Indices of goodness of fit of the character data to the topology (e.g., consistency index $[\mathrm{CI}]$, retention index [RI], rescaled consistency index [RC], and homoplasy index [HI]) were calculated in PAUP. To assess support of internal nodes, bootstrap values were calculated using the fast-stepwise addition option.

The parsimony analysis recovered 36 most parsimonious trees (MPT), each with 1789 steps (Consistency Index [CI $]=0.315$; Homoplasy Index [HI $]=0.739$; Retention Index $[\mathrm{RI}]=0.642$; Rescaled Consistency Index $[\mathrm{RC}]=0.203)$. The strict consensus of the results recovers FMNH MCP 367 as a molgophid and the sister taxon to Brachydectes newberryi (Fig. 3.4). This relationship is supported by Characters 1 state $=0,26$ state $=0$, 194 state $=0 / 1,195$ state $=1$ (all character numbers refer to those used in the analysis of Pardo et al., 2017). A bootstrap value of 94 reveals that this relationship is strongly supported (Fig. 3.4). The strict consensus tree also recovered ACFGM V-1634 as a brachstelechid occurring at one node more crownward than Quasicaecilia, as the sister taxon to a clade including Batropetes + Carrolla (Fig. 3.4). The position of ACFGM V1634 in the parsimony result is supported by Character 40 state $=1$ and Character 68 state $=1$. 


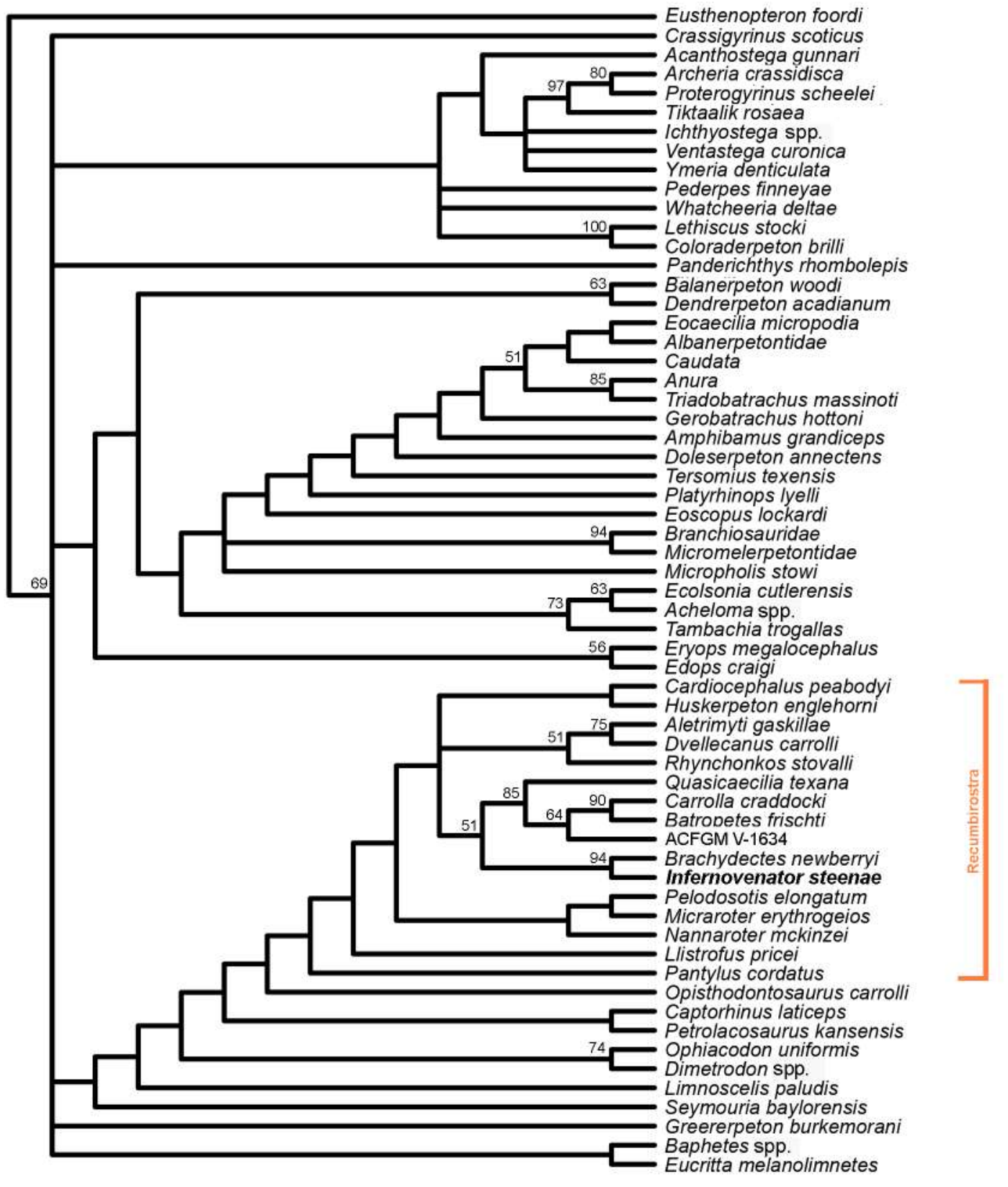

Figure 3.4 Strict consensus tree of the parsimony analysis. Infernovenator steenae gen. et sp. nov. is indicated in bold. Numbers above branches represent bootstrap values. 


\subsection{Discussion}

\section{Infernovenator steenae and the origin of Molgophidae}

Two putative lysorophian specimens have been reported from deposits older than that in which Infernovenator steenae was found, but both are of questionable taxonomic identity. Wellstead (1998) reported BMNH R. 8468 from the lowermost Westphalian of Jarrow Collier, Kilkenny, Ireland. Wellstead (1998) did not assign this material to any particular taxon, and recognised a range of characters in the material that conflict with a lysorophian identity, including a more posteriorly located jaw joint and an abnormally long mandibular ramus. Ultimately Wellstead viewed this material as inconclusive due to its poor condition. It is possible that this material represents a poorly-preserved specimen of the aïstopod Ophiderpeton brownriggi, also known from Jarrow, which would account for the aberrations in the mandibular anatomy, but this will be difficult to determine with confidence without an updated description of $O$. brownriggi in line with other recent anatomical descriptions of aïstopods (e.g., Pardo et al., 2017). A second skeleton was reported from the Lower Pennsylvanian Westphalian B coal deposits of Newsham Colliery, Newcastle Upon Tyne (Boyd, 1982). The Newsham skeleton preserves a short section of recumbirostran postcranial skeleton with no associated appendicular or cranial material. The presence of an unfused suture line between neural arches and unfused neurocentral suture is consistent with a molgophid affinity of this skeleton, but these characteristics more generally reflect juvenile status in recumbirostrans and therefore may not have taxonomic utility (Pardo \& Anderson, 2016) leaving the molgophid status of this specimen uncertain. Given that no definitive lysorophian material has been produced from any earlier Carboniferous localities, the lysorophian material presented here from 'Mazon Creek' assemblage remains the oldest definitive material of the group.

The mosaic of plesiomorphic and derived recumbirostran features and the stratigraphically early occurrence of Infernovenator steenae (Westphalian C, approximately 315-311 Ma, comparable to the first half of the Moscovian) provides new and important insights into the temporal and phylogenetic context of the origin of the Molgophidae. Specifically, Infernovenator preserves a more complete circumorbital series that includes a postfrontal (in contrast with other molgophids), a large lacrimal 
consistent with the anatomy seen in more conservative recumbirostrans (Huttenlocker et al., 2013; Szostakiwskyj et al., 2015) and a moderately elongate trunk, while at the same time showing the strongly canted suspensorium, lack of a jugal, short mandibular ramus, and mandibular fenestra consistent with a molgophid affinity. While other molgophids from 'Mazon Creek' show morphology consistent with the derived molgophids from later Carboniferous-Permian transition deposits (Wellstead, 1991; Pardo \& Anderson, 2016), many features of Infernovenator appear to bear more resemblance to other recumbirostran groups. Some unique features include a more complete circumorbital series with the presence of a postfrontal, as well as the configuration of the snout in general. The lacrimal and prefrontal are larger and more extensive in their contribution to the snout, similar to recumbirostran groups such as gymnarthrids, rhynchonkids, and other less specialised forms such as Huskerpeton. Overall the snout of Infernovenator also appears to have a noticeable taper reminiscent of Aletrimyti and Rhynchonkos (Szostakiwskyj et al., 2015). In particular, this suggests that molgophids may have included both shovel-snouted ecomorphs (such as Infernovenator) as well as roundheaded morphs (such as Brachydectes). This may provide an explanation for the bizarre morphology described by Glienke (2012) for the fragmentary recumbirostran Altenglanerpton, which also preserves a pointed rostrum but an otherwise molgophid-like skull.

It is somewhat appealing to hypothesize that the pointed snout of Infernovenator may indicate stepwise acquisition of molgophid-like morphology from a rhynchonkid or ostodolepid ancestor, particularly given moderate body elongation in Aletrimyti gaskillae or Pelodosotis elongatum, greater body elongation in Infernvenator, and extreme body elongation in Brachydectes. However, we note several problems with this interpretation. First and foremost, our phylogenetic analysis still preserves a close relationship between molgophids and brachystelechids. Among brachystelechids, a short trunk and welldeveloped limbs are present in all taxa with well-preserved postcrania (Glienke, 2013, 2015: Pers Obs.), and skulls lack clear temporal fenestrae as well as pointed shovel-like rostra (Fig. 3.5; Maddin et al., 2011; Pardo et al., 2015). Furthermore, ecomorphology exhibits high levels of convergence in modern fossorial reptile diversifications (Kearny \& Stuart, 2004), so similarities in snout shape between rhynchonkids or ostodolepids on the 
one hand, and Infernovenator steenae on the other can likely be attributed to convergence (Fig. 3.5), whereas deeper similarities in braincase structure between molgophids and brachystelechids may be more phylogenetically informative. However, recumbirostran phylogeny lacks a strong consensus at present for a range of reasons. These include incomplete revision of the comparative morphology of the group in general, unreliable descriptions of early and supposedly plesiomorphic members of the clade, historical burden in the interpretation of osteological correlates of soft tissue anatomy, historical burden in interpretation of appropriate outgroups, and inconsistent quality of morphological description of putative outgroups. In this context, interpretation of the phylogenetic placement of Infernovenator steenae remains somewhat provisional pending solutions to the above challenges, specifically a complete anatomical and phylogenetic treatment of Recumbirostra. 


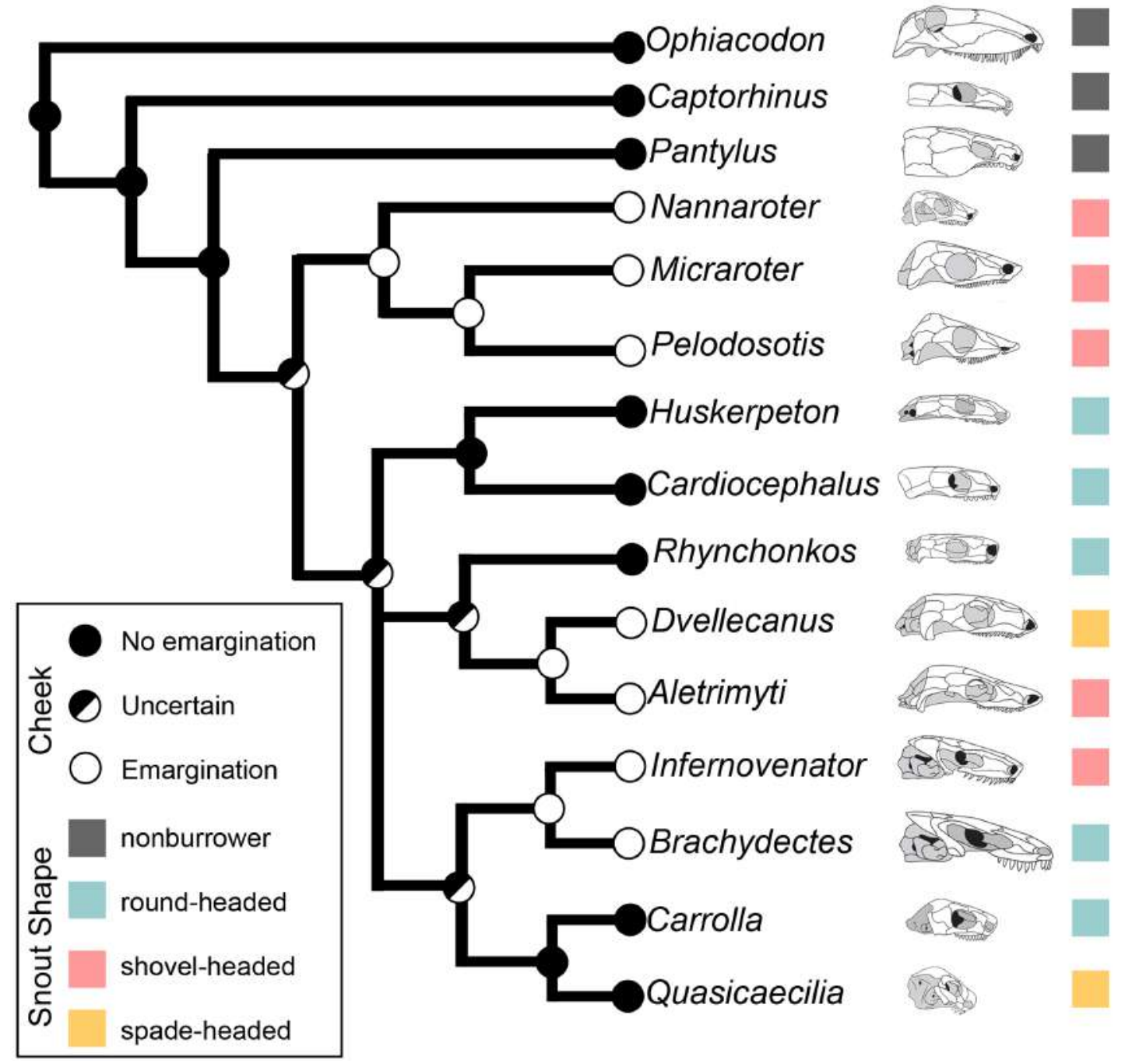

Figure 3.5 A pruned phylogenetic tree depicting relationships of recumbirostrans highlighting fossorial morphology of the cranium. Ancestral character states for cheek condition represent hypothetical optimizations given their distributions among terminal taxa. Different snout shapes are indicated by coloured boxes adjancent to the taxa, representing the conditions explained in the figure legend.

\section{Molgophids in the Mazon Creek tetrapod fauna}

Prior to our study only one species of lysorophian, Brachydectes newberryi, was recognised across the Permo-Carboniferous localities. Here with our description of Infernovenator steenae we increase that diversity to at least two. However, a full systematic revision of lysorophians is necessary to truly assess taxonomic differences particularly between Carboniferous and Permian forms. In this study we also sought to identify the taxonomic and morphological diversity, as well as ecology, of lysorophians in the 'Mazon Creek' fossil assemblage. We were able to find records of three 
lysorophian specimens including the holotype of Infernovenator steenae (FMNH MCP 367), the partial vertebral column identified by Wellstead (1991) (USNM 4313), and a third new specimen also from Pitt 11, that is tentatively assigned to Brachydectes (FMNH PR 1031) (Fig. 3.3). Of most interest here is FMNH PR 1031, a diminutive ( $>6 \mathrm{~cm}$ total length) virtually complete specimen of Brachydectes. This small specimen likely represents a juvenile based on the low level of ossification in the cranium and lack of sutural closure, but it preserves a number of features that distinguish it from Infernovenator, including over 70 presacral vertebrae and robust ribs that expand distally showcasing the fan-shape morphology seen in other specimens of Brachydectes (Fig. 3.3E and F). A full description of this specimen will be the subject of a forthcoming publication. Of interest here, this specimen reveals the presence of at least two lysorophian taxa in the Mazon Creek assemblage and, more specifically, two lysorophians present at the Pit 11 locality. The Mazon Creek assemblage is thought to be estuarine, divisible into the proximal terrestrial-influenced Braidwood fauna and a distal marine-influenced Essex fauna. It is the latter that is primarily represented at Pit 11. Despite the fauna being overwhelmingly dominated by aquatic invertebrates, fish, and likely aquatic aïstopod stem-tetrapods (Phlegethontia and Oestocephalus) (Carroll, 1998; Anderson, 2002, 2003) there are a few tetrapod species also known from this site. These primarily include a variety of temnospondyls, including multiple specimens of Amphibamus grandiceps, Isodectes obtusus, and a variety of larval temnospondyls (Milner, 1982). The presence of two lysorophian taxa from Pit 11 adds to the terrestrial component of this fauna, further supporting hypotheses of spatial and/or temporal mixing of depositional environments within the larger Mazon Creek assemblage.

However, we strongly advise additional work to sort out the paleoecology of molgophids more generally, and, therefore, the interpretation of molgophids within the Mazon Creek system. Molgophids have traditionally been interpreted as largely or fully aquatic based on the heavily-ossified branchial skeleton, fenestrate cheek, and presence in burrow systems interpreted as estivation assemblages (Wellstead, 1991; etc.). However, the interpretation of the branchial skeleton and fenestrate cheek have largely depended on the assumption that recumbirostrans underwent salamander-like metamorphosis and, by extension, that molgophids show adaptations to an aquatic 
lifestyle via salamander-like neoteny (Schoch \& Milner, 2004; Marjanović \& Laurin, 2008). Detailed study of the skull has not upheld this interpretation. Bolt \& Wassersug (1975) identified a number of features of the skull consistent with headfirst burrowing in consolidated sediment, including a thickened skull roof and interdigitating sutures. Pardo \& Anderson (2016) further challenged the neotenic hypothesis by showing advanced ossification in the molgophid braincase and postcrania, and by showing that specific craniofacial features, such as the expanded temporal fenestra, are more consistent with functional adaptation to headfirst burrowing than neoteny. Although the presence of molgophids at Mazon Creek cannot directly inform that debate, the somewhat shovel-like and recumbent rostrum is consistent with potential fossorial adaptive morphology among other recumbirostrans (Anderson et al., 2009; Maddin et al., 2011; Huttenlocker et al., 2013; Szostakiwskyj et al., 2015; Pardo et al., 2015), supporting the interpretation that molgophids were burrowers rather than aquatic neotenes. However, the common presence of lysorophians in lowland environments near water bodies may indicate that their livelihood was dependent on aquatic environments, in terms of foraging and construction of their burrows.

\subsection{Conclusions}

Infernovenator steenae gen. et sp. nov. is described thoroughly in this paper, and is assigned to the Molgophidae, representing one of the oldest fossils known from the group (Figs. 3.1 \& 3.6). The mosaic of plesiomorphic and derived recumbirostran traits provides new insights into molgophid morphological diversity and is consistent with predictions of early phases of the group's evolution. Unlike Brachydectes, Infernovenator possesses a more typical recumbirostran construction of the cranium. In particular Infernovenator has a more extensive snout and near complete circumorbital series. These features clarify and support the placement of Molgophidae within Recumbirostra as previously suggested by Pardo \& Anderson (2016) and Pardo et al. (2017). Additionally, we demonstrate high levels of convergence in the distribution of snout morphology and temporal emargination within recumbirostrans that suggests a high level of mosaicism, 
but warrants further consideration of the detailed construction of the snouts, which may retain the phylogenetically informative characters.

We were also able to provide an updated review of lysorophians in the Mazon Creek tetrapod assemblage, bringing the total diversity to two taxa. New data from a specimen of Brachydectes newberryi additionally brings the total diversity of the Pit 11 locality in particular to two taxa as well. Reinterpretation of fossoriality, rather than neoteny, in these lysorophians adds a new element to paleoecological considerations, and suggests a more complicated paleoenvironment is represented within the Mazon Creek assemblage than previously thought.

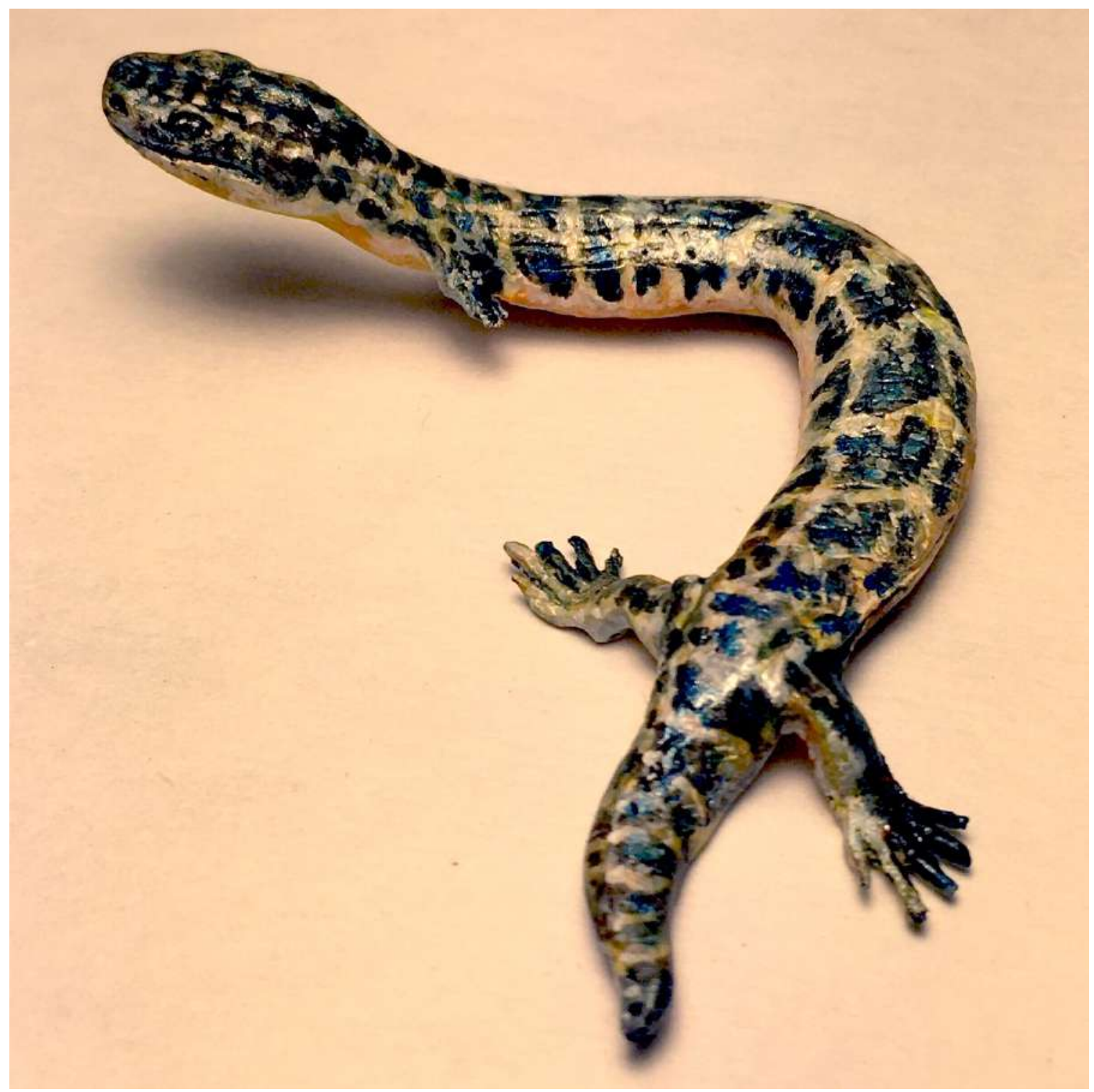

Figure 3.6 Flesh reconstruction of Infernovenator steenae gen et sp. nov. (sculpted by David Duck). 


\subsection{Acknowledgements}

We thank J. Bolt, W. Simpson and A. Stroup for access to collections at the FMNH. We thank C. Mehling and M. Norell for access to collections at the AMNH. We thank A. Howell for access to collections at the Redpath Museum. In addition, we thank S. Roussel, R. Paterson and M. Thompson for their support.

\subsection{References}

Anderson JS. (2007). Incorporating ontogeny into the matrix: a phylogenetic evaluation of developmental evidence for the origin of modern amphibians. In: Anderson JS, Sues H-D, editors. Major Transitions in Vertebrate Evolution. Indiana: Indiana University Press. pp. 182-227.

Anderson JS. (2002). Revision of the aïstopod genus Phlegethontia (Tetrapoda: Lepospondyli). Journal of Paleontology 76: 1029-1046.

Anderson JS. (2003). Cranial anatomy of Coloraderpeton brilli, postcranial anatomy of Oestocephalus amphiuminus, and reconsideration of Ophiderpetontidae (Tetrapoda: Lepospondyli: Aïstopoda). Journal of Vertebrate Paleontology 23(3): $532-543$.

Anderson JS, Scott D, Reisz RR. (2009). Nannaroter mckinziei, a new ostodolepid 'microsaur'(Tetrapoda, Lepospondyli, Recumbirostra) from the Early Permian of Richards Spur (Ft. Sill), Oklahoma. Journal of Vertebrate Paleontology 29(2): $379-388$.

Bolt JR, Wassersug RJ. (1975). Functional morphology of the skull in Lysorophus: a snake-like Paleozoic amphibian (Lepospondyli). Paleobiology 1: 320-332. 
Boyd MJ. (1982). Morphology and relationships of the Upper Carboniferous aistopod amphibian Ophiderpeton nanum. Palaeontology 25(1): 209-214.

Carroll RL. (1998). Order Microsauria. In: Encyclopedia of paleoherpetology, Part 1: Lepospondyli (P. Wellnhofer, ed.).Verlag Dr. Friedrich Pfeil, Munchen 133-148.

Carroll RL, Gaskill P. (1978). The order Microsauria. Memoirs of the American Philosophical Society 126: 1-211.

Carroll RL, Baird D. (1968). The Carboniferous amphibian Tuditanus (Eosauravus) and the distinction between microsaurs and reptiles. American Museum novitates 2337: $1-50$.

Chenoweth C. (2015). Directory of Coal Mines in Illinois, 7.5 minute quadrangles series ipava quadrangle Fulton County. Illinois State Geological Survey.

Cope ED. (1868). Synopsis of the extinct Batrachia of North America. Proceedings of the Academy of Natural Scienes of Philadelphia 20: 208-221.

Cope ED. (1875). Synopsis of the extinct Batrachia from the Coal Measures. Ohio Geological Survey 2: 349-411.

Glienke S. (2012). A new “microsaur”(Amphibia; Lepospondyli) from the Rotliegend of the Saar-Palatinate region (Carboniferous/Permian transition; West Germany). Paläontologische Zeitschrift, 86(3): 297-311.

Glienke S. (2013). A taxonomic revision of Batropetes (Amphibia, Microsauria) from the Rotliegend (basal Permian) of Germany. Neues Jahrbuch für Geologie und Paläontologie-Abhandlungen 269: 73-96. 
Glienke S. (2015). Two new species of the genus Batropetes (Tetrapoda, Lepospondyli) from the Central European Rotliegend (basal Permian) in Germany. Journal of Vertebrate Paleontology 35: e918041.

Hembree DI, Martin LD, Hasiotis ST. (2004). Amphibian burrows and ephemeral ponds of the Lower Permian Speiser Shale, Kansas: evidence for seasonality in the midcontinent. Palaeogeography, Palaeoclimatology, Palaeoecology 203: 127152.

Huttenlocker AK, Pardo JD, Small BJ, Anderson JS. (2013). Cranial morphology of recumbirostrans (Lepospondyli) from the Permian of Kansas and Nebraska, and early morphological evolution inferred by micro-computed tomography. Journal of Vertebrate Paleontology 33: 540-552.

Huttenlocker AK, Pardo JD, Small BJ. (2005). An earliest Permian nonmarine vertebrate assemblage from the Eskridge Formation, Nebraska. New Mexico Museum of Natural History and Science Bulletin 30: 133-143.

Kearney M, Stuart BL. (2004). Repeated evolution of limblessness and digging heads in worm lizards revealed by DNA from old bones. Proceedings of the Royal Society B: Biological Sciences 271(1549): 1677.

Maddin HC, Olori JC, Anderson JS. (2011). A redescription of Carrolla craddocki (Lepospondyli: Brachystelechidae) based on high-resolution CT, and the impacts of miniaturization and fossoriality on morphology. Journal of Morphology 272: 722-743.

Marjanović D, Laurin M. (2008). A reevaluation of the evidence supporting an unorthodox hypothesis on the origin of extant amphibians. Contributions to Zoology 77(3). 
Marjanović D, Laurin M. (2013). The origin(s) of extant amphibians: a review with emphasis on the "lepospondyl hypothesis". Geodiversitas 35(1): 207-272.

Milner AR. 1982. Small temnospondyl amphibians from the Middle Pennsylvanian of Illinois. Palaeontology 25(3): 635-664.

Pardo JD, Anderson JS. (2016). Cranial morphology of the Carboniferous-Permian tetrapod Brachydectes newberryi (Lepospondyli, Lysorophia): New Data from $\mu \mathrm{CT}$. PloS one 11: e 0161823 .

Pardo JD, Szostakiwskyj M, Ahlberg PE, Anderson JS. (2017). Hidden morphological diversity among early tetrapods. Nature 546: 642-645.

Pardo JD, Szostakiwskyj M, Anderson JS. (2015). Cranial morphology of the brachystelechid 'microsaur' Quasicaecilia texana Carroll provides new insights into the diversity and evolution of braincase morphology in recumbirostran 'microsaurs'. PloS one 10: e0130359.

Schoch RR, Milner AR. (2004). Structure and implications of theories on the origin of lissamphibians. Recent advances in the origin and early radiation of vertebrates $345-377$.

Sollas, W J. (1920). XI.-On the structure of lysorophus, as exposed by serial sections. Phil. Trans. R. Soc. Lond. B, 209(360-371): 481-527.

Swofford DL. (2002). PAUP*: phylogenetic analysis using parsimony (* and other methods). Sunderland, MA.

Szostakiwskyj M, Pardo JD, Anderson JS. (2015). Micro-CT study of Rhynchonkos stovalli (Lepospondyli, Recumbirostra), with description of two new genera. PLoS One 10: e0127307. 
Vallin G, Laurin M. (2004). Cranial morphology and affinities of Microbrachis, and a reappraisal of the phylogeny and lifestyle of the first amphibians. Journal of Vertebrate Paleontology 24: 56-72.

Wellstead CF. (1991). Taxonomic revision of the Lysorophia, Permo-Carboniferous lepospondyl amphibians. Bulletin American Museum of Natural History 209: 190.

Wellstead CF. (1998). Order Lysorophia: in Encyclopedia of paleoherpetology, Part 1: Lepospondyli (P. Wellnhofer, ed.). Verlag Dr. Friedrich Pfeil, Munchen 133-148. 


\section{| Chapter 4: Carbonodraco lundi gen et sp. nov., the oldest parareptile, from Linton, Ohio, and new insights into the early radiation of reptiles.}

\subsection{Authors and Addresses}

Arjan Mann, Emily J. McDaniel, Emily R. McColville, and Hillary C. Maddin

Department of Earth Sciences, Carleton University, 1125 Colonel By Drive, Ottawa, Ontario K1S 5B6, Canada

\subsection{Preface}

The following manuscript has been published in the journal Royal Society Open Science. Arjan Mann was fully involved in setting up and conducting the research, preparing samples, running all analyses, developing methodology, writing the manuscript and drafting final figures in this co-authored article. Hillary C. Maddin, provided discussion and editing of content. Emily J. Mcdaniel and Emily R. McColville provided discussion and aid in figure construction. The manuscript has been modified slightly to accommodate the formatting requirements for Carleton University dissertations. The article should be cited as such:

Mann, A., McDaniel, E. J., McColville, E. R., \& Maddin, H. C. (2019). Carbonodraco lundi gen et sp. nov., the oldest parareptile, from Linton, Ohio, and new insights into the early radiation of reptiles. Royal Society Open Science, 6(11), 191191.

\subsection{Abstract}

Redescription of the holotype specimen of Cephalerpeton ventriarmatum Moodie, 1912, from the Middle Pennsylvanian (Moscovian) Francis Creek Shale of Mazon Creek, Illinois, confirms that it is a basal eureptile with close postcranial similarities to other protorothyridids, such as Anthracodromeus and Paleothyris. The skull is long and lightly built, with large orbits and a dorsoventrally short mandible similar to most basal 
eureptiles. Two specimens referred previously to Cephalerpeton $\mathrm{cf}$. C. ventriarmatum from the approximately coeval Linton, Ohio, locality differ significantly from the holotype in cranial and mandibular proportions and tooth morphology. This material and an additional Linton specimen compare favorably to "short-faced" parareptiles, such as Colobomycter and Acleistorhinus, and justify recognition of an acleistorhinid parareptile in the Linton assemblage. The new binomen is thus the oldest known parareptile.

\subsection{Introduction}

Amniotes can be divided into two major lineages, synapsids (mammals and their extinct relatives) and reptiles (crocodiles, birds, and lepidosaurs, and their extinct relatives). The origin and early diversification of these groups are believed to have occurred during the early Carboniferous because the oldest amniotes, the reptile Hylonomus lyelli and the possible synapsid Asaphestera platyris, are known from the classic locality of Joggins, Nova Scotia, Canada (318-315 Ma) (Mann et al., 2020). Other early records of non-synapsid amniotes are from the Coal Measure localities of Mazon Creek, Illinois, and Linton, Ohio, USA (Cephalerpeton and Anthracodromeus); Florence, Nova Scotia (Paleothyris); and Nýřany, Czech Republic (Brouffia and Coelostegus). These taxa were regarded by Carroll and Baird (1972) as stem-reptiles within the now-defunct family Romeriidae and were assigned subsequently to the Protorothyrididae in a number of papers (Carroll, 1982; Heaton and Reisz, 1986; Reisz, 1977). The most recent phylogenetic analysis of these taxa found the Protorothyrididae to be an array of basal eureptiles and thus paraphyletic (Müller and Reisz, 2006). Yet, these same authors recognized a clade consisting of Cephalerpeton, Anthracodromeus, and the Lower Permian Protorothyris from North-Central Texas as a sister taxon of diapsids.

Cephalerpeton ventriarmatum Moodie 1912 was described from an articulated anterior half skeleton preserved in a concretion that lacks a counterpart from the Francis Creek Shale of the classic Mazon Creek region. Moodie (1912) briefly described this animal as a microsaurian amphibian, which at that time was an amalgamation of small tetrapods. The specimen was described more fully by Gregory (1948) and by Carroll and 
Baird (1972). Reisz and Baird (1983) reported additional material of Cephalerpeton from Linton, Ohio. These remains consist of a macerated skull (CM 23055) and a mandible (NHMUK R. 2667). Because of perceived differences with the Mazon Creek holotype, Reisz and Baird (1983) referred the Linton material to Cephalerpeton cf. aff. $C$. ventriarmatum.

Since these descriptive works, Cephalerpeton has rarely been included in phylogenetic analysis of reptiles or amniotes despite being important to the origin and evolution of Reptilia. Here, we provide new, comprehensive, and comparative descriptions of all specimens that have been referred to Cephalerpeton from Mazon Creek and Linton. In our study, we were able to study original latex peels and casts of Cephalerpeton ventriarmatum from Mazon Creek in order to supplement anatomical analysis of the damaged holotype specimen. We recognize new craniodental features of Cephalerpeton ventriarmatum that distinguish it from the Linton material, which we assign to the new acleistorhinid parareptile, Carbonodraco lundi gen et. sp. nov. As a result, Carbonodraco lundi represents the oldest known parareptile.

\subsection{Material and Methods}

Specimens were studied at: American Museum of Natural History (AMNH), New York, New York; Carnegie Museum of Natural History (CM), Pittsburgh, Pennsylvania; Field Museum of Natural History (FMNH), Chicago, Illinois; Redpath Museum at McGill University (RM), Montreal, Quebec; Smithsonian Institution (USNM), Washington D.C.; and Yale Peabody Museum (YPM), New Haven, Connecticut. Additional specimens held by the following institutions were studied on the basis of casts, latex peels, or publications: Natural History Museum (formerly British Museum [Natural History]), London (NHMUK); Museum of Comparative Zoology, Cambridge, Massachusetts (MCZ); and Museum für Naturkunde, Humboldt Universität, Berlin (MB). The dataset thus includes nearly all basal eureptiles from the Carboniferous, including notable material from Mazon Creek, Illinois, and Linton, Ohio. We were also able to study material of the following parareptiles: Delorhynchus, Colobomycter, Acleistorhinus, and Erpetonyx that were on loan to Robert R. Reisz at the University of 
Toronto Mississauga at the time of this study. A Sony Alpha ILCE 5000 camera with a F3.5 macro lens was used for photography.

Illustration of YPM 796 was redrawn and modified from Carroll and Baird (1972), and CM 23055 was redrawn and modified from Reisz and Baird (1983). Anatomical illustrations of CM 81536 and CM 41714 were drawn from original specimens and casts or peels. All figure drawings were generated and formatted in Photoshop CS6 (Adobe, San Jose, CA).

\subsection{Anatomical abbreviations}

$\mathbf{a a}=$ atlantal arch; $\mathbf{a c}=$ anterior coracoid; $\mathbf{a n}=$ angular; $\mathbf{a r}=\operatorname{articular} ; \mathbf{a x a}=$ axis $\operatorname{arch}$; $\mathbf{a x p}=$ axis pleurocentrum; bo=basioccipital; $\mathbf{c}=$ clavicle; $\mathbf{c t h}=$ cleithrum; $\mathbf{d v}=$ dorsal vertebrae; $\mathbf{d}=$ dentary $(\mathbf{r d} / \mathbf{l d}=$ right/left $) ; \mathbf{e c t}=$ ectopterygoid; $\mathbf{e o}=$ exoccipital; $\mathbf{f}=$ frontal; $\mathbf{g s}=$ gastralia; $\mathbf{h}=$ humerus; $\mathbf{l}=$ lacrimal; $\mathbf{j}=$ jugal; $\mathbf{m}=$ maxilla; $\mathbf{m c}=$ =metacarpals; $\mathbf{n}=$ nasal; $\mathbf{p}=$ parietal; $\mathbf{p f}=$ postfrontal; $\mathbf{p f o}=$ pineal foramen; $\mathbf{p m x}=$ premaxilla; $\mathbf{p p}=$ postparietal; $\mathbf{p r f}=$ prefrontal; $\mathbf{p l}=$ palatine; $\mathbf{p t}=$ =terygoid; $\mathbf{p r o}=$ proatlas; $\mathbf{q}=$ quadrate; $\mathbf{q} \mathbf{j}=$ =quadratojugal; $\mathbf{r}=$ radius; $\mathbf{s}=$ scapula; $\mathbf{s c l}=$ scleral ossicles; $\mathbf{s m = s e p t o m a x i l l a ; ~} \mathbf{s o}=$ supraoccipital; $\mathbf{s q}=$ squamosal; sa=surangular; $\mathbf{s t}=$ stapes; $\mathbf{s v}=$ sacral vertebra; $\mathbf{s p}=$ splenial; $\mathbf{t}=$ tabular; $\mathbf{t f p t}=$ transverse flange of the pterygoid; $\mathbf{u}=\mathrm{ulna} ; \mathbf{v}=$ vomer.

\subsection{Systematic Paleontology}

Tetrapoda Jaekel, 1909

Amniota Haeckel, 1866

Eureptilia Olson, 1947

Cephalerpeton Moodie, 1912

Cephalerpeton ventriarmatum Moodie, 1912

(Figs. 4.1 and 4.2) 
Hototype: YPM 796, anterior portion of a skeleton, including the upper limbs, cranium, and lower jaws.

Locality and Horizon: Mazon Creek, Grundy County, Illinois, U.S.A. Francis Creek Shale, above the Morris (no. 2) Coal, Carbondale Formation, Middle Pennsylvanian (Moscovian).

Revised Diagnosis: A basal eureptile diagnosed by the following autapomorphies: 16 wide-based conical teeth in maxilla; maxillary dentition significantly enlarged compared to dentary teeth; maxillary dentition bears multiple peaks in tooth height; palatal bones covered in a shagreen of denticles. Shares a slender, rod-like ulna and radius with Anthracodromeus, Paleothyris, and basal diapsids.

Comments: With the recognition of Carbonodraco lundi gen. et sp. nov. (see below), Cephalerpeton is known only from YPM 796. One similarity between Cephalerpeton and Carbonodraco is the presence of plicidentine and intense enamel fluting on the tooth crowns. This trait is also widely shared with other parareptiles and synapsids (MacDougall et al., 2014). Because of its wide dispersal, this trait is not included in the diagnosis, although it may be unique to Cephalerpeton among "protorothyridid" reptiles. 


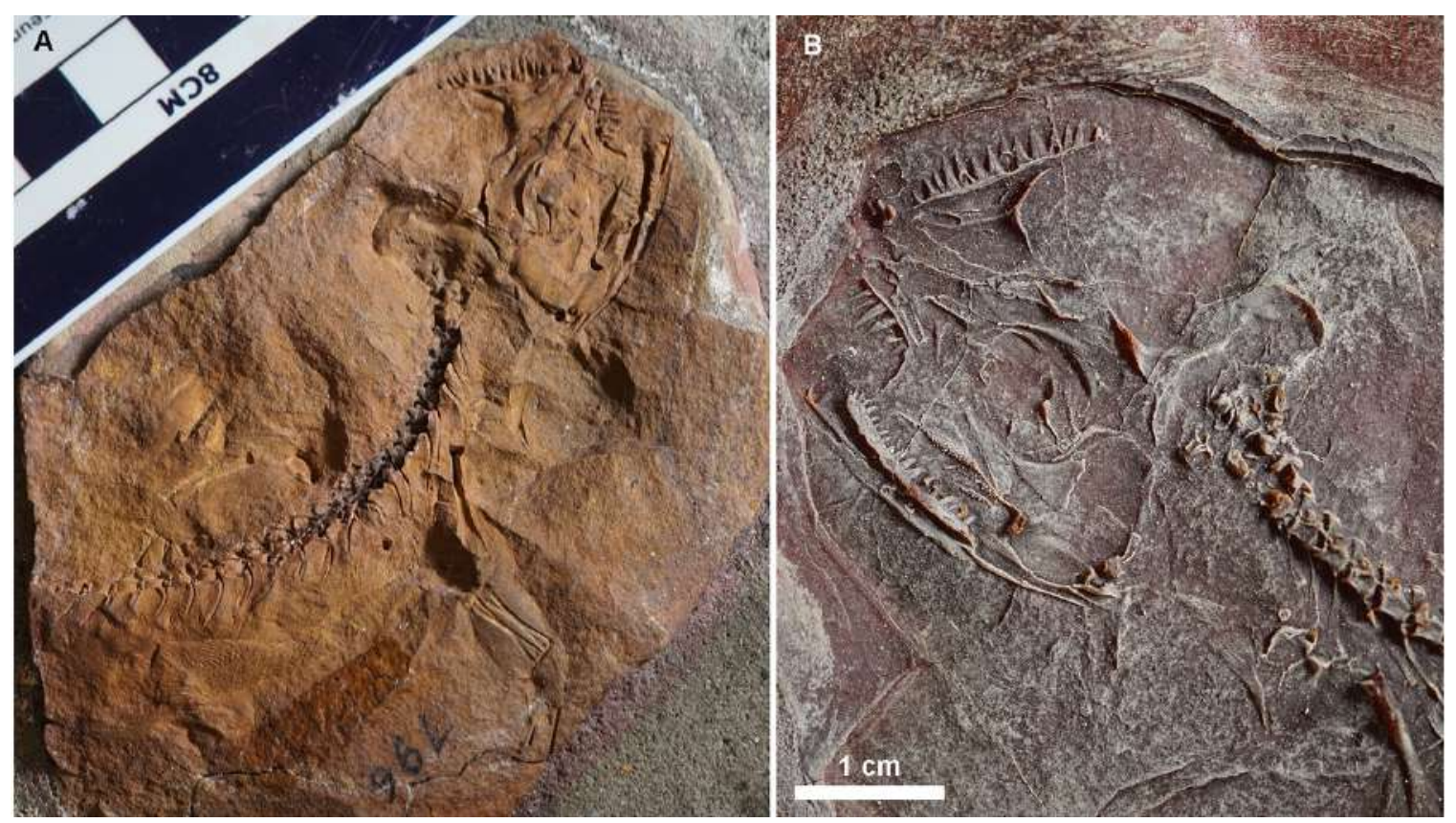

Figure 4.1 Cephalerpeton ventriarmatum (YPM 796), A) original nodule (cranium in ventral aspect: postcranium in dorsal lateral aspect), and $B$ ) resin cast of the original nodule. 

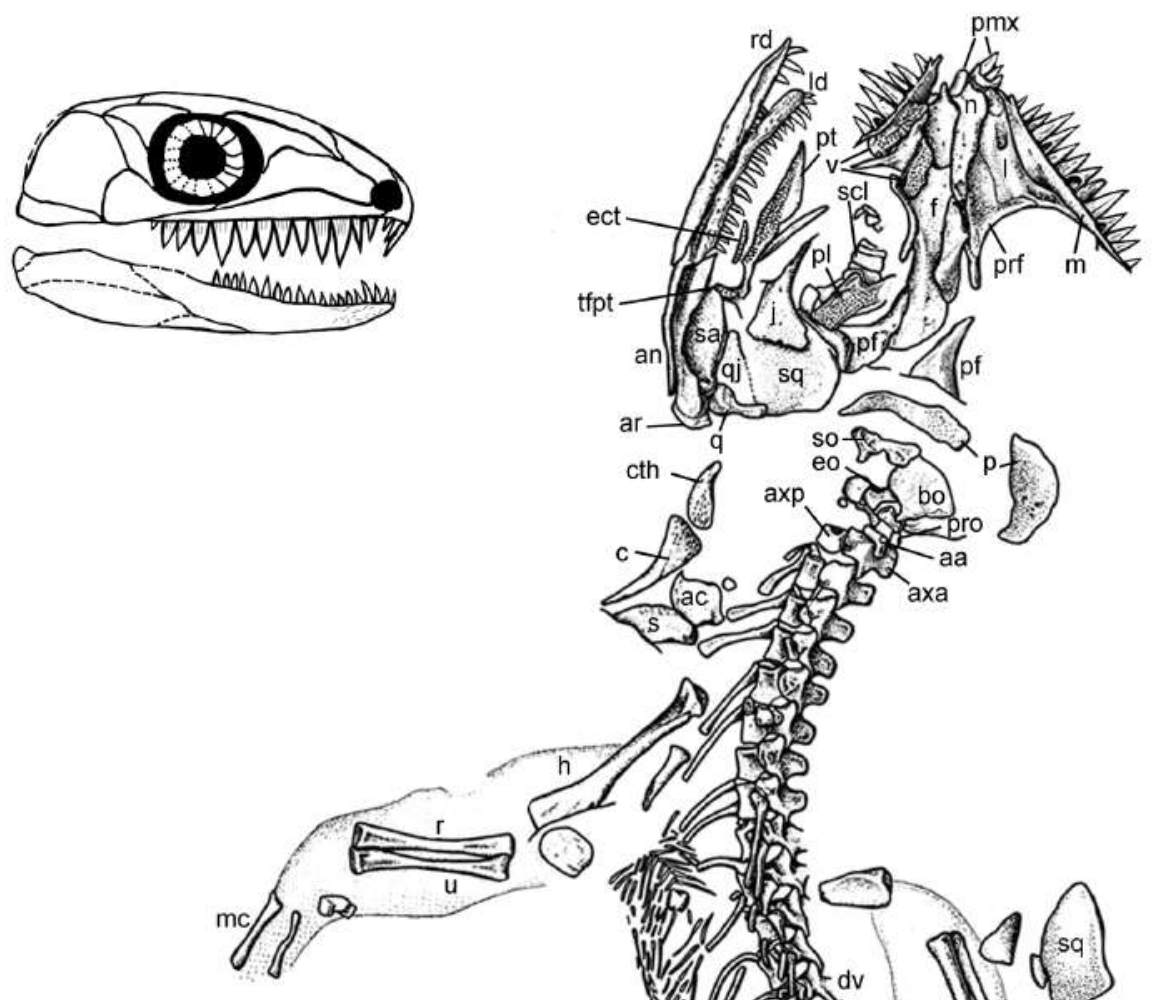

Figure 4.2 Illustration of the cranial and postcranial anatomy of Cephalerpeton ventriarmatum (YPM 796), modified from Carroll and Baird (1972), and a cranial reconstruction.

\subsection{Description}

\section{Cranial anatomy of Cephalerpeton}

The skull of YPM 796 is crushed and incompletely preserved (Figs. 4.1 and 4.2). Many of the cranial elements are preserved in ventral or medial views and reveal their internal anatomy. As such, dermal ornament of the skull roof cannot be described. Pieces of the palate are disarticulated and poorly represented. Both lower jaws are shifted to the anatomical right side of the cranium. In general, the right side of the cranium is better 
preserved, showing a nearly complete cheek region that is absent from the left side of the skull. The cranial anatomy of Cephalerpeton is overall lightly built, with the elements being thin and with the skull build being quite narrow. This compares well with contemporaneous Carboniferous "protorothyridids," early captorhinids such as Euconcordia (Reisz et al., 2016), as well as diapsids such as Spinoequalis (deBraga and Reisz, 1995), Petrolacosaurus (Reisz, 1977; 1981), and Araeoscelis (Reisz et al., 1984). Because the premaxillae are not well preserved and because most of the skull table is absent, estimation of the skull length is difficult.

Anteriormost on the skull are preserved remnants of a single left premaxilla. The premaxilla is lightly built and has spaces for at least three teeth. Unlike the reconstruction of Gregory (1948), we interpret the premaxilla as bearing a slightly recurved dorsal ascending process, similar to that of other early eureptiles, such as "protorothyridids" and araeoscelids, but not as hooked as that in captorhinids or recumbirostrans. The dorsal ascending process of the premaxilla has an elongate morphology. The lateral contact between the premaxilla and the maxilla is not preserved in any of the peels or casts examined.

Both maxillae are preserved in medial perspective. The left maxilla is the most completely preserved. There, a thin and delicately built anatomy is seen, similar to that of other basal eureptiles such as Hylonomus, Palaeothyris, Thuringothyris, and most captorhinids. Anteriorly the bone descends to a thin short anterior process that narrowly contributes to the posterior edge of external naris. Just anterior to the orbit, the maxilla ascends to a low facial lamina similar to that of most "protorothyridid" reptiles. There is a thin, long posterior process that terminates approximately below the posterior margin of the orbit. It appears this area of the maxilla was excluded from the orbit by a point contact between the lacrimal and jugal. The left maxilla preserves 16 tooth positions, and 14 teeth in place. Each tooth consists of a wide cone that bears crenulations on the base and enamel fluting on the crown, and some of the teeth show resorption pits at their bases. The teeth express a greater degree of heterodonty than present in most other early "protorothyridids". Although the largest maxillary teeth are located directly under the facial lamina, the largest tooth is located under the anterior margin of the orbit. This means there is no single, distinct area of tooth enlargement or "caniniform region", but 
rather at least two peaks in maximum height along the tooth row. There is also no noticeable diminution in tooth height posteriorly as described below in Carbonodraco.

The lacrimals are exposed on both sides of the cranium in medial aspect. Their morphology is shared with most "protorothyridid" reptiles, as well as araeoscelids such as Petrolacosaurus (Reisz, 1977; 1981). Whereas the right lacrimal is obscured by the vomer, the left is nearly perfectly represented. It is a long element that meets the naris anteriorly and contributes to the anterior orbital margin. The left lacrimal also reveals a long lacrimal canal represented by a raised tube terminating at an opening just posterior to the narial opening. The length of the lacrimal canal is significantly longer than that of Carbonodraco as described below. Posteriorly on the left lacrimal, there is a recess for the ventrally directed process of the adjoining prefrontal. Both lacrimals preserve a long posteroventrally extending process that meets the anterior process of the jugal, as described by Carroll and Baird (1972).

Both prefrontals are present, and the left is more completely exposed. It is excluded from the external naris by a broad contact between the nasal and lacrimal on the lateral surface of the snout. The prefrontal is roughly Y-shaped, with prominent anterior, ventral, and posterior processes. These processes are part of a system found on nearly every circumorbital element, a system common among early reptiles, including parareptiles. In Cephalerpeton, the anterior process of the prefrontal is extensive, covering a large portion of the lateral snout; the posterior process is quite long and thin, similar to that of other "protorothyridids"; and the ventrally directed process forms much of the anterior margin of the orbit and fits into a facet on the lacrimal.

The postfrontals are falciform elements preserved in ventral aspect. Each has a somewhat long anterior process and a rather short posterolateral extension onto the cheek. The postfrontal morphology is similar to the condition seen in other basal eureptiles like Hylonomus (Carroll and Baird, 1972), as well as some diapsids such as Petrolacosaurus (Reisz, 1977).

The nasals are preserved in ventral aspect and have a long, narrow, subrectangular outline. The right nasal slightly overlaps the left; this is a result of taphonomic processes. There is a slight anterior expansion directed toward the narial margin away from the 
midline. The anteriormost end of the nasals taper to a point and create a midline internasal recess that accommodated the thin ascending dorsal process of the premaxilla.

The frontals are preserved in a similar manner to the nasals in being slightly overlapping, with the right better exposed. They are long rectangular elements that show a small contribution to the dorsal orbital margin. This is indicated by a pinching laterally in mid-region of the frontal. Overall, both the frontals and nasals are extremely narrow, as noted by previous studies (Gregory, 1948; Carroll and Baird, 1972). The anterior margin of the frontal appears to form a straight sutural contact with the nasal. Because the parietals have shifted out of place and are not well preserved, it is not possible to determine the sutural contact between the frontals and parietals.

The parietals are represented by two large semi-lunate ossifications. Both appear incomplete and possibly would have been better represented on the unknown counterpart. Based on the somewhat short space between the occipital elements and the frontals, it is assumed the parietals were anteroposteriorly short and only moderately expanded lateromedially.

The cheek region comprises of a jugal, postorbital, squamosal and quadratojugal. These are all represented only on the right side (except for the squamosal), preserved in medial view. Anteriorly, the jugal forms a thin process that contributes to the posteroventral margin of the orbit. This process meets, and possibly slightly overlapped, the lacrimal. The cheek region of the jugal is moderately expanded. There is a small notched contact dorsally where the jugal would have accepted the postorbital and a straight contact posteriorly with the squamosal. The postorbital is not well represented on the right side, where it is overlapped by the squamosal. Considering the relationship of the other cheek elements, the postorbital is likely a small quadrangular element that extends from the top of the orbital margin adjacent to the postfrontal, ventrally towards the jugal, and contacts the squamosal posteriorly. It appears the small width of the postorbital is responsible for the short appearance of the postorbital region. The squamosal forms the majority of the lateral cheek and is represented by a large plate-like element on the right side of the cranium, as well as a displaced left squamosal that is present near the left forelimb. The squamosal is taller than it is wide, and indicates a relatively high cheek region. The contacts with most other cheek and dorsal skull 
elements are not clear. On the right side, a relatively straight, ventral contact with the quadratojugal can be observed. The quadratojugal morphology itself is not well-known due to the posteriormost area of the element being damaged on the original fossil. The right quadratojugal is preserved in medial aspect like the rest of the cheek. It is roughly triangular in shape with the wider end being posteriorly located. Posteriorly, the quadratojugal is partially overlapped by the quadrate. The right quadrate is a long, cylindrical element. It is incomplete anteriorly and lacks the process that would meet the pterygoid. Ventrally the articular surface for the mandible is well preserved and shows a median depression between two condyles.

Because the skull is preserved in ventral aspect, the palate is well represented though disarticulated. The preserved elements of the palate include both vomers, the right ectopterygoid, the right pterygoid, and the right palatine. All of these elements are covered in a shagreen of small denticles. The vomer is represented anteriorly in the skull and is a quadrangular element with few distinctive qualities. Both left and right vomers appear to be tapered anteriorly and create a space that likely accommodated the internal median processes of the premaxillae. The contacts with other elements can only be speculated upon, but it is likely that the vomer met the palatine posterolaterally and the pterygoid medially. A single partial right palatine is present as a wide quadrangular element that bears an emargination on the anterolateral surface where the internal naris would reside. The right ectopterygoid is represented by an extremely thin, denticulate element. It is likely the element was slightly wider than this in life based on the apparently broken margins of the bone. The right pterygoid is well represented and lacks only the quadrate ramus. A prominent anterior ramus is seen in ventromedial aspect and bears a shagreen of denticles. It is possible that the anterior ramus of the pterygoid is slightly raised to a small boss, similar to that of other basal eureptiles, but this is difficult to determine given the lack of association with the other palatal elements. The most striking feature of the pterygoid is the well-developed transverse flange, which occurs at an approximately 90 -degree angle to the midline margin of the anterior ramus. The teeth on the transverse flange are not well preserved on any peel, but a field of slightly larger teeth can be observed on the resin cast and latex peels. 
The occiput is represented by a few elements, including the supraoccipital, a partial basioccipital, and at least one exoccipital. The supraoccipital is a large plate-like element that is roughly butterfly shaped. The middle of the supraoccipital is slightly raised to form a small, sagitally oriented ridge. Underlying the supraoccipital is an amorphous element identified as the basioccipital by Carroll and Baird (1972). Little can be said about this element other than it is slightly concave in dorsal aspect. At least one exoccipital, probably the left, is present and disarticulated near the atlas and axis. It is an elongated, cylindrical element. A medially located depression on the exoccipital likely represents the location of the jugular foramen. An element identified by Carroll and Baird (1972) as the atlas pleurocentrum may in fact be the other exoccipital; however, it is not preserved well enough to be confidently identified.

Lastly, there is a series of seven to nine scleral ossicles. Scleral ossicles are commonly preserved in Mazon Creek tetrapods. Those observed in temnospondyls from Mazon Creek are often small, quadrangular elements numbering around 22-24. Those observed in YPM 796 differ in being large, rectangular ossicles that more closely resemble those found in other amniotes, such as the captorhinid Reiszorhinus (Sumida et al., 2010).

\section{Mandible of Cephalerpeton}

Preservation of the mandible of YPM 796 includes the entire right jaw in medial perspective and the left dentary in lateral aspect (Fig. 4.2). The mandible, in general, displays a very gracile morphology. This is in contrast to the more robust elements found in the specimens assigned here to Carbonodraco lundi gen et sp. nov. The lateral surface of the dentary shows a pitted and slightly rugose ornamentation characteristic of captorinids.

The left and right dentaries are thinly built with an unexpanded symphysis that tapers gradually anteriorly. On the right dentary, preserved in lingual aspect, the symphysis appears even thinner and is excavated towards the centre. There may be a splenial attached to the right dentary but no sutures can be discerned. Neither dentary preserves their coronoid processes. The right surangular, angular, and articular are preserved in medial aspect. These postdentary bones make up over one third of the length 
of the lower jaw. The surangular is the best represented of the postdentary bones. It is an irregular, oval-shaped element in lateral aspect. The angular is represented by an elongated element, and the articular is a small, likely oval-shaped ossification at the posteriormost end of the jaw. Because the articular is preserved in medial aspect, the extent and shape of the lateral surface is unknown, this includes whether or not there was a well-developed retroarticular process.

The dentition on the dentaries differs slightly from that of the upper jaws. The left dentary has 18 teeth in place with spaces for a few more teeth. Carroll and Baird (1972) estimated 24 teeth, with which we agree. The dentition on the lower jaws consists of sharply pointed conical teeth that are recurved apically. At the anteriormost end of the dentary, the dentition is slightly enlarged and anteriorly directed similar to that of most "protorothyridid" reptiles. Overall the dentition on the dentaries appears less wide and tall than that on either maxilla.

\section{Postcranial anatomy of Cephalerpeton}

Our interpretation of the postcranial anatomy is largely consistent with the detailed descriptions provided by Carroll and Baird (1972). Here we briefly overview the anatomy and provide a few updated comparisons. The postcranial skeleton consists mostly of the presacral vertebral column (including the atlas-axis vertebrae), dorsal ribs, ventral gastralia, pectoral girdle elements, and forelimbs. The vertebral count proposed by Gregory (1948) of 25 to 26 vertebrae was identified by Carroll and Baird (1972) as erroneously including elements of the occiput into the cervical vertebral series. Whereas 23 presacral vertebrae can be identified, we agree with Carroll and Baird (1972) that a 28 total presacral vertebrae count is plausible.

The proatlas is represented in Cephalerpeton by a small round ossification in between the occipital elements and the atlas vertebra. Although the atlantal vertebral components cannot be confidently identified, a number of elements were identified by Carroll and Baird (1972), including the atlantal arch and pleurocentrum (here alternatively considered an exoccipital). We also note that unidentified elements (unlabelled in Fig. 4.2) adjacent to the right exoccipital may also represent elements of the atlas, such as the atlas intercentrum. The small cylindrical axial pleurocentrum and 
large somewhat fan-like axial arch are present. It appears as though the arches are fused to the pleurocentra throughout the vertebral column due to the tight association of the two. The observed line running between the two may simply be a crack. The neural arch morphology throughout the vertebral column remains consistent, with strongly overlapping and well-developed prezygapophysis and postzygapophysis. The neural arches also bear a small anterior excavation that is depressed into the base of the neural spine. The neural spines are only fully preserved on approximately the eight anteriormost vertebrae. There they can be seen to have somewhat rounded margins, possibly indicating they were weakly ossified. Their height is comparable to early reptiles such as Anthracodromeus, but also some varanopids and other early pelycosaurian-grade tetrapods. A small transverse process can also be observed on some of the vertebrae. The pleurocentra are formed by large elongated cylinders that are concave on the lateral surfaces and that do not bear any noticeable keels or ridges. Ventrally, wedged between each pleurocentrum is a small, likely crescent-shaped, intercentrum. The dorsal ribs are well-represented along the postcranial skeleton. All ribs are single headed. The cervical ribs have a short but thick, bar-like morphology and develop slight recurvature moving posteriorly down the series. The dorsal ribs posterior to the pectoral girdle are the longest at approximately three times the vertebral length. These ribs are also thin, and highly recurved. Towards the posterior end of the preserved column the ribs shorten to a thin bar-like morphology and indicate the approach of the pelvic region.

The pectoral girdle is represented by the cleithrum, clavicle, scapula, and anterior coracoid (procoracoid). Overall the pectoral girdle is lightly built like that of early basal eureptiles, such as Anthracodromeus, Paleothyris, Hylonomus, Brouffia, and early diapsids (Carroll, 1969; Carroll and Baird, 1972; Reisz, 1981). The left cleithrum is teardrop shaped and slightly concave indicating it is the interior surface. The clavicle is roughly horn shaped and widens medially towards where the head of the interclavicle would have been. The left clavicle appears to have a somewhat short lateral process, but this bone may be incomplete. The clavicular head is ornamented with linear grooves. Although a piece of the right clavicle was identified by Carroll and Baird (1972) next to the left humerus, we regard this element as unidentifiable. A partial right scapula is also 
preserved and reveals its exterior surface. The anterior coracoid is ovoid in outline and slightly overlapped by the scapula.

The right and left forelimbs are well preserved with only the phalanges and most of the carpal elements lacking. Overall the long morphology of the forelimb elements closely resembles the forelimbs of early diapsids, such as Spinoequalis (deBraga and Reisz, 1995), Petrolacosaurus (Reisz, 1977), and Araeoscelis (Reisz et al., 1984), but differs from the squat and robust limb morphology or Thuringothyris, captorhinids, and recumbirostrans. Both humeri are preserved as long rod-like shafts with a small proximal end with a moderately developed head. The distal end is greatly expanded. Both proximal and distal ends appear to be rotated at about 90 degrees to one another. The left distal humerus is rotated to reveal its articular surface that includes a shallow capitulum, and weakly developed entepicondyle. As pointed out by Carroll and Baird (1972), no ridges or supinator process can be found on the humerus. This may indicate immaturity in the animal.

The ulna and radius are represented in both forelimbs as long rod-like elements that are approximately equivalent in length and only slightly shorter than the humerus. This is shared with Spinoequalis, Petrolacosaurus, and Araeoscelis (deBraga and Reisz, 1995; Reisz, 1977; Reisz et al., 1984). The proximal and distal ends of these elements appear both small in width and poorly developed. The ulna has no olecranon process, unlike that of captorhinids such as Ophisthodontosaurus (Reisz et al., 2015). Five metacarpals are preserved on the right manus and two on the left manus. They are also long and rod-like, the greatest of which is half the length of the zeugopodial elements, likely indicating the manus was long, similar to that of Anthracodromeus. The right manus also shows two to three overlapping distal carpals that are roughly cuboid in shape.

One of the remarkable features of YPM 796 is the presence of a suite of ventral gastralia, as well as soft-tissue, integumentary impressions hugging the forelimbs. The gastralia are thin, elongate rods that are canted anteriorly to meet at the midline to form a chevron. They are of the "reptilian" morphology in that they are thin and unornamented (no concentric growth lines), and thus are similar to those found in Hylonomus, Anthracodromeus, as well as in varanopids and some recumbirostrans. 


\subsection{Systematic Paleontology}

Tetrapoda Jaekel, 1909

Amniota Haeckel, 1866

Parareptilia Olson, 1947

Acleistorhinidae Daly, 1969

Carbonodraco gen. nov.

(Figs. 4.3-4.5)

Diagnosis: As for the type and only species.

Carbonodraco lundi sp. nov. =Cephalerpeton cf. C. ventriarmatum Reisz and Baird 1983

Holotype: CM 23055, a disarticulated skull that includes maxillae, left premaxilla, right lacrimal, left prefrontal, left parietal, left frontal, dentaries and, splenials, left surangular, and vomers; collected by Richard Lund, 1972.

Etymology: Generic name derived from the latin words 'Carbo' (coal), and 'Draco' (serpent). Specific name is in honor of Dr. Richard Lund, who found the holotype.

Referred Material: NHMUK R. 2667, right mandible in lingual perspective; probably collected by John S. Newberry, circa 1870, later given to James W. Davis ("Davies" of Reisz and Baird, 1983), and eventually purchased by the British Museum [Natural History] in 1895. CM 81536, a pair of dentaries preserved in lingual perspective; collected by Scott McKenzie, 2004. 
Locality and Horizon: Coal mine operated originally by the Ohio Diamond Coal Company at Linton, Saline Township, Jefferson County, Ohio, U.S.A. (see Hook and Baird, 1986, for details). Local cannel coal immediately below the Upper Freeport coal, Allegheny Group, Middle Pennsylvanian (Moscovian).

Diagnosis: An acleistorhinid parareptile diagnosed by the following unique combination of characters: vomers covered in a shagreen of denticles; parietals wide; pineal foramen anteriorly located. Additional characters shared with acleistorhinids: two enlarged anterior teeth on maxillae and anteriormost premaxillary tooth enlarged to the height of enlarged maxillary teeth (shared with Colobomycter); lacrimal short and excluded from external naris (shared with Colobomycter and Acleistorhinus); high facial lamina of the maxilla and pitted ornamentation shared with all acleistorhinids. 


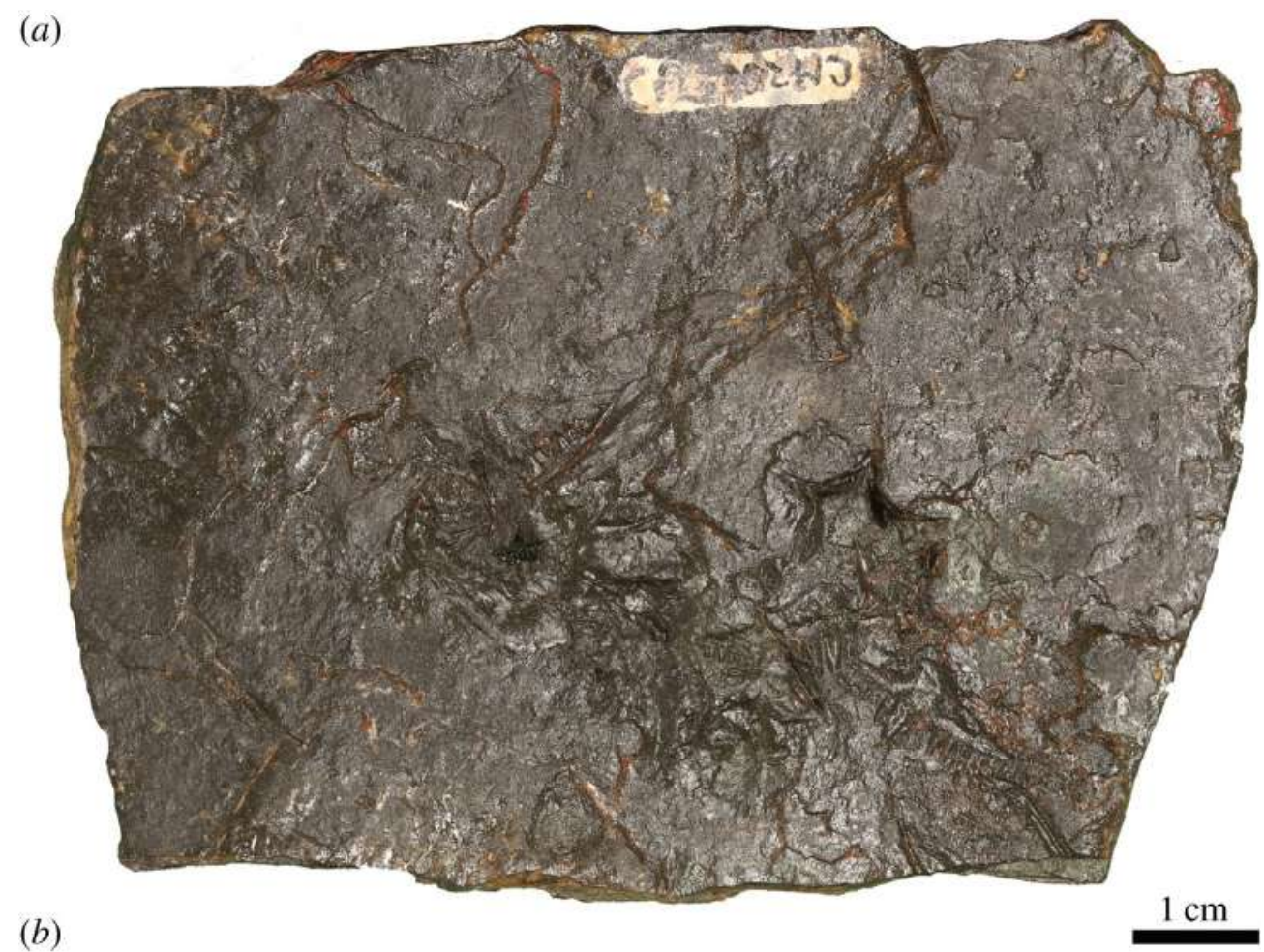

(b)

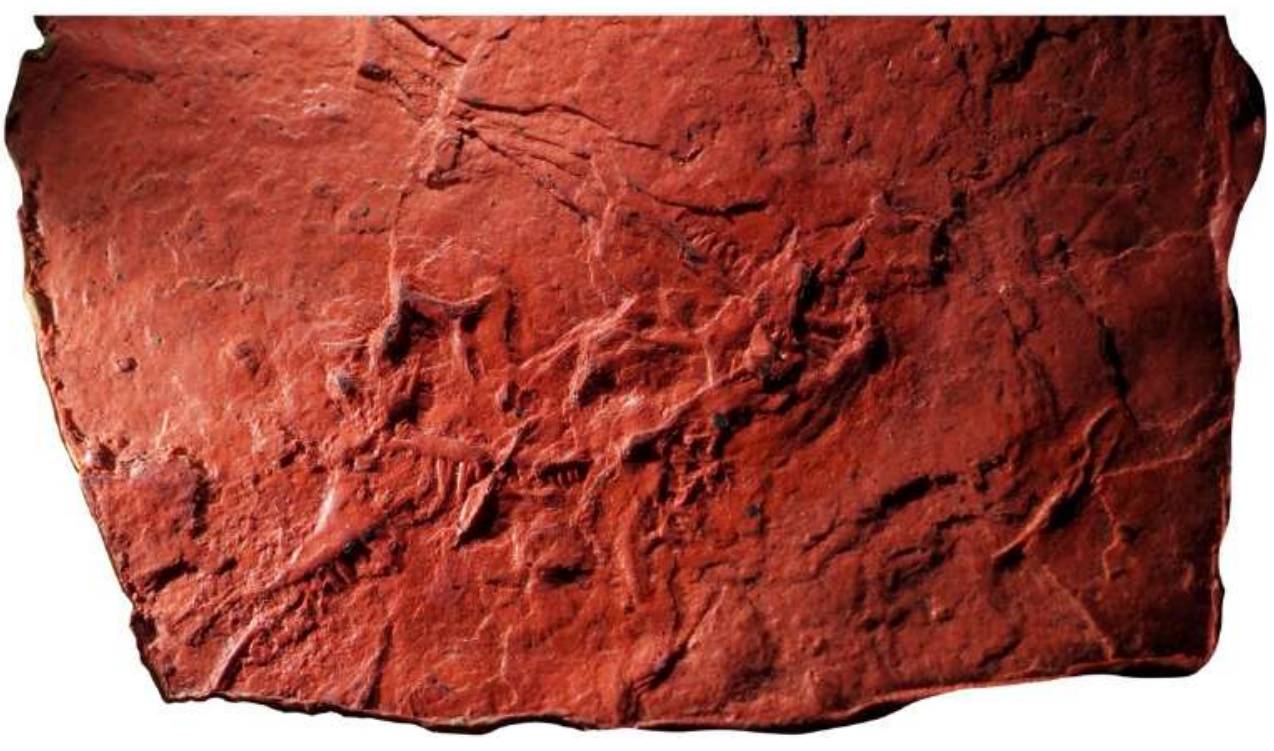

Figure 4.3 Carbonodraco lundi gen. et sp. nov., A) the holotype specimen (CM 23055) (Amy C. Henrici photo) and B) latex peel of the holotype specimen. 


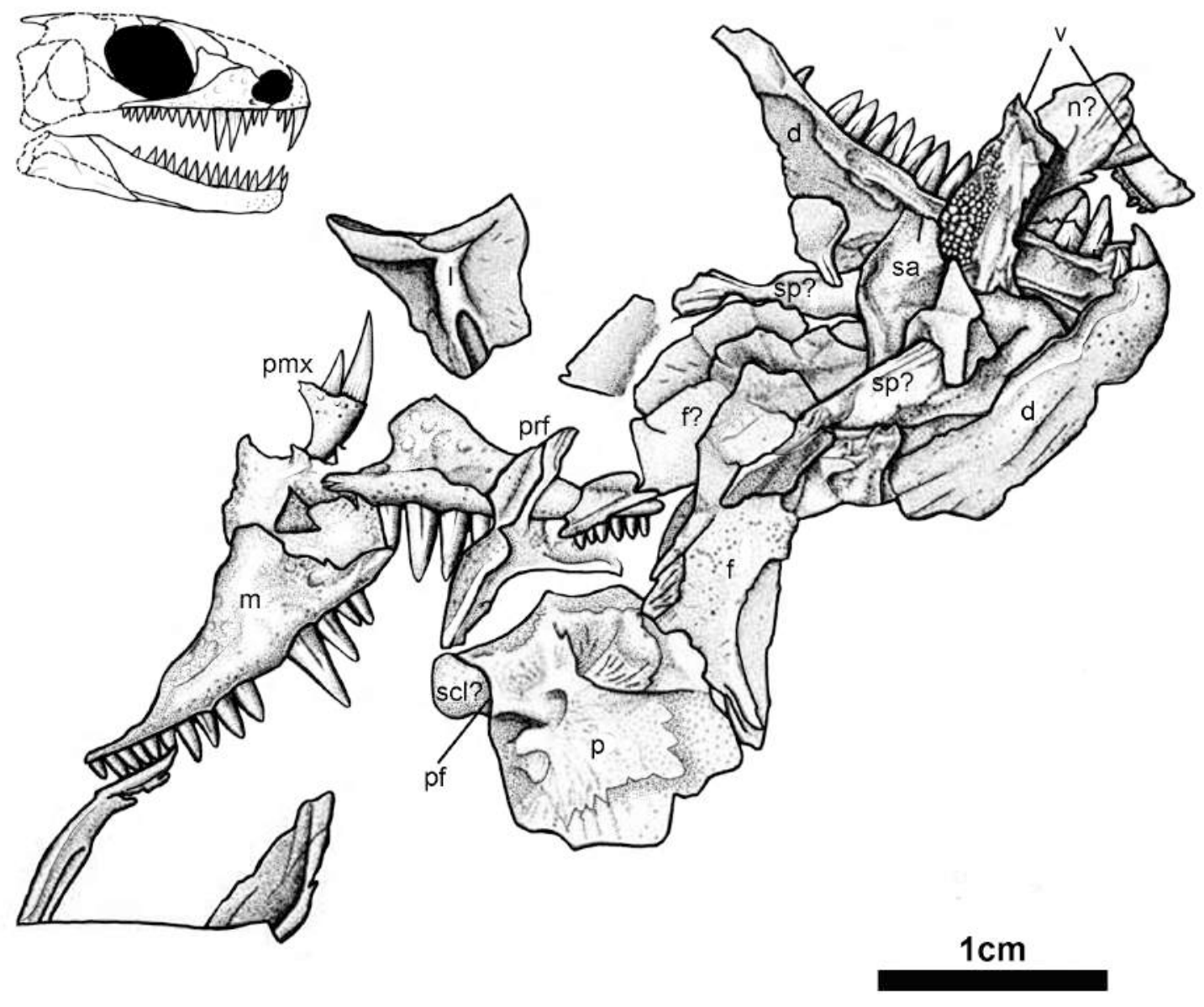

Figure 4.4 Illustration of the cranial anatomy of the holotype of Carbonodraco lundi gen. et sp nov. (CM 23055), and a reconstruction. 


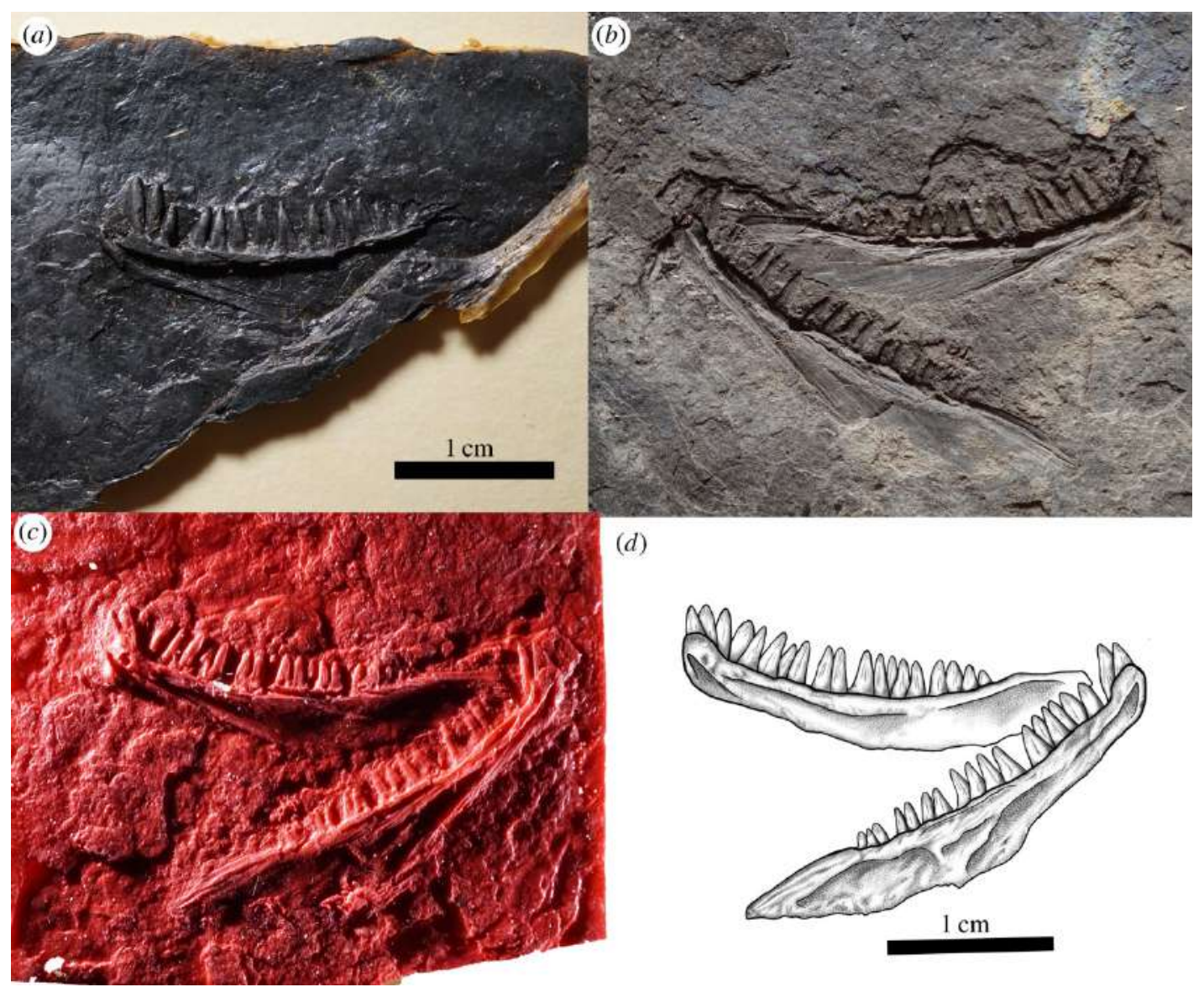

Figure 4.5 Referred specimens of Carbonodraco lundi gen. et sp. nov. A) Latex peel of NHMUK R. 2667 showing a right jaw in lingual perspective (Kathy Bossy peel). B-D) CM 81536. B) Original cannel coal specimen, C) latex peel, and D) drawing, showing a pair of dentaries preserved in lingual perspective.

\subsection{Description}

A left premaxilla is preserved in the holotype specimen. It appears to have a short lateral process and a high dorsal ascending process. The lateral surface is ornamented with tiny pits that probably are foramina. The premaxilla has spaces for approximately three teeth, two of which are in place, and one of which is significantly enlarged. This large tooth is the anterior most, and its length equals that of the most enlarged maxillary teeth. All premaxillary teeth are gently recurved towards the apex. Along the base of the enlarged premaxillary tooth there can be seen large grooves likely indicating the presence of plicidentine. Overall the structure and size of the tooth is most similar to that of the 
parareptile Colobomycter vaughni, whereas the tooth in Colobomycter pholeter is even larger (MacDougall et al., 2016).

CM 23055 preserves the right and left maxilla in lateral view (Figs. 4.3 and 4.4). The ornamentation consists of distinct, large pitting similar to that of other known parareptilian taxa, including acleistorhinids such as Colobomycter and Delorhynchus. The large pitting on the facial lamina of the maxillae is highly comparable to that of Colobomycter pholeter and Colobomycter vaughni (MacDougall et al., 2016, 2017). The facial lamina of the maxilla is tall and narrows slightly dorsally. The subnarial process of the maxilla bears an anterolateral foramen adjacent to the naris similar to the maxilla of Acleistorhinus, Colobomycter, and other parareptiles. The posterior process tapers significantly away from the facial lamina. The conical and sharply pointed tooth crowns display substantial heterodonty in terms of size along the tooth row. Two enlarged teeth of similar size, at positions four and five, are significantly larger than the rest. Many of the teeth clearly show linear grooves that begin at the tooth base and end midway towards the crown.

The lacrimal is represented only on the left side and is preserved in medial view in CM 23055. It forms a portion of the anterior orbital margin and is comparatively shorter than that of basal reptiles, such as "protorothyridids" and captorhinids, and also many recumbirostran taxa. Although Reisz and Baird (1983) figured the lacrimal as being incomplete anteriorly, we find this unlikely because an anterior margin is present on both the latex peel and original specimen. The short morphology of the lacrimal resembles that of some acleistorhinid parareptiles (Acleistorhinus, Colobomycter, and some specimens of Delorhynchus), where the lacrimal is excluded from the naris and partially overlapped by the high facial lamina of the maxilla (MacDougall et al., 2016). A long groove that accepts the ventral process of the prefrontal is present on the posterodorsal edge of the medial surface of the lacrimal. The posteroventral process of the lacrimal is short, dissimilar to that of Cephalerpeton and other basal eureptiles, but close morphologically to that of Colobomycter and Acleistorhinus.

A single left prefrontal is preserved in CM 23055, also in medial aspect. This element is roughly Y-shaped with all of the processes approximately the same length and width. The ventral process can be elegantly matched with the posterodorsal recess on the 
lacrimal. This ventral process of the prefrontal, in conjunction with the posterior process of the prefrontal, form the anterodorsal margin of the orbit.

A right nasal is tentatively identified in CM 23055, disarticulated and now located between the vomers. The posterior margin of the nasal is obscured by the right vomer, but its anterior margin is visible and reveals what appears to be the dorsal surface. There is an anterolateral flange that extends to what may be the anterior margin of the external naris. Anteromedially, there is recess that may have housed the ascending dorsal process of the premaxilla.

The left frontal is preserved in ventral aspect, and the right frontal may also be present, overlapped by the anterior end of the left. The bone is long and rectangular with a small median lappet that likely formed a contribution to the dorsal margin of the orbit. Overall, the frontal is also quite wide, and both frontals together would have formed a wide interorbital region. This is another feature that is drastically different from the condition seen in Cephalerpeton but similar that of acleistorhinid parareptiles.

The parietals are represented only by the left element that is preserved in ventral aspect. It is basically square in outline and is very wide in comparison to that of most "protorothyridids," early eureptiles, and even most parareptiles. The straight anterior margin of the parietal indicates that the suture with the frontal was likely simple and not strongly interdigitated. The posteromedial margin of the parietal is emarginated slightly to create, together with its antimere, a recess for the postparietal. The parietal-parietal contact is straight with the exception of a small emargination for the anteriorly located pineal foramen. This anterior location of the pineal foramen is unique to Carbonodraco in comparison to other acleistorhinids. The ventral surface is ornamented with striae and bears a slightly raised medial surface that extends from the posterolateral edge.

The only palatal elements identifiable in CM 23055 are the vomers. The right vomer is preserved in ventromedial aspect, while the left vomer is only visible in lateral aspect. They both show a high median lamina. The right vomer is better exposed and shows that the vomers are roughly triangular in ventral aspect. The right vomer narrows anteriorly towards the internal median premaxillary contact and widens posteriorly towards both the palatine and pterygoid. The vomer is covered in a shagreen of denticles. This is unique for a parareptile, where the vomers often bear a continuation of teeth from 
a denticulate boss on the pterygoid. The vomerine dentition of Carbonodraco may be primitive in this regard.

The mandible of Carbonodraco lundi gen. et sp. nov. is represented by both dentaries, two tentatively identified splenials, and a left surangular (Figs. 4.4 and 4.5). The dentary is by far the best represented mandibular element and is preserved on the holotype specimen (CM 23055), as well as the two referred specimens (NHMUK R. 2667 and CM 81536). The dentary is comparatively robust, particularly in the area of the slightly upturned symphysis. The lateral surface has some gentle rugosity and small foramina anteriorly. Medially, there are fine ridges preserved that may indicate the location of at least one coronoid ventral to a relatively low coronoid process.

The tooth-count estimates vary between specimens but are within the range of variation seen in extant reptiles (Brown et al., 2015). Whereas the dentaries of CM 23055 have 16 to 17 tooth positions, which agrees with 16 positions in NHMUK R. 2667, CM 81536 has places for 19 teeth. The teeth of CM 81536 bear only a weak degree of heterodonty, with the anteriormost dentary teeth being slightly larger than the rest. Unlike Cephalerpeton, the dentary teeth of Carbonodraco lundi gen et sp. nov. are approximately the same size, if not larger, than the opposing teeth on the maxillae and are of the same morphology in that they are not recurved. CM 81536 preserves details of the dentition better than any other specimen of Carbonodraco lundi gen et sp. nov. The morphology of each individual tooth is conical and tapered more abruptly in the apical portion of the tooth crown. Each tooth crown bears distinct enamel fluting consisting of very fine parallel grooves. The tooth bases and midsections also show large grooves, often three or more. These larger grooves are interpreted as plicidentine, similar to that found in parareptiles such as Colobomycter, as well as a variety of other Paleozoic tetrapods.

The splenial is a flat, long element with a posterior lappet that may have cupped the posterior end of the dentary (CM 23055, Fig. 4.4). The left splenial is located adjacent to the left dentary and appears to be preserved showing its exterior surface, whereas the right splenial appears to be showing its lingual surface. The left surangular is preserved partially and overlapped by the right splenial. It has a moderately developed crest, which 
is confluent with the coronoid process of the dentary, and a slightly concave lateral surface.

\subsection{Systematic Paleontology}

Tetrapoda Jaekel, 1909

Amniota Haeckel, 1866

Reptilia indet.

Fig. 4.6

Material: CM 41714, a partial left jaw, including a dentary (broken into two pieces), splenial, angular, and surangular, preserved in lateral view, as well as rib fragments and a partial centrum; collected by Carl F. Wellstead, 1983.

Locality and Horizon: Coal mine operated originally by the Ohio Diamond Coal Company at Linton, Saline Township, Jefferson County, Ohio, U.S.A. (see Hook and Baird, 1986, for details). Local cannel coal immediately below the Upper Freeport coal, Allegheny Group, Middle Pennsylvanian (Moscovian).

Comment: The general mandibular morphology indicates a relatively long-jawed reptile unlike Carbonodraco. There is no significant anatomical overlap between this specimen and the solitary Linton specimen that represents Anthracodromeus (see Carroll and Baird, 1972). Thus, we recognise CM 41714 as a distinct, but indeterminate, reptile taxon in the Linton assemblage. 


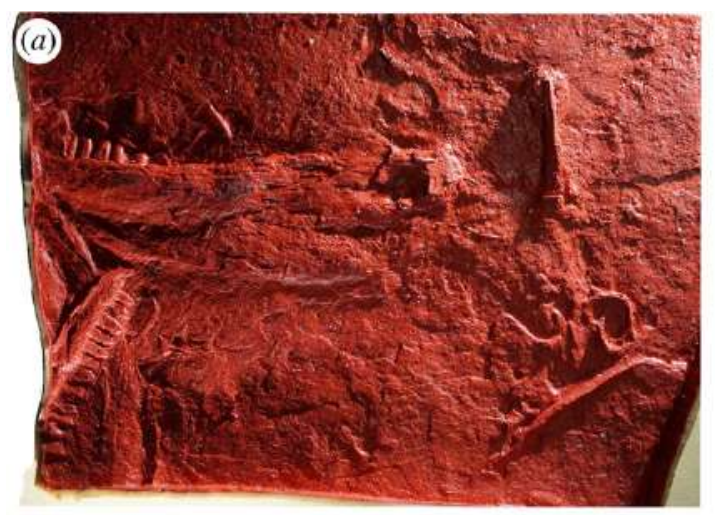

(b)

(c)
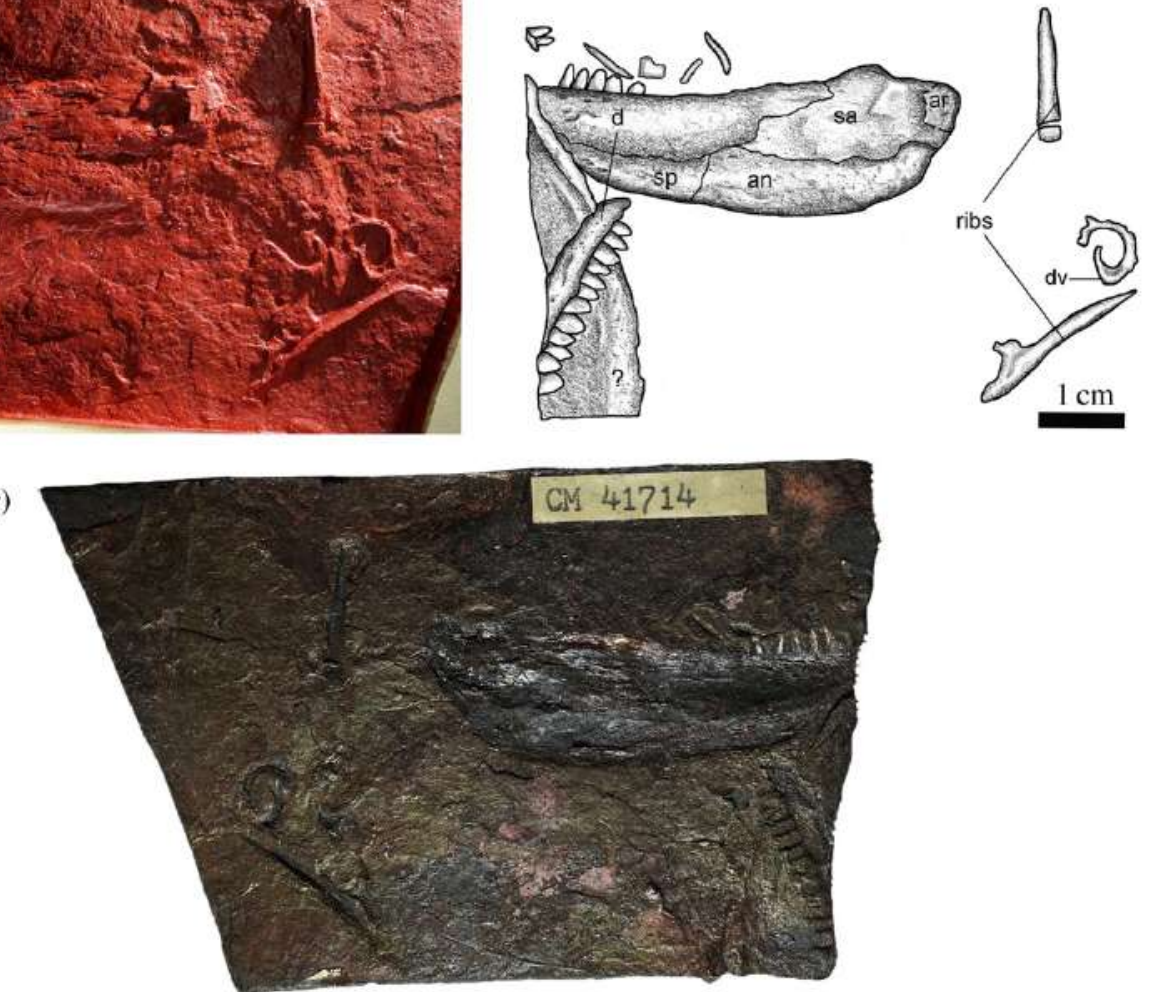

Figure 4.6 Indeterminate reptilian amniote from Linton, Ohio (CM 41714). A) Latex peel, B) drawing, and C) actual specimen.

\subsection{Description}

CM 41714 includes a left jaw and associated postcranial fragments that bear some resemblance to early reptiles (Fig. 4.6). The preserved mandible includes a dentary (the anteriormost portion of which is broken and displaced), splenial, angular, surangular, and articular, all preserved in lateral view. Postcranial fragments include a few rib fragments and a partial centrum. Additionally, there is a large unidentifiable bone located on the edge of the block beneath the anterior dentary fragment.

The anterior portion of the dentary shows a rapidly narrowing morphology that ends in a small unexpanded symphysis; this is unlike the dentary of Carbonodraco. The posterior portion of the dentary is deep dorsoventrally and has a strongly convex ventral margin. The lateral surface shows a slightly rugose ornamentation, with small foramina dispersed throughout, similar to the ornamentation seen in some captorhinid eureptiles. In total, seventeen teeth are preserved, with spaces for more at the posterior end. The teeth 
are homodont, with wide, bulbous bases. The crowns are worn, yet they retain a somewhat pointed apex. Although some captorhinids and recumbirostrans show a similar tooth morphology, the teeth of CM 41714 are insufficient for detailed comparisons. Unlike Carbonodraco or Cephalerpeton, no evidence of enamel fluting or plicidentine grooves can be found on the teeth of CM 41714.

The splenial is elongate and buttresses the ventral surface of the dentary. Its ventral margin continues the convex shape of the entire jaw. The splenial also bears rugose ornamentation and pitting similar to the dentary. Posteriorly, the splenial contacts the angular in a simple straight suture. Together, the surangular and angular contribute to about a third of the mandible length. The surangular is a large irregularly-shaped element that bears a low coronoid process about midway along its dorsal margin. At the posterodorsal edge of the surangular, a small quadrangular ossification probably represents an articular; the vague expression of this element suggests that it may have been poorly ossified. The angular occupies the posteroventral region of the lower jaw. Its ventral margin is strongly curved, especially at its posterior terminus.

\subsection{Discussion}

\section{Cephalerpeton ventriarmatum, an early eureptile from Mazon Creek}

Here we conducted the first restudy of the anatomy and systematic considerations of early reptiles from the Pennsylvanian-aged sites of Mazon Creek, Illinois, and Linton, Ohio, since the 1980s. Our anatomical analysis supports the placement of Cephalerpeton ventriarmatum within Eureptilia but found characteristics in common with both Carboniferous basal eureptiles and more derived diapsid eureptiles, such as the araeoscelids. Considering that Müller and Reisz (2006) recovered Cephalerpeton as a member of the sister clade (together with Anthracodromeus and Protorothyris) to Diapsida, and that the oldest araeoscelids occur in the Late Carboniferous (Kasimovian), it is not unreasonable to consider Cephalerpeton as more closely related to diapsids than previously thought. This phylogenetic position, and the question of whether or not Cephalerpeton (and by proxy, Anthracodromeus and Protorothyris) should be included within Diapsida, remains a possibility that needs to be tested with a comprehensive 
phylogenetic analysis. We did not perform such an analysis here because we believe that it would be premature in the absence of revisions of other relevant early reptiles. At present, our understanding of the anatomy of most Pennsylvanian-aged reptiles (i.e., most members of Protorothyrididae) is somewhat dated, and was generated when a much smaller comparative database was available. Additionally, several recent studies have proposed major shifts in the amniote phylogenetic tree, including the inclusion of recumbirostrans as early reptiles (Pardo et al., 2017) and varanopids as early diapsids (Ford and Benson, 2019). A comprehensive reevaluation of early amniote phylogeny, synthesizing and testing these new hypotheses, is the appropriate first step towards a better understanding of enigmatic Carboniferous forms such as Cephalerpeton.

Our restudy of the anatomy of Cephalerpeton ventriarmatum provides a revised diagnosis for the genus and recognises that the genus is restricted to Mazon Creek. Previously referred material from Linton, Ohio, is identified here as the new parareptile Carbonodraco lundi. Although we restrict Cephalerpeton remains at this time to only occurring in the Mazon Creek assemblage, without the complete revision of reptile remains from Linton, Ohio, including the closely related Anthracodromeus, as well as reptile remains from other Carboniferous sites, there is no way to be certain about the level of endemism occurring in closely aged Carboniferous amniote communities.

Cephalerpeton ventriarmatum represents the oldest known reptile aside from Hylonomus from Joggins, Nova Scotia. Unlike the upright tree stump assemblages of Nova Scotia, Cephalerpeton occurs in a siderite nodule at Mazon Creek, which is believed to represent an estuarine setting (Clements et al., 2019). The Mazon Creek assemblage is dominated by aquatic invertebrates, insects, and fish (Shabica and Hay, 1997). Tetrapods found in Mazon Creek nodules are believed to have been washed in from the adjacent near-shore environment (Clements et al., 2019). In contrast to this traditional scenario, recent study of tetrapods from this locality have identified a number of terrestrial tetrapods in the assemblage (Mann et al., 2019; Mann and Maddin, 2019). Interestingly, these recumbirostrans display several adaptations to fossoriality, suggesting the terrestrial component of Mazon Creek tetrapods has been understated. Additionally, recumbirostrans were recently recovered as a group of reptiles (Pardo et al., 2017) 
revealing the estuarine paleoenvironment of the Mazon Creek lagerstätte was likely home to a significant diversity of reptile and reptile-like terrestrial taxa.

Traditional hypotheses of amniote origins have described the establishment of dry, "upland" ecosystems as a possible driver of early amniote diversification. Testing of this idea has been lacking until the recent attempts of Pardo et al., (2019). Records of terrestrial amniotes (including synapsids, eureptiles, and parareptiles) at Mazon Creek and Linton-clearly lower delta plain and alluviated upper delta plain settings, respectively-also suggests a more complicated paleoenvironmental and ecological scenario for early amniote diversification.

There are some important early ecological adaptations revealed by the current reanalysis of the anatomy of Cephalerpeton. The most obvious of these is the dental configuration, which includes large, wide-based conical teeth and multiple enlarged teeth irregularly spaced along the maxillary tooth row with smaller recurved teeth in the dentary tooth row. Carroll and Baird (1972) and Reisz and Baird (1983) described the maxillary dentition of Cephalerpeton as adequate for the processing of hard-shelled arthropod material, which represent a widely available food source at Mazon Creek and most Carboniferous coal measure localities (Modesto et al. 2009). We agree that the teeth were likely used for a form of durophagous carnivory/insectivory. The wide, conical teeth with multiple peaks along the tooth row would have done well piercing the chitinous exoskeletons of small insects, as the lower dentition held prey in place (hence the recurvature) (see Melstrom, 2017, for interpretation of tooth types in reptiles). The dentition of Cephalerpeton seems to represents an alternative approach to insectivorous durophagy contrasting with the very wide, teardrop-shaped dentition present in durophagous gymnarthrids, pantylids, the captorhinid Opisthodontosaurus, and durophagous modern squamates (Carroll and Gaskill, 1978; Reisz et al., 2015; Melstrom, 2017). The ogival tooth morphology seen in other captorhinids is yet another example of durophagous dentition among early reptiles (Leblanc et al., 2015). This "captorhinid" type dentition could be convergently shared with CM 41714, the indeterminate reptile from Linton, Ohio. Additionally, similar maxillary teeth are seen in Cephalerpeton and Carbondraco, as well as a number of parareptiles (Modesto et al., 2009), which suggests that this durophagus tooth morphology may also be prone to convergence. 
Another interesting aspect of Cephalerpeton is the length of the forelimbs, which are proportionally longer than those present in most "protorothyridids" with the exception of the closely related Anthracodromeus. As described above, the length of the forelimbs more closely resembles the proportions of those of later occurring diapsids (e.g. Petrolacosaurus). Carroll and Baird (1972) recognized similarities in limb proportions and morphology of the manus and pes of the Linton taxon Anthracodromeus to those of extant arboreal reptiles. Given the extensive lycopsid forests present in the Carboniferous, the idea that Anthracodromeus was arboreal is certainly plausible. As such, it is also plausible that Cephalerpeton was also adapted for some form of arboreal or at least scansorial lifestyle.

\section{Carbonodraco lundi as the oldest parareptile}

The identification of CM 23055 as a distinct taxon from Cephalerpeton increases the taxonomic diversity of amniotes at Linton, which now includes representatives of Synapsida, Eureptilia, and Parareptilia. Our interpretation of the taxonomic affinity of Carbonodraco further makes it the oldest known member of Parareptilia, the early diverging sister clade to Eureptilia. Previously, the oldest known parareptile was Erpetonyx arsenaultorum (Modesto et al., 2015), from the uppermost Carboniferous (Gzhelian) Egmont Bay Formation of Prince Edward Island, Canada. Erpetonyx is a generalized parareptile and was placed in the relatively early-branching clade Bolosauria. Modesto et al. (2015) also established that parareptiles began their evolutionary radiation before the end of the Carboniferous Period. As a result, their time-calibrated phylogeny of parareptiles revealed long ghost lineages for basal parareptilian clades (e.g., Mesosauridae and Millerosauria) since these taxa appear in the fossil record in the Permian. The evolutionary framework presented in this time-calibrated phylogeny additionally shows an Early Permian diversification of the clade Ankyramorpha (i.e., lanthanosuchids, nyctiphuretids, and procolophonids). Recent studies by MacDdougall et al. (2019) on parareptile species richness and diversity through time also support this framework. Thus, our identification of Carbonodraco as an acleistorhinid parareptile is of high importance to the interpretation of the timing and diversification of the previously identified Permian-aged adaptive radiation of not only the Ankyramopha, but the entirety 
of the parareptile clades to as early as the Moscovian. The occurrence of Carbonodraco lundi gen et sp. nov. in the Carboniferous aligns the first appearance of parareptiles close to that of eureptiles represented by Hylonomus in the Bashkirian, though many long ghost lineages for parareptiles still remain.

It now seems likely that the previously identified timing of parareptile evolution is an artifact derived from a sampling bias of Permian-aged localities, such as Richards Spur. This revelation highlights the importance of research on new and existing tetrapod fossils from earlier, Carboniferous-aged localities. Furthermore, phylogenetic analyses of various reptilian groups need to be less exclusive and consider wider taxonomic sampling from groups including early eureptiles (Müller and Reisz, 2006), early diapsids (Ford and Benson, 2019) and recumbirostrans (Pardo et al., 2017). Inclusions of these groups and revised anatomical analyses have the potential to alter currently accepted evolutionary relationships of Reptilia.

\subsection{Acknowledgements}

We thank Amy C. Henrici and David S Berman for facilitating work at the Carnegie Museum of Natural History. Diane Scott and Robert R. Reisz (University of Toronto) allowed access to parareptile material from Oklahoma and Texas localities under their care. Bryan M. Gee, Sean P. Modesto, and Jason D. Pardo provided stimulating discussions. The late John R. Bolt was a much-valued colleague who contributed directly to this work. Likewise, the late Donald Baird prepared much of the material reported in this study; we thank Robert W. Hook for access to Baird's original research materials. We also thank three anonymous reviewers for their helpful comments. Lastly but perhaps foremost, we thank Richard Lund, Scott McKenzie, and Carl F. Wellstead for their generous donations of specimens from Linton that form the basis of much of this research. 


\subsection{References}

Brown, C. M., VanBuren, C. S., Larson, D. W., Brink, K. S., Campione, N. E., Vavrek, M. J., \& Evans, D. C. (2015). Tooth counts through growth in diapsid reptiles: implications for interpreting individual and size-related variation in the fossil record. Journal of Anatomy, 226, 322-333.

Carroll, R. L. (1969). A Middle Pennsylvanian captorhinomorph and the interrelationships of primitive reptiles. Journal of Paleontology, 43, 151-170.

Carroll, R. L. (1982). Early evolution of reptiles. Annual review of ecology and Systematics, 13(1), 87-109.

Carroll, R. L., \& Baird, D. (1972). Carboniferous stem-reptiles of the family Romeriidae. Bulletin of the Museum of Comparative Zoology, 143, 321-364.

Carroll, R. L. \& Gaskill, P. (1978). The Order Microsauria. Memoirs of the American Philosophical Society, 126, 1-211.

Clements, T., Purnell, M., \& Gabbott, S. (2019). The Mazon Creek Lagerstätte: a diverse late Paleozoic ecosystem entombed within siderite concretions. Journal of the Geological Society, 176, 1-11.

deBraga, M., \& Reisz, R. R. (1995). A new diapsid reptile from the uppermost Carboniferous (Stephanian) of Kansas. Palaeontology, 38, 199-212.

Ford, D. P., \& Benson, R. B. (2019). A redescription of Orovenator mayorum (Sauropsida, Diapsida) using high-resolution $\mu \mathrm{CT}$, and the consequences for early amniote phylogeny. Papers in Palaeontology, 5, 197-239. 
Gregory, J. T. (1948). The structure of Cephalerpeton and affinities of the Microsauria. American Journal of Science, 246(9), 550-568.

Heaton, M. J., \& Reisz, R. R. (1980). A skeletal reconstruction of the Early Permian captorhinid reptile Eocaptorhinus laticeps (Williston). Journal of Paleontology, $54,136-143$.

Heaton, M. J., \& Reisz, R. R. (1986). Phylogenetic relationships of captorhinomorph reptiles. Canadian Journal of Earth Sciences, 23, 402-418.

Hook, R.W., \& Baird, D. (1986). The Diamond Coal Mine of Linton, Ohio, and its Pennsylvanian-age vertebrates. Journal of Vertebrate Paleontology, 6, 174-190.

Laurin, M., \& Reisz, R. R. (1995). A reevaluation of early amniote phylogeny. Zoological Journal of the Linnean Society, 113, 165-223.

LeBlanc, A. R., Brar, A. K., May, W. J., \& Reisz, R. R. (2015). Multiple tooth-rowed captorhinids from the Early Permian fissure fills of the Bally Mountain Locality of Oklahoma. Vertebrate Anatomy Morphology Palaeontology, 1, 35-49.

MacDougall, M. J., LeBlanc, A. R. H., \& Reisz, R. R. (2014). Plicidentine in the Early Permian parareptile Colobomycter pholeter, and its phylogenetic and functional significance among coeval members of the clade. PLoS ONE, 9(5), e96559.

MacDougall, M. J., Modesto, S. P., \& Reisz, R. R. (2016). A new reptile from the Richards Spur Locality, Oklahoma, U.S.A., and patterns of Early Permian parareptile diversification. Journal of Vertebrate Paleontology, 36, e1179641.

MacDougall, M. J., Scott, D., Modesto, S. P., Williams, S. A., \& Reisz, R. R. (2017). New material of the reptile Colobomycter pholeter (Parareptilia: 
Lanthanosuchoidea) and the diversity of reptiles during the Early Permian (Cisuralian). Zoological Journal of the Linnean Society, 180, 661-671.

MacDougall, M. J., Brocklehurst, N., \& Fröbisch, J. (2019). Species richness and disparity of parareptiles across the end-Permian mass extinction. Proceedings of the Royal Society B, 286(1899), 20182572.

Mann, A., \& Maddin, H. C. (2019). Diabloroter bolti, a short-bodied recumbirostran 'microsaur' from the Francis Creek Shale, Mazon Creek, Illinois. Zoological Journal of the Linnean Society.

Mann, A., Pardo, J. D., \& Maddin, H. C. (2019). Infernovenator steenae, a new serpentine recumbirostran from the 'Mazon Creek'Lagertätte further clarifies lysorophian origins. Zoological Journal of the Linnean Society.

Mann, A., Gee, B. M., Pardo, J. D., Marjanović, D., Adams, G. R., Calthorpe, A. S., \& Anderson, J. S. (2020). Reassessment of historic 'microsaurs' from Joggins, Nova Scotia, reveals hidden diversity in the earliest amniote ecosystem. Papers in Palaeontology.

Melstrom, K. M. (2017). The relationship between diet and tooth complexity in living dentigerous saurians. Journal of Morphology, 278, 500-522.

Modesto, S. P. (1999). Colobomycter pholeter from the Lower Permian of Oklahoma: a parareptile, not a protorothyridid. Journal of Vertebrate Paleontology, 19, 466472.

Modesto, S. P., \& Reisz, R. R. (2008). New material of Colobomycter pholeter, a small parareptile from the Lower Permian of Oklahoma. Journal of Vertebrate Paleontology, 28, 677-684. 
Modesto, S. P., Scott, D. M., \& Reisz, R. R. (2009). Arthropod remains in the oral cavities of fossil reptiles support inference of early insectivory. Biology Letters, 5, $838-840$.

Modesto, S. P., Scott, D. M., MacDougall, M. J., Sues, H. D., Evans, D. C., \& Reisz, R. R. (2015). The oldest parareptile and the early diversification of reptiles. Proceedings of the Royal Society B: Biological Sciences, 282, 20141912.

Moodie, R. L. (1912). The Pennsylvanic [sic] Amphibia of the Mazon Creek, Illinois, shales. The Kansas University Science Bulletin, 6, 323-359.

Müller, J., \& Reisz, R. R. (2006). The phylogeny of early eureptiles: comparing parsimony and Bayesian approaches in the investigation of a basal fossil clade. Systematic Biology, 55, 503-511.

Müller, J., Berman, D. S, Henrici, A. C., Martens, T., \& Sumida, S. S. (2006). The basal reptile Thuringothyris mahlendorffae (Amniota: Eureptilia) from the Lower Permian of Germany. Journal of Paleontology, 80, 726-739.

Pardo, J. D., Szostakiwskyj, M., Ahlberg, P. E., \& Anderson, J. S. (2017). Hidden morphological diversity among early tetrapods. Nature, 546, 642.

Pardo, J. D., Small, B. J., Milner, A. R., \& Huttenlocker, A. K. (2019). CarboniferousPermian climate change constrained early land vertebrate radiations. Nature Ecology \& Evolution, 3, 200.

Reisz, R. R. (1977). Petrolacosaurus, the oldest known diapsid reptile. Science, 196, 1091-1093.

Reisz, R. R. (1981). A diapsid reptile from the Pennsylvanian of Kansas. University of Kansas Museum of Natural History, Special Publication, 7, 1-74. 
Reisz, R. R., \& Baird, D. (1983). Captorhinomorph" stem" reptiles from the Pennsylvanian coal-swamp deposit of Linton, Ohio. Annals of Carnegie Museum, $52,393-411$.

Reisz, R. R., Berman, D. S, \& Scott, D. (1984). The anatomy and relationships of the Lower Permian reptile Araeoscelis. Journal of Vertebrate Paleontology, 4, 57-67.

Reisz, R. R., LeBlanc, A. R. H., Sidor, C. A., Scott, D., \& May, W. (2015). A new captorhinid reptile from the Lower Permian of Oklahoma showing remarkable dental and mandibular convergence with microsaurian tetrapods. The Science of Nature, 102, 50.

Reisz, R., Haridy, Y., \& Müller, J. (2016). Euconcordia nom. nov., a replacement name for the captorhinid eureptile Concordia Müller and Reisz, 2005 (non Kingsley, 1880), with new data on its dentition. Vertebrate Anatomy Morphology Palaeontology, 3, 1-6.

Shabica, C. W., \& Hay, A. (Eds.). (1997). Richardson's Guide to the Fossil Fauna of Mazon Creek. Northeastern Illinois University, Chicago: xviii, 308 p.

Sumida, S.S., Dodick, J., Metcalf, A., \& Albright, G. (2010). Reiszorhinus olsoni, a new single-tooth captorhinids reptile from the Lower Permian of Texas. Journal of Vertebrate Paleontology, 30, 704-714. 


\section{| Chapter 5: A new, exceptionally preserved, recumbirostran from the Mazon Creek Lagerstätte reveals patterns of integumentary evolution in Recumbirostra.}

\subsection{Authors and Addresses}

Arjan Mann, and Hillary C. Maddin

Department of Earth Sciences, Carleton University, 2115 Herzberg Laboratories, 1125 Colonel By Drive, Ottawa, Ontario, K1S 5B6, Canada.

\subsection{Preface}

The following manuscript is formatted to be submitted for publication to the journal Royal Society Open Science. Arjan Mann was fully involved in setting up and conducting the research, preparing samples, running all analyses, developing methodology, writing the manuscript and drafting final figures in this co-authored article. Hillary C. Maddin provided discussion and editing of content. The manuscript has been modified slightly to accommodate the formatting requirements for Carleton University dissertations.

\subsection{Abstract}

The Carboniferous Pennsylvanian-aged (309-307 Ma) Mazon Creek Lagerstätte produces some of the earliest fossils of major Paleozoic tetrapod lineages. Recently, several new tetrapod specimens collected from Mazon Creek have come to light, including the earliest fossorially-adapted recumbirostrans. Here we describe a new genus and species of long-bodied recumbirostran, known from a single part and counterpart concretion (FMNH 1309) bearing a virtually complete skeleton. Uniquely, FMNH 1309 preserves a full suite of dorsal, flank, and ventral scales, but lacks any trace of gastralia. Investigation of these scales using Scanning Electron Microscopy (SEM) reveals ultrastructural ridge and pit morphologies, revealing complexities comparable to the scale 
ultrastructure of extant snakes and fossorial reptiles, which have scales modified for body-based propulsion and shedding substrate. Our new taxon also represents an important early record of an elongate recumbirostran bauplan, wherein several features linked to fossoriality, including a characteristic recumbent snout, are present. We utilized parsimony phylogenetic methods to conduct phylogenetic analyses using the updated recumbirostran-focused matrix of Gee et al., (2020). The analysis recovers the new taxon within the Cocytinoidea clade as sister taxon to all brachystelechids. Finally, we review integumentary patterns in Recumbirostra, noting losses of gastralia and osteoderms associated with body elongation and, thus, likely also associated with increased fossoriality.

\subsection{Introduction}

Recent resurgence in the study of certain 'microsaurs' known as recumbirostrans has resulted in their renewed relevance in the origin of amniotes (Vaughn, 1964; Pardo et al., 2017). Debates specifically concern whether Recumbirostra belong to the amniote stem group (Laurin and Reisz, 1995; Reisz et al., 2015), or are instead crown amniotes derived from a reptilian ancestor (Pardo et al., 2017). The timing of the origin of amniotes is earmarked at the mid-Carboniferous, with the oldest unambiguous amniotes residing in the Bashkirian-aged (318-315 Ma) strata of Joggins, Nova Scotia (Mann et al., 2020). Already at this stage, and onward through the Permo-Carboniferous, recumbirostrans are morphologically diverse, showing a range in degree of development of a variety of stereotypical cranial and postcranial adaptations for a fossorial lifestyle (Huttenlocker et al., 2013; Pardo et al., 2015; Szostakiwskyj et al., 2015; Pardo and Anderson, 2016; Mann et al., 2017). Thus, the inclusion of Recumbirostra into Eureptilia would redefine the nature of the radiation of the group and reveal details of the ecology and diversity in some of the earliest phases of reptile evolution. Recent studies (Mann and Maddin, 2019; Mann et al., 2019a; Mann et al., 2019b; Mann and Gee, 2020) on tetrapod fossils from the Moscovian-aged (309-307 Ma) Mazon Creek Lagerstätte have revealed a diverse recumbirostran-amniote fauna. Because Mazon Creek often provides fossils of entire organisms, including soft-tissue structures entombed within siderite 
concretions, a diverse array of bauplans has been preserved, questioning past ideas about terrestrial tetrapod diversity in Carboniferous ecosystems (Milner, 1982; Ahlberg and Milner, 1984; Sues and Reisz, 1998; Sahney et al., 2010; Dunne et al., 2018; but see Pardo et al., 2019).

Here we describe FMNH 1309, a new genus and species of long-bodied recumbirostran from Mazon Creek, Francis Creek Shale, Illinois (Figs. 5.1, 5.2). FMNH 1309 provides an ecomorphological intermediate between the extreme body elongation and limb reduction seen in molgophid recumbirostrans such as the contemporaneous Infernovenator and the short-bodied, robustly built brachystelechid recumbirostran Diabloroter (Mann and Maddin, 2019; Mann et al., 2019a). FMNH 1309 is exceptionally preserved, at the higher end of the quality scale for Mazon Creek fossils. It includes alongside the full skeleton visible in dorsal and ventral aspects, a detailed soft tissue impression of the body complete with scales. Detailed examination of the scales of FMNH 1309 reveal a unique ultrastructural pattern, and provide the first comprehensive description of scale morphology of this kind in a Paleozoic tetrapod. 


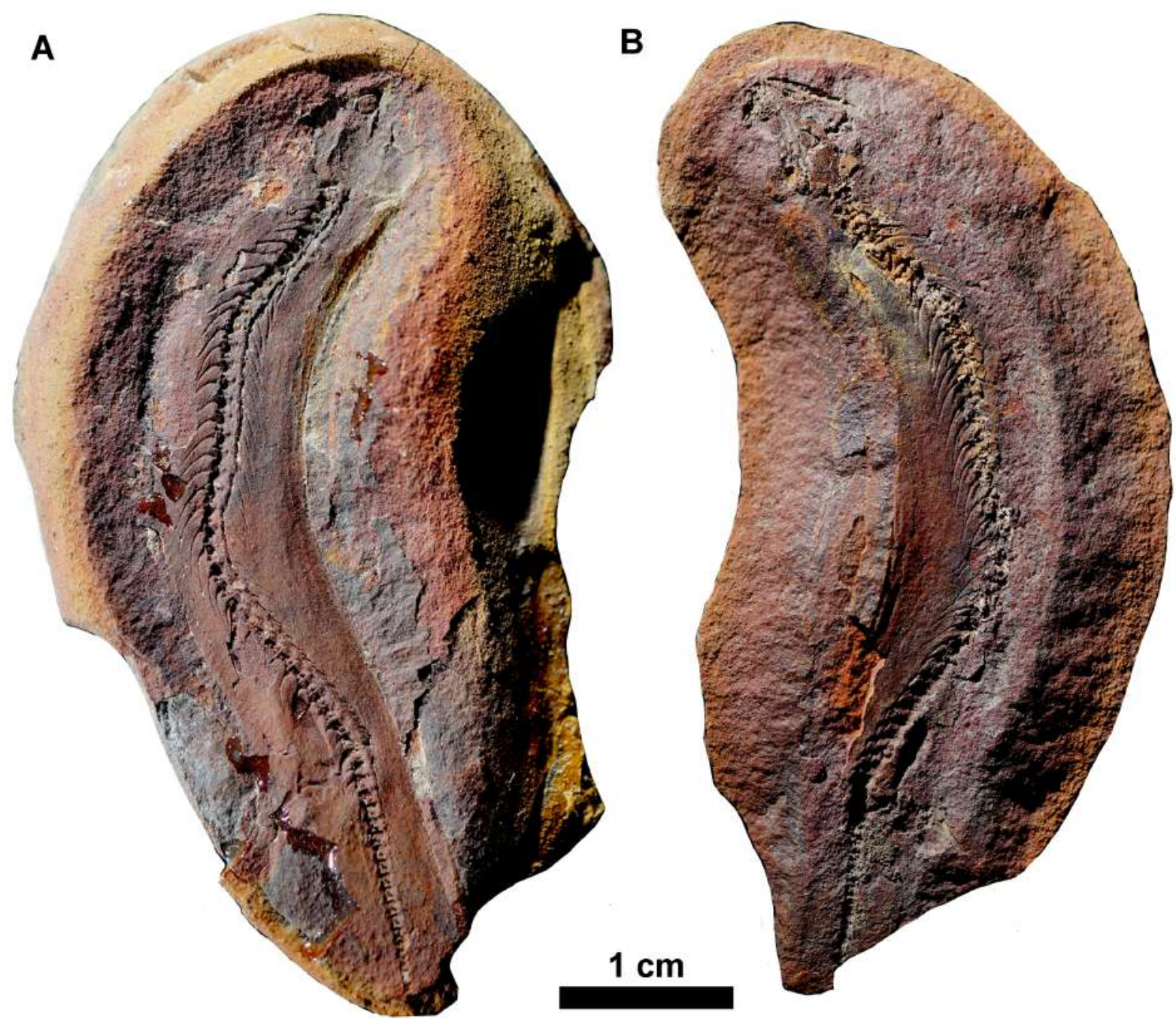

Figure 5.1 Photographs of the holotype (FMNH 1309). A, the part specimen showing the dorsal view; $B$, the counterpart specimen showing the ventral view. 
A

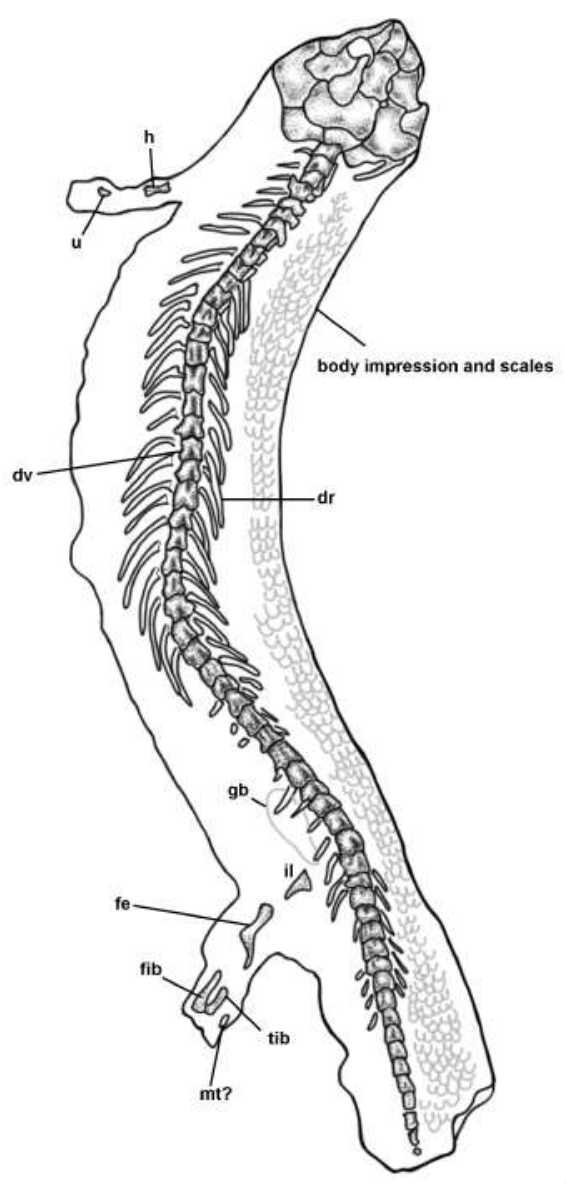

B

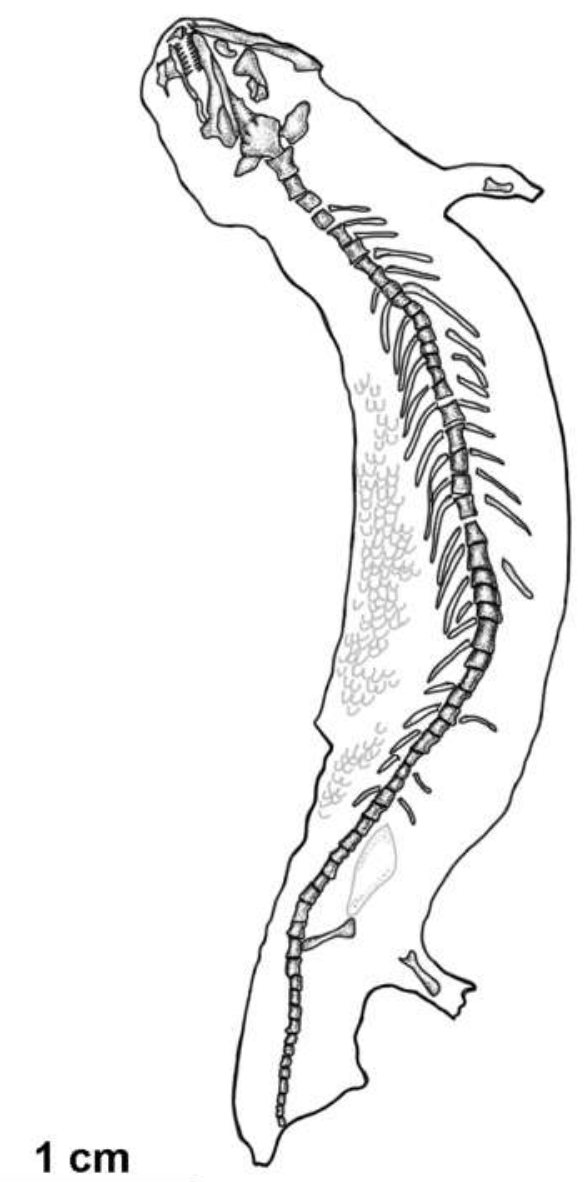

Figure 5.2 Illustrations of the holotype (FMNH 1309). A, dorsal and B, ventral aspects of FMNH 1309.

\subsection{Materials and Methods}

Specimens were studied at: Augustana College's Fryxell Geology Museum (ACFGM), Rock Island, USA; American Museum of Natural History (AMNH), New York, USA; Carnegie Museum of Natural History (CM), Pittsburgh, USA; Denver Museum of Nature and Science (DMNH), Denver, USA; Field Museum of Natural History (FMNH), Chicago, USA; University of Kansas Natural History Museum (KUVP), Lawrence, USA; University of Nebraska State Museum (UNSM), Lincoln, USA; Smithsonian Institution (USNM), Washington DC, USA; and Yale Peabody Museum (YPM), New Haven, USA. Additional comparative specimens from the British Museum of Natural History (BMNH), London, UK, the Harvard Museum of 
Comparative Zoology (MCZ), Cambridge, USA, Museum für Naturkunde (MB), Berlin, Germany, were compared based on casts, latex peels, and existing literature.

Only 1 latex peel was made of the dorsal aspect of the skeleton, and is catalogued with the original material at the FMNH. This latex cast was used to describe the dorsal cranial and postcranial elements; however, the ventral half of the skeleton is described solely off of the corresponding counterpart. Photography was conducted using a Sony Alpha ILCE 5000 camera, F3.5 lens. All figures were drawn and formatted in Photoshop CS6 (Adobe, San Jose, CA). For phylogenetic methodology see the phylogenetic analysis section below.

In order to interpret features of the morphology of the scales preserved on FMNH 1309 , a comparative dataset was compiled, consisting of extant squamate scales belonging to a number of terrestrial, arboreal and fossorial forms housed in the research collections of the Canadian Museum of Nature, Gatineau, Quebec. The selected extant squamate specimens can be found in Appendix C. Scanning Electron Microscopy (SEM) was conducted at the Canadian Museum of Nature research facility using a JEOL 6610LV SEM.

\subsection{Anatomical abbreviations}

ang $=$ angular; $\mathbf{b o}=$ basioccipital; $\mathbf{c o}=$ co-ossified occipital and otic elements; $\mathbf{d v}=$ dorsal vertebrae; $\mathbf{d r}=$ dorsal ribs; $\mathbf{d}=$ dentary; $\mathbf{f}=$ frontal; $\mathbf{f e}=$ femur; fib=fibula; $\mathbf{g b}=$ gastric bolus; $\mathbf{g s}=$ gastralia; $\mathbf{h}=$ humerus; $\mathbf{i l}=$ ilium; $\mathbf{j}=$ jugal; $\mathbf{l}=$ lacrimal; $\mathbf{m}=$ maxilla; $\mathbf{m t}=$ metatarsal; $\mathbf{n}=$ nasal; $\mathbf{p}=$ =parietal; pas=parasphenoid; $\mathbf{p f}=$ postfrontal; $\mathbf{p m x}=$ =premaxilla; $\mathbf{p r f}=$-prefrontal; $\mathbf{p l = p a l a t i n e ; ~} \mathbf{q j}=$ =quadratojugal; $\mathbf{s o}=$ supraoccipital; $\mathbf{s q}=$ squamosal; $\mathbf{s v =}=$ sacral vertebra; $\mathbf{s p}=$ splenial; $\mathbf{t}=$ tabular; $\mathbf{t i b}=$ tibia; $\mathbf{u}=$ ulna.

\subsection{Systematic Paleontology}

Tetrapoda Jaekel, 1909

Recumbirostra Anderson, 2007

gen. et sp. nov. 
(Figs. 5.1-5.3)

Zoobank LSID: Will be provided with publication.

Holotype. FMNH 1309, part and counterpart of a siderite concretion containing a virtually complete skeleton and soft body impression in dorsal and ventral views.

Locality and Horizon: Mazon Creek, Grundy County, Illinois, USA. Francis Creek Shale, above the Morris (no. 2) Coal, Carbondale Formation, Middle Pennsylvanian (Moscovian).

Etymology. Will be provided with publication.

Differential Diagnosis. A small recumbirostran with the following unique combination of characters: 40 presacral vertebrae; short tail with 17 caudal vertebrae; dentary and maxillary tooth rows short; short snout; large rectangular parietal that reaches the postorbital and squamosal; large quadrangular postfrontal that invades the anterior margin of the parietal; braincase co-ossified but retaining a distinct supraoccipital; body covered in uniform scales; scales ornamented with linear ridges and unevenly distributed pits. Differs from all brachystelechids in having a long body and the absence of supraorbital pits. Differs from molgophids and some ostodolepids in the absence of cheek emargination. Differs from gymnarthids in the absence of bulbous dentition. Differs from microbrachomorphs including Hyloplesion and Microbrachis in having a co-ossified braincase region, with a robust cultiform process, and lacking anastomosing cranial ornamentation.

Comments. The 'microsaur' Odonterpeton triangulare (Moodie, 1909), was placed by Carroll and Gaskill (1978) into 'Microbrachomorpha'. However, the anatomy of this taxon has not been properly reassessed since, and thus comparisons between it and recumbirostrans are limited. Our own personal examination of original latex peels of Odonterpeton (created by the late Donald Baird) reveal general similarities in vertebral 
architecture and cranial morphology to recumbirostrans. Odonterpeton is small and bears the most similarity to juvenile molgophids and brachystelechids. There also appears to be a number of similarities between FMNH 1309 and Odonterpeton, including general size, widened parietals, large triangular shape of the parasphenoid, anterior position of the orbits, and short snout. These may indicate a close relationship between these two taxa; however, FMNH 1309 can at least be generically distinguished from Odonterpeton by a well-developed cheek region (which is reduced and likely emarginated in Odonterpeton), a large postfrontal, and rounded skull shape. Additionally, the anterior limbs in Odonterpeton are diminutive but well-ossified, whereas the anterior limbs of FMNH 1309 appear proportionally longer. 

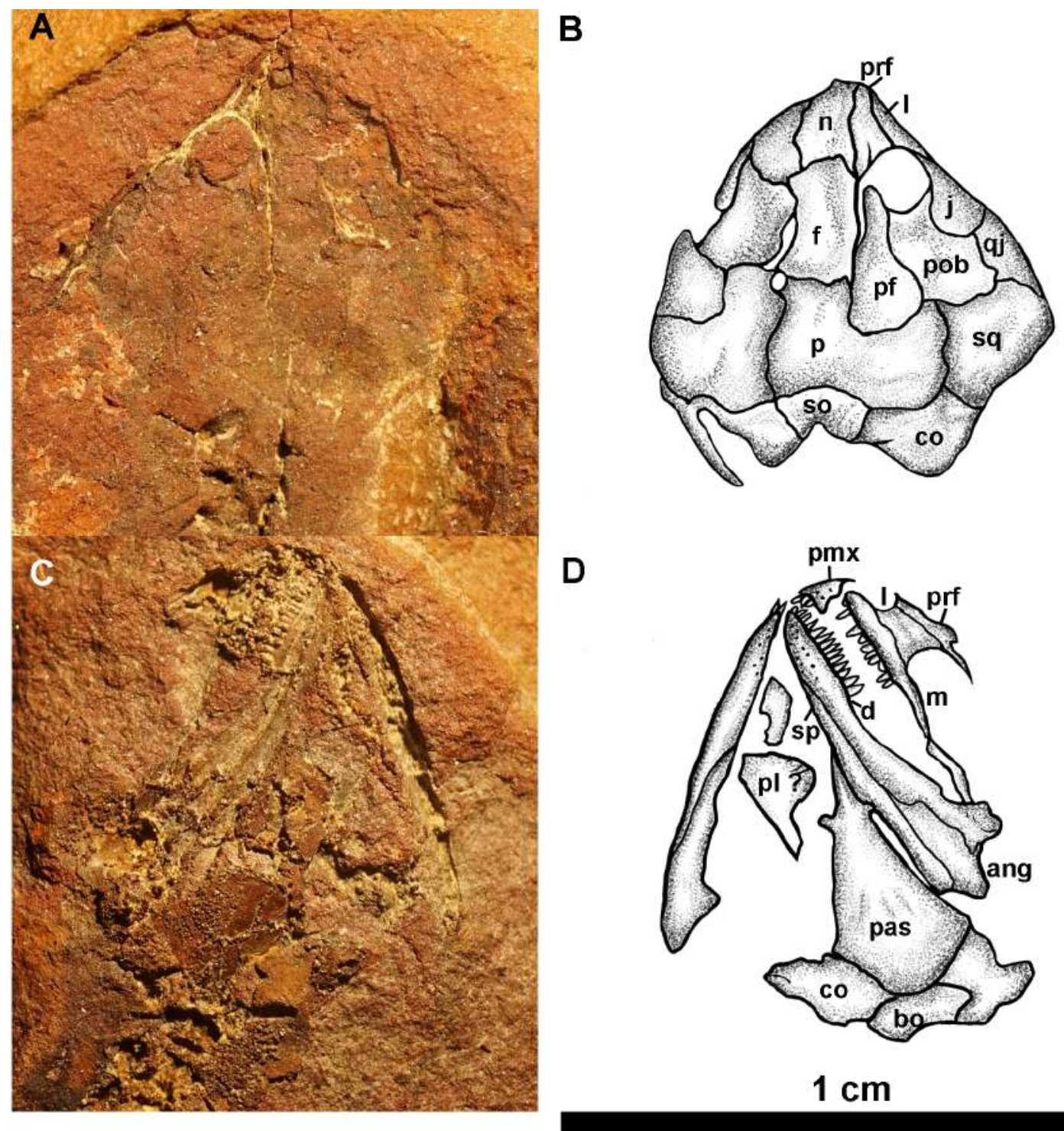

\section{$1 \mathrm{~cm}$}

Figure 5.3 Illustrations of the dorsal (A and B) and ventral (C and D) aspects of the skull of FMNH 1309. Illustrations have been digitally reversed in photoshop to show true anatomical orientations.

\subsection{Description}

\section{Cranial anatomy}

The dorsal cranium is well-preserved; however, it is folded-over on the left side revealing the right-lateral surface including the orbital and snout morphology (Fig. 5.3). The left orbit is not visible because it is hidden under the dorsal skull on that side. There is no cranial ornamentation present on the dorsal skull elements, which may indicate the animal is a juvenile (Mann, 2018). Like many recumbirostrans the entire skull is robust 
and somewhat rounded as the skull transitions from the dorsal to lateral surfaces. The dorsal outline of the cranium is roughly triangular. FMNH 1309 bears the most similarity in gross skull morphology to round-headed ecomorphs such as Carrolla and Cardiocephalus (Maddin et al., 2011; Mann et al., 2019).

The paired nasals are located at the anteriormost portion of the preserved dorsal skull and are rectangular in shape (Fig. 5.3). The right nasal is better preserved than the left, the latter of which is partially obstructed by the right nasal, but also appears to dip under the skull in this area. There is no indication that the dorsal surfaces of the nasals were invaded by the dorsal processes of the premaxillae. The nasals are longer than they are wide. They are shorter than the frontals in length but still quite wide posteriorly and taper slightly anteriorly. The nasals appear to curve ventrally along with the rest of the snout (ie. prefrontal, lacrimal).

The frontals are paired, rectangular, and isolated from the orbital margin by long anterior processes of the postfrontals and a smaller contribution from the prefrontals (Fig. 5.3). The morphology of the interfrontal suture cannot be discerned because the right frontal is slightly overlapping the left. However, it is likely that the suture was straight based on medial margins of the frontals that are visible. The frontals only very slightly expand in width posteriorly towards the parietals. The frontals contact the parietals at a simple, straight suture.

The parietals are paired, massive elements that are great in width and slightly longer in length than the frontals (Fig. 5.3). They are roughly rectangular, invaded anterolaterally by the main ramus of the postfrontal. A small pineal foramen is present between the two parietals and is anteriorly located similar to that in Diabloroter (Mann and Maddin, 2019). The large parietals are reminiscent of brachystelechids.

The occipital margin is round in shape. The occipital and otic elements are coossified into a single ossification (often called an os basale in brachystelechids), with only a distinct rectangular supraoccipital element visible. The ventral margin of the supraoccipital is excavated for the dorsal margin of the foramen magnum. The large coossified mass connects to the squamosals anterolaterally. The squamosals are large and irregularly-shaped elements. Each squamosal contacts the corresponding parietal 
medially at an undulating suture; anteriorly, there are also contacts with both the postorbital and quadratojugal creating a similarly undulating suture.

The postorbitals are large, quadrangular-shaped elements that are slightly expanded posteriorly (Fig. 5.3). Anteriorly, the postorbitals are excavated by the respective posterior orbital margins. Anterolaterally, the postorbitals are excavated by the jugals which invade the postorbitals at a rounded suture. A relatively expansive, subrectangular-shaped lateral exposure of the quadratojugal (equal in size to the jugal) is visible between the jugal and the squamosal on the right side of the cranium (Fig. 5.3). Also, on the right side of the cranium, a teardrop-shaped jugal is present, with a wide expansive ramus on the cheek that tapers to a small elongated anterior process. The anterior process of the jugal rests atop of the maxilla and smoothly attenuates atop the ventral process of the lacrimal forming most of the ventral border of the orbit.

The lacrimals are long and sub-rectangular in shape. They extend from the nares to the orbit where there are small dorsal and ventral orbital processes (Fig. 5.3). The lacrimals are visible in the dorsal profile on the right side of the skull and in lateral profile on the counterpart. Dorsal to the lacrimals are the prefrontals, represented on either side of the cranium. The right prefrontal is better represented, where it is seen to be a long, triangular-shaped element that leads into the nares at its narrowest point. There are prominent posterior processes on the prefrontals that meet the anterior processes of each postfrontal. Together these exclude the corresponding frontal from the dorsal orbital margin.

The upper jaw elements preserved include the maxilla and the premaxilla that are only preserved on the left side of the skull (Fig. 5.3). The maxilla is long, extending to just beyond the posterior limit of the orbit (Fig. 5.3). There is a low facial process and a long posterior process. Interestingly, the teeth do not extend onto the posterior process but rather extend from the anteriormost end to just below the orbit. There are approximately 11 to 12 tooth positions on the maxilla. The teeth that are in place are simple and conical in morphology. The premaxilla is only visible in lateral aspect revealing a slightly recurved dorsal process that is not flattened or as drastically recurved as in other recumbirostrans (Fig. 5.3). The dorsal process is also very short and likely did 
not extend onto the dorsal skull. The premaxilla appears to bear around 6 small tooth positions. The tooth morphology is the same as that of the maxilla.

The lower jaws are well represented on the counterpart showing the ventral aspect of the specimen, but also visible on part in left lateral view (Fig. 5.3). The dentaries are represented by both the right dentary in lateral aspect and the left dentary in ventral aspect. The anterior ramus of the dentary is long, and slender, and there is a raised coronoid process posteriorly. This process is comparable in height to that of some gymnarthrids such as Cardiocephalus (Carroll and Gaskill, 1978). The dentary appears ornamented with small innervation pits. The angular is preserved on the left lower jaw, but is not preserved well enough to discern its anatomy. A single long splenial is observed buttressing the dentary, best represented on the left lower jaw as well. There are 14 to 16 tooth positions preserved on the left dentary of FMNH 1309 (Fig. 5.3). Each tooth has a conical morphology with a simple point at the apex. Both the tooth rows of the dentaries and maxillae appear to be short in comparison with the length of each element, with preserved teeth occupying approximately only the anterior half of each element's length.

Preserved on the counterpart (ventral aspect), between the lower jaws, are elements of the palate and braincase (Fig. 5.3). Most of the palatal elements are not preserved well enough to confidently assign to a specific bone. There is a small, quadrangular element adjacent to the right dentary, but this element does not bear any distinguishing features. This element may either be the right palatine or ectopterygoid. A larger palatal element posterior to the unidentified element is likely part of the right pterygoid, and bears a process that is likely part of the quadrate branch of the pterygoid. Of the braincase there is a large parasphenoid with small basipterygoid processes and a somewhat short but thin cultriform process. Posterior to the parasphenoid there is a small quadrangular-shaped basioccipital preserved in the ventral aspect that is flanked by the co-ossified occipital elements on either side.

\section{Postcranial anatomy}

Nearly the entire postcranial anatomy is preserved in the part and counterpart (Figs. 5.1, 5.2), however, the distalmost area of the limbs are obscured by a dissolution 
gradient around the outer margins of the concretion. There are approximately 40 presacral vertebrae (Fig. 5.2). No atlas elements can be discerned, but the axis centrum is visible and is slightly expanded compared to the other cervical centra. Most of the dorsal vertebrae are of a typical recumbirostran morphology, being represented by robust quadrangular centra. The tail is markedly short compared to the length of the trunk with 17 caudal vertebrae that taper in size drastically to a very small terminal caudal vertebra. The dorsal ribs are well preserved and show a dicephalic rib head morphology. The dorsal ribs are thin and taper distally as in most recumbirostrans. Starting from the cervical region, the ribs gradually increase in length moving posteriorly down the axis before shortening in length again toward the sacral region. The caudal ribs are preserved up to the $10^{\text {th }}$ caudal vertebra. They are straighter than those of the dorsal vertebrae in their morphology and also decrease in length posteriorly.

The limb osteology is not particularly well-preserved but shows a left forelimb with a poorly-ossified humerus and an unidentified zeugopodial element (Fig. 5.2). Parts of the left and right hindlimb are preserved on either side. Overall the hindlimb appears better ossified than the forelimb. The femur is well-developed, long, and rod-like in shape. The tibia and fibula are also well-developed, but they are short and moderately bowed. On the left side there is a singular tarsal element. There may have been more of the pes ossified in life, but this is obscured by the dissolution artifact around the edges of the concretion. There is no ossification of the pectoral region whatsoever, and there is very little of the pelvic girdle which is only represented by a sliver of partial ilium.

\section{Soft tissue preservation and scales}

FMNH 1309 preserves a fair amount of soft tissue anatomy, including soft body impressions, a gastric bolus, and numerous scales of which the tissue composition is unclear (Figs. 5.1, 5.2). The integumentary impression of the body reveals a long, tubular body plan. There is a slight expansion in the width of the animal at the base of the skull, but otherwise there is no constriction in the cervical region. Instead, the integumentary impression is consistent in width from the cervical to sacral region (Fig. 5.2). The 
postcranial skeleton occupies approximately one-third of the body width. Integumentary impressions around the limbs show somewhat long limbs, despite being incompletely ossified. The short tail appears to be expanded and rounded, similar to the morphology of the tails of some modern geckos and some skinks, which use their tails for fat storage (Daniels, 1984; Bedford and Christian, 1996) (Fig. 5.2).

FMNH 1309 also preserves a full suite of dorsal, flank, and ventral scales. Scales are oval-shaped (wider than long) and arranged into linear rows that are overlapping, but not significantly so. Individual scales are small ( $\sim 500 \mu \mathrm{m}$ in width) and nearly impossible to see with the unaided eye. The scales are the same size, shape, and thickness on both dorsal and ventral parts of FMNH 1309. Similarly, there is little observable difference between anterior and posterior body scales. The scales possess a unique iteration of 'microsaurian' ornamentation (Fig. 5.2). Under a light microscope, the scales appear to have a clam shell-like ( $o r$ scallop-like) pattern on their surfaces caused by a series of longitudinal ridges that fan out slightly toward the lateral edges of each scale. There are no thickened or fimbriated regions on any of the scales, unlike those of some other 'microsaurs' (Carroll and Gaskill, 1978; pers. obs. A. Mann). The cranial scales of FMNH 1309 differ slightly from the trunk scales in that they are simply pitted and lack the raised ridges that form the patterns present on the body and appendicular scales (see Supplementary Information for SEM image of cranial scales).

Using scanning electron microscopy (SEM) we were able to observe ultrastructural details of the scales preserved in FMNH 1309 (Fig. 5.4). The SEM revealed a rugose texture of the longitudinal ridges and additional features in the trenches between (Fig. 5.4). Numerous tiny pits are seen within the floor of each trench. In many cases there is a single row of pits, but in some places the pits are more unevenly distributed resulting regions with partial double rows of pits between ridges.

Worthy of direct comparison are the full suite of scales found associated with a specimen referred to Hyoplesion (FMNH PR 981) - another exceptionally preserved 'microsaur' from Mazon Creek. The scales of FMNH PR 981 differ from those of FMNH 1309 in a few aspects, including their profile which is quadrangular and the orientation of the ridged ornamentation that is not aligned with the anteroposterior axis of the animal (Carroll and Gaskill, 1978). Differences in scale morphology, including ultrastructural 
anatomy likely reflect taxonomic differences among microsaurs and may be useful for species diagnoses.

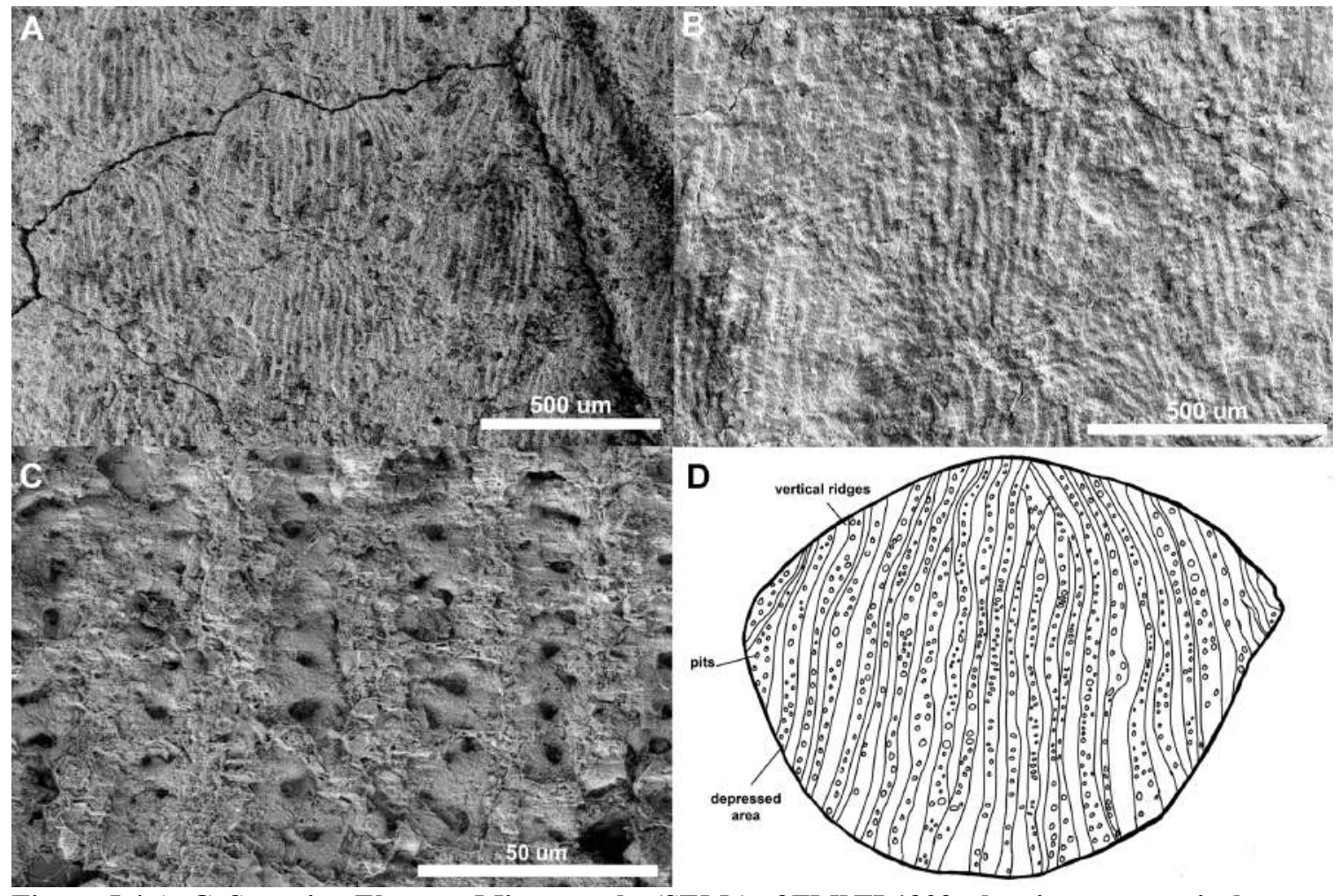

Figure 5.4 A-C, Scanning Electron Micrographs (SEMs) of FMNH 1309, showing progressively closer structures of the dermal scales. $D$, an idealised illustration of a single dermal scale (not to scale).

\subsection{Phylogenetic Analysis}

We explored the phylogenetic relationships of FMNH 1309 using a modified version of the recent matrix of Pardo et al. (2017; see Appendix C.1 for matrix), which provides the most up to date matrix for assessing recumbirostran interrelationships. The matrix used has been taxonomically modified in recent studies by Mann and Maddin (2019), Mann et al., (2019), and Gee et al., (2020). These modifications were retained in the current analysis. We performed a parsimony analysis using PAUP software v4.0b10 (Swofford, 2002) and Eusthenopteron was specified as the outgroup. We used the heuristic search option with the TBR search algorithm and 1000 random addition sequence replicates. Maxtrees was set at 10,000, and automatically increased by 100 . All characters were equally weighted. All multistate taxa were treated as polymorphic. All ambiguous character states were resolved using the ACCTRAN setting. Indices of 
goodness of fit of the character data to the topology (e.g., consistency index [CI], retention index $[\mathrm{RI}]$, rescaled consistency index $[\mathrm{RC}]$, and homoplasy index $[\mathrm{HI}]$ ) were calculated in PAUP. To assess support of internal nodes, bootstrap values were calculated using the fast-stepwise addition option.

The parsimony analysis recovered 18 most parsimonious trees (MPT), each with 1853 steps $(\mathrm{CI}=0.305 ; \mathrm{HI}=0.748 ; \mathrm{RI}=0.657 ; \mathrm{RC}=0.201)$. The strict consensus of the results recovered FMNH 1309 as sister taxon to the clade including all brachystelechids (Fig. 5). This relationship is supported by five characters: 13 state $=1,29$ state $=0,52$ state $=1,75$ state $=2$, and 267 state $=0$ (all character numbers refer to those used in the analysis of Pardo et al., 2017). All bootstrap values above 50\% are reported on Figure 5.5 . 


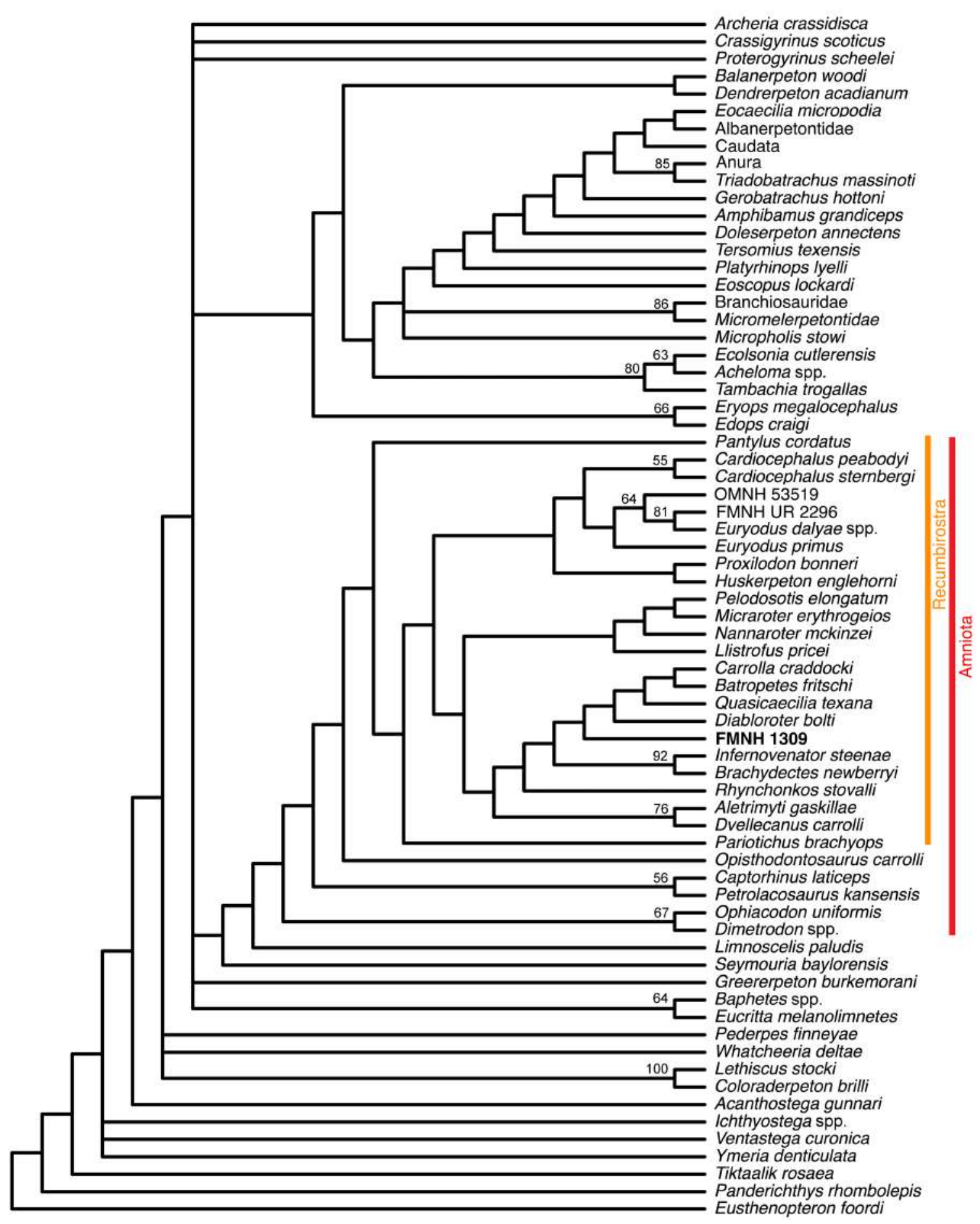

Figure 5.5 Results of the parsimony phylogenetic analysis showing the position of FMNH 1309 as sister taxon to all brachystelechids. Bootstrap values are located on top of nodes (only those over 50 reported). Total-group Recumbirostra indicated in orange and total-group Amniota is indicated in red. 


\subsection{Discussion}

\section{Homology and terminology of integumentary structures in Recumbirostra}

Despite the exceptional preservation of scales and other integumentary structures in a variety of Paleozoic tetrapod groups (e.g. temnospondyls, microsaurs, reptiles), rather few studies on the diversity and evolutionary importance of these structures exist (see Witzmann, 2007, 2011; Buchwitz et al., 2012). Witzmann (2007) and Hook (1983) provided useful discussions of the terminology applied to tetrapod scales and scale-like ossifications in the paleontological literature. These authors settled on a preferred terminology based on structural differences that is followed here: 'osteoderms', plate-like dermal ossifications that can bear pits on the outer surface; 'dermal scales', thinner than osteoderms but still composed of bone, ovular or round in profile, and can be overlapping; and 'gastralia', ventrally located elongate ossifications often collectively arranged into a chevron pattern. The thin, rod-like gastralia of early amniotes are likely derived from the dermal gastral scales of basal tetrapods (Baur, 1889; Voeltzkow and Döderlein, 1901; Romer, 1956; Witzmann, 2007). Furthermore, these are likely deeply homologous with the gastralia (gastral-ribs) in extant amniotes. In crocodilians and Sphenodon the gastralia develop within the dermis and are secondarily integrated during ontogeny into the abdominal musculature (Voeltzkow and Döderlein, 1901; Howes and Swinnerton, 1901; Claessens, 2004; but also see Hirasawa and Kuratani, 2015). The scales (dorsal, flank, and ventral) of many recumbirostran 'microsaurs' predominantly fall into the dermal scale classification, as they appear to be composed of bone, are thin, and arranged in overlapping clusters. However, the scales found on FMNH 1309 appear aberrant in their detailed ultrastructural morphology and in their preserved association with soft tissue impressions. As such, it is possible that these scales are keratinous. This would offer an explanation to the uncanny ultrastructural resemblances between these and other 'microsaur' scales (including Recumbirostra) and those of extant lepidosaurs (Ruibal, 1968; Jackson and Reno, 1975; Gans and Baic, 1977; Klein and Gorb 2014; Abdel-Aal, 2018). Alternatively, the scales of FMNH 1309 may represent a combination of bone and keratinous scale covering. This could explain the roughened texture of the ridges (maybe the keratinous portion) residing atop a pitted base (maybe the bone 
portion). Characterizing the histology of these recumbirostran scales may provide insights into the homology of integumentary structures in these animals; however, this remains a task yet to be completed. Additionally, given that only exceptionally preserved fossils from Permo-Carboniferous lagerstätten with unique preservation conditions retain evidence of in situ delicate integumentary structures, a rigorous analysis of the influence of taphonomy on scale composition and histology is required to confirm their homology.

\section{Evolution of integumentary patterns in Recumbirostra}

The abundance of scales preserved on 'microsaur' fossils led Carroll and Gaskill (1978) to comprehensively review the scale morphology of these animals. Generally, it seems likely that most 'microsaurs' were completely covered in dermal scales, including the dorsal, flank, and ventral regions, as well as the appendages (limbs and tail) (Fig. 5.6). Most scales that have been observed in 'microsaurs' bear some variation of ridge patterning, if not other ultrastructural details (e.g. pits, secondary ridges, tubercles), that are only visible with microscopy. Despite this, Carroll and Gaskill (1978) hypothesized that most microsaur scales were smooth and that the ridge patterns found on scales are internal structures that were only superficially exposed by either taphonomic forces, or wear. 


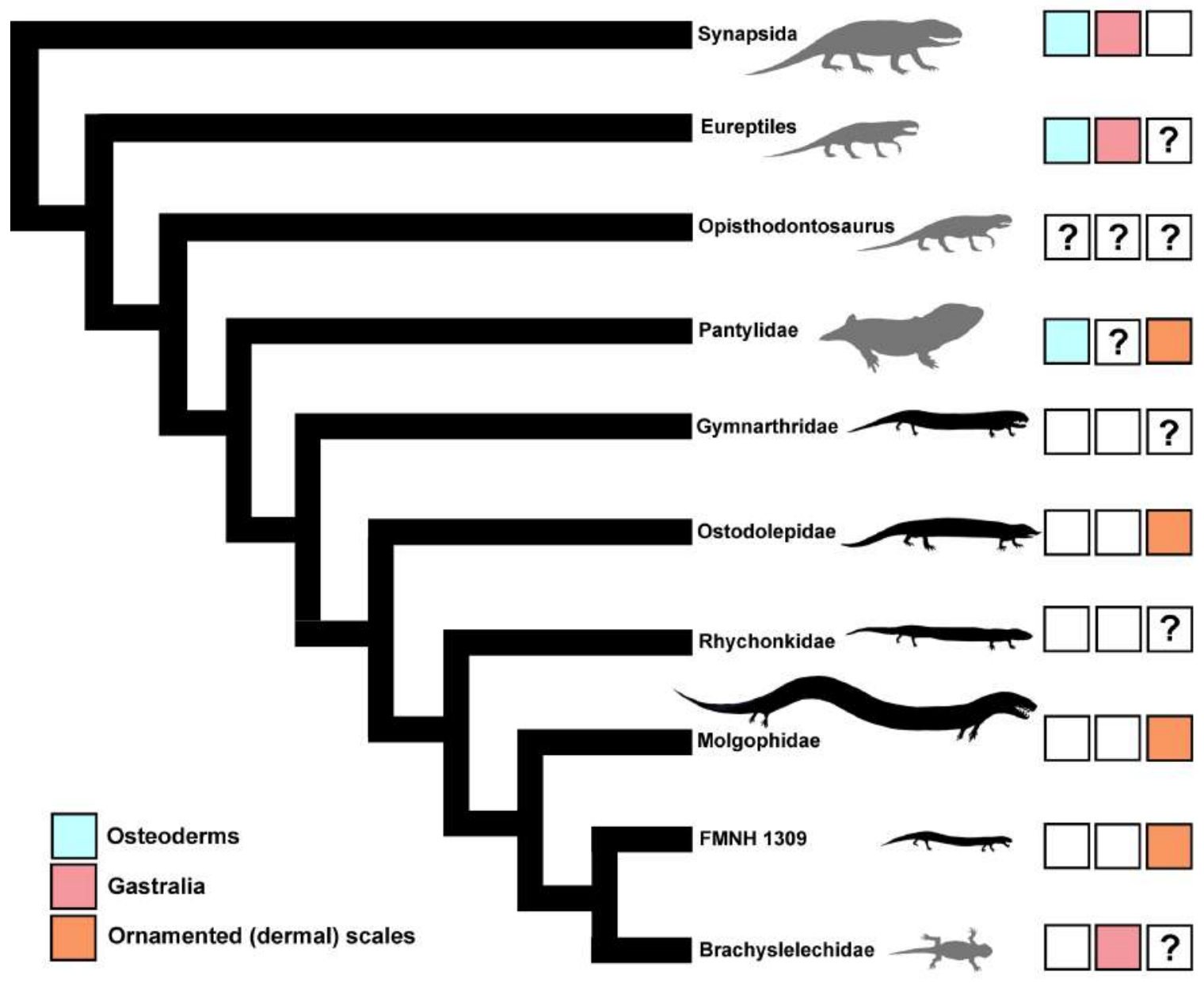

Figure 5.6 Simplified phylogeny of recumbirostrans showing integumentary structures and body elongation, (?) indicates uncertain states. Body elongation is indicated in silhouettes with grey=no body elongation; black=body elongation present.

Careful examination of the scales of both recumbirostrans and other 'microsaurs' reveals this is certainly not the case - the scales on FMNH 1309 are just one example to the contrary. Ornamented dermal scales are also well-represented on specimens of Microbrachis, Hyloplesion (at present including FMNH PR 981), Sparodus, Crinodon, Pelodosotis, Llistrofus (see Gee et al., 2019), among others. Comparatively, only a few temnospondyl groups have convergently evolved similarly ornate scales to those of microsaurs. Anastomosing longitudinal striae can be observed on micromelerpetontids and some amphibamiformes (Mann and Gee, 2020; Witzmann, 2007). Among fossorially-adapted recumbirostrans, such as FMNH 1309, it is possible that the distinct ridge patterns and other ultrastructural details are adaptations to burrowing where they 
would help shed substrate, similar to what is seen in extant fossorial reptile scales (Gans and Baic, 1977).

Carroll and Gaskill (1978) noted that there are likely systematic differences in scale morphology across the many microsaurian families. However, at the time the infrequent occurrence of scales allowed only for morphological descriptions and not for assessment of evolutionary patterns. What morphological patterns of scalature that can now be summarized for Recumbirostra are discussed here and reveal some clade level distinctions (Fig. 5.6). Early diverging, more generalised recumbirostrans such as Steenerpeton (formerly Asaphestera intermedia, see Mann et al., 2020) bear large, smooth, plate-like ovular scales that sometimes show concentric rings (possibly growth rings). This morphology is aberrant among recumbirostrans and may represent the plesiomorphic condition. Hapsidoparieontidids, which appear to occupy a basal position in recumbirostran phylogeny (Mann et al., 2019b; Gee et al., 2020), have scales known from Hapsidoparieon, Llistrofus, and Saxonerpeton. The ovular scales of Llistrofus (see Gee et al., 2019) are highly ornamented bearing ridges that form a radiating, clam shelllike pattern, sometimes with a bony webbing connecting ridges. The scales of Llistrofus can also bear a thicker raised margin on either of the anterior or posterior articulating ends. The scales of Crinodon appear morphologically similar to Llistrofus, however, placement of this microsaur is currently uncertain. Ostodolepids show interesting variations in scale morphology with very fine, 'matted' scales present on Pelodostis (see Fig. 130C from Carroll and Gaskill [1978]), whereas Micraroter (BPI 3839) bears very thick dermal scales that are even thicker on the ventral parts of the animal. Ornamentation may be present on these scales; however, they are not preserved well enough to parse out any details of the pattern.

Among the Cocytinoidea, brachystelechids and FMNH 1309 appear to bear similar types of dermal scales that are very thin with ridged ornamentation. Molgophids appear to also bear thin dermal scales, but the details of these are not well-preserved on any known specimen. Of the Pantylidae, Sparodus has the best examples of an ornate scale morphology consisting of fine ridges and perpendicular, evenly spaced, concentric circles. No specimen of Pantylus shows dermal scalation, save one specimen (FM UR 1069) that only bears fragments. However, given this specimen and that the other 
members of this clade possess scales, it is likely Pantylus did as well. Trachystegos is heavily scaled, although its referral to Pantylidae is at present questionable. Scales are not known in any member of the Rhynkonkidae, or curiously any member of the Gymnarthridae. Although scales are often found preserved alongside gymnarthrids at Joggins, their association with a gymnarthrid is not certain due to the fragmentary nature of microsaur material at the site and the presence of multiple tetrapods within a single stump. Furthermore, neither fossils of Cardiocephalus nor fossils of Euryodus preserve any remains of scales. Because ornamented scales phylogenetically bracket this group, it is likely that they were present in these animals as well and that the conditions where these fossils are found did not favour the preservation of such delicate structures.

The morphologies of both dorsal and ventral scales are identical to one another in FMNH 1309. Some recumbirostrans, however, show considerable variation in dermal scalation across the body, typically between the dorsal and ventral scales. For example, in Micraroter the ventral scales are considerably thickened in comparison to the dorsal scales. Ventral scale differentiation in these recumbirostrans are still dermal scale in origin and not homologous with gastralia. That being said, there are a few cases where amniote-like gastralia are found in recumbirostrans. The early recumbirostran Steenerpeton appears to bear a scattering of cylindrical gastralia. Similarly, gastralia are also present in articulation on the short-bodied brachystelechids, e.g. Diabloroter and Batropetes, where they appear as thin, cylindrical structures that are morphologically similar to the gastralia of basal amniotes (Mann and Maddin, 2019). Given revamped phylogenetic hypotheses that recumbirostrans are in fact amniotes descended from a captorhinid-like ancestor (Pardo et al., 2017), it is possible that recumbirostrans at some point had true gastralia (Figs. 5.5, 5.6). In this scenario basal recumbirostrans such as Steenerpeton would retain the plesiomorphic condition for Recumbirostra, whereas brachystelechids reveal a reversal possibly associated with a unique ecology (Fig. 5.6; Mann and Maddin, 2019). This starkly contrasts the hypothesis of Carroll and Gaskill (1978) who considered the order Microsauria to be stem-amniotes (Lepospondyli). In this scenario, their morphology was considered as derived from a basal tetrapod antecedent. In addition to dermal scales and gastralia, Carroll and Gaskill (1978) noted the presence of another kind of integumentary structure, bony 'ossicles' (a term used for 
small osteoderms), along the ventral regions of certain shorter bodied microsaurs (Fig. 5.6). Pantylus, Stegotretus, and Saxonerpeton all bear unique hexagon-shaped osteoderms that line the ventral pectoral region of the animal (Fig. 6). Personal examination of these ossicles on Pantylus, Stegotretus, and an unnamed pantylid from Nova Scotia, reveal a dense assembly of these osteoderms that form a mosaic within the inter-dentary space extending posterior to the pectoral girdle (when preserved). These ossicles bear resemblance to the inter-dentary osteoderms found on Tuditanus, Crinodon and Cardiocephalus and are likely homologous structures (Carroll and Gaskill, 1978). Carroll (1968) proposed these osteoderms were derived from the ventral gastralia, however, we note that these ventral scales are not morphologically (small ossicles in a mosaic) or positionally (pectoral to inter-dentary space) similar to ventral gastralia, and are likely instead independently derived ossifications.

Unlike other Permo-Carboniferous groups such as dissorophids (Witzmann, 2007), recumbirostrans do not possess 'bulky' or large osteoderms. This is likely due to the functional constraints associated with a fossorial lifestyle, where large osteoderms protruding from the dermis would hinder both the locomotion and flexibility needed to achieve burrowing. Instead the bodies of recumbirostrans such as FMNH 1309 appear from body outline impressions to have been streamlined, cylindrical, and relatively smooth (Fig. 5.7). Extant fossorial reptiles also have streamlined bodies that appear relatively smooth (e.g. amphisbaenians), lacking large osteoderms or other protruding keratinous scales or structures (Gans and Baic, 1977).

Finally, body-elongation associated with increased fossoriality is common among recumbirostrans (only absent in brachystelechids, pantylids, and basal recumbirostrans) and even reaches extreme lengths in molgophids such as Brachydectes (upto 99 presacral vertebrae). However, similar to the lack of osteoderms or 'bony-ossicles' in longer bodied recumbirostrans such as FMNH 1309 and molgophids, there is also an absence of gastralia (Fig. 5.6). Long-bodied recumbirostrans such as FMNH 1309 likely relied on lateral undulation or maybe some form of sidewinding (Catena and Hembree, 2014) as a locomotory mode, and a reduction of ventral ossifications including loss of the gastralia may have aided in providing flexibility to the ventrum (Fig. 5.6). 


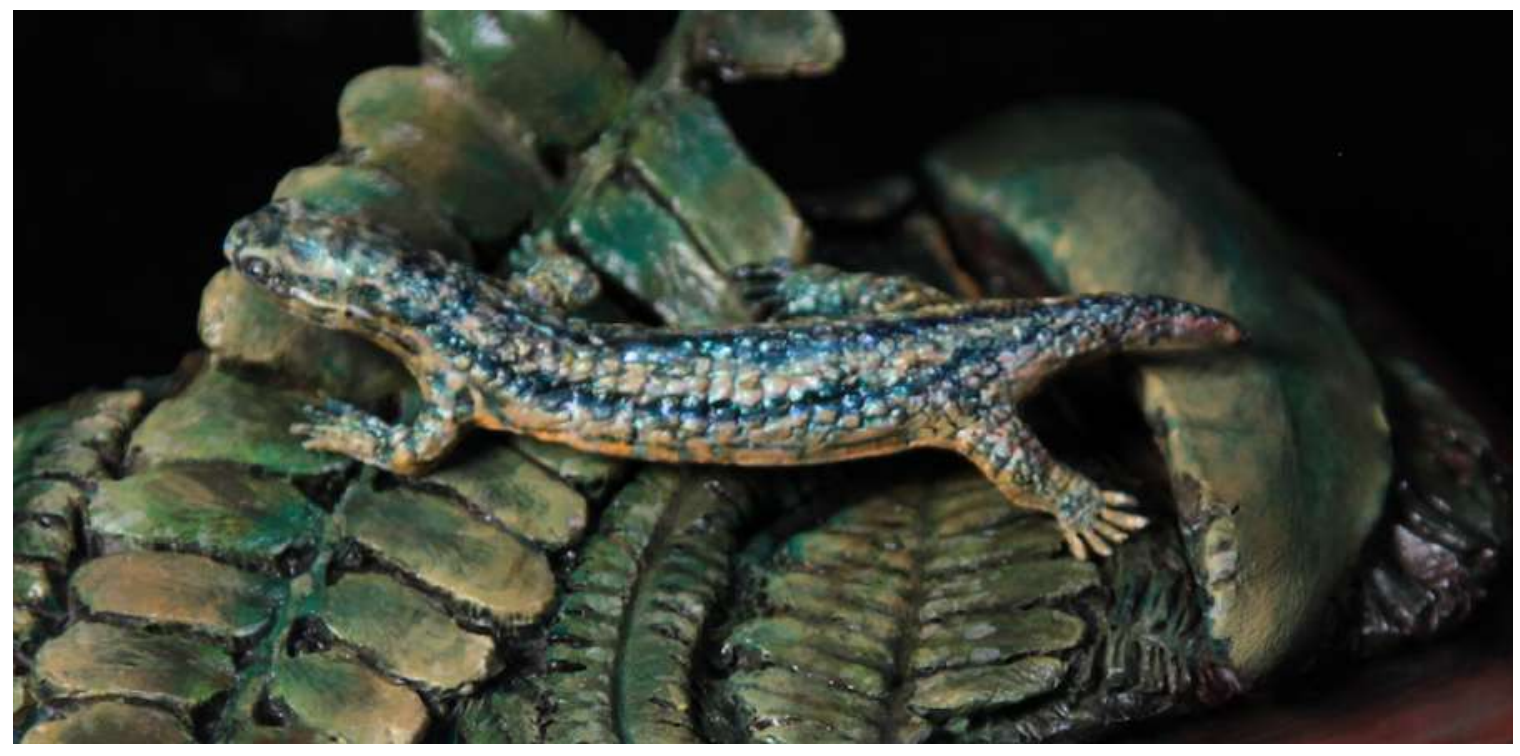

Figure 5.7 Flesh reconstruction of FMNH 1309. (sculpted by David Duck)

\subsection{Acknowledgements}

We would like to thank William Simpson, Adrienne Stroup, Diane Scott, Robert Reisz, Dave Berman, Amy Henrici, and Robert Hook for access to comparative material and specimens. We thank Ami S. Calthorpe, Emily J. McDaniel and Robert W. Hook for stimulating discussion. Additionally, we are indebted to Ami S. Calthorpe for her assistance with figures. Finally, we thank and are indebted to the late John R. Bolt for his kindness and generosity with sharing his knowledge and material.

\subsection{References}

Abdel-Aal, H. A. (2018). Surface structure and tribology of legless squamate reptiles. Journal of the mechanical behavior of biomedical materials, 79, 354-398.

Anderson, J. S. (2007). Incorporating ontogeny into the matrix: a phylogenetic evaluation of developmental evidence for the origin of modern amphibians; pp. 182-227 in J. S. Anderson and H.-D. Sues (eds.), Major Transitions in Vertebrate Evolution. Indiana University Press, Bloomington, Indiana. 
Ahlberg, P. E., \& Milner, A. R. (1994). The origin and early diversification of tetrapods. Nature, 368(6471), 507-514.

Baur G 1889. Palaeohatteria Credner, and the Proganosauria. American Journal of Science 37: 310-313.

Bedford, G. S., \& Christian, K. A. (1996). Tail morphology related to habitat of varanid lizards and some other reptiles. Amphibia-Reptilia, 17(2), 131-140.

Buchwitz, M., Witzmann, F., Voigt, S., \& Golubev, V. (2012). Osteoderm microstructure indicates the presence of a crocodylian-like trunk bracing system in a group of armoured basal tetrapods. Acta Zoologica, 93(3), 260-280.

Claessens LPAM 2004. Dinosaur gastralia; origin, morphology, and function. Journal of Vertebrate Paleontology 24: 89-106.

Catena, A., Hembree, D.I., 2014. Swimming through the substrate: the neoichnology of Chalcides ocellatus and biogenic structures of sand-swimming vertebrates. Palaeontologia Electronica, v. 17.3.37A, p. 1-19.

Castanet J, Francillon-Vieillot H, De Ricqlès A, Zylberberg L 2003. The skeletal histology of the Amphibia. In: Heatwole H, Davies M, eds Amphibian Biology, Vol. 5 Osteology. Chipping Norton: Surrey Beatty \& Sons, 1598-1683.

Daniels, C. B. (1984). The importance of caudal lipid in the gecko Phyllodactylus marmoratus. Herpetologica, 337-344.

Dunne, E. M., Close, R. A., Button, D. J., Brocklehurst, N., Cashmore, D. D., Lloyd, G. T., \& Butler, R. J. (2018). Diversity change during the rise of tetrapods and the 
impact of the 'Carboniferous rainforest collapse'. Proceedings of the Royal Society B: Biological Sciences, 285(1872), 20172730.

Gans, C., \& Baic, D. (1977). Regional specialization of reptilian scale surfaces: relation of texture and biologic role. Science, 195(4284), 1348-1350.

Gee, B. M., Bevitt, J. J., \& Reisz, R. R. (2020). Computed tomographic analysis of the cranium of the early Permian recumbirostran 'microsaur' Euryodus dalyae reveals new details of the braincase and mandible. Papers in Palaeontology (early view).

Gee, B. M., Bevitt, J. J., Garbe, U., \& Reisz, R. R. (2019). New material of the 'microsaur' Llistrofus from the cave deposits of Richards Spur, Oklahoma and the paleoecology of the Hapsidopareiidae. PeerJ, 7, e6327.

Hirasawa, T., \& Kuratani, S. (2015). Evolution of the vertebrate skeleton: morphology, embryology, and development. Zoological letters, 1(1), 2.

Howes GB, Swinnerton HH 1901. On the development of the skeleton of the Tuatara, Sphenodon punctatus with remarks on the egg, on the hatching and on the hatched young. Transactions of the Zoological Society of London 16: 1-86.

Hook, R. W. (1983). Colosteus scutellatus (Newberry): a primitive temnospondyl amphibian from the Middle Pennsylvanian of Linton, Ohio. American Museum novitates; no. 2770.

Huttenlocker, A. K., Pardo, J. D., Small, B. J., \& Anderson, J. S. (2013). Cranial morphology of recumbirostrans (Lepospondyli) from the Permian of Kansas and Nebraska, and early morphological evolution inferred by micro-computed tomography. Journal of Vertebrate Paleontology, 33(3), 540-552. 
Jackson, M. K., \& Reno, H. W. (1975). Comparative skin structure of some fossorial and subfossorial leptotyphlopid and colubrid snakes. Herpetologica, 350-359.

Jaekel, O. (1909). Über die Klassen der Tetrapoden [About the classes of the tetrapods]. Zoologischer Anzeiger 34:193-212.

Klein, M. C. G., \& Gorb, S. N. (2014). Ultrastructure and wear patterns of the ventral epidermis of four snake species (Squamata, Serpentes). Zoology, 117(5), 295314.

Laurin, M., \& Reisz, R. R. (1995). A reevaluation of early amniote phylogeny. Zoological Journal of the Linnean Society, 113(2), 165-223.

Mann, A. (2018). Cranial ornamentation of a large Brachydectes newberryi (Recumbirostra: Lysorophia) from Linton, Ohio. Vertebrate Anatomy Morphology Palaeontology, 6, 91-96.

Mann, A., Pardo, J. D., \& Maddin, H. C. (2019a). Infernovenator steenae, a new serpentine recumbirostran from the 'Mazon Creek'Lagerstätte further clarifies lysorophian origins. Zoological Journal of the Linnean Society, 187(2), 506-517.

Mann, A., \& Maddin, H. C. (2019). Diabloroter bolti, a short-bodied recumbirostran 'microsaur'from the Francis Creek Shale, Mazon Creek, Illinois. Zoological Journal of the Linnean Society, 187(2), 494-505.

Mann, A., McDaniel, E. J., McColville, E. R., \& Maddin, H. C. (2019b). Carbonodraco lundi gen et sp. nov., the oldest parareptile, from Linton, Ohio, and new insights into the early radiation of reptiles. Royal Society Open Science, 6(11), 191191. 
Mann, A., \& Gee, B. M. (2020). Lissamphibian-like toepads in an exceptionally preserved amphibamiform from Mazon Creek. Journal of Vertebrate Paleontology, e1727490.

Milner, A. R. (1987). The Westphalian tetrapod fauna; some aspects of its geography and ecology. Journal of the Geological Society, 144(3), 495-506.

Moodie, R. L. (1909). Carboniferous air-breathing vertebrates of the United States National Museum (Vol. 37).

Pardo, J. D., Szostakiwskyj, M., Ahlberg, P. E., \& Anderson, J. S. (2017). Hidden morphological diversity among early tetrapods. Nature, 546(7660), 642-645.

Pardo, J. D., Szostakiwskyj, M., \& Anderson, J. S. (2015). Cranial morphology of the brachystelechid 'microsaur' Quasicaecilia texana Carroll provides new insights into the diversity and evolution of braincase morphology in recumbirostran 'microsaurs'. PloS one, 10(6).

Pardo, J. D., \& Anderson, J. S. (2016). Cranial morphology of the Carboniferous-Permian tetrapod Brachydectes newberryi (Lepospondyli, Lysorophia): new data from $\mu \mathrm{CT}$. PloS one, 11(8).

Pardo, J. D., Small, B. J., Milner, A. R., \& Huttenlocker, A. K. (2019). CarboniferousPermian climate change constrained early land vertebrate radiations. Nature ecology \& evolution, 3(2), 200-206.

Reisz, R. R., LeBlanc, A. R., Sidor, C. A., Scott, D., \& May, W. (2015). A new captorhinid reptile from the Lower Permian of Oklahoma showing remarkable dental and mandibular convergence with microsaurian tetrapods. The Science of Nature, 102(9-10), 50. 
Romer A.S. 1956. Osteology of the Reptiles. Chicago: University of Chicago Press.

Ruibal, R. (1968). The ultrastructure of the surface of lizard scales. Copeia, 698-703.

Sahney, S., Benton, M. J., \& Falcon-Lang, H. J. (2010). Rainforest collapse triggered Carboniferous tetrapod diversification in Euramerica. Geology, 38(12), 10791082.

Szostakiwskyj, M., Pardo, J. D., \& Anderson, J. S. (2015). Micro-CT study of Rhynchonkos stovalli (Lepospondyli, Recumbirostra), with description of two new genera. PLoS One, 10(6).

Sues, H. D., \& Reisz, R. R. (1998). Origins and early evolution of herbivory in tetrapods. Trends in Ecology \& Evolution, 13(4), 141-145.

Taylor, T. N., \& Scott, A. C. (1983). Interactions of plants and animals during the Carboniferous. Bioscience, 33(8), 488-493.

Vaughn, P. P. (1962). The Paleozoic microsaurs as close relatives of reptiles, again. American Midland Naturalist, 79-84.

Voeltzkow A, Döderlein L 1901. Beiträge zur Entwicklungsgeschichte der Reptilien III. Zur Frage nach der Bildung der Bauchrippen. Abhandlungen der Senckenbergischen Naturforschenden Gesellschaft, 26: 313-336.

Witzmann, F. (2011). Morphological and histological changes of dermal scales during the fish-to-tetrapod transition. Acta Zoologica, 92(3), 281-302.

Witzmann, F. (2007). The evolution of the scalation pattern in temnospondyl amphibians. Zoological Journal of the Linnean Society, 150(4), 815-834. 


\section{| Chapter 6: A farewell to arms: a new molgophid reveals amniote-like limb loss in recumbirostrans}

\subsection{Authors and Addresses}

Arjan Mann, Jason D. Pardo, and Hillary C. Maddin

Department of Earth Sciences, Carleton University, 1125 Colonel By Drive, Ottawa, Ontario K1S 5B6, Canada.

Department of Comparative Biology and Experimental Medicine, University of Calgary, 3330 Hospital Drive NW, Calgary T2N 4N1, Canada.

McCaig Institute for Bone and Joint Health, University of Calgary, 3280 Hospital Drive NW, Calgary T2N 4Z6, Canada.

\subsection{Preface}

The following manuscript is formatted to be submitted for publication to the journal Nature ecology and Evolution. Arjan Mann was fully involved in setting up and conducting the research, preparing samples, running all analyses, developing methodology, writing the manuscript and drafting final figures in this co-authored article. Hillary C. Maddin provided discussion and editing of content. Jason D. Pardo assisted with comparative material, editing of content and provided discussion. The manuscript has been modified slightly to accommodate the formatting requirements for Carleton University dissertations.

\subsection{Abstract}

Among modern tetrapods, many lineages have converged on a snakelike body plan, where extreme axial elongation is accompanied by reduction or loss of paired limbs. However, the fossil record of how and when this adaptive strategy evolved in various tetrapod groups remains poorly understood. For example, limb reduction and loss is 
known in a handful of early, stem-group tetrapods and total-group lissamphibians, whereas the fossil record of limb reduction and loss within the amniote lineage is sparse. We here provide new insights into these questions by reporting on a new molgophid recumbirostran from the Francis Creek Shale (309-307 Ma) of Illinois, USA, that exhibits extreme axial elongation and corresponding limb reduction. The new molgophid, represented by two exceptionally-preserved specimens preserving complete body outlines, shows affinities with Brachydectes and Infernovenator. However, unlike in these taxa, the forelimb and pectoral girdle are entirely absent in the new molgolphid, thus representing the earliest occurrence of complete loss of a limb in a taxon recovered phylogenetically within amniotes. The presence of a complete hindlimb and pelvic girdle contrasts with the condition seen in limb-reduced amphibians and some limb-reduced reptiles, where there is a hindlimb-first reduction process that is characterized by the loss and/or reduction in size of hindlimb elements, and rudimentary pelvic girdle elements are often retained. Instead, the morphology of the new molgophid is consistent with a pattern of limb reduction that is seen in modern snakes, where the forelimb and pectoral girdle are lost first. In snakes the loss of the forelimb is caused by the failure to form a discrete forelimb field due to homogenous $T b x 5$ expression over the entire pre-cloacal flank region, rather than a discrete $T b x 5$ domain to signal forelimb bud initiation. The similar morphology between the new molgophid and snakes suggests a common limb-reduction mechanism may be operating more broadly across the amniote tree.

\subsection{Introduction}

The origin and refinement of the tetrapod limb is an important episode in the origin and evolution of terrestrial vertebrates. Although the tetrapod limb plays a central role in locomotion, reduction of the limb is a relatively common evolutionary event among extant tetrapods, with over 60 independent reductions of the limb in extant squamates alone, and a number of others among extant lissamphibians (Caldwell, 2003). In fact, several major tetrapod lineages (snakes, amphisbaenians, pygopodids, and dibamids among reptiles and caecilians among lissamphibians) display such extreme limb reduction that total loss of the limbs and associated girdle elements represent aspects of 
the characteristic body plan found in these lineages (Caldwell, 2003) - i.e. extreme axial elongation with reduced/lost limbs. This body plan is generally thought to represent a shift in locomotory environment, with elongate limblessness considered as an adaptation to fossoriality (Gans, 1973; 1975) or swimming (Caldwell, 2003). Thus, the evolution of this body plan is a major mode of ecomorphological diversification among tetrapods.

Despite the importance of limblessness in the diversity of modern tetrapods, such limb loss is phylogenetically restricted. The majority of acquisitions of the extreme axial elongation and limb reduced body plan are restricted to the Squamata, with possibly three independent origins in salamanders (Caudata) and a single origin at the base of caecilians (Gymnophiona). Several major tetrapod lineages, including mammals, chelonians, archosaurs, and anurans, completely lack representatives with this body plan. It is therefore unclear whether the lability within squamates and salamanders reflects an ancient adaptive mode within tetrapods or whether unique events in axial and appendicular skeleton evolution arose within these limb-reduced lineages. One way of testing this is to identify similar patterns of limb reduction and loss occur within different groups of limb-reduced taxa. Unfortunately, the evolution of limb loss is relatively rarely recorded in the fossil record. This is likely a function of preservation, as identifying elongate, limb-reduced forms in the fossil record requires relatively complete preservation of the pre-sacral vertebral column, as well as delicate limb elements which can be expected to be lost rapidly to decay. Thus, although elongate body plans are welldocumented in a range of fossil tetrapods, the acquisition of complete limb loss is very poorly documented. Definitive limb loss has been documented among total-group ophidians (Tchernov et al., 2000), aïstopod stem-tetrapods (Anderson, 2000, Pardo et al., 2017a), and adelospondyl stem-tetrapods (Andrews and Carroll, 1993), three lineages across a fossil tetrapod record of 370 million years of tetrapod evolution. In these cases, limbless tetrapods are difficult to place within limb-reduced diversifications, making it challenging to interpret complete limb loss in the context of ecomorphological adaptation.

We here report a new limbless tetrapod from the Carboniferous Francis Creek Shale of Mazon Creek, Illinois, USA, that exhibits complete loss of the forelimb and pectoral girdle. The new animal is identified confidently as a molgophid recumbirostran, 
a group of potential early stem-group reptiles, which is characterized by multiple origins of body elongation and digit reduction, but no record of limblessness to date. Exceptional soft tissue preservation and complete body outlines for two specimens representing two ontogenetic stages shows strong evidence for a complete lack of a pectoral skeleton and forelimb. Comparison of this morphology with other limb-reduced reptiles suggests a common mechanism for obtaining this form of limb loss may be operating more broadly across amniotes and/or their close relatives.

\subsection{Material and Methods}

Specimens were studied at the following institutions: American Museum of Natural History (AMNH), New York; Carnegie Museum of Natural History (CM), Pittsburgh; Field Museum of Natural History (FMNH), Chicago; Milwaukee Public Museum (MPM), Wisconsin; Canadian Museum of Nature (CMN), Ottawa; Redpath Museum (RM), Montreal; and Yale Peabody Museum (YPM), New Haven. Additional specimens from the Natural History Museum (NHMUK), London, and the Museum of Comparative Zoology at Harvard University (MCZ), Cambridge, MA, were studied from casts, latex peels, and the cited literature.

All specimens were photographed with a Nikon D700 Camera using an AF-S NIKKOR 24-85mm lens. Digital photographs were processed using Adobe Photoshop CS6. Figures were assembled using Adobe Illustrator CS6. Scanning Electron Microscopy (SEM) was performed on the skull and body of FMNH PR 1301 using a JEOL 6610LV SEM housed at the CMN.

\subsection{Systematic Paleontology}

Tetrapoda Jaekel, 1909

Recumbirostra Anderson, 2007

Molgophidae Cope, 1875 
gen. et sp. nov.

Zoobank LSID. Will be provided with publication.

Holotype. MPM VP359229.2, a virtually complete specimen of the anterior half of a skeleton (36 presacrals preserved) (in part and counterpart) (Figs. 6.1 AB and 6.2)

Referred material. FMNH PR 1301, a complete diminutive skeleton in part and counterpart (82-85 presacrals) (Figs. 6.3, 6.4, D.2 and D.3).

Etymology. Will be provided with publication.

Locality and Horizon. Mazon Creek, Grundy County, Illinois, USA. Francis Creek Shale above the Morris (no. 2) Coal, Carbondale Formation, Middle Pennsylvanian (Moscovian).

Differential Diagnosis. A molgophid recumbirostran diagnosed by a unique combination of characters: complete loss of forelimbs and pectoral girdle. Differs from Infernovenator, but shares with Brachydectes, a round-headed snout shape, absence of the postfrontal, and reduction of the lacrimal. Differs from Brachydectes in the complete absence of the forelimb and pectoral girdle. Differs from all recumbirostrans but shares with molgophids cheek emargination forming a bar-like tabular-squamosal complex.

Comments. The referred material, FMNH PR 1031, is a newly discovered, virtually complete juvenile lysorophian skeleton. FMNH PR 1031 was prepared by Eugene Richardson to reveal the hindlimb, including a femur, tibia, fibula, and near complete pes, but even with preparation there does not appear to be any trace of a forelimb of any state. On this basis, and on the basis of consistency in cranial morphology to the holotype, we refer FMNH PR 1031 to the new molgophid taxon (MPM VP359229.2). Often, Mazon Creek concretions are 'cleaned'. Cleaned concretions have had the kaolinite that infills impressions or bone space manually removed. FMNH PR 1031 is a prepared but 
'uncleaned' concretion. The bone space in FMNH PR 1031 is mostly infilled with framboidal pyrite, and a little bit kaolinite (see Appendix D.3). Pyrite has been shown to be associated with non-biomineralised tissues (Farrell, 2017) and we thus interpret that this animal is immature, at least likely neonatal, with little ossification at the time of death.

Forelimb reduction is also present in the contemporary (also from Pitt 11) Infernovenator steenae; however, the degree to which the forelimb is reduced is unclear due to the uncertain identification of a possible forelimb element in the single fossil known for that species (see Mann et al., 2019a). 


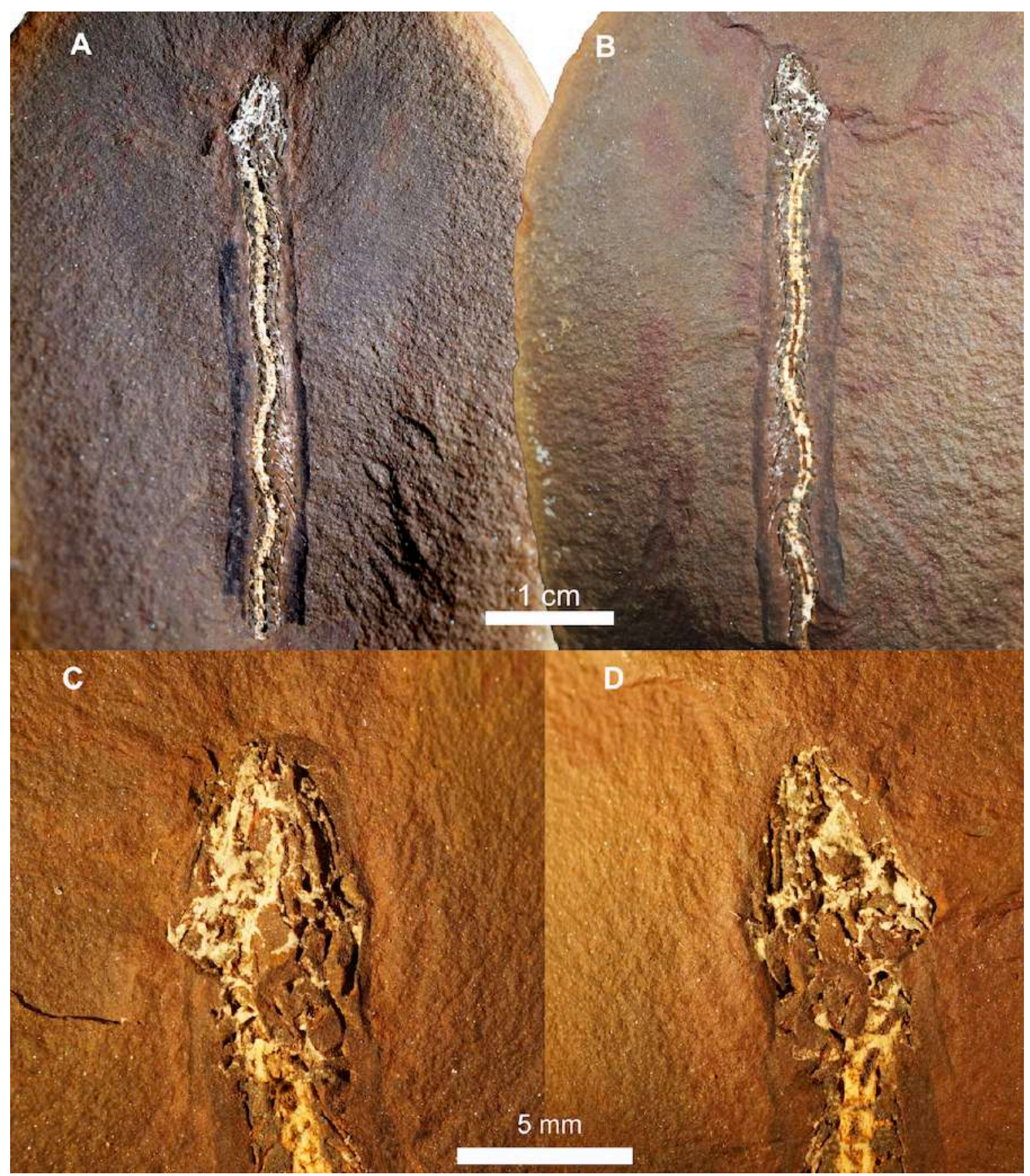

Figure 6.1 Photographs of the new molgophid (MPM VP359229.2). A and B, the entire holotype, MPM VP359229.2, part and counterpart, respectively. C and D, close up photographs of the skull in part and counterpart, respectively. 
A

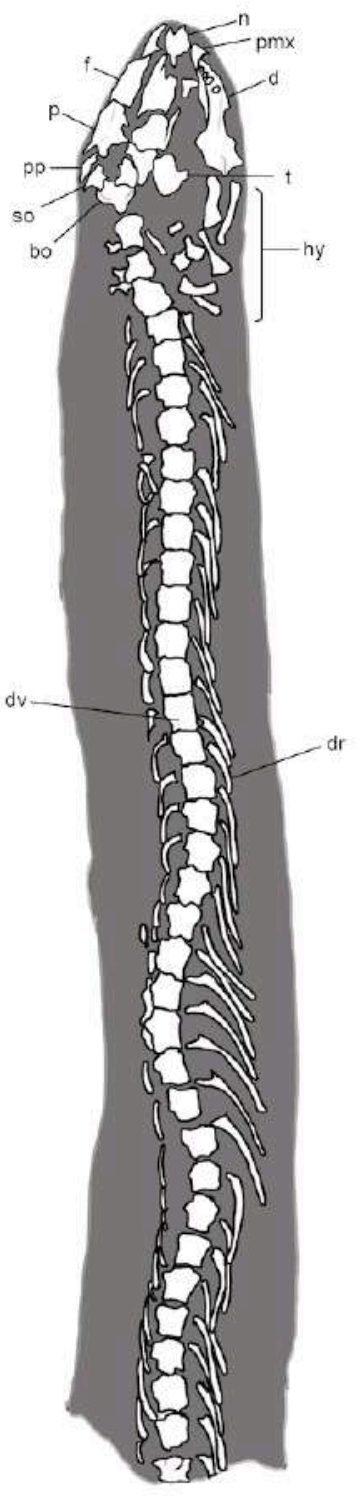

B

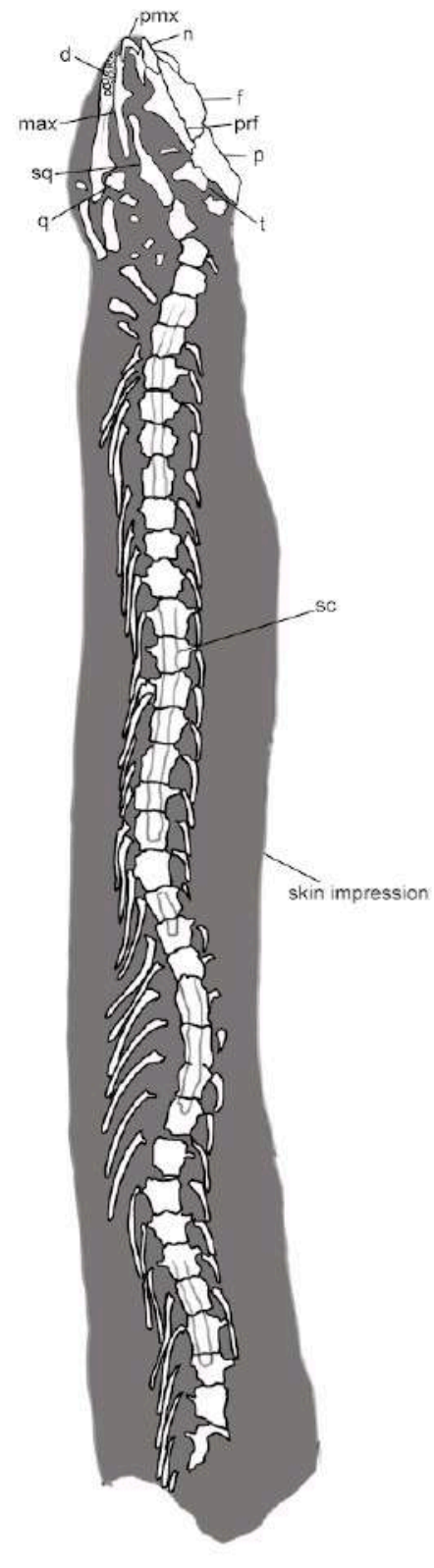

\section{$1 \mathrm{~cm}$}

Figure 6.2 Illustrations of the part A, and counterpart B, of the holotype of the new molgophid taxon (MPM VP359229.2). 


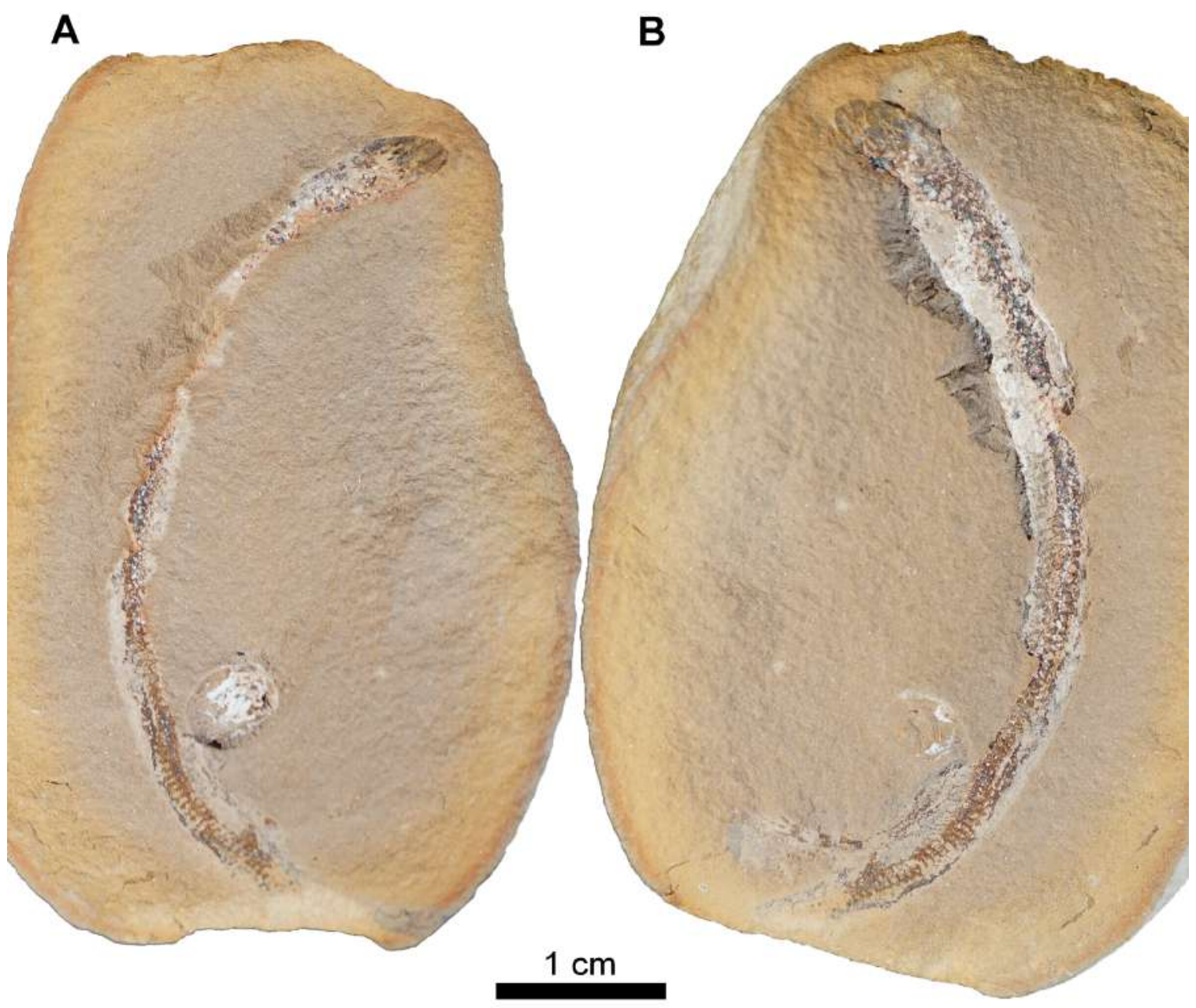

Figure 6.3 Photographs of the specimen FMNH PR 1301, that is referred to the new molgophid genus and species, revealing both part $A$, and counterpart $B$. 
A

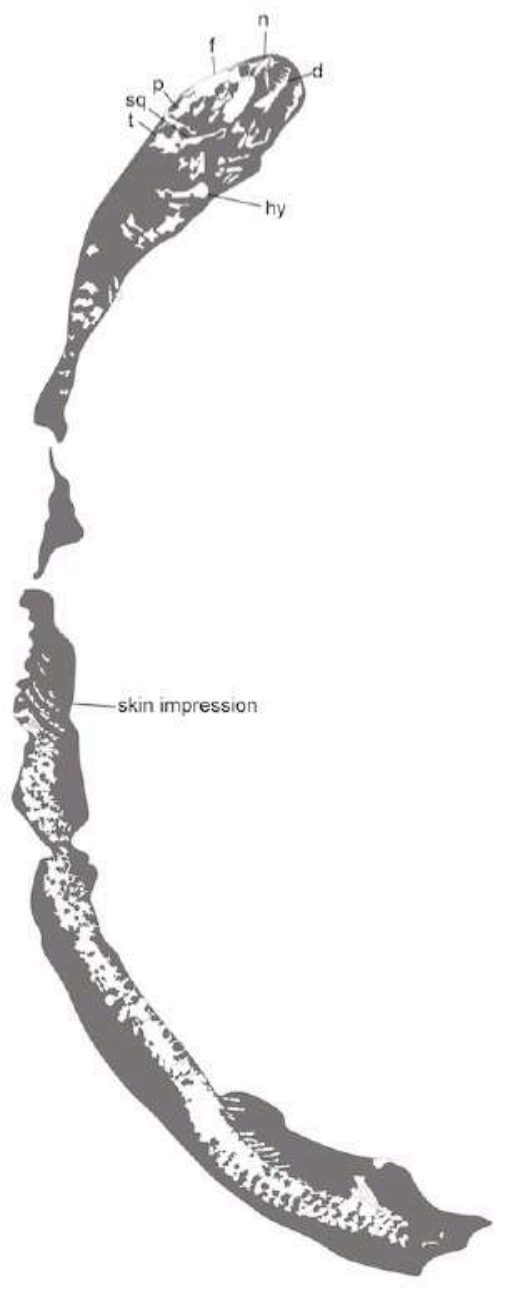

B

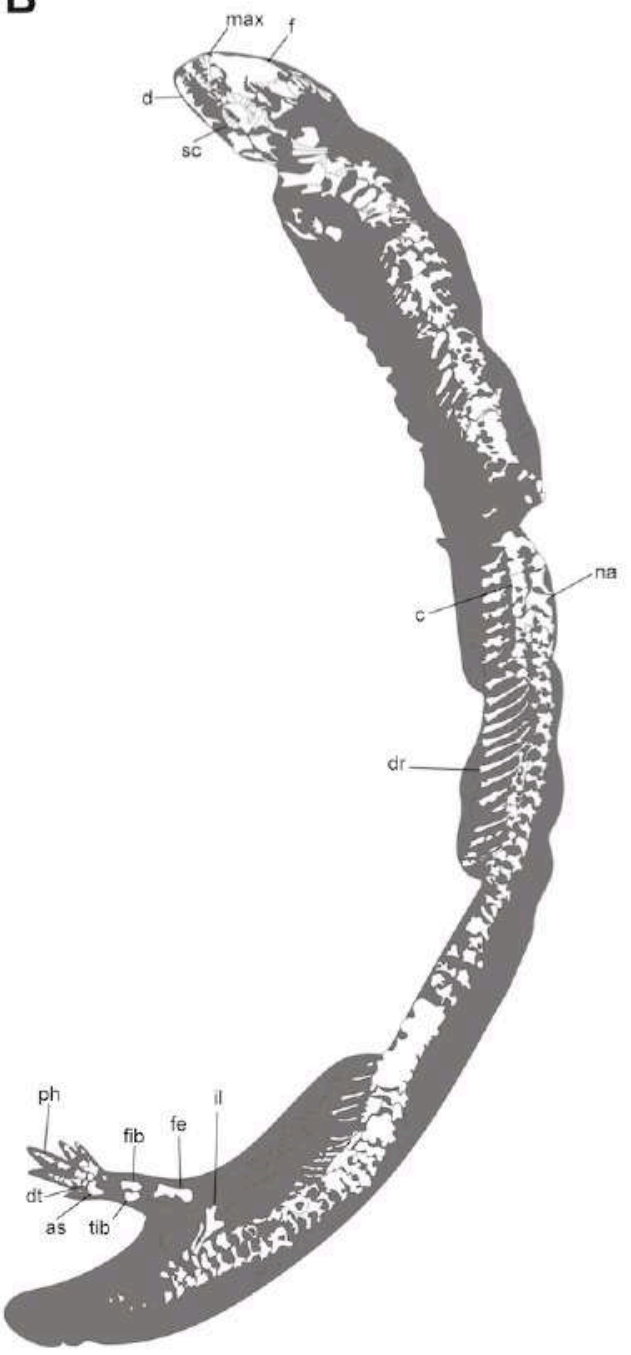

$1 \mathrm{~cm}$

Figure 6.4 Illustrations of the part A, and counterpart B, of the referred specimen (FMNH PR 1301) of the new molgophid.

\subsection{Descriptions}

\section{Description of MPM VP359229.2.}

MPM VP359229.2, the holotype specimen, consists of a skull and partial postcranial skeleton in part and counterpart (Figs. 6.1, 6.2). The cranium is somewhat difficult to decipher due to an uneven separation of elements on both part and counterpart. That is to say, the sides do not simply represent dorsal and ventral 
components as seen in some tetrapod concretions from Mazon Creek. Overall the gross morphology of the skull appears to be that of a round-headed fossorial ecomorph similar to Brachydectes (Pardo and Anderson, 2016) and differing from the shovel-headed ecomorph Infernovenator (Mann et al., 2019). Some of the dorsal skull elements visible include the right premaxilla, right maxilla, nasals, frontals, parietals, postparietals, right tabular-squamosal complex with quadrate, basioccipital, and right dentary.

The snout and orbital region are not constructed in the same way as Infernovenator. There is a substantially less-developed circumorbital series with no postfrontal, and a small lacrimal indicated by the adjoining process on the maxilla and prefrontal. Additionally, it appears that the narial opening would have been much larger than that in Infernovenator, but comparable to that in specimens of Brachydectes. The maxilla is very thin, with a long anterior process, a small thin medially located facial lamina, which likely articulated with the lacrimal, and a long and equally thin posterior process that terminates at the level of the posterior end of the frontal. The prefrontal is morphologically identical to that of Brachydectes, where it is a long element that reaches the external nares anteriorly, and the anterolateral margin of the parietal posteriorly. The prefrontal extends anteriorly with a process pinching ventrolateral that likely met a reduced lacrimal.

The premaxilla is short and has a rounded dorsal process. There also is a welldeveloped thin lateral process that articulates with the maxilla. Laterally the premaxilla is well excavated showing that there would have been a large narial opening. The nasals curve ventrally at their anterior extent where they meet the premaxilla. The nasals are short, square to diamond-shaped elements that meet the frontals at an interdigitating suture. The frontals are long rectangular elements that are thinner but approximately the same length as the parietals. The parietals are relatively large rectangular sheets that appear unornamented. The parietals are similar in proportion to Brachydectes, but slightly larger than those present in Infernovenator. The tabular is somewhat plate-like and subrounded in its dorsal exposure. The squamosal is long and rodlike as in all known lysorophians and is connected with the tabular, by a lateral lappet on that element. The jaw articulation is visible in partial articulation with a small quadrangular quadrate. 
The only teeth preserved on MPM VP359229.2 are on the right dentary and maxilla, although the latter is not well preserved. The dentary tooth row is short and bears 7 to 8 tooth positions as in most known specimens of Brachydectes. Although the postdentary bones appear to be present, no sutures can be identified.

Posteroventral to the skull, the suspensorium is well represented by at least four rod-like hyobranchial elements. Their precise identity is uncertain. There is no indication of any forelimb or pectoral elements of any kind. Additionally, the well-preserved body impression around the cervical region shows no signs of soft tissue structures, including any belonging to forelimbs, that are commonly seen in other Mazon Creek tetrapods, even when osteology is not well represented (Milner, 1982; Godfrey 1997; Mann and Maddin, 2019, Mann et al., 2019a, Mann et al., 2019b).

The postcranial anatomy is well-preserved showing a body impression and approximately 36-37 presacral vertebrae with articulated dorsal ribs. The axial column is only partially represented (36 presacrals), and cannot be directly compared to the total counts for Infernovenator (61 presacrals) or Brachydectes (up to 99 presacrals). Part and counterpart appear to have been unevenly separated, with elements of the skull, both dorsal and ventral, visible on both parts, whereas the vertebrae appear to be cracked down the middle in places, exposing pyritized remnants of the spinal cord (Fig. 6.2). The vertebrae are holopondylous and typically lysorophian in morphology in that they are cubic in dorsal/ventral view and bear a rounded, ventral keel. There are small transverse processes preserved in articulation with dorsal ribs. Where visible, the dorsal profile of the vertebrae shows paired low neural spines. The dorsal ribs are dicephalous, in addition to possessing a small distal expansion commonly seen in molgophids, particularly in larger individuals of Brachydectes (Wellstead, 1991; Pardo and Anderson, 2016). The ribs are slender, strongly recurved, and lengthen towards the mid-region. The ribs and vertebral column occupy approximately $1 / 3$ the total space of the preserved soft tissue impression.

\section{Description of FMNH PR 1031.}

FMNH PR 1031, a referable juvenile specimen is by far the more complete of the two known specimens of the new molgophid (Figs. 6.3, 6.4). Support for a neonatal state 
of FMNH PR 1031 is reinforced by its exceptionally small size at approximately $54 \mathrm{~mm}$ in length and only $4 \mathrm{~mm}$ at its widest. Comparatively, adult specimens of Brachydectes can reach almost $1 \mathrm{~m}$ in length (pers. obs. A. Mann). Similar to all lysorophians, the specimen has a highly elongated body and proportionally small limbs. The skull is small and its outline is confluent with the width of the body posteriorly, as indicated by the preserved soft tissue impression. FMNH PR 1031 preserves substantial remains of soft tissue in addition to the skeleton. The body outline is preserved in both part and counterpart, with some infilling of kaolinite. The ventral portion of the torso preserves numerous small, dark, ovoid-shaped structures that we interpret as scales. It is unclear whether these scales are keratinous scales or ossified structures, but ossified scales appear to be absent in all known molgophids (Wellstead, 1991), suggesting that these scales were likely keratinous. Gill filaments, commonly seen in larval temnospondyls from Mazon Creek (Milner, 1982; Godfrey, 2003), are completely absent. There is no evidence of lateral line canals in the skull or postcranium, although these are only intermittently preserved in Mazon fossils (contrast Milner, 1982 with Sallan and Coates, 2014). Soft tissue preserved around the digits of the hindlimb shows clear separation of digits, suggesting that there was no interdigital webbing. There is no evidence of yolk, either internalized or external. Traces of yolk sacs are present in some embryonic chondrichthyans (Sallan and Coates, 2014) and coelacanths (Balon, 1991) from Mazon Creek, and so would be expected to be preserved had a yolk sac been present.

The skull is partially preserved although weakly ossified. The dorsal portion of the head region is darkly stained in both part and counterpart. Paired rectangular structures represent centers of ossification for the frontals, parietals, and postparietals, but are difficult to discern from the surrounding hematite staining of oxidized organic material that makes up most of the head. Scanning electron microscopy shows that the posterior skull roof is only weakly ossified, with much of the region being occupied of pyrite frambules indicative of soft tissue decay (Allison and Briggs, 1993; Briggs, 2003) (see Appendix D.3).

A thin, partially-ossified, strip of bone cants anteriorly in the region of the suspensorium. Given the shape, orientation, and position, this is likely an early 
ossification center of the squamosal. Anterior to the squamosal, a small triangular element may be a maxilla. A dentary is present with 5-8 simple conical teeth exhibiting typical pleurodont implantation. Teeth are narrower and needle-like than those in larger juveniles and adults, where the teeth are somewhat swollen. The dentary is notched posteriorly where it contributes to the margin of the mandibular fenestra. A faint trace of bone suggests a possible ossification of the splenial. Otherwise, postdentary bones are not preserved. A faint outline of Meckel's cartilage suggests it is completely unossified.

The hyobranchial apparatus is found posterior to the skull, at the position of the third through seventh vertebrae. It is preserved as several nondescript bar-like structures, which may be ossified or simply cartilaginous. External gills and branchial denticles are completely absent. The quality of preservation of FMNH PR 1031, the posterior position of the hyobranchial apparatus, and the presence of external gills in other Mazon Creek tetrapods (Milner, 1982; Godfrey, 2003) is strong evidence that gills of any sort were completely absent in FMNH PR 1031, and thus likely absent in molgophids at all posthatching stages of development.

An estimated 82-85 presacral vertebrae are present. Arches and centra are both present and tightly associated, although not sutured as in larger juveniles and adults. Neural arches are more completely ossified anteriorly, with clear pre- and postzygopophyses and a tall, narrow neural spine. Posteriorly, the spine is less welldeveloped, but the pre- and post-zygopophyses are still clearly seen in articulation. Centra are anteroposteriorly short and tightly packed as in late-stage embryos and neonates of modern amniotes (Rieppel, 1993; Sheil, 2005; Roscito and Rodrigues, 2012) in contrast to relatively blocky and widely-spaced centra seen in larval salamanders (Boisvert, 2008), Paleozoic temnospondyls (Milner, 1982, Godfrey, 1993) as well as discosauriscid stem-amniotes (Klembara and Janiga, 1993). It appears that the elongated spool-like morphology of the typical lysorophian centrum must have arisen later in postnatal ontogeny. No intercentra are present. Posterior to the sacrum, four caudal vertebrae appear ossified, although the outline for the tail extends posteriorly. The first three preserve both neural arch and centrum, but the last preserves only a weak trace of 
ossification within the neural arch. Ribs are present, thin, elongated, and weakly ossified.

The pelvic girdle and hindlimb of the new molgophid are only known from the referred specimen, FMNH PR 1031. Ossifications of the ilium and pubis are present. The ilium is long and extends posterodorsal at presacral positions 82-85. Ventrally, the ossification of the ilium is weakly concave to form part of the acetabular surface. The pubis is a short rod-like element directly anteroventral to the acetabulum and may participate in it. The hindlimb consists of a femur, tibia, fibula, metatarsals, tarsals, and four digits. The tibia and fibula are equally well-ossified. The distal tarsal elements of the ankle are also well-ossified. In addition, a large well-ossified calcaneus and a single small ossified anterior element (here interpreted as the astragalus) are present in the proximal ankle. Four digits are preserved and likely was so in life as no impressions of a fifth can be seen. The digital formula appears to be 2-3-4-3. The last digit is substantially more well-ossified than the anteriormost digit, suggesting the presence of post-axial dominance of hindlimb ossification.

\subsection{Phylogenetic analysis}

We explored the phylogenetic relationships of the new molgophid, using a modified version of the recent matrix of Pardo et al., (2017; see Appendix D.1 for matrix), which provides the most up to date matrix for assessing recumbirostran interrelationships. The matrix used has been taxonomically modified from recent studies by Mann and Maddin (2019), Mann et al., (2019a), and Gee et al., (2019) (see Supplementary Information file for details). These modifications were retained in the current analysis. We performed parsimony analysis using PAUP software v4.0b10 (Swofford, 2002) with Eusthenopteron specified as the outgroup. We used the heuristic search option with a TBR search algorithm and performed 1000 random sequence additions. Maxtrees were set at 10,000 and automatically increased by 100. All characters were equally weighted. All multistate taxa were treated as polymorphic. All ambiguous character states were resolved using the ACCTRAN setting. Indices of goodness of fit of the character data to the topology (e.g., consistency index [CI], retention index [RI], 
rescaled consistency index [RC], and homoplasy index [HI]) were calculated in PAUP. To assess support of internal nodes, bootstrap values were calculated using the faststepwise addition option. The new taxon was coded as a composite (MPM VP359229.2 and FMNH PR 1301) to achieve the most comprehensive character sampling.

The parsimony analysis recovered 18 most parsimonious trees (MPT), each with 1853 steps $(\mathrm{CI}=0.305 ; \mathrm{HI}=0.784 ; \mathrm{RI}=0.661 ; \mathrm{RC}=0.202)$. The strict consensus of the results recovered the new molgophid taxon as sister taxon to Infernovenator steenae, to the exclusion of Brachydectes newberryi (Figs. 6.5-6.6). The sister taxon relationship between the new molgophid taxon and Infernovenator steenae is supported by character 59 state $=1$ (all character numbers refer to those used in the analysis of Pardo et al., 2017). The position of Brachydectes is supported by character 1 state $=2$; character 24 state $=1$; character 165 state $=0 / 1$; character 358 state $=1$ (Fig. 6.5). For a full distribution of bootstrap values supporting these relationships refer to figure 6.5 . 


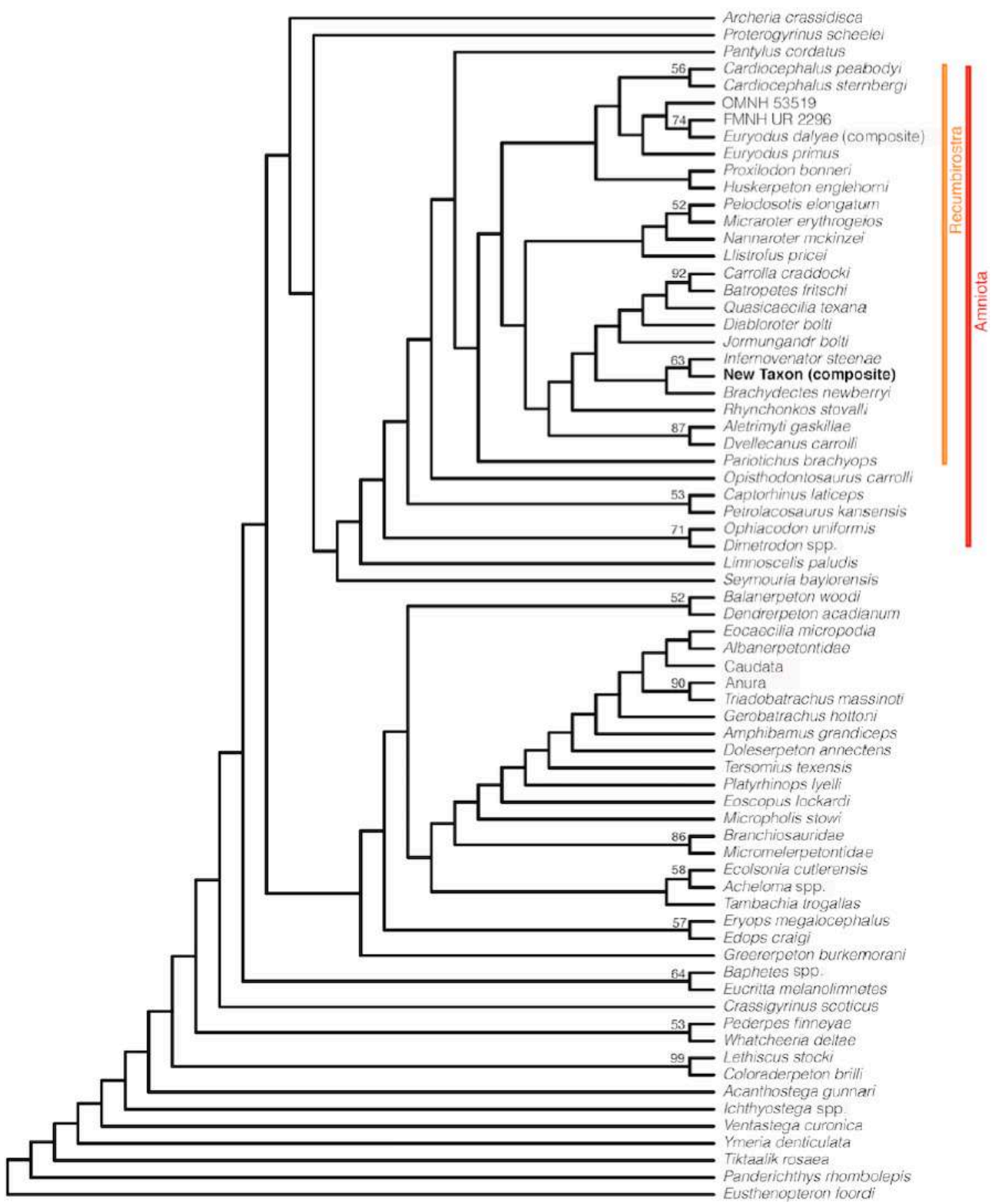

Figure 6.5 Results of the phylogenetic parsimony analysis showing the position of the new molgophid as sister taxon to Infernovenator. Bootstrap values are located on top of nodes (only those over 50 reported). Total-group Recumbirostra indicated in orange and total-group Amniota is indicated in red. 


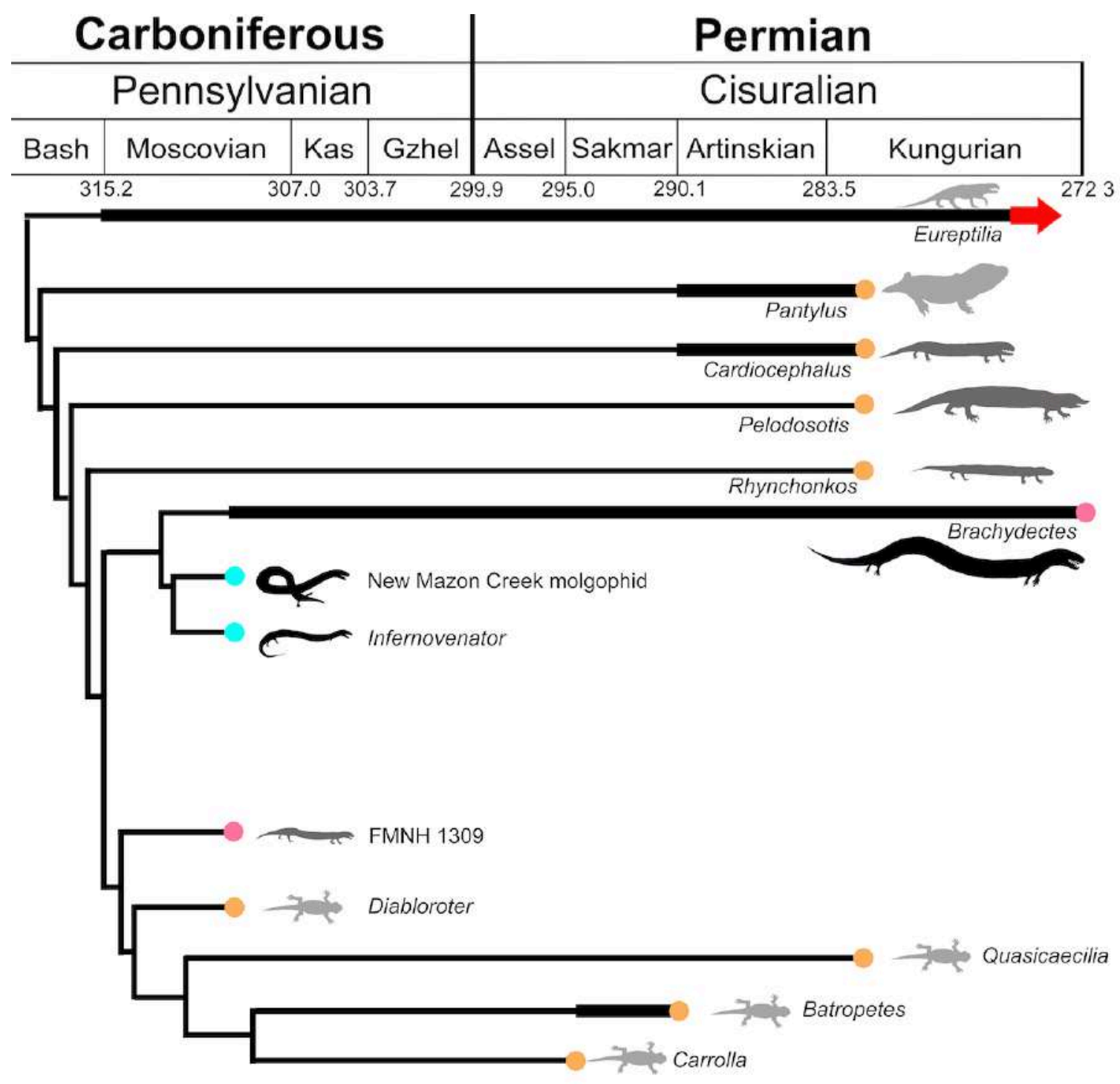

Figure 6.6 Simplified time-calibrated phylogeny of recumbirostrans showing limb reduction and body elongation. Limb reduction is indicated by coloured dots on terminal branches, pale orange=indicates no reduction; pink=slightly reduced limbs (including digital reduction); light blue $=$ fore or hindlimb absence or extreme limb reduction. Body elongation is indicated in silhouettes with light grey=no body elongation; dark grey=slight elongation; black=extreme body elongation.

\subsection{Discussion}

\section{Molgophids and the ecological diversity of the Mazon Creek Tetrapoda}

The new molgophid taxon is the second definitive molgophid and the fifth recumbirostran identified from Mazon Creek. It is also the first recumbirostran represented by more than a single specimen at Mazon Creek. This supports previous 
work showing that recumbirostrans were highly diverse within the Mazon Creek assemblage (Mann and Maddin 2019; Mann et al., 2019a) and, if considered to be amniotes (Pardo et al., 2017), recumbirostrans made up the majority of pan-amniote diversity within that fauna (Fig. 6.7). This is consistent with the suggestion of Mann et al., (2020) that the Pennsylvanian amniote fauna was already dominated by a diverse assemblage of recumbirostran forms with clear adaptations to fossoriality.

A

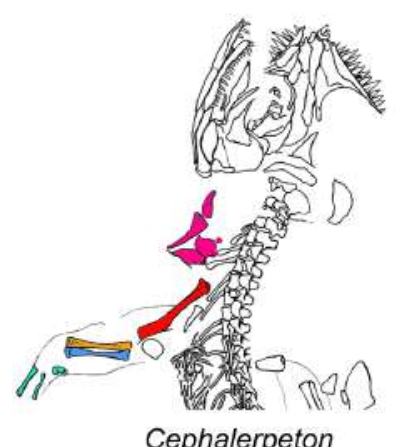

Cephalerpeton
B

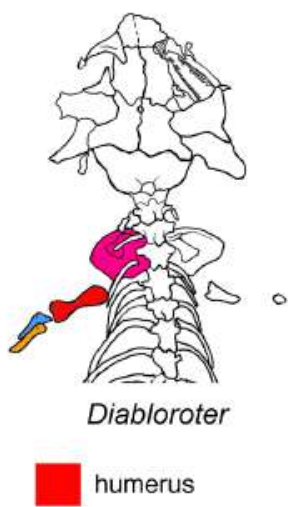

C

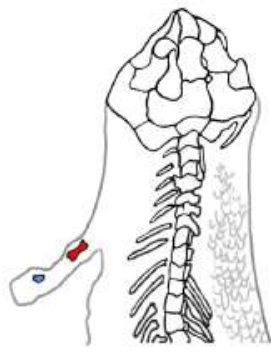

FMNH 1309
D

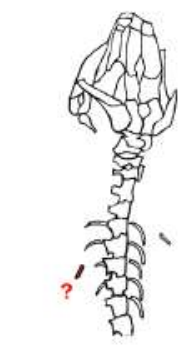

Infernovenator

E

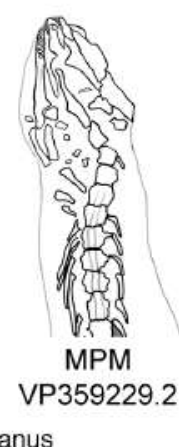

Figure 6.7 Comparative pectoral and forelimb morphology of Mazon Creek amniotes and amniotelike taxa. Note the diverse ecomorphology of the Mazon Creek pan-amniote fauna revealing a range of well-developed (Cephalerpeton) to completely absent forelimb morphology (MPM VP359229.2).

The inclusion of Recumbirostra in Amniota (Pardo et al., 2017) reveals a greater diversity of amniote bauplans than previously recognized appearing rapidly after the midCarboniferous origin of the clade (Figs. 6.5, 6.7). The Mazon Creek record of amniotes demonstrates this diversity, with the presence of generalized ecomorphs (Cephalerpeton), short-bodied forms (Diabloroter), and long-bodied forms with reduced limbs (FMNH 1309, Infernovenator, MPM VP359229.2) (Figs. 6.6, 6.7). The new molgophid taxon further adds another facet to early amniote ecomorphology, showing highly derived modifications for fossorial lifestyle, including the complete loss of forelimbs and body elongation (Fig. 6.7). Such morphological innovations are only paralleled by the contemporaneous limbless aïstopods among Paleozoic forms, although it remains unclear whether aïstopods were fossorial or whether limb reduction in this lineage was associated with aquatic-based anguilliform locomotion. Aïstopods were recently recovered deep on the tetrapod stem (Pardo et al., 2017), thus demonstrating greater ecological 
experimentation among Devono-Carboniferous tetrapodomorphs than previously acknowledged. Additionally, several other early tetrapod groups show some form of limb-reduction (e.g. digit reduction, shortening of limb elements) that relate to unique ecologies, including nectrideans and adelogyninids. Therefore, when these observations are combined, it is evident that early ecomorphological diversity and niche-space occupancy in the terrestrial realm has been understated.

When considering ecological diversity at the Mazon Creek lagerstatte, the wellsampled strip-mine locality of Pitt 11 provides the most comprehensive dataset. Historically, part of the 'Essex fauna', the Pitt 11 locality represents a marine-influenced, estuarine paleoenvironmental setting that is dominated by an aquatic fauna including a mix of marine and freshwater invertebrates and fish. Mazon Creek tetrapod fossils, especially highly terrestrial forms such as Cephalerpeton and Diabloroter are believed to have been washed-out from terrestrial environments by seasonal flooding and storm related activity (Feldman et al., 1993; Cunningham and Dickson, 1996; Clements et al., 2018). Whereas temnospondyls like Amphibamus are also likely part of this wash-out fauna, the many diverse 'larval' forms abundant at Pitt 11 were likely living in the freshwater portions of these more distal environments (Mann and Gee, 2020; Milner, 1982).

Among total-group tetrapods preserved at Pitt 11, the most diverse clades are the aïstopods and molgophid recumbirostrans. In terms of relative abundance, the fauna is overwhelmingly dominated by aïstopods with dozens of concretions having been identified. From Pitt 11 records exist for the aïstopods Phlegethontia, Pseudophlegethontia and Oestocephalus (Carroll, 1998; Anderson, 2002, 2003). The diversity and high abundance of aïstopods may indicate these animals either preferred living in soft, muddy substrate in near shore environments or were aquatic. Although molgophids are not nearly as abundant (total number $=4$ ) as aïstopods (total number $=80+$ ), they are equally as diverse - Infernovenator (Mann et al., 2019a), the new molgophid (FMNH 1301) and Brachydectes (Wellstead, 1991). Pardo and Anderson (2016) provided anatomical support from the cranium and suspensorium for a terrestrial lifestyle of molgophids, differing from prior interpretations of being aquatic by Wellstead 
(1992). This would mean the molgophids that are present were washed in from the terrestrial environments, similar to other recumbirostrans. Despite this, contention still remains with the existence of possible 'aestivation' assemblages of molgophids in Permian-aged deposits that may support a soft sediment burrowing ecology along the margins of aquatic environments (Olson, 1939; Olson, 1971). The seemingly strict preservation taphofacies at Mazon Creek may preclude ever knowing if molgophids exhibited any aestivation behaviour at this locality.

\section{Multiple paths to limb reduction in recumbirostrans.}

The complete absence of limb and girdle rudiments in the pectoral region of the new molgophid permits some speculation about the mechanisms responsible for limblessness in this taxon, and thus the diversity and distribution of limb-reduction mechanisms present among early tetrapods. Limb development can be divided into several phases. First, early patterning within the lateral plate mesoderm specifies a field of limb precursor tissues which will condense to form a limb bud. Second, morphogenesis and patterning within the limb bud drives specification of the proximaldistal and anterior-posterior compartments of the limb as well as condensation of chondrocyte precursors within those compartments. Finally, the initiation of osteogenesis within the diaphysis of the cartilaginous skeletal scaffold triggers the organization of the metaphyseal chondrocytes into a zonal transit amplification system, with a putative stem cell niche (resting zone), transit amplifying population (proliferative zone) and differentiating population (hypertrophic zone) - a system known as the epiphyseal growth plate (Mizuhashi et al., 2018; Marchini and Rolian 2018; Rolian 2020). Production of chondrocytes within the epiphyseal growth plate is responsible for the majority of longitudinal growth of the skeletal element.

Although the mechanisms of limb reduction in many tetrapod lineages remain incompletely understood, it appears that limb reduction and loss can be accomplished by failures or disruptions to normal development during any of the three phases of limb development, each with its own distinct morphological outcome. Disruptions to growth plate development, particularly the rate of longitudinal growth or timing of growth plate 
closure, are most common, and typically lead to conditions where the majority of limb elements are retained but are reduced in overall size (e.g. in mice, Weir et al., 1996, Terpstra et al., 2003). Disruptions in limb morphogenesis and patterning will often result in loss of distinct limb modules, commonly the loss of entire digits (Shapiro et al. 2003) but also the loss of other distal (but not proximal) elements, including carpals and/or tarsals (Leal and Cohn, 2016, 2018; Lande, 1978). Failure in the early establishment of the limb field is relatively rare. This is the mechanism identified as resulting in the loss of the pectoral limb and girdle and associated musculature in caecilians and snakes (Woltering et al., 2009).

Although failures in the initial patterning of the embryonic limb characterizes the two most diverse lineages of limbless tetrapods (Woltering et al., 2009), this mechanism is relatively rare in comparison to the more frequently-observed disruptions of later limb patterning and growth that is seen in both extinct and extant taxa (e.g. living skinks, Crassigyrinus, aïstopods; Anderson, 2002, 2003; Shapiro et al., 2003; Shapiro, 2012; Lande, 1978; Herbst and Hutchinson, 2019). The absence of forelimbs and pectoral girdle elements in the new molgophid suggests that a similar mechanism to that operating in snakes and caecilians may have been responsible for the complete loss of the forelimb, thus expanding the evolutionary range. Interestingly, reduction in overall limb size and reduction in digit number are common phenomena among recumbirostrans (Figs. 6.66.7)(Carroll and Gaskill 1978). Some of the earliest snakes (Tchernov et al., 2000) and caecilians (Jenkins et al., 2007) also exhibit progressively reduced limbs prior to complete loss in their evolutionary histories. This suggests reduction of digit number and element size through modest disruptions of limb development may be a prerequisite for complete disruption of limb bud formation. The progressively non-functional limb that would result from modest reductions would free the limb field from developmental constraint and thus perturbations to its specification would not be deleterious.

Finally, the presence of diverse limb-reduced and axially-elongated forms, including forms like the new molgophid taxon with complete forelimb loss, at the base of Amniota supports the idea that limb reduction and axial elongation is an ancestral adaptive mode for amniotes, and possibly tetrapods. This is supported by the realization 
that limbless forms, such as the aïstopod Lethiscus, were products of the initial Devonian diversification of tetrapods (Pardo et al., 2017) and suggests that the absence of serpentine body forms in several extant clades (anurans, mammals, archosaurs, chelonians) may be the product of developmental or evolutionary constraints within those groups. For example, it has been proposed that persistence of the forelimb in all modern mammal lineages may be a side effect of constraints on the diaphragm, which is derived in part from the limb field (Hirasawa and Kuratani, 2013). If so, early tetrapods may have shown similar lack of constraint on limb loss to that seen in modern squamates and salamanders.

\subsection{Acknowledgements}

We would like to thank Patricia Coorough Burke, Diane Scott, Robert Reisz, Dave Berman, Amy Henrici, and Robert Hook for access to comparative material and specimens. We would like to thank Bryan Gee and Ami Calthorpe for stimulating discussions. Finally, we thank Ami Calthorpe for her tireless assistance with assembling figures.

\subsection{References}

Anderson, J. S. (2002). Revision of the aïstopod genus Phlegethontia (Tetrapoda: Lepospondyli). Journal of Paleontology, 76(6), 1029-1046.

Anderson, J. S. (2003). A new aïstopod (Tetrapoda: Lepospondyli) from Mazon Creek, Illinois. Journal of Vertebrate Paleontology, 23(1), 79-88.

Andrews, S. M., \& Carroll, R. L. (1991). The order Adelospondyli: Carboniferous lepospondyl amphibians. Earth and Environmental Science Transactions of The Royal Society of Edinburgh, 82(3), 239-275.

Balon, E. K. (1991). Probable evolution of the coelacanth's reproductive style: lecithotrophy and orally feeding embryos in cichlid fishes and in Latimeria chalumnae. Environmental Biology of Fishes, 32(1-4), 249-265. 
Caldwell, M. W. (2003). " Without a leg to stand on": on the evolution and development of axial elongation and limblessness in tetrapods. Canadian Journal of Earth Sciences, 40(4), 573-588.

Clements, T., Purnell, M., \& Gabbott, S. (2019). The Mazon Creek Lagerstätte: a diverse late Paleozoic ecosystem entombed within siderite concretions. Journal of the Geological Society, 176(1), 1-11.

Cunningham, C. R., \& Dickson III, E. D. (1996). Distributions of Kansas PermoCarboniferous vertebrate assemblages as a function of wet and dry seasons. Transactions of the Kansas Academy of Science (1903), 16-28.

Farrell, Ú. (2014). Pyritization of Soft Tissues in the Fossil Record: An Overview. The Paleontological Society Papers, 20, 35-58. doi:10.1017/S1089332600002795.

Feldman, H. R., Archer, A. W., Kvale, E. P., Cunningham, C. R., Maples, C. G., \& West, R. R. (1993). A tidal model of Carboniferous Konservat-Lagerstätten formation. Palaios, 8(5), 485-498.

Gans, C. (1973). Locomotion and burrowing in limbless vertebrates. Nature, 242(5397), 414-415.

Gans, C. (1975). Tetrapod limblessness: evolution and functional corollaries. American Zoologist, 15(2), 455-467.

Head, J. J., \& Polly, P. D. (2015). Evolution of the snake body form reveals homoplasy in amniote Hox gene function. Nature, 520(7545), 86-89.

Herbst, E. C., \& Hutchinson, J. R. (2019). New insights into the morphology of the Carboniferous tetrapod Crassigyrinus scoticus from computed tomography. Earth and Environmental Science Transactions of the Royal Society of Edinburgh, 109(1-2), 157-175. 
Hirasawa, T., \& Kuratani, S. (2013). A new scenario of the evolutionary derivation of the mammalian diaphragm from shoulder muscles. Journal of anatomy, 222(5), 504517.

Jenkins, P. A., \& Walsh, D. M. (1993). An Early Jurassic caecilian with limbs. Nature, $365(6443), 246-250$.

Klembara, J., \& Janiga, M. (1993). Variation in Discosauriscus austriacus (Makowsky, 1876) from the Lower Permian of the Boskovice Furrow (Czech Republic). Zoological journal of the Linnean Society, 108(3), 247-270.

Lande, R. (1978). Evolutionary mechanisms of limb loss in tetrapods. Evolution, 32(1), 73-92.

Leal, F., \& Cohn, M. J. (2016). Loss and re-emergence of legs in snakes by modular evolution of Sonic hedgehog and HOXD enhancers. Current Biology, 26(21), 2966-2973.

Leal, F., \& Cohn, M. J. (2018). Developmental, genetic, and genomic insights into the evolutionary loss of limbs in snakes. Genesis, 56(1), e23077.

Mann, A., \& Maddin, H. C. (2019). Diabloroter bolti, a short-bodied recumbirostran 'microsaur' from the Francis Creek Shale, Mazon Creek, Illinois. Zoological Journal of the Linnean Society, 187(2), 494-505.

Mann, A., Pardo, J. D., \& Maddin, H. C. (2019a). Infernovenator steenae, a new serpentine recumbirostran from the 'Mazon Creek' Lagerstätte further clarifies lysorophian origins. Zoological Journal of the Linnean Society, 187(2), 506-517.

Mann, A., McDaniel, E. J., McColville, E. R., \& Maddin, H. C. (2019b). Carbonodraco lundi gen et sp. nov., the oldest parareptile, from Linton, Ohio, and new insights into the early radiation of reptiles. Royal Society Open Science, 6(11), 191191. 
Mann, A., \& Gee, B. M. (2020). Lissamphibian-like toepads in an exceptionally preserved amphibamiform from Mazon Creek. Journal of Vertebrate Paleontology, e1727490.

Mann A., Gee B. M., Pardo J. D., Marjanovic D., Adams G. R., Calthorpe A. S., Maddin H. C., and Anderson J. S. (2020). Reassessment of historic 'microsaurs' from Joggins, Nova Scotia, reveals hidden diversity in the earliest amniote ecosystem. Papers in Palaeontology (early view).

Marchini, M., \& Rolian, C. (2018). Artificial selection sheds light on developmental mechanisms of limb elongation. Evolution, 72(4), 825-837.

Mizuhashi, K., Ono, W., Matsushita, Y., Sakagami, N., Takahashi, A., Saunders, T.L., Nagasawa, T., Kronenberg, H.M. and Ono, N. (2018). Resting zone of the growth plate houses a unique class of skeletal stem cells. Nature, 563(7730), 254-258.

Olson, E. C. (1971). A skeleton of Lysorophus tricarinatus (Amphibia: Lepospondyli) from the Hennessey Formation (Permian) of Oklahoma. Journal of Paleontology, 443-449.

Olson, E. C. (1939). The fauna of the Lysorophus pockets in the Clear Fork Permian Baylor County, Texas. The Journal of Geology, 47(4), 389-397.

Pardo, J. D., Szostakiwskyj, M., Ahlberg, P. E., \& Anderson, J. S. (2017a). Hidden morphological diversity among early tetrapods. Nature, 546(7660), 642-645.

Rieppel, O. (1993). Studies on skeleton formation in reptiles. V. Patterns of ossification in the skeleton of Alligator mississippiensis Daudin (Reptilia, Crocodylia). Zoological Journal of the Linnean Society, 109(3), 301-325.

Roscito, J. G., \& Rodrigues, M. T. (2012). Skeletal development in the fossorial gymnophthalmids Calyptommatus sinebrachiatus and Nothobachia ablephara. Zoology, 115(5), 289-301. 
Rolian, C. (2020). Endochondral ossification and the evolution of limb proportions. Wiley Interdisciplinary Reviews: Developmental Biology, e373.

Sallan, L. C., \& Coates, M. I. (2014). The long-rostrumed elasmobranch Bandringa Zangerl, 1969, and taphonomy within a Carboniferous shark nursery. Journal of Vertebrate Paleontology, 34(1), 22-33.

Shapiro, M. D., Hanken, J., \& Rosenthal, N. (2003). Developmental basis of evolutionary digit loss in the Australian lizard Hemiergis. Journal of Experimental Zoology Part B: Molecular and Developmental Evolution, 297(1), 48-56.

Shapiro, M. D. (2002). Developmental morphology of limb reduction in Hemiergis (Squamata: Scincidae): chondrogenesis, osteogenesis, and heterochrony. Journal of Morphology, 254(3), 211-231.

Sheil, C. A. (2005). Skeletal development of Macrochelys temminckii (Reptilia: Testudines: Chelydridae). Journal of Morphology, 263(1), 71-106.

Terpstra, L., Prud'homme, J., Arabian, A., Takeda, S., Karsenty, G., Dedhar, S., \& StArnaud, R. (2003). Reduced chondrocyte proliferation and chondrodysplasia in mice lacking the integrin-linked kinase in chondrocytes. The Journal of cell biology, 162(1), 139-148.

Tchernov, E., Rieppel, O., Zaher, H., Polcyn, M. J., \& Jacobs, L. L. (2000). A fossil snake with limbs. Science, 287(5460), 2010-2012.

Weir, E. C., Philbrick, W. M., Amling, M., Neff, L. A., Baron, R., \& Broadus, A. E. (1996). Targeted overexpression of parathyroid hormone-related peptide in chondrocytes causes chondrodysplasia and delayed endochondral bone formation. Proceedings of the National Academy of Sciences, 93(19), 10240-10245.

Woltering, J. M., Vonk, F. J., Müller, H., Bardine, N., Tuduce, I. L., de Bakker, M. A., \& Richardson, M. K. (2009). Axial patterning in snakes and caecilians: evidence for an alternative interpretation of the Hox code. Developmental biology, 332(1), 8289. 


\section{|Chapter 7: Conclusions}

\subsection{Thesis Redux}

This dissertation proposed to address three questions: first, what is the alphataxonomic diversity of the amniote fauna of Mazon Creek? Second, what is the ecomorphological diversity of the amniote fauna of Mazon Creek? Third, and finally, what can the Mazon Creek amniote fauna tell us about adaptive radiation of amniotes? Cumulatively, within the previous five chapters, I have provided answers to these three queries. To summarize:

In Chapter 2, the new short-bodied (17 presacrals), highly terrestrial, earlydiverging, brachystelechid recumbirostran, Diabloroter bolti gen. et sp. nov., was described as the first tetrapod from the Fulton County tetrapod locality. The earlydiverging position of Diabloroter contextualizes the unique craniodental specializations of later Permian brachystelechids. I put forward the hypothesis that the unique tricuspate tooth morphology of these later brachystelechids may have been used for algivorous feeding-filling a previously unrecognized niche among the Permo-Carboniferous tetrapods. In Chapter 3, the serpentine molgophid recumbirostran, Infernovenator steenae gen. et sp. nov., was described revealing it possessed extremely diminutive forelimbs. The unique cranial morphology of Infernovenator, including a near complete circumorbital series and shovel-headed snout morphology, allows for both the clarified position of molgophids within Recumbirostra, and reveals the presence of mosaic evolution with respect to cheek emargination and snout ecomorphotypes (i.e. round, shovel, and spade-headed). In Chapter 4, a reappraisal of fossils attributed to the basal eureptile Cephalerpeton ventriarmatum, led to the discovery of the oldest parareptile, Carbonodraco lundi gen. et sp. nov. (formerly Cephalerpeton aff. C. ventriarmatum from Linton, Ohio). The anatomy of Cephalerpeton reveals a gracile, highly terrestrial form, possibly occupying a scansorial niche. Chapter 5 provided a description of the new recumbirostran, FMNH 1309, yet another fossorially-adapted, long-bodied ecomorph that uniquely retains well-developed limbs. The exceptional preservation of soft tissues in FMNH 1309, including body outlines and scales, reveal ultrastructural integumentary 
adaptations to a fossorial lifestyle, comparable to those of modern squamates. Finally, in Chapter 6, a new molgophid recumbirostran was described (MPM VP359229.2), introducing the first occurrence of complete loss of the forelimb, including girdle elements, in a Paleozoic amniote. The pattern of limb-loss in the new molgophid (i.e. forelimbs lost first) is similar to that of modern snakes, suggesting a common mechanism of limb-reduction may occur more broadly across the amniote tree. Furthermore, the description of this forelimbless taxon completes the picture of reptilian amniote bauplan diversity at Mazon Creek, showing a diverse assemblage of long-bodied fossorial ecomorphs (Brachydectes, Infernovenator, MPM VP359229.2) and diverse short-bodied, highly terrestrial ecomorphs (Diabloroter, Cephalerpeton).

The combined taxonomic and ecological diversity at Mazon Creek is what is to be expected under the predictions of the short-fuse hypothesis and adaptive radiation of amniotes. In totality, the Mazon Creek amniote assemblage shows considerable taxonomic diversity with at least six reptilian taxa (at present), four of which were described in this thesis. Although the inclusion of Recumbirostra into Amniota remains controversial, the phylogenetic analyses performed in this thesis continue to support this phylogenetic hypothesis. With this result in mind, the amniotes of Mazon Creek appear equally as taxonomically diverse as those of Joggins and Florence Nova Scotia, and even more diverse than those of Linton, Ohio and other Moscovian-aged cannel-coal localities (Reisz, 1972; Hook and Baird, 1986; 1993; Mann et al., 2020). Overall, the tetrapod fauna of Mazon Creek appears compositionally similar to that of most PermoCarboniferous tetrapod localities (see taxonomic list below), revealing that even in lowland ecosystems amniotes were present and in greater diversity than previously recognised. The only glaring absence from Mazon Creek are the synapsids, possibly indicating that the 'lowland' estuarine environments of Mazon Creek were not densely populated by early pelycosaur-grade forms; however, time may prove otherwise.

\subsection{Revised systematics of the Mazon Creek Tetrapoda}

Detailed below is an updated taxonomic list for the total-group Tetrapoda of Mazon Creek. This is formatted in an unranked taxonomic scheme with no equivalency 
of higher taxa implied, however, traditional ranks are provided in brackets for convenience. Citations have been provided for recent additions and/or updated systematics to the fauna. Those identified in this thesis are bolded.

Tetrapodomorpha (clade)

Rhizodontida (order)

cf. Rhizodus

Aistopoda (order)

Phlegethontia longissma

Oestocephalus amphiuminus

Pseudophlegethontia turnbullorum

Embolomeri (order)

Spondylerpeton spinatum

Tetrapoda (superclass)

Temnospondyli (order)

Dvinosauroidea (superfamily)

Isodectes obtusus

Dissorophoidea (superfamily) Amphibamus grandiceps amphibamiform undet. (Mann and Gee, 2020) unnamed branchiosaurid (Pers. obs., A. Mann)

Nectridea (order) Ptyonius marshii

Microbrachomorpha (suborder)

Hyloplesiontidae (family) cf. Hyloplesion (FMNH PR 981)

Amniota (clade)

Eureptilia (clade)

Protorothyrididae (family)

Cephalerpeton ventriarmatum (Mann et al., 2019)

Recumbirostra (family)

Brachydectes newberryi

Infernovenator steenae (Mann et al., 2019)

MPM VP359229.2 (Mann et al., In Prep)

Diabloroter bolti (Mann and Maddin., 2019)

FMNH 1309 (Mann et al., In Prep)

Parareptilia (clade)

unnamed brachystelechid (Pers. obs., A. Mann)

Acleistorhinidae (family)

cf. Carbonodraco (Pers. obs., A. Mann) 


\subsection{Future systematic research on the Mazon Creek Tetrapoda}

At the start of my dissertation, I encountered an overwhelming amount of new tetrapod material from Mazon Creek that was already present in museum collections - far more than could ever be worked into one dissertation. Since then, the number of Mazon Creek tetrapods has grown even larger. This is largely due to amateur collectors now offering their knowledge and private collections for study, enticed by my recent published work. This thesis has acted as the small falling stones that have in turn started an avalanche. Some of the new identifiable material includes a new species of brachystelechid recumbirostran, a new well-preserved nectridean, Ptyonius, and a possible diminutive colosteid. However, the most surprising post-thesis discovery has been the existence of an acliestorhinid parareptile specimen at Mazon Creek, which is likely an earlier representation of Carbonodraco.

The largest Mazon Creek project that I will be approaching in the coming years will be dealing with systematics of the next most diverse clade of tetrapods from the Mazon Creek fossil assemblage - the temnospondyls. Although some of the species are well established, including Amphibamus, several new complete fossils have come to light that can allow for more comprehensive anatomical analysis, in addition to new species that may be represented among the new sample. Furthermore, there is a diverse assemblage of larval tetrapods from Mazon Creek, most of which are temnospondyls, that may be useful in addressing questions of development in Paleozoic tetrapods.

Together this work will provide the most up-to-date and comprehensive systematic review of a Late Carboniferous tetrapod assemblage, permitting large-scale paleoecological analyses of well-sampled tetrapod communities within the Mazon Creek lagerstätte such as 'Pitt 11'. Studies on the Mazon Creek tetrapod fauna will hopefully serve as a baseline for systematic approaches to other global Carboniferous tetrapod sites.

\subsection{References}

Hook, R. W., \& Baird, D. (1986). The diamond coal mine of Linton, Ohio, and its Pennsylvanian-age vertebrates. Journal of Vertebrate Paleontology, 6(2), 174 190. 
Hook, R. W., \& Baird, D. (1993). A new fish and tetrapod assemblage from the Allegheny Group (Late Westphalian, Upper Carboniferous) of eastern Ohio, USA. New research on Permo-Carboniferous faunas. Compiled by U. Heidtke. Pollichia-Buch, 29, 143-154.

Mann, A., Gee, B. M., Pardo, J. D., Marjanović, D., Adams, G. R., Calthorpe, A. S., \& Anderson, J. S. (2020). Reassessment of historic 'microsaurs' from Joggins, Nova Scotia, reveals hidden diversity in the earliest amniote ecosystem. Papers in Palaeontology (early view).

Mann, A., \& Gee, B. M. (2020). Lissamphibian-like toepads in an exceptionally preserved amphibamiform from Mazon Creek. Journal of Vertebrate Paleontology, e1727490.

Reisz, R. (1972). Pelycosaurian reptiles from the middle Pennsylvanian of North America. Harvard University, 144(2), 1-61. 


\section{Appendices}

\section{Appendix A - Chapter 2 Supplementary Information}

\section{A.1 Parsimony strict consensus tree recovered using the heuristic search option}

of Pardo et al. (2017), including the new taxon, Diabloroter bolti gen et sp. nov.

Strict consensus tree

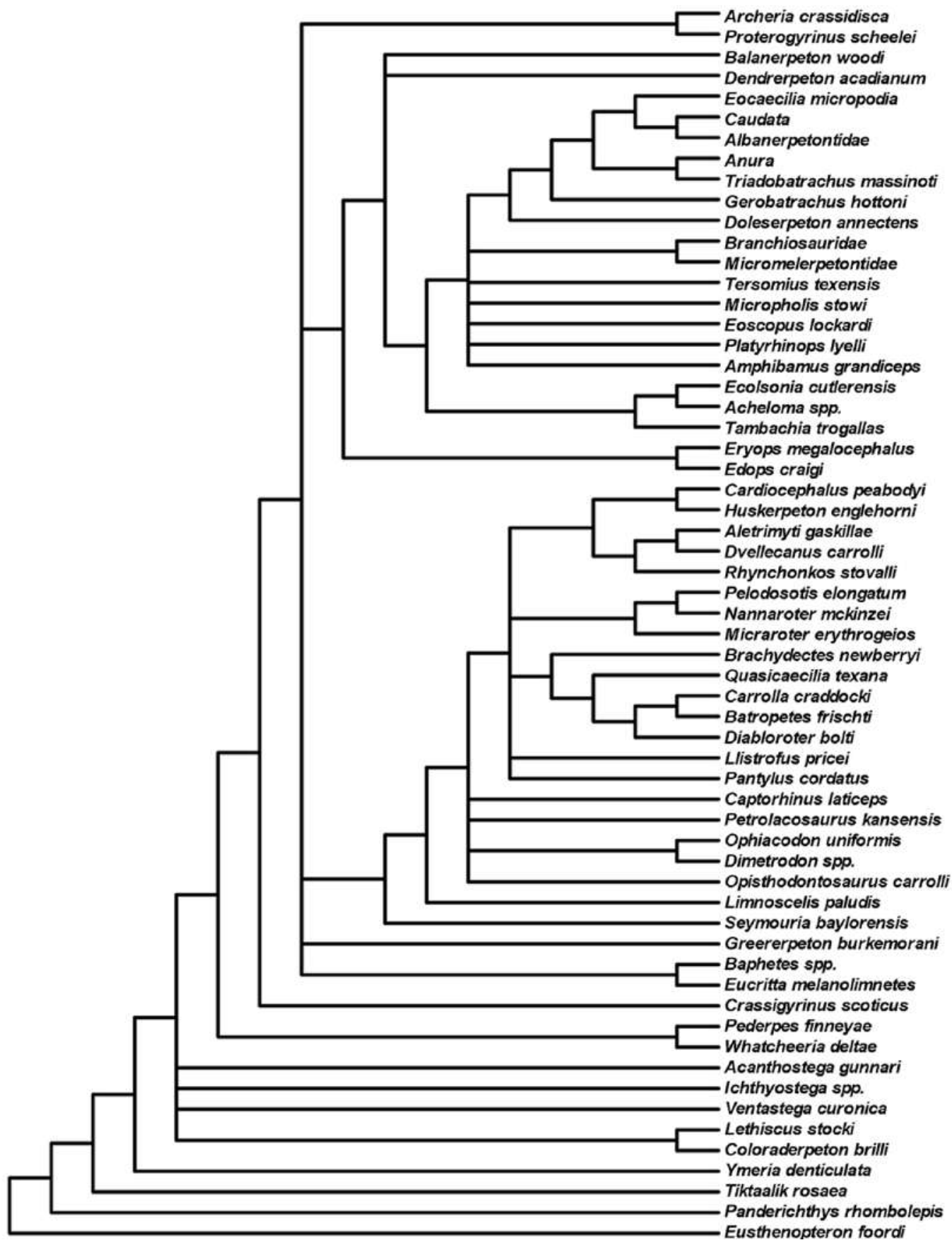


A.2 Resulting Bayesian tree using the matrix of Pardo et al. (2017), including the new taxon, Diabloroter bolti gen. et sp. nov. Posterior probability values are present above nodes.

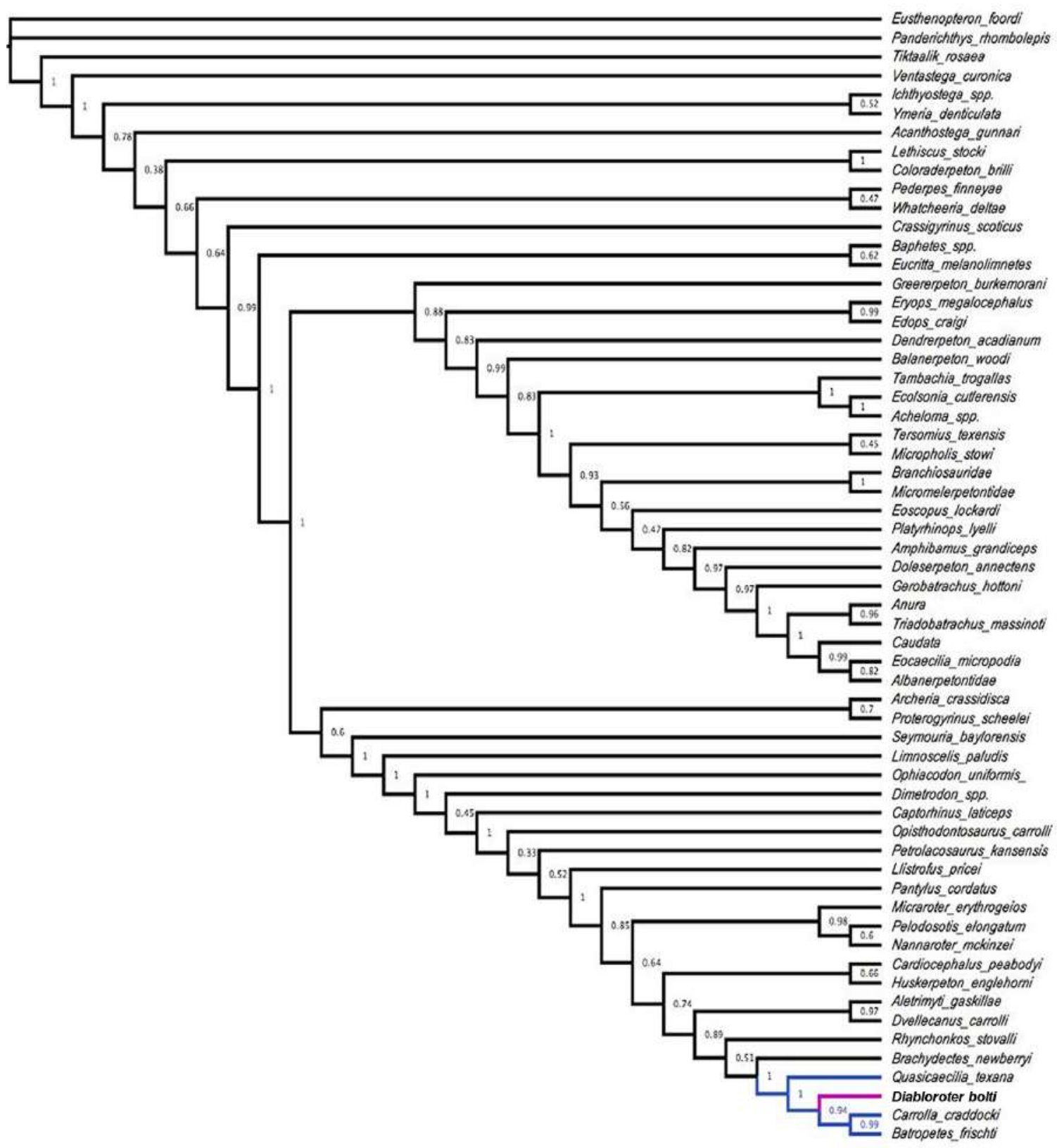

\section{A.3 Nexus File used for phylogenetic analyses of Diabloroter bolti gen et sp. nov.}

\#NEXUS

[written Tue Oct 02 11:11:06 EDT 2018 by Mesquite version 3.2 (build 801) at ArjansMacBook-Pro.local/192.168.40.84]

BEGIN TAXA; 
TITLE Taxa;

DIMENSIONS NTAX $=60$;

TAXLABELS

Archeria_crassidisca Crassigyrinus_scoticus Acanthostega_gunnari

Eusthenopteron_foordi Ichthyostega_spp. Panderichthys_rhombolepis Pederpes_finneyae

Tiktaalik_rosaea Ventastega_curonica Whatcheeria_deltae Ymeria_denticulata

Proterogyrinus_scheelei Balanerpeton_woodi Dendrerpeton_acadianum

Cardiocephalus_peabodyi Huskerpeton_englehorni Pelodosotis_elongatum

Nannaroter_mckinzei Micraroter_erythrogeios Eocaecilia_micropodia

Brachydectes_newberryi Greererpeton_burkemorani Seymouria_baylorensis

Limnoscelis_paludis Branchiosauridae Micromelerpetontidae Tersomius_texensis

Ecolsonia_cutlerensis Acheloma_spp. Eryops_megalocephalus Doleserpeton_annectens Caudata Anura Albanerpetontidae Micropholis_stowi Eoscopus_lockardi

Tambachia_trogallas Triadobatrachus_massinoti Gerobatrachus_hottoni

Platyrhinops_lyelli Amphibamus_grandiceps Lethiscus_stocki Coloraderpeton_brilli

Edops_craigi Captorhinus_laticeps Petrolacosaurus_kansensis Ophiacodon_uniformis

Baphetes_spp. Eucritta_melanolimnetes Llistrofus_pricei Aletrimyti_gaskillae

Dvellecanus_carrolli Rhynchonkos_stovalli Dimetrodon_spp.

Opisthodontosaurus_carrolli Pantylus_cordatus Quasicaecilia_texana Carrolla_craddocki Batropetes_frischti Diabloroter_bolti

END;

\section{BEGIN CHARACTERS;}

TITLE 'Matrix in file "Pardo\&al_2017_lepospondyls.nex"';

DIMENSIONS NCHAR $=370$;

FORMAT DATATYPE $=$ STANDARD GAP $=-$ MISSING $=?$ SYMBOLS $="$

01234567 8";

CHARSTATELABELS

1 Basal_Skull_Length / ' $>70 \mathrm{~mm}$ ' '50-70mm' ' $30-50 \mathrm{~mm}$ ' '<30mm', 2

Skull_trunk / $0.450 .30 \_0.450 .20 \_0.290 .20,3$ Skull_proportions / longer_than_wide wider_than_long, 4 Intertemporal / present

Replaced_by_anterior_extension_of_supratemporal_or_tabular

replaced_by_lateral_extension_of_parietal, 5 Supratemporal / present absent, 6

ST_exposure_on_occiput / absent present, 7 Postfrontal_shape / broadly_quadrangular falciform, 8 Squamosal_Tabular / absent present fused, 9 Lacrimal_prefrontal_suture / simple_butt_joint interdigitating prefrontal_broadly_underplates_lacrimal, 10 Lacrimal / present absent, 11 L_to_naris / present absent, 12 L_to_orbit / absent present, 13 lacrimal_orbital_processes / only_ventral_present dorsal_and_ventral_present neither_present, 14 lacrimal_jugal_contact / present absent, $1 \overline{5}$ Quadratojugal / present absent, 16 Quadratojugal_Jugal_contact / present absent, 17

Quadratojugal_Maxillary_contact / present absent, 18 Frontals / paired fused, 19 Frontal_into_orbit / no yes, 20 Anterior_laterally_flaring_frontals / absent present, 21 Nasals / present absent, 22 Narial_flange / absent present, 23 
alary_processes_of_premax / absent present, 24 Septomaxilla / ossified unossified, 25 Prefrontal_into_external_naris / distant_from near present, 26 external_naris_in_dorsal_view / exposed not_exposed, 27 External_naris_shape / circular 'posteriorly extended, along L-PF suture' posteriorly_extended_excavation_of_L_only, 28 dorsal_exposure_of_premax / broad narrow none, 29 dorsal_shape_of_skull / triangular diamond rounded, 30

Posterior_skull_margin / concave straight convex undulating., 31 snout_shape / blunt pointed, 32 snout_length / short long, 33 Q_internal_flange_of_Sq / absent present, 34 otic_notch_presence / present absent, 35 Large_otic_notch_approaching_orbit / absent intermediate close, 36 otic_notch_structure / open_posteriorly closed_posteriorly, 37 semilunar_flange_of_supratempor / absent present, 38 supratympanic_flange / absent 'present "trematopid"' present_trematopid 'present "dissorophid"' present_dissorophid, 39 supratympanic_shelf / absent present, 40 raised_orbital_rim / absent present, 41 Postorbital / present absent, 42 J_PO_interfingered_processes / absent present, 43 PO_in_orbital_margin / present absent, 44 shape_of_postorbital / irregular_trapezoid 'triangular, apex caudal', 45 Palpebral_ossifications / absent mosaic_of_bone_plates_present_in_orbit Single_large_plate_above_orbit, 46 parietal_tabular_contact / absent present, 47 postparietal_fusion / paired fused absent, 48 parietal_foramen / present absent, 49 postparietal_size / moderate large, 50 postparietal_squamosal_contact / absent present, 51 postparietal_length / 'large, quadrangular' 'abbreviated anteroposteriorly, elongate lateral rectangle', 52 squamosal_jugal_contact / present absent, 53 Tabular / present absent, 54 Posterolateral_projection_from_lateral_margin_of_tabular_above_squamosal_embaymen t/ absent present, 55 Tabular_horns / absent present, 56 Tabular_horns_shape / parallel_or_slightly_divergent widely_divergent, 57 Sq_forms_base_of_tabular_horn / absent present, 58 Lateral_line_canal_grooves / present absent, 59 Dermal_sculpturing / circular_pits shallow_ridges_and_grooves little_to_none tuberculate, 60 premaxilla_anterior_margin / vertical overturnè,,$\overline{6} 1$ Maxilla_into_external_naris / present absent, 62 Maxilla_entire_ventral_naris / absent present, 63 maxilla / longer_than_palatine shorter_than_palatine, 64 marginal_teeth_orientation / vertical turned_medially, 65 marginal_teeth_largest_anterior / absent present, 66 marginal_teeth_shape / pointed_pegs blunt_pegs large_cones, 67 Number_of_premax_teeth / '10-20' '5-9' ' $<5$ ' 20_or_more, 68 Number_of_max_teeth / '30-40' '20-29' '15-19' ' $<15^{\prime}$ ' $>40$ ', 69 teeth_laterally_compressed / no yes, 70 Enlarged_teeth_mid_toothrow / absent present, 71 teeth / simple_points multiple_cusps, 72 Multiple_Cusp_Orientation / 'Labio-lingual' 'antero-posterior', 73 Enamel_fluting / absent present, 74 labyrinthine_in_folding / present absent, 75 jaw_articulation / posterior_to_occiput even_with_occiput anterior_to_occiput 'far anterior $(>20 \% \mathrm{BSL})$ ', 76 Internal_nares / widely_separated narrowly_separated, 77 LEP / absent present, 78 Anterior_palatine / short_anteromedial_process_articulating_with_vomer_at_choana long_anteromedial_process_more_medial_than_lateral palatine_absent, 79 teeth_on_pterygoid/ absent present, 80 tooth_pedicely / absent present, 81 Palatal_teeth_size / larger_than_marginals equal_to_marginals smaller_than_marginals, 82 parasphenoid / medial_of_stapes under_footplate_of_stapes, 83 interpterygoid_vaccuities / narrow_closed wide fused_at_midline, 84 Anterior_extent_of_Pterygoids / Pterygoids_contact_anteriorly 
Pterygoids_exclude_vomer_from_interpterygoid_vacuity_but_excluded_from_median_c ontact_by_parasphenoid

pterygoids_contact_vomer_but_do_not_exclude_vomer_from_interpterygoid_vacuity pterygoids_reach_anteriorly_only_as_far_as_palatine

pterygoids_reach_ectopterygoid_only

pterygoids_do_not_contact_lateral_palatal_bones_at_all, 85

lat process_of_pt into_posttemp / absent present, $8 \overline{6}$ Ectopterygoid palatine_width / wider_than_maxilla narrower_than_maxilla, 87 pharangeobranchial_pouches / absent present, 88 dentary / long short, 89 dentary_forms_coronoid_process / absent present, 90 surangular / normal reduced absent, 91 angular / narrow deep, 92

number_of_splenials / 210,93 splenial_exposed laterally / present absent, 94 meckelian fossae / 2 or_more 10,95 Ventral border_of_Meckel_s foss / splenial angular, 96 retroarticular_process_presence / absent present, 97

retroarticular_process_shape / straight hooked, 98 articulation_to_tooth_row / above equal below, 99 angular_extends_to_lat_view / posterior_tooth_row middle_of_tooth_row, 100 number_of_coronoids / 3210,101 symphysis / dentary_and_splenial dentary_alone, 102 jaw_sculpture / present absent, 103 ossified_hyoids / present absent, 104 Gill_Osteoderms / absent present_noninterdigitating toothed_interdigitating_rakers, 105 parahyoid / absent present, 106 number_of_accessory_articulation / 012 1 or_more, 107 number_of_presacrals / 25 -35 20_24 35 20, 108 vertebral_development / arches_then_centra centra_and_arches_simultaneously, 109 caudal_processes_btw_depression / absent present, 110 trunk_intercentra / present absent, 111 trunk_neural_arch_to_centrum / loosely_articulated sutured fused, 112 base_of_neural_spine / equal_to_or_wider_than_haemal smaller_than_haemal_spine, 113 height_of_neural_spines / even alternating, $\overline{1} 14$

Dermal_armor_associated_with_neural_arches / Absent Present, 115

neural_spine_shape_lat / ant_post_sides_parallel_rect non_parallel_triangular, 116 Neural_spine_lateral_suface / smooth crenulated, 117 Pleurocentra / paired_rhachitomous closely_approaching_ventrally fused_dominant_weight_bearing_element embolomerous, 118 haemal_arch_presence / present absent, 119 haemal_arch_fusion / loosely_articulated_intercentr fused_to_mid_length_of_centrum, 120 haemal_arch_length / longer_than_or_equal_to_neurals shorter_than_neurals, 121 haemal_accessory_articulations / none one two, 122 haemal_arch_shape / non_parallel_triangular parallel_rectangular, 123 tail_termination / tapers deep_with_sudden_end, 124 Tail_length / elongate_equal_to_or_exceeding_trunk_and_skull_length forshortened_markedly_shorter_than_trunk, 125 trunk_arches / paired fused, 126 spinal_nerve_foramina / absent present, 127 extended_transverse_processes / absent present, 128 transverse_process / on_arch_pedicle on_centrum, 129 atlas_axis_intercentra / present absent, 130 Atlas_Anterior_centrum / same_size_as_posterior laterally_expanded, 131 atlas_centrum / multipartite single_notochordal single_odontoid, 132 atlas_neural_arch_centrum_fusion / loosely_articulated sutured_to_centrum fused_to_centrum, 133 atlas_parapophyses / on_centrum on_transverse_process absent, $13 \overline{4}$ atlas_neural_arch_midline_fusion / 
paired sutured_at_midline fused_at_midline, 135 atlas_acessory_articulation / absent zygosphene zygantra, 136 Proatlantes / present absent, 137 second_cervical_arch / expanded_to_more_posterior equal_to_more_posterior shorter_than_more_posterior, 138 atlas_ribs / one_pair two_pairs absent, 139 cervical_rib_distal_shape / spatulate pointed, 140 ribs_anterior_to_sacrum / short long, 141 Ribs / elongated_and_sometimes_curved straight short_simple_rod, 142 Costal_Process_at_rib_head / absent present, 143 number_of_sacrals / 123,144 sacral_parapophysis / on_centrum on_transverse_process, 145 number_pairs_of_caudal_ribs / 5_or_more 432 or_fewer, $14 \overline{6}$ interclavicle_posterior_stem_length / no_or_short long, $\overline{147}$ interclavicle_posterior_stem_breadth / wide narrow, 148 interclavicle_shape / diamond_shaped t_shaped, 149 interclavicle_anterior_plate / broad narrow, 150 interclavicle_shape_diamond / broad_diamond narrow_diamond, 151 interclavicle_anterior_fimbrati / present absent, 152 interclavicle_sculpture / present absent, 153 Cleithrum_head_dorsal_extent / aligned_along_anterior_rim_of_scapula posterodorsally_enlarged_head_wrapping_around_dorsal_scapula, 154 Cleithrum_head_size_and_shape / dorsally_greatly_expanded_much_wider_than_shaft simple_rod_without_or_slight_dorsal_expansion, 155 Cleithrum_ossification / ossified unossified, 156 cleithrum_overall_shape / rounded_or_pointed_ōdorsally t_or_y_shaped, 157 proximal_clavicle_blades / widely_separate articulate_medially interdigitate, 158 supraglenoid_foramen / present absent, 159 number_coracoid_foramina / none 12,160 scapulocoracoid_occification / both scapula_only absent, 161 tortion_in_humerus / absent less_than_80_degrees more_than_80_degrees, 162 deltapectoral_crest / weak intermediate prominant, 163 Supinator_process / absent present, 164 humerus_length / long_4_trunk_centra short, 165 radius_humerus / 0.70 .5 _0.7 0.5, 166 olecranon_process / unossified ossified, 167 carpals / fully_or_partially_ossified unossified, 168 basale_commune / absent present, 169 number_digits_manus / $543^{\prime}>5^{\prime}$, 170 pelvis / fused sutured poorly_ossified, 171 Anteriorly_inclined_ilium / absent present, 172 illiac_blade / 2_dorsal_processes narrowly_bifurcate single_blade, 173 internal_trochanter_articulatio / disctinct continuous, 174 femoral_shaft / robust slender, 175 femur / long short, 176 tarsals / ossified unossified, 177 elongate_tibiale_and_fibulare / absent present, 178 number_of_distal_tarsals / 6 5_or_fewer, 179 astragalus / absent present, 180 number_of_digits_pes / 54 or_less $'>5$ ', 181 dorsal_margin_of_splenial_only_contacts_first_coronoid / absent present, 182 postparietal_lappet / mostly_exposed_posteriorly equal_posteriorly_and_dorsally mostly_exposed_dorsally, $18 \overline{8}$ cheek_emargination / absent present, 184 Parietal_anterior_waisting / absent present, 185 Parietal_width_relative_to_frontal / greater equal_or_less, 186 Trabecula_cranii / 'Without significant median fusion posterior to solum nasi (platytrabic)' 'fused medially posterior to solum nasi to form elongate trabecula communis (tropitrabic)', 187 Dorsal_trabeculae / dorsal_trabeculae_provide_dorsolateral_bridge_between_sphenoid_region_and_nasal_ca psule 'dorsal trabeculae absent or incomplete, no dosolateal bridge between sphenoid region and nasal capsule', 188 Ossification_between_optic_foramen_and_pila_antotica / ossification_complete_between_optic_foramen_and_pila_antotica pila_metoptica_and_associated_cartilaginous_taeniae_unossified, 189 Ossification_within_columella_ethmoidalis / absent present, 190 Path_of_profundus_branch_of_trigeminal_nerve / 
enclosed_in_lateral_wall_of_sphenoid_region_of_braincase_and_exits_separately_from_ maxillomandibular_branch_via_series_of_small_foramina 'extramural, exits antotic fissure with other branches of trigeminal', 191

Foramina_for_optic_nerve_and_trigeminal_nerve / confluent widely_separate, 192 Lateral_head_vein / No_distinct_foramen_for_lateral_head_vein

Distinct_foramen_within the antotic_fissure_serving_the_lateral_head_vein, 193

Anterior_extent_of_cultriform_process_of_parasphenoid /

cultriform_process_extends_to_anterior_margin_of_sphenethmoid

cultriform_process_extends_far_anterior_to_sphenethmoid

cultriform_process_does_not_reach_anterior_margin_of_sphenethmoid, 194

Olfactory_bulbs / narrow 'endocasts swollen, leaving considerable impressions in lateral

and ventral wall of sphenoid region and in ventral surface of frontal', 195

Flange_from_skull_roof_articulating_with_sphenethmoid / absent

present_on_frontal_and_parietal present_on_frontal_only, 196 'Descending lamina of

parietal invades medial orbital wall between "pleurosphenoid" and "sphenethmoid"

elements' / no yes, 197 Foramen_for_oculomotor_nerve /

exits braincase far dorsal to foramen for optic nerve

exits_braincase_at_or_below_optic_nerve, 198 Intermaxillary_fossa / present absent, 199 Intermaxillary_fossa / paired unpaired, 200

Sphenethmoid_forms_interorbital_septum / no yes, 201

Anterior_extent_of_cultriform_process_along_palate /

cultriform process extends anteriorly to level of posterior margin of choana 'cultriform process dramatically shortened, barely reaching the level of the posterior margin of the orbit', 202

Sutural_contact_between_cultriform_process_of_parasphenoid_and_vomer / no yes, 203 Lateral_wall_of_the_nasal_capsule_underplated_by_lateral_processes_of_the_vomer_an d_palatine / no yes, 204 Cultriform_process_vaulted high_above palatal_surface / no yes, 205 Posterior_extent_of_parasphenoid_beneath_braincase /

floors_sphenoid_region_only floors_sphenoid_and_otic_region 'floors sphenoid, otic, and occipital regions', 206 Basal_tubera / 'present, with significant endochondral contribution' 'present, with contribution of parasphenoid only' absent, 207

Path_of_common_internal_carotid_artery / 'does not run alongside braincase, enters braincase directly in region of sella turcica' 'follows vidian sulcus along posterior surface of basal plate of parasphenoid, enters parasphenoid via vidian canal in basal plate of parasphenoid, divides into cerebral and palatal branches after entering parasphenoid' 'follows vidian sulcus along posterior surface of basal plate of parasphenoid or lateral wall of braincase, divides into cerebral and palatal branches prior to entering the skull', 208 Bucohypophyseal_foramen_in_parasphenoid / open absent, 209

Morphology_of_pila_antotica / 'pila antotica is a thin, broad sheet' pila_antotica_is_a_robust_dorsoventral_pillar_bracing_the_skull_roof_against_the_palat e, 210 Basicranial_fissure / present absent, 211 Location_of_vidian_sulcus / along_ventral_surface_of_braincase along_lateral_surface_of_braincase, 212 Basipterygoid_joint / epipterygoid_comprises_entire_conus_recessus substantial contribution to conus recessus by pterygoid conus_recessus_comprised_entirely_of_pterygoid_without_epipterygoid_participation pterygoid_and_parasphenoid_broadly_sutured_without_development_of_a_conus_recess 
us, 213 Hypophyseal_fossa / single_unpaired_sulcus pairedsulci_divided_medially_by_ridge_originating_on_dorsum_sellae, 214 Bone flanking the dorsum sellae / consurrent with fully ossified lateral skull roof 'subparallel with sagittal plane ("pleurosphenoid")' 'strongly oblique to or perpendicular to sagittal plane ("laterosphenoid")' restricted_to_dorsum_sellae_only, 215

Basal_plate_of_parasphenoid / 'roughly quadrangular, basipterygoid articulations narrowly spaced' 'rectangular laterally, anteroposteriorly narrow, basipterygoid articulations distant', 216 Sphenethmoid / ossified unossified, 217

Ossification_within_the_synotic_tectum / synotic_tectum_massively_coossified_with_otic_capsules supraoccipital_paired_at_some_point_in_ontogeny supraoccipital unpaired throughout_ontogeny 'no supraoccipital bone; synotic tectum invaded by dorsal processes of exoccipitals', 218

Median_ascending_process_of_supraoccipital / absent present, 219

Lateral_ascending_processses_of_the_supraoccipital / absent present, 220

Margin_of_fenestra_vestibuli / ' parasphenoid excluded by neurocranial elements (basisphenoid and basioccipital)' parasphenoid_contributes_to_anteroventral_margin_of_fenestra_vestibuli parasphenoid_floors_entire_fenestra_vestibuli

Ossification_of_otic_capsule_surrounds_entire_fenestra_vestibuli, 221

Crista intervestibulara / crista intervestibularis absent crista intervestibularis present, 222 Morphology_of crista parotica / 'crista parotica meets exoccipitals only, forming lateral wall of posttemporal fossa but not bracing against dermal skull' crista_parotica_drawn_out_dorsolaterally_into_paroccipital_process_that_contacts_the_t abular 'crista parotica drawn out laterally into paroccipital process that contacts the cheek and/or suspensorium', 223 Dorsal_process of_stapes / absent present, 224

Facets_on_dorsal_surface_of_supraoccipital / absent present, 225 Otoccipital_fissure / present absent, 226 Crista_parotica / Descends_posteriorly

Horizontal_along the extent_of_its_length, 227

Position_of quadrate with respect to otic_capsules /

quadrates_ventral_and_lateral_to_otic_capsules

quadrates_mostly_lateral_to_and_greater_or_equal_to_twice_the_width_of_the_otic_cap sules quadrates_mostly_ventral_to_otic_capsules

quadrates_approaching_or_abutting_lateral_wall_of_otic_capsules, 228

Size_of_otic_capsuiles / 'otic capsules comprise less than $2 / 3$ the width of otoccipital region' 'otic capsules comprise greater than $2 / 3$ total width of otoccipital region', 229

Otic_trough / absent present, 230 Articulation_between_the epipterygoid_and prootic / none elongate_facet_on_anterior_surface_of_prootic_for_articulation_of_epipterygoid, 231 Opisthotic_obscures_occipital_in_lateral_view / no yes, 232 'Fenestra vestibularis at end of broad, winglike lateral extension of the otic capsule' / no yes, 233

Cristae in otoccipital region /

comprised_primarily_of_ascending_flanges_from_braincase

comprisd_primarily_of_descending_flanges_from_skull_roof, 234

Opisthotic_excluded_from_the_occipital_surface_by_tabular_process_of_the_exoccipital / no yes, 235 Insertion of epaxial musculature on occiput / deep_within_temporal_fossae 'in broad, shallow fossae along occipital surface of 
postparietals', 236 Foramen_for_internal_jugular_vein /

between_supraoccipital_and_exoccipital between_opisthotic_and_exoccipital

through exoccipital Posterior notch of fenestra vestibuli, 237

Foramina_for_hypoglossal_nerve / multiple single none, 238 Occipital_condyle_shape /

round 'U-shaped' paired, 239

Ventral_process_of_exoccipital_reaches_basipterygoid_joint_along_palatal_surface /

absent present, 240 Occipital_condyle_shape / Concave Convex, 241

Columella_of_stapes / perforate imperforate, 242 Orientation_of_stapes / 'Dorsal, towards tabular or otic notch' 'anteroventral, towards quadrate', 243

Stapedial_footplate_shape / oval round palmate, 244

Dorsal_sinus_between_synotic_tectum_and_skull_roof / absent present, 245

Ossification_within_septum_internasale / absent 'present, sphenethmoid' 'present, mesethmoid', 246 Ossification_of_septum_internasale_invades_nasal_tectum / absent present, 247 Insertion_of_hypaxial_musculature / sphenoid otic basioccipital, 248

Prootic_supported_by_pedicel_extending_from_basisphenoid_lateral_to_prootic_forame n / no yes, 249 Position_of_pineal_foramen_with_respect_to_hypophyseal_foramen / anterior to approximately the same far_posterior_to, 250 Pineal fossa / well_anterior_to_posterior_margin_of_cerebral_fossa

at_or_behind_posterior_margin_of_cerebral_fossa, 251 Median_wall_of_otic_capsule / completely_unossified ossification_of_opisthotic ossification of supraoccipital and basioccipital, 252 Conical recess in basioccipital / absent present, 253 Semicircular_canals / separated_from_utricular_region_by_bone not_separated_from_utricular_region_by_bone, 254 Basioccipital /

Robust_ossification_ventral_to_foramen_magnum_present absent, 255 Accessory_articulation_processes_with_proatlantal_facet_on_exoccipitals / absent prominent, 256 Exoccipital_proatlantal_facets_incorporated_into_occipital_joint / no yes, 257 Anterior_tectal / anterior_tectal_present absent, 258 'Ectopterygoid/palatine exposure' / more_or_less_confined_to_tooth_row broad_mesial_exposure_additional_to_tooth_row reduced_to_thin_sliver, 259 Ectopterygoi $\bar{d} /$ Present Absent, $2 \overline{60}$ Ectopterygoid_as_long_or_longer_than_palatines / yes no, 261 Ectopterygoid_reaches_subtemporal_fossa / no yes, 262 Frontal / absent present, 263 Jugal / does_not_extend_anterior_to_orbit extends_anterior_to_orbit, 264 Lateral_rostral_present / yes no, 265 Maxilla_makes_interdigitating_suture_with_vomer / no yes, 266 Maxilla_external_contact_with_premaxilla / narrow contact point not interdigitated interdigitating suture, 267 Maxilla_extends_behind_level_of posterior_margin_of_orbit / yes no, 268 Median_rostral / single paired absent, 269 Opercular / present absent, 270 Prefrontal / 'twice as long as broad, or less' three_times_as_long_as_broad, 271 Prefrontal / transverse_anterior_suture_with_tectal tapers_to_a_point_anteriorly, 272 Preopercular / present absent, 273 Pterygoid_quadrate_ramus_margin_in_subtemporal_vacuity / concave with_some_convex_component, 274 'Vomers separated by parasphenoid $>$ half length' / yes no, $27 \overline{5}$ Vomers / as_broad_as_long_or_broader about_twice_as_long_as_broad_or_longer, 276 Basipterygoid_process / not_strongly_projecting_with_concave_anterior_face strongly projecting with flat anterior_face, $27 \overline{7}$ Ethmoid / fully_ossified partly_or_wholly_unossified, 278 Hypophyseal_region / 
solid_side_wall_pierced_by_small_foramina_for_pituitary_vein_and_other_vessels single_large_foramen, $2 \overline{7} \overline{9}$

Lateral_commissure_of_otic_capsule_bearing_hyomandibular_facets / present absent, 280 Parasphenoid / does_not_overlap_basioccipital overlaps_basioccipital, 281

Denticulate_field_of_parasphenoid / present absent, 282 Sphenoid / 'fully ossified, terminating posteriorly in intracranial joint or fused to otoccipital'

separated_from_otoccipital_by_unossified_gap, 283 Ectopterygoid_fang_pairs / present absent, 284 'Ectopterygoid row (3+) of smaller teeth' / present absent, 285

'Ectopterygoid/palatine shagreen field' / absent present, 286

Palatine_row_of_smaller_teeth / present absent, 287 'Pterygoid shagreen (palatine ramus)' / dense organized_radiating_rows_of_denticles disorganized_patches_or_absent, 288 Dentition_of_transverse_flange_of_pterygoid /

Denticle_field_indistinct_from_palatine_denticle_field distinct_raised_denticle_field organized_tooth_row absent, 289 Premaxillary_tooth_proportions /

all_approximately_same_size

posteriormost_teeth_at_least_twice_height_of_anteriomost_teeth

Anteriormost teeth largest, 290 Vomerine fang pairs / present absent, 291

Vomerine_fang_pairs_noticeably_smaller_than_other_palatal_fang_pairs / no yes, 292

Vomer_anterior_wall_forming_posterior_margin_of_palatal_fossa_bears_tooth_row_me eting_at_midline / yes no, 293 Vomerine_row_of_small_teeth / present absent, 294 Vomerine_shagreen_field / absent present, $29 \overline{5}$ Adductor_fossa / faces_dorsally

faces medially, 296 Adductor_crest / absent 'peak anterior to adductor fossa, dorsal margin of fossa concave' 'peak above anterior part of adductor fossa, dorsal margin of fossa convex', 297 'Angular-prearticular contact' /

prearticular_contacts_angular_edge_to_edge absent

medial_lamina_of_angular_sutures_with_prearticular, 298 'Coronoid (anterior) contacts splenial' / no yes, 299

Prearticular_extends_between_infradentaries_and_middle_coronoid / Yes No, 300

'Coronoid (middle) contacts postsplenial' / no yes, 301 'Coronoid (posterior)

posterodorsal process' / no yes, 302 'Coronoid (posterior) posterodorsal process visible in lateral view' / no yes, 303 'Dentary external to angular \& surangular, with chamfered ventral edge and no interdigitations' / no yes, 304 Dentary_ventral_edge /

smooth_continuous_line 'abruptly tapering or "stepped" margin', $3 \overline{05}$

Dentary_suture_with_splenial_\&_postsplenial_marked_by_deep_furrow / no yes, 306

Mandibular_sensory_canal / present absent, 307 Mandibular_canal_exposure / 'entirely

enclosed, opens through lines of pores' 'postly enclosed, short sections of open grooves' 'mostly open grooves, short sections opening through pores' entirely_open, 308 'Oral sulcus/surangular pit line of mandible' / present absent, 309

Meckelian_bone_floors_precoronoid_sulcus / yes no, 310

Meckelian_bone_ossified_in_middle_part_of_jaw / yes little_or_no_ossification, 311

Meckelian_bone_exposure_in_middle_part_of jaw / depth_much_less_than_prearticular depth_similar_to_prearticular, 312 'Meckelian foramina/fenestrae, dorsal margins' /

Meckelian_bone prearticular infradentary, 313 'Meckelian foramina/fenestrae height' /

much_lower_than_adjacent_prearticular

equal_to_or_greater_than_depth_of_adjacent_prearticular, 314

Parasymphyseal lateral foramen present / no yes, 315 
Parasymphyseal_mesial_foramen_present / no yes, 316

Postsplenial_with_mesial_lamina / no small 'expanded, contacting precoronoid', 317

Postsplenial pit line present / yes no, 318

Postsplenial_suture_with_prearticular_present / no yes, 319

Prearticular_sutures_with_surangular/ no yes, 320 Medial_lamina_of_splenial / absent present, 321 Prearticular_with_longitudinal_ridge_below_coronoids / no yes, 322

'Prearticular with mesially-projecting flange on dorsal edge along posterior border of adductor fossa' / no yes, 323 Prearticular_centre_of_radiation_of_striations /

level_with_posterior_end_of_posterior_coronoide-vel_with_midd̄le_of_adductor_fossa level_with_posterior_end_of_adductor_fossa, 324 Splenial_has_free_ventral_flange / yes no, 325 'Splenial, rearmost extension of medial lamina' / closer_to anterior_end_of jaw than to adductor_fossa equidistant closer_to_anterior_margin_of_adductor_fossa_than_to_the_anterior_end_of_the jaw, 326 'Coronoids; at least one has fang pair recognizable because at least twice the height of coronoid teeth' / yes no, 327 'Coronoids: at least one has fangs recognizable because noticeable mesial to vertical lamina of bone and to all other teeth' / yes no, 328

'Coronoids: at least one has organized tooth row' / yes no, 329 'Coronoids: at least one carries shagreen' / no yes, 330 'Coronoids: size of teeth (excluding fangs) on anterior and middle coronoids relative to dentary tooth size' / about_the_same

half_the_height_or_less, 331 Dentary_tooth_row / homodont markedly_heterodont, 332

Dentary_with_parasymphyseal_fangs_internal_to_marginal_tooth_row / yes no, 333

Dentary_teeth / same_size_as_maxillary_teeth larger_than_maxillary_teeth

smaller_than_maxillary_teeth, 334

Dentary_with_a_row_of_very_small_teeth_or_denticles_lateral_to_tooth_row / yes no, 335 Parasymphyseal_tooth_plate / present absent, 336 Parasymphyseal_plate_dentition / shagreen_or_irregular_tooth_field organied_dentition_aligned_parallel_to_jaw_margin no_dentition, 337 Parasymphyseal_plate_has_fang_pair / no yes, 338

Parasymphyseal_plate_has_tooth_row / no 'short tooth row, separated from coronoid row by diastema' long_tooth_row_reaching_coronoid, 339

Prearticular_shagreen field distribution / gradually_decreasing from dorsal to ventral 'well-defined dorsal longitudinal band' scattered_patches_or_absent, 340

Anterior_palatal_fenestra / single_double absent, 341 Dorsal_fontanelle_on_snout / absent present, 342 Interpterygoid_vacuities / absent at_least_2x_wider_than_long 2x_longer_than_wide, 343 Intracranial_joint / present_in_dermal_skull_roof absent in_dermal_skull_roof, 344 Nature of dermal_ornament / tuberculate fairly_regular_pit_and_ridge irregular absent_or_almost_absent, 345 'Nature of ornament: starbursts of radiating ornament on at least some bones' / no yes, 346 Anocleithrum / oblong_with_distinct_anterior_overlap_area 'drop-shaped with no anterior overlap area' absent, 347 Cleithrum / ornamented not_ornamented, 348 'Cleithrum, postbranchial lamina' / present absent, 349 Digits / absent present, 350 Humerus / narrow_tapering_entepicondyle 'square or parallelogram-shaped entepicondyle', $351^{-}$'Ilium, iliac canal' / absent present, 352 'Ilium, posterior process' / oriented_posterodorsally oriented_approximately_horizontally_posteriorly, 353 Interclavicle / small_and_concealed_or_absent large_and_exposed, 354

Interclavicle_shape / ovoid kite_shaped with_posterior_stalk, 355

Lepidotrichia_in_paired_appendages / present absent, 356 
Posttemporal_and_supracleithrum / present absent, 357 Radius_and_ulna / radius_much_longer_than_ulna approximately_equal_in_length, $358^{-}$'Ribs, trunk' / all_cylindrical

some_or_all_bear_flanges_from_posterior_margin_which_narrow_distally some_or_all_flare_distally, 359 Scapular_blade / absent small_with_narrow_top large_with_broad_top, 360 Scapulocoracoid / small_and_tripodal large_plate, 361 Subscapular_fossa / broad_and_shallow deeply_impressed_posteriorly, 362 Squamation / 'complete body covering of scales, all similar' ventral_armour_of_gastralia, 363 Pectoral_process / absent present, 364 Proximal_limb_of_oblique_ridge / 'present, separated from anterior margin of humerus by prepectoral space' 'absent, replaced by deltopectoral crest', 365 Latissimus_dorsi_attachment / diffuse_ridged_area distinct process, 366 Foramina piercing oblique ventral ridge / many one_moderately_large_foramen_in_addition_to_entepicondylar_foramen 'entepicondylar foramen is the only large opening, other foramina ar epinpricks or absent' none, 367 'Humerus with well-developed anterior plate' / yes no, 368 Subclavicular_ossifications / Absent Sometimes_present, 369 Radial_capitulum / approximately same size as ulnar facet 'greatly enlarged and rounded, $>2 \mathrm{x}$ size of ulnar facet', 370 Lissamphibian_inner_ear / no yes ;

MATRIX

Archeria_crassidisca $\quad 02000000100100001001000 ? 01000011000000001---$ 01000000010--01000000000100-010000002100000000100000010001???2?000000003000000010010000020112010000????????????????1211???0?00 0???????00010100101?00100100000100101?000000001?1100020000000001000?0?00-101??0000100001110012111111 ?1111110?0??000?????122110110100311111001111111?121111-0(0 1)01000021001212111100111110211111120000

Crassigyrinus scoticus 0100001010000000000100101000000110000000000000001000010--0001-000011000$000000000100000000000010-$ 010001???0?000?0000?00?????0?0100?000??1??1000??000001000000???12110000?20 000100???0?0101?0?0???????00??0000001?0???00???1??0?0?000000??0??000??????0??????0?$1000010111021011010 ? ? ? ? 10 ? 0000000000000020000001003111 ? 100001001 ? ? 112111$ $1 ? 101101101110121 ? 1111 ? ? 111110 ? ? ? 11111000 ?$

Acanthostega gunnari 000100010000?000000000000000000000000000000000000000010--00000000000000000000000000000000000000-0100000000?0000000000000000\{0 $1\} 000000000000000000000000000000000000000000030000100000200000 ? 0$ $100 ? 000000000000000000 ? ? 00000000 ? 000001 ? 00000000000000000 ? 00 ? ? ? ? 000-$ $00001111000111 ? 001011110001000001000000011000 ? 10001111010010100110000110$ 010001011111101111101100111102010111120000

Eusthenopteron_foordi 01000000000100010100--0-11010-00-------000000001000000--0301-000000000-001000000-01?00000000?10-

01000020????????????????????????????????????????????????????????????????????? ??????????????????????1?????????????????0-??????????????????????0?????0??- 
000000000000000000?00000000000000000000010000?00000000000000000000?00000 $00010000000000000000000 ? 0000000 ? 000100 ? ? 0$

Ichthyostega spp. $\quad 01010001100020000000000-$ 1100000110000000000000001000000--00100000012010-000000002000?00000100-(0 1) 0 01000????0?00000000000100011000??????????0000010110111010001??01201010031 $00 ? 1100-$ 021?010????0????00?01?000002?100?0?00????0000?10000000000??0001?10??0?????0 ??-0100111?1000111001011?1000(0 1)000231001000001000?1000?1100000101001?000011001002101112000111?1011111 21111011?10010000

Panderichthys_rhombolepis

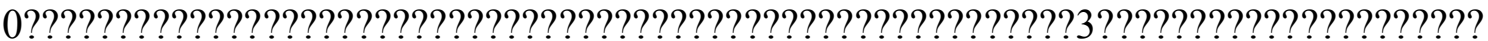

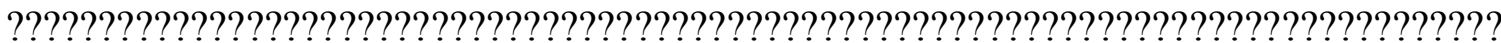

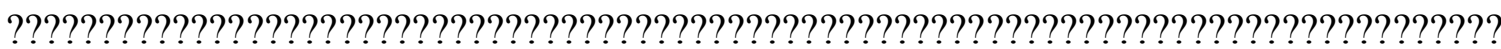

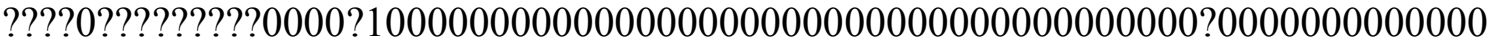
0000000?000000000000000000010000000??0?000101?0000?0??0

Pederpes_finneyae 0100000010012000100?0??0000?011110100000000000??1000000--01?000000?2010$000000000100 ? 000001 ? 0 ? ? 0-$

01??01???0?000?00000???????11100000??0?1??00000?00000?0100010?11200101?310 00011???2??0??????????????00?00000??1???0??0???????0???0?????????????0?????0?? ????????1?01101000?1010?1?1??110?001000??????????????????????????????????????? ??????????????0111?11110112111111?11112000?

Tiktaalik_rosaea 01010010100120000001100?1100000110100000000000001000000--030000000000000000000001010000000000(0 1)0-0?000000?2-------------????????????????010--

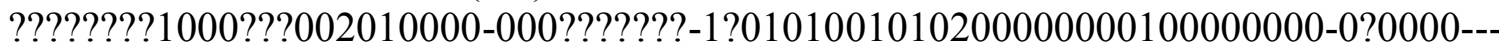
$-?-? 0 ? 10000000 ? ? ? ? 0 ?---0--001 ? ? ? ? 00-$

??0??11??00?11?000?00?0000????000?????0000000?00000?000?0000??0000???000000 $0 ? 10 ? 0 ? 0 ? 0010000000 ? ? 0 ? 0 ? 0 ? 010 ? 00000 ? ? 0$

Ventastega curonica 0?000000000020000011000?110001011010000000000??01000000--00001000011000$00000000010 ? ? 00000000010-$

0100????????????????????????????????????????????010111010000??0?????????000??? ?????0?010100??1?20?0?010100000010010?000???0?1??0110?0?0000???0???????0??? ???????0???111000111?00101101000??000?100?000001000?100000100001100001100 $00010010001010210101111110 ? 0011 ? 1 ? ? 010 ? ? ? ? ? ? ? 0$

Whatcheeria_deltae 0000000010002000100000010000011110000000000100001000000--01000000011010$00000000110 ? ? 00000100 ?(0$ 1)0000001???1?000?00001???????1?00??????????00000?000000001000001012000000310

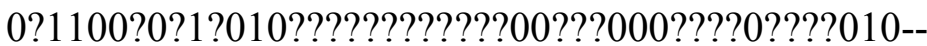
$0 ? 10 ? 01000 ? 00000 ? ? ? 0 ? ? ? ? ? ? ? 0 ? ? ? ? ? ? ? ?-$ 10000111?00210100111??11??0000001001101001001000002010000000100110102110 01002101011?00131?1011011211?121??1112000? 
Ymeria_denticulata

0?1??????????????????????10?0?01?????????????????????????010010000?2000-

$000000001 ? 00 ? 00000000 ? 10-$

01000??????????????????????????????????????????????????????????????????????????

?????????????????????????????????????????????????????????????????????0??????????

1001????00?????0?0???????00?0??100?0?00(1

2)?000?100021?0000??010??0?00?01000000101110?0?31?????????????????????????

Proterogyrinus scheelei $010000\{01\} 0\{0$

1\}001?0001000000?0000000000000000000001000000010--00000000000000-

000000000000000000000?00-00\{0 1

2\} 1000000?00000000300001?0100000000000000?00000000001000000020100?101001

0111000100?00101?101?11000?1-11000100??00003000--

$1 ? 00 ? 0020000000001000 ? 0 ? 00 ? 10 ? ? ? ? ? 00-$

10000101001210111111???11?0100000?????1221????0101?111?11001111?11?12???1?

00011---2200121211110011111021?11112000?

Balanerpeton woodi

000000101001000000000?110000000000000000000?10000000000--10000000000000000000000011100000100000 -

$0001010001 ? 000000000000000 ? 00000000 ? 000020010000000000000000 ? ? 0220011001$

10211000100?0000?????????????????00??????????00??????0????????????1 $200 ? 000 ? ? ?$

$1 ? ? ? ? ? ? 00-$

$110011011 ? 02101111011 ? ? 101011100000111112111 ? ? 0101 ? 111 ? 20002110100 ? 10111$

1?00111?--22021112111100111112?1?11112100?

Dendrerpeton_acadianum

000000001001000000000?100000000000000000000?00000000000--10000000000000$000000000011000000001110-$

$00 ? 1010001 ? 00000000000001 ? ? 10000000 ? 00 ? 0 ? 0010000000000000000010220011001$

002?00?0??0000001??01????00?0??01001221?10013013--2010-

110000000001?00000000?10??1?100-10001101?102101111111111(0

1) $10111000011111(1$

2)21??110101?1?1?11??1111??0?111111?0?11????2202111211110011111021?1111210

01

Cardiocephalus_peabodyi 32011-012001100010000?001101121001-$00010000210\{01\} 10000-0--12100$ ?102231110113?0??0?????0?0111?1??0-

20??110002??01?00102???????100001220?0110000010????????1000?0-

121012?0??202010?????11010????????????1?????01?????????????????????????00??11

?000?1??0?21??2110111??????????????????????????????????????????????????????? ?????????????????????????????????????????????????10??

Huskerpeton_englehorni 3?011-012001110010000?002101011001-$00010000210110000-0--121000100 ? 2010-$

01200000??010?0011101111010211????????????????????????????????????????????? ??????????????????????????????020101110111112011-

$00000122101110100201212 ? 011310000-$

0011100???00?21??2110111101010100121011111111111110002301-1?01220--100101111-1000-1-0100-121100101011---2202130211????12?1??21???????0?0 
Pelodosotis_elongatum 03011-012001100110000?001001031001-00000000010110010-0--1211-010012010-012?000021010000\{0 1\}0111111020?1100002??01?10102???????10001121?10110010010?0111-111000111220021???00201000????1110?100111001011-

$000002121011 ? ? 1102 ? ? 2 ? 2111 ? 3 ? 0 ? 000011110011210 ? 21 ? ? 2 ? 00111101010100121011$ 111111110010100301-111122????00101-111-10??1110100-1??????0?011--220212021111??12111021?-11021000

Nannaroter mckinzei 3?011-01200110???0000?0011010?00?1-0001000001011?0?0-0--12100010113010-

012?00002?01000010101??1020201?????????????????????????????????????????????

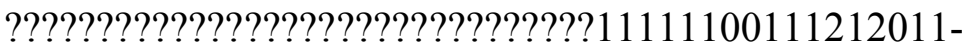

$000002121010 ? 0110 ? ? ? 2 ? ? ? ? 1 ? 3 ? ? 000-$

01???0?????0??1????10111101???????????????11110010100301-1?11221-??????1-

111-1000-1-0100-121111111011---2202120????????????????????????

Micraroter_erythrogeios 03011-012001110110000?000001030001-$00010000210\left\{\begin{array}{ll}0 & 1\end{array}\right\} \begin{cases}0 & 1\} 0010-0--12100010113010-\end{cases}$

$012000002000000010101 ? ? 102021100000 ? 00101010200001001000012200011000002$ ? ???????1000?0-1??0??????102110??????11101100111001011-

0000021210111 1002?12?211113000000011110001110?21??211011??0?????????????? ????????????0301-1?11221-??????1-111-100?-1-0100-1211?1?01011---

2202130??????????1?????-?????0?0

Eocaecilia_micropodia 3301?-0?-1----0000000?011101121001--00011--0?011100?----120000000000010013000011013\{0 1\}0?0---????101?3?110002?002?0002?????0111010122-201121000013?????????????0220121002?0?011001?1?-

0000011110210011-00110221111?203003--30?011?010-00-12?20001001?10??1?010?111--101100211111001111-0110000001-10011------01-1-1---000--------110000101010222011202--11??0-111021?-01?21??1

Brachydectes_newberryi 23021--100010-1--00000012101120001--00001--0101110-000--12000000013000-

$01310000110200011001111102031100002 ? 011000102000010100001121020012110000$ 31110-11000001001001\{0 1\}11?12021110??10?110011111110000?1000002221110101002102121111310000-011110011002?2???211011111-10100121111111111111111012301-1001220--100101-111-1000-1-0100?121110-01011--2200130211110012111121??11?21000

Greererpeton_burkemorani $0200000100110000000000012100030101-----$ 0000000001000000--00000000000000-0000000000000000000001000000010002?00000000000000??10100000?0000211100000010000000111011011110100201010--0?00001010?1?1000?00000001001-10103003-$1 ? 10-111000000001100000000-100 ? ? 0 ? 00-$ $110011010002110101011111010000001011101221001101001011 ?(1$ 2)1000100100?1200011101101102111111210110011111111?111120000

Seymouria_baylorensis 01000000100100000000000000000010000100000000001000000000--00000000012010$1000000010000000000000\left\{\begin{array}{lll}0 & 1\end{array}\right\}\left\{\begin{array}{ll}0 & 1\end{array}\right\}-2000001001 ? 000000\{0$ 1\}02000010010000000000110000010011000100100102012101000000111100?00?0010 1?1011?0020?1-110001021-1110310-??1?11-100000111001010010?00?1???1??00- 
11011111001211111111111101111111000111122110110101-111-11001111100-

111111-11211---22001102111101121110211111121000

Limnoscelis paludis

0101010110010000100000000000001001000000000001100010000--12100001022010-

$0011001010010000000101\{01\} 0-$

0010110000?000000002000000010000000000100000010011000??0100?0?0221010100

10111000110?00001?1011?0020?1-110011021-

$11103001001 ? 111102010111011000101 ? 00 ? 2 ? ? ? 1 ? 000-$

1101110111121011111111111111111221-11012200-100101-111-1100-1-0100-121110-

11011---2202130211110112111021?-11121000

Branchiosauridae

311100100001210000000?10100001000020???0000010000010010--11000000010000-

$00\left\{\begin{array}{l}0 \\ 1\}\end{array} 0000\{01\} 1\right.$ 1?13010????????0-

?????020010000?00?0000?0?0000000?????0?1200200?00-

$000 ? ? 000 ? ? ? ? 20000101 ? 120211010--$

0?0010???????????????????????????111????????????00??????0?????0?1??????10-

1???????????????????????????????????????????????????????????????????????????????

????????????????????????????310??

Micromelerpetontidae $\quad 311100100001010000100 ? 1000000\{0$

1\}000000???0000?11000010010--01000000000000-

00?010000?13100???????????????010000000?00?0000?0?00000?0?????0?1210000?00000??000????20001101?120211010--

0?0001?????????????????????????????01??????????????0??????00?0??0?1??????10-

1??????????????????????????????????????????????????????????????????????????????

????????????????????????????310??

Tersomius texensis $\quad 2 ? 0100\{01\} 010010\{01\} 00001101100000010000\{0$ $1\} 00010000$ ? $10001000000--1100000000000\{01\} 00\left\{\begin{array}{l}0 \\ 1\}\end{array}\right\} 0010000 ? 131100000000\{0$ $1\} 0-$

0101010?0??????????1????????????????????????????????????????????????????????

0????0001????????????01??????????????00??????0???????00???1?200100?0?1??????1

??100101010000101111011111?1010100000110112111110101-111-

10002110100?10111?-010101012011111?????????????????????0??

Ecolsonia cutlerensis

0? $11000110011100001001102020000000011210000000001000000--1000000001\{0$

$1\} 010-000010000 ? 1210000000 ? 0\{01\} 0$ -

0?000?000??00010100000001011000???????????100?????????0000?010?11??0?0?100

110?0????0000?????????????????????????????0???????????????00?????100????0?1????

$? ? 10-$

1????????????????????????????????????????????????????????????????????????????

?????????????????????????????3101?

Acheloma spp.

0?010001100??000001001?020200000000111100?0000001000000--10000?00011010-

$000010000 ? 12 ? 000 ? 0100 ? ? 0-$

01?00?000??00000000000000?01000?????????001???????????000????02210?1001?0?

????0????0000?0001101000101001002111010002003--2?10-

$100001001001110110200 ? 1 ? ? ? ? ? ? 10-$ 
$10011101010210111111111101011100101101122111110101-111-$ 10002110100?101111-000110002011111211110?12111121??1113101?

Eryops_megalocephalus $010100 ? 11000-$ 000000?001?0000000100?00000000000000000000-10000000000010000000000?121000?00????0?????0?0?01?00000000000000001000??????????0000??00000?000000??02211?10010?1???0?000?00011001111000011-000002111011100003-$1 ? 10-110001000001110000201 ? 1 ? ? ? ? ? 000-$ $11001111010210111101111100011100001111122100110101-$ 111?20001110100?101111?00011???2001111211110-111111211?1113101\{0 1\}

Doleserpeton annectens 3?010010100100000010011?0000010000200000000?10000010000-$11000000000001001001001\{01\} ? 13110000000000-010 ? 010001 ? 00\{1$ 2\}?0000200?0??110000?12220??2??200?????????010????????????0??0?????0????0001 001011?1100?01001002211?10113103--2010-111101000001120010000?1???0?0101200110100021011110111110110000001--011121??100101-1--10002110101?101100001010101201113021111?0111110210-01-31011

Caudata $\quad-2\{01\} 11---00012-0110100-1000002\{12\} 0001--00001---$ $0-21----1-0--120000000\{01\} 0001001\{23\} 002011015\{01\}-0002-2-2-0-10\{23\} 010\{1$ $2\} 003\{01\} 0120000020100100111011222201120020013-------1--$ $11112001001120211000\{0$ 1\}00?-10000101101(0 1)(0 1)01(0 1)100100221111-20?0(0

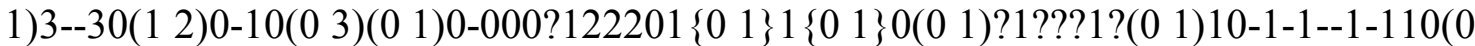
1)(1 2) 1 ? $110\left(\begin{array}{lll}0 & 1\end{array}\right)\left(\begin{array}{ll}0 & 1\end{array}\right)-1-$ 1??????????????????????????????????????????????????????????????????????????????? ???????31011

Anura $\quad$-1111----1----1--\{0 1\}100-10-0002100002000101---0-20--$1-0--120000000\{01\} 00010010001011014\{01\}-0002-\{12\} 12-0-11301001030012-$ 000021----1101011122201120020013-------10110011001000101211001100?0??0010110010011-00100221111?20?1(0 1)3--3010-101(0 1)0-0000(0 1)2220110\{0 $1\} 0(0$ 1)?1???1?(0 1)10-121--

1????????????????1?????????????????????????????????????????????????????????????

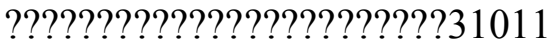

Albanerpetontidae 3?011---1001211--1100?0?20001100012-00001---1-21--01-0--11000-000??1011012?0?00???3???002-2-111021301?000\{0 $1\}$ ?012?00002??????011001122220122002001????????-1 ????0???0???0??0??10?0?0??-

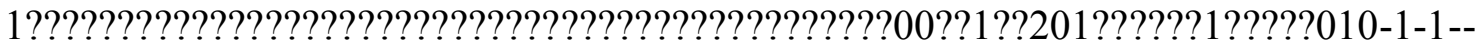
?????????????????1??????????????????????????????????????????????????????????????

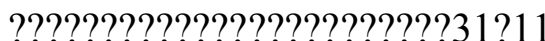

Micropholis_stowi $20\{01\} 1000\{01\} 10012100000\{01\} 0110\{0$ $1\} 000000000000000000010000001000--1-0000000\{01\}\left\{\begin{array}{l}0 \\ 1\end{array}\right\} 000-$ $00001000001311000000111100101000003 ? 000 ? 00001 ? ? ? ? ? 011010 ? 0002 ? 0 ? 1200200 ? ?$ 0-00000010001?120001100000201000100?0011????????????01???????????????\{0 1\}0??????????????00?????200000?0?1??????10-1000110110021011110111?10?\{0 $1\} 1\{01\} 100000110122111110101-111-$ 11??2110100?10?????0?01????201111121111011111102?0?01-3101? 
Eoscopus_lockardi $\quad 2 ? 01001\{01\} 100101000011011 ? 000000000020\{0$ $1\} 210000$ ? 10000010010--11000000000000-000010000?1311000000?\{0 1\}?0?0?00?0001000000000100001011000???0200?\{0 1\}200200100$00000010 ? ? ? ? 0110 ? 21001\{0$ 1\}0201000100?0001????????????01???????????????01??????0???????00??????0?000?0 ?1??????10-1000110110021011110111?101010100000110122111000111-11110002110100?101111?0001????20011102??1101111110?????1?3101?

Tambachia_trogallas 2?01000110010000001001102020000000001110000000001000000--11000000011010$000010000 ? 121000 ? ? 1\{01\} 1 ? ? 0-$

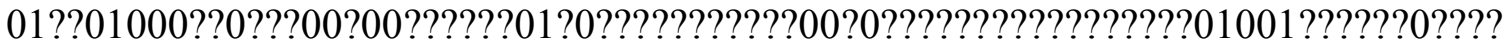
?0????0001????????????????????????????????????0???????????????0?0?0???1+?????1 0-1001110111121011110111?10????100001111?22?????0101-1?110??2110100?10?????0?01?????0011112??1101??111?????11?31???

Triadobatrachus_massinoti 21111-1-??????0--0100???????21???020-0101---

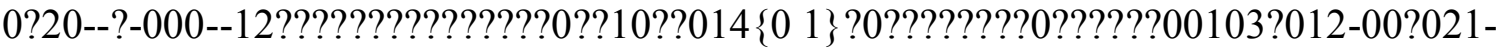
$---011010 ? 1 ? ? ? 20\{01\} 1 ? 002001\{03\}-------?-10 ? ? ? 010001100 ?\{12\} 12-1001 ? 0 ? ?-$ 0???????????????????????????????10??????0???????00?????2011?0???1??????10-?21-1???????????????????????????????????????????????????????????????????????????????

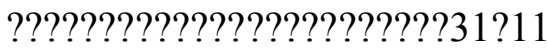

Gerobatrachus hottoni 2111001010012100001101?000?02100002000000???00000010010--??000000000000$0120010120141100 ? ? ? ? ? ? ? 0-$

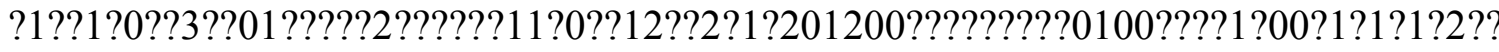
?0???0??001?????????????????????????????10?????????????????????2019?????1?????? 1??120?1101?0021011110111?1?1111?2001-100122?????01?1?111-

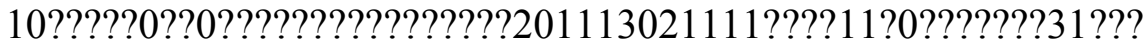

Platyrhinops_lyelli 210100?01001?10000010?1100?0200000200000000010000010010-1110000000000100?0010?0??131100000201?0-?0??010000??02$0000100 ? ? 0 ? 110000102 ? 2 ? 1 ? 200200 ? 00-$ 0????0100???01??0111010?2?1000??0?0001????????????01???????????????00????????

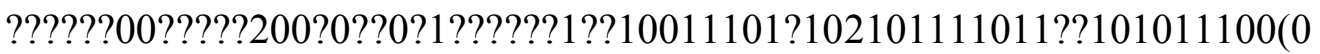
1)00111122111110101-111-1000211?100-10111100010000220111121111?0111110210?01?3101?

Amphibamus grandiceps 211100?01001010000000?1000?0200000200000000?1000001001???111000000000010 $010010010 ? 13110000 ? ? ? ? ? 0-$ $0 ? ? ? ? 10001 ? ? 00 ? 0000200 ? ? 00110000 ? 00 ? 2 ? 1 ? 200200 ? 00-$ 00000010000 (0?1?0100?1102?1?00??0?0001????????????01???????????????11??????? ???????00??????00000?0?1??????1??12??????????????????????????????0?+???????????

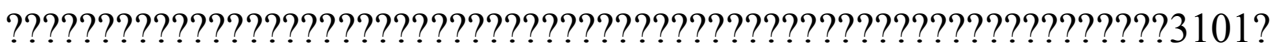

Lethiscus_stocki 230100010001110011100011200101101000000001-01101001010--?2000000012000-011000000110000000000000000001???2??120000021---01111(0 1)102222001210110???????????????????????????????????0-1101000010000111-00000000000-000000-- 
0010-110000000001?00010000-001?00100-

$1000110100021011001010101011 ? ? ? 001010 ? 0001000-$

100???10010110110010?10111?-010102002000130211----0--1?????1???--?-0

Coloraderpeton_brilli 13010001000111001000????????01001000100010-01001000010--02000000012100-010?00002100000000000000-000001---2??120000021---01111(0 1)102222001210110-????????????????????????????????????0-

1101000010000111-00000000000-000000--0010-110000000001?000?0?00-001100000?000110?000?10?00?1010100010000001?-0000010?0-1000\{0 1\}110?1011011001010111?-01011???20?0130???-----?-1?????1???--?-0

Edops_craigi 0100000010002000000000000000001100000000000100000000000-10000000011000$000000000112000000001 ? ? 0-$

10000??????????00???????????????????????????????????????????????????????????????

???000011001111000011-000001101011100003--1010-11000000000111000021?1??????00-10001111010210111111111100011100101111122100100?01-11110000110100?101111?00011---2202111????100????1????111?21?0?

Captorhinus laticeps 0102011-20011000101000000101031101-000000000--0---0100--11000001123010-0111001021000-00100111(0

1) $101021000001 ? 0020000021----$ 0110000102220010010011311100110?1?101022101100000201000110-01011111??2010?1-100002221$110030021121211103000000001000101001021 ? ? 2 ? 100-1 ? 1-$ 010100121011111111111--111221---0122-?-100101-111-1000?1?0100-121110-11011$--22021202-111 ?-12111021 ?-11121000$

Petrolacosaurus_kansensis 02020111200100001010000?0101011101-0000000100000011000--12000000011010-0111001021000000000012--00211100?0??020000021----0010000002020010110011311111010100010111001000102?1000110-00101?10???0?10?1-?00002221$11003012112 ? 211113000000001110101000 ? 21 ? ? 2 ? ? 010 ? 101110100121011111111 ? 10 ?$ 11111001-1111221--100101-111-

10001110100?1????????????????????????????????????????100?

Ophiacodon uniformis 0102010010012000101000100101011101----0000101100001000--12000000011110$01010010210000000011111111021110 ? ? 0 ? 002000002001000010000002120100100010$ 01101011010010102210010001020000011000010111011?1020?1-11001102111103001--30111102010101011100101002?20????0001101011100121011111111111111011221-1101221--110101-111-1000-1-0101-12111001211---22021302111101121110211-11121000

Baphetes_spp.

0?00001010011000000100000000010110000000010100001000000--0100000000?000$001000000000 ? 00000100 ? ? 0-$

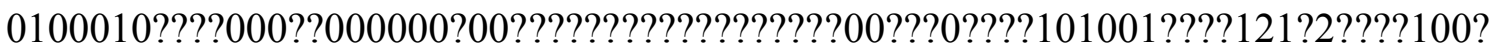

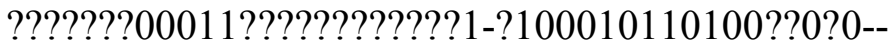
$1010 ? 011000000003 ? 000 ? 0 ? 0 ? ? 1 ? ? ? ? ? ? 0 ?-$ 010011?1010110110101111100011100000111????????????????????????????????????? ??0010?200111?111100??1?1????111120??? 
Eucritta_melanolimnetes

00000000100110000000000?0000210010001000000000001000000--1100?0000?1000$0000000 ? 0 ? 00 ? 00000000 ? ? 0-$

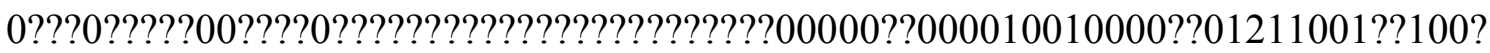
$1100 ? ? 0 ? ? 010 ? ? ? ? ? ? ? ? ? ? ? 1-$

?100012?1?1?0??0???????????1????0?????????????1???????-

$11011101010210111101 ? ? ? ? 0 ? 1011000 ? ? ? ? ? ? 0 ? ? ? ? ? ? ? ? 1-$

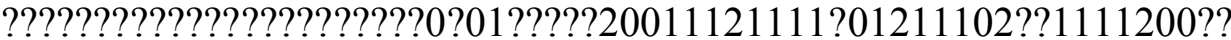

Llistrofus pricei 3?011-0120011101101000?0200?020001-----

1000121000011000--10?000001?2000-0111?0002101000011011110-

102111???1?011?00002???????1000????????????00??????????????????????01?2??????

?????-0110111011?01?011-000002221?111??002??2????1?010?00?0011100???00-

2??????0??110??101001211111111111101??1?03?1-1111221??100101-111-

10???1?0100?101100111011---22?2121?????????1110????????????

Aletrimyti_gaskillae 32011-012001111--00000001102121101----$10000210 ? 1011000--12100010013000-$

012100002100000010101111020211??????????????2??????????????????????????????? ?????????????????????????????-21111101111011011-00000222101110100211210111310000-0111100?1000-210121101111010101001210111111111111100023011?01220--110101-111-1000-1-0100-121110-11011---220213021111??12111021?$? 1 ? 21 ? 00$

Dvellecanus carrolli 3?011-01200111???00000001102120001----1000021011011000--12100011013000-012100002100000010011110-

20211???????????????????????????????????????????????????????????????????????????

???-21111100111011011-000002221011101102112120110310000-0111100?100021012110111101010100121011011111111010002301-1?01220--110101-111-1000-10100-121110-11011---2202130??????????1????????????0

Rhynchonkos stovalli 3?011-012001111--00000001102210001----1000121000110000--12100010013010-

0121000021000000100?1111020211???????????????????????????????????????????

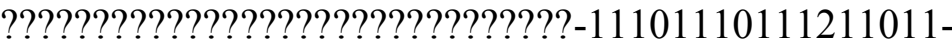

$00000222101010110211212011131000000111100 ? 1100-$

21012110111101010100121011111111111110002301-1?01220--100101-111-1000-1-

0100-121110-01011---2202130?????????1?????????????0

Dimetrodon spp. $\quad 0102010010112000101000000001001101----$

00000001000-0000--12000000023110-0111001021000000111102-

112110110?????1200000201100001000010?????0?10001??1111-

11????????2210?1000002010000000-1101?1111?1020?1-

110011121 ? $1110300 ? 0030111102010100001000101002020211 ? 0000110101110112111$ 1111111110111111221-1101221--100101-111---00-1-0101-121110-11011--22021302111101121110211-11121000

Opisthodontosaurus carrolli 1?02??0?200110001000??0011010?0101----100000??0???0?????12100000213010-111100102100000011111??010201???????12??0002??????1000??????????1?00???1111-11--1$1010221001000002110 ? ? ? ? ?-$

?0001?????????????????????????????????????????????????????????????1?2?????1???? 
??????????????????????????????????????????????????????????????????????????????? ????????????????????????0??

Pantylus cordatus 00011-0120010000100000000101011001-00000000010110000-0--10100000223010-0111000011000000100011\{0

1\}102020000001?01101010200000011000012202011101000?01111$101000201022002100110211000110 ? 10001100111212011-$ $100001221011101002112121 ? 113000000001110011011 ? 21 ? ? 211011111--$ 111001211110111111111--100321-1111221??110101-11110001111100?111100111011---2202111211110012111021?-11021000

Quasicaecilia_texana 3?121-1-1001001--01000??210?220001--00000001220---0100--

121??????????????310?0??1120?0????????1?????1???????????0??????????????????????

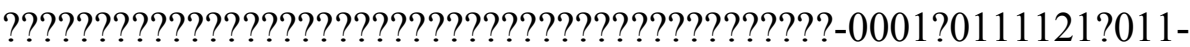
100002221110??110???2???11?3?0000-01111001??0212101-11011?11-101???21011???1111?11110?23???????????????????????????????????????????????? ?021302?????????1??????????????

Carrolla craddocki 3?021-1-200100???01000?0210?130001-----00?00220---01----1211-0101230011013000001120001100111110103111 ?????????????????????????????????????????????????????? ????????????????????--00011111110000?1-1000022?111?101100?12?21111310000011120111001?21??-100111111010100121011101111111111012301-110122-----0101111-1000-?-?100?11-----01011---2202130??????????1?????????????0

Batropetes_frischti 3?021-1-200100???01000??210?130001-----00?002-20--01----1211-010123001101300000-

11200011001111101031110??4?0?1000????????001????12?????000000?01111$10 ? ? ? ? ? ? 02 ? ? 1 ? 1001102 ? 1100110--000 ? ? ? ? ? ? ? 0 ? ? 0 ? 1-$ ?00??22???1????100?12??111?3??000-01??2011100??2???1?0111111010100121011?01111111111012301-110122-----0101-111-1000-?-?100?11----01011---220213021111?01211?021?11102100?

Diabloroter bolti 3?021-1-?????????0100???21??1300?1-----10?002-20--?1----12???0100?1000013?0??0???????1????????1???110??4?0?1000????????001????12??????000000?0???? ?????????02??1?1????02?11?0????000??????????0???????????????????0?????11193???0?-0???????1???22????????1????10??0121011?????????????????????12??????+1?????????00??-???????----01011---??0?1302???1?0??11?021????0?100?

;

END;

BEGIN ASSUMPTIONS;

TYPESET * UNTITLED = unord: 1 - 370;

END;

BEGIN MESQUITECHARMODELS; 


$$
\text { ProbModelSet * UNTITLED = 'Mk1 (est.)': } 1 \text { - 370; }
$$

END;

Begin MESQUITE;

MESQUITESCRIPTVERSION 2;

TITLE AUTO;

tell ProjectCoordinator; timeSaved 1538493066564;

getEmployee \#mesquite.minimal.ManageTaxa.ManageTaxa;

tell It;

setID 08448515054581849959 ;

tell It;

setDefaultOrder 012345678910111213151617

1819202223242526272829303132333435363738394041424344454748

4950515253545556571446215859 ;

attachments ;

endTell;

endTell;

getEmployee

\#mesquite.charMatrices.ManageCharacters.ManageCharacters;

tell It;

setID 0 5979214557219699653;

mqVersion 320;

checksumv 032141803588 null getNumChars 370 numChars 370

getNumTaxa 60 numTaxa 60 short true bits 2305843009213694015 states 63

sumSquaresStatesOnly 58853.0 sumSquares -3.08982963234635E20

longCompressibleToShort false usingShortMatrix true NumFiles 1 NumMatrices 1; mqVersion;

\section{endTell;}

getWindow;

tell It;

suppress;

setResourcesState false false 100;

setPopoutState 300;

setExplanationSize 0;

setAnnotationSize 0;

setFontIncAnnot 0;

setFontIncExp 0;

setSize 1272 671;

setLocation 8 23;

setFont SanSerif;

setFontSize 10;

getToolPalette;

tell It;

endTell;

desuppress; 
endTell;

getEmployee

\#mesquite.charMatrices.BasicDataWindowCoord.BasicDataWindowCoord;

tell It;

showDataWindow \#5979214557219699653

\#mesquite.charMatrices.BasicDataWindowMaker.BasicDataWindowMaker; tell It;

getWindow;

tell It;

setExplanationSize 30;

setAnnotationSize 20;

setFontIncAnnot 0 ;

setFontIncExp 0;

setSize 1172 599;

setLocation 8 23;

setFont SanSerif;

setFontSize 10;

getToolPalette;

tell It;

setTool

mesquite.charMatrices.BasicDataWindowMaker.BasicDataWindow.ibeam;

endTell;

setActive;

setTool

mesquite.charMatrices.BasicDataWindowMaker.BasicDataWindow.ibeam; colorCells

\#mesquite.charMatrices.NoColor.NoColor;

colorRowNames

\#mesquite.charMatrices.TaxonGroupColor.TaxonGroupColor; colorColumnNames

\#mesquite.charMatrices.CharGroupColor.CharGroupColor; colorText

\#mesquite.charMatrices.NoColor.NoColor; setBackground White; toggleShowNames on; toggleShowTaxonNames on; toggleTight off; toggleThinRows off; toggleShowChanges on; toggleSeparateLines off; toggleShowStates on; toggleAutoWCharNames on; toggleAutoTaxonNames off; toggleShowDefaultCharNames off; toggleConstrainCW on; toggleBirdsEye off; 


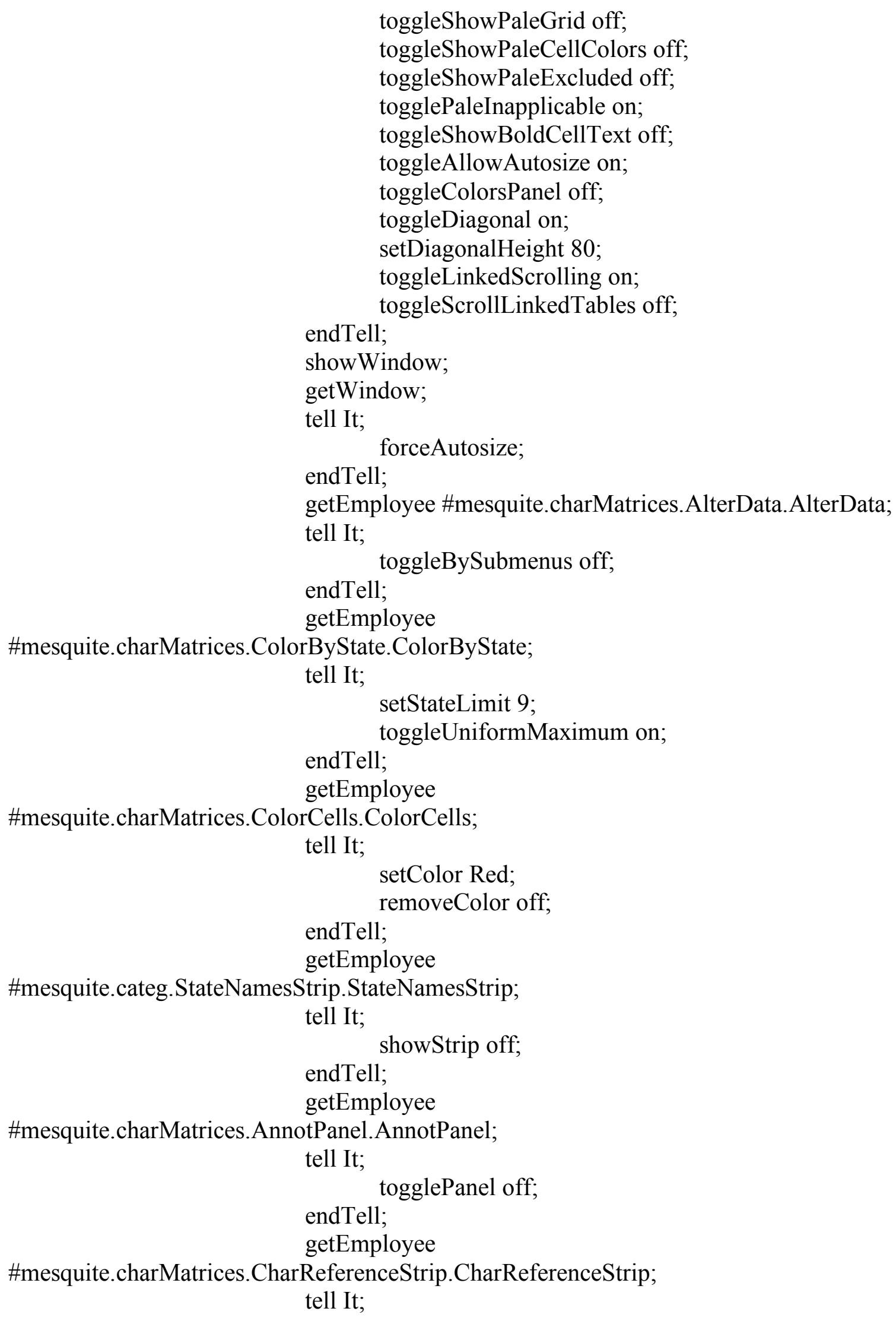




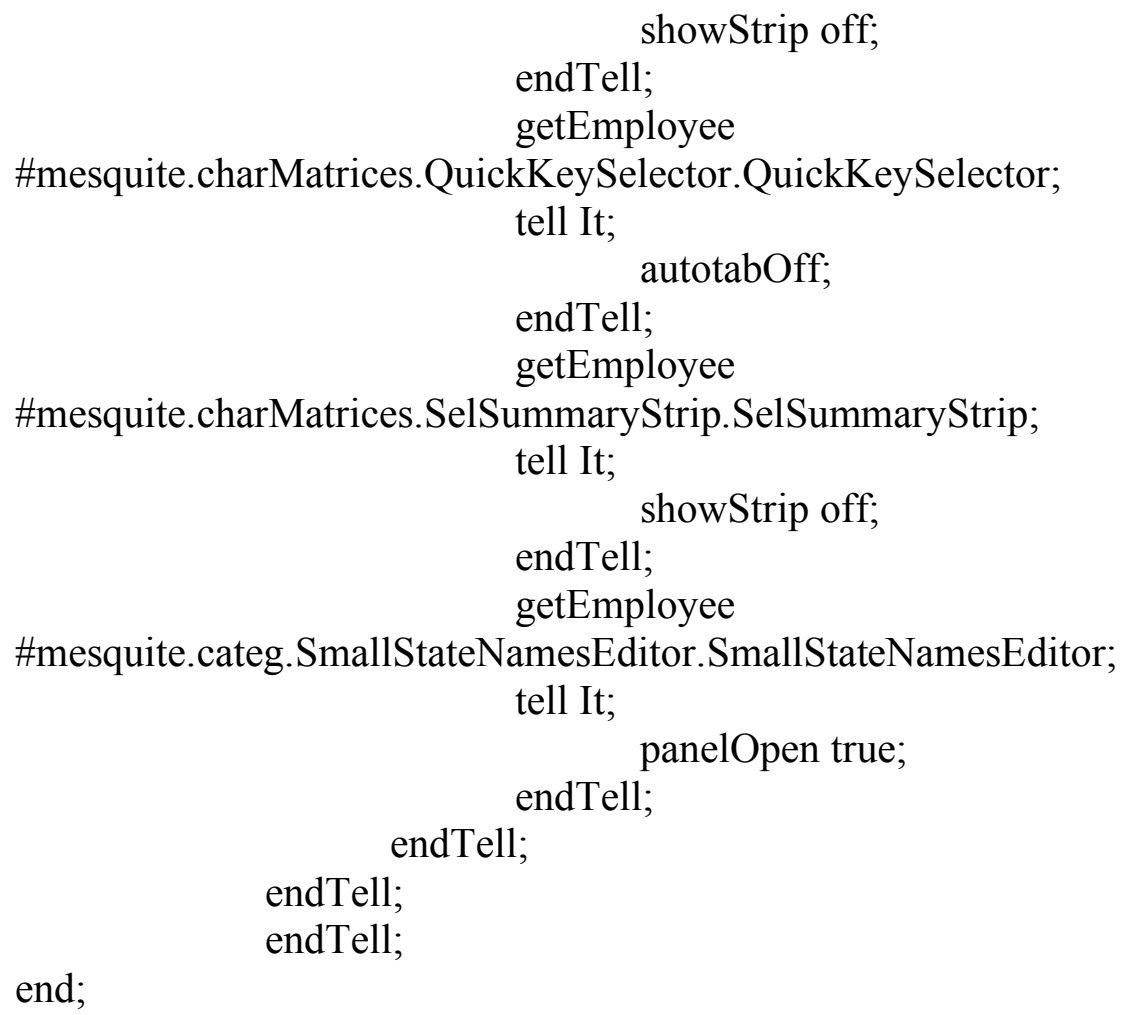

end;

A.4 List of 370 cranial, dental, and postcranial characters used in the analysis of Pardo et al. (2017). The original source of character is noted by the following acronyms: HPSA: Huttenlocker, Pardo, Small, and Anderson (2013), MA: Maddin \& Anderson (2012), CABF: Clack, Ahlberg, Blom, and Finney (2012), N: Neurocranial character novel to Pardo et al. (2017), C: Composite character. Finally, this is the phylogenetic character list used throughout the entire thesis.

1. Basal Skull Length (HPSA 001): (0)>70mm; (1) 50-70mm; (2) 30-50mm; (3)

2. Skull:trunk ratio (HPSA 002): (0) 0.45; (1) 0.30-0.45; (2) 0.20-0.29; (3) 0.20.

3. Skull proportions (HPSA 003): (0) longer than wide; (1) wider than long.

4. Intertemporal (C 01): (0) present; (1) Replaced by anterior extension of supratemporal or tabular; (2) replaced by lateral extension of parietal. Note: this character serves as a replacement for HPSA 004, 007, 008, 050, 051, and 052.

5. Supratemporal (HPSA 005): (0) present; (1) absent.

6. ST exposure on occiput (HPSA 006): (0) absent; (1) present.

7. Postfrontal shape (HPSA 009): (0) broadly quadrangular; (1) falciform.

8. Squamosal-Tabular contact (HPSA 010): (0) absent; (1) present; (2) fused. 
9. Lacrimal-prefrontal suture (HPSA 012): (0) simple butt joint; (1) interdigitating; (2) prefrontal broadly underplates lacrimal.

10. Lacrimal (HPSA 013): (0) present; (1) absent.

11. Lacrimal extends to naris (HPSA 014): (0) present; (1) absent.

12. Lacrimal extends to orbit (HPSA 015): (0) absent; (1) present.

13. Lacrimal orbital processes (HPSA 016): (0) only ventral present; (1) dorsal and ventral present; (2) neither present.

14. Lacrimal-jugal contact (HPSA 017): (0) present; (1) absent.

15. Quadratojugal (HPSA 018): (0) present; (1) absent.

16. Quadratojugal-Jugal contact (HPSA 019); (0) present; (1) absent.

17. Quadratojugal-Maxillary contact (HPSA 020): (0) present; (1) absent.

18. Frontals (HPSA 021): (0) paired; (1) fused.

19. Frontal into orbital margin (HPSA 022): (0) no; (1) yes.

20. Anterior laterally flaring frontals (HPSA 023): (0) absent; (1) present.

21. Nasals (HPSA 024): (0) present; (1) absent. 22. Narial flange (HPSA 025): (0) absent;

(1) present.

23. Alary processes of premaxilla (HPSA 026): (0) absent; (1) present.

24. Septomaxilla (HPSA 028): (0) ossified; (1) unossified.

25. Prefrontal into external narial margin (HPSA 029): (0) distant from; (1) near; (2) present.

26. External naris in dorsal view (HPSA 030): (0) exposed; (1) not exposed.

27. External naris shape (HPSA 031): (0) circular; (1) posteriorly extended, along lacrimal-prefrontal suture; (2) posteriorly extended excavation of lacrimal only.

28. Dorsal exposure of premaxilla (HPSA 032): (0) broad pars dorsalis anteromedial to external naris; (1) pars dorsalis limited, but nasopremaxillary suture exposed dorsally (2) none.

29. Dorsal shape of skull (HPSA 033): (0) triangular; (1) diamond; (2) rounded.

30. Posterior skull margin (HPSA 034): (0) concave; (1) straight; (2) convex; (3) undulating.

31. Snout shape (HPSA 035): (0) blunt; (1) pointed. 
32. Snout length (HPSA 036): (0) less than $1 / 4$ total skull length; (1) greater than $1 / 4$ total skull length.

33. Quadrate articulates along internal flange of squamosal (HPSA 037): (0) absent; (1) present. 34. Otic/spiracular notch (HPSA 038): (0) present; (1) absent.

35. Large otic notch approaching orbit (HPSA 039): (0) more than $1 / 2$ postorbital length of skull; (1) between $1 / 4$ and $1 / 2$ postorbital length of skull; (2) less than $1 / 4$ postorbital length of skull.

36. Otic notch structure (HPSA 040): (0) open posteriorly; (1) closed posteriorly.

37. Semilunar flange of supratemporal (HPSA 041): (0) absent; (1) present.

38. Supratympanic flange (HPSA 042): (0) absent; (1) present.

39. Supratympanic shelf (HPSA 043): (0) absent; (1) present.

40. Raised orbital rim (HPSA 044): (0) absent; (1) present.

41. Postorbital (HPSA 045): (0) present; (1) absent.

42. Jugal-postorbital interfingered processes (HPSA 046): (0) absent; (1) present.

43. Postorbital participates in orbital margin (HPSA 047): (0) present; (1) absent.

44. Shape of postorbital (HPSA 048): (0) irregular trapezoid; (1) triangular, apex caudal. 45. Palpebral ossifications (HPSA 049): (0) absent; (1) mosaic of bony plates in orbit (new state); (2) Single large plate above orbit (new state).

46. Parietal-tabular contact (HPSA 052): (0) absent; (1) present.

47. Postparietals (HPSA 053): (0) paired; (1) fused; (2) absent.

48. Parietal foramen (HPSA 054): (0) present; (1) absent.

49. Postparietal size (HPSA 055): (0) much smaller than parietals; (1) approximately as large or larger than parietals.

50. Postparietal squamosal contact (HPSA 056): (0) absent; (1) present.

51. Postparietal length (HPSA 057): (0) large, quadrangular; (1) abbreviated anteroposteriorly, elongate lateral rectangle.

52. Squamosal-jugal contact (HPSA 058): (0) present; (1) absent.

53. Tabular (HPSA 059): (0) present; (1) absent.

54. Posterolateral projection from lateral margin of tabular above squamosal embayment (HPSA 060): (0) absent; (1) present.

55. Tabular horns (HPSA 061): (0) absent; (1) present. 
56. Tabular horns shape (HPSA 062): (0) parallel or slightly divergent; (1) widely divergent.

57. Squamosal forms base of tabular horn (HPSA 063): (0) absent; (1) present.

58. Lateral line canal grooves (HPSA 064): (0) present; (1) absent.

59. Dermal sculpturing (HPSA 065): (0) circular pits; (1) shallow ridges and grooves; (2)

little to none; (3) tuberculate.

60. Premaxilla anterior margin (HPSA 066): (0) vertical; (1) overturned.

61. Maxilla into external naris (HPSA 068): (0) present; (1) absent.

62. Maxilla entire ventral naris (HPSA 069): (0) absent; (1) present.

63. Maxilla (HPSA 070): (0) longer than palatine; (1) shorter than palatine.

64. Marginal teeth orientation (HPSA 071): (0) vertical; (1) turned medially.

65. Marginal teeth largest anterior (HPSA 072): (0) absent; (1) present.

66. Marginal teeth shape (HPSA 073): (0) pointed pegs; (1) blunt pegs; (2) large cones.

67. Number of premax teeth (HPSA 074): (0) 10-20; (1) 5-9; (2)<5; (3) 20 or more.

68. Number of max teeth (HPSA 075): (0) 30-40; (1) 20-29; (2) 15-19; (3) 40.

69. Teeth laterally compressed (HPSA 076): (0) no; (1) yes.

70. Enlarged teeth mid toothrow (maxillary) (HPSA 077): (0) absent; (1) present.

71. Teeth (HPSA 078): (0) simple points; (1) multiple cusps.

72. Multiple cusp orientation (HPSA 079): (0) Labio-lingual; (1) antero-posterior.

73. Enamel fluting (HPSA 080): (0) absent; (1) present.

74. Labyrinthine infolding (HPSA 081): (0) present; (1) absent.

75. Jaw articulation (HPSA 087): (0) posterior to occiput; (1) even with occiput; (2)

anterior to occiput; (3) far anterior ( $>20 \%$ basal skull length).

76. Internal nares (HPSA 088): (0) widely separated; (1) narrowly separated.

77. Lateral exposure of the palatine (LEP) (HPSA 091): (0) absent; (1) present.

78. Anterior palatine (HPSA 092): (0) short anteromedial process articulating with vomer at choana; (1) long anteromedial process more medial than lateral; (2) palatine absent.

79. Teeth on pterygoid (HPSA 098): (0) absent; (1) present.

80. Tooth pedicely (HPSA 099): (0) absent; (1) present.

81. Palatal teeth size (HPSA 103): (0) larger than marginal teeth; (1) equal to marginal;

(2) smaller than marginal. 
82. Parasphenoid (HPSA 104): (0) medial of stapes; (1) under footplate of stapes. 83. Interpterygoid vacuities (HPSA 115): (0) narrow or closed; (1) wide; (2) fused at midline.

84. Anterior extent of pterygoids (C 02): (0) Pterygoids contact anteriorly; (1) Pterygoids exclude vomer from interpterygoid vacuity but excluded from median contact by parasphenoid; (2) pterygoids contact vomer but do not exclude vomer from interpterygoid vacuity; (3) pterygoids reach anteriorly only as far as palatine; (4) pterygoids reach ectopterygoid only; (5) pterygoids do not contact lateral palatal bones at all Note: This character serves as a replacement for HPSA 116, 118, and 119) 85. Lateral process of pterygoid into posttemporal fossa (HPSA 120): (0) absent; (1) present.

86. Ectopterygoid palatine width (HPSA 122): (0) wider than maxilla; (1) narrower than maxilla. 87. Pharyngeobranchial pouches (HPSA 123): (0) absent; (1) present.

88. Dentary (HPSA 124): (0) tooth row greater than 50\% of total jaw length; (1) tooth row less than $50 \%$ of total jaw length.

89. Dentary forms coronoid process (HPSA 125): (0) absent; (1) present.

90. Surangular (HPSA 126): (0) subequal in size to angular; (1) substantially smaller than angular (2) absent.

91. Angular (HPSA 127): (0) approximately as deep as the dentary mid-tooth-row, or less; (1) deeper than dentary mid-toothrow.

92. Number of splenials (HPSA 128): (0) 2; (1) 1 ; (2) 0.

93. Splenial exposed laterally (HPSA 129): (0) present; (1) absent.

94. Meckelian fossae (HPSA 130): (0) 2 or more; (1) 1; (2) 0.

95. Ventral border of Meckel's fossa (HPSA 131): (0) splenial; (1) angular.

96. Retroarticular process presence (HPSA 132): (0) absent; (1) present.

97. Retroarticular process shape (HPSA 133): (0) straight; (1) hooked.

98. Vertical position of jaw articulation relative to tooth row (HPSA 134): (0) above; (1) equal; (2) below.

99. Extent of angular in lateral view (HPSA 135): (0) posterior tooth row; (1) middle of tooth row.

100. Number of coronoids (HPSA 136): (0) 3; (1) 2; (2) 1; (3) 0. 
101. Splenial participates in symphysis (HPSA 139): (0) yes; (1) no.

102. Jaw sculpture (HPSA 140): (0) present; (1) absent.

103. Ossified hyoids (HPSA 141): (0) present; (1) absent.

104. Gill osteoderms (HPSA 142): (0) absent; (1) present noninterdigitating; (2) toothed interdigitating rakers.

105. Parahyoid (HPSA 143): (0) absent; (1) present.

106. Number of accessory articulations (HPSA 144): (0) 0; (1) 1; (2) 2 or more.

107. Number of presacrals (HPSA 145): (0) 25-35; (1) 20-24; (2)>35; (3)<20.

108. Vertebral development (HPSA 146): (0) arches then centra; (1) centra and arches simultaneously.

109. Caudal processes between depressions (HPSA 147): (0) absent; (1) present.

110. Trunk intercentra (HPSA 148): (0) present; (1) absent.

111. Trunk neural arch to centrum in adults (HPSA 149): (0) loosely articulated; (1) sutured; (2) fused.

112. Base of neural spine (HPSA 150): (0) equal to or wider than haemal; (1) smaller than haemal spine.

113. Height of neural spines (HPSA 151): (0) even; (1) alternating.

114. Dermal armor associated with neural arches (HPSA 152): (0) Absent; (1) Present. Note: This character was established to recognize the expanded, sculptured structures seen at the top of neural arches in some nectrideans. Upon further examination, this character represents fusion of osteoderms to the neural arch. As this is present in a number of temnospondyls as well as chroniosuchians, we have amended this diagnosis to allow for comparisons outside nectrideans. 115. Neural spine shape in lateral view (HPSA 153): (0) anterior and posterior sides parallel, forming a rectangular surface; (1) non-parallel, triangular

116. Neural spine lateral surface (HPSA 154): (0) smooth; (1) crenulated.

117. Pleurocentra (HPSA 155): (0) paired rhachitomous; (1) closely approaching ventrally; (2) fused dominant weight bearing element; (3) embolomerous (new state). 118. Haemal arch presence (HPSA 156): (0) present; (1) absent.

119. Haemal arch fusion (HPSA 157): (0) loosely articulated to intercentra; (1) fused to mid length of centrum. 
120. Haemal arch length (HPSA 158): (0) longer than or equal to neurals; (1) shorter than neurals.

121. Haemal accessory articulations (HPSA 159): (0) none; (1) one; (2) two.

122. Haemal arch shape (HPSA 160): (0) non parallel triangular; (1) parallel rectangular. 123. Tail termination in skeleton (HPSA 161): (0) tapers; (1) deep with sudden end.

124. Tail length (HPSA 162): (0) elongate equal to or exceeding trunk and skull length;

(1) foreshortened markedly shorter than trunk.

125. Trunk arches (HPSA 163): (0) paired; (1) fused.

126. Spinal nerve foramina (HPSA 164): (0) absent; (1) present.

127. Extended transverse processes (HPSA 165): (0) absent; (1) present.

128. Transverse process (HPSA 166): (0) on arch pedicle; (1) on centrum.

129. Atlas axis intercentra (HPSA 167): (0) present; (1) absent.

130. Atlas Anterior centrum (HPSA 168): (0) same size as posterior; (1) laterally expanded.

131. Atlas centrum (HPSA 169): (0) multipartite; (1) single notochordal; (2) single odontoid. 132. Atlas neural arch centrum fusion (HPSA 170): (0) loosely articulated; (1) sutured to centrum; (2) fused to centrum.

133. Atlas parapophyses (HPSA 171): (0) on centrum; (1) on transverse process; (2) absent.

134. Atlas neural arch midline fusion (HPSA 172): (0) paired; (1) sutured at midline; (2) fused at midline.

135. Atlas accessory articulation (HPSA 173): (0) absent; (1) zygosphene; (2) zygantra. 136. Proatlantes (HPSA 174): (0) present; (1) absent.

137. Second cervical arch (HPSA 175): (0) more expanded to subsequent; (1) equal to subsequent; (2) shorter than subsequent.

138. Atlas ribs (HPSA 176): (0) one pair; (1) two pairs; (2) absent.

139. Cervical rib distal shape (HPSA 177): (0) spatulate; (1) pointed.

140. Ribs anterior to sacrum (HPSA 178): (0) short; (1) long.

141. Ribs (HPSA 179): (0) elongated and sometimes curved; (1) straight; (2) short simple rod. 142. Costal process at rib head (HPSA 180): (0) absent; (1) present.

143. Number of sacrals (HPSA 181): (0) 1; (1) 2; (2) 3. 
144. Sacral parapophysis (HPSA 182): (0) on centrum; (1) on transverse process. 145. Number pairs of caudal ribs (HPSA 183): (0) 5 or more; (1) 4; (2) 3; (3) 2 or fewer. 146. Interclavicle posterior stem length (HPSA 184): (0) no or short; (1) long. 147. Interclavicle posterior stem breadth (HPSA 185): (0) wide; (1) narrow. 148. Interclavicle shape (HPSA 186): (0) diamond shaped; (1) T-shaped. 149. Interclavicle anterior plate (HPSA 187): (0) broad; (1) narrow. 150. Interclavicle shape (if diamond present) (HPSA 188): (0) broad diamond; (1) narrow diamond.

151. Interclavicle anterior fimbriation (HPSA 189): (0) present; (1) absent.

152. Interclavicle sculpture (HPSA 190): (0) present; (1) absent.

153. Cleithrum head dorsal extent (HPSA 191): (0) aligned along anterior rim of scapula; (1) posterodorsally enlarged head wrapping around dorsal scapula.

154. Cleithrum head size and shape (HPSA 192): (0) dorsally greatly expanded much wider than shaft; (1) simple rod without or slight dorsal expansion. 155. Cleithrum ossification (HPSA 193): (0) ossified; (1) unossified. 156. Cleithrum overall shape (HPSA 194): (0) rounded or pointed dorsally; (1) T or Y shaped. 157. Proximal clavicle blades (HPSA 195): (0) widely separate; (1) articulate medially; (2) interdigitate.

158. Supraglenoid foramen (HPSA 196): (0) present; (1) absent. 159. Number coracoid foramina (HPSA 197): (0) none; (1) 1; (2) 2.

160. Scapulocoracoid ossification (HPSA 198): (0) both; (1) scapula only; (2) absent. 161. Torsion in humerus (HPSA 200): (0) absent; (1) less than 80 degrees; (2) more than 80 degrees.

162. Deltapectoral crest (HPSA 201): (0) weak or absent; (1) intermediate; (2) prominent. 163. Supinator process (HPSA 202): (0) absent; (1) present.

164. Humerus length (HPSA 203): (0) long ( 4 trunk centra); (1) short.

165. Radius-humerus ratio (HPSA 204): (0) $>0.7$; (1) $0.5-0.7$; (2) $<0.5$.

166. Olecranon process (HPSA 205): (0) unossified; (1) ossified.

167. Carpals (HPSA 206): (0) fully or partially ossified; (1) unossified.

168. Basale commune (HPSA 207): (0) absent; (1) present.

169. Number digits manus (HPSA 208): (0) 5; (1) 4; (2) 3; (3) $>5$. 
170. Pelvis (HPSA 209): (0) fused; (1) sutured; (2) poorly ossified.

171. Anteriorly inclined ilium (HPSA 210): (0) absent; (1) present.

172. Iliac blade (HPSA 211): (0) 2 dorsal processes; (1) narrowly bifurcate; (2) single blade.

173. Internal trochanter articulation (HPSA 212): (0) distinct; (1) continuous.

174. Femoral shaft (HPSA 213): (0) robust; (1) slender.

175. Femur (HPSA 214): (0) long; (1) short.

176. Tarsals (HPSA 215): (0) ossified; (1) unossified.

177. Elongate tibiale and fibulare (HPSA 216): (0) absent; (1) present.

178. Number of distal tarsals (HPSA 217): (0) 6; (1) 5 or fewer.

179. Astragalus (HPSA 218): (0) absent; (1) present.

180. Number of digits pes (HPSA 219): (0) 5 ; (1) 4 or less; (2) $>5$.

181. Dorsal margin of splenial only contacts first coronoid (HPSA 220): (0) absent; (1) present. 182. Postparietal lappet (HPSA 224): (0) mostly exposed posteriorly; (1) equal posteriorly and dorsally; (2) mostly exposed dorsally.

183. Cheek emargination (HPSA 225): (0) absent; (1) present.

184. Parietal anterior waisting (HPSA 226): (0) absent; (1) present.

185. Parietal width relative to frontal (HPSA 227): (0) greater; (1) equal or less.

186. Trabecula cranii (N 01): (0) Without significant median fusion posterior to solum nasi (platytrabic); (1) fused medially posterior to solum nasi to form elongate trabecula communis (tropitrabic).

187. Dorsal trabeculae (N 02): (0) dorsal trabeculae provide dorsolateral bridge between sphenoid region and nasal capsule; (1) dorsal trabeculae absent or incomplete, no dorsolateral bridge between sphenoid region and nasal capsule.

188. Ossification between optic foramen and pila antotica (N 03): (0) ossification complete between optic foramen and pila antotica; (1) pila metoptica and associated cartilaginous taenia unossified.

189. Ossification within columella ethmoidalis (N 04): (0) absent; (1) present. 190. Path of profundus branch of trigeminal nerve (N 05): (0) enclosed in lateral wall of sphenoid region of braincase and exits separately from maxillomandibular branch via 
series of small foramina; (1) extramural, exits antotic fissure with other branches of trigeminal.

191. Foramina for optic nerve and trigeminal nerve (N 06): (0) confluent; (1) widely separate. 192. Lateral head vein (N 07): (0) No distinct foramen for lateral head vein; (1) Distinct foramen within the antotic fissure serving the lateral head vein. 193. Anterior extent of cultriform process of parasphenoid (N 08): (0) cultriform process extends to anterior margin of sphenethmoid; (1) cultriform process extends far anterior to sphenethmoid; (2) cultriform process does not reach anterior margin of sphenethmoid. 194. Olfactory bulbs (N 09): (0) narrow; (1) endocasts swollen, leaving considerable impressions in lateral and ventral wall of sphenoid region and in ventral surface of frontal.

195. Flange from skull roof articulating with sphenethmoid (modified from HPSA 223): (0) absent; (1) present on frontal and parietal; (2) present on frontal only. 196. Descending lamina of parietal invades medial orbital wall between 'pleurosphenoid' and 'sphenethmoid' elements (N 10): (0) no; (1) yes.

197. Foramen for oculomotor nerve (N 11): (0) exits braincase far dorsal to foramen for optic nerve; (1) exits braincase at or below optic nerve.

198. Intermaxillary fossa (modified from HPSA 095): (0) present; (1) absent. 199. Intermaxillary fossa (N 12): (0) paired; (1) unpaired.

200. Sphenethmoid forms interorbital septum (N 13): (0) no; (1) yes.

201. Anterior extent of cultriform process along palate (N 14): (0) cultriform process extends anteriorly to level of posterior margin of choana; (1) cultriform process dramatically shortened, barely reaching the level of the posterior margin of the orbit. 202. Sutural contact between cultriform process of parasphenoid and vomer (N 15): (0) no; (1) yes.

203. Lateral wall of the nasal capsule underplated by lateral processes of the vomer and palatine (N 16): (0) no; (1) yes.

204. Cultriform process vaulted high above palatal surface (N 17): (0) no; (1) yes. 205. Posterior extent of parasphenoid beneath braincase (N 18): (0) floors sphenoid region only; (1) floors sphenoid and otic region; (2) floors sphenoid, otic, and occipital regions. 
206. Basal tubera (N 19): (0) present, with significant endochondral contribution; (1) present, with contribution of parasphenoid only; (2) absent 207. Path of common internal carotid artery (N 20): (0) does not run alongside braincase, enters braincase directly in region of sella turcica; (1) follows vidian sulcus along posterior surface of basal plate of parasphenoid, enters parasphenoid via vidian canal in basal plate of parasphenoid, divides into cerebral and palatal branches after entering parasphenoid; (2) follows vidian sulcus along posterior surface of basal plate of parasphenoid or lateral wall of braincase, divides into cerebral and palatal branches prior to entering the skull 208. Buccohypophyseal foramen in parasphenoid (N 21): (0) open; (1) absent. 209. Morphology of pila antotica (N 22): (0) pila antotica is a thin, broad sheet; (1) pila antotica is a robust dorsoventral pillar bracing the skull roof against the palate. 210. Basicranial fissure (N 23): (0) present; (1) absent.

211. Location of vidian sulcus (N 24): (0) along ventral surface of braincase; (1) along lateral surface of braincase.

212. Basipterygoid joint (N 25): (0) epipterygoid comprises entire conus recessus; (1) substantial contribution to conus recessus by pterygoid; (2) conus recessus comprised entirely of pterygoid without epipterygoid participation; (3) pterygoid and parasphenoid broadly sutured without development of a conus recessus

213. Hypophyseal fossa (N 26): (0) single unpaired sulcus; (1) paired sulci divided medially by ridge originating on dorsum sellae.

214. Bone flanking the dorsum sellae (N 27): (0) concurrent with fully ossified lateral braincase; (1) subparallel with sagittal plane ('pleurosphenoid'); (2) strongly oblique to or perpendicular to sagittal plane ('laterosphenoid'); (3) restricted to dorsum sellae only. 215. Basal plate of parasphenoid (HPSA 105): (0) roughly quadrangular, basipterygoid articulations narrowly spaced; (1) rectangular laterally, anteroposteriorly narrow, basipterygoid articulations distant.

216. Sphenethmoid (HPSA 114): (0) ossified; (1) unossified.

217. Ossification within the synotic tectum (N 28): (0) synotic tectum massively coossified with otic capsules; (1) supraoccipital paired at some point in ontogeny; (2) 
supraoccipital unpaired throughout ontogeny; (3) no supraoccipital bone; synotic tectum invaded by dorsal processes of exoccipitals.

218. Median ascending process of supraoccipital (N 29): (0) absent; (1) present. 219. Lateral ascending processes of the supraoccipital (N 30): (0) absent; (1) present. 220. Margin of fenestra vestibuli (N 31): (0) parasphenoid excluded by neurocranial elements (basisphenoid and basioccipital); (1) parasphenoid contributes to anteroventral margin of fenestra vestibuli; (2) parasphenoid floors entire fenestra vestibuli; (3) Ossification of otic capsule surrounds entire fenestra vestibuli. 221. Crista intervestibularis (N 32): (0) crista intervestibularis absent; (1) crista intervestibularis present.

222. Morphology of crista parotica (N 33): (0) crista parotica meets exoccipitals only, forming lateral wall of posttemporal fossa but not bracing against dermal skull; (1) crista parotica drawn out dorsolaterally into paroccipital process that contacts the tabular; (2) crista parotica drawn out laterally into paroccipital process that contacts the cheek and/or suspensorium.

223. Dorsal process of stapes (HPSA 111): (0) absent; (1) present.

224. Facets on dorsal surface of supraoccipital (N 34): (0) absent; (1) present.

225. Otoccipital fissure (N 35): (0) present; (1) absent.

226. Crista parotica (N 36): (0) Descends posteriorly; (1) Horizontal along the extent of its length.

227. Position of quadrate with respect to otic capsules (modified from HPSA 82): (0) quadrates ventral and lateral to otic capsules; (1) quadrates mostly lateral to and greater or equal to twice the width of the otic capsules; (2) quadrates mostly ventral to otic capsules; (3) quadrates approaching or abutting lateral wall of otic capsules. 228. Size of otic capsules (N 37): (0) otic capsules comprise less than $2 / 3$ the width of otoccipital region; (1) otic capsules comprise greater than $2 / 3$ total width of otoccipital region.

229. Otic trough (N 38): (0) absent; (1) present.

230. Articulation between the epipterygoid and prootic (N 39): (0) none; (1) elongate facet on anterior surface of prootic for articulation of epipterygoid.

231. Opisthotic obscures occipital in lateral view (N 40): (0) no; (1) yes. 
232. Fenestra vestibularis at end of broad, winglike lateral extension of the otic capsule (N 41): (0) no; (1) yes.

233. Cristae in otoccipital region (N 42): (0) comprised primarily of ascending flanges from braincase; (1) comprised primarily of descending flanges from skull roof 234. Opisthotic excluded from the occipital surface by tabular process of the exoccipital (N 43): (0) no; (1) yes.

235. Insertion of epaxial musculature on occiput (N 44): (0) deep within post-temporal fossae; (1) in broad, shallow fossae along occipital surface of postparietals.

236. Foramen for internal jugular vein (N 45): (0) between supraoccipital and exoccipital; (1) between opisthotic and exoccipital; (2) through exoccipital; (3) Posterior notch of fenestra vestibule.

237. Foramina for hypoglossal nerve (N 46): (0) multiple; (1) single; (2) none.

238. Occipital condyle shape (modified from HPSA 085): (0) round; (1) U-shaped; (2) paired. 239. Ventral process of exoccipital reaches basipterygoid joint along palatal surface (N 47): (0) absent; (1) present.

240. Occipital condyle shape (HPSA 084): (0) Concave; (1) Convex.

241. Columella of stapes (modified from HPSA 108): (0) perforate; (1) imperforate.

242. Orientation of stapes (modified from HPSA 109): (0) Dorsal, towards tabular or otic notch; (1) anteroventral, towards quadrate.

243. Stapedial footplate shape (HPSA 110): (0) oval; (1) round; (2) palmate.

244. Dorsal sinus between synotic tectum and skull roof (modified from HPSA 222): (0) absent; (1) present.

245. Ossification within septum internasale (N 48): (0) absent; (1) present, sphenethmoid; (2) present, mesethmoid.

246. Ossification of septum internasale invades nasal tectum (N 49): (0) absent; (1) present.

247. Insertion of hypaxial musculature (N 50): (0) sphenoid; (1) otic; (2) basioccipital. 248. Prootic supported by pedicel extending from basisphenoid lateral to prootic foramen (N 51): (0) no; (1) yes.

249. Position of pineal foramen with respect to hypophyseal foramen (N 52): (0) anterior to; (1) approximately the same; (2) far posterior to. 
250. Pineal foramen or fossa (N 53): (0) well anterior to posterior margin of cerebral fossa; (1) at or behind posterior margin of cerebral fossa.

251. Median wall of otic capsule (N 54): (0) completely unossified; (1) ossification of opisthotic; (2) ossification of supraoccipital and basioccipital.

252. Conical recess in basioccipital (N 55): (0) absent; (1) present.

253. Semicircular canals (N 56): (0) separated from utricular region by bone; (1) not separated from utricular region by bone.

254. Basioccipital (N 57): (0) Robust ossification ventral to foramen magnum present; (1) absent.

255. Accessory articulation processes with proatlantal facet on exoccipitals (N 58): (0) absent; (1) prominent.

256. Exoccipital proatlantal facets incorporated into occipital joint (N 59): (0) no; (1) yes. 257. Anterior tectal (modified from CABF 001): (0) anterior tectal present; (1) absent. 258. Ectopterygoid/palatine exposure (CABF 002): (0) more or less confined to tooth row; (1) broad medial exposure additional to tooth row; (2) reduced to thin sliver. 259. Ectopterygoid: (0) Present; (1) Absent.

260. Ectopterygoid as long or longer than palatines (CABF 003): (0) yes; (1) no.

261. Ectopterygoid reaches subtemporal fossa (CABF 004): (0) no; (1) yes.

262. Frontal (CABF 005): (0) absent; (1) present.

263. Jugal (CABF 007): (0) does not extend anterior to orbit; (1) extends anterior to orbit. 264. Lateral rostral present (CABF 009): (0) yes; (1) no.

265. Maxilla makes interdigitating suture with vomer (CABF 010): (0) no; (1) yes.

266. Maxilla external contact with premaxilla (CABF 011): (0) narrow contact point, not interdigitated; (1) interdigitating suture.

267. Maxilla extends behind level of posterior margin of orbit (CABF 012): (0) yes; (1) no.

268. Median rostral (CABF 013): (0) single; (1) paired; (2) absent. 269. Opercular (CABF 014): (0) present; (1) absent.

270. Prefrontal (CABF 015): (0) twice as long as broad, or less; (1) three times as long as broad. 271. Prefrontal (CABF 016): (0) transverse anterior suture with tectal; (1) tapers to a point anteriorly. 
272. Preopercular (CABF 017): (0) present; (1) absent.

273. Pterygoid quadrate ramus margin in subtemporal vacuity (CABF 018): (0) concave; (1) with some convex component.

274. Vomers separated by parasphenoid > half length (CABF 019): (0) yes; (1) no. 275. Vomers (CABF 022): (0) as broad as long or broader; (1) about twice as long as broad or longer.

276. Basipterygoid process (CABF 023): (0) not strongly projecting with concave anterior face; (1) strongly projecting with flat anterior face.

277. Ethmoid (CABF 024): (0) fully ossified; (1) partly or wholly unossified.

278. Hypophyseal region (CABF 025): (0) solid side wall pierced by small foramina for pituitary vein and other vessels; (1) single large foramen.

279. Lateral commissure of otic capsule bearing hyomandibular facets (CABF 026): (0) present; (1) absent.

280. Parasphenoid (CABF 027): (0) does not overlap basioccipital; (1) overlaps basioccipital. 281. Denticulate field of parasphenoid (CABF 028): (0) present; (1) absent. 282. Sphenoid (CABF 029): (0) fully ossified, terminating posteriorly in intracranial joint or fused to otoccipital; (1) separated from otoccipital by unossified gap.

283. Ectopterygoid fang pairs (CABF 030): (0) present; (1) absent.

284. Ectopterygoid row (3+) of smaller teeth (CABF 031): (0) present; (1) absent. 285. Ectopterygoid/palatine shagreen field (CABF 032): (0) absent; (1) present. 286. Palatine row of smaller teeth (CABF 034): (0) present; (1) absent. 287. Pterygoid shagreen (palatine ramus) (modified from CABF 035): (0) dense; (1) organized radiating rows of denticles; (2) disorganized patches or absent. 288. Dentition of transverse flange of pterygoid (new character): (0) Denticle field indistinct from palatine denticle field; (1) distinct raised denticle field; (2) organized tooth row; (3) absent. 289. Premaxillary tooth proportions (CABF 036): (0) all approximately same size; (1) posteriormost teeth at least twice height of anteriomost teeth; (2) Anteriormost teeth largest. 290. Vomerine fang pairs (CABF 037): (0) present; (1) absent. 291. Vomerine fang pairs noticeably smaller than other palatal fang pairs (CABF 038): (0) no; (1) yes. 
292. Vomer anterior wall forming posterior margin of palatal fossa bears tooth row meeting at midline (CABF 039): (0) yes; (1) no.

293. Vomerine row of teeth (CABF 040): (0) present; (1) absent.

294. Vomerine shagreen field (CABF 041): (0) absent; (1) present.

295. Adductor fossa (CABF 042): (0) faces dorsally; (1) faces medially.

296. Adductor crest (CABF 043): (0) absent; (1) peak anterior to adductor fossa, dorsal margin of fossa concave; (2) peak above anterior part of adductor fossa, dorsal margin of fossa convex. 297. Angular-prearticular contact (CABF 044): (0) prearticular contacts angular edge to edge; (1) absent; (2) medial lamina of angular sutures with prearticular. 298. Coronoid (anterior) contacts splenial (CABF 045): (0) no; (1) yes.

299. Prearticular extends between infradentaries and middle coronoid (modified from CABF 046): (0) Yes; (1) No.

300. Coronoid (middle) contacts postsplenial (CABF 047): (0) no; (1) yes.

301. Coronoid (posterior) posterodorsal process (CABF 048): (0) no; (1) yes.

302. Coronoid (posterior) posterodorsal process visible in lateral view (CABF 049): (0) no; (1) yes.

303. Dentary external to angular \& surangular, with chamfered ventral edge and no interdigitations (CABF 050): (0) no; (1) yes.

304. Dentary ventral edge (CABF 051): (0) smooth continuous line; (1) abruptly tapering or "stepped" margin.

305. Dentary suture with splenial \& postsplenial marked by deep furrow (CABF 052): (0) no; (1) yes.

306. Mandibular sensory canal (CABF 053): (0) present; (1) absent.

307. Mandibular canal exposure (CABF 054): (0) entirely enclosed, opens through lines of pores; (1) mostly enclosed, short sections of open grooves; (2) mostly open grooves, short sections opening through pores; (3) entirely open.

308. Oral sulcus/surangular pit line of mandible (CABF 055): (0) present; (1) absent. 309. Meckelian bone floors precoronoid sulcus (CABF 056): (0) yes; (1) no. 310. Meckelian bone ossified in middle part of jaw (CABF 057): (0) yes; (1) little or no ossification. 
311. Meckelian bone exposure in middle part of jaw (CABF 058): (0) depth much less than prearticular; (1) depth similar to prearticular.

312. Meckelian foramina/fenestrae, dorsal margins (CABF 059): (0) Meckelian bone; (1) prearticular; (2) infradentary

313. Meckelian foramina/fenestrae height (CABF 060): (0) much lower than adjacent prearticular; (1) equal to or greater than depth of adjacent prearticular.

314. Parasymphyseal lateral foramen present (CABF 061): (0) no; (1) yes.

315. Parasymphyseal mesial foramen present (CABF 62): (0) no; (1) yes.

316. Postsplenial with medial lamina (CABF 063): (0) no; (1) small; (2) expanded, contacting precoronoid.

317. Postsplenial pit line present (CABF 064): (0) yes; (1) no.

318. Postsplenial suture with prearticular present (modified from CABF 065): (0) no; (1)

yes. 319. Prearticular sutures with surangular (CABF 066): (0) no; (1) yes.

320. Medial lamina of splenial (modified from CABF 067): (0) absent; (1) present.

321. Prearticular with longitudinal ridge below coronoids (CABF 068): (0) no; (1) yes.

322. Prearticular with mesially-projecting flange on dorsal edge along posterior border of adductor fossa (CABF 069): (0) no; (1) yes.

323. Prearticular centre of radiation of striations (CABF 070): (0) level with posterior end of posterior coronoid; (1) level with middle of adductor fossa; (2) level with posterior end of adductor fossa.

324. Splenial has free ventral flange (CABF 071): (0) yes; (1) no.

325. Splenial, rearmost extension of medial lamina (CABF 072): (0) closer to anterior end of jaw than to adductor fossa; (1) equidistant; (2) closer to anterior margin of adductor fossa than to the anterior end of the jaw.

326. Coronoids; at least one has fang pair recognizable because at least twice the height of coronoid or marginal teeth (CABF 073): (0) yes; (1) no.

327. Coronoids: at least one has fangs recognizable because noticeable lingual to vertical lamina of bone and to all other teeth (CABF 074): (0) yes; (1) no.

328. Coronoids: at least one has organized tooth row (CABF 075): (0) yes; (1) no.

329. Coronoids: at least one carries shagreen (CABF 076): (0) no; (1) yes. 
330. Coronoids: size of teeth (excluding fangs) on anterior and middle coronoids relative to dentary tooth size (CABF 077): (0) about the same; (1) half the height or less.

331. Dentary tooth row (CABF 078): (0) homodont; (1) markedly heterodont.

332. Dentary with parasymphyseal fangs internal to marginal tooth row (CABF 079): (0) yes; (1) no.

333. Dentary teeth (CABF 080): (0) same size as maxillary teeth; (1) larger than maxillary teeth; (2) smaller than maxillary teeth

334. Dentary with a row of very small teeth or denticles lateral to tooth row (CABF 081):

(0) yes; (1) no.

335. Parasymphyseal tooth plate (CABF 082): (0) present; (1) absent.

336. Parasymphyseal plate dentition (CABF 083): (0) shagreen or irregular tooth field;

(1) organized dentition aligned parallel to jaw margin; (2) no dentition.

337. Parasymphyseal plate has fang pair (CABF 084): (0) no; (1) yes.

338. Parasymphyseal plate has tooth row (CABF 085): (0) no; (1) short tooth row, separated from coronoid row by diastema; (2) long tooth row reaching coronoid. 339. Prearticular shagreen field distribution (CABF 086): (0) gradually decreasing from dorsal to ventral; (1) well-defined dorsal longitudinal band; (2) scattered patches or absent.

340. Anterior palatal fenestra (CABF 087): (0) single; (1) double; (2) absent.

341. Dorsal fontanelle on snout (CABF 088): (0) absent; (1) present.

342. Interpterygoid vacuities (CABF 089): (0) absent; (1) at least 2x wider than long; (2) $2 \mathrm{x}$ longer than wide.

343. Intracranial joint (CABF 090): (0) present in dermal skull roof; (1) absent in dermal skull roof.

344. Nature of dermal ornament (CABF 091): (0) tuberculate; (1) fairly regular pit and ridge; (2) irregular; (3) absent or almost absent

345. Nature of ornament: starbursts of radiating ornament on at least some bones (CABF 092): (0) no; (1) yes

346. Anocleithrum (CABF 093): (0) oblong with distinct anterior overlap area; (1) dropshaped with no anterior overlap area; (2) absent. 
347. Cleithrum (CABF 094): (0) ornamented; (1) not ornamented.

348. Cleithrum, postbranchial lamina (CABF 095): (0) present; (1) absent.

349. Autopod (modified from CABF 096): (0) radials; (1) digits.

350. Humerus (CABF 097): (0) narrow tapering entepicondyle; (1) square or

parallelogram-shaped entepicondyle.

351. Ilium, iliac canal (CABF 098): (0) absent; (1) present.

352. Ilium, posterior process (CABF 099): (0) oriented posterodorsally; (1) oriented approximately horizontally posteriorly.

353. Interclavicle (CABF 100): (0) small and concealed or absent; (1) large and exposed. 354. Interclavicle shape (CABF 101): (0) ovoid; (1) kite shaped; (2) with posterior stem. 355. Lepidotrichia in paired appendages (CABF 102): (0) present; (1) absent. 356. Posttemporal and supracleithrum (CABF 103): (0) present; (1) absent. 357. Radius and ulna (CABF 104): (0) radius much longer than ulna; (1) approximately equal in length.

358. Ribs, trunk (CABF 107): (0) all cylindrical; (1) some or all bear flanges from posterior margin which narrow distally; (2) some or all flare distally.

359. Scapular blade (CABF 108): (0) absent; (1) small with narrow top; (2) large with broad top. 360. Scapulocoracoid (modified from CABF 109): (0) small and tripodal; (1) large plate.

361. Subscapular fossa (CABF 110): (0) broad and shallow; (1) deeply impressed posteriorly. 362. Squamation (CABF 111): (0) complete body covering of scales, all similar; (1) ventral armour of gastralia.

363. Pectoral process (CABF112): (0) absent; (1) present.

364. Proximal limb of oblique ridge (CABF 113): (0) present, separated from anterior margin of humerus by prepectoral space; (1) absent, replaced by deltopectoral crest. 365. Latissimus dorsi attachment (CABF 114): (0) diffuse ridged area; (1) distinct process.

366. Foramina piercing oblique ventral ridge (CABF 115): (0) many; (1) one moderately large foramen in addition to entepicondylar foramen; (2) entepicondylar foramen is the only large opening, other foramina are pinpricks or absent; (3) none. 367. Humerus with well-developed anterior plate (new character): (0) yes; (1) no. 
368. Subclavicular ossifications (new character): (0) Absent; (1) Sometimes present. 369. Radial capitulum (new character, modified from Sigurdsen \& Green, 2011): (0) approximately same size as ulnar facet; (1) greatly enlarged and rounded, $>2 x$ size of ulnar facet.

370. Lissamphibian inner ear sensu Maddin and Anderson (2012) (MA 220): (0) no; (1) yes.

\section{Appendix B - Chapter 3 Supplemental Information}

\section{B.1 Nexus File used for phylogenetic analyses of Infernovenator steenaegen et sp. nov.}

\section{NEXUS}

[written Fri Jul 20 15:26:32 EDT 2018 by Mesquite version 3.2 (build 801) at ArjansMacBook-Pro.local/192.168.0.11]

\section{BEGIN TAXA;}

TITLE Taxa;

DIMENSIONS NTAX $=61$;

\section{TAXLABELS}

Archeria_crassidisca Crassigyrinus_scoticus Acanthostega_gunnari

Eusthenopteron_foordi Ichthyostega_spp. Panderichthys_rhombolepis Pederpes_finneyae

Tiktaalik_rosaea Ventastega_curonica Whatcheeria_deltae Ymeria_denticulata

Proterogyrinus_scheelei Balanerpeton_woodi Dendrerpeton_acadianum

Cardiocephalus_peabodyi Huskerpeton_englehorni Pelodosotis_elongatum

Nannaroter_mckinzei Micraroter_erythrogeios Eocaecilia_micropodia

Greererpeton_burkemorani Seymouria_baylorensis Limnoscelis_paludis

Branchiosauridae Micromelerpetontidae Tersomius texensis Ecolsonia cutlerensis

Acheloma_spp. Eryops_megalocephalus Doleserpeton_annectens Caudāa Anura

Albanerpetontidae Micropholis_stowi Eoscopus_lockardi Tambachia_trogallas

Triadobatrachus_massinoti Gerobatrachus_hottoni Platyrhinops_lyelli

Amphibamus_grandiceps Lethiscus_stocki Coloraderpeton_brilli Edops_craigi Captorhinus_laticeps Petrolacosaurus_kansensis Ophiacodon_uniformis_Baphetes_spp. Eucritta_me-anolimnetes Llistrofus_pricei Aletrimyti_gaskillae Dvellecanus_carrolli Rhynchonkos_stovalli Dimetrodon_spp. Opisthodontosaurus_carrolli Pantylus_cordatus Quasicaecilia_texana Carrolla_craddocki Batropetes_frischti FMNH_PR_847

Brachydectes_newberryi Infernovenator_mazonensis 
END;

BEGIN CHARACTERS;

TITLE 'Matrix in file "Pardo\&al_2017_lepospondyls.nex"';

DIMENSIONS NCHAR $=370$;

FORMAT DATATYPE $=$ STANDARD GAP $=-$ MISSING $=$ ? SYMBOLS $=$ "

012345678 ";

CHARSTATELABELS

1 Basal_Skull_Length / '>70mm' '50-70mm' '30-50mm' '<30mm', 2

Skull_trunk / $0.450 .30 \_0.450 .20 \_0.290 .20,3$ Skull_proportions / longer_than_wide

wider_than_long, 4 Intertemporal / present

Replaced_by_anterior_extension_of_supratemporal_or_tabular

replaced_by_lateral_extension_of_parietal, 5 Supratemporal / present absent, 6

ST_exposure_on_occiput / absent present, 7 Postfrontal_shape / broadly_quadrangular

falciform, 8 Squamosal_Tabular / absent present fused, 9 Lacrimal_prefrontal_suture / simple_butt_joint interdigitating prefrontal_broadly_underplates_lacrimal, 10 Lacrimal / present absent, 11 L_to_naris / present absent, 12 L_to_orbit / absent present, 13 lacrimal_orbital_processes / only_ventral_present dorsal_and_ventral_present neither_present, 14 lacrimal_jugal_contact / present absent, 15 Quadratojugal / present absent, 16 Quadratojugal_Jugal_contact / present absent, 17

Quadratojugal_Maxillary_contact / present absent, 18 Frontals / paired fused, 19

Frontal_into_orbit / no yes, 20 Anterior_laterally_flaring_frontals / absent present, 21

Nasals / present absent, 22 Narial_flange / absent present, 23

alary_processes_of_premax / absent present, 24 Septomaxilla / ossified unossified, 25

Prefrontal_into_external_naris / distant_from near present, 26

external_naris_in_dorsal_view / exposed not_exposed, 27 External_naris_shape /

circular 'posteriorly extended, along L-PF suture'

posteriorly_extended_excavation_of_L_only, 28 dorsal_exposure_of_premax / broad

narrow none, 29 dorsal_shape_of_skull/ triangular diamond rounded, 30

Posterior_skull_margin / concave straight convex undulating., 31 snout_shape / blunt pointed, 32 snout_length / short long, 33 Q_internal_flange_of_Sq / absent present, 34 otic_notch_presence / present absent, 35 Large_otic_notch_approaching_orbit / absent intermediate close, 36 otic_notch_structure / open_posteriorly closed_posteriorly, 37 semilunar_flange_of_supratempor / absent present, 38 supratympanic_flange / absent 'present "trematopid"' present_trematopid 'present "dissorophid"' present_dissorophid, 39 supratympanic_shelf / absent present, 40 raised_orbital_rim / absent present, 41 Postorbital / present absent, 42 J_PO_interfingered_processes / absent present, 43 PO_in_orbital_margin / present absent, 44 shape_of_postorbital / irregular_trapezoid 'triangular, apex caudal', 45 Palpebral_ossifications / absent mosaic_of_bone_plates_present_in_orbit Single_large_plate_above_orbit, 46 parietal_tabular_contact / absent present, 47 postparietal_fusion / paired fused absent, 48 parietal_foramen / present absent, 49 postparietal_size / moderate large, 50 postparietal_squamosal_contact / absent present, 51 postparietal_length / 'large, quadrangular' 'abbreviated anteroposteriorly, elongate lateral rectangle', 52 
squamosal_jugal_contact / present absent, 53 Tabular / present absent, 54 Posterolateral_projection_from_lateral_margin_of_tabular_above_squamosal_embaymen t / absent present, 55 Tabular_horns / absent present, 56 Tabular_horns_shape / parallel_or_slightly_divergent widely_divergent, $57 \mathrm{Sq}$ forms_base_of_tabular_horn / absent present, 58 Lateral_line_canal_grooves / present absent, 59 Dermal_sculpturing / circular_pits shallow_ridges_and_grooves little_to_none tuberculate, 60 premaxilla_anterior_margin / vertical overturned, 61 Maxilla_into_external_naris / present absent, 62 Maxilla_entire_ventral_naris / absent present, $6 \overline{3}$ maxilla / longer_than_palatine shorter_than_palatine, 64 marginal_teeth_orientation / vertical turned_medially, 65 marginal_teeth_largest_anterior / absent present, 66 marginal_teeth_shape / pointed_pegs blunt_pegs large_cones, 67 Number_of_premax_teeth / '10-20' '5-9' ' $<5$ ' 20_or_more, 68 Number_of_max_teeth / '30-40' '20-29' '15-19' '<15' '>40', 69 teeth_laterally_compressed / no yes, 70 Enlarged_teeth_mid_toothrow / absent present, 71 teeth / simple_points multiple_cusps, 72 Multiple_Cusp_Orientation / 'Labio-lingual' 'antero-posterior', 73 Enamel_fluting / absent present, 74 labyrinthine_in_folding / present absent, 75 jaw_articulation / posterior_to_occiput even_with_occiput anterior_to_occiput 'far anterior $(>20 \%$ BSL)', 76 Internal_nares / widely_separated narrowly_separated, 77 LEP / absent present, 78 Anterior_palatine / short_anteromedial_process_articulating_with_vomer_at_choana long_anteromedial_process_more_medial_than_lateral palatine_absent, 79 teeth_on_pterygoid / absent present, 80 tooth_pedicely / absent present, 81 Palatal_teeth_size / larger_than_marginals equal_to_marginals smaller_than_marginals, 82 parasphenoid / medial_of_stapes under_footplate_of_stapes, 83 interpterygoid_vaccuities $/$ narrow_closed wide fused_at_midline, 84 Anterior_extent_of_Pterygoids / Pterygoids_contact_anteriorly Pterygoids_exclude_vomer_from_interpterygoid_vacuity_but_excluded_from_median_c ontact_by_parasphenoid pterygoids_contact_vomer_but_do_not_exclude_vomer_from_interpterygoid_vacuity pterygoids_reach_anteriorly_only_as_far_as_palatine pterygoids_reach_ectopterygoid_only pterygoids_do_not_contact_lateral_palatal_bones_at_all, 85 lat_process_of_pt_into_posttemp / absent present, $8 \overline{6}$ Ectopterygoid_palatine_width / wider_than_maxilla narrower_than_maxilla, 87 pharangeobranchial_pouches $/$ absent present, 88 dentary / long short, 89 dentary_forms_coronoid_process / absent present, 90 surangular / normal reduced absent, 91 angular / narrow deep, 92 number_of_splenials / 210,93 splenial_exposed_laterally / present absent, 94 meckelian_fossae / 2_or_more 10,95 Ventral_border_of_Meckel_s_foss / splenial angular, $9 \overline{6}$ retroarticular_process_presence / absent present, 97 retroarticular_process_shape / straight hooked, 98 articulation_to_tooth_row / above equal below, 99 angular_extends_to_lat_view / posterior_tooth_row middle_of_tooth_row, 100 number_of_coronoids / 3210,101 symphysis / dentary_and_splenial dentary_alone, 102 jaw_sculpture / present absent, 103 ossified_hyoids / present absent, 104 Gill_Osteoderms / absent present_noninterdigitating toothed_interdigitating_rakers, 105 parahyoid / absent present, 106 number_of_accessory_articulation / 012 12or_more, 107 number_of_presacrals / 25_35 20_24 35 20, 108 vertebral_development / 
arches_then_centra centra_and_arches_simultaneously, 109

caudal processes btw depression / absent present, 110 trunk intercentra / present absent, 111 trunk_neural_arch_to_centrum / loosely_articulated sutured fused, 112 base_of_neural_spine / equal_to_or_wider_than_haemal smaller_than_haemal_spine, 113 height_of_neural_spines / even alternating, 114

Dermal_armor_associated_with_neural_arches / Absent Present, 115

neural_spine_shape_lat / ant_post_sides_parallel_rect non_parallel_triangular, 116

Neural_spine_lateral_suface / smooth crenulated, 117 Pleurocentra /

paired_rhachitomous closely_approaching_ventrally

fused_dominant_weight_bearing_element embolomerous, 118 haemal_arch_presence /

present absent, 119 haemal_arch_fusion / loosely_articulated_intercentr

fused_to_mid_length_of_centrum, 120 haemal_arch_length /

longer_than_or_equal_to_neurals shorter_than_neurals, 121

haemal_accessory_articulations / none one two, 122 haemal_arch_shape /

non_parallel_triangular parallel_rectangular, 123 tail_termination / tapers

deep_with_sudden_end, 124 Tail_length /

elongate_equal_to_or_exceeding_trunk_and_skull_length

forshortened_markedly_shorter_than_trunk, 125 trunk_arches / paired fused, 126

spinal_nerve_foramina / absent present, 127 extended_transverse_processes / absent

present, 128 transverse_process / on_arch_pedicle on_centrum, 129

atlas_axis_intercentra / present absent, 130 Atlas_Anterior_centrum /

same_size_as_posterior laterally_expanded, 131 atlas_centrum / multipartite

single_notochordal single_odontoid, 132 atlas_neural_arch_centrum_fusion /

loosely_articulated sutured_to_centrum fused_to_centrum, 133 atlas_parapophyses /

on_centrum on_transverse_process absent, 134 atlas_neural_arch_midline_fusion /

paired sutured_at_midline fused_at_midline, 135 atlas_acessory_articulation / absent

zygosphene zygantra, 136 Proatlantes / present absent, 137 second_cervical_arch /

expanded_to_more_posterior equal_to_more_posterior shorter_than_more_posterior, 138

atlas_ribs / one_pair two_pairs absent, 139 cervical_rib_distal_shape / spatulate pointed, 140 ribs_anterior_to_sacrum / short long, $141 \mathrm{Ribs} /$ elongated_and_sometimes_curved straight short_simple_rod, 142 Costal_Process_at_rib_head / absent present, 143

number_of_sacrals / 123,144 sacral_parapophysis / on_centrum

on_transverse_process, 145 number_pairs_of_caudal_ribs / 5_or_more 432 or_fewer, $14 \overline{6}$ interclavicle_posterior_stem_length / no_or_short long, 147

interclavicle_posterior_stem_breadth / wide narrow, 148 interclavicle_shape /

diamond shaped $t$ shaped, 149 interclavicle anterior_plate / broad narrow, 150

interclavicle_shape_diamond / broad_diamond narrow_diamond, 151

interclavicle_anterior_fimbrati / present absent, 152 interclavicle_sculpture / present absent, 153 Cleithrum_head_dorsal_extent / aligned_along_anterior_rim_of_scapula posterodorsally_enlarged_head_wrapping_around_dorsal_scapula, 154

Cleithrum_head_size_and_shape / dorsally_greatly_expanded_much_wider_than_shaft simple_rod_without_or_slight_dorsal_expansion, $15 \overline{5}$ Cleithrum_ossification / ossified unossified, 156 cleithrum_overall_shape / rounded_or_pointed_dorsally t_or_y_shaped, 157 proximal_clavicle_blades / widely_separate articulate_medially interdigitate, 158 supraglenoid_foramen / present absent, 159 number_coracoid_foramina / none 12, 160 scapulocoracoid_occification / both scapula_only absent, 161 tortion_in_humerus / 
absent less_than_80_degrees more_than_80_degrees, 162 deltapectoral_crest / weak intermediate prominant, 163 Supinator_process / absent present, 164 humerus_length / long_4_trunk_centra short, 165 radius_humerus / $0.70 .5 \_0.70 .5,166$ olecranon_process / unossified ossified, 167 carpals / fully_or_partially_ossified unossified, 168 basale_commune / absent present, 169 number_digits_manus / $543^{\prime}>5^{\prime}$, 170 pelvis / fused sutured poorly_ossified, 171 Anteriorly_inclined_ilium / absent present, 172 illiac_blade / 2_dorsal_processes narrowly_bifurcate single_blade, 173 internal_trochanter_articulatio / disctinct continuous, 174 femoral_shaft / robust slender, 175 femur / long short, 176 tarsals / ossified unossified, 177

elongate_tibiale_and_fibulare / absent present, 178 number_of_distal_tarsals / 6 5_or_fewer, 179 astragalus / absent present, 180 number_of_digits_pes / 54_or_less '>5', 181 dorsal_margin_of_splenial_only_contacts_first_coronoid / absent present, 182 postparietal_lappet / mostly_exposed_posteriorly equal_posteriorly_and_dorsally mostly_exposed_dorsally, 183 cheek_emargination / absent present, 184 Parietal_anterior_waisting / absent present, 185 Parietal_width_relative_to_frontal / greater equal_or_less, 186 Trabecula_cranii / 'Without significant median fusion posterior to solum nasi (platytrabic)' 'fused medially posterior to solum nasi to form elongate trabecula communis (tropitrabic)', 187 Dorsal_trabeculae /

dorsal_trabeculae_provide_dorsolateral_bridge_between_sphenoid_region_and_nasal_ca psule 'dorsal trabeculae absent or incomplete, no dosolateal bridge between sphenoid region and nasal capsule', 188 Ossification_between_optic_foramen_and_pila_antotica / ossification_complete_between_optic_foramen_and_pila_antotica pila_metoptica_and_associated_cartilaginous_taeniae_unossified, 189

Ossification_within_columella_ethmoidalis / absent present, 190

Path_of profundus_branch_of_trigeminal_nerve / enclosed_in_lateral_wall_of_sphenoid_region_of_braincase_and_exits_separately_from maxillomandibular_branch_via_series_of_small_foramina 'extramural, exits antotic fissure with other branches of trigeminal', 191

Foramina_for_optic_nerve_and_trigeminal_nerve / confluent widely_separate, 192 Lateral_head_vein / No_distinct_foramen_for_lateral_head_vein

Distinct_foramen_within_the_antotic_fissure_serving_the_lateral_head_vein, 193 Anterior_extent_of_cultriform_process_of_parasphenoid / cultriform_process_extends_to_anterior_margin_of_sphenethmoid cultriform_process_extends_far_anterior_to_sphenethmoid cultriform_process_does_not_reach_anterior_margin_of_sphenethmoid, 194 Olfactory_bulbs / narrow 'endocasts swollen, leaving considerable impressions in lateral and ventral wall of sphenoid region and in ventral surface of frontal', 195 Flange_from_skull_roof_articulating_with_sphenethmoid / absent present_on_frontal_and_parietal present_on_frontal_only, 196 'Descending lamina of parietal invades medial orbital wall between "pleurosphenoid" and "sphenethmoid" elements' / no yes, 197 Foramen_for_oculomotor_nerve / exits_braincase_far_dorsal_to_foramen_for_optic_nerve exits_braincase_at_or_below_optic_nerve, 198 Intermaxillary_fossa / present absent, 199 Intermaxillary_fossa / paired unpaired, 200 Sphenethmoid_forms_interorbital_septum / no yes, 201 Anterior_extent_of_cultriform_process_along_palate / 
cultriform_process_extends_anteriorly_to_level_of_posterior_margin_of_choana 'cultriform process dramatically shortened, barely reaching the level of the posterior margin of the orbit', 202

Sutural_contact_between_cultriform_process_of_parasphenoid_and_vomer / no yes, 203 Lateral_wall_of_the_nasal_capsule_underplated_by_lateral_processes_of_the_vomer_an d_palatine / no yes, 204 Cultriform_process_vaulted_high_above_palatal_surface / no yes, 205 Posterior_extent_of_parasphenoid_beneath_braincase /

floors_sphenoid_region_only floors_sphenoid_and_otic_region 'floors sphenoid, otic, and occipital regions', 206 Basal_tubera / 'present, with significant endochondral contribution' 'present, with contribution of parasphenoid only' absent, 207

Path_of_common_internal_carotid_artery / 'does not run alongside braincase, enters braincase directly in region of sella turcica' 'follows vidian sulcus along posterior surface of basal plate of parasphenoid, enters parasphenoid via vidian canal in basal plate of parasphenoid, divides into cerebral and palatal branches after entering parasphenoid' 'follows vidian sulcus along posterior surface of basal plate of parasphenoid or lateral wall of braincase, divides into cerebral and palatal branches prior to entering the skull', 208 Bucohypophyseal_foramen in parasphenoid / open absent, 209 Morphology_of_pila_antotica / 'pila antotica is a thin, broad sheet' pila_antotica_is_a_robust_dorsoventral_pillar_bracing_the_skull_roof_against_the_palat e, 210 Basicranial_fissure / present absent, 211 Location_of_vidian_sulcus / along_ventral_surface_of_braincase along_lateral_surface_of_braincase, 212 Basipterygoid_joint / epipterygoid_comprises_entire_conus_recessus substantial_contribution_to_conus_recessus_by_pterygoid conus_recessus_comprised_entirely_of_pterygoid_without_epipterygoid_participation pterygoid_and_parasphenoid_broadly_sutured_without_development_of_a_conus_recess us, 213 Hypophyseal_fossa / single_unpaired_sulcus

pairedsulci_divided_medially_by_ridge_originating_on_dorsum_sellae, 214 Bone_flanking_the_dorsum_sellae / consurrent_with_fully_ossified_lateral_skull_roof 'subparallel with sagittal plane ("pleurosphenoid")' 'strongly oblique to or perpendicular to sagittal plane ("laterosphenoid")' restricted_to_dorsum_sellae_only, 215

Basal_plate_of_parasphenoid / 'roughly quadrangular, basipterygoid articulations narrowly spaced' 'rectangular laterally, anteroposteriorly narrow, basipterygoid articulations distant', 216 Sphenethmoid / ossified unossified, 217

Ossification_within_the_synotic_tectum /

synotic_tectum_massively_coossified_with_otic_capsules supraoccipital_paired_at_some_point_in_ontogeny supraoccipital_unpaired_throughout_ontogeny 'no supraoccipital bone; synotic tectum invaded by dorsal processes of exoccipitals', 218

Median_ascending_process_of_supraoccipital / absent present, 219

Lateral_ascending_processses_of_the_supraoccipital / absent present, 220 Margin_of_fenestra_vestibuli / 'parasphenoid excluded by neurocranial elements (basisphenoid and basioccipital)' parasphenoid_contributes_to_anteroventral_margin_of_fenestra_vestibuli parasphenoid_floors_entire_fenestra_vestibuli Ossification_of_otic_capsule_surrounds_entire_fenestra_vestibuli, 221 Crista_intervestibulara / crista_intervestibularis_absent crista_intervestibularis_present, 
222 Morphology_of_crista_parotica / 'crista parotica meets exoccipitals only, forming lateral wall of posttemporal fossa but not bracing against dermal skull'

crista_parotica_drawn_out_dorsolaterally_into_paroccipital_process_that_contacts_the_t abular 'crista parotica $\overline{d r a w n}$ out laterally into paroccipital process that contacts the $\bar{c}$ cheek and/or suspensorium', 223 Dorsal_process_of_stapes / absent present, 224

Facets_on_dorsal_surface_of_supraoccipital / absent present, 225 Otoccipital_fissure / present absent, 226 Crista_parotica / Descends_posteriorly

Horizontal along the extent of its length, 227

Position_of_quadrate_with_respect_to_otic_capsules /

quadrates_ventral_and_lateral_to_otic_capsules

quadrates_mostly_lateral_to_and_greater_or_equal_to_twice_the_width_of_the_otic_cap sules quadrates_mostly_ventral_to_otic_capsules

quadrates_approaching_or_abutting_lateral_wall_of_otic_capsules, 228

Size_of_otic_capsuiles / 'otic capsules comprise less than $2 / 3$ the width of otoccipital region' 'otic capsules comprise greater than $2 / 3$ total width of otoccipital region', 229 Otic_trough / absent present, 230 Articulation_between_the_epipterygoid_and_prootic / none elongate_facet_on_anterior_surface_of_prootic_for_articulation_of_epipterygoid, 231 Opisthotic_obscures_occipital_in_lateral_view / no yes, 232 'Fenestra vestibularis at end of broad, winglike lateral extension of the otic capsule' / no yes, 233

Cristae_in_otoccipital_region /

comprised_primarily_of_ascending_flanges_from_braincase

comprisd primarily of descending flanges from skull roof, 234

Opisthotic_excluded_from_the_occipital_surface_by_tabular_process_of_the_exoccipital / no yes, 235 Insertion_of_epaxial_musculature_on_occiput /

deep_within_temporal_fossae 'in broad, shallow fossae along occipital surface of postparietals', 236 Foramen_for_internal_jugular_vein /

between_supraoccipital_and_exoccipital between_opisthotic_and_exoccipital

through_exoccipital Posterior_notch_of_fenestra_vestibuli, 237

Foramina_for_hypoglossal_nerve / multiple single none, 238 Occipital_condyle_shape /

round 'U-shaped' paired, 239

Ventral_process_of_exoccipital_reaches_basipterygoid_joint_along_palatal_surface /

absent present, 240 Occipital_condyle_shape / Concave Convex, 241

Columella_of_stapes / perforate imperforate, 242 Orientation_of_stapes / 'Dorsal, towards tabular or otic notch' 'anteroventral, towards quadrate', 243

Stapedial_footplate_shape / oval round palmate, 244

Dorsal_sinus_between_synotic_tectum_and_skull_roof / absent present, 245

Ossification_within_septum_internasale / absent 'present, sphenethmoid' 'present, mesethmoid', 246 Ossification_of_septum_internasale_invades_nasal_tectum / absent present, 247 Insertion_of_hypaxial_musculature / sphenoid otic basioccipital, 248 Prootic_supported_by_pedicel_extending_from_basisphenoid_lateral_to_prootic_forame n / no yes, 249 Position_of_pineal_foramen_with_respect_to_hypophyseal_foramen / anterior_to approximately_the_same far_posterior_to, 250 Pineal_fossa /

well_anterior_to_posterior_margin_of_cerebral_fossa

at_or_behind_posterior_margin_of_cerebral_fossa, 251 Median_wall_of_otic_capsule / completely_unossified ossification_of_opisthotic

ossification_of_supraoccipital_and_basioccipital, 252 Conical_recess_in_basioccipital / 
absent present, 253 Semicircular_canals / separated_from_utricular_region_by_bone not separated from utricular region by bone, 254 Basioccipital /

Robust ossification ventral to foramen magnum present absent, 255

Accessory_articulation_processes_with_proatlantal_facet_on_exoccipitals / absent prominent, 256 Exoccipital_proatlantal_facets_incorporated_into_occipital_joint / no yes, 257 Anterior_tectal / anterior_tectal_present absent, 258 'Ectopterygoid/palatine exposure' / more_or_less_confined_to_tooth_row

broad_mesial_exposure_additional_to_tooth_row reduced_to_thin_sliver, 259

Ectopterygoid / Present Absent, $2 \overline{60}$ Ectopterygoid_as_long_or_longer_than_palatines / yes no, 261 Ectopterygoid_reaches_subtemporal_fossa / no yes, 262 Frontal / absent present, 263 Jugal / does_not_extend_anterior_to_orbit extends_anterior_to_orbit, 264

Lateral_rostral_present / yes no, 265 Maxilla_makes_interdigitating_suture_with_vomer / no yes, 266 Maxilla_external_contact_with_premaxilla / narrow_contact_point_not_interdigitated interdigitating_suture, 267 Maxilla_extends_behind_level_of_posterior_margin_of_orbit / yes no, 268 Median_rostral / single paired absent, 269 Opercular / present absent, 270 Prefrontal / 'twice as long as broad, or less' three times as long as broad, 271 Prefrontal / transverse_anterior_suture_with_tectal tapers_to_a_point_anteriorly, 272 Preopercular / present absent, 273 Pterygoid_quadrate_ramus_margin_in_subtemporal_vacuity / concave with_some_convex_component, 274 'Vomers separated by parasphenoid $>$ half length' / yes no, $27 \overline{5}$ Vomers / as_broad_as_long_or_broader about_twice_as_long_as_broad_or_longer, 276 Basipterygoid_process / not_strongly_projecting_with_concave_anterior_face strongly_projecting_with_flat_anterior_face, $27 \overline{7}$ Ethmoid / fully_ossified partly_or_wholly_unossified, 278 Hypophyseal_region / solid_side_wall_pierced_by_small_foramina_for_pituitary_vein_and_other_vessels single_large_foramen, 279

Lateral_commissure_of_otic_capsule_bearing_hyomandibular_facets / present absent, 280 Parasphenoid / does_not_overlap_basioccipital overlaps_basioccipital, 281

Denticulate_field_of_parasphenoid / present absent, 282 Sphenoid / 'fully ossified, terminating posteriorly in intracranial joint or fused to otoccipital' separated_from_otoccipital_by_unossified_gap, 283 Ectopterygoid_fang_pairs / present absent, 284 'Ectopterygoid row (3+) of smaller teeth' / present absent, 285

'Ectopterygoid/palatine shagreen field' / absent present, 286

Palatine_row_of_smaller_teeth / present absent, 287 'Pterygoid shagreen (palatine ramus)' / dense organized_radiating_rows_of_denticles disorganized_patches_or_absent, 288 Dentition_of_transverse_flange_of_pterygoid /

Denticle_field_indistinct_from_palatine_denticle_field distinct_raised_denticle_field organized_tooth_row absent, 289 Premaxillary_tooth_proportions /

all_approximate $\overline{l y}$ _same_size

posteriormost_teeth_at_least_twice_height_of_anteriomost_teeth

Anteriormost_teeth_largest, 290 Vomerine_fang_pairs / present absent, 291

Vomerine_fang_pairs_noticeably_smaller_than_other_palatal_fang_pairs / no yes, 292 Vomer anterior wall forming posterior margin of palatal fossa bears tooth row me eting_at_midline / yes no, 293 Vomerine_row_of_small_teeth / present absent, 294 Vomerine_shagreen_field / absent present, $29 \overline{5}$ Adductor_fossa / faces_dorsally 
faces_medially, 296 Adductor_crest / absent 'peak anterior to adductor fossa, dorsal margin of fossa concave' 'peak above anterior part of adductor fossa, dorsal margin of fossa convex', 297 'Angular-prearticular contact' /

prearticular_contacts_angular_edge_to_edge absent

medial_lamina_of_angular_sutures_with_prearticular, 298 'Coronoid (anterior) contacts splenial' / no yes, 299

Prearticular_extends_between_infradentaries_and_middle_coronoid / Yes No, 300 'Coronoid (middle) contacts postsplenial' / no yes, 301 'Coronoid (posterior)

posterodorsal process' / no yes, 302 'Coronoid (posterior) posterodorsal process visible in lateral view' / no yes, 303 'Dentary external to angular \& surangular, with chamfered ventral edge and no interdigitations' / no yes, 304 Dentary_ventral_edge /

smooth_continuous_line 'abruptly tapering or "stepped" margin', 305

Dentary_suture_with_splenial_\&_postsplenial_marked_by_deep_furrow / no yes, 306 Mandibular_sensory_canal / present absent, $3 \overline{0} 7$ Mandibular_canal_exposure / 'entirely enclosed, opens through lines of pores' 'postly enclosed, short sections of open grooves' 'mostly open grooves, short sections opening through pores' entirely_open, 308 'Oral sulcus/surangular pit line of mandible' / present absent, 309

Meckelian_bone_floors_precoronoid_sulcus / yes no, 310

Meckelian_bone_ossified_in_middle_part_of_jaw / yes little_or_no_ossification, 311

Meckelian_bone_exposure_in_middle_part_of_jaw / depth_much_less_than_prearticular depth_similar_to_prearticular, 312 'Meckelian foramina/fenestrae, dorsal margins' /

Meckelian bone prearticular infradentary, 313 'Meckelian foramina/fenestrae height' / much_lower_than_adjacent_prearticular equal_to_or_greater_than_depth_of_adjacent_prearticular, 314

Parasymphyseal_lateral_foramen_present / no yes, 315

Parasymphyseal mesial foramen present / no yes, 316

Postsplenial_with_mesial_lamina / no small 'expanded, contacting precoronoid', 317

Postsplenial_pit_line_present / yes no, 318

Postsplenial_suture_with_prearticular_present / no yes, 319

Prearticular_sutures with surangular/ no yes, 320 Medial lamina of splenial / absent present, 321 Prearticular_with_longitudinal_ridge_below_coronoids / no yes, 322 'Prearticular with mesially-projecting flange on dorsal edge along posterior border of adductor fossa' / no yes, 323 Prearticular_centre_of_radiation_of_striations / level_with_posterior_end_of_posterior_coronoid level_with_middle_of_adductor_fossa level_with_posterior_end_of_adductor_fossa, 324 Splenial_has_free_ventral_flange / yes no, 325 'Splenial, rearmost extension of medial lamina' / closer_to_anterior_end_of_jaw_than_to_adductor_fossa equidistant closer_to_anterior_margin_of_adductor_fossa_than_to_the_anterior_end_of the jaw, 326 'Coronoids; at least one has fang pair recognizable because at least twice the height of coronoid teeth' / yes no, 327 'Coronoids: at least one has fangs recognizable because noticeable mesial to vertical lamina of bone and to all other teeth' / yes no, 328 'Coronoids: at least one has organized tooth row' / yes no, 329 'Coronoids: at least one carries shagreen' / no yes, 330 'Coronoids: size of teeth (excluding fangs) on anterior and middle coronoids relative to dentary tooth size' / about_the_same

half_the_height_or_less, 331 Dentary_tooth_row / homodont markedly_heterodont, 332 Dentary_with_parasymphyseal_fangs_internal_to_marginal_tooth_row / yes no, 333 
Dentary_teeth / same_size_as_maxillary_teeth larger_than_maxillary_teeth smaller_than_maxillary_teeth, 334

Dentary_with_a_row_of_very_small_teeth_or_denticles_lateral_to_tooth_row / yes no, 335 Parasymphyseal_tooth_plate / present absent, 336 Parasymphyseal_plate_dentition / shagreen_or_irregular_tooth_field organied_dentition_aligned_parallel_to_jaw_margin no_dentition, 337 Parasymphyseal_plate_has fang pair / no yes, 338

Parasymphyseal_plate_has_tooth_row / no 'short tooth row, separated from coronoid row by diastema' long_tooth_row_reaching_coronoid, 339

Prearticular_shagreen_field_distribution / gradually_decreasing_from_dorsal_to_ventral 'well-defined dorsal longitudinal band' scattered patches_or_absent, 340

Anterior_palatal_fenestra / single_double absent, 341 Dorsal_fontanelle_on_snout / absent present, 342 Interpterygoid_vacuities / absent at least_ $2 \mathrm{x}$-wider than long $2 x$ longer_than_wide, 343 Intracranial_joint / present_in_dermal_skull_roof absent_in_dermal_skull_roof, 344 Nature_of_dermal_ornament / tuberculate fairly_regular_pit_and_ridge irregular absent_or_almost_absent, 345 'Nature of ornament: starbursts of radiating ornament on at least some bones' / no yes, 346 Anocleithrum / oblong with distinct anterior_overlap_area 'drop-shaped with no anterior overlap area' absent, 347 Cleithrum / ornamented not_ornamented, 348 'Cleithrum, postbranchial lamina' / present absent, 349 Digits / absent present, 350 Humerus / narrow_tapering_entepicondyle 'square or parallelogram-shaped entepicondyle', 351 'Ilium, iliac canal' / absent present, 352 'Ilium, posterior process' / oriented posterodorsally oriented approximately horizontally posteriorly, 353 Interclavicle / small_and_concealed_or_absent large_and_exposed, 354 Interclavicle_shape / ovoid kite_shaped with_posterior_stalk, 355 Lepidotrichia_in_paired_appendages / present absent, 356 Posttemporal_and_supracleithrum / present absent, 357 Radius_and_ulna / radius_much_longer_than_ulna approximately_equal_in_length, 358 'Ribs, trunk' / all_cylindrical

some_or_all_bear_flanges_from_posterior_margin_which_narrow_distally some_or_all_flare_distally, 359 Scapular_blade / absent small_with_narrow_top large_with_broad_top, 360 Scapulocoracoid / small_and_tripodal large_plate, 361 Subscapular_fossa / broad_and_shallow deeply_impressed_posteriorly, 362 Squamation / 'complete body covering of scales, all similar' ventral_armour_of_gastralia, 363 Pectoral_process / absent present, 364 Proximal_limb_of_oblique_ridge / 'present, separated from anterior margin of humerus by prepectoral space' 'absent, replaced by deltopectoral crest', 365 Latissimus_dorsi_attachment / diffuse_ridged_area distinct_process, 366 Foramina_piercing_oblique_ventral_ridge / many one_moderately_large_foramen_in_addition_to_entepicondylar_foramen 'entepicondylar foramen is the only large opening, other foramina ar epinpricks or absent' none, 367 'Humerus with well-developed anterior plate' / yes no, 368 Subclavicular_ossifications / Absent Sometimes_present, 369 Radial capitulum / approximately_same_size_as_ulnar_facet 'greatly enlarged and rounded, $>2 \mathrm{x}$ size of ulnar facet', 370 Lissamphibian_inner_ear/ no yes ;

MATRIX

Archeria crassidisca $\quad 02000000100100001001000 ? 01000011000000001---$ 01000000010--01000000000100-010000002100000000100000- 
010001???2?000000003000000010010000020112010000????????????????1211???0?00 $0 ? ? ? ? ? ? ? ? 00010100101 ? 001001-$ 00000100101?000000001?1100020000000001000?0?00-101??0000100001110012111111?1111110?0??000?????122110110100311111001111111?121111-0(0 1)01000021001212111100111110211111120000 Crassigyrinus_scoticus 0100001010000000000100101000000110000000000000001000010--0001-000011000$000000000100000000000010-$ 010001???0?000?0000?00?????0?0100?000??1??1000??000001000000???12110000?20 $000100 ? ? ? 0 ? 0101 ? 0 ? 0 ? ? ? ? ? ? ? 00 ? ? 0000001 ? 0-$ ???00???1??0?0?000000??0??000??????0??????0?1000010111021011010????10?0000000000000020000001003111?100001001??112111 $1 ? 101101101110121 ? 1111 ? ? 111110 ? ? ? 11111000$ ?

Acanthostega_gunnari 000100010000?000000000000000000000000000000000000000010--00000000000000000000000000000000000000-0100000000?0000000000000000\{0 $1\} 000000000000000000000000000000000000000000030000100000200000 ? 0-$ $100 ? 000000000000000000 ? ? 00000000 ? 000001 ? 00000000000000000 ? 00 ? ? ? ? 000-$ $00001111000111 ? 001011110001000001000000011000 ? 10001111010010100110000110$ 010001011111101111101100111102010111120000

Eusthenopteron foordi 01000000000100010100--0-11010-00-------000000001000000-0301-000000000-001000000-01?00000000?10-

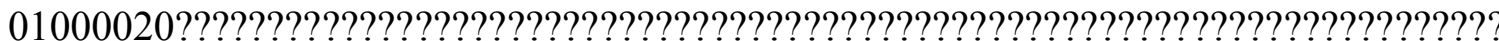
????????????????????????1???????????????????0-???????????????????????0?+??20??000000000000000000?00000000000000000000010000?00000000000000000000?00000 $0001000000000000000000 ? 00000000 ? 000100 ? ? 0$

Ichthyostega spp. $\quad 01010001100020000000000-$ 1100000110000000000000001000000--00100000012010-000000002000?00000100-(0 1) 0 01000????0?00000000000100011000??????????0000010110111010001??01201010031 $00 ? 1100-$ 021?010????0????00?01?000002?100?0?00????0000?10000000000??0001?10??0?????0 ??-0100111?1000111001011?1000(0 1)000231001000001000?1000?1100000101001?000011001002101112000111?1011111 21111011?10010000

Panderichthys rhombolepis

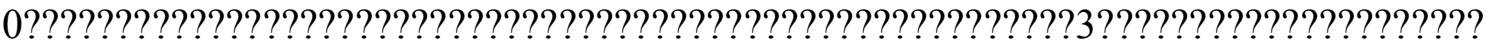

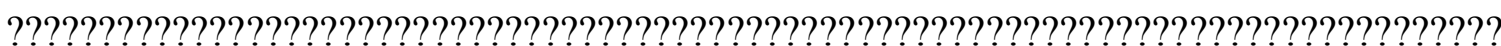
?????????????????????????????????????????????????????????????????????????????????

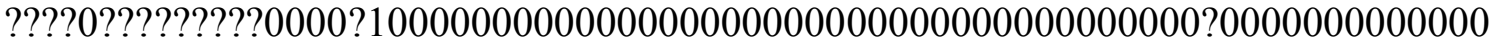
0000000?000000000000000000010000000??0?000101?0000?0??0

Pederpes_finneyae 0100000010012000100?0??0000?011110100000000000??1000000--01?000000?2010$000000000100 ? 000001 ? 0 ? ? 0-$

01??01???0?000?00000???????11100000??0?1??00000?00000?0100010?11200101?310

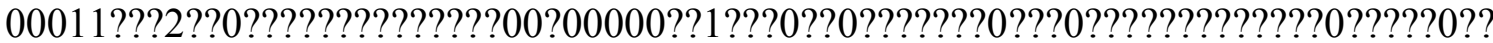


????????1?01101000?1010?1?1??110?001000????????????????????????????????????? ??????????????0111?11110112111111?11112000?

Tiktaalik rosaea 01010010100120000001100?11000001101000000000000001000000--030000000000000000000001010000000000(0 1)0-0?000000?2------------?????????????????010-????????1000???002010000-000???????-1?0101001010200000000100000000-0?0000--$-?-? 0 ? 10000000 ? ? ? ? 0 ?---0--001 ? ? ? ? 00-$

??0??11??00?11?000?00?0000????000?????0000000?00000?000?0000??0000???000000 0?10?0?0?0010000000??0?0?0?010?00000??0

Ventastega curonica 0?000000000020000011000?110001011010000000000??01000000--00001000011000$00000000010 ? ? 00000000010-$ 0100????????????????????????????????????????????010111010000??0?????????000??? ?????0?010100??1?20?0?010100000010010?000???0?1??0110?0?0000???0???????0??? ???????0???111000111?00101101000??000?100?000001000?100000100001100001100 $00010010001010210101111110 ? 0011 ? 1 ? ? 010 ? ? ? ? ? ? ? 0$

Whatcheeria deltae 0000000010002000100000010000011110000000000100001000000--01000000011010$00000000110 ? ? 00000100 ?(01) 0$ 000001???1?000?00001???????1?00??????????00000?000000001000001012000000310 0?1100?0?1?010????????????00???000????0????010--

0 ?10?01000?00000???0???????0????????-

$10000111 ? 00210100111 ? ? 11 ? ? 0000001001101001001000002010000000100110102110$ 01002101011?00131?1011011211?121??1112000?

Ymeria denticulata 0?1??????????????????????10?0?01??????????????????????010010000?2000$000000001 ? 00 ? 00000000 ? 10-$

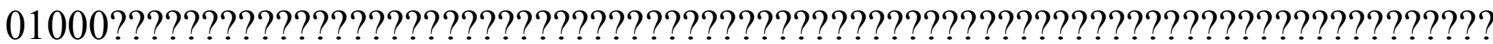
?????????????????????????????????????????????????????????????????????0?+???????? $1001 ? ? ? ? 00 ? ? ? ? ? 0 ? 0 ? ? ? ? ? ? ? 00 ? 0 ? ? 100 ? 0 ? 00(1$

2)?000?100021?0000??010??0?00?01000000101110?0?31?????????????????????????

Proterogyrinus scheelei $010000\{01\} 0\{0$ $1\} 001 ? 0001000000 ? 0000000000000000000001000000010--00000000000000-$ 00000000000000000000?00-00\{0 1

2\}1000000?00000000300001?0100000000000000?00000000001000000020100?101001 0111000100?00101?101?11000?1-11000100??00003000-$1 ? 00 ? 0020000000001000 ? 0 ? 00 ? 10 ? ? ? ? ? 00-$ $10000101001210111111 ? ? ? 11 ? 0100000 ? ? ? ? ? 1221 ? ? ? ? 0101 ? 111 ? 11001111 ? 11 ? 12 ? ? ? 1 ?$ 00011---2200121211110011111021?11112000?

Balanerpeton_woodi 000000101001000000000?110000000000000000000?10000000000--10000000000000000000000011100000100000 $0001010001 ? 000000000000000 ? 00000000 ? 000020010000000000000000 ? ? 0220011001$ 10211000100?0000????????????????00??????????00??????0????????????1?00?000??? $1 ? ? ? ? ? ? 00-$ 
$110011011 ? 02101111011 ? ? 101011100000111112111 ? ? 0101 ? 111 ? 20002110100 ? 10111$ 1?00111?--22021112111100111112?1?11112100?

Dendrerpeton acadianum

000000001001000000000?100000000000000000000?00000000000--10000000000000$000000000011000000001110-$

00? 1010001?00000000000001??10000000?00?0?0010000000000000000010220011001

002?00?0??0000001??01????00?0??01001221?10013013--2010-

110000000001?00000000?10??1?100-10001101?102101111111111(0

1) $10111000011111(1$

2)21??110101?1?1?11??1111??0?111111?0?11????2202111211110011111021?1111210

01

Cardiocephalus_peabodyi 32011-012001100010000?001101121001-$00010000210\{01\} 10000-0--12100 ? 102231110113 ? 0 ? ? 0 ? ? ? ? ? 0 ? 0111 ? 1 ? ? 0-$ 20??110002??01?00102???????100001220?0110000010????????1000?0-

121012?0??202010?????11010????????????1?????01?????????????????????????00??11

?000?1??0?21??2110111???????????????????????????????????????????????????????? ???????????????????????????????????????????????????10??

Huskerpeton englehorni 3?011-012001110010000?002101011001-$00010000210110000-0--121000100 ? 2010-$

01200000??010?0011101111010211??????????????????????????????????????????????

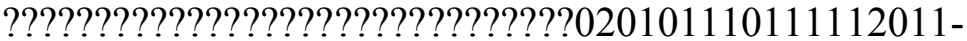

$00000122101110100201212 ? 011310000-$

0011100???00?21??2110111101010100121011111111111110002301-1?01220--100101-

111-1000-1-0100-121100101011---2202130211????12?1??21???????0?0

Pelodosotis elongatum 03011-012001100110000?001001031001-00000000010110010-0--1211-010012010-012?000021010000\{0 1\}0111111020?1100002??01?10102???????10001121?10110010010?0111-111000111220021???00201000????1110?100111001011-

$000002121011 ? ? 1102 ? ? 2 ? 2111 ? 3 ? 0 ? 000011110011210 ? 21 ? ? 2 ? 00111101010100121011$ 111111110010100301-111122????00101-111-10??1110100-1?????0?011--220212021111??12111021?-11021000

Nannaroter mckinzei 3?011-01200110???0000?0011010?00?1-0001000001011 ? 0 ? $0-0--12100010113010-$

012?00002?01000010101??1020201???????????????????????????????????????????????

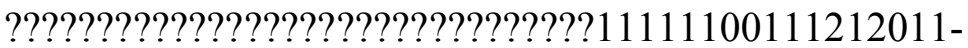

$000002121010 ? 0110 ? ? ? 2 ? ? ? ? 1 ? 3 ? ? 000-$

01???0?????0??1????10111101????????????????11110010100301-1?11221-?????1-

111-1000-1-0100-121111111011---2202120????????????????????????

Micraroter_erythrogeios 03011-012001110110000?000001030001-$00010000210\{01\}\{01\} 0010-0--12100010113010-$

$012000002000000010101 ? ? 102021100000 ? 00101010200001001000012200011000002$ ? ????????1000?0-1??0??????102110??????111011001110010110000021210111?1002?12?211113000000011110001110?21??211011??0?????????????? ?????????????0301-1?11221-??????1-111-100?-1-0100-1211?1?01011--2202130?????????1?????-?????0?0 
Eocaecilia_micropodia 3301?-0?-1----0000000?011101121001--00011--0?011100?----1200000000000010013000011013\{0 1\}0?0---????101?3?110002?002?0002?????0111010122-201121000013??????????????0220121002?0?011001?1?-

0000011110210011-00110221111?203003--30?011?010-00--

12?20001001?10??1?010?111--101100211111001111-0110000001-10011------01-1-1---000--------110000101010222011202--11??0-111021?-01?21??1

Greererpeton_burkemorani 0200000100110000000000012100030101----0000000001000000--00000000000000-0000000000000000000001000000010002?00000000000000??10100000?0000211100000010000000111011011110100201010--0?00001010?1?1000?00000001001-10103003-$1 ? 10-111000000001100000000-100 ? ? 0 ? 00-$ $110011010002110101011111010000001011101221001101001011 ?(1$ 2)1000100100?1200011101101102111111210110011111111?111120000

Seymouria_baylorensis 0100000010010000000000000000010000100000000001000000000--00000000012010$1000000010000000000000\left\{\begin{array}{lll}0 & 1\end{array}\right\}\left\{\begin{array}{ll}0 & 1\end{array}\right\}-2000001001 ? 000000\{0$ 1\}02000010010000000000110000010011000100100102012101000000111100?00?0010 1?1011?0020?1-110001021-1110310-??1?11-100000111001010010?00?1???1??0011011111001211111111111101111111000111122110110101-111-11001111100111111-11211---22001102111101121110211111121000

Limnoscelis paludis 0101010110010000100000000000001001000000000001100010000--12100001022010$0011001010010000000101\{01\} 0-$ 0010110000?000000002000000010000000000100000010011000??0100?0?0221010100 10111000110?00001?1011?0020?1-110011021$11103001001 ? 111102010111011000101 ? 00 ? 2 ? ? ? 1 ? 000-$ 1101110111121011111111111111111221-11012200-100101-111-1100-1-0100-12111011011---2202130211110112111021?-11121000

Branchiosauridae 311100100001210000000?10100001000020???0000010000010010--11000000010000$00\left\{\begin{array}{l}0 \\ 1\}\end{array} 0000\{01\} 1\right.$ ? $13010 ? ? ? ? ? ? ? ? 0-$ ?????020010000?00?0000?0?0000000?????0?1200200?00$000 ? ? 000 ? ? ? ? 20000101 ? 120211010--$ 0?0010???????????????????????????111?????????????00?????20?????0?1,?????101????????????????????????????????????????????????????????????????????????????? ???????????????????????????310??

Micromelerpetontidae $\quad 311100100001010000100 ? 1000000\{0$ 1\}000000???0000?11000010010--0100000000000000?010000?13100??????????????010000000?00?0000?0?00000?0?????0?1210000?00000??000????20001101?120211010--

0?0001???????????????????????????01??????????????0??????00?0??0?1??????101??????????????????????????????????????????????????????????????????????????????? ?????????????????????????????310??

Tersomius_texensis $\quad 2 ? 0100\{01\} 010010\{01\} 00001101100000010000\{0$ $1\} 00010000$ ?10001000000--1100000000000\{0 1\}00\{0 1\}0010000?131100000000\{0 $1\} 0-$ 
0101010?0??????????1??????????????????????????????????????????????????????????? 0????0001????????????01???????????????00??????0???????00???1?200100?0?1??????1 ??100101010000101111011111?1010100000110112111110101-11110002110100?10111?-010101012011111????????????????????0??

Ecolsonia_cutlerensis 0?11000110011100001001102020000000011210000000001000000--1000000001\{0 $1\} 010-000010000 ? 1210000000 ? 0\{01\} 0-$ 0?000?000??00010100000001011000????????????100?????????0000?010?11??0?0?100 110?0????0000?????????????????????????????0???????????????00?????100????0?1???? ??10-

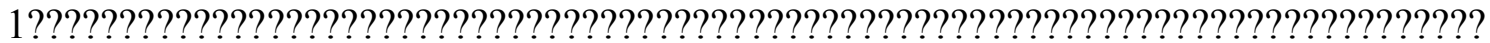

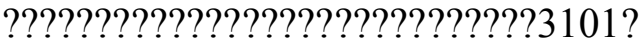

Acheloma_spp.

0?010001100??000001001?020200000000111100?0000001000000--10000?00011010$000010000 ? 12 ? 000 ? 0100 ? ? 0-$ 01?00?000??00000000000000?01000??????????001???????????000????02210?1001?0? ????0????0000?0001101000101001002111010002003--2?10$100001001001110110200 ? 1 ? ? ? ? ? ? 10-$ 10011101010210111111111101011100101101122111110101-11110002110100?101111-000110002011111211110?12111121??1113101?

Eryops megalocephalus $010100 ? 11000$ 000000?001?0000000100?00000000000000000000--10000000000010000000000?121000?00????0?????0?0?01?00000000000000001000??????????0000??00000?000000??02211?10010?1???0?000?00011001111000011-000002111011100003-$1 ? 10-110001000001110000201 ? 1 ? ? ? ? ? 000-$ $11001111010210111101111100011100001111122100110101-$ 111?20001110100?101111?00011???2001111211110-111111211?1113101\{0 1\}

Doleserpeton_annectens 3?010010100100000010011?0000010000200000000?10000010000-$11000000000001001001001\{01\} ? 13110000000000-010 ? 010001 ? 00\{1$ 2\}?0000200?0??110000?12220??2??200????????010????????????0??0?????0????0001 001011?1100?01001002211?10113103--2010-111101000001120010000?1???0?0101200110100021011110111110110000001--011121??100101-1--10002110101?101100001010101201113021111?0111110210-01-31011

Caudata $\quad-2\{01\} 11---00012-0110100-1000002\{12\} 0001--00001---$ $0-21----1-0--120000000\{01\} 0001001\{23\} 002011015\{01\}-0002-2-2-0-10\{23\} 010\{1$ $2\} 003\{01\} 0120000020100100111011222201120020013--------1--$ $11112001001120211000\{0$ 1\}00?-10000101101(0 1)(0 1)01(0 1)100100221111-20?0(0

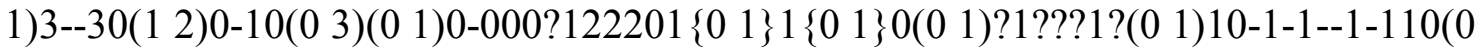
1)(1 2) 1 ? $110\left(\begin{array}{lll}0 & 1\end{array}\right)\left(\begin{array}{lll}0 & 1\end{array}\right)-1-$ 1??????????????????????????????????????????????????????????????????????????????? ???????31011

Anura $\quad$-1111----1----1--\{0 1 1$\} 100-10-0002100002000101---0-20---$ $1-0--120000000\{01\} 00010010001011014\{01\}-0002-\{12\} 12-0-11301001030012-$ 000021----1101011122201120020013-------10110011001000101211001100?0??0010110010011-00100221111?20?1(0 1)3--3010-101(0 1)0-0000(0 1)2220110\{0 
1\}0(0 1)?1???1?(0 1)10-121--

1????????????????1???????????????????????????????????????????????????????????? ????????????????????????31011

Albanerpetontidae 3?011---1001211--1100?0?20001100012-00001---1-21--01-0--11000-000??1011012?0?00???3???002-2-111021301?000\{0

1\}?012?00002??????011001122220122002001????????--

1 ????0???0???0??0?,10?0?0??-

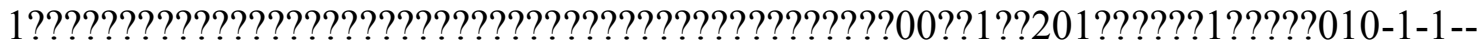
?????????????????1?????????????????????????????????????????????????????????????? ????????????????????????31?11

Micropholis_stowi $20\{01\} 1000\{01\} 10012100000\{01\} 0110\{0$ $1\} 000000000000000000010000001000-1-0000000\{01\}\{01\} 000-$ $00001000001311000000111100101000003 ? 000 ? 00001 ? ? ? ? ? 011010 ? 0002 ? 0 ? 1200200 ? ?$ 0-00000010001?120001100000201000100?0011????????????01???????????????\{0 1\}0??????????????00?????200000?0?1??????10-1000110110021011110111?10?\{0 $1\} 1\{01\} 100000110122111110101-111-$ 11??2110100?10?????0?01????201111121111011111102?0?01-3101?

Eoscopus_lockardi $\quad 2 ? 01001\{01\} 100101000011011 ? 000000000020\{0$ 1\}210000?10000010010--11000000000000-000010000?1311000000?\{0 1\}?0?0?00?0001000000000100001011000???0200?\{0 1\}200200100$00000010 ? ? ? ? 0110 ? 21001\{0$ 1\}0201000100?0001???????????01??????????????01??????0??????00??????0?000?0 ?1??????10-1000110110021011110111?101010100000110122111000111-11110002110100?101111?0001????20011102??1101111110?????1?3101?

Tambachia_trogallas 2?01000110010000001001102020000000001110000000001000000--11000000011010$000010000 ? 121000 ? ? 1\{01\} 1 ? ? 0-$

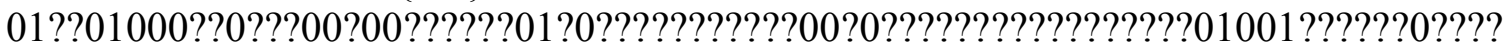
?0????0001?????????????????????????????????????0???????????????0?0?0???1??????1 0-1001110111121011110111?10????100001111?22?????0101-1?110??2110100?10?????0?01?????0011112??1101??111?????11?31???

Triadobatrachus massinoti 21111-1-??????0--0100???????21???020-0101---

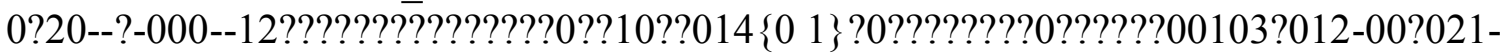
$---011010 ? 1 ? ? ? 20\{01\} 1 ? 002001\{03\}-------?-10 ? ? ? 010001100 ?\{12\} 12-1001 ? 0 ? ?-$ 0???????????????????????????????10??????0???????00?????2011?0???1?????+10-?21-1???????????????????????????????????????????????????????????????????????????????

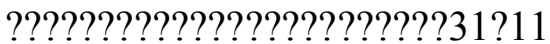

Gerobatrachus hottoni 2111001010012100001101?000?02100002000000???00000010010--??000000000000$0120010120141100 ? ? ? ? ? ? ? 0-$

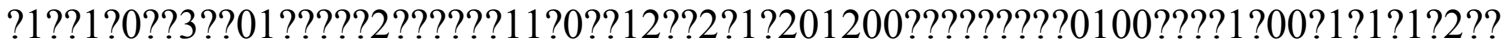

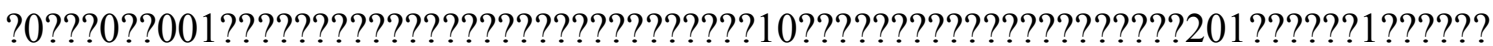
1??120?1101?0021011110111?1?1111?2001-100122?????01?1?11110?????0??0???????????????201113021111????11?0???????31???

Platyrhinops lyelli 210100?01001?10000010?1100?0200000200000000010000010010-- 
1110000000000100?0010?0??131100000201?0-?0??010000??02-

$0000100 ? ? 0 ? 110000102 ? 2 ? 1 ? 200200 ? 00-$

0????0100???01??0111010?2?1000??0?0001????????????01???????????????00????????

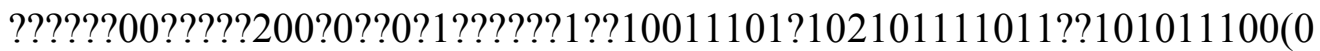

1)00111122111110101-111-1000211?100-101111-

00010000220111121111?0111110210?01?3101?

Amphibamus grandiceps

211100?01001010000000?1000?0200000200000000?1000001001???111000000000010 $010010010 ? 13110000 ? ? ? ? ? 0-$

$0 ? ? ? ? 10001 ? ? 00 ? 0000200 ? ? 00110000 ? 00 ? 2 ? 1 ? 200200 ? 00-$

00000010000 (0?120100?1102?1?00??0?0001????????????01???????????????11???????

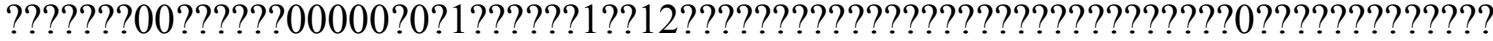

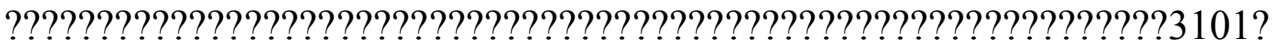

Lethiscus_stocki $\quad 230100010001110011100011200101101000000001--$ 01101001010--?2000000012000-011000000110000000000000-

$000001 ? ? ? 2 ? ? 120000021---01111(0$ 1)102222001210110-

??????????????????????????????????0-1101000010000111-00000000000-000000--

0010-110000000001?00010000-001?00100-

$1000110100021011001010101011 ? ? ? 001010 ? 0001000-$

100???10010110110010?10111?-010102002000130211----0--1?????1???--?-0

Coloraderpeton brilli 13010001000111001000????????01001000100010-01001000010--02000000012100-010?00002100000000000000-000001---2??120000021---01111(0 1)102222001210110-??????????????????????????????????0-

1101000010000111-00000000000-000000--0010-110000000001?000?0?00-001100000?000110?000?10?00?1010100010000001?-0000010?0-1000\{0 1\}110?1011011001010111?-01011???20?0130???-----?-1?????1???--?-0

Edops_craigi 0100000010002000000000000000001100000000000100000000000--10000000011000$000000000112000000001 ? ? 0-$

10000??????????00?????????????????????????????????????????????????????????????

???000011001111000011-000001101011100003--1010-1100000000011100002-

1?1??????00-10001111010210111111111100011100101111122100100?01-11110000110100?101111?00011---2202111????100????1????111?21?0?

Captorhinus_laticeps 0102011-20011000101000000101031101-000000000--0---0100--11000001123010-0111001021000-00100111(0

1) 101021000001 ? $0020000021---$

0110000102220010010011311100110?1?101022101100000201000110--

01011111??2010?1-100002221-

$110030021121211103000000001000101001021 ? ? 2 ? 100-1 ? 1-$

0101001210111111111111--111221---0122-?-100101-111-1000?1?0100-121110-11011$--22021202-111 ?-12111021 ?-11121000$

Petrolacosaurus kansensis 02020111200100001010000?0101011101-0000000100000011000--12000000011010-0111001021000000000012--00211100?0??020000021----0010000002020010110011311111010100010111001000102?1000110-00101?10???0?10?1-?00002221$11003012112 ? 211113000000001110101000 ? 21 ? ? 2 ? ? 010 ? 101110100121011111111 ? 10$ ? 
11111001-1111221--100101-111-

10001110100?1???????????????????????????????????????100?

Ophiacodon_uniformis_ $\quad 0102010010012000101000100101011101----$ 0000101100001000--12000000011110-

$01010010210000000011111111021110 ? ? 0 ? 002000002001000010000002120100100010$ 01101011010010102210010001020000011000010111011?1020?1-11001102111103001--30111102010101011100101002?20????0001101011100121011111111111111011221-1101221--110101-111-1000-1-0101-12111001211---22021302111101121110211-11121000

Baphetes spp. 0?00001010011000000100000000010110000000010100001000000--0100000000?000$001000000000 ? 00000100 ? ? 0-$

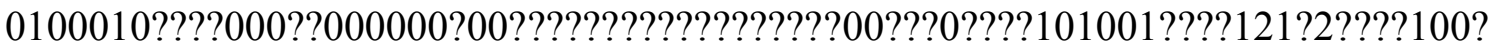

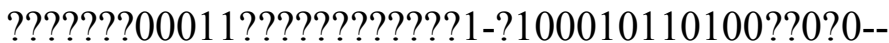
1010?011000000003?000?0?0??1??????0?010011?1010110110101111100011100000111?????????????????????????????????? ??0010?200111?111100??1?1????111120???

Eucritta melanolimnetes 00000000100110000000000?0000210010001000000000001000000--1100?0000?1000$0000000 ? 0 ? 00 ? 00000000 ? ? 0-$

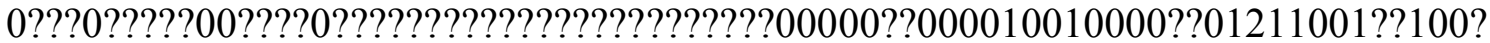
$1100 ? ? 0 ? ? 010 ? ? ? ? ? ? ? ? ? ? ? ? 1-$ ?100012?1?1?0??0???????????1????0?????????????1????????$11011101010210111101 ? ? ? ? 0 ? 1011000 ? ? ? ? ? ? 0 ? ? ? ? ? ? ? ? ? 1-$

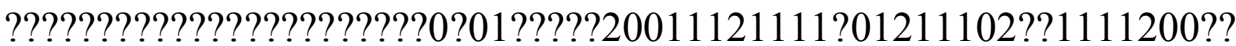

Llistrofus pricei 3?011-0120011101101000?0200?020001----1000121000011000--10?000001?2000-0111?0002101000011011110102111???1?011?00002???????1000????????????00???????????????????????01?2?????? ?????-0110111011?01?011-000002221?111??002??2????1?010?00?0011100???002??????0??110??101001211111111111101??1?03?1-1111221??100101-11110???1?0100?101100111011---22?2121?????????1110????????????

Aletrimyti gaskillae 32011-012001111--00000001102121101----$10000210 ? 1011000-12100010013000-$

012100002100000010101111020211?????????????2????????????????????????????????

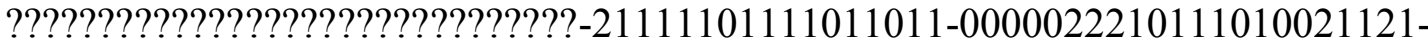
0111310000-0111100?1000-210121101111010101001210111111111111100023011?01220--110101-111-1000-1-0100-121110-11011---220213021111??12111021?$? 1 ? 21 ? 00$

Dvellecanus_carrolli 3?011-01200111???00000001102120001---1000021011011000--12100011013000-01210000210000001001111020211??????????????????????????????????????????????????????????????????????????? ???-21111100111011011-000002221011101102112120110310000-0111100?100021012110111101010100121011011111111010002301-1?01220--110101-111-1000-10100-121110-11011---2202130??????????1?????????????0

Rhynchonkos stovalli 3?011-012001111--00000001102210001----1000121000110000--12100010013010- 
0121000021000000100?1111020211????????????????????????????????????????????? ??????????????????????????????-11101110111211011$00000222101010110211212011131000000111100 ? 1100-$ 21012110111101010100121011111111111110002301-1?01220--100101-111-1000-10100-121110-01011---2202130?????????1????????????0

Dimetrodon_spp. $\quad 0102010010112000101000000001001101-----$ 00000001000-0000--12000000023110-0111001021000000111102112110110?????1200000201100001000010?????0?10001??111111???????2210?1000002010000000-1101?1111?1020?1110011121 ?1110300?0030111102010100001000101002020211?0000110101110112111 1111111110111111221-1101221--100101-111---00-1-0101-121110-11011--22021302111101121110211-11121000

Opisthodontosaurus_carrolli 1?02??0?200110001000??0011010?0101----100000??0???0?????12100000213010-111100102100000011111??010201??????12??0002???????1000??????????1?00???1111-11--1$1010221001000002110 ? ? ? ? ?-$

?0001??????????????????????????????????????????????????????????1?2?????1???? ????????????????????????????????????????????????????????????????????????????????? ????????????????????????0??

Pantylus_cordatus 00011-0120010000100000000101011001-00000000010110000-0--10100000223010-0111000011000000100011\{0 1\}102020000001?01101010200000011000012202011101000?01111$101000201022002100110211000110 ? 10001100111212011-$ 100001221011101002112121 ? $113000000001110011011 ? 21 ? ? 211011111--$ 111001211110111111111--100321-1111221??110101-11110001111100 ?111100111011---2202111211110012111021?-11021000 Quasicaecilia texana 3?121-1-1001001--01000??210?220001--00000001220---0100--

121??????????????310?0??1120?0????????1?????1??????????0?????????????????????

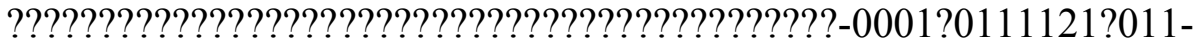
100002221110??110???2???11?3?0000-01111001??0212101-11011?11-101???21011???1111?11110?23????????????????????????????????????????????????? ?021302?????????1?????????????

Carrolla_craddocki 3?021-1-200100???01000?0210?130001-----00?00220---01----1211-010123001101300000-

$1120001100111110103111 ? ? ? ? ? ? ? ? ? ? ? ? ? ? ? ? ? ? ? ? ? ? ? ? ? ? ? ? ? ? ? ? ? ? ? ? ? ? ? ? ? ? ? ? ? ? ? ? ? ? ? ? ?$ ????????????????????--00011111110000?1-1000022?111?101100?12?21111310000011120111001?21??-100111111010100121011101111111111012301-110122-----0101111-1000-?-?100?11-----01011---2202130??????????1?????????????0

Batropetes frischti 3?021-1-200100???01000??210?130001-----00?002-20--01----1211-010123001101300000-

11200011001111101031110??3?0?1000????????001????12??????000000?01111$10 ? ? ? ? ? ? ? 02 ? ? 1 ? 1001102 ? 1100110--000 ? ? ? ? ? ? ? 0 ? ? 0 ? 1-$ ?00??22???1????100?12??111?3??000-01??2011100??2???1?0111111010100121011?01111111111012301-110122-----0101-111-1000-?-?100?11----01011---220213021111?01211?021?11102100? 
FMNH PR 847

3?021-1-?????????0100???21??1300?1-----10?002-

20---?1----12???0100?1000-

013?0??0???????1?????????1???110??3?0?1000????????001????12??????000000?0????

??????????02??1?1????02?11?0????-

000??????????0???????????????????0????+11133???0?-0???????1????2???-

?????1????10190121011????????????????????12??????1????????00??-??????-----

01011---??0?1302???1?0??11?021????0?100?

Brachydectes newberryi 23021--100010-1--00000012101120001--00001---

0101110-000--11000000013000-

$01310000110200011001111102031100002 ? 011000102000010100001121020012110000$

31110-11000001001001\{0 1\}11?12021110??10?110011111110000?1-

000002221110101002102121111310000-011110011002?2???211011111--

10100121111111111111111012301-1001220--100101-111-1000-1-0100?121110-01011-

--2200130211110012111121??11?21000

Infernovenator_mazonensis 33021-0100010-1--000000021011200?1--00001---

0101110-000--

11000???????????3?0??????????1100??1110????100002?01100010200001??000011?1

0200121100003??????????????????????2???11??????1100?????????????????????????

???????10?????1?????00-

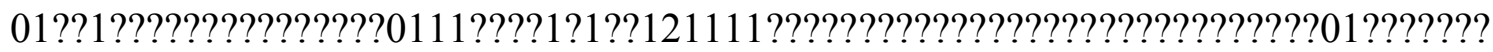

10??????????????????????????0?1302????????11?0???????????

;

END;

BEGIN ASSUMPTIONS;

TYPESET * UNTITLED = unord: 1 - 370;

END;

BEGIN MESQUITECHARMODELS;

END;

ProbModelSet * UNTITLED = 'Mk1 (est.)': 1 - 370;

Begin MESQUITE;

MESQUITESCRIPTVERSION 2;

TITLE AUTO;

tell ProjectCoordinator; timeSaved 1532114793091;

getEmployee \#mesquite.minimal.ManageTaxa.ManageTaxa;

tell It;

setID 0 8448515054581849959;

tell It;

setDefaultOrder 012345678910111213151617

1819202324252627282930313233343536373839404142434445474849

5051525354555657144621585922 60; 


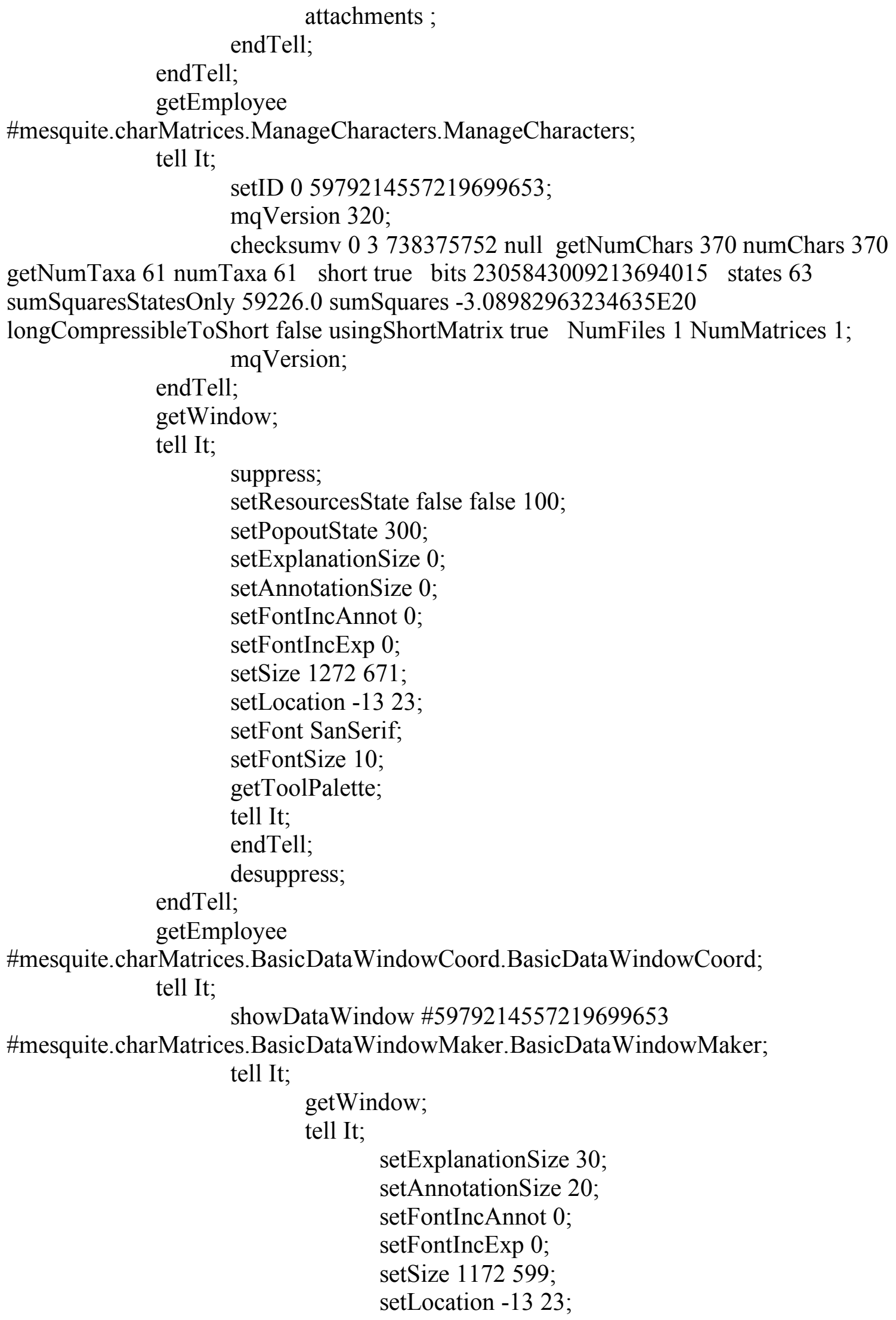


setFont SanSerif;

setFontSize 10;

getToolPalette;

tell It;

setTool

mesquite.charMatrices.BasicDataWindowMaker.BasicDataWindow.ibeam;

endTell;

setActive;

setTool

mesquite.charMatrices.BasicDataWindowMaker.BasicDataWindow.ibeam; colorCells

\#mesquite.charMatrices.NoColor.NoColor; colorRowNames

\#mesquite.charMatrices.TaxonGroupColor.TaxonGroupColor; colorColumnNames

\#mesquite.charMatrices.CharGroupColor.CharGroupColor; colorText

\#mesquite.charMatrices.NoColor.NoColor; setBackground White; toggleShowNames on; toggleShowTaxonNames on; toggleTight off; toggleThinRows off; toggleShowChanges on; toggleSeparateLines off; toggleShowStates on; toggleAutoWCharNames on; toggleAutoTaxonNames off; toggleShowDefaultCharNames off; toggleConstrainCW on; toggleBirdsEye off; toggleShowPaleGrid off; toggleShowPaleCellColors off; toggleShowPaleExcluded off; togglePaleInapplicable on; toggleShowBoldCellText off; toggleAllowAutosize on; toggleColorsPanel off; toggleDiagonal on; setDiagonalHeight 80; toggleLinkedScrolling on; toggleScrollLinkedTables off; endTell; showWindow; getWindow;

tell It; 


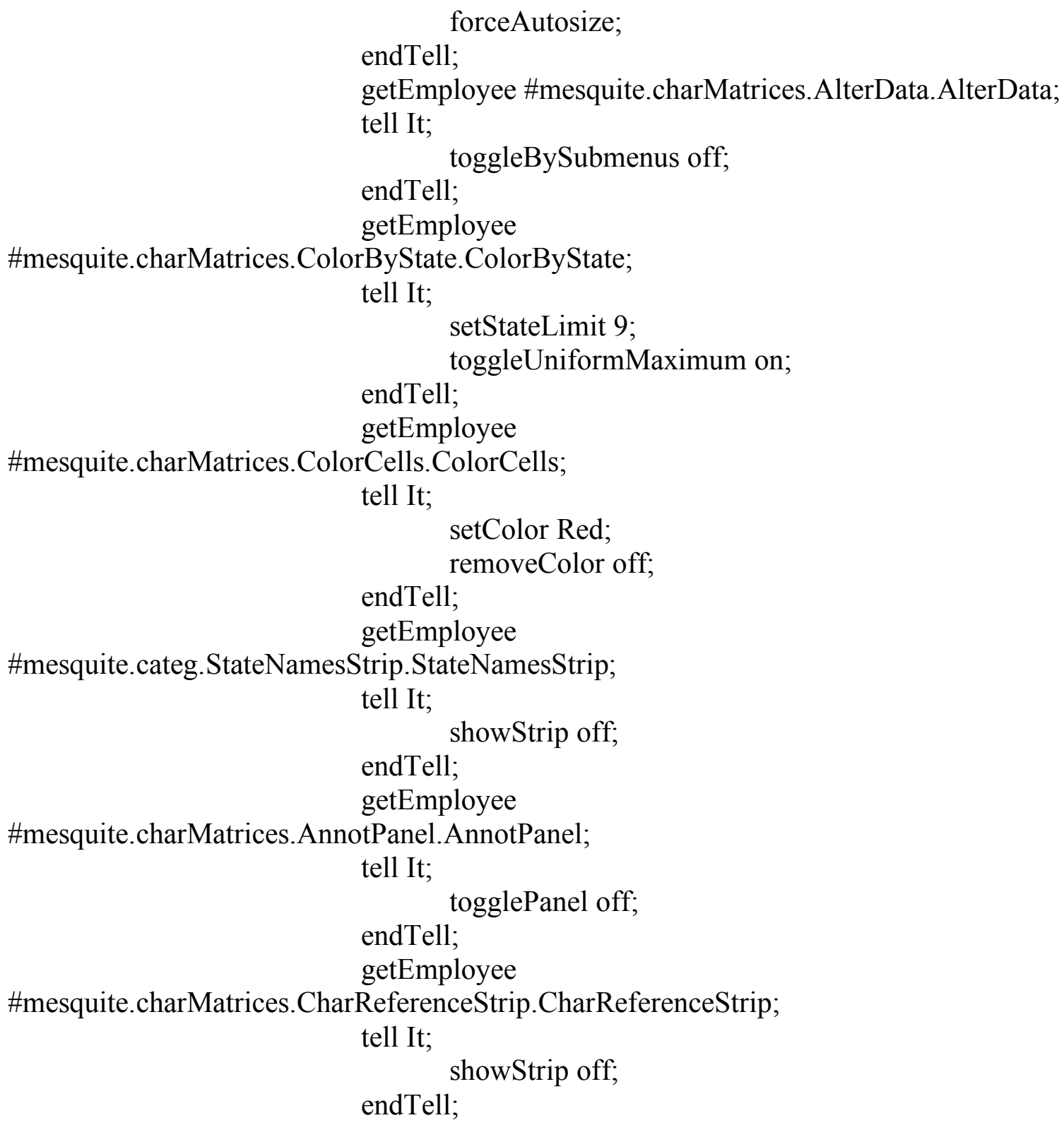

\section{Appendix C - Chapter 5 Supplemental Information}

\section{C.1 Modified Nexus File of phylogeny from Gee et al. (2020) used in Chapter 5.}

\#NEXUS

[written Mon Jan 20 14:08:08 EST 2020 by Mesquite version 3.51 (build 898) at dhcp71-163.cu-internet.carleton.ca/172.17.71.163] 


\section{BEGIN TAXA;}

TITLE Taxa;

DIMENSIONS NTAX $=69$;

TAXLABELS

Archeria_crassidisca Crassigyrinus_scoticus Acanthostega_gunnari

Eusthenopteron_foordi İchthyostega_spp. Panderichthys_rhombolepis Pederpes_finneyae

Tiktaalik_rosaea Ventastega_curonica Whatcheeria_deltae Ymeria_denticulata

Proterogyrinus scheelei Balanerpeton woodi Dendrerpeton acadianum

Pantylus_cordatus Cardiocephalus_peabodyi Cardiocephalus_sternbergi

Pariotichus_brachyops OMNH_53519 FMNH_UR_2296 'Euryodus dalyae (composite)'

Euryodus_primus Proxilodon_bonneri Huskerpeton_englehorni Pelodosotis_elongatum

Nannaroter_mckinzei Micraroter_erythrogeios Eocaecilia micropodia

Carrolla_craddocki Quasicaecilia_texana Llistrofus_pricei Aletrimyti_gaskillae

Dvellecanus_carrolli Rhynchonkos_stovalli Diabloroter_bolti J`rmungandr_bolti

Batropetes_fritschi Captorhinus_laticeps Infernovenator_steenae

Brachydectes_newberryi Greererpeton_burkemorani Seymouria_baylorensis

Limnoscelis_paludis Branchiosauridae Micromelerpetontidae Tersomius texensis

Ecolsonia_cutlerensis Acheloma_spp. Eryops_megalocephalus Doleserpeton_annectens

Caudata Anura Albanerpetontidae Micropholis_stowi Eoscopus_lockardi

Tambachia_trogallas Triadobatrachus_massinoti Gerobatrachus_hottoni

Platyrhinops lyelli Amphibamus grandiceps Lethiscus_stocki Coloraderpeton brilli

Edops_craigi Petrolacosaurus_kansensis Ophiacodon_uniformis_Baphetes_spp.

Eucritta_melanolimnetes Dimetrodon_spp. Opisthodontosaurus_carrolli ;

END;

BEGIN CHARACTERS;

TITLE 'Matrix in file "Pardo et al 2017 with recoded Llistrofus.nex"';

DIMENSIONS NCHAR $=370$;

FORMAT DATATYPE $=$ STANDARD GAP $=-$ MISSING $=$ ? SYMBOLS $="$

01234567 8";

CHARSTATELABELS

1 Basal_Skull_Length / '>70mm' '50-70mm' '30-50mm' '<30mm',

2 Skull trunk / $0.450 .30 \quad 0.450 .20 \_0.290 .20$,

3 Skull_proportions / longer_than_wide wider_than_long,

4 Intertemporal / present

Replaced_by_anterior_extension_of_supratemporal_or_tabular

replaced_by_lateral_extension_of_parietal,

5 Supratemporal / present absent,

6 ST_exposure_on_occiput / absent present,

7 Postfrontal_shape / broadly_quadrangular falciform,

8 Squamosal_Tabular/absent present fused,

9 Lacrimal_prefrontal_suture / simple_butt_joint interdigitating

prefrontal_broadly_underplates_lacrimal, 
10 Lacrimal / present absent,

11 L_to_naris / present absent,

12 L_to_orbit / absent present,

13 lacrimal_orbital_processes / only_ventral_present

dorsal_and_ventral_present neither_present,

14 lacrimal_jugal_contact / present absent,

15 Quadratojugal / present absent,

16 Quadratojugal_Jugal_contact/ present absent,

17 Quadratojugal_Maxillary_contact/ present absent,

18 Frontals / paired fused,

19 Frontal_into_orbit / no yes,

20 Anterior_laterally_flaring_frontals / absent present,

21 Nasals / present absent,

22 Narial_flange / absent present,

23 alary_processes_of_premax / absent present,

24 Septomaxilla / ossified unossified,

25 Prefrontal into external naris / distant from near present,

26 external_naris_in_dorsal_view / exposed not_exposed,

27 External_naris_shape / circular 'posteriorly extended, along L-PF

suture' posteriorly_extended_excavation_of_L_only,

28 dorsal_exposure_of_premax / broad narrow none,

29 dorsal_shape_of_skull / triangular diamond rounded,

30 Posterior_skull_margin / concave straight convex undulating.,

31 snout_shape / blunt pointed,

32 snout_length / short long,

33 Q_internal_flange_of_Sq / absent present,

34 otic_notch_presence / present absent,

35 Large_otic_notch_approaching_orbit / absent intermediate close,

36 otic_notch_structure / open_posteriorly closed_posteriorly,

37 semilunar_flange_of_supratempor / absent present,

38 supratympanic_flange / absent 'present "trematopid"'

present_trematopid 'present "dissorophid"' present_dissorophid,

39 supratympanic_shelf / absent present,

40 raised_orbital_rim / absent present,

41 Postorbital / present absent,

42 J_PO interfingered processes / absent present,

43 PO_in_orbital_margin / present absent,

44 shape_of_postorbital / irregular_trapezoid 'triangular, apex caudal',

45 Palpebral_ossifications / absent

mosaic_of_bone_plates_present_in_orbit Single_large_plate_above_orbit,

46 parietal_tabular_contact/absent present,

47 postparietal_fusion / paired fused absent,

48 parietal_foramen/present absent,

49 postparietal size / moderate large,

50 postparietal_squamosal_contact / absent present, 
51 postparietal_length / 'large, quadrangular' 'abbreviated anteroposteriorly, elongate lateral rectangle',

52 squamosal_jugal_contact / present absent,

53 Tabular / present absent,

54

Posterolateral_projection_from_lateral_margin_of_tabular_above_squamos / '/' absent present,

55 Tabular_horns / absent present,

56 Tabular_horns_shape / parallel_or_slightly_divergent widely_divergent,

$57 \mathrm{Sq}$ forms_base_of_tabular_horn / absent present,

58 Lateral_line_canal_grooves / present absent,

59 Dermal_sculpturing / circular_pits shallow_ridges_and_grooves little_to_none tuberculate,

60 premaxilla anterior margin / vertical overturned,

61 Maxilla_into_external_naris / present absent,

62 Maxilla_entire_ventral_naris / absent present,

63 maxilla/ longer_than_palatine shorter_than_palatine,

64 marginal_teeth_orientation / vertical turned_medially,

65 marginal_teeth_largest_anterior / absent present,

66 marginal_teeth_shape / pointed_pegs blunt_pegs large_cones,

67 Number_of_premax_teeth / '10-20' '5-9' ' $<5$ ' 20 or_more,

68 Number_of_max_teeth / '30-40' '20-29' '15-19' ' $<1 \overline{5}^{\prime}$ ' $>40$ ',

69 teeth_laterally_compressed / no yes,

70 Enlarged_teeth_mid_toothrow / absent present,

71 teeth / simple_points multiple_cusps,

72 Multiple_Cusp_Orientation / 'Labio-lingual' 'antero-posterior',

73 Enamel_fluting / absent present,

74 labyrinthine_in_folding / present absent,

75 jaw_articulation / posterior_to_occiput even_with_occiput

anterior_to_occiput 'far anterior ( $>20 \%$ BSL)',

76 Internal_nares / widely_separated narrowly_separated,

77 LEP / absent present,

78 Anterior_palatine /

short_anteromedial_process_articulating_with_vomer_at_choana

long_anteromedial_process_more_medial_than_lateral palatine_absent,

79 teeth_on_pterygoid / absent present,

80 tooth_pedicely / absent present, smaller_than_marginals,

81 Palatal_teeth_size / larger_than_marginals equal_to_marginals

82 parasphenoid / medial_of_stapes under_footplate_of_stapes,

83 interpterygoid_vaccuities / narrow_closed wide fused_at_midline,

84 Anterior_extent_of_Pterygoids / Pterygoids_contact_anteriorly

Pterygoids_exclude_vomer_from_interpterygoid_vacuity_but_excluded_from median_contact_by_parasphenoid

pterygoids_contact_vomer_but_do_not_exclude_vomer_from_interpterygoid_vacuity 
pterygoids_reach_anteriorly_only_as_far_as_palatine

pterygoids_reach_ectopterygoid_only

pterygoids_do_not_contact_lateral_palatal_bones_at_all,

85 lat_process_of_pt_into_posttemp / absent present,

86 Ectopterygoid_palatine_width / wider_than_maxilla

narrower_than_maxilla,

87 pharangeobranchial pouches / absent present,

88 dentary / long short,

89 dentary_forms_coronoid_process / absent present,

90 surangular / normal reduced absent,

91 angular / narrow deep,

92 number_of_splenials / 210 ,

93 splenial_exposed laterally / present absent,

94 meckelian_fossae / 2_or_more 10 ,

95 Ventral_border_of_Meckel_s_foss / splenial angular,

96 retroarticular_process_presence / absent present,

97 retroarticular process shape / straight hooked,

98 articulation_to_tooth_row / above equal below,

99 angular_extends_to_tat_view / posterior_tooth_row

middle_of_tooth_row,

$1 \overline{00}$ number_of coronoids / 3210 ,

101 symphysis / dentary_and_splenial dentary_alone,

102 jaw_sculpture / present absent,

103 ossified_hyoids / present absent,

104 Gill_Osteoderms / absent present_noninterdigitating

toothed_interdigitating_rakers,

105 parahyoid / absent present,

106 number_of_accessory_articulation / 012 2or_more,

107 number_of_presacrals / 25_35 20_2435 20,

108 vertebral_development / arches_then_centra

centra_and_arches_simultaneously,

109 caudal_processes_btw_depression / absent present,

110 trunk_intercentra / present absent,

111 trunk_neural_arch_to_centrum / loosely_articulated sutured fused,

112 base_of_neural_spine / equal_to_or_wider_than_haemal

smaller_than_haemal_spine,

113 height_of_neural_spines / even alternating,

114 Dermal_armor_associated_with_neural_arches / Absent Present,

115 neural_spine_shape_lat / ant_post_sides_parallel_rect

non_parallel_triangular,

116 Neural spine lateral suface / smooth crenulated,

117 Pleurocentra / paired_rhachitomous closely_approaching_ventrally

fused_dominant_weight_bearing_element embolomerous,

118 haemal_arch_presence / present absent,

119 haemal arch fusion / loosely articulated intercentr

fused_to_mid_length_of_centrum, 
120 haemal_arch_length / longer_than_or_equal_to_neurals shorter_than_neurals,

121 haemal_accessory_articulations / none one two,

122 haemal_arch_shape / non_parallel_triangular parallel_rectangular,

123 tail_termination / tapers deep_with_sudden_end,

124 Tail length /

elongate_equal_to_or_exceeding_trunk_and_skull_length

forshortened_markedly_shorter_than_trunk,

125 trunk_arches / paired fused,

126 spinal_nerve_foramina / absent present,

127 extended_transverse_processes / absent present,

128 transverse_process / on_arch_pedicle on_centrum,

129 atlas_axis_intercentra / present absent,

130 Atlas_Anterior_centrum / same_size_as_posterior

laterally_expanded,

131 atlas_centrum / multipartite single_notochordal single_odontoid,

132 atlas_neural_arch_centrum_fusion / loosely_articulated

sutured_to_centrum fused_to_centrum,

133 atlas_parapophyses / on_centrum on_transverse_process absent, fused_at_midline,

134 atlas_neural_arch_midline_fusion / paired sutured_at_midline

135 atlas_acessory_articulation / absent zygosphene zygantra,

136 Proatlantes / present absent,

137 second_cervical_arch / expanded_to_more_posterior

equal_to_more_posterior shorter_than_more_posterior,

138 atlas_ribs / one_pair two_pairs absent,

139 cervical_rib_distal_shape / spatulate pointed,

140 ribs_anterior_to_sacrum / short long,

$141 \mathrm{Ribs} /$ elongated_and_sometimes_curved straight short_simple_rod,

142 Costal_Process_at_rib_head / absent present,

143 number_of_sacrals / 123 ,

144 sacral_parapophysis / on_centrum on_transverse_process,

145 number_pairs_of_caudal_ribs / 5_or_more 432 2_or_fewer,

146 interclavicle_posterior_stem_length / no_or_short long,

147 interclavicle_posterior_stem_breadth / wide narrow,

148 interclavicle_shape / diamond_shaped t_shaped,

149 interclavicle_anterior_plate / broad narrow,

150 interclavicle_shape_diamond / broad_diamond narrow_diamond,

151 interclavicle_anterior_fimbrati / present absent,

152 interclavicle_sculpture / present absent,

153 Cleithrum head_dorsal_extent /

aligned_along_anterior_rim_of_scapula

posterodorsally_enlarged_head_wrapping_around_dorsal_scapula,

154 Cleithrum_head_size_and_shape /

dorsally_greatly_expanded_much_wider_than_shaft

simple_rod_without_or_slight_dorsal_expansion, 
155 Cleithrum_ossification / ossified unossified,

156 cleithrum_overall_shape / rounded_or_pointed_dorsally

t_or_y_shaped,

157 proximal_clavicle_blades / widely_separate articulate_medially

interdigitate,

158 supraglenoid_foramen / present absent,

159 number_coracoid_foramina / none 12 ,

160 scapulocoracoid_occification / both scapula_only absent,

161 tortion_in_humerus / absent less_than_80_degrees

more_than_80_degrees,

162 deltapectoral_crest / weak intermediate prominant,

163 Supinator_process / absent present,

164 humerus_length / long_4_trunk_centra short,

165 radius_humerus / $0.70 .5 \_0.70 . \overline{5}$,

166 olecranon_process / unossified ossified,

167 carpals / fully_or_partially_ossified unossified,

168 basale commune / absent present,

169 number_digits_manus / $543^{\prime}>5$ ',

170 pelvis / fused sutured poorly_ossified,

171 Anteriorly_inclined_ilium / absent present,

172 illiac_blade / 2_dorsal_processes narrowly_bifurcate single_blade,

173 internal trochanter_articulatio / disctinct continuous,

174 femoral_shaft / robust slender,

175 femur/ long short,

176 tarsals / ossified unossified,

177 elongate tibiale and fibulare / absent present,

178 number_of_distal_tarsals / 65 _or_fewer,

179 astragalus / absent present,

180 number_of_digits_pes / 54_or_less ' $>5$ ',

181 dorsal_margin_of_splenial_only_contacts_first_coronoid / absent

present,

182 postparietal_lappet / mostly_exposed_posteriorly

equal_posteriorly_and_dorsally mostly_exposed_dorsally,

183 cheek_emargination / absent present,

184 Parietal_anterior_waisting / absent present,

185 Parietal_width_relative_to_frontal / greater equal_or_less,

186 Trabecula_cranii / 'Without significant median fusion posterior to solum nasi (platytrabic)' 'fused medially posterior to solum nasi to form elongate trabecula communis (tropitrabic)',

187 Dorsal_trabeculae /

dorsal trabeculae provide dorsolateral bridge between sphenoid region and_nasal_capsule 'dorsal trabeculae absent or incomplete, no dosolateal bridge between sphenoid region and nasal capsule',

188 Ossification_between_optic_foramen_and_pila_antotica /

ossification complete between_optic foramen and pila antotica

pila metoptica and associated cartilaginous taeniae unossified, 
189 Ossification_within_columella_ethmoidalis / absent present,

190 Path_of_profundus_branch_of_trigeminal_nerve /

enclosed in lateral wall of sphenoid region of braincase and exits sep arately_from_maxillomandibular_branch_via_series_of_small_foramina 'extramural, exits antotic fissure with other branches of trigeminal',

191 Foramina_for_optic_nerve_and_trigeminal_nerve / confluent widely_separate,

192 Lateral head_vein / No_distinct foramen for_lateral head_vein Distinct_foramen_within_the_antotic_fissure_serving_the_lateral_head_- $\mathrm{v}$ ein,

193 Anterior_extent_of_cultriform_process_of_parasphenoid / cultriform_process_extends_to_anterior_margin_of_sphenethmoid cultriform process extends far anterior to sphenethmoid cultriform_process_does_not_reach_anterior_margin_of_sphenethmoid,

194 Olfactory_bulbs / narrow 'endocasts swollen, leaving considerable impressions in lateral and ventral wall of sphenoid region and in ventral surface of frontal',

195 Flange from skull roof articulating with sphenethmoid/ absent present_on_frontal_and_parietal present_on_frontal_only,

196 'Descending lamina of parietal invades medial orbital wall between "pleurosphenoid" and "sphenethmoid" elements' / no yes,

197 Foramen for oculomotor nerve /

exits_braincase_far_dorsal_to_foramen_for_optic_nerve exits_braincase_at_or_below_optic_nerve,

198 Intermaxillary_fossa / present absent,

199 Intermaxillary_fossa / paired unpaired,

200 Sphenethmoid_forms_interorbital_septum / no yes,

201 Anterior_extent_of_cultriform_process_along_palate /

cultriform_process_extends_anteriorly_to_level_of_posterior_margin_of_choana 'cultriform process dramatically shortened, barely reaching the level of the posterior margin of the orbit',

202

Sutural_contact_between_cultriform_process_of_parasphenoid_and_vomer / no yes, 203

Lateral_wall_of_the_nasal_capsule_underplated_by_lateral_processes_of_/ '/' no yes, 204 Cultriform_process_vaulted_high_above_palatal_surface / no yes, 205 Posterior_extent_of_parasphenoid_beneath_braincase /

floors_sphenoid_region_only floors_sphenoid_and_otic_region 'floors sphenoid, otic, and occipital regions',

206 Basal_tubera / 'present, with significant endochondral contribution' 'present, with contribution of parasphenoid only' absent,

207 Path_of_common_internal_carotid_artery / 'does not run alongside braincase, enters braincase directly in region of sella turcica' 'follows vidian sulcus along posterior surface of basal plate of parasphenoid, enters parasphenoid via vidian canal in basal plate of parasphenoid, divides into cerebral and palatal branches after entering parasphenoid' 'follows vidian sulcus along posterior surface of basal plate of 
parasphenoid or lateral wall of braincase, divides into cerebral and palatal branches prior to entering the skull',

208 Bucohypophyseal foramen in parasphenoid / open absent,

209 Morphology_of_pila_antotica / 'pila antotica is a thin, broad sheet'

pila_antotica_is_a_robust_dorsoventral_pillar_bracing_the_skull_roof_a gainst_the_palate,

210 Basicranial_fissure / present absent,

211 Location_of_vidian_sulcus / along_ventral_surface_of_braincase along_lateral_surface_of_braincase,

212 Basipterygoid_joint / epipterygoid_comprises_entire_conus_recessus substantial_contribution_to_conus_recessus_by_pterygoid

conus_recessus_comprised_entirely_of_pterygoid_without_epipterygoid_pa rticipation pterygoid_and_parasphenoid_broadly_sutured_without_development_of_a_co nus_recessus,

213 Hypophyseal_fossa / single_unpaired_sulcus pairedsulci_divided_medially_by_ridge_originating_on_dorsum_sellae,

214 Bone flanking the dorsum sellae /

consurrent_with_fully_ossified_lateral_skull_roof 'subparallel with sagittal plane ("pleurosphenoid")' 'strongly oblique to or perpendicular to sagittal plane ("laterosphenoid")' restricted_to_dorsum_sellae_only,

215 Basal plate of parasphenoid / 'roughly quadrangular, basipterygoid articulations narrowly spaced' 'rectangular laterally, anteroposteriorly narrow, basipterygoid articulations distant',

216 Sphenethmoid / ossified unossified,

217 Ossification_within_the_synotic_tectum /

synotic_tectum_massively_coossified_with_otic_capsules

supraoccipital_paired_at_some_point_in_ontogeny

supraoccipital_unpaired_throughout_ontogeny 'no supraoccipital bone; synotic tectum invaded by dorsal processes of exoccipitals',

218 Median_ascending_process_of_supraoccipital / absent present,

219 Lateral_ascending_processses_of_the_supraoccipital / absent present,

220 Margin_of_fenestra_vestibuli / 'parasphenoid excluded by

neurocranial elements (basisphenoid and basioccipital)'

parasphenoid_contributes_to_anteroventral_margin_of_fenestra_vestibuli

parasphenoid_floors_entire_fenestra_vestibuli

Ossification_of_otic_capsule_surrounds_entire_fenestra_vestibuli,

221 Crista_intervestibulara / crista_intervestibularis_absent

crista_intervestibularis_present,

222 Morphology_of_crista_parotica / 'crista parotica meets exoccipitals only, forming lateral wall of posttemporal fossa but not bracing against dermal skull' crista_parotica_drawn_out_dorsolaterally_into_paroccipital_process_tha t_contacts the _tabular 'crista parotica drawn out laterally into paroccipital process that contacts the cheek and/or suspensorium',

223 Dorsal_process_of_stapes / absent present,

224 Facets_on_dorsal_surface_of_supraoccipital/ absent present,

225 Otoccipital_fissure / present absent, 
226 Crista_parotica / Descends_posteriorly

Horizontal along the extent of its length,

227 Position_of_quadrate_with_respect_to_otic_capsules /

quadrates_ventral_and_lateral_to_otic_capsules

quadrates_mostly_lateral_to_and_greater_or_equal_to_twice_the_width_of the_otic_capsules quadrates_mostly_ventral_to_otic_capsules quadrates_approaching_or_abutting_lateral_wall_of_otic_capsules,

228 Size of otic_capsuiles / 'otic capsules comprise less than $2 / 3$ the width of otoccipital region' 'otic capsules comprise greater than $2 / 3$ total width of otoccipital region',

229 Otic trough / absent present,

230 Articulation between the epipterygoid_and prootic/ none

elongate_facet_on_anterior_surface_of_prootic_for_articulation_of_epip terygoid,

231 Opisthotic_obscures_occipital_in_lateral_view / no yes,

232 'Fenestra vestibularis at end of broad, winglike lateral extension of the otic capsule' / no yes,

233 Cristae in otoccipital region /

comprised_primarily_of_ascending_flanges_from_braincase

comprisd_primarily_of_descending_flanges_from_skull_roof,

234

Opisthotic_excluded_from_the_occipital_surface_by_tabular_process_of_t / '/' no yes,

235 Insertion_of_epaxial_musculature_on_occiput /

deep_within_temporal_fossae 'in broad, shallow fossae along occipital surface of postparietals',

236 Foramen_for_internal_jugular_vein /

between_supraoccipital_and_exoccipital between_opisthotic_and_exoccipital

through_exoccipital Posterior_notch_of_fenestra_vestibuli,

237 Foramina_for_hypoglossal_nerve / multiple single none,

238 Occipital_condyle_shape / round 'U-shaped' paired,

239

Ventral_process_of_exoccipital_reaches_basipterygoid_joint_along_palat / '/' absent present,

240 Occipital_condyle_shape / Concave Convex,

241 Columella_of_stapes / perforate imperforate,

242 Orientation_of_stapes / 'Dorsal, towards tabular or otic notch'

'anteroventral, towards quadrate',

243 Stapedial_footplate_shape / oval round palmate,

244 Dorsal_sinus_between_synotic_tectum_and_skull_roof / absent

present,

245 Ossification_within_septum_internasale / absent 'present, sphenethmoid' 'present, mesethmoid',

246 Ossification_of_septum_internasale_invades_nasal_tectum / absent

present,

247 Insertion_of_hypaxial_musculature / sphenoid otic basioccipital, 248

Prootic_supported_by_pedicel_extending_from_basisphenoid_lateral_to_pr / '/' no yes, 
249 Position_of_pineal_foramen_with_respect_to_hypophyseal_foramen / anterior_to approximately_the_same far_posterior_to,

250 Pineal_fossa / well_anterior_to_posterior_margin_of_cerebral_fossa at_or_behind_posterior_margin_of_cerebral_fossa,

251 Median_wall_of_otic_capsule / completely_unossified

ossification_of_opisthotic ossification_of_supraoccipital_and_basioccipital,

252 Conical_recess_in_basioccipital / absent present,

253 Semicircular_canals / separated_from_utricular_region_by_bone

not_separated_from_utricular_region_by_bone,

254 Basioccipital /

Robust_ossification_ventral_to_foramen_magnum_present absent,

255

Accessory_articulation_processes_with_proatlantal_facet_on_exoccipital / '/' absent prominent,

256 Exoccipital_proatlantal_facets_incorporated_into_occipital_joint / no yes,

257 Anterior_tectal / anterior_tectal_present absent, 258 'Ectopterygoid/palatine exposure' /

more_or_less_confined_to_tooth_row broad_mesial_exposure_additional_to_tooth_row reduced to thin sliver,

259 Ectopterygoid / Present Absent,

260 Ectopterygoid_as_long_or_longer_than_palatines / yes no,

261 Ectopterygoid_reaches_subtemporal_fossa / no yes,

262 Frontal / absent present,

263 Jugal / does_not_extend_anterior_to_orbit extends_anterior_to_orbit,

264 Lateral_rostral_present / yes no,

265 Maxilla_makes_interdigitating_suture_with_vomer / no yes,

266 Maxilla_external_contact_with_premaxilla /

narrow_contact_point_not_interdigitated interdigitating_suture,

267 Maxilla_extends_behind_level_of_posterior_margin_of_orbit / yes

no,

268 Median_rostral / single paired absent,

269 Opercular / present absent,

270 Prefrontal / 'twice as long as broad, or less'

three_times_as_long_as_broad,

271 Prefrontal / transverse_anterior_suture_with_tectal

tapers_to_a_point_anteriorly,

272 Preopercular / present absent,

273 Pterygoid_quadrate_ramus_margin_in_subtemporal_vacuity / concave with_some_convex_component,

274 'Vomers separated by parasphenoid > half length' / yes no,

275 Vomers / as_broad_as_long_or_broader

about_twice_as_long_as_broad_or_longer,

276 Basipterygoid_process /

not_strongly_projecting_with_concave_anterior_face

strongly_projecting_with_flat_anterior_face, 
277 Ethmoid / fully_ossified partly_or_wholly_unossified,

278 Hypophyseal region /

solid_side_wall_pierced_by_small_foramina_for_pituitary_vein_and_other_vessels single_large_foramen,

279 Lateral_commissure_of_otic_capsule_bearing_hyomandibular_facets / present absent,

280 Parasphenoid / does_not_overlap_basioccipital

overlaps_basioccipital,

281 Denticulate_field_of_parasphenoid / present absent,

282 Sphenoid / 'fully ossified, terminating posteriorly in intracranial joint or fused to otoccipital' separated_from_otoccipital_by_unossified_gap,

283 Ectopterygoid_fang_pairs / present absent,

284 'Ectopterygoid row (3+) of smaller teeth' / present absent,

285 'Ectopterygoid/palatine shagreen field' / absent present,

286 Palatine_row_of_smaller_teeth / present absent,

287 'Pterygoid shagreen (palatine ramus)' / dense

organized_radiating_rows_of_denticles disorganized_patches_or_absent,

288 Dentition_of_transverse_flange_of_pterygoid /

Denticle_field_indistinct_from_organized tooth_row absent,

$2 \overline{8} 9$ Premaxillary_tooth_proportions / all_approximately_same_size

posteriormost_teeth_at_least_twice_height_of_anteriomost_teeth

Anteriormost_teeth_largest,

290 Vomerine_fang_pairs / present absent,

291

Vomerine_fang_pairs_noticeably_smaller_than_other_palatal_fang_pairs / no yes, 292

Vomer_anterior_wall_forming_posterior_margin_of_palatal_fossa_bears_to / '/' yes no,

293 Vomerine_row_of_small_teeth / present absent,

294 Vomerine_shagreen_field / absent present,

295 Adductor_fossa / faces_dorsally faces_medially,

296 Adductor_crest / absent 'peak anterior to adductor fossa, dorsal

margin of fossa concave' 'peak above anterior part of adductor fossa, dorsal margin of fossa convex',

297 'Angular-prearticular contact' /

prearticular_contacts_angular_edge_to_edge absent

medial_lamina_of_angular_sutures_with_prearticular,

298 'Coronoid (anterior) contacts splenial' / no yes,

Yes No,

299 Prearticular_extends_between_infradentaries_and_middle_coronoid /

300 'Coronoid (middle) contacts postsplenial' / no yes,

301 'Coronoid (posterior) posterodorsal process' / no yes,

302 'Coronoid (posterior) posterodorsal process visible in lateral view' /

no yes,

303 'Dentary external to angular \& surangular, with chamfered ventral edge and no interdigitations' / no yes, 
"stepped" margin',

304 Dentary_ventral_edge / smooth_continuous_line 'abruptly tapering or

305

Dentary_suture_with_splenial_\&_postsplenial_marked_by_deep_furrow / no yes,

306 Mandibular_sensory_canal / present absent,

307 Mandibular_canal_exposure / 'entirely enclosed, opens through lines

of pores' 'postly enclosed, short sections of open grooves' 'mostly open grooves, short sections opening through pores' entirely_open,

308 'Oral sulcus/surangular pit line of mandible' / present absent,

309 Meckelian_bone_floors_precoronoid_sulcus / yes no,

310 Meckelian_bone_ossified_in_middle_part_of_jaw / yes

little_or_no_ossification,

311 Meckelian_bone_exposure_in_middle_part_of_jaw /

depth_much_less_than_prearticular $\bar{d}$ depth_similar_to_prearticular,

312 'Meckelian foramina/fenestrae, dorsal margins' / Meckelian_bone prearticular infradentary,

313 'Meckelian foramina/fenestrae height' /

much_lower_than_adjacent_prearticular

equal_to_or_greater_than_depth_of_adjacent_prearticular,

314 Parasymphyseal_lateral_foramen_present / no yes,

315 Parasymphyseal_mesial_foramen_present / no yes,

precoronoid',

316 Postsplenial_with_mesial_lamina / no small 'expanded, contacting

317 Postsplenial_pit_line_present / yes no,

318 Postsplenial_suture_with_prearticular_present / no yes,

319 Prearticular_sutures_with_surangular/ no yes,

320 Medial_lamina_of_splenial / absent present,

321 Prearticular_with_longitudinal_ridge_below_coronoids / no yes,

322 'Prearticular with mesially-projecting flange on dorsal edge along

posterior border of adductor fossa' / no yes,

323 Prearticular_centre of radiation_of_striations /

level_with_posterior_end_of_posterior_coronoid level_with_middle_of_adductor_fossa level_with_posterior_end_of_adductor_fossa,

324 Splenial_has_free_ventral_flange / yes no,

325 'Splenial, rearmost' / absent,

326 'Coronoids: at least one has fang pair recognizable because at least

twice the height of coronoid teeth ' / yes no,

327 ' Coronoids : at least one has fangs recognizable because noticeable

mesial to vertical lamina of bone and to all other teeth ' / yes no,

328 ' Coronoids : at least one has organized tooth row' / yes no,

329 ' Coronoids : at least one carries shagreen '/ no yes,

330 ' Coronoids : size of teeth ( excluding fangs ) on anterior and middle

coronoids relative to dentary tooth size ' / about_the_same half_the_height_or_less,

331 Dentary_tooth_row / homodont markedly_heterodont,

332

Dentary_with_parasymphyseal_fangs_internal_to_marginal_tooth_row / yes no, 
333 Dentary_teeth / same_size_as_maxillary_teeth

larger_than_maxillary_teeth smaller_than_maxillary_teeth,

334

Dentary_with_a_row_of_very_small_teeth_or_denticles_lateral_to_tooth_r / '/' yes no,

335 Parasymphyseal_tooth_plate / present absent,

336 Parasymphyseal_plate_dentition / shagreen_or_irregular_tooth_field organied_dentition_aligned_parallel_to_jaw_margin no_dentition,

337 Parasymphyseal_plate_has_fang_pair / no yes,

338 Parasymphyseal_plate_has_tooth_row / no

short_tooth_row_separated_from_coronoid_row_by_diastema long_tooth_row_reaching_coronoid,

339 Prearticular shagreen field distribution /

gradually_decreasing_from_dorsal_to_ventral 'well-defined dorsal longitudinal band'

scattered_patches_or_absent,

$34 \overline{0}$ Anterior_palatal_fenestra / single_double absent,

341 Dorsal_fontanelle_on_snout / absent present,

342 Interpterygoid_vacuities / absent at_least_2x_wider_than_long

$2 x$ _longer_than_wide,

343 Intracranial_joint / present_in_dermal_skull_roof

absent_in_dermal_skull_roof,

$34 \overline{4}$ Nature_of_dermal_ornament / tuberculate

fairly_regular_pit_and_ridge irregular absent_or_almost_absent,

$34 \overline{5}$ 'Nature of ornament: starbursts of radiating ornament on at least some bones' / no yes,

346 Anocleithrum / oblong_with_distinct_anterior_overlap_area 'dropshaped with no anterior overlap area' absent,

347 Cleithrum / ornamented not_ornamented,

348 Cleithrum_postbranchial_lamina / present absent,

349 Digits / absent present,

350 Humerus / narrow_tapering_entepicondyle 'square or parallelogramshaped entepicondyle',

351 'Ilium_iliac canal' / absent present,

352 'Ilium_posterior process' / oriented_posterodorsally

oriented_approximately_horizontally_posteriorly,

353 Interclavicle / small_and_concealed_or_absent large_and_exposed,

354 Interclavicle_shape / ovoid kite_shaped with_posterior_stalk,

355 Lepidotrichia_in_paired_appendages / present absent,

356 Posttemporal_and_supracleithrum / present absent,

357 Radius_and_ulna / radius_much_longer_than_ulna

approximately_equal_in_length,

358 'Ribs_trunk' / all_cylindrical

some_or_all_bear_flanges_from_posterior_margin_which_narrow_distally

some_or_all_flare_distally,

359 Scapular_blade / absent small_with_narrow_top

large_with_broad_top,

$36 \overline{0}$ Scapulocoracoid / small_and_tripodal large_plate, 
361 Subscapular_fossa / broad_and_shallow

deeply_impressed_posteriorly,

362 Squamation / 'complete body covering of scales all similar'

ventral_armour_of_gastralia,

363 Pectoral_process / absent present,

364 Proximal_limb_of_oblique_ridge / 'present_separated from anterior margin of humerus by prepectoral space' 'absent_replaced by deltopectoral crest',

365 Latissimus_dorsi_attachment / diffuse_ridged_area distinct_process,

366 Foramina_piercing_oblique_ventral_ridge / many

one_moderately_large_foramen_in_addition_to_entepicondylar_foramen 'entepicondylar foramen is the only large opening_other foramina ar epinpricks or absent' none,

367 'Humerus with well-developed anterior plate' / yes no,

368 Subclavicular_ossifications / Absent Sometimes_present,

369 Radial_capitulum / approximately_same_size_as_ulnar_facet 'greatly enlarged and rounded $>2 x$ size of ulnar facet , ' 370 Lissamphibian_inner_ear '/' no yes,

MATRIX

370 lissamphibian inner ear ;

Archeria crassidisca $\quad 02000000100100001001000 ? 01000011000000001---$ 01000000010--01000000000100-010000002100000000100000-

010001???2?000000003000000010010000020112010000????????????????1211???0?00

0????????00010100101?001001-

00000100101?000000001?1100020000000001000?0?00-101??0000-

100001110012111111?1111110?0??000?????1221101101003111-

11001111111?121111-0(0 1)01000021001212111100111110211111120000

Crassigyrinus_scoticus

0100001010000000000100101000000110000000000000001000010--0001-000011000-

$000000000100000000000010-$

010001???0?000?0000?00?????0?0100?000??1??1000??000001000000???12110000?20

000100???0?0101?0?0???????00??0000001?0-

???00???1??0?0?000000??0??000??????0??????0?-

$1000010111021011010 ? ? ? ? 10 ? 0000000000000020000001003111 ? 100001001 ? ? 112111$

$1 ? 101101101110121 ? 1111 ? ? 111110 ? ? ? 11111000 ?$

Acanthostega_gunnari

000100010000?000000000000000000000000000000000000000010--00000000000000-

000000000000000000000000-0100000000?0000000000000000\{0

$1\} 000000000000000000000000000000000000000000030000100000200000 ? 0$ $100 ? 000000000000000000 ? ? 00000000 ? 000001 ? 00000000000000000 ? 00 ? ? ? ? 000-$

$00001111000111 ? 001011110001000001000000011000 ? 10001111010010100110000110$

010001011111101111101100111102010111120000

Eusthenopteron foordi 01000000000100010100--0-11010-00-------00000-

0001000000--0301-000000000-001000000-01?00000000?10-

01000020?????????????????????????????????????????????????????????????????????

????????????????????????1???????????????????0-???????????????????????0?????0??-

$000000000000000000 ? 00000000000000000000010000 ? 00000000000000000000 ? 00000$

00010000000000000000000?00000000?000100??0 
Ichthyostega_spp. $\quad 01010001100020000000000-$ 1100000110000000000000001000000--00100000012010-000000002000?00000100-(0 1)001000????0?00000000000100011000?????????0000010110111010001??01201010031 $00 ? 1100-$ 021?010????0????00?01?000002?100?0?00????0000?10000000000??0001?10??0????0 ??-0100111?1000111001011?1000(0 1)000231001000001000?1000?1100000101001?000011001002101112000111?1011111 $21111011 ? 10010000$

Panderichthys_rhombolepis 0????????????????????????????????????????????????????3???????????????????? ????????????????????????????????????????????????????????????????????????????????? ?????????????????????????????????????????????????????????????????????????????????

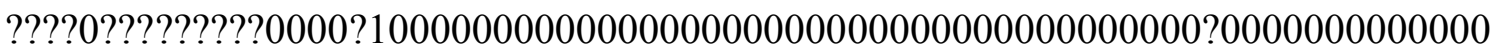
0000000?000000000000000000010000000??0?000101?0000?0??0

Pederpes finneyae 0100000010012000100?0??0000?011110100000000000??1000000--01?000000?2010$000000000100 ? 000001 ? 0 ? ? 0-$

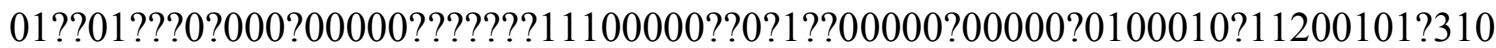

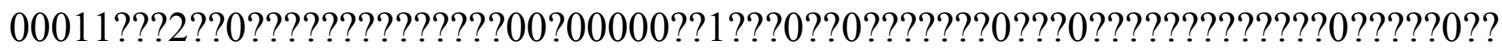
????????1?01101000?1010?121??110?001000???????????????????????????????????????

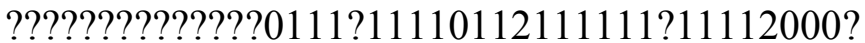

Tiktaalik_rosaea 01010010100120000001100?1100000110100000000000001000000--03000000000000$0000000001010000000000(0$ 1)0-0?000000?2 -?????????????????010--

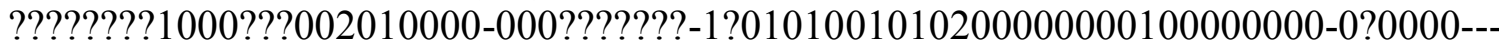
$-?-? 0 ? 10000000 ? ? ? ? 0 ?---0--001 ? ? ? ? 00-$

??0??11??00?11?000?00?0000????000?????0000000?00000?000?0000??0000???000000 $0 ? 10 ? 0 ? 0 ? 0010000000 ? ? 0 ? 0 ? 0 ? 010 ? 00000 ? ? 0$

Ventastega_curonica 0?000000000020000011000?110001011010000000000??01000000--00001000011000$00000000010 ? ? 00000000010-$ 0100????????????????????????????????????????????010111010000??0????????+000???

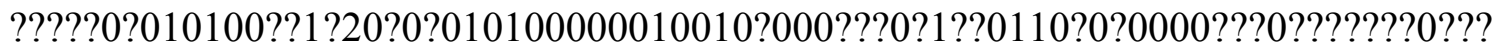
???????0???111000111?00101101000??000?100?000001000?100000100001100001100 $00010010001010210101111110 ? 0011 ? 1 ? ? 010 ? ? ? ? ? ? ? 0$

Whatcheeria_deltae 0000000010002000100000010000011110000000000100001000000--0100000001101000000000110??00000100?(0 1)0000001???1?000?00001???????1?00?????????00000?000000001000001012000000310 0 ?1100?0?1?010????????????00???000????0????010-$0 ? 10 ? 01000 ? 00000 ? ? ? 0 ? ? ? ? ? ? ? 0 ? ? ? ? ? ? ? ?-$ $10000111 ? 00210100111 ? ? 11 ? ? 0000001001101001001000002010000000100110102110$ 01002101011?00131?1011011211?121??1112000?

Ymeria denticulata 0?1??????????????????????10?0?01???????????????????????010010000?2000- 
$000000001 ? 00 ? 00000000 ? 10-$

01000???????????????????????????????????????????????????????????????????????????

?????????????????????????????????????????????????????????????????????0??????????

$1001 ? ? ? ? 00 ? ? ? ? ? 0 ? 0 ? ? ? ? ? ? ? 00 ? 0 ? ? 100 ? 0 ? 00(1$

2)?000?100021?0000??010??0?00?01000000101110?0?31??????????????????????????

Proterogyrinus_scheelei $010000\{01\} 0\{0$

1\}001?0001000000?0000000000000000000001000000010--00000000000000-

$00000000000000000000 ? 00-00\{01$

2\}1000000?00000000300001?0100000000000000?00000000001000000020100?101001

0111000100?00101?101?11000?1-11000100??00003000--

$1 ? 00 ? 0020000000001000 ? 0 ? 00 ? 10 ? ? ? ? ? 00-$

10000101001210111111???11?0100000?????1221????0101?111?11001111?11?12???1?

00011---2200121211110011111021?11112000?

Balanerpeton_woodi

000000101001000000000?110000000000000000000?10000000000--10000000000000$000000000011100000100000-$

$0001010001 ? 000000000000000 ? 00000000 ? 000020010000000000000000 ? ? 0220011001$ 10211000100?0000?????????????????00??????????00??????0????????????1?00?000??? $1 ? ? ? ? ? ? 00-$

$110011011 ? 02101111011 ? ? 101011100000111112111 ? ? 0101 ? 111 ? 20002110100 ? 10111$ 1?00111?--22021112111100111112?1?11112100?

Dendrerpeton acadianum

000000001001000000000?100000000000000000000?00000000000--10000000000000$000000000011000000001110-$

00? 1010001?00000000000001??10000000?00?0?0010000000000000000010220011001

002?00?0??0000001??01????00?0??01001221?10013013--2010-

110000000001?00000000?10??1?100-10001101?102101111111111(0

1) $10111000011111(1$

2)21??110101?1?1?11??1111??0?111111?0?11????2202111211110011111021?1111210 01

Pantylus_cordatus ０0011-0120010000100000000101011001-00000000010110000-0--10100000223010-0111000011000000100011\{0

1\}102020000001?01101010200000011000012202011101000?01111$101000201022002100110211000110 ? 10001100111212011-$ 100001221011101002112121?113000000001110011011?21??211011111-111001211110111111111--100321-1111221??110101-11110001111100?111100111011---2202111211110012111021?-11021000

Cardiocephalus_peabodyi 32011-012001100010000?001101121001-$00010000210\{01\} 10000-0--12100$ ?102231110113?0??0?????0?0111?1??020??110002??01?00102???????100001220?0110000010????????1000?0-

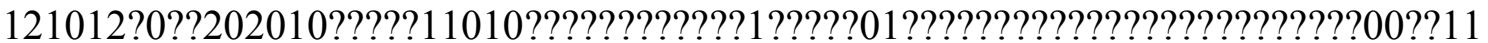

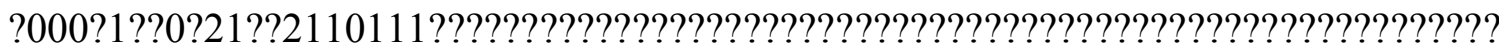
???????????????????????????????????????????????????10??

Cardiocephalus_sternbergi 3?011-01200111???000000001010210?1-00010000210 (0 1)10000-0--12100010223100-11300010200000001?101??020?111000?????????????????????????????????????????????????????????????????????? 
????1010???????????1-

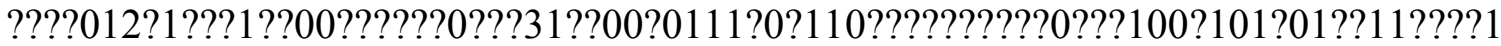
???11?10002?01-?00112?????01?1-1?1-??????10??0???11???010?1--??02?30???????????????????????

Pariotichus_brachyops 3?011-01200110???0000???01?????0?1-$00010000010110000-0--12 ? ? ? ? 102 ? 3 ? 00-$

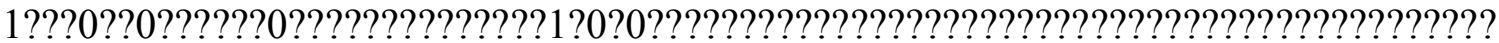

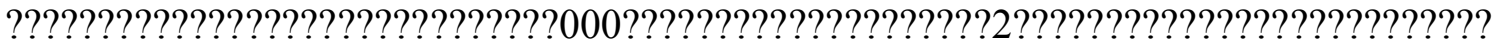

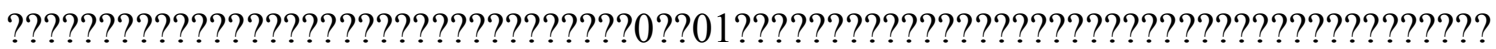
???????????????????????????????3-?????????????????????????

OMNH 53519 3?011-0120011????00000?0????01?001---

00100000100100?0-0--12???010223000-

0120000020000000101011110200111000???????????????????????2?????????????????

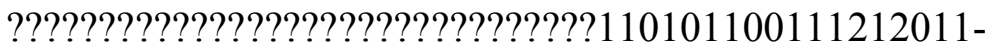

$000001221010101002102120110310000-$

011100001100?210?2110111100010100121111111111111110002301-1001121-

0100101-111-10000110100-1?11001010?1---2202021????????????????????????0

FMNH UR 2296 3?011-0120011?0?1000000?1101011001---

$0010000010010000-0--12100010223000-$

012000002000000010101??00200111000???????????????????????????????????????????

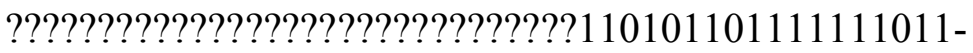

$0000012210111010021121 ? 011 ? 310000-$

011100001100?210?211011110001010012111111111111111000?301-1001121-

0100101-111-10000110100-1?11001010?1---2202021???????????????????????0

'Euryodus dalyae (composite)'3?011-0120011?0?1000000?1101011001---

$0010000010010000-0--12100010223000-$

012000002000000010101??00200111000???02000102???????1000012202011?????10??

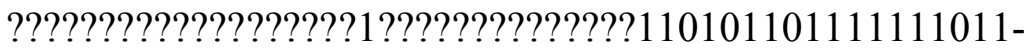

$0000012210111010021121 ? 011 ? 310000-$

011100001100?210?211011110001010012111111111111111000?301-1001121-

0100101-111-10000110100-1?11001010?1---2202021??????????????????????0

Euryodus primus 3?011-0120011000000000001101111001---

$0010000010110000-0--12100010223010-$

112000002000000010101??1020?111000???02000102???????1000??220201???000???0

$111-$

11 ?????1012101210??1020100?????1000???????????????00?012?1???1???????????????

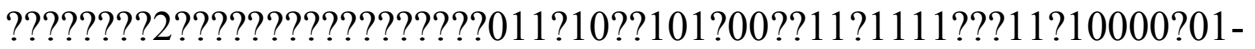

???112?????01?1-1?1-???????0??0-1??????010?1---

??02?21???11?012111021??11031000

Proxilodon bonneri 3?011-01200111001000001?21010110?1---

$001000001011 ? 0 ? 0-0-1210001001 ? 0 ? 0-$

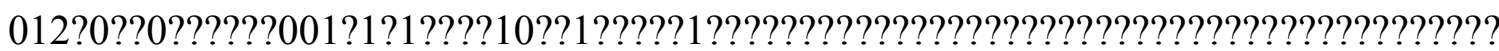

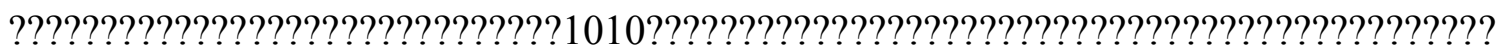

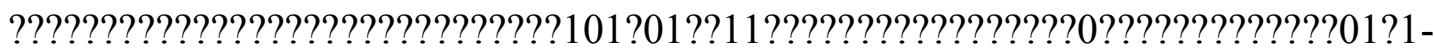

1??????????????????????0?0???????0??30????????????????????????? 
Huskerpeton_englehorni 3?011-012001110010000?002101011001-00010000210110000-0--121000100?2010-

01200000??010?0011101111010211?????????????????????????????????????????????

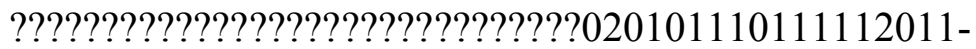

$00000122101110100201212 ? 011310000-$

0011100???00?21??2110111101010100121011111111111110002301-1?01220--100101111-1000-1-0100-121100101011---2202130211????12?1??21???????0?0

Pelodosotis_elongatum 03011-012001100110000?001001031001--

00000000010110010-0--1211-010012010-012?000021010000\{0

1\}0111111020?1100002??01?10102???????10001121?10110010010?0111-111000111220021???00201000????1110?100111001011-

$000002121011 ? ? 1102 ? ? 2 ? 2111 ? 3 ? 0 ? 000011110011210 ? 21 ? ? 2 ? 00111101010100121011$ 111111110010100301-111122????00101-111-10??1110100-1??????0?011---

220212021111??12111021?-11021000

Nannaroter_mckinzei 3?011-01200110???0000?0011010?00?1-0001000001011?0?0-0--12100010113010-

012?00002?01000010101??1020201????????????????????????????????????????????

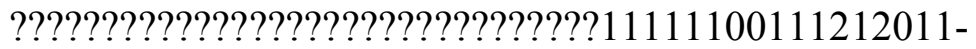

$000002121010 ? 0110 ? ? ? 2 ? ? ? ? 1 ? 3 ? ? 000-$

01???0?????0??1????10111101????????????????11110010100301-1?11221-??????1-

111-1000-1-0100-121111111011---2202120????????????????????????

Micraroter erythrogeios 03011-012001110110000?000001030001-$00010000210\left\{\begin{array}{ll}0 & 1\end{array}\right\} \begin{cases}0 & 1\} 0010-0--12100010113010-\end{cases}$

$012000002000000010101 ? ? 102021100000 ? 00101010200001001000012200011000002$ ? ????????1000?0-1??0??????102110??????11101100111001011-

0000021210111 ?1002?12?211113000000011110001110?21??211011??0?????????????? ????????????0301-1?11221-??????1-111-100?-1-0100-1211?1?01011---

2202130??????????1?????-?????0?0

Eocaecilia_micropodia 3301?-0?-1----0000000?011101121001--00011--0?011100?----1200000000000010013000011013\{0 1\}0?0---????101?3?110002?002?0002?????0111010122-201121000013?????????????0220121002?0?011001?1?-

0000011110210011-00110221111?203003--30?011?010-00--

12?20001001?10??1?010?111--101100211111001111-0110000001-10011------01-1-1---000---------110000101010222011202--11??0-111021?-01?21??1

Carrolla_craddocki 3?021-1-2?0100???01000?0210?130001-----00?00220---01----1211-010123001101300000-

1120001100111110103111 ???????????????????????????????????????????????????????? ????????????????????--00011111110000?1-1000022?111?101100?12?21111310000011120111001?21??-100111111010100121011101111111111012301-110122-----0101111-1000-?-?100?11-----01011---2202130??????????1????????????0

Quasicaecilia_texana 3?121-1-1001001--01000??210?220001--00000001220---0100--

121??????????????310?0??1120?0???????+1?????1???????????0??????????????????????

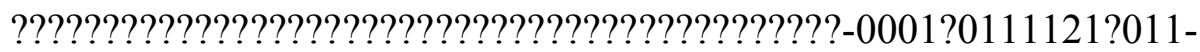
100002221110??110???2???11?3?0000-01111001??0212101-11011?11-- 
101???21011???1111?11110?23????????????????????????????????????????????????? ?021302?????????1?????????????

Llistrofus pricei 3?011-012001100110100010200?020001----1000121000011000--12?00000111000-

0111000021010000110111110102111???1?011?00002???????10000?2200??????00????

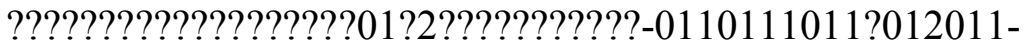

$000002221011101002002 ? ? 0 ? 1 ? 010000 ? 00111001 ? 100-$

21??2??01?1101?10100121111111111110110100301-1111221----0101-111-1000-10100-101100111011---2202121????????1110????????????

Aletrimyti_gaskillae 32011-012001111--00000001102121101----10000210?1011000--12100010013000-

012100002100000010101111020211?????????????2???????????????????????????????? ?????????????????????????????-21111101111011011-00000222101110100211210111310000-0111100?1000-210121101111010101001210111111111111100023011?01220--110101-111-1000-1-0100-121110-11011---220213021111??12111021?$? 1 ? 21 ? 00$

Dvellecanus_carrolli 3?011-01200111???00000001102120001----1000021011011000--12100011013000-012100002100000010011110-

20211????????????????????????????????????????????????????????????????????????? ???-21111100111011011-000002221011101102112120110310000-0111100?100021012110111101010100121011011111111010002301-1?01220--110101-111-1000-10100-121110-11011---2202130?????????1?????????????0

Rhynchonkos_stovalli 3?011-012001111--00000001102210001----1000121000110000--12100010013010-

0121000021000000100?1111020211???????????????????????????????????????????????

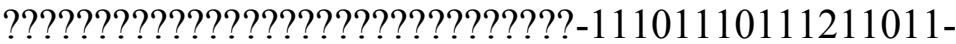
$00000222101010110211212011131000000111100 ? 1100-$ 21012110111101010100121011111111111110002301-1?01220--100101-111-1000-10100-121110-01011---2202130?????????1?????????????

Diabloroter bolti 3?021-1-?????????0100???21??1300?1-----10?002-20--?1----12???0100?1000013?0??0??????01?????????1???110??3?0?1000????????001900?12??????000000?0???? ?????????02??1?1????02?11?0????000??????????0???????????????????0?????11133???0?-0???????1???22????????1????101?0121011?????????????????????12???????1?????????00??-???????----01011---??0?1302???1?0??11?021????0?100?

J`rmungandr_bolti 33021-0-?00111???0000???21020300?1--00010000020---11----12?00?000? 1 ?00-

0?2?0??0??????011??1???1010?1110?02?0110??002?????011?00?1???????010000?0??? ?????????????????????????????????000?????????????????????????????????????????

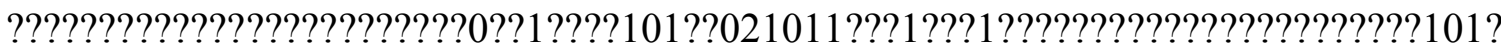
???????????????????????010?1---?????30?????????11?0????????????

Batropetes_fritschi 3?021-1-200100???01000??210?130001-----00?002-20--01----1211-010123001101300000-

11200011001111101031110??3?0?1000????????001?00?12??????000000?0111110???????02??1?1001102?1100110--000???????0??0?1- 
?00??22???1????100?12??111?3??000-01??2011100??2???-

1?0111111010100121011?01111111111012301-110122-----0101-111-1000-?-?100?11----01011---220213021111?01211?021?11102100?

Captorhinus_laticeps 0102011-20011000101000000101031101--

000000000--0---0100--11000001123010-0111001021000-00100111(0

1) $101021000001 ? 0020000021----$

0110000102220010010011311100110?1?101022101100000201000110--

$01011111 ? ? 2010 ? 1-100002221-$

$110030021121211103000000001000101001021 ? ? 2 ? 100-1 ? 1-$

0101001210111111111111--111221---0122-?-100101-111-1000?1?0100-121110-11011$--22021202-111 ?-12111021 ?-11121000$

Infernovenator steenae 33021-0100010-1--000000021011200?1--00001--0101110-000--

11000????????????3?0?????????01100??1110????100002?01100010200001??000011?1 0200121100003????????????????????????2???11??????1100????????????????????????? ??????10?????1?????00-

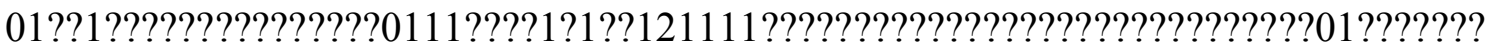
10???????????????????????????0?1302???????+11?0????????????

Brachydectes_newberryi 23021--100010-1--00000012101120001--00001--0101110-000--12000000013000-

$01310000110200011001111102031100002 ? 011000102000010100001121020012110000$ 31110-11000001001001\{0 1\}11?12021110??10?110011111110000?1-

000002221110101002102121111310000-011110011002?2???211011111--

10100121111111111111111012301-1001220--100101-111-1000-1-0100?121110-01011--2200130211110012111121??11?21000

Greererpeton_burkemorani $0200000100110000000000012100030101-----$ 0000000001000000--00000000000000-0000000000000000000001000000010002?00000000000000??10100000?0000211100000010000000111011011110100201010--0?00001010?1?1000?00000001001-10103003-$1 ? 10-111000000001100000000-100 ? ? 0 ? 00-$ $110011010002110101011111010000001011101221001101001011 ?(1$

2)1000100100?1200011101101102111111210110011111111?111120000

Seymouria_baylorensis 0100000010010000000000000000010000100000000001000000000--00000000012010$1000000010000000000000\left\{\begin{array}{lll}0 & 1\end{array}\right\}\left\{\begin{array}{ll}0 & 1\end{array}\right\}-2000001001 ? 000000\{0$

$1\} 02000010010000000000110000010011000100100102012101000000111100 ? 00 ? 0010$ 1?1011?0020?1-110001021-1110310-??1?11-100000111001010010?00?1???1??0011011111001211111111111101111111000111122110110101-111-11001111100111111-11211---22001102111101121110211111121000

Limnoscelis paludis 0101010110010000100000000000001001000000000001100010000--12100001022010$0011001010010000000101\{01\} 0-$ 0010110000?000000002000000010000000000100000010011000??0100?0?0221010100 10111000110?00001?1011?0020?1-110011021$11103001001 ? 111102010111011000101 ? 00 ? 2 ? ? ? 1 ? 000-$ 
1101110111121011111111111111111221-11012200-100101-111-1100-1-0100-12111011011---2202130211110112111021?-11121000

Branchiosauridae

311100100001210000000?10100001000020???0000010000010010--11000000010000$00 \begin{cases}0 & 1\} 0000\{01\} 1 ? 13010 ? ? ? ? ? ? ? ? 0-\end{cases}$

?????020010000?00?0000?0?0000000?????0?1200200?00-

000??000????20000101?120211010--

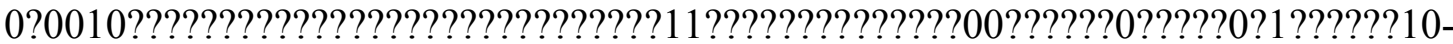
1????????????????????????????????????????????????????????????????????????? ???????????????????????????310??

Micromelerpetontidae $\quad 311100100001010000100 ? 1000000\{0$

$1\} 000000 ? ? ? 0000 ? 11000010010--01000000000000-$

00?010000?13100??????????????010000000?00?0000?0?00000?0?????0?1210000?00$000 ? ? 000 ? ? ? ? 20001101 ? 120211010--$

0?0001???????????????????????????01??????????????0??????00?0??0?1??????101??????????????????????????????????????????????????????????????????????????????? ??????????????????????????310??

Tersomius texensis $\quad 2 ? 0100\{01\} 010010\{01\} 00001101100000010000\{0$

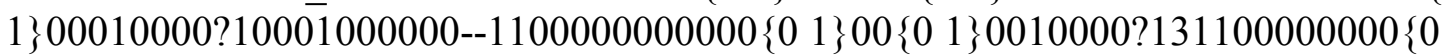
$1\} 0-$ 0101010?0??????????1?????????????????????????????????????????????????????????? 0????0001????????????01???????????????00??????0???????00???1?200100?0?1??????1 ??100101010000101111011111?1010100000110112111110101-11110002110100?10111?-010101012011111?????????????????????0??

Ecolsonia_cutlerensis $0 ? 11000110011100001001102020000000011210000000001000000--1000000001\{0$ $1\} 010-000010000 ? 1210000000 ? 0\{01\} 0-$ 0?000?000??00010100000001011000???????????100?????????0000?010?11??0?0?100 110?0????0000????????????????????????????0???????????????00?????100????0?1???? $? ? 10-$ 1???????????????????????????????????????????????????????????????????????????????

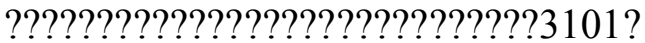

Acheloma_spp.

0?010001100??000001001?020200000000111100?0000001000000--10000?00011010$000010000 ? 12 ? 000 ? 0100 ? ? 0-$

01?00?000??00000000000000?01000??????????001???????????000????02210?1001?0? ????0????0000?0001101000101001002111010002003--2?10$100001001001110110200 ? 1 ? ? ? ? ? ? 10-$ $10011101010210111111111101011100101101122111110101-111-$ 10002110100?101111-000110002011111211110?12111121??1113101?

Eryops megalocephalus 010100?11000000000?001?0000000100?00000000000000000000--10000000000010000000000?121000?00????0?????0?0?01?00000000000000001000??????????0000??00000?000000??02211?10010?1???0?000?00011001111000011-000002111011100003-1?10-110001000001110000201?1?????000- 
$11001111010210111101111100011100001111122100110101-$ 111?20001110100?101111?00011???2001111211110-111111211?1113101\{0 1$\}$

Doleserpeton annectens 3?010010100100000010011?0000010000200000000?10000010000-$11000000000001001001001\{01\} ? 13110000000000-010 ? 010001 ? 00\{1$ 2\}?0000200?0??110000?12220??2??200?????????010????????????0??0?????0????0001 001011?1100?01001002211?10113103--2010-111101000001120010000?1???0?0101200110100021011110111110110000001--011121??100101-1--10002110101?101100001010101201113021111?0111110210-01-31011

Caudata $\quad-2\{01\} 11---00012-0110100-1000002\{12\} 0001--00001---$ 0-21----1-0--120000000\{0 1\}0001001\{2 3\}002011015\{0 1\}-0002-2-2-0-10\{2 3$\} 010\{1$ $2\} 003\{01\} 0120000020100100111011222201120020013-------1--$ $11112001001120211000\{0$ 1\}00?-10000101101(0 1)(0 1)01(0 1)100100221111-20?0(0

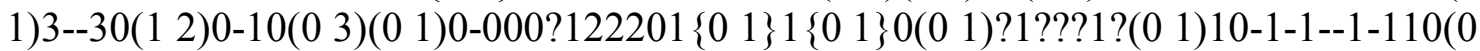
1)(1 2$) 1$ ? $110\left(\begin{array}{lll}0 & 1\end{array}\right)\left(\begin{array}{ll}0 & 1\end{array}\right)-1-$

1????????????????????????????????????????????????????????????????????????? ???????31011

Anura $\quad$-1111----1----1-- $\{01\} 100-10-0002100002000101---0-20---$ $1-0--120000000\{01\} 00010010001011014\{01\}-0002-\{12\} 12-0-11301001030012-$ 000021-----1101011122201120020013-------10110011001000101211001100?0??0010110010011-00100221111?20?1(0 1)3--3010-101(0 1)0-0000(0 1)2220110\{0 $1\} 0\left(\begin{array}{ll}0 & 1) ? 1 ? ? ? 1 ?(0) 1) 10-121--\end{array}\right.$ 1????????????????1??????????????????????????????????????????????????????????????

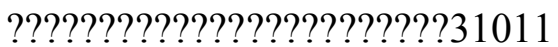

Albanerpetontidae 3?011---1001211--1100?0?20001100012-00001---1-21--01-0--11000-000??1011012?0?00???3???002-2-111021301?000\{0 $1\}$ ?012?00002??????011001122220122002001????????-$1 ? ? ? ? 0 ? ? ? 0 ? ? ? 0 ? ? 0 ? ? 10 ? 0 ? 0 ? ?-$

1???????????????????????????????????????????????00??1??201??????1????+010-1-1-?????????????????1??????????????????????????????????????????????????????????????

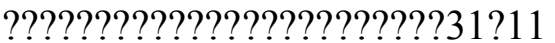

Micropholis_stowi $20\{01\} 1000\{01\} 10012100000\{01\} 0110\{0$ $1\} 000000000000000000010000001000--1-0000000\left\{\begin{array}{ll}0 & 1\end{array}\right\}\left\{\begin{array}{l}0 \\ 1\end{array}\right\} 000-$ $00001000001311000000111100101000003 ? 000 ? 00001 ? ? ? ? ? 011010 ? 0002 ? 0 ? 1200200 ? ?$ 0-00000010001?120001100000201000100?0011???????????01?????????????? 0 1\}0??????????????00?????200000?0?1??????10-1000110110021011110111?10?\{0 $1\} 1\{01\} 100000110122111110101-111-$ 11??2110100?10?????0?01????201111121111011111102?0?01-3101?

Eoscopus_lockardi $\quad 2 ? 01001\{01\} 100101000011011 ? 000000000020\{0$ 1\}210000?10000010010--11000000000000-000010000?1311000000?\{0 1\}?0?0?00?0001000000000100001011000???0200?\{0 1\}200200100$00000010 ? ? ? ? 0110 ? 21001\{0$ 1\}0201000100?0001????????????01???????????????01??????0???????00??????0?000?0 ?1??????10-1000110110021011110111?101010100000110122111000111-11110002110100?101111?0001????20011102??1101111110?????1?3101? 
Tambachia_trogallas

2?01000110010000001001102020000000001110000000001000000--11000000011010$000010000 ? 121000 ? ? 1\{01\} 1 ? ? 0-$

01??01000??0???00?00??????01?0???????????00?0????????????????+01001??????0????

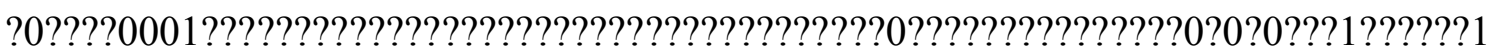

0-1001110111121011110111?10????100001111?22?????0101-1?1-

$10 ? ? 2110100 ? 10 ? ? ? ? ? 0 ? 01 ? ? ? ? ? 0011112 ? ? 1101 ? ? 111 ? ? ? ? ? 11 ? 31 ? ? ?$

Triadobatrachus massinoti 21111-1-??????0--0100???????21???020-0101---

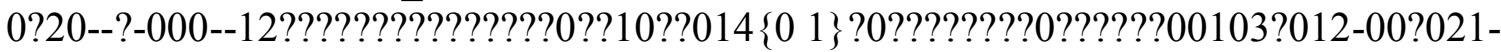
---011010?1???20\{0 1\}1?002001\{0 3\}-------?-10???010001100?\{1 2\}12-1001?0??0????????????????????????????+10??????0???????00?????201110???1??????10-?21-1??????????????????????????????????????????????????????????????????????????????? ???????????????????????31?11

Gerobatrachus hottoni

2111001010012100001101?000?02100002000000???00000010010--??000000000000$0120010120141100 ? ? ? ? ? ? ? 0-$

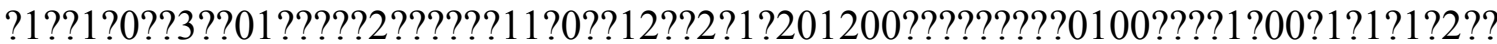
?0???0??001?????????????????????????????10?????????????????????201??????1??????

$1 ? ? 120 ? 1101 ? 0021011110111 ? 1 ? 1111 ? 2001-100122 ? ? ? ? ? 01 ? 1 ? 111-$ 10?????0??0???????????????201113021111????11?0???????31???

Platyrhinops lyelli 210100?01001?10000010?1100?0200000200000000010000010010-1110000000000100?0010?0??131100000201?0-?0??010000??02$0000100 ? ? 0 ? 110000102 ? 2 ? 1 ? 200200 ? 00-$

0????0100???01??0111010?2?1000??0?0001????????????01???????????????00???????? ??????00?????200?0??0?1??????1??10011101?102101111011??101011100(0

1)00111122111110101-111-1000211?100-10111100010000220111121111?0111110210?01?3101?

Amphibamus_grandiceps 211100?01001010000000?1000?0200000200000000?1000001001???111000000000010 $010010010 ? 13110000 ? ? ? ? ? 0-$ $0 ? ? ? ? 10001 ? ? 00 ? 0000200 ? ? 00110000 ? 00 ? 2 ? 1 ? 200200 ? 00-$ 00000010000?0?1?0100?1102?1?00??0?0001????????????01??????????????11???????

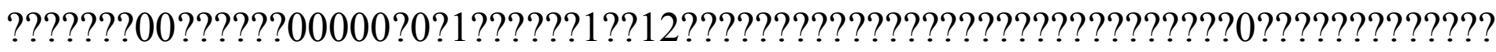

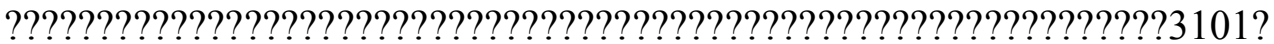

Lethiscus stocki $230100010001110011100011200101101000000001-$ 01101001010--?2000000012000-011000000110000000000000$000001 ? ? ? 2 ? ? 120000021----01111(0$ 1)102222001210110??????????????????????????????????0-1101000010000111-00000000000-000000-0010-110000000001?00010000-001?00100$1000110100021011001010101011 ? ? ? 001010 ? 0001000-$ 100???10010110110010?10111?-010102002000130211----0--1?????1???--?-0

Coloraderpeton_brilli 13010001000111001000???????01001000100010-01001000010--02000000012100-010?00002100000000000000-000001---2??120000021---01111(0 1)102222001210110-?????????????????????????????????01101000010000111-00000000000-000000--0010-110000000001?000?0?00-001100000- 
?000110?000?10?00?1010100010000001?-0000010?0-1000\{0 1\}110?1011011001010111?-01011???20?0130???-----?-1?????1???--?-0

Edops craigi 0100000010002000000000000000001100000000000100000000000--10000000011000$000000000112000000001 ? ? 0-$

10000??????????00??????????????????????????????????????????????????????????????

???000011001111000011-000001101011100003--1010-11000000000111000021?1??????00-10001111010210111111111100011100101111122100100?01-11110000110100?101111?00011---2202111????100????1????111?21?0?

Petrolacosaurus kansensis 02020111200100001010000?0101011101-0000000100000011000--12000000011010-0111001021000000000012--00211100?0??020000021----0010000002020010110011311111010100010111001000102?1000110-00101?10???0?10?1-?00002221$11003012112 ? 211113000000001110101000 ? 21 ? ? 2 ? ? 010 ? 101110100121011111111 ? 10$ ? 11111001-1111221--100101-11110001110100?1??????????????????????????????????????+100?

Ophiacodon uniformis $\quad 0102010010012000101000100101011101----$ 0000101100001000--12000000011110$01010010210000000011111111021110 ? ? 0 ? 002000002001000010000002120100100010$ 01101011010010102210010001020000011000010111011?1020?1-11001102111103001--30111102010101011100101002?20????0001101011100121011111111111111011221-1101221--110101-111-1000-1-0101-12111001211---22021302111101121110211-11121000

Baphetes_spp. 0?00001010011000000100000000010110000000010100001000000--0100000000?000$001000000000 ? 00000100 ? ? 0-$

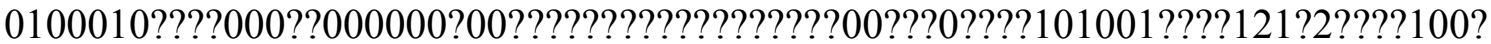

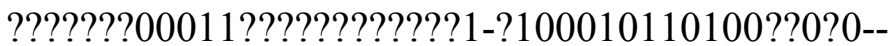
1010?011000000003?000?0?0??1??????0?010011?1010110110101111100011100000111??????????????????????????????????? ??0010?200111?111100??1?1????111120???

Eucritta melanolimnetes 00000000100110000000000?0000210010001000000000001000000--1100?0000?1000$0000000 ? 0 ? 00 ? 00000000 ? ? 0-$

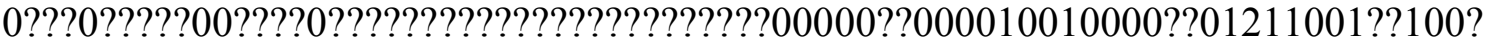

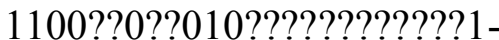
?100012?1?1?0??0???????????1????0?????????????1????????$11011101010210111101 ? ? ? ? 0 ? 1011000 ? ? ? ? ? ? 0 ? ? ? ? ? ? ? ? ? 1-$ ???????????????????????0?01?????20011121111?01211102??1111200??

Dimetrodon_spp. $\quad 0102010010112000101000000001001101----$ 00000001000-0000--12000000023110-0111001021000000111102112110110?????1200000201100001000010?????0?10001??1111$11 ? ? ? ? ? ? ? ? 2210 ? 1000002010000000-1101 ? 1111 ? 1020 ? 1-$ $110011121 ? 1110300 ? 0030111102010100001000101002020211 ? 0000110101110112111$ 1111111110111111221-1101221--100101-111---00-1-0101-121110-11011--$22021302111101121110211-11121000$ 
Opisthodontosaurus_carrolli 1?02??0?200110001000??0011010?0101----100000??0???0?????12100000213010-111100102100000011111??010201???????12??0002???????1000??????????1?00???1111-11--1$1010221001000002110 ? ? ? ? ?-$

?0001??????????????????????????????????????????????????????????1?2?????1???? ??????????????????????????????????????????????????????????????????????????? ???????????????????????0??

;

END;

BEGIN ASSUMPTIONS;

TYPESET * UNTITLED = unord: 1- 370;

END;

BEGIN MESQUITECHARMODELS;

END;

ProbModelSet * UNTITLED = 'Mk1 (est.)': 1- 370;

Begin MESQUITE;

MESQUITESCRIPTVERSION 2;

TITLE AUTO;

tell ProjectCoordinator; timeSaved 1579547288723;

getEmployee \#mesquite.minimal.ManageTaxa.ManageTaxa;

tell It;

setID 0 4897592968813884373;

tell It;

setDefaultOrder 012345678910111213141524

1732322020212223242526275561616263286831325533343536373839

40414243444546474849505152535657585964656566 67;

attachments ; endTell;

endTell;

getEmployee

\#mesquite.charMatrices.ManageCharacters.ManageCharacters;

tell It;

setID 0 6605800557590130524;

mqVersion 351;

checksumv 031428389708 null getNumChars 370 numChars 370

getNumTaxa 69 numTaxa 69 short true bits 2305843009213694015 states 63

sumSquaresStatesOnly 65974.0 sumSquares -3.08982963234635E20

longCompressibleToShort false usingShortMatrix true NumFiles 1 NumMatrices 1;

mqVersion;

endTell; 
getWindow;

tell It;

suppress;

setResourcesState false false 100;

setPopoutState 300;

setExplanationSize 0;

setAnnotationSize 0;

setFontIncAnnot 0;

setFontIncExp 0;

setSize 1890 975;

setLocation 21 23;

setFont SanSerif;

setFontSize 10;

getToolPalette;

tell It;

endTell;

desuppress;

endTell;

getEmployee

\#mesquite.charMatrices.BasicDataWindowCoord.BasicDataWindowCoord; tell It;

showDataWindow \#6605800557590130524

\#mesquite.charMatrices.BasicDataWindowMaker.BasicDataWindowMaker; tell It;

getWindow;

tell It;

getTable;

tell It;

endTell;

rowNamesWidth 116;

setExplanationSize 30;

setAnnotationSize 20;

setFontIncAnnot 0;

setFontIncExp 0;

setSize 1790 903;

setLocation 21 23;

setFont SanSerif;

setFontSize 10;

getToolPalette;

tell It;

setTool

mesquite.charMatrices.BasicDataWindowMaker.BasicDataWindow.ibeam;

endTell;

setActive;

setTool

mesquite.charMatrices.BasicDataWindowMaker.BasicDataWindow.ibeam; 


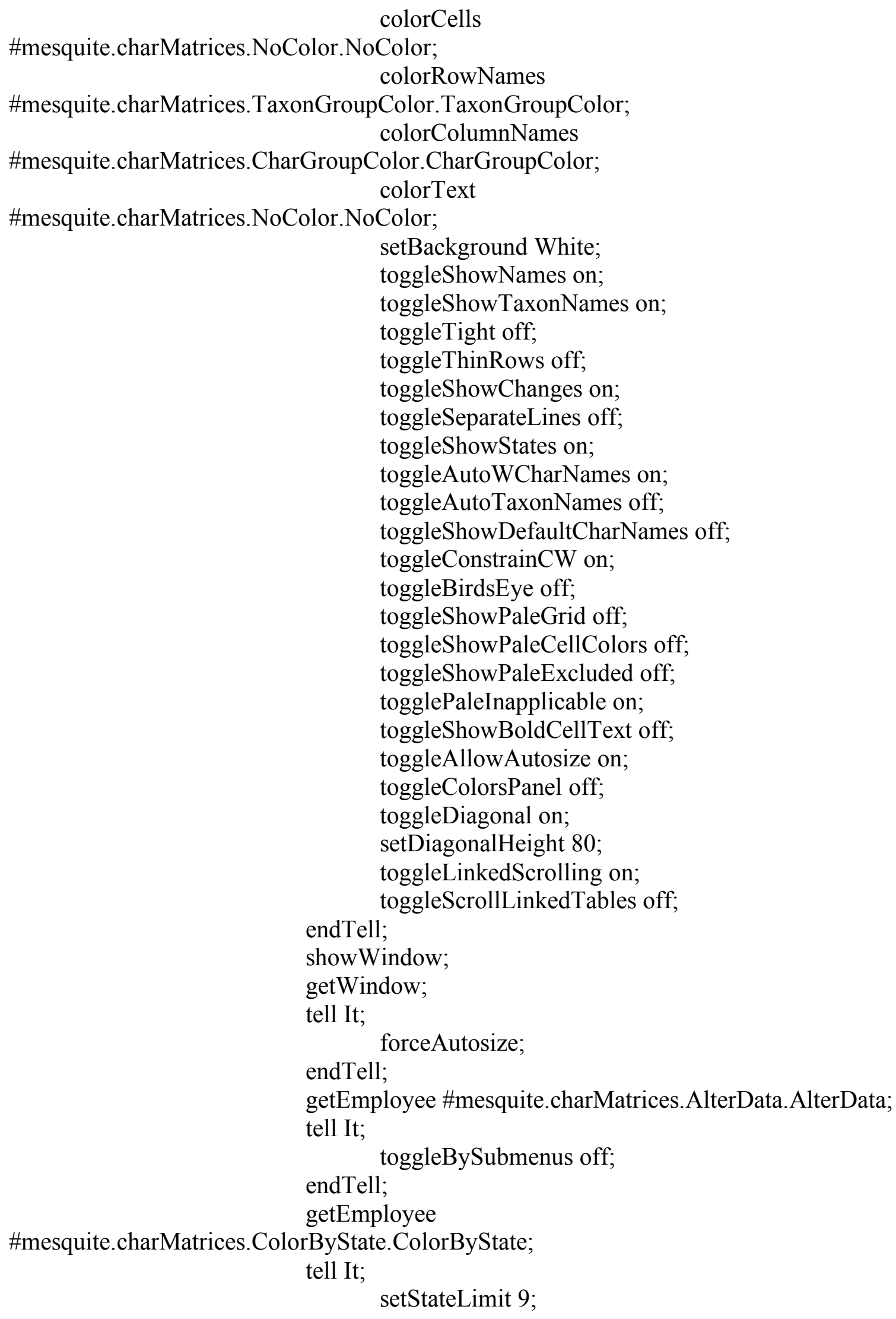




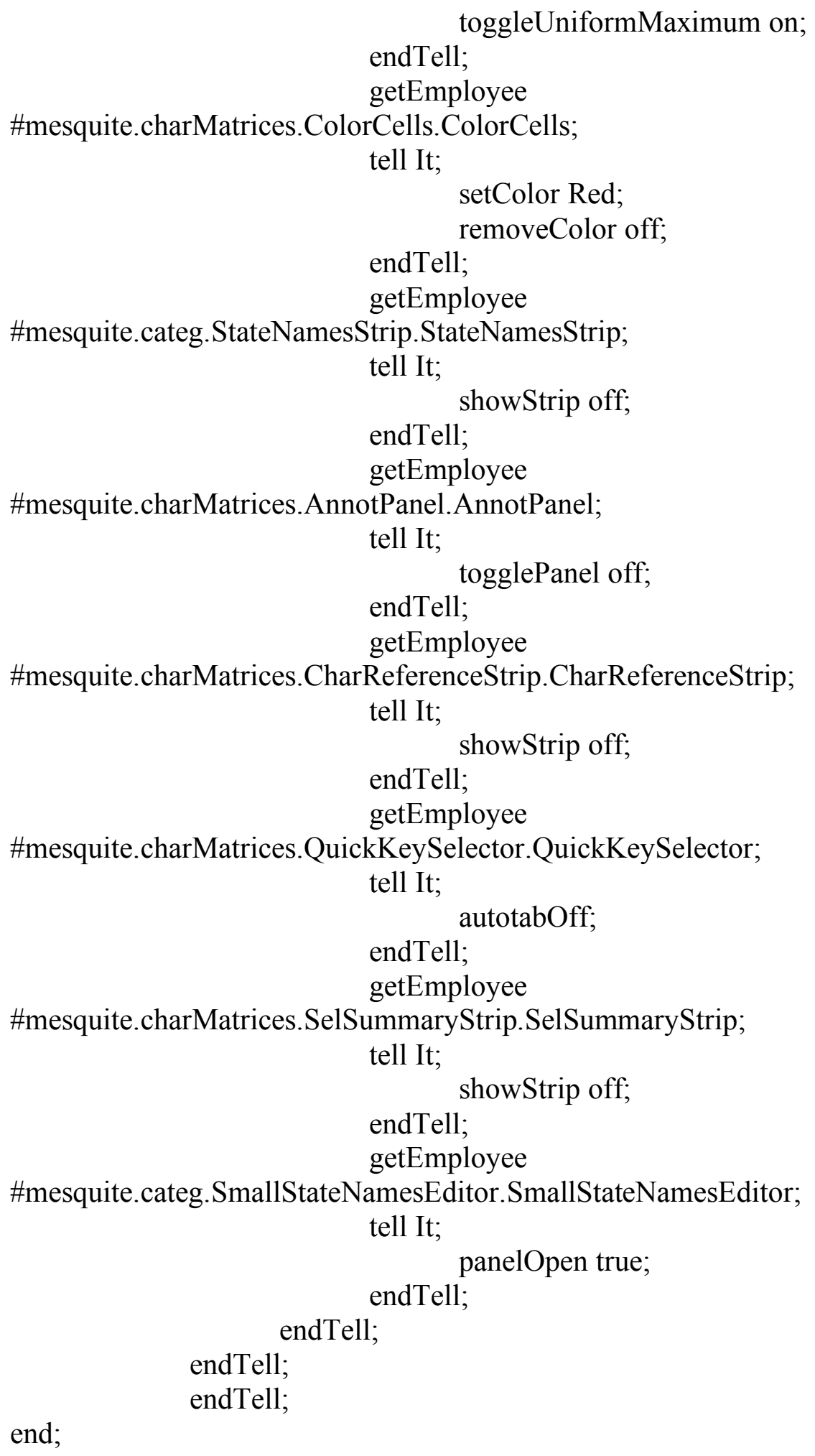

end; 


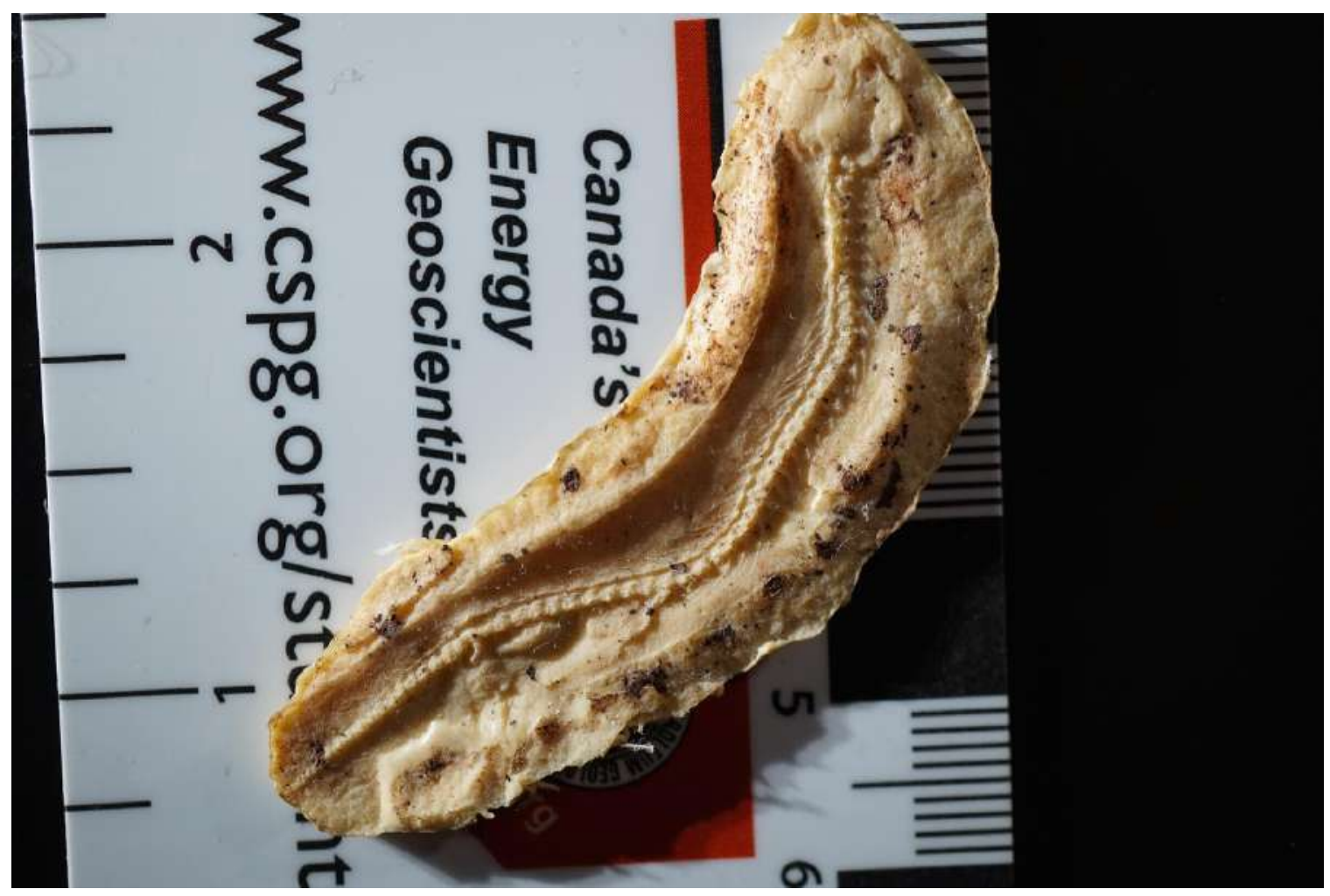

C.3 Scanning Electron Micrograph of cranial scales on FMNH 1309. 


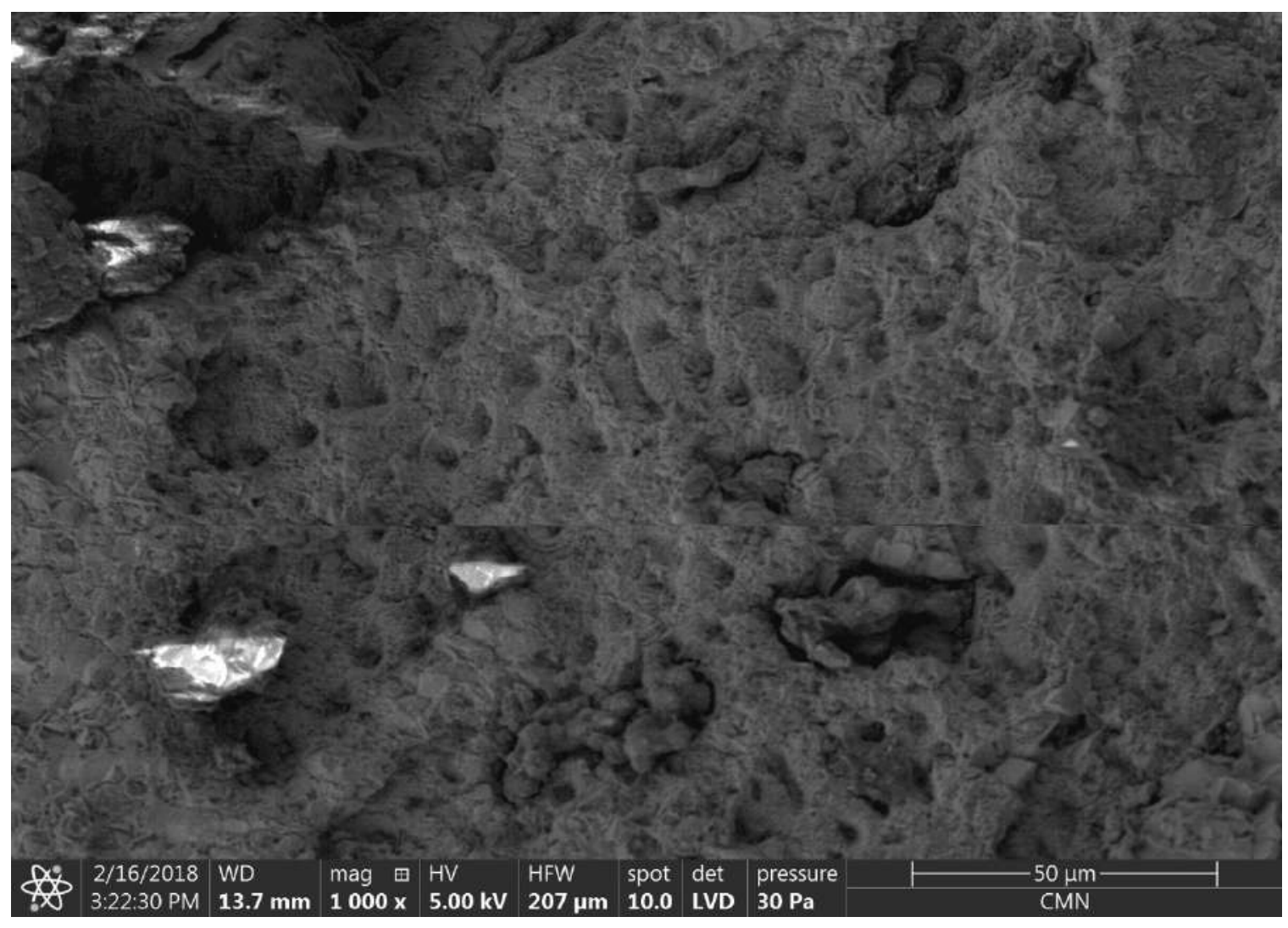

C.4 Preserved reptile specimens at the Canadian Musseum of Nature used for comparative anatomical data on scales

\begin{tabular}{|l|l|l|l|}
\hline ID NUMBER & CATEGORY & LABEL NAME & HIGHER TAXA \\
\hline CMNAR 3158 & fossorial & Typhlops & $\begin{array}{l}\text { Animalia; Chordata; } \\
\text { Vertebrata; Reptilia; } \\
\text { Lepidosauria; Squamata; } \\
\text { Serpentes; Typhlopoidea; } \\
\text { Typhlopidae }\end{array}$ \\
\hline CMNAR 5713 & fossorial & $\begin{array}{l}\text { Leptotyphlops } \\
\text { humilis } \\
\text { cahuilae }\end{array}$ & $\begin{array}{l}\text { Animalia; Chordata; } \\
\text { Vertebrata; Reptilia; } \\
\text { Lepidosauria; Squamata; } \\
\text { Serpentes; Typhlopoidea; } \\
\text { Leptotyphlopidae; } \\
\text { Leptotyphlops; Leptotyphlops } \\
\text { humilis }\end{array}$ \\
\hline
\end{tabular}




\begin{tabular}{|c|c|c|c|}
\hline $\begin{array}{l}\text { CMNAR } \\
12634\end{array}$ & fossorial & $\begin{array}{l}\text { Typhlops } \\
\text { boulengeri }\end{array}$ & $\begin{array}{l}\text { Animalia; Chordata; } \\
\text { Vertebrata; Reptilia; } \\
\text { Lepidosauria; Squamata; } \\
\text { Serpentes; Typhlopoidea; } \\
\text { Typhlopidae; Typhlops }\end{array}$ \\
\hline $\begin{array}{l}\text { CMNAR } \\
15427\end{array}$ & fossorial & $\begin{array}{l}\text { Acontias } \\
\text { meleagris }\end{array}$ & $\begin{array}{l}\text { Animalia; Chordata; } \\
\text { Vertebrata; Reptilia; } \\
\text { Lepidosauria; Squamata; } \\
\text { Lacertilia; Scincidae; } \\
\text { Acontiinae; Acontias }\end{array}$ \\
\hline $\begin{array}{l}\text { CMNAR } \\
24994\end{array}$ & fossorial & $\begin{array}{l}\text { Ophisaurus } \\
\text { apodus }\end{array}$ & $\begin{array}{l}\text { Animalia; Chordata; } \\
\text { Vertebrata; Reptilia; } \\
\text { Lepidosauria; Squamata; } \\
\text { Lacertilia; Diploglossa; } \\
\text { Anguidae; Gerrhonotinae; } \\
\text { Ophisaurus }\end{array}$ \\
\hline $\begin{array}{l}\text { CMNAR } \\
25631\end{array}$ & fossorial & $\begin{array}{l}\text { Celestus } \\
\text { barbouri }\end{array}$ & $\begin{array}{l}\text { Animalia; Chordata; } \\
\text { Vertebrata; Reptilia; } \\
\text { Lepidosauria; Squamata; } \\
\text { Lacertilia; Diploglossa; } \\
\text { Anguidae; Diploglossinae; } \\
\text { Celestus }\end{array}$ \\
\hline $\begin{array}{l}\text { CMNAR } \\
27255\end{array}$ & fossorial & $\begin{array}{l}\text { Scincus } \\
\text { scincus }\end{array}$ & $\begin{array}{l}\text { Animalia; Chordata; } \\
\text { Vertebrata; Reptilia; } \\
\text { Lepidosauria; Squamata; } \\
\text { Lacertilia; Scincidae; } \\
\text { Scincinae; Scincus }\end{array}$ \\
\hline $\begin{array}{l}\text { CMNAR } \\
29529\end{array}$ & fossorial & $\begin{array}{l}\text { Scincus } \\
\text { scincus }\end{array}$ & $\begin{array}{l}\text { Animalia; Chordata; } \\
\text { Vertebrata; Reptilia; } \\
\text { Lepidosauria; Squamata; } \\
\text { Lacertilia; Scincidae; } \\
\text { Scincinae; Scincus }\end{array}$ \\
\hline $\begin{array}{l}\text { CMNAR } \\
33947\end{array}$ & fossorial & $\begin{array}{l}\text { Chalcides } \\
\text { chalcides } \\
\text { tridactylus }\end{array}$ & $\begin{array}{l}\text { Animalia; Chordata; } \\
\text { Vertebrata; Reptilia; } \\
\text { Lepidosauria; Squamata; } \\
\text { Lacertilia; Scincidae; } \\
\text { Scincinae; Chalcides; } \\
\text { Chalcides chalcides }\end{array}$ \\
\hline $\begin{array}{l}\text { CMNAR } \\
33949\end{array}$ & fossorial & Anguis fragilis & $\begin{array}{l}\text { Animalia; Chordata; } \\
\text { Vertebrata; Reptilia; } \\
\text { Lepidosauria; Squamata; } \\
\text { Lacertilia; Diploglossa; } \\
\text { Anguidae; Anguinae; Anguis }\end{array}$ \\
\hline
\end{tabular}




\begin{tabular}{|c|c|c|c|}
\hline $\begin{array}{l}\text { CMNAR } \\
35195\end{array}$ & fossorial & $\begin{array}{l}\text { Amphisbaena } \\
\text { alba }\end{array}$ & $\begin{array}{l}\text { Animalia; Chordata; } \\
\text { Vertebrata; Reptilia; } \\
\text { Lepidosauria; Squamata; } \\
\text { Amphisbaenia }\end{array}$ \\
\hline CMNAR 9103 & terrestrial/arboral & $\begin{array}{l}\text { Eumeces } \\
\text { laticeps }\end{array}$ & $\begin{array}{l}\text { Animalia; Chordata; } \\
\text { Vertebrata; Reptilia; } \\
\text { Lepidosauria; Squamata; } \\
\text { Lacertilia; Scincidae; } \\
\text { Scincinae; Eumeces }\end{array}$ \\
\hline $\begin{array}{l}\text { CMNAR } \\
25761\end{array}$ & terrestrial & Leiocephalus & $\begin{array}{l}\text { Animalia; Chordata; } \\
\text { Vertebrata; Reptilia; } \\
\text { Lepidosauria; Squamata; } \\
\text { Lacertilia; Iguanidae }\end{array}$ \\
\hline $\begin{array}{l}\text { CMNAR } \\
34886\end{array}$ & Terrestrial/arboreal & $\begin{array}{l}\text { Basiliscus } \\
\text { basiliscus }\end{array}$ & $\begin{array}{l}\text { Animalia; Chordata; } \\
\text { Vertebrata; Reptilia; } \\
\text { Lepidosauria; Squamata; } \\
\text { Lacertilia; Iguanidae; } \\
\text { Basiliscus }\end{array}$ \\
\hline Uncatalogued & Arboreal & $\begin{array}{l}\text { Elgaria } \\
\text { coerulea }\end{array}$ & $\begin{array}{l}\text { Animalia; Chordata; } \\
\text { Vertebrata; Reptilia; } \\
\text { Lepidosauria; Squamata; } \\
\text { Sauria; Anguimorpha; } \\
\text { Diploglossa; Anguidae } \\
\text { (Gerrhonotinae) }\end{array}$ \\
\hline
\end{tabular}




\section{Appendix D - Chapter 6 Supplementary Information}

\section{D.1 Codings for the matrix of Gee et al., 2020, including the new taxon from Chapter 6.}

\#NEXUS

[written Thu Feb 06 14:10:29 EST 2020 by Mesquite version 3.51 (build 898) at dhcp-83-68.cu-internet.carleton.ca/172.17.83.68]

\section{BEGIN TAXA;}

TITLE Taxa;

DIMENSIONS NTAX=70;

TAXLABELS

Archeria_crassidisca Crassigyrinus_scoticus Acanthostega_gunnari

Eusthenopteron_foordi Ichthyostega_spp. Panderichthys_rhombolepis

Pederpes_finneyae Tiktaalik_rosaea Ventastega_curonica Whatcheeria_deltae

Ymeria_denticulata Proterogyrinus_scheelei Balanerpeton_woodi

Dendrerpeton_acadianum Pantylus_cordatus Cardiocephalus_peabodyi

Cardiocephalus_sternbergi Pariotichus_brachyops OMNH_53519 FMNH_UR_2296

'Euryodus dalyae (composite)' Euryodus_primus Proxilodon_bonneri

Huskerpeton_englehorni Pelodosotis_elongatum Nannaroter_mckinzei

Micraroter_erythrogeios Eocaecilia_micropodia Carrolla_craddocki

Quasicaecilia_texana Llistrofus_pricei Aletrimyti_gaskillae Dvellecanus_carrolli

Rhynchonkos_stovalli Diabloroter_bolti Jormungandr_bolti Batropetes_fritschi

Captorhinus_laticeps Infernovenator_steenae Brachydectes_newberryi

New_Molgophid(composite) Greererpeton_burkemorani Seymouria_baylorensis

Limnoscelis_paludis Branchiosauridae Micromelerpetontidae Tersomius_texensis

Ecolsonia_cutlerensis Acheloma_spp. Eryops_megalocephalus

Doleserpeton_annectens Caudata Anura Albanerpetontidae Micropholis_stowi

Eoscopus_lockardi Tambachia_trogallas Triadobatrachus_massinoti

Gerobatrachus_hottoni Platyrhinops_lyelli Amphibamus_grandiceps

Lethiscus_stocki Coloraderpeton_brilli Edops_craigi Petrolacosaurus_kansensis

Ophiacodon_uniformis_Baphetes_spp. Eucritta_melanolimnetes Dimetrodon_spp.

Opisthodontosaurus_carrolli

END;

BEGIN CHARACTERS;

TITLE 'Matrix in file "Pardo et al 2017 with recoded Llistrofus.nex"';

DIMENSIONS NCHAR=370;

FORMAT DATATYPE $=$ STANDARD GAP $=-$ MISSING $=$ ? SYMBOLS $=" 0123$

45678 ;"; 


\section{CHARSTATELABELS}

1 Basal_Skull_Length / '>70mm' '50-70mm' '30-50mm' '<30mm',

2 Skull_trunk / 0.45 0.30_0.45 0.20_0.29 0.20,

3 Skull_proportions / longer_than_wide wider_than_long,

4 Intertemporal / present

Replaced_by_anterior_extension_of_supratemporal_or_tabular

replaced_by_lateral_extension_of_parietal,

5 Supratemporal / present absent,

6 ST_exposure_on_occiput / absent present,

7 Postfrontal_shape / broadly_quadrangular falciform,

8 Squamosal_Tabular / absent present fused,

9 Lacrimal_prefrontal_suture / simple_butt_joint interdigitating

prefrontal_broadly_underplates_lacrimal,

10 Lacrimal / present absent,

11 L_to_naris / present absent,

12 L_to_orbit / absent present,

13 lacrimal_orbital_processes / only_ventral_present

dorsal_and_ventral_present neither_present,

14 lacrimal_jugal_contact / present absent,

15 Quadratojugal / present absent,

16 Quadratojugal_Jugal_contact / present absent,

17 Quadratojugal_Maxillary_contact / present absent,

18 Frontals / paired fused,

19 Frontal_into_orbit / no yes,

20 Anterior_laterally_flaring_frontals / absent present,

21 Nasals / present absent,

22 Narial_flange / absent present,

23 alary_processes_of_premax / absent present,

24 Septomaxilla / ossified unossified,

25 Prefrontal_into_external_naris / distant_from near present,

26 external_naris_in_dorsal_view / exposed not_exposed,

27 External_naris_shape / circular 'posteriorly extended, along L-PF

suture' posteriorly_extended_excavation_of_L_only,

28 dorsal_exposure_of_premax / broad narrow none,

29 dorsal_shape_of_skull / triangular diamond rounded,

30 Posterior_skull_margin / concave straight convex undulating.,

31 snout_shape / blunt pointed,

32 snout_length / short long,

33 Q_internal_flange_of_Sq / absent present,

34 otic_notch_presence / present absent,

35 Large_otic_notch_approaching_orbit / absent intermediate close,

36 otic_notch_structure / open_posteriorly closed_posteriorly,

37 semilunar_flange_of_supratempor / absent present,

38 supratympanic_flange / absent 'present "trematopid"'

present_trematopid 'present "dissorophid"' present_dissorophid,

39 supratympanic_shelf / absent present, 
40 raised_orbital_rim / absent present,

41 Postorbital / present absent,

42 J_PO_interfingered_processes / absent present,

43 PO_in_orbital_margin / present absent,

caudal',

44 shape_of_postorbital / irregular_trapezoid 'triangular, apex

45 Palpebral_ossifications / absent

mosaic_of_bone_plates_present_in_orbit Single_large_plate_above_orbit,

46 parietal_tabular_contact / absent present,

47 postparietal_fusion / paired fused absent,

48 parietal_foramen / present absent,

49 postparietal_size / moderate large,

50 postparietal_squamosal_contact / absent present,

51 postparietal_length / 'large, quadrangular' 'abbreviated

anteroposteriorly, elongate lateral rectangle',

52 squamosal_jugal_contact / present absent,

53 Tabular / present absent,

54

Posterolateral_projection_from_lateral_margin_of_tabular_above_squamos / '/' absent present,

55 Tabular_horns / absent present,

56 Tabular_horns_shape / parallel_or_slightly_divergent

widely_divergent,

57 Sq_forms_base_of_tabular_horn / absent present,

58 Lateral_line_canal_grooves / present absent,

59 Dermal_sculpturing / circular_pits shallow_ridges_and_grooves

little_to_none tuberculate,

60 premaxilla_anterior_margin / vertical overturned,

61 Maxilla_into_external_naris / present absent,

62 Maxilla_entire_ventral_naris / absent present,

63 maxilla / longer_than_palatine shorter_than_palatine,

64 marginal_teeth_orientation / vertical turned_medially,

65 marginal_teeth_largest_anterior / absent present,

66 marginal_teeth_shape / pointed_pegs blunt_pegs large_cones,

67 Number_of_premax_teeth / '10-20' '5-9' '<5' 20_or_more,

68 Number_of_max_teeth / '30-40' '20-29' '15-19' '<15' '>40',

69 teeth_laterally_compressed / no yes,

70 Enlarged_teeth_mid_toothrow / absent present,

71 teeth / simple_points multiple_cusps,

72 Multiple_Cusp_Orientation / 'Labio-lingual' 'antero-posterior',

73 Enamel_fluting / absent present,

74 labyrinthine_in_folding / present absent,

75 jaw_articulation / posterior_to_occiput even_with_occiput

anterior_to_occiput 'far anterior ( $>20 \%$ BSL)',

76 Internal_nares / widely_separated narrowly_separated,

77 LEP / absent present, 
78 Anterior_palatine /

short_anteromedial_process_articulating_with_vomer_at_choana

long_anteromedial_process_more_medial_than_lateral palatine_absent,

79 teeth_on_pterygoid / absent present,

80 tooth_pedicely / absent present,

81 Palatal_teeth_size / larger_than_marginals equal_to_marginals

smaller_than_marginals,

82 parasphenoid / medial_of_stapes under_footplate_of_stapes,

83 interpterygoid_vaccuities / narrow_closed wide fused_at_midline,

84 Anterior_extent_of_Pterygoids / Pterygoids_contact_anteriorly

Pterygoids_exclude_vomer_from_interpterygoid_vacuity_but_excluded_from _median_contact_by_parasphenoid

pterygoids_contact_vomer_but_do_not_exclude_vomer_from_interpterygoid_vacuity

pterygoids_reach_anteriorly_only_as_far_as_palatine

pterygoids_reach_ectopterygoid_only

pterygoids_do_not_contact_lateral_palatal_bones_at_all,

85 lat_process_of_pt_into_posttemp / absent present,

86 Ectopterygoid_palatine_width / wider_than_maxilla

narrower_than_maxilla,

87 pharangeobranchial_pouches / absent present,

88 dentary / long short,

89 dentary_forms_coronoid_process / absent present,

90 surangular / normal reduced absent,

91 angular / narrow deep,

92 number_of_splenials / 210 ,

93 splenial_exposed_laterally / present absent,

94 meckelian_fossae / 2_or_more 10 ,

95 Ventral_border_of_Meckel_s_foss / splenial angular,

96 retroarticular_process_presence / absent present,

97 retroarticular_process_shape / straight hooked,

98 articulation_to_tooth_row / above equal below,

middle_of_tooth_row,

99 angular_extends_to_lat_view / posterior_tooth_row

100 number_of_coronoids / 3210 ,

101 symphysis / dentary_and_splenial dentary_alone,

102 jaw_sculpture / present absent,

103 ossified_hyoids / present absent,

104 Gill_Osteoderms / absent present_noninterdigitating

toothed_interdigitating_rakers,

105 parahyoid / absent present,

106 number_of_accessory_articulation / 012 2_or_more,

107 number_of_presacrals / 25_35 20_24 35 20,

108 vertebral_development / arches_then_centra

centra_and_arches_simultaneously,

109 caudal_processes_btw_depression / absent present,

110 trunk_intercentra / present absent, 
fused,

111 trunk_neural_arch_to_centrum / loosely_articulated sutured

112 base_of_neural_spine / equal_to_or_wider_than_haemal

smaller_than_haemal_spine,

113 height_of_neural_spines / even alternating,

114 Dermal_armor_associated_with_neural_arches / Absent Present,

115 neural_spine_shape_lat / ant_post_sides_parallel_rect

non_parallel_triangular,

116 Neural_spine_lateral_suface / smooth crenulated,

117 Pleurocentra / paired_rhachitomous

closely_approaching_ventrally fused_dominant_weight_bearing_element embolomerous,

118 haemal_arch_presence / present absent,

119 haemal_arch_fusion / loosely_articulated_intercentr

fused_to_mid_length_of_centrum,

120 haemal_arch_length / longer_than_or_equal_to_neurals

shorter_than_neurals,

121 haemal_accessory_articulations / none one two,

122 haemal_arch_shape / non_parallel_triangular

parallel_rectangular,

123 tail_termination / tapers deep_with_sudden_end,

124 Tail_length /

elongate_equal_to_or_exceeding_trunk_and_skull_length

forshortened_markedly_shorter_than_trunk,

125 trunk_arches / paired fused,

126 spinal_nerve_foramina / absent present,

127 extended_transverse_processes / absent present,

128 transverse_process / on_arch_pedicle on_centrum,

129 atlas_axis_intercentra / present absent,

130 Atlas_Anterior_centrum / same_size_as_posterior

laterally_expanded,

131 atlas_centrum / multipartite single_notochordal single_odontoid,

132 atlas_neural_arch_centrum_fusion / loosely_articulated

sutured_to_centrum fused_to_centrum,

133 atlas_parapophyses / on_centrum on_transverse_process absent,

134 atlas_neural_arch_midline_fusion / paired sutured_at_midline

fused_at_midline,

135 atlas_acessory_articulation / absent zygosphene zygantra,

136 Proatlantes / present absent,

137 second_cervical_arch / expanded_to_more_posterior

equal_to_more_posterior shorter_than_more_posterior,

138 atlas_ribs / one_pair two_pairs absent,

139 cervical_rib_distal_shape / spatulate pointed,

140 ribs_anterior_to_sacrum / short long,

141 Ribs / elongated_and_sometimes_curved straight

short_simple_rod, 
142 Costal_Process_at_rib_head / absent present, 143 number_of_sacrals / 123 , 144 sacral_parapophysis / on_centrum on_transverse_process, 145 number_pairs_of_caudal_ribs / 5_or_more 43 2_or_fewer, 146 interclavicle_posterior_stem_length / no_or_short long, 147 interclavicle_posterior_stem_breadth / wide narrow, 148 interclavicle_shape / diamond_shaped t_shaped, 149 interclavicle_anterior_plate / broad narrow, 150 interclavicle_shape_diamond / broad_diamond narrow_diamond, 151 interclavicle_anterior_fimbrati / present absent, 152 interclavicle_sculpture / present absent, 153 Cleithrum_head_dorsal_extent /

aligned_along_anterior_rim_of_scapula posterodorsally_enlarged_head_wrapping_around_dorsal_scapula,

154 Cleithrum_head_size_and_shape /

dorsally_greatly_expanded_much_wider_than_shaft simple_rod_without_or_slight_dorsal_expansion,

155 Cleithrum_ossification / ossified unossified, 156 cleithrum_overall_shape / rounded_or_pointed_dorsally t_or_y_shaped, interdigitate, 157 proximal_clavicle_blades / widely_separate articulate_medially

158 supraglenoid_foramen / present absent, 159 number_coracoid_foramina / none 12 , 160 scapulocoracoid_occification / both scapula_only absent, 161 tortion_in_humerus / absent less_than_80_degrees

more_than_80_degrees,

162 deltapectoral_crest / weak intermediate prominant, 163 Supinator_process / absent present, 164 humerus_length / long_4_trunk_centra short, 165 radius_humerus / 0.70 .5 0.7 0.5, 166 olecranon_process / unossified ossified, 167 carpals / fully_or_partially_ossified unossified, 168 basale_commune / absent present, 169 number_digits_manus / 543 '>5', 170 pelvis / fused sutured poorly_ossified, 171 Anteriorly_inclined_ilium / absent present, 172 illiac_blade / 2_dorsal_processes narrowly_bifurcate

single_blade,

173 internal_trochanter_articulatio / disctinct continuous, 174 femoral_shaft / robust slender, 175 femur / long short, 176 tarsals / ossified unossified, 177 elongate_tibiale_and_fibulare / absent present, 178 number_of_distal_tarsals / 6 5_or_fewer, 179 astragalus / absent present, 
180 number_of_digits_pes / 5 4_or_less '>5',

181 dorsal_margin_of_splenial_only_contacts_first_coronoid / absent

present,

182 postparietal_lappet / mostly_exposed_posteriorly

equal_posteriorly_and_dorsally mostly_exposed_dorsally,

183 cheek_emargination / absent present,

184 Parietal_anterior_waisting / absent present,

185 Parietal_width_relative_to_frontal / greater equal_or_less,

186 Trabecula_cranii / 'Without significant median fusion posterior

to solum nasi (platytrabic)' 'fused medially posterior to solum nasi to form elongate trabecula communis (tropitrabic)',

187 Dorsal_trabeculae /

dorsal_trabeculae_provide_dorsolateral_bridge_between_sphenoid_region_

and_nasal_capsule 'dorsal trabeculae absent or incomplete, no dosolateal bridge between sphenoid region and nasal capsule',

188 Ossification_between_optic_foramen_and_pila_antotica /

ossification_complete_between_optic_foramen_and_pila_antotica

pila_metoptica_and_associated_cartilaginous_taeniae_unossified,

189 Ossification_within_columella_ethmoidalis / absent present,

190 Path_of_profundus_branch_of_trigeminal_nerve /

enclosed_in_lateral_wall_of_sphenoid_region_of_braincase_and_exits_sep

arately_from_maxillomandibular_branch_via_series_of_small_foramina 'extramural, exits antotic fissure with other branches of trigeminal', widely_separate,

191 Foramina_for_optic_nerve_and_trigeminal_nerve / confluent

192 Lateral_head_vein / No_distinct_foramen_for_lateral_head_vein

Distinct_foramen_within_the_antotic_fissure_serving_the_lateral_head_v ein,

193 Anterior_extent_of_cultriform_process_of_parasphenoid /

cultriform_process_extends_to_anterior_margin_of_sphenethmoid

cultriform_process_extends_far_anterior_to_sphenethmoid

cultriform_process_does_not_reach_anterior_margin_of_sphenethmoid,

194 Olfactory_bulbs / narrow 'endocasts swollen, leaving

considerable impressions in lateral and ventral wall of sphenoid region and in ventral surface of frontal',

195 Flange_from_skull_roof_articulating_with_sphenethmoid / absent

present_on_frontal_and_parietal present_on_frontal_only,

196 'Descending lamina of parietal invades medial orbital wall

between "pleurosphenoid" and "sphenethmoid" elements' / no yes,

197 Foramen_for_oculomotor_nerve /

exits_braincase_far_dorsal_to_foramen_for_optic_nerve

exits_braincase_at_or_below_optic_nerve,

198 Intermaxillary_fossa / present absent,

199 Intermaxillary_fossa / paired unpaired,

200 Sphenethmoid_forms_interorbital_septum / no yes,

201 Anterior_extent_of_cultriform_process_along_palate /

cultriform_process_extends_anteriorly_to_level_of_posterior_margin_of_choana 
'cultriform process dramatically shortened, barely reaching the level of the posterior margin of the orbit',

202

Sutural_contact_between_cultriform_process_of_parasphenoid_and_vomer / no yes, 203

Lateral_wall_of_the_nasal_capsule_underplated_by_lateral_processes_of_/ '/' no yes, 204 Cultriform_process_vaulted_high_above_palatal_surface / no yes, 205 Posterior_extent_of_parasphenoid_beneath_braincase /

floors_sphenoid_region_only floors_sphenoid_and_otic_region 'floors sphenoid, otic, and occipital regions',

206 Basal_tubera / 'present, with significant endochondral contribution' 'present, with contribution of parasphenoid only' absent, 207 Path_of_common_internal_carotid_artery / 'does not run

alongside braincase, enters braincase directly in region of sella turcica' 'follows vidian sulcus along posterior surface of basal plate of parasphenoid, enters parasphenoid via vidian canal in basal plate of parasphenoid, divides into cerebral and palatal branches after entering parasphenoid' 'follows vidian sulcus along posterior surface of basal plate of parasphenoid or lateral wall of braincase, divides into cerebral and palatal branches prior to entering the skull',

208 Bucohypophyseal_foramen_in_parasphenoid / open absent,

209 Morphology_of_pila_antotica / 'pila antotica is a thin, broad sheet' pila_antotica_is_a_robust_dorsoventral_pillar_bracing_the_skull_roof_a gainst_the_palate,

210 Basicranial_fissure / present absent,

211 Location_of_vidian_sulcus / along_ventral_surface_of_braincase along_lateral_surface_of_braincase,

212 Basipterygoid_joint /

epipterygoid_comprises_entire_conus_recessus

substantial_contribution_to_conus_recessus_by_pterygoid

conus_recessus_comprised_entirely_of_pterygoid_without_epipterygoid_pa

rticipation

pterygoid_and_parasphenoid_broadly_sutured_without_development_of_a_co

nus_recessus,

213 Hypophyseal_fossa / single_unpaired_sulcus

pairedsulci_divided_medially_by_ridge_originating_on_dorsum_sellae,

214 Bone_flanking_the_dorsum_sellae /

consurrent_with_fully_ossified_lateral_skull_roof 'subparallel with sagittal plane

("pleurosphenoid")' 'strongly oblique to or perpendicular to sagittal plane

("laterosphenoid")' restricted_to_dorsum_sellae_only,

215 Basal_plate_of_parasphenoid / 'roughly quadrangular, basipterygoid articulations narrowly spaced' 'rectangular laterally, anteroposteriorly narrow, basipterygoid articulations distant',

216 Sphenethmoid / ossified unossified,

217 Ossification_within_the_synotic_tectum /

synotic_tectum_massively_coossified_with_otic_capsules

supraoccipital_paired_at_some_point_in_ontogeny 
supraoccipital_unpaired_throughout_ontogeny 'no supraoccipital bone; synotic tectum invaded by dorsal processes of exoccipitals',

218 Median_ascending_process_of_supraoccipital / absent present,

219 Lateral_ascending_processses_of_the_supraoccipital / absent

present,

220 Margin_of_fenestra_vestibuli / 'parasphenoid excluded by

neurocranial elements (basisphenoid and basioccipital)'

parasphenoid_contributes_to_anteroventral_margin_of_fenestra_vestibuli

parasphenoid_floors_entire_fenestra_vestibuli

Ossification_of_otic_capsule_surrounds_entire_fenestra_vestibuli,

221 Crista_intervestibulara / crista_intervestibularis_absent

crista_intervestibularis_present,

222 Morphology_of_crista_parotica / 'crista parotica meets

exoccipitals only, forming lateral wall of posttemporal fossa but not bracing against dermal skull'

crista_parotica_drawn_out_dorsolaterally_into_paroccipital_process_tha

t_contacts_the_tabular 'crista parotica drawn out laterally into paroccipital process that contacts the cheek and/or suspensorium',

223 Dorsal_process_of_stapes / absent present,

224 Facets_on_dorsal_surface_of_supraoccipital / absent present,

225 Otoccipital_fissure / present absent,

226 Crista_parotica / Descends_posteriorly

Horizontal_along_the_extent_of_its_length,

227 Position_of_quadrate_with_respect_to_otic_capsules /

quadrates_ventral_and_lateral_to_otic_capsules

quadrates_mostly_lateral_to_and_greater_or_equal_to_twice_the_width_of

_the_otic_capsules quadrates_mostly_ventral_to_otic_capsules

quadrates_approaching_or_abutting_lateral_wall_of_otic_capsules,

228 Size_of_otic_capsuiles / 'otic capsules comprise less than $2 / 3$ the width of otoccipital region' 'otic capsules comprise greater than $2 / 3$ total width of otoccipital region',

229 Otic_trough / absent present,

230 Articulation_between_the_epipterygoid_and_prootic / none elongate_facet_on_anterior_surface_of_prootic_for_articulation_of_epip terygoid,

231 Opisthotic_obscures_occipital_in_lateral_view / no yes,

232 'Fenestra vestibularis at end of broad, winglike lateral extension of the otic capsule' / no yes,

233 Cristae_in_otoccipital_region /

comprised_primarily_of_ascending_flanges_from_braincase

comprisd_primarily_of_descending_flanges_from_skull_roof,

234

Opisthotic_excluded_from_the_occipital_surface_by_tabular_process_of_t / '/' no yes,

235 Insertion_of_epaxial_musculature_on_occiput /

deep_within_temporal_fossae 'in broad, shallow fossae along occipital surface of postparietals', 
236 Foramen_for_internal_jugular_vein /

between_supraoccipital_and_exoccipital between_opisthotic_and_exoccipital

through_exoccipital Posterior_notch_of_fenestra_vestibuli,

237 Foramina_for_hypoglossal_nerve / multiple single none,

238 Occipital_condyle_shape / round 'U-shaped' paired,

239

Ventral_process_of_exoccipital_reaches_basipterygoid_joint_along_palat / '/' absent present,

240 Occipital_condyle_shape / Concave Convex,

241 Columella_of_stapes / perforate imperforate,

242 Orientation_of_stapes / 'Dorsal, towards tabular or otic notch'

'anteroventral, towards quadrate',

243 Stapedial_footplate_shape / oval round palmate,

244 Dorsal_sinus_between_synotic_tectum_and_skull_roof / absent

present,

245 Ossification_within_septum_internasale / absent 'present, sphenethmoid' 'present, mesethmoid',

246 Ossification_of_septum_internasale_invades_nasal_tectum / absent present,

247 Insertion_of_hypaxial_musculature / sphenoid otic basioccipital, 248

Prootic_supported_by_pedicel_extending_from_basisphenoid_lateral_to_pr / '/' no yes,

249

Position_of_pineal_foramen_with_respect_to_hypophyseal_foramen / anterior_to approximately_the_same far_posterior_to,

250 Pineal_fossa /

well_anterior_to_posterior_margin_of_cerebral_fossa

at_or_behind_posterior_margin_of_cerebral_fossa,

251 Median_wall_of_otic_capsule / completely_unossified

ossification_of_opisthotic ossification_of_supraoccipital_and_basioccipital,

252 Conical_recess_in_basioccipital / absent present,

253 Semicircular_canals / separated_from_utricular_region_by_bone

not_separated_from_utricular_region_by_bone,

254 Basioccipital /

Robust_ossification_ventral_to_foramen_magnum_present absent, 255

Accessory_articulation_processes_with_proatlantal_facet_on_exoccipital / '/' absent prominent,

no yes,

256 Exoccipital_proatlantal_facets_incorporated_into_occipital_joint /

257 Anterior_tectal / anterior_tectal_present absent,

258 'Ectopterygoid/palatine exposure' /

more_or_less_confined_to_tooth_row

broad_mesial_exposure_additional_to_tooth_row reduced_to_thin_sliver,

259 Ectopterygoid / Present Absent, 
260 Ectopterygoid_as_long_or_longer_than_palatines / yes no,

261 Ectopterygoid_reaches_subtemporal_fossa / no yes,

262 Frontal / absent present,

263 Jugal / does_not_extend_anterior_to_orbit

extends_anterior_to_orbit,

264 Lateral_rostral_present / yes no,

265 Maxilla_makes_interdigitating_suture_with_vomer / no yes,

266 Maxilla_external_contact_with_premaxilla /

narrow_contact_point_not_interdigitated interdigitating_suture,

267 Maxilla_extends_behind_level_of_posterior_margin_of_orbit / yes

no,

268 Median_rostral / single paired absent,

269 Opercular / present absent,

270 Prefrontal / 'twice as long as broad, or less'

three_times_as_long_as_broad,

271 Prefrontal / transverse_anterior_suture_with_tectal tapers_to_a_point_anteriorly,

272 Preopercular / present absent,

273 Pterygoid_quadrate_ramus_margin_in_subtemporal_vacuity /

concave with_some_convex_component,

274 'Vomers separated by parasphenoid > half length' / yes no,

275 Vomers / as_broad_as_long_or_broader

about_twice_as_long_as_broad_or_longer,

276 Basipterygoid_process /

not_strongly_projecting_with_concave_anterior_face

strongly_projecting_with_flat_anterior_face,

277 Ethmoid / fully_ossified partly_or_wholly_unossified,

278 Hypophyseal_region /

solid_side_wall_pierced_by_small_foramina_for_pituitary_vein_and_other_vessels

single_large_foramen,

279

Lateral_commissure_of_otic_capsule_bearing_hyomandibular_facets / present absent,

280 Parasphenoid / does_not_overlap_basioccipital

overlaps_basioccipital,

281 Denticulate_field_of_parasphenoid / present absent,

282 Sphenoid / 'fully ossified, terminating posteriorly in intracranial

joint or fused to otoccipital' separated_from_otoccipital_by_unossified_gap,

283 Ectopterygoid_fang_pairs / present absent,

284 'Ectopterygoid row (3+) of smaller teeth' / present absent,

285 'Ectopterygoid/palatine shagreen field' / absent present,

286 Palatine_row_of_smaller_teeth / present absent,

287 'Pterygoid shagreen (palatine ramus)' / dense

organized_radiating_rows_of_denticles disorganized_patches_or_absent, 
288 Dentition_of_transverse_flange_of_pterygoid /

Denticle_field_indistinct_from_palatine_denticle_field distinct_raised_denticle_field organized_tooth_row absent,

289 Premaxillary_tooth_proportions / all_approximately_same_size posteriormost_teeth_at_least_twice_height_of_anteriomost_teeth

Anteriormost_teeth_largest,

290 Vomerine_fang_pairs / present absent,

291

Vomerine_fang_pairs_noticeably_smaller_than_other_palatal_fang_pairs / no yes, 292

Vomer_anterior_wall_forming_posterior_margin_of_palatal_fossa_bears_to / '/' yes no,

293 Vomerine_row_of_small_teeth / present absent,

294 Vomerine_shagreen_field / absent present,

295 Adductor_fossa / faces_dorsally faces_medially,

296 Adductor_crest / absent 'peak anterior to adductor fossa, dorsal margin of fossa concave' 'peak above anterior part of adductor fossa, dorsal margin of fossa convex',

297 'Angular-prearticular contact' /

prearticular_contacts_angular_edge_to_edge absent

medial_lamina_of_angular_sutures_with_prearticular,

298 'Coronoid (anterior) contacts splenial' / no yes,

299

Prearticular_extends_between_infradentaries_and_middle_coronoid / Yes No,

300 'Coronoid (middle) contacts postsplenial' / no yes,

301 'Coronoid (posterior) posterodorsal process' / no yes,

302 'Coronoid (posterior) posterodorsal process visible in lateral view' / no yes,

303 'Dentary external to angular \& surangular, with chamfered ventral edge and no interdigitations' / no yes,

304 Dentary_ventral_edge / smooth_continuous_line 'abruptly tapering or "stepped" margin',

305

Dentary_suture_with_splenial_\&_postsplenial_marked_by_deep_furrow / no yes,

306 Mandibular_sensory_canal / present absent,

307 Mandibular_canal_exposure / 'entirely enclosed, opens through

lines of pores' 'postly enclosed, short sections of open grooves' 'mostly open

grooves, short sections opening through pores' entirely_open,

308 'Oral sulcus/surangular pit line of mandible' / present absent,

309 Meckelian_bone_floors_precoronoid_sulcus / yes no,

310 Meckelian_bone_ossified_in_middle_part_of_jaw / yes

little_or_no_ossification,

311 Meckelian_bone_exposure_in_middle_part_of_jaw /

depth_much_less_than_prearticular depth_similar_to_prearticular,

312 'Meckelian foramina/fenestrae, dorsal margins' /

Meckelian_bone prearticular infradentary, 
313 'Meckelian foramina/fenestrae height' /

much_lower_than_adjacent_prearticular

equal_to_or_greater_than_depth_of_adjacent_prearticular,

314 Parasymphyseal_lateral_foramen_present / no yes,

315 Parasymphyseal_mesial_foramen_present / no yes,

316 Postsplenial_with_mesial_lamina / no small 'expanded, contacting precoronoid',

317 Postsplenial_pit_line_present / yes no,

318 Postsplenial_suture_with_prearticular_present / no yes,

319 Prearticular_sutures_with_surangular / no yes,

320 Medial_lamina_of_splenial / absent present,

321 Prearticular_with_longitudinal_ridge_below_coronoids / no yes,

322 'Prearticular with mesially-projecting flange on dorsal edge along posterior border of adductor fossa' / no yes,

323 Prearticular_centre_of_radiation_of_striations /

level_with_posterior_end_of_posterior_coronoid

level_with_middle_of_adductor_fossa level_with_posterior_end_of_adductor_fossa,

324 Splenial_has_free_ventral_flange / yes no,

325 'Splenial, rearmost' / absent,

326 'Coronoids: at least one has fang pair recognizable because at least twice the height of coronoid teeth ' / yes no,

327 ' Coronoids : at least one has fangs recognizable because

noticeable mesial to vertical lamina of bone and to all other teeth ' / yes no,

328 ' Coronoids : at least one has organized tooth row ' / yes no,

329 ' Coronoids : at least one carries shagreen ' / no yes,

330 ' Coronoids : size of teeth ( excluding fangs ) on anterior and

middle coronoids relative to dentary tooth size ' / about_the_same

half_the_height_or_less,

331 Dentary_tooth_row / homodont markedly_heterodont,

332

Dentary_with_parasymphyseal_fangs_internal_to_marginal_tooth_row / yes no,

333 Dentary_teeth / same_size_as_maxillary_teeth

larger_than_maxillary_teeth smaller_than_maxillary_teeth,

334

Dentary_with_a_row_of_very_small_teeth_or_denticles_lateral_to_tooth_r / '/' yes no,

335 Parasymphyseal_tooth_plate / present absent,

336 Parasymphyseal_plate_dentition /

shagreen_or_irregular_tooth_field

organied_dentition_aligned_parallel_to_jaw_margin no_dentition,

337 Parasymphyseal_plate_has_fang_pair / no yes,

338 Parasymphyseal_plate_has_tooth_row / no

short_tooth_row_separated_from_coronoid_row_by_diastema

long_tooth_row_reaching_coronoid, 
339 Prearticular_shagreen_field_distribution /

gradually_decreasing_from_dorsal_to_ventral 'well-defined dorsal longitudinal band' scattered_patches_or_absent,

340 Anterior_palatal_fenestra / single_double absent,

341 Dorsal_fontanelle_on_snout / absent present,

342 Interpterygoid_vacuities / absent at_least_2x_wider_than_long

2x_longer_than_wide,

343 Intracranial_joint / present_in_dermal_skull_roof

absent_in_dermal_skull_roof,

344 Nature_of_dermal_ornament / tuberculate

fairly_regular_pit_and_ridge irregular absent_or_almost_absent,

345 'Nature of ornament: starbursts of radiating ornament on at least some bones' / no yes,

346 Anocleithrum / oblong_with_distinct_anterior_overlap_area 'drop- shaped with no anterior overlap area' absent,

347 Cleithrum / ornamented not_ornamented,

348 Cleithrum_postbranchial_lamina / present absent,

349 Digits / absent present,

350 Humerus / narrow_tapering_entepicondyle 'square or

parallelogram-shaped entepicondyle',

351 'Ilium_iliac canal' / absent present,

352 'Ilium_posterior process' / oriented_posterodorsally oriented_approximately_horizontally_posteriorly,

353 Interclavicle / small_and_concealed_or_absent large_and_exposed,

354 Interclavicle_shape / ovoid kite_shaped with_posterior_stalk,

355 Lepidotrichia_in_paired_appendages / present absent,

356 Posttemporal_and_supracleithrum / present absent,

357 Radius_and_ulna / radius_much_longer_than_ulna approximately_equal_in_length,

358 'Ribs_trunk' / all_cylindrical

some_or_all_bear_flanges_from_posterior_margin_which_narrow_distally

some_or_all_flare_distally,

359 Scapular_blade / absent small_with_narrow_top

large_with_broad_top,

360 Scapulocoracoid / small_and_tripodal large_plate,

361 Subscapular_fossa / broad_and_shallow

deeply_impressed_posteriorly,

362 Squamation / 'complete body covering of scales_all similar' ventral_armour_of_gastralia,

363 Pectoral_process / absent present,

364 Proximal_limb_of_oblique_ridge / 'present_separated from

anterior margin of humerus by prepectoral space' 'absent_replaced by deltopectoral crest',

365 Latissimus_dorsi_attachment / diffuse_ridged_area

distinct_process, 
366 Foramina_piercing_oblique_ventral_ridge / many

one_moderately_large_foramen_in_addition_to_entepicondylar_foramen

'entepicondylar foramen is the only large opening_other foramina ar epinpricks or absent' none,

367 'Humerus with well-developed anterior plate' / yes no,

368 Subclavicular_ossifications / Absent Sometimes_present,

369 Radial_capitulum / approximately_same_size_as_ulnar_facet

'greatly enlarged and rounded $>2 x$ size of ulnar facet, ' 370

Lissamphibian_inner_ear '/' no yes,

370 lissamphibian_inner_ear ;

MATRIX

Archeria_crassidisca

02000000100100001001000?01000011000000001---01000000010--

01000000000100-010000002100000000100000-

010001???2?000000003000000010010000020112010000????????????????1211???

0?000????????00010100101?001001-

00000100101?000000001?1100020000000001000?0?00-101??0000-

$100001110012111111 ? 1111110 ? 0 ? ? 000 ? ? ? ? ? 1221101101003111-$

11001111111?121111-0(0 1)01000021001212111100111110211111120000

Crassigyrinus_scoticus

0100001010000000000100101000000110000000000000001000010--0001-

000011000-000000000100000000000010-

010001???0?000?0000?00?????0?0100?000??1??1000??000001000000???1211000

0?20000100???0?0101?0?0???????00??0000001?0-

???00???1??0?0?000000??0??000??????0??????0?-

$1000010111021011010 ? ? ? ? 10 ? 0000000000000020000001003111 ? 100001001 ? ?$

1121111?101101101110121?1111??111110???11111000?

Acanthostega_gunnari

000100010000?000000000000000000000000000000000000000010--

00000000000000-000000000000000000000000-

$0100000000 ? 0000000000000000\{0$

1\}000000000000000000000000000000000000000000030000100000200000?0-

$100 ? 000000000000000000 ? ? 00000000 ? 000001 ? 00000000000000000 ? 00 ? ? ? ? 000$

$00001111000111 ? 001011110001000001000000011000 ? 1000111101001010011$ 0000110010001011111101111101100111102010111120000

Eusthenopteron_foordi 01000000000100010100--0-11010-00----.-00000-0001000000--0301-000000000-001000000-01?00000000?1001000020???????????????????????????????????????????????????????????????????????

??????????????????????1???????????????????0-???????????????????????0?????0??-

$000000000000000000 ? 00000000000000000000010000 ? 0000000000000000000$ 0?0000000010000000000000000000?00000000?000100??0

Ichthyostega_spp. $\quad 01010001100020000000000$ 1100000110000000000000001000000--00100000012010000000002000?00000100-(0 1)0-

01000????0?00000000000100011000??????????0000010110111010001??0120101 
$003100 ? 1100-$

021?010????0????00?01?000002?100?0?00????0000?10000000000??0001?10??0?? ???0??-0100111?1000111001011?1000(0 1)000231001000001000?1000?1100000101001?000011001002101112000111?1 $01111121111011 ? 10010000$

Panderichthys_rhombolepis

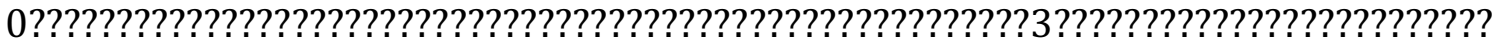

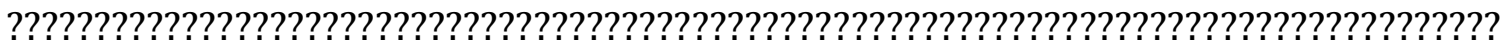

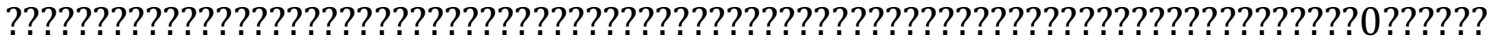
???0000?1000000000000000000000000000000000000000?00000000000000000 000?000000000000000000010000000??0?000101?0000?0??0

Pederpes_finneyae 0100000010012000100?0??0000?011110100000000000??1000000-01?000000?2010-000000000100?000001?0??001??01???0?000?00000???????11100000??0?1??00000?00000?0100010?11200101

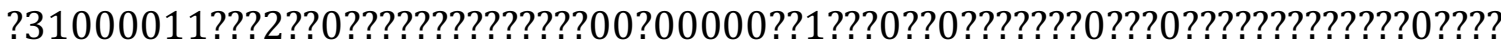

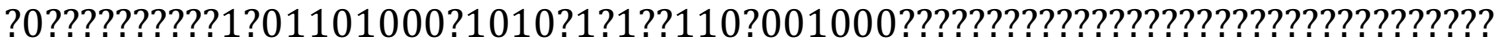

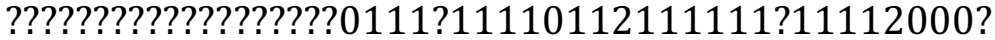

Tiktaalik_rosaea 01010010100120000001100?1100000110100000000000001000000-03000000000000-0000000001010000000000(0 1)0-0?000000?2------------?????????????????010--????????1000???002010000-000???????1?0101001010200000000100000000-0?0000----?-?0?10000000????0?---0-$001 ? ? ? ? 00-$

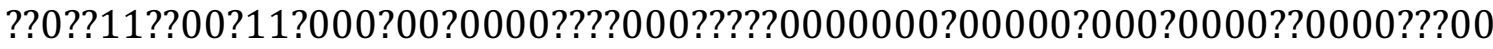
00000?10?0?0?0010000000??0?0?0?010?00000??0

Ventastega_curonica 0?000000000020000011000?110001011010000000000??01000000-00001000011000-00000000010??00000000010-

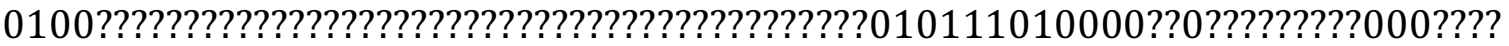

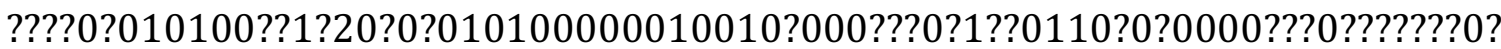

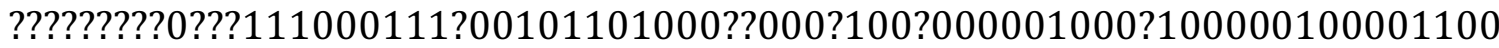
$00110000010010001010210101111110 ? 0011 ? 1 ? ? 010 ? ? ? ? ? ? ? ? 0$

Whatcheeria_deltae 0000000010002000100000010000011110000000000100001000000-01000000011010-00000000110??00000100?(0 1)0000001???1?000?00001???????1?00??????????00000?00000000100000101200000 03100?1100?0?1?010????????????00???000????0????010-0 ?10?01000?00000???0???????0????????$10000111 ? 00210100111 ? ? 11 ? ? 0000001001101001001000002010000000100110$ $10211001002101011 ? 00131 ? 1011011211 ? 121 ? ? 1112000 ?$

Ymeria_denticulata

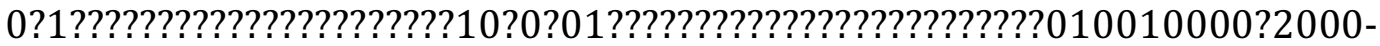
$000000001 ? 00 ? 00000000 ? 10-$

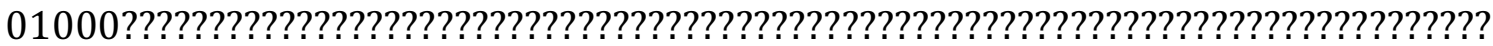

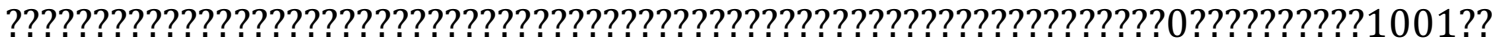




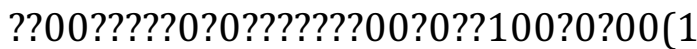

2)?000?100021?0000??010??0?00?01000000101110?0?31????????????????????????

??

Proterogyrinus_scheelei $\quad 010000\{01\} 0\{0$

1\}001?0001000000?0000000000000000000001000000010--00000000000000000000000000000000000?00-00\{0 1

2\}1000000?00000000300001?0100000000000000?00000000001000000020100? $1010010111000100 ? 00101 ? 101 ? 11000 ? 1-11000100 ? ? 00003000--$

$1 ? 00 ? 0020000000001000 ? 0 ? 00 ? 10 ? ? ? ? ? 00-$

10000101001210111111???11?0100000?????1221????0101?111?11001111?11?12 ???1?00011---2200121211110011111021?11112000?

Balanerpeton_woodi 000000101001000000000?110000000000000000000?10000000000-10000000000000-000000000011100000100000$0001010001 ? 000000000000000 ? 00000000 ? 000020010000000000000000 ? ? 0220$ 01100110211000100?0000?????????????????00??????????00??????0????????????1?00 ?000???1??????00-

$110011011 ? 02101111011 ? ? 101011100000111112111 ? ? 0101 ? 111 ? 20002110100$ ?101111?00111?--22021112111100111112?1?11112100?

Dendrerpeton_acadianum 000000001001000000000?100000000000000000000?00000000000-10000000000000-000000000011000000001110$00 ? 1010001 ? 00000000000001 ? ? 10000000 ? 00 ? 0 ? 0010000000000000000010220$ 011001002?00?0??0000001??01????00?0??01001221?10013013--2010$110000000001 ? 00000000 ? 10 ? ? 1 ? 100-10001101 ? 102101111111111(0$

1) $10111000011111(1$

2)21??110101?1?1?11??1111??0?111111?0?11????2202111211110011111021?11 1121001

Pantylus_cordatus [00011-0120010000100000000101011001-00000000010110000-0--10100000223010-0111000011000000100011\{0 1\}102020000001?01101010200000011000012202011101000?01111$101000201022002100110211000110 ? 10001100111212011-$ 100001221011101002112121?113000000001110011011?21??211011111-111001211110111111111--100321-1111221??110101-11110001111100?111100111011---2202111211110012111021?-11021000

Cardiocephalus_peabodyi 32011-012001100010000?001101121001-$00010000210\{01\} 10000-0--12100 ? 102231110113 ? 0 ? ? 0 ? ? ? ? ? 0 ? 0111 ? 1 ? ? 0-$ 20??110002??01?00102???????100001220?0110000010????????1000?0-

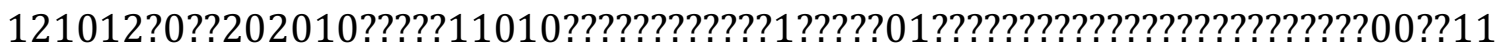
?000?1??0?211?2110111??????????????????????????????????????????????????????????? ??????????????????????????????????????????????????10??

Cardiocephalus_sternbergi 3?011-01200111???000000001010210?1-00010000210(0 1)10000-0--12100010223100-11300010200000001?101??0-

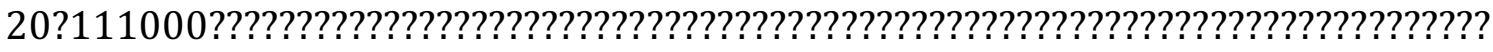
??1010????????????1-

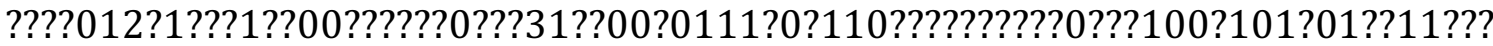


?1???11?10002?01-?00112?????01?1-1?1-??????10??0???11???010?1--??02?30?????????????????????????

Pariotichus_brachyops 3?011-01200110???0000???01?????0?1-$00010000010110000-0--12 ? ? ? ? 102 ? 3 ? 00-$

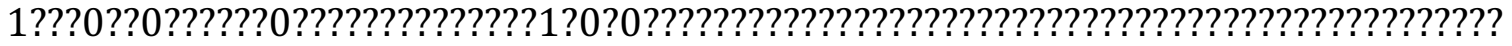

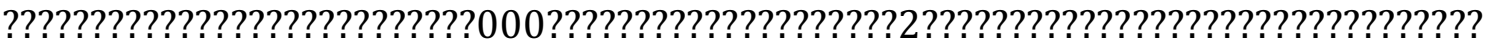

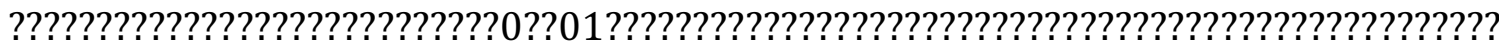
?????????????????????3-?????????????????????????

OMNH_53519 3?011-0120011????00000?0????01?001--00100000100100?0-0--12???0102230000120000020000000101011110200111000????????????????????????2???????????????

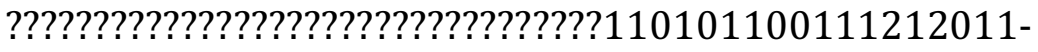
$000001221010101002102120110310000-$ 011100001100?210?2110111100010100121111111111111110002301-10011210100101-111-10000110100-1?11001010?1---2202021????????????????????????0

FMNH_UR_2296 3?011-0120011?0?1000000?1101011001--0010000010010000-0--12100010223000012000002000000010101??00200111000?????????????????????????????????????????

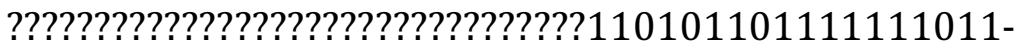
$0000012210111010021121 ? 011 ? 310000-$ 011100001100?210?211011110001010012111111111111111000?301-10011210100101-111-10000110100-1?11001010?1---2202021????????????????????????0

'Euryodus dalyae (composite)'3?011-0120011?0?1000000?1101011001--0010000010010000-0--12100010223000012000002000000010101??00200111000???02000102???????1000012202011???

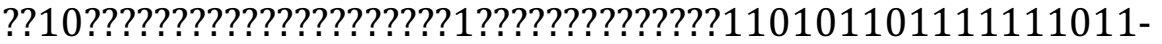
$0000012210111010021121 ? 011 ? 310000-$ 011100001100?210?211011110001010012111111111111111000?301-10011210100101-111-10000110100-1?11001010?1---2202021????????????????????????0

Euryodus_primus 3?011-0120011000000000001101111001--0010000010110000-0--12100010223010112000002000000010101??1020?111000???02000102???????1000??220201???00 $0 ? ? ? 0111-$

11?????1012101210??1020100?????1000???????????????00?012?1???1?????????????

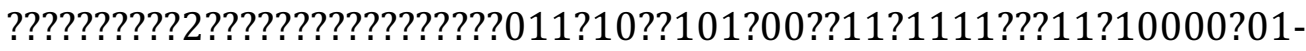
???112?????01?1-1?1-???????0??0-1??????010?1--??02?21???11?012111021??11031000

Proxilodon_bonneri 3?011-01200111001000001?21010110?1--001000001011?0?0-0--1210001001?0?0012?0??0??????001?1?1????10??1?????1????????????????????????????????????????????

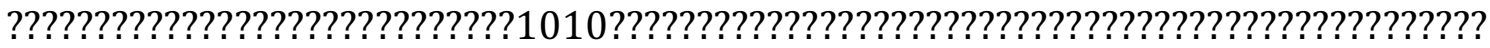

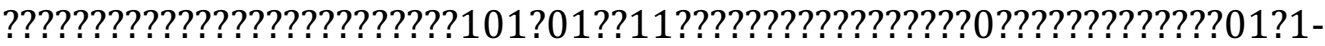

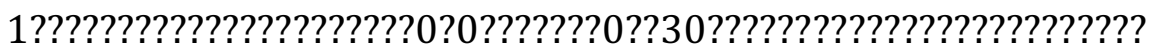

Huskerpeton_englehorni 3?011-012001110010000?002101011001-00010000210110000-0--121000100?201001200000??010?0011101111010211???????????????????????????????????????????? 


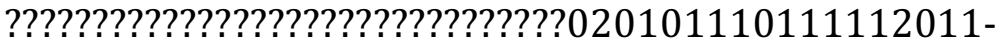
$00000122101110100201212 ? 011310000-$ 0011100???00?21??2110111101010100121011111111111110002301-1?01220-100101-111-1000-1-0100-121100101011---2202130211????12?1??21???????0?0

Pelodosotis_elongatum 03011-012001100110000?001001031001-00000000010110010-0--1211-010012010-012?000021010000\{0 1\}0111111020?1100002??01?10102???????10001121?10110010010?011111100011-1220021???00201000????1110?100111001011$000002121011 ? ? 1102 ? ? 2 ? 2111 ? 3 ? 0 ? 000011110011210 ? 21 ? ? 2 ? 00111101010100$ 121011111111110010100301-111122????00101-111-10??1110100-1??????0?011--220212021111??12111021?-11021000

Nannaroter_mckinzei 3?011-01200110???0000?0011010?00?1-0001000001011?0?0-0--12100010113010012?00002?01000010101??1020201??????????????????????????????????????????????

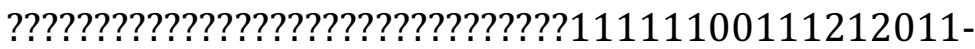
$000002121010 ? 0110 ? ? ? 2 ? ? ? ? 1 ? 3 ? ? 000-$ 01???0?????0??1????10111101???????????????+11110010100301-1?11221-??????1111-1000-1-0100-121111111011---2202120?????????????????????????

Micraroter_erythrogeios 03011-012001110110000?000001030001-$00010000210\{01\}\{01\} 0010-0--12100010113010-$ $012000002000000010101 ? ? 102021100000 ? 00101010200001001000012200011$ 000002?????????1000?0-1??0??????102110??????11101100111001011$0000021210111 ? 1002 ? 12 ? 211113000000011110001110 ? 21 ? ? 211011 ? ? 0 ? ? ? ? ? ? ? ? ?$ ??????????????????0301-1?11221-??????1-111-100?-1-0100-1211?1?01011--2202130??????????1?????-?????0?0

Eocaecilia_micropodia 3301?-0?-1----0000000?011101121001--00011--0?011100?----120000000000010013000011013\{0 1\}0?0--????101?3?110002?002?00-02?????0111010122201121000013??????????????0220121002?0?011001?1?-000001111021001100110221111?203003--30?011?010-00--12?20001001?10??1?010?111-101100211111001111-0110000001-10011------01-1-1----000--------110000101010222011202--11??0-111021?-01?21??1

Carrolla_craddocki 3?021-1-2?0100???01000?0210?130001----00?002-20---01----1211-010123001101300000-

1120001100111110103111???????????????????????????????????????????????????????? ?????????????????????--00011111110000?11000022?111?101100?12?21111310000-011120111001?21??100111111010100121011101111111111012301-110122-----0101-111-1000-??100?11-----01011---2202130??????????1?????????????0

Quasicaecilia_texana 3?121-1-1001001--01000??210?220001-$000000012-20---0100--$

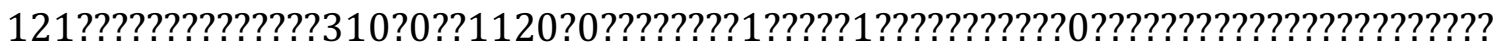

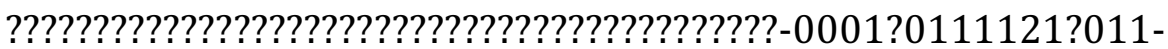
100002221110??110???2???11?3?0000-01111001??0212101-11011?11-101 ???21011???1111?11110?23??????????????????????????????????????????????????? 021302?????????1????????????? 
Llistrofus_pricei 3?011-012001100110100010200?020001----1000121000011000--12?00000111000-

0111000021010000110111110102111???1?011?00002???????10000?2200??????0

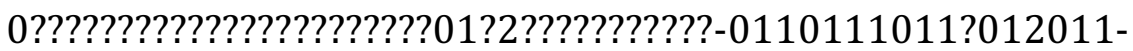
$000002221011101002002 ? ? 0 ? 1 ? 010000 ? 00111001 ? 100-$ 21??2??01?1101?10100121111111111110110100301-1111221----0101-1111000-1-0100-101100111011---2202121?????????1110????????????

Aletrimyti_gaskillae 32011-012001111--00000001102121101----10000210?1011000--12100010013000-

012100002100000010101111020211?????????????2????????????????????????????

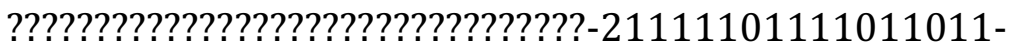
0000022210111010021121-0111310000-0111100?100021012110111101010100121011111111111110002301-1?01220--110101-1111000-1-0100-121110-11011---220213021111??12111021?-?1?21?00

Dvellecanus_carrolli 3?011-01200111???00000001102120001----1000021011011000--12100011013000-012100002100000010011110-

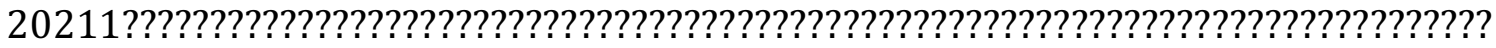
-21111100111011011-000002221011101102112120110310000-0111100?100021012110111101010100121011011111111010002301-1?01220--110101-1111000-1-0100-121110-11011---2202130??????????1?????????????0

Rhynchonkos_stovalli 3?011-012001111--00000001102210001----1000121000110000--121000100130100121000021000000100?1111020211??????????????????????????????????????????????

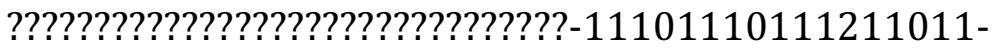
$00000222101010110211212011131000000111100 ? 1100-$ 21012110111101010100121011111111111110002301-1?01220--100101-1111000-1-0100-121110-01011---2202130??????????1?????????????0

Diabloroter_bolti 3?021-1-?????????0100???21??1300?1-----10?002-20$--? 1----12 ? ? ? 0100 ? 1000-$

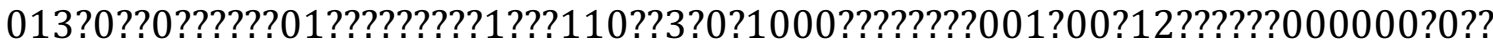

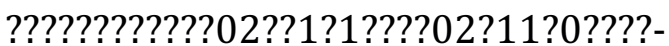

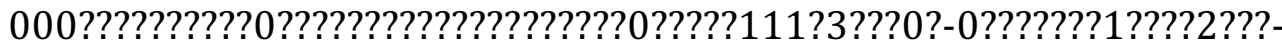

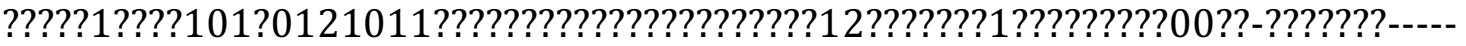
01011---??0?1302???1?0??11?021????0?100?

Jormungandr_bolti 33021-0-?00111???0000???21020300?1-000100000-20---11----12?00?000?1?00-

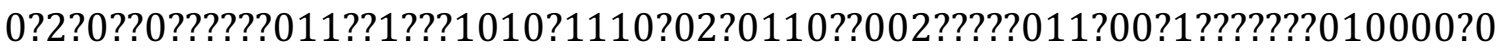

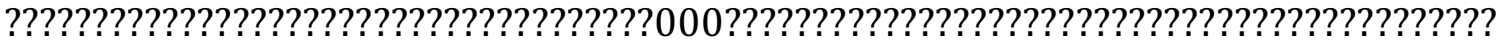

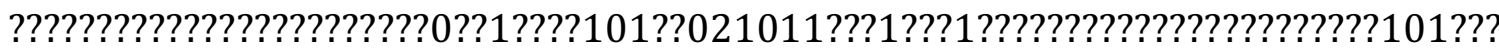
?????????????????????010?1---?????30?????????11?0????????????

Batropetes_fritschi 3?021-1-200100???01000??210?130001-----00?00220---01----1211-010123001101300000$11200011001111101031110 ? ? 3 ? 0 ? 1000 ? ? ? ? ? ? ? ? 001 ? 00 ? 12 ? ? ? ? ? ? 000000 ? 01111-$ $10 ? ? ? ? ? ? ? 02 ? ? 1 ? 1001102 ? 1100110--000 ? ? ? ? ? ? ? 0 ? ? 0 ? 1-$ ?00??22???1????100?12??111?3??000-01??2011100??2???- 
1?0111111010100121011?01111111111012301-110122----0101-111-1000-??100?11-----01011---220213021111?01211?021?11102100?

Captorhinus_laticeps 0102011-20011000101000000101031101-000000000--0---0100--11000001123010-0111001021000-00100111(0 1)101021000001?0020000021---0110000102220010010011311100110?1?101022101100000201000110-$01011111 ? ? 2010 ? 1-100002221-$ $110030021121211103000000001000101001021 ? ? 2 ? 100-1 ? 1-$ 0101001210111111111111--111221---0122-?-100101-111-1000?1?0100-12111011011---22021202-111?-12111021?-11121000

Infernovenator_steenae 33021-0100010-1--000000021011200?1-$00001--0101110-000--$

11000????????????3?0?????????01100??1110????100002?01100010200001??00001

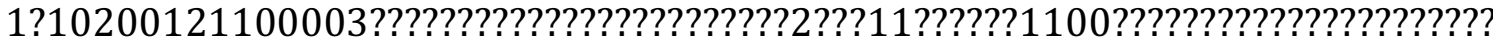
??????????10?????1,????00-

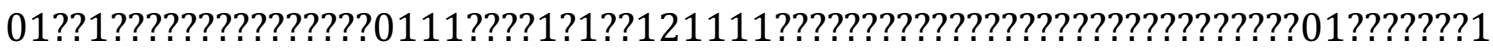
0???????????????????????????0?1302???????+11?0????????????

Brachydectes_newberryi 23021--100010-1--00000012101120001-00001---0101110-000--12000000013000-

$01310000110200011001111102031100002 ? 01100010200001010000112102001$ 211000031110-11000001001001\{0 1\}11?12021110??10?110011111110000?1000002221110101002102121111310000-011110011002?2???211011111-10100121111111111111111012301-1001220--100101-111-1000-10100?121110-01011---2200130211110012111121??11?21000

New_Molgophid(composite) 33021-0100010-1--000000021011200?1$-00001--0101110-000--$

11000????????????3?0?????????01100??1110????100002?01100010200001??00001 1?10200121100003????????????????????????2???11??????1100?????????????????????? ??????????10?????1?????00-

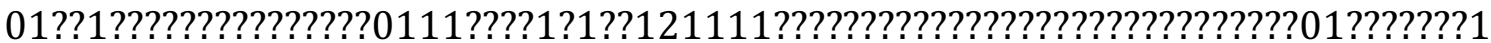
0???????????????????????????0?1302????????11,0????????????

Greererpeton_burkemorani $\quad 0200000100110000000000012100030101---$ --0000000001000000--00000000000000-000000000000000000000100$0000010002 ? 00000000000000 ? ? 10100000 ? 0000211100000-$ 010000000111011011110100201010--0?00001010?1?1000?0000000100110103003--1?10-111000000001100000000-100??0?00110011010002110101011111010000001011101221001101001011 ?(1 2)1000100100?1200011101101102111111210110011111111?111120000

Seymouria_baylorensis 0100000010010000000000000000010000100000000001000000000-00000000012010-1000000010000000000000\{0 1\}\{0 1\}-2000001001?000000\{0 1\}02000010010000000000110000010011000100100102012101000000111100? 00?00101?1011?0020?1-110001021-1110310-??1?11$100000111001010010 ? 00 ? 1 ? ? ? 1 ? ? 00-$ $11011111001211111111111101111111000111122110110101-111-$ 11001111100-111111-11211---22001102111101121110211111121000 
Limnoscelis_paludis

0101010110010000100000000000001001000000000001100010000-12100001022010-0011001010010000000101\{0 1\}0-

0010110000?000000002000000010000000000100000010011000??0100?0?0221 01010010111000110?00001?1011?0020?1-110011021-

$11103001001 ? 111102010111011000101 ? 00 ? 2 ? ? ? 1 ? 000-$

1101110111121011111111111111111221-11012200-100101-111-1100-1-0100121110-11011---2202130211110112111021?-11121000

Branchiosauridae

311100100001210000000?10100001000020???0000010000010010-$11000000010000-00\{01\} 0000\{01\} 1$ 1313010????????0-

?????020010000?00?0000?0?0000000?????0?1200200?00-

$000 ? ? 000 ? ? ? ? 20000101 ? 120211010--$

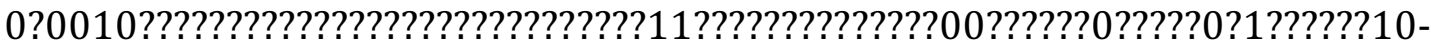

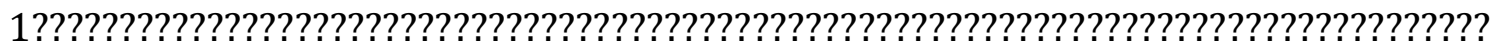

?????????????????????????310??

Micromelerpetontidae $\quad 311100100001010000100 ? 1000000\{0$

1\}000000???0000?11000010010--01000000000000-

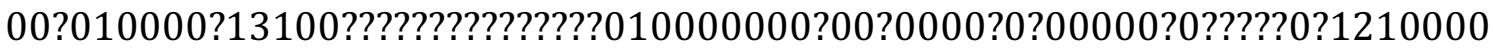

?00-000??000????20001101?120211010--

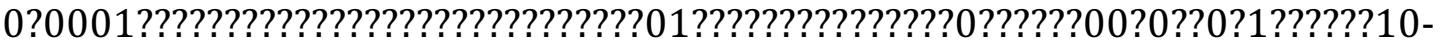

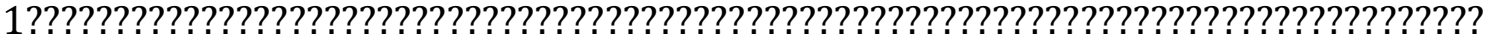

?????????????????????????310??

Tersomius_texensis $\quad 2 ? 0100\{01\} 010010\{0$

$1\} 00001101100000010000\{01\} 00010000 ? 10001000000--1100000000000\{0$

$1\} 00\{01\} 0010000 ? 131100000000\{01\} 0-$

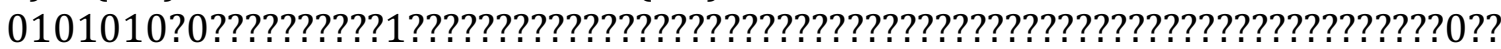

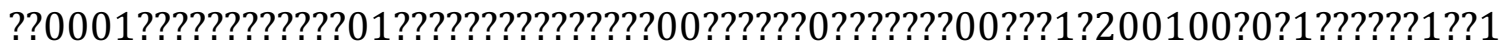

00101010000101111011111?1010100000110112111110101-111-

10002110100?10111?-010101012011111????????????????????0??

Ecolsonia_cutlerensis

0?11000110011100001001102020000000011210000000001000000--

$1000000001\{01\} 010-000010000 ? 1210000000 ? 0\{01\} 0-$

0?000?000??00010100000001011000????????????100?????????0000?010?11??0?0?

100110?0????0000?????????????????????????????0???????????????00?????100????0?1?

?????10-

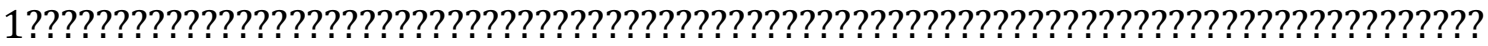

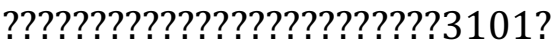

Acheloma_spp.

0?010001100??000001001?020200000000111100?0000001000000--

$10000 ? 00011010-000010000 ? 12 ? 000 ? 0100 ? ? 0-$

01?00?000??00000000000000?01000??????????001???????????000????02210?1001

?0?????0????0000?0001101000101001002111010002003--2?10-

$100001001001110110200 ? 1 ? ? ? ? ? ? 10-$

$10011101010210111111111101011100101101122111110101-111-$

10002110100?101111-000110002011111211110?12111121??1113101? 
Eryops_megalocephalus $\quad 010100 ? 11000-$ 000000?001?0000000100?00000000000000000000--10000000000010000000000?121000?00????0?????0?0?01?00000000000000001000??????????0000 ??00-000?000000??02211?10010?1???0?000?00011001111000011000002111011100003--1?10-110001000001110000201?1?????000$11001111010210111101111100011100001111122100110101-$ 111 ?20001110100?101111?00011???2001111211110-111111211?1113101\{0 1\} Doleserpeton_annectens 3?010010100100000010011?0000010000200000000?10000010000-$11000000000001001001001\{01\} ? 13110000000000-010 ? 010001 ? 00\{1$ 2\}?0000200?0??110000?12220??2??200?????????010????????????0??0?????0????000 1001011?1100?01001002211?10113103--2010$111101000001120010000 ? 1 ? ? ? 0 ? 010-1200110100021011110111110110000001-$ $-011121 ? ? 100101-1---$ 10002110101?101100001010101201113021111?0111110210-01-31011

Caudata $\quad-2\{01\} 11---00012-0110100-1000002\{12\} 0001-00001-$ --0-21----1-0--120000000\{0 1\}0001001\{2 3\}002011015\{0 1\}-0002-2-2-0-10\{2 $3\} 010\{12\} 003\{01\} 0120000020100100111011222201120020013--------1--$ $11112001001120211000\{0$ 1\}00?-10000101101(0 1)(0 1)01(0 1)10010022111120?0(0 1)3--30(1 2)0-10(0 3)(0 1)0-000?122201\{0 1\}1\{0 1\}0(0 1)?1???1?(0 1)10$1-1-1-110(0$ 1)(1 2)1?110(0 1)(0 1)-1-

1?????????????????????????????????????????????????????????????????????????????????? ???31011

Anura $\quad$-1111----1----1--\{0 1\}100-10-0002100002000101---0-20---1-0--120000000\{0 1\}00010010001011014\{0 1\}-0002-\{1 2\}12-011301001030012-000021----1101011122201120020013 10110011001000101211001100?-0??0010110010011-00100221111?20?1(0 1)3-3010-101(0 1)0-0000(0 1)2220110\{0 1\}0(0 1)?1???1?(0 1)10-121--

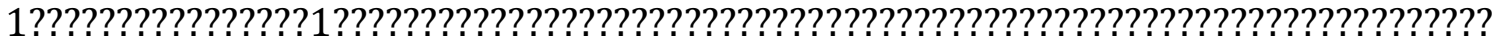
????????????????????31011

Albanerpetontidae 3?011---1001211--1100?0?20001100012-00001--1-21---01-0--11000-000??1011012?0?00???3???002-2-111021301?000\{0 1\}?012?00002??????011001122220122002001????????-$1 ? ? ? ? 0 ? ? ? 0 ? ? ? 0 ? ? 0 ? ? 10 ? 0 ? 0 ? ?-$

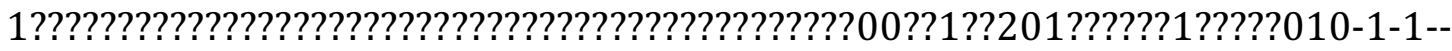

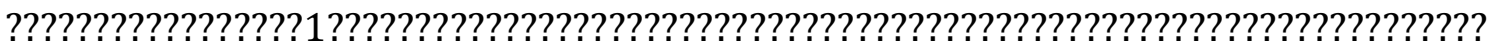
????????????????????31?11

Micropholis_stowi $\quad 20\{01\} 1000\{01\} 10012100000\{01\} 0110\{0$ 1\}000000000000000000010000001000--1-0000000\{0 1\}\{0 1\}000$00001000001311000000111100101000003 ? 000 ? 00001 ? ? ? ? ? 011010 ? 0002 ? 0 ? 120$ 0200??000000010001?120001100000201000100?0011????????????01???????????????\{0 1\}0??????????????00?????200000?0?1??????10-1000110110021011110111?10?\{0 $1\} 1\{01\} 100000110122111110101-111-$ 11??2110100?10?????0?01????201111121111011111102?0?01-3101? 
Eoscopus_lockardi $\quad 2 ? 01001\{01\} 100101000011011 ? 000000000020\{0$ 1\}210000?10000010010--11000000000000-000010000?1311000000?\{0 1\}?0?0?00?0001000000000100001011000???0200?\{0 1\}20020010000000010 ????0110?21001\{0

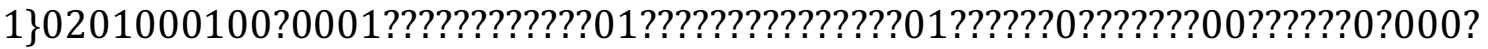
0?1??????10-1000110110021011110111?101010100000110122111000111-11110002110100?101111?0001????20011102??1101111110?????1?3101?

Tambachia_trogallas 2?01000110010000001001102020000000001110000000001000000-$11000000011010-000010000 ? 121000 ? ? 1\{01\} 1$ ??0-

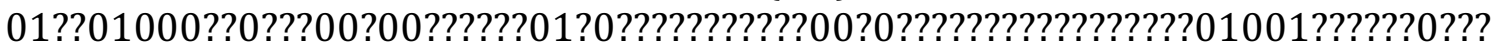

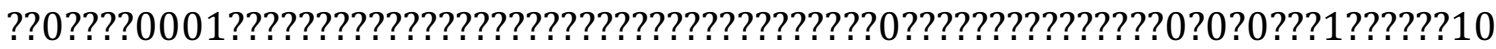
$-1001110111121011110111 ? 10 ? ? ? ? 100001111 ? 22 ? ? ? ? ? 0101-1 ? 1-$ 10??2110100?10?????0?01?????0011112??1101??111?????11?31???

Triadobatrachus_massinoti 21111-1-??????0--0100???????21???020-0101--

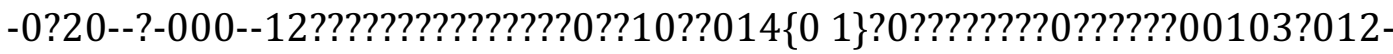
00?021----011010?1???20\{0 1\}1?002001\{0 3\}-------?-10???010001100?\{1 2\}12$1001 ? 0 ? ?-$

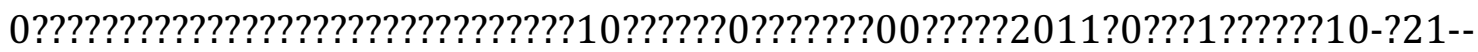

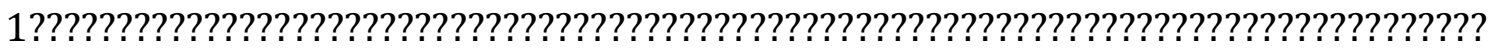
???????????????????31?11

Gerobatrachus_hottoni 2111001010012100001101?000?02100002000000???00000010010-??000000000000-0120010120141100???????0-

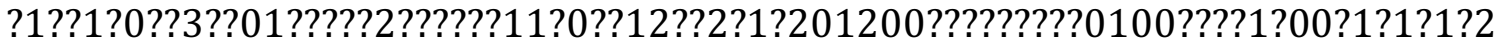

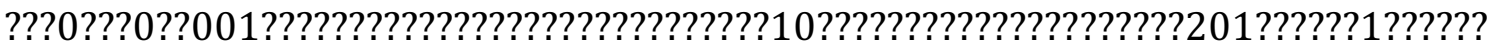
1??120?1101?0021011110111?1?1111?2001-100122?????01?1?11110?????0??0????????????????201113021111????11?0???????31???

Platyrhinops_lyelli 210100?01001?10000010?1100?0200000200000000010000010010-$1110000000000100 ? 0010 ? 0 ? ? 131100000201 ? 0-? 0 ? ? 010000 ? ? 02-$ $0000100 ? ? 0 ? 110000102 ? 2 ? 1 ? 200200 ? 00-$

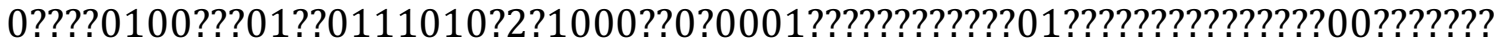
???????00?????200?0??0?1??????1??10011101?102101111011??101011100(0 1)00111122111110101-111-1000211?100-101111$00010000220111121111 ? 0111110210 ? 01 ? 3101$ ?

Amphibamus_grandiceps 211100?01001010000000?1000?0200000200000000?1000001001???111000000 $000010010010010 ? 13110000 ? ? ? ? ? 0-$ $0 ? ? ? ? 10001 ? ? 00 ? 0000200 ? ? 00110000 ? 00 ? 2 ? 1 ? 200200 ? 00-$ 00000010000?0?1?0100?1102?1?00??0?0001????????????01???????????????11?????

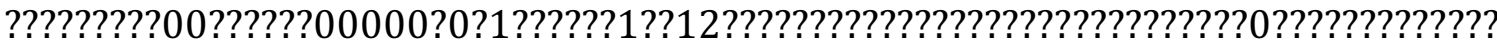

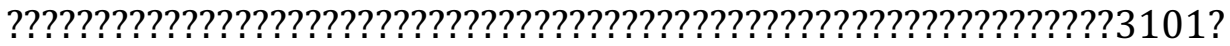

Lethiscus_stocki 230100010001110011100011200101101000000001--01101001010-?2000000012000-011000000110000000000000-000001???2??120000021---- 
01111(0 1)102222001210110-????????????????????????????????????0-

1101000010000111-00000000000-000000--0010-110000000001?00010000001?00100-1000110100021011001010101011???001010?0001000100???10010110110010?10111?-010102002000130211----0--1?????1???--?-0

Coloraderpeton_brilli 13010001000111001000????????01001000100010--01001000010-02000000012100-010?00002100000000000000-000001---2??120000021---01111(0 1)102222001210110-????????????????????????????????????01101000010000111-00000000000-000000--0010-110000000001?000?0?00001100000-?000110?000?10?00?1010100010000001?-0000010?0-1000\{0 1\}110?10110110010-10111?-01011???20?0130???-----?-1?????1???--?-0

Edops_craigi 0100000010002000000000000000001100000000000100000000000-$10000000011000-000000000112000000001 ? ? 0-$

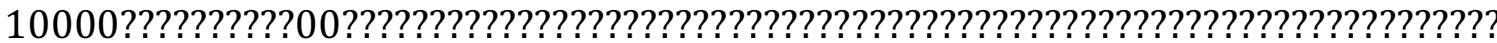
000011001111000011-000001101011100003--1010-11000000000111000021?1??????00-10001111010210111111111100011100101111122100100?01-11110000110100?101111?00011---2202111????100????1????111?21?0?

Petrolacosaurus_kansensis $\quad 02020111200100001010000 ? 0101011101$-0000000100000011000--12000000011010-0111001021000000000012--00211100?0??020000021----0010000002020010110011311111010100010111001000102?1000110-00101?10???0?10?1-?00002221$11003012112 ? 211113000000001110101000 ? 21 ? ? 2 ? ? 010 ? 101110100121011111$ $111 ? 10 ? 11111001-1111221--100101-111-$ $10001110100 ? 1 ? ? ? ? ? ? ? ? ? ? ? ? ? ? ? ? ? ? ? ? ? ? ? ? ? ? ? ? ? ? ? ? ? ? ? ? ? ? ?+100 ?$

Ophiacodon_uniformis_ $\quad 0102010010012000101000100101011101----$ 0000101100001000--12000000011110$01010010210000000011111111021110 ? ? 0 ? 00200000200100001000000212010$ $010001001101011010010102210010001020000011000010111011 ? 1020 ? 1-$ 110011021-11103001--30111102010101011100101002?20????0001101011100121011111111111111011221-1101221--110101-111-1000-1-0101121110-01211---22021302111101121110211-11121000

Baphetes_spp. 0?00001010011000000100000000010110000000010100001000000-$0100000000 ? 000-001000000000 ? 00000100 ? ? 0-$ 0100010????000??000000?00??????????????????00???0????101001????121?2????10 0????????00011????????????1-?100010110100??0?0-$1010 ? 011000000003 ? 000 ? 0 ? 0 ? ? 1 ? ? ? ? ? ? 0 ?-$ 010011?1010110110101111100011100000111?????????????????????????????????? ?????0010?200111?111100??1?1????111120???

Eucritta_melanolimnetes 00000000100110000000000?0000210010001000000000001000000-$1100 ? 0000 ? 1000-0000000 ? 0 ? 00 ? 00000000 ? ? 0-$

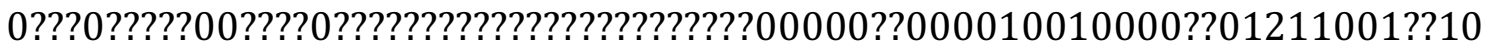
$0 ? 1100 ? ? 0 ? ? 010 ? ? ? ? ? ? ? ? ? ? ? ? 1-$ ?100012?1?1?0??0???????????1????0?????????????1????????- 


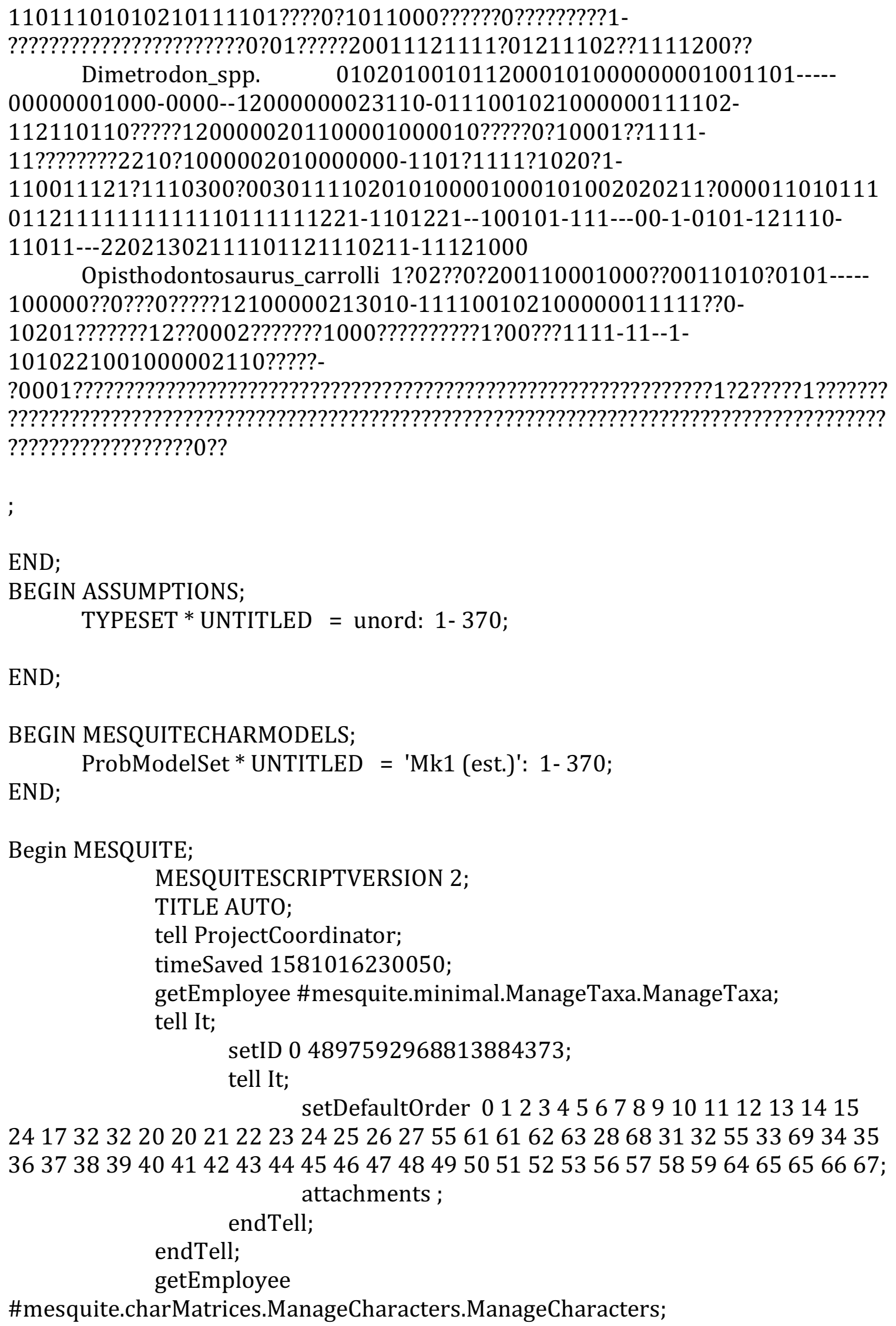

END;

BEGIN ASSUMPTIONS;

TYPESET * UNTITLED = unord: 1-370;

END;

BEGIN MESQUITECHARMODELS;

END;

ProbModelSet*UNTITLED = 'Mk1 (est.)': 1- 370;

Begin MESQUITE;

MESQUITESCRIPTVERSION 2;

TITLE AUTO;

tell ProjectCoordinator; timeSaved 1581016230050;

getEmployee \#mesquite.minimal.ManageTaxa.ManageTaxa;

tell It;

setID 0 4897592968813884373;

tell It;

setDefaultorder 0123456789101112131415

241732322020212223242526275561616263286831325533693435 3637383940414243444546474849505152535657585964656566 67; attachments ; endTell;

endTell;

getEmployee

\#mesquite.charMatrices.ManageCharacters.ManageCharacters; 
tell It;

setID 0 6605800557590130524;

mqVersion 351;

checksumv 033134152167 null getNumChars 370 numChars

370 getNumTaxa 70 numTaxa 70 short true bits 2305843009213694015 states

63 sumSquaresStatesOnly 66740.0 sumSquares -3.08982963234635E20

longCompressibleToShort false usingShortMatrix true NumFiles 1 NumMatrices 1; mqVersion;

endTell;

getWindow;

tell It;

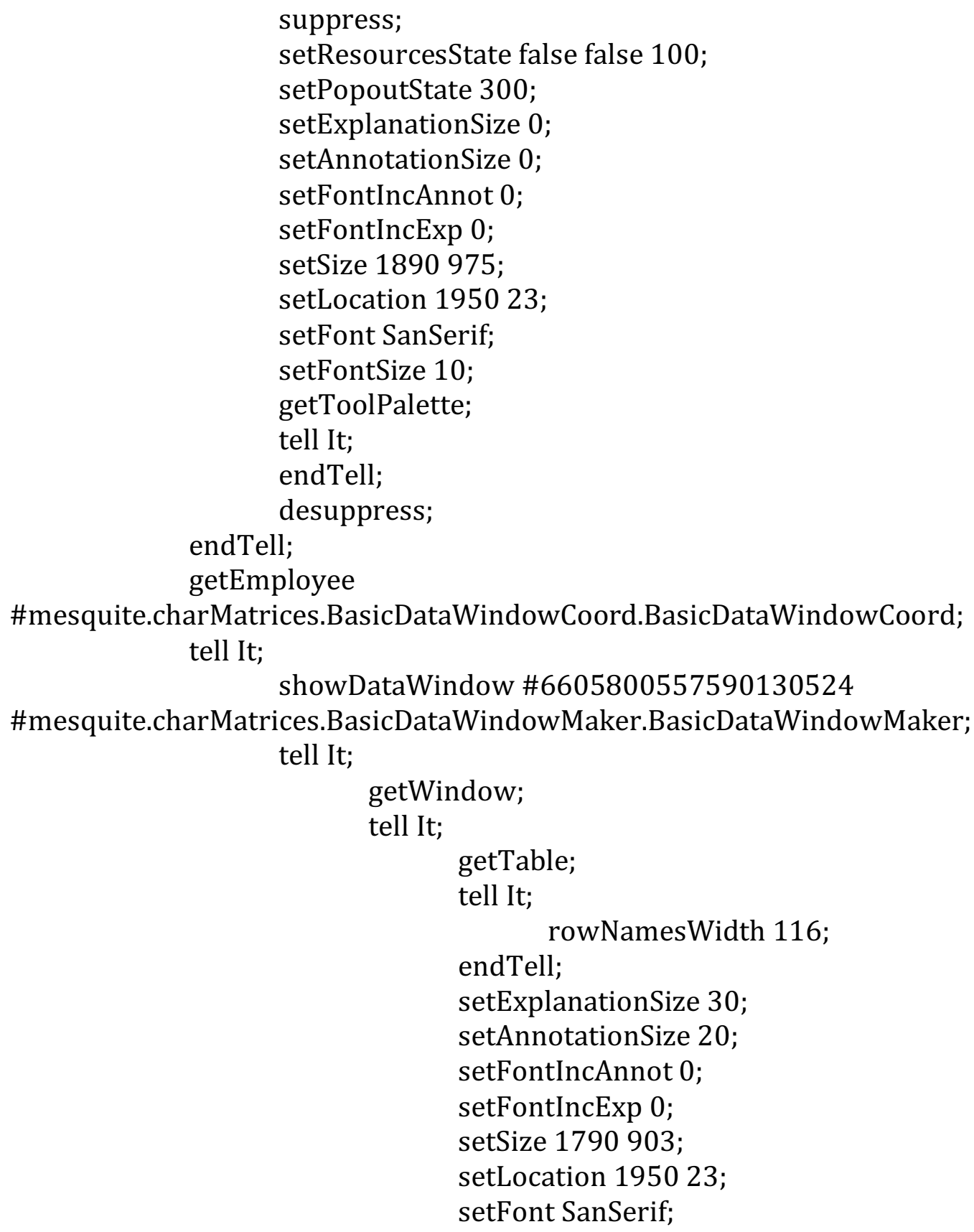


setFontSize 10;

getToolPalette;

tell It;

setTool

mesquite.charMatrices.BasicDataWindowMaker.BasicDataWindow.ibeam;

endTell;

setActive;

setTool

mesquite.charMatrices.BasicDataWindowMaker.BasicDataWindow.ibeam; colorCells

\#mesquite.charMatrices.NoColor.NoColor;

colorRowNames

\#mesquite.charMatrices.TaxonGroupColor.TaxonGroupColor;

colorColumnNames

\#mesquite.charMatrices.CharGroupColor.CharGroupColor;

colorText

\#mesquite.charMatrices.NoColor.NoColor;

setBackground White;

toggleShowNames on;

toggleShowTaxonNames on;

toggleTight off;

toggleThinRows off;

toggleShowChanges on;

toggleSeparateLines off;

toggleShowStates on;

toggleAutoWCharNames on;

toggleAutoTaxonNames off;

toggleShowDefaultCharNames off;

toggleConstrainCW on;

toggleBirdsEye off;

toggleShowPaleGrid off;

toggleShowPaleCellColors off;

toggleShowPaleExcluded off;

togglePaleInapplicable on;

toggleShowBoldCellText off;

toggleAllowAutosize on;

toggleColorsPanel off;

toggleDiagonal on;

setDiagonalHeight 80;

toggleLinkedScrolling on;

toggleScrollLinkedTables off;

endTell;

showWindow;

getWindow;

tell It;

forceAutosize; 


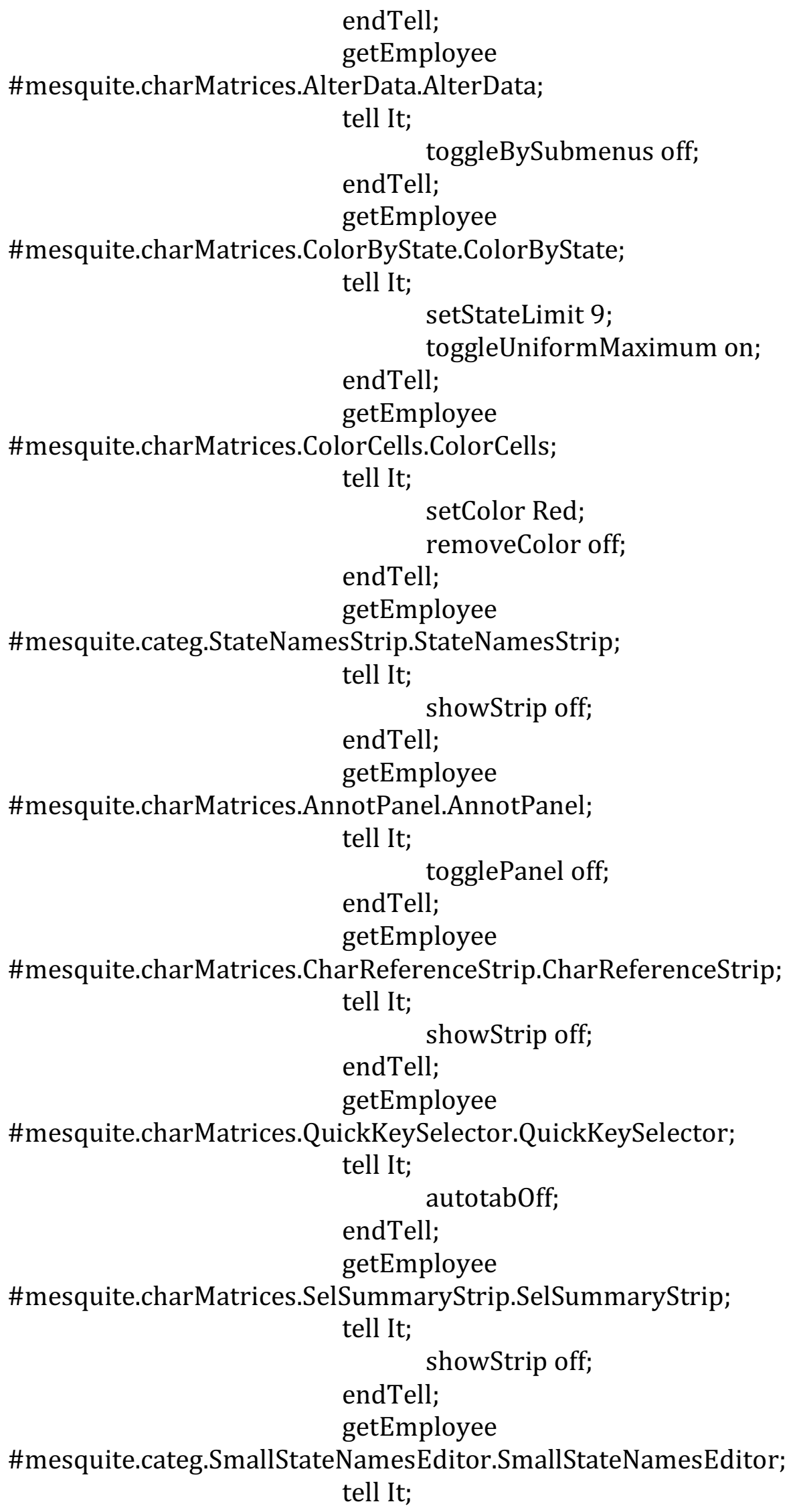




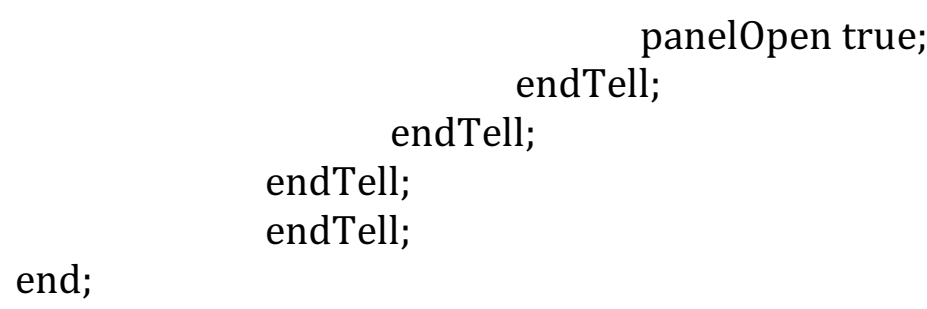

D.2 Digitally stitched (using photoshop CS6), high resolution image of FMNH PR 1301.

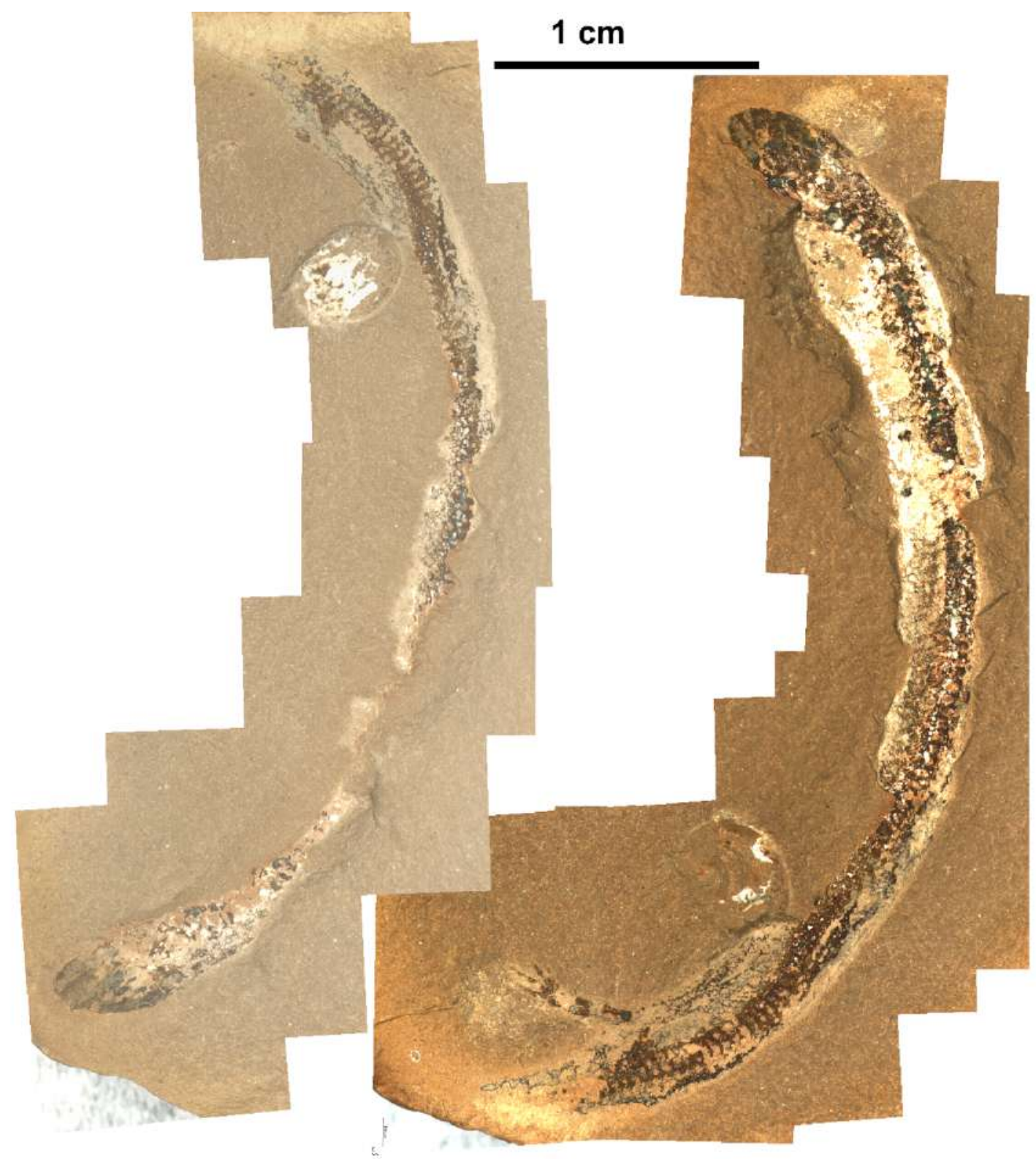




\section{D.3 Scanning Electron Micrographs (SEMs) of FMNH PR 1301 A-D, showing incomplete}

ossification of the cranium. A-D, respectively show progressively smaller images including close up images of framboidal pyrite $\mathrm{D}$, which likely is replacing cartilage and other soft tissues.

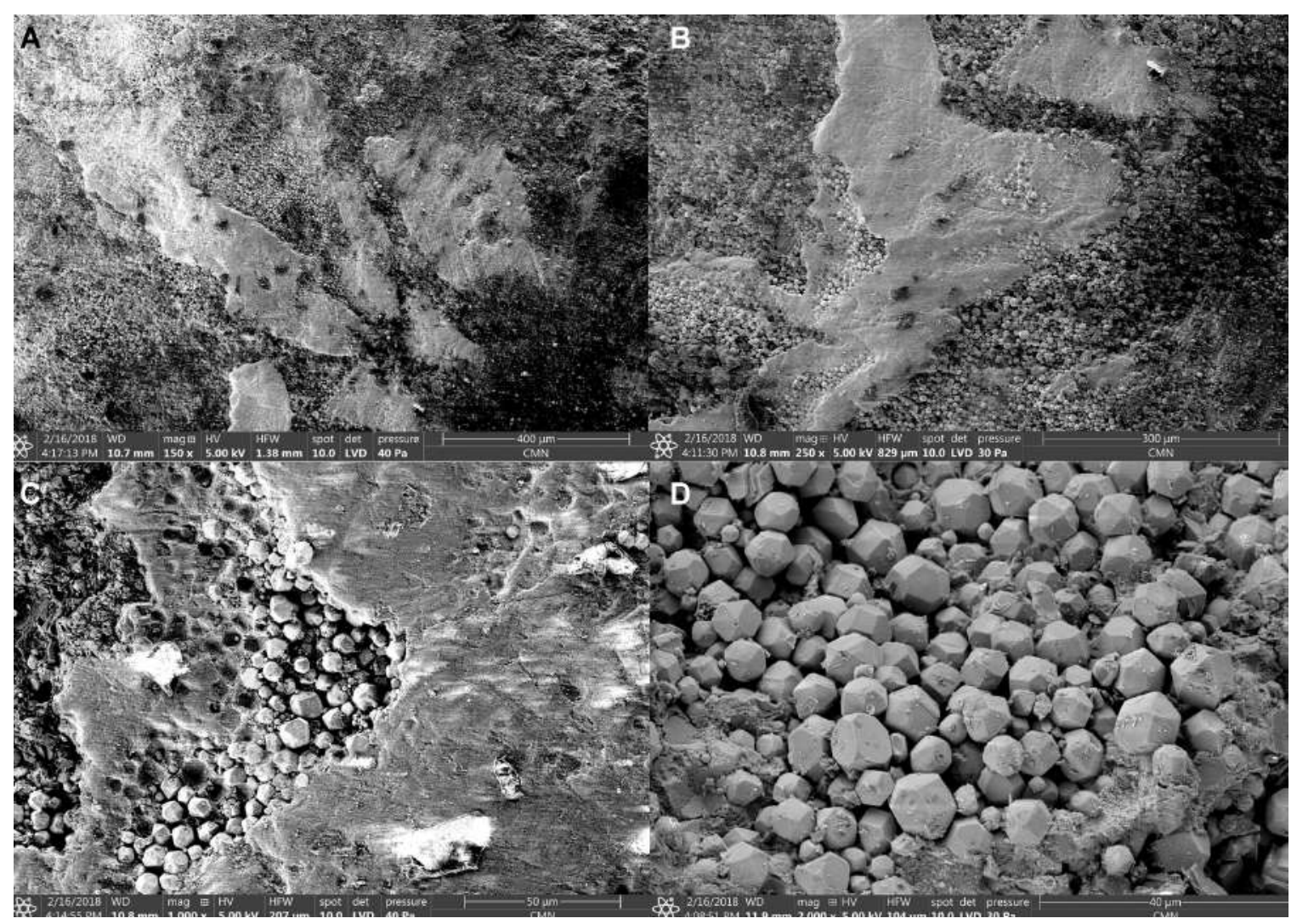

\section{D.4 Table of measurements for FMNH PR 1301.}

\begin{tabular}{|l|l|}
\hline Anatomical feature & Measurements in (mm) \\
\hline Total body length & 54.0 \\
\hline Width at mid-torso (body impression) & 4.0 \\
\hline
\end{tabular}




\begin{tabular}{|l|l|}
\hline Skull length & 6.0 \\
\hline skull width & 4.0 \\
\hline Hindlimb & 6.0 \\
\hline caudal vertebrae length (tail) & 9.0 \\
\hline
\end{tabular}

